\title{
Impacts of anthropogenic activities on the ecology and ecosystem service delivery of Lake Ziway, Ethiopia
}

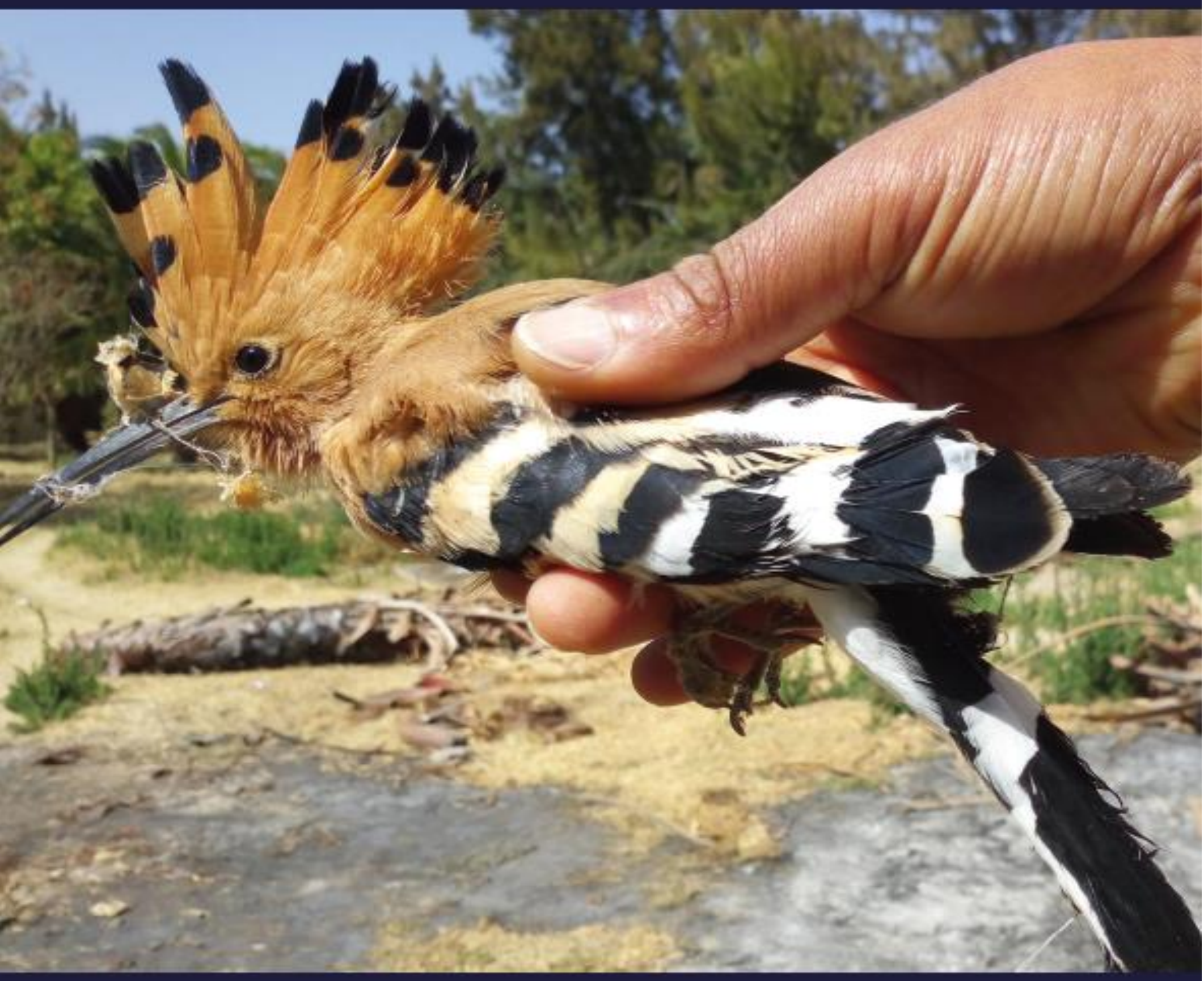

Lemessa B. Merga 


\section{Propositions}

1. Lack of knowledge and concern with user farmers on pesticide safety is threatening human health and the environment in Ethiopia.

(this thesis)

2. Safe ecological threshold levels of pesticides based on data from temperate regions may not be protective for tropical ecosystems.

(this thesis)

3. Current poverty reduction practices are opposing natural resource conservation.

4. Scientific knowledge cannot solve complex social problems unless it is integrated with local knowledge.

5. Multidisciplinary researches are imperative to address global challenges.

6. Collective action is more important than coordination to avert collective risks.

7. Social innovations should be given priority over technological innovations to transform smallholder agriculture.

8. Reducing youth out-migration in Africa requires more effort beyond persuasive media campaigns.

Propositions belonging to the thesis, entitled Impacts of anthropogenic activities on the ecology and ecosystem service delivery of Lake Ziway, Ethiopia

Lemessa Benti Merga

Wageningen, 27 January 2021 


\section{Impacts of anthropogenic activities on the ecology and ecosystem service delivery of Lake Ziway, Ethiopia}

Lemessa B. Merga 


\section{Thesis committee}

\section{Promotor}

Professor Dr Paul J. van den Brink

Personal chair, Aquatic Ecology and Water Quality Management

Wageningen University \& Research

\section{Co-promotor}

Dr Jack H. Faber, Sustainable Soil Use

Senior researcher

Wageningen University \& Research

Dr Alemayehu Abebaw Mengistie

Associate professor, Department of Chemistry

Ambo University, Ethiopia

\section{Other committee members}

Professor Dr Violette Geissen

Wageningen University \& Research

Professor Dr Fulco Ludwig

Wageningen University \& Research

Professor Dr Kees van Gestel

Vrije Universiteit Amsterdam

Professor Dr Victor Wepener

North West University, Potchefstroom, South Africa

This research was conducted under the auspices of the Graduate School for Socio-Economic and Natural Sciences of the Environment (SENSE) 


\title{
Impacts of anthropogenic activities on the ecology and ecosystem service delivery of Lake Ziway, Ethiopia
}

\author{
Lemessa B. Merga
}

Thesis

Submitted in fulfilment of the requirements for the degree of doctor at Wageningen University by the authority of the Rector Magnificus

Prof. Dr A.P.J. Mol, in the presence of the

Thesis Committee appointed by the Academic Board to be defended in public on Wednesday 27 January 2021 at 1.30 p.m. in the Aula 


\section{Lemessa Benti Merga}

Impacts of anthropogenic activities on the ecology and ecosystem service delivery of Lake Ziway, Ethiopia, 294 pages.

PhD thesis, Wageningen University, Wageningen, The Netherlands (2021)

With references, with summaries in English, Afaan Oromo and Amharic

DOI: https://doi.org/10.18174/536456

ISBN: 978-94-6395-638-3 
Dedicated to the memory of my late mom 


\section{Contents}

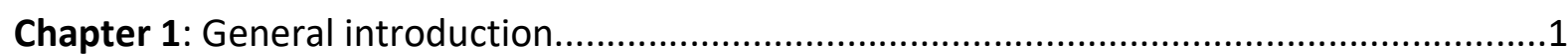

Chapter 2: Trends in chemical pollution and ecological status of Lake Ziway, Ethiopia: A review focussing on nutrients, metals and pesticides..........................................15

Chapter 3: Ecosystem services provided by the freshwater Lake Ziway in Ethiopia and the potential impact of pesticide use in local agriculture.

Chapter 4: Biological and chemical monitoring, and ecological risk assessment of residual pesticides in Lake Ziway, Ethiopia

Chapter 5: Distribution of microplastics across four fish species and sediment in an African lake.

Chapter 6: Ecological effects of imidacloprid on a tropical freshwater ecosystem and its recovery dynamics. .185

Chapter 7: General discussion and conclusion. .225

References: .245

Summary (English):. .273

Summary (Afaan oroomo): .279

Summary (Amharic) .285

Acknowledgements: 289

About the Author: 


\section{CHAPTER 1}

General introduction 


\subsection{Agricultural development and trends in agrochemicals usage in Ethiopia}

Ethiopia is an agrarian country where about $85 \%$ of the country's population is engaged in the agricultural sector (UNDP, 2015). Thus agriculture is the backbone for the Ethiopian economy (Welteji, 2018). The sector contributes to $40 \%$ of the growth domestic product in 2013/14 (Chipeta et al., 2015) and about 85 - 90\% of the country's export earnings (UNDP, 2015; Welteji, 2018). Ethiopian agriculture has enjoyed a substantial growth for the last two decades as a result of the given attention from the Ethiopian government, international donors, and non-governmental organizations, (Chipeta et al., 2015; UNDP, 2015). For instance, the crop yield recorded in 2014/15 was almost three times the yield reported in 2004/05 (Bachewe et al., 2018). Indeed, increasing crop production and to maintain high agricultural growth and alleviate food security problem of the growing population of the country is one of the priority agenda for the government of Ethiopia (FAO, 2011). For example, the number 1 strategic objective in the Growth and Transformation Plan of the country is increasing crop production and productivity through intensive use of agrochemical inputs (e.g., fertilizers and pesticides) and improved agricultural practices (e.g., use of improved seed) (Mellor and Dorosh, 2010; MoFED, 2010; Chipeta et al., 2015).

The use of synthetic pesticides in Ethiopia started in the 1950s to control a few pests such as desert locust and armyworm (MoANR, 2016), while the use of mineral fertilizers was introduced into Ethiopian agriculture in the late 1960s (Rashid et al., 2013). Until 1994/5, the use of both agrochemicals (pesticides and fertilizers) was low (Amera and Abate, 2008; Rashid et al., 2013). But, following the implementation of agricultural intensification policy in 1995, Ethiopian consumption of these chemicals has shown a substantial increase (Abate, 2006; Amera and Abate, 2008; Endale, 2011; Rashid et al., 2013). Statistical data by the Food and Agriculture Organization of the United Nations (FAO 2019) showed the increasing trends of agricultural use of pesticides and fertilizers in Ethiopia (Figure 1.1), predominantly through the expansion of large scale horticulture and floriculture investments by foreign and domestic investors in the country (Amera and Abate, 2008; Teklu, 2016). According to Teklu (2016), about $80 \%$ of the nationally imported pesticides is used by large scale floriculture and horticulture farms. The current development strategy of the country, the Growth and Transformation Plan, also strongly promotes the intensive use of agrochemicals by smallholder farmers to promote agricultural growth by increasing crop production and 
productivity in this sector (MoFED, 2010; IFDC, 2012; Chipeta et al., 2015). The use of pesticides to reduce crop losses to pests and use of fertilizers to amend the soil fertility of agricultural land are expected to continue to increase in the future. Crop loss to pests is one of the challenging problems for Ethiopian agriculture and estimated from $30-40 \%$ of loss annually (Amera and Abate, 2008).

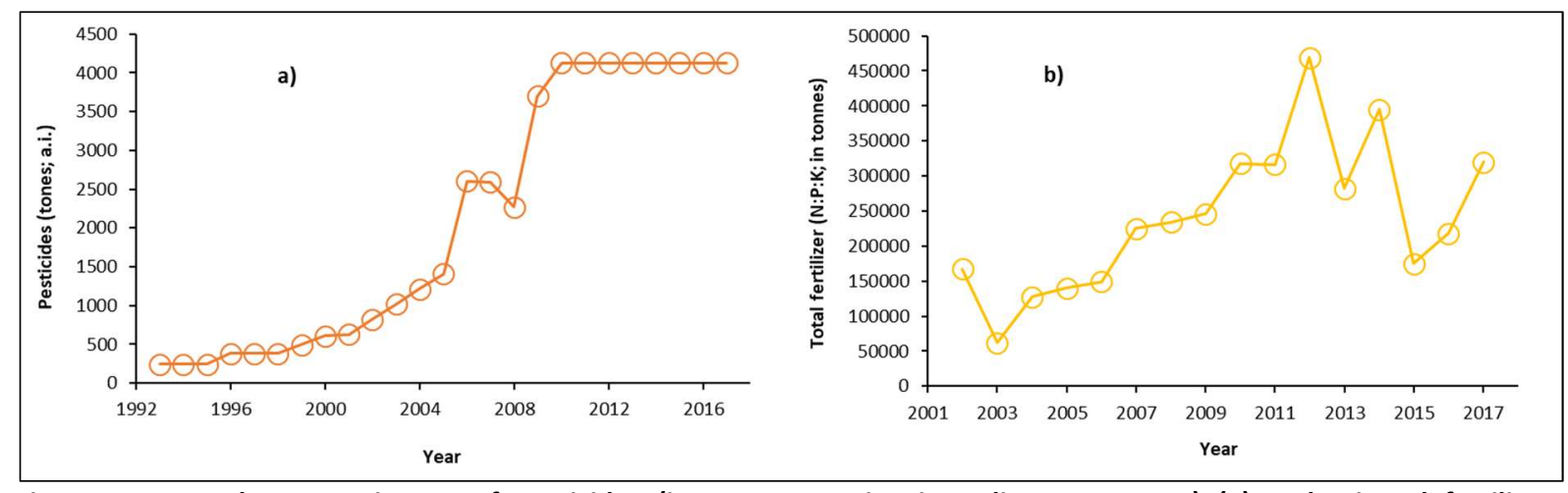

Figure 1.1. Developments in use of pesticides (in tonnage active ingredients per year) (a) and mineral fertilizers (tonnes/year) (b) in Ethiopia. The graphs were constructed based on data by FAO (http://www.fao.org/faostat/en/\#data).

\subsection{Current challenges for the use of water resources in Ethiopia}

Ethiopia is one of the water resource richest African countries, endowed with 12 river basins with an annual mean flow of about 123 billion $\mathrm{m}^{3}$ (MoWR, 2002; Awulachew et al., 2007; Berhanu et al., 2014) and about 70 billion $\mathrm{m}^{3}$ lake water (Berhanu et al., 2014). The water bodies cover about $0.7 \%$ of the surface area of the country (Berhanu et al., 2014). The west-flowing (Abay, Baro-Akobo, Omo-Gibe and Tekeze), the northeast flowing (Awash), the south-flowing (Rift Valley) and the east-flowing (Wabi-Shebele and Genale-Dawa) river basins contributed to $99 \%$ of the annual mean flow of the country. The remaining river basins (Mereb, Afar/Denakil, Aysha and Ogaden) have a low contribution (MoWR, 2002; Awulachew et al., 2007; Berhanu et al., 2014). In total, the country has about 11 freshwater and 9 saline water lakes, most of which are found in the Rift Valley Basin of Ethiopia (Awulachew et al., 2007). According to the FAO AQUASTAT data, in 2015 about 1,958,340 hectares of land was irrigated for agriculture (FAO, 2016). Apart from supply of irrigation water, these aquatic ecosystems provide a wide range of ecosystem goods and services (see section 1.4).

Although Ethiopia endows a large amount of water resources, their protection has not been given sufficient attention (Teklu, 2016; Fetahi, 2019). These precious ecosystems of the country have experienced several challenges due to anthropogenic activities (Lemma and Desta, 2016; Teklu, 2016). In particular, human activities such as watershed forest clearance 
for agricultural land expansion, release of agrochemicals, over-abstraction of irrigation water, and discharge of untreated urban effluents are the dominant pressures towards aquatic ecosystems in Ethiopia (Legesse and Ayenew, 2006; Mengistie et al., 2015; Teklu, 2016; Fetahi, 2019; Kebede et al., 2020). These destructive human practices as reported by many authors (Foley et al., 2005; de van Meutter et al., 2006; Holland et al., 2011; Schäfer, 2012; Fetahi 2019), can lead to a deterioration of ecosystem structure and function which reduces the capacity of the water bodies to deliver ecosystem goods and services (see section 1.4).

\subsection{Effects of chemicals and plastics on aquatic ecosystems}

Pollutants can enter aquatic ecosystems through various pathways, such as terrestrial runoffs, drainage channels, accidental spills, and air deposition (Van Wijngaarden et al., 2005; Schäfer et al., 2010; Karthik et al., 2018; Constant et al., 2020). They may cause undesired effects on non-target aquatic organisms (Daam and Van den Brink, 2011; Pathiratne and Kroon, 2016). Pesticides (Schulz, 2004), nutrients (Carey and Migliaccio, 2009; Rathore et al., 2016) and trace metals (Gheorghe et al., 2017; Väänänen et al., 2018) are the major pollutants causing a detrimental effect on aquatic ecosystems, while the effects of plastics are receiving increased attention (Li et al., 2018; Li et al., 2020).

The pollutants discussed in this section are among the major pollutants to African water bodies in particular to Lake Ziway, Ethiopia due to anthropogenic activities (e.g., urbanization and agriculture) (Merga et al., 2020b). As this thesis studied their ecological impacts to Lake Ziway, the following sections provide background information for readers using available literature.

\subsubsection{Pesticides}

Pesticides are important chemicals to reduce crop loss in agriculture that target different pests and diseases such as insects (insecticides), weeds (herbicides), fungi (fungicides), mites and ticks (acaricides) and nematodes (nematicides) (Van Wijngaarden et al., 2005; Schäfer et al., 2010; McKnight et al., 2015). In addition to its agricultural use, in many developing countries (e.g., Ethiopia), pesticides also are applied in the public health sector, for example, to control malaria vectors (Loha et al., 2018). These applications make pesticides among the most common pollutants affecting surface waters (McKnight et al., 2015). 
Pesticides affect all kinds of biological groups in the aquatic ecosystem, starting from primary producers to the top predators in food web. But, the sensitivity of the organisms to pesticides is highly dependent on the compound's mode of action (Schäfer et al., 2010). For instance, insecticides are more toxic to aquatic arthropods and vertebrates, herbicides are more toxic to aquatic plants while the most sensitive group for fungicides depends on their mode of action (Maltby et al., 2005; Van den Brink et al., 2006; Maltby et al., 2009). The direct physiological effects of pesticides on biological groups (e.g., algae, macrophytes, periphyton, zooplanktons, macroinvertebrates, fishes) may initiate food-web mediated cascading effects (indirect effects). Indirect effects can result from a change in interactions between different groups in the food-web as a result of the direct effect on a single group by a pesticide (Brock et al., 2000b; Fleeger et al., 2003; Schäfer et al., 2010) or other causes (Schmitz et al., 2004).

A direct physiological effect of an insecticide (Brock et al., 2000b; Fleeger et al., 2003) or fungicide (Bundschuh et al., 2019) on sensitive invertebrate grazers can cause an increase in phytoplankton abundance and biofilm biomass (indirect effect) when primary producers are released from grazing pressure. As a result, herbivore invertebrates less sensitive to insecticides and fungicides (mostly species from Rotifera, Gastropoda and oligochaeta) may increase in abundance (indirect effect). This can be explained by a decreased competition with sensitive herbivores (e.g., Copepoda, Cladocera and Insecta) and by an increase of food such as periphyton and phytoplankton that are insensitive to the pesticides (Brock et al., 2000b; Fleeger et al., 2003).

Moreover, the direct toxicity of herbicides to aquatic primary producers (macrophytes, phytoplankton and periphyton) can likely initiate indirect effects such as a decrease in abundance of herbivorous invertebrates (e.g., zooplankton, Gastropoda) (Brock et al., 2000a; Fleeger et al., 2003; Schuler and Rand, 2008). This is explained by shortage of food sources (i.e., primary producers) (Fleeger et al., 2003). Again, less sensitive primary producers, or ones that can easily adapt to the herbicide can increase in biomass, as herbicides directly affect the most sensitive primary producers, reducing competition for resources (e.g., $\mathrm{CO}_{2}$, nutrients, space, light) between groups (Brock et al., 2000a). 


\subsubsection{Nutrients}

Urban wastes, sewage and nutrients (e.g., nitrates, phosphates) are released into surface waters from various human activities and ultimately lead to eutrophication of natural ecosystems (Skei et al., 2000; Conley et al., 2009; Struijs et al., 2011; Fetahi, 2019). The problem of eutrophication is threatening surface waters worldwide (Skei et al., 2000; Struijs et al., 2011; Fetahi, 2019). Eutrophication can cause severe ecological damage (e.g., fish kills) by depleting oxygen concentrations (i.e., hypoxia), through extended growth of primary producers, particularly phytoplankton and periphyton (Camargo and Alonso, 2006; Fetahi, 2019). Eutrophication can also promote the occurrence and blooming of toxic algae, including cyanobacteria, and cause toxicological effects towards aquatic life and human health (Camargo and Alonso, 2006; Conley et al., 2009). Indirect effects of eutrophication in aquatic ecosystems are also reported. For instance, a low level of oxygen (hypoxia) can stimulate the formation of hydrogen sulfide and other reduced compounds, which can be toxic to fish and aquatic invertebrates (Camargo and Alonso, 2006). Furthermore, by increasing the population growth of a snail host, eutrophication promotes the transmission of trematode parasite (Ribeiroia ondatrae) to amphibians, which may cause limb malformation and mortality to freshwater amphibians (Johnson et al., 2007).

\subsubsection{Metals}

Aquatic ecosystems may be exposed to high levels of trace metals as a result of urbanization, agriculture and mining (Skei et al., 2000; Mendi and Uluozlu, 2007; Costas et al., 2018). Some trace metals are essential for metabolic processes (e.g., $\mathrm{Zn}, \mathrm{Fe}, \mathrm{Mn}, \mathrm{Cu}, \mathrm{Co}, \mathrm{Se}$ ) at low concentrations, while other metals are non-essential, like $\mathrm{Hg}, \mathrm{Pb}$ and $\mathrm{Cd}$ (Walker et al., 2012). In concentrations beyond the window of essentiality trace metals can cause adverse effects on aquatic organisms such as phytoplankton, fish and zooplankton (Gheorghe et al., 2017; Sfakianakis et al., 2015; de Souza Machado et al., 2016). Several toxicological effects have been reported from growth inhibition, and swelling of hepatopancreatic digestive cells up to mortality in snails, and gill necrosis or fatty degeneration of the liver in fish and crustaceans (Gheorghe et al., 2017). Fish larval deformities (e.g., head deformities, spinal curvatures vertebral deformity) were also reported due to trace metals toxicity affecting survival and growth rates of the organisms (Sfakianakis et al., 2015). Moreover, trace metals 
are persistent and can undergo bioaccumulation through food chain and reach concentration levels that can cause physiological impact including mortality to the top predator (Mendi and Uluozlu, 2007; Vukosav et al., 2014).

\subsubsection{Plastics}

Plastics are synthetic or semisynthetic polymers with a wide range of industrial and domestic applications (Vert et al., 2012; Wagner et al., 2014). As a result of unsustainable waste management, microplastics (within a size range of $0.001 \mathrm{~mm}-5 \mathrm{~mm}$ ) are widely present in aquatic ecosystems, and its pollution has recently become a global concern (SAPEA, 2019; Deng et al., 2020; Edo et al., 2020). Wastewater treatment plants effluents, shoreline debris, river discharges, landfills, urban and industrial wastes, illegal waste dumping into aquatic systems, and atmospheric deposition are the major sources of microplastic pollution to aquatic ecosystems (Eerkes-Medrano and Thompson, 2018; Li et al., 2020). Many field studies have reported the widespread distribution of microplastics in various freshwater compartments including sediment, water column, aquatic invertebrates and fishes (EerkesMedrano and Thompson, 2018; Li et al., 2018; Li et al., 2020). However, only a handful of studies are available for African aquatic ecosystems (Biginagwa et al., 2016; Khan et al., 2018).

Some empirical investigations indicate that ingestion and surface adsorption of microplastics is harmful to aquatic organisms . For instance, for aquatic animals several effects of ingestion microplastics have been reported, including mortality, blocking of digestive tracts, and reduced feeding rate, growth and reproduction capacity (Eerkes-Medrano and Thompson, 2018; Li et al., 2020). Tissue and cellular level effects of ingested microplastic on aquatic animals includes the formation of granulocytomas in the digestive tissues, reduced stability of cell membranes, glycogen depletion, fatty vacuolation and single-cell necrosis (Eerkes-Medrano and Thompson, 2018). Effect on morphology and life history of aquatic animals (e.g., Daphnia magna), such as increase body length and decrease number of offspring due to microplastic constituents like diisononylphthalate plasticizer, was also reported (Schrank et al., 2019; Li et al., 2020). Furthermore, reduction of algal growth on aquatic plants (e.g., Pseudokirchneriella subcapitata, Chlorella sp., Scenedesmus sp.) due to surface adsorption of microplastics was reported as it hinders the absorption and utilization of photons and $\mathrm{CO}_{2}$ by algal cells (Li et al., 2020). 


\subsection{Ecosystem goods and services of aquatic ecosystems}

Ecosystem goods and services (ES) are the output of ecosystems that directly or indirectly contribute to the well-being of people (MEA, 2005; Alahuhta et al., 2013; Grizzetti et al., 2015). Aquatic ecosystems provide multiple ES that grouped under provisioning services (e.g., drining water, biomaterials, irrigation water, plant and animal food), regulation and maintenance servcies (e.g., lifecycle maintenance, habitat, water storage and flow regulation) and cultural services (aesthetic value, spritual value, and recreational activities like boating, bird watching) (Schallenberg et al., 2013; Ondiek et al., 2016). In ES hierarchy (Alahuhta et al., 2013; Grizzetti et al., 2015) the biological entities (service providing units (SPU)) of an ecosystem perform the underlying functions and processes and translate it into ES (Luck et al., 2003; Forbes and Calow 2012; Andersson et al., 2015). The ES in turn contributes to benefit of people including food security, livelihood and income, protection/safety, economy and good health.

There could be trade-offs (i.e., opposite interaction) and synergies (i.e., positive interaction) between sets of ES. Therefore, in managing ecosystem to increase the supply of some ES may decrease the delivery of others (Maes et al., 2012; Faber et al., 2019). For example, decrease in surface area of lake ecosystem due to excessive water withdrawal for agricultural irrigation may affect tourism activities and drinking water supply by affecting wetland macrophytes (i.e., trade-offs). Macrophytes support bird population important for tourism activities (bird watching) by serving as roosting, nesting and stopover sites and also support drinking water supply by trapping sediment load, absorbing nutrients and detoxifying organic pollutants (Merga et al., 2020b).

\subsection{Ecological risk assessment of chemicals}

Generally, Ecological Risk Assessment (ERA) is a process in which the possible direct and indirect environmental adverse effects of stressors' exposure are assessed. The assessment may be retrospective for chemicals already used and emitted to the environment, or prospective for new chemicals to be introduced to the market (Forbes and Calow, 2002; Brock et al., 2006; Shea and Thorsen, 2012). Both types of assessment entail some or all of the following : exposure assessment, risk characterization and effect assessment, (van Leeuwen and Vermeire, 2007; Shea and Thorsen, 2012). Retrospective assessments may also be used to evaluate mitigation measures (Faber, 2006). 
A key part of risk assessment involves determining emissions, routes and movement rates of pollutants and their transformation to estimate the concentration to which environmental components are or may be exposed. In retrospective ecological risk assessment, exposure assessment can be done by measuring the concentrations in the relevant compartments of the ecosystem under study; for instance, through chemical monitoring once the pollutants are produced, used and emitted (Forbes and Calow, 2002; van Leeuwen and Vermeire, 2007). However, in prospective risk assessment, exposure assessment can only be predicted using models (van Leeuwen and Vermeire, 2007).

Effect assessment defines the anticipated adverse effects in the species or ecosystem of concern given exposure routes and levels to the stressor, such as pesticides (Forbes and Calow, 2002; Shea and Thorsen, 2012). The assessment can provide qualitative as well as quantitative effect thresholds, such as predicted no-effect concentration (PNEC) for pesticides. Such information contributes to the protection of the ecosystem under study (Brock et al., 2006). There are multiple methods to quantitatively or qualitatively relate the ecological effect to the concentration of the target pollutant, such as, the results of singlespecies toxicity test, Species Sensitivity Distribution (SSD), and multiple species toxicity experiments using outdoor or indoor micro- and mesocosms.

Single species toxicity tests are often used as the first stage ('first tier') in the effect assessment, where the toxic effects of chemicals are assessed using protocolised experiments. The experiment takes relatively little time, low cost, and is easy to construct and handle (Calow and Forbes, 2003; EFSA, 2013). Data generated by such standard experiments are generated using a continuous exposure pattern, thus, considered to represent a worst-case exposure scenario. Effect/lethal concentrations such as EC50 and LC50 (concentration of a chemical at which $50 \%$ of the test species is affected or dead, respectively) and NOEC (no observed effect concentration) are estimated. Toxicity data generated from single species tests can be used to derive a predicted no-effect concentration (PNEC) by dividing a toxicity value (LC50acute or NOECchronic) by an assessment factor. E.g., in the EU pesticide risk assessment an assessment factors between 10 and 100 are used to extrapolate the results of acute and chronic tests to acute and chronic PNEC values (Van Wijngaarden et al., 2005; Brock et al., 2006).

The most widely employed tool to derive the PNEC in a 'second-tier' effect assessment (using effect threshold data from single species testing in a first tier) is the SSD approach. A SSD is a statistical distribution of the sensitivity data for multiple species and is compiled from 
effect concentrations such as EC50/LC50 or NOEC/EC10 values resulting from acute or chronic exposures, respectively. For pesticides a minimum of eight toxicity data, for example of sensitive invertebrate species, are required to construct an SSD curve while five species toxicity data are needed for vertebrates (EFSA, 2013; Diepens et al., 2017). From the SSD curve, hazard concentrations ( $\mathrm{HCX}$ ), usually the HC5 (hazard concentration at which $95 \%$ of the species are protected), can be estimated and considered as the PNEC (Van den Brink et al., 2006; EFSA, 2013; Pathiratne and Kroon, 2016). However, Van Wijngaarden et al. (2015) suggested using an additional assessment factor of $3-6$ to be protective for a wide range of chemicals (e.g., insecticides).

Micro- and mesocosm experiments are a higher tier tool which can be used to investigate direct and indirect effects at the population, community and/or ecosystem level (Solomon and Sibley, 2002). Cosms can be constructed either by incorporating parts of the natural ecosystem into an artificially established container or by secreting parts of the naturally existing ecosystem. Incorporating different processes and structure (e.g. trophic levels) increases the complexity of the system to mimic the natural environment (Brock et al., 2000b; EFSA, 2013). Cosm studies provide many advantages over the other lower tier effect assessment tools. First, cosms have the ability to integrate relatively realistic exposure regimes and enables the study of the fate of the chemical in the different compartments of the ecosystem. Secondly, cosm experiments are suitable to study inter- and intra-species interactions and indirect effects under realistic community structure. Furthermore, as model ecosystem experiments are performed for a longer period of time, they can provide an opportunity to assess latency of effects and population and community level recovery (Daam and Van den Brink, 2007; Brock et al., 2009). Assessment endpoints, including the NOECpopulation and the NOECcommunity, are usually derived from cosm experiments, which can be used as PNEC estimates. A case by case based review, for instance, considering protection goal, is recommended to establish the assessment factor used to estimate PNEC from cosm NOECs (Lepper, 2005). For instance, an assessment factor of 3 is used to derive the freshwater risk limit for the insecticide imidacloprid in Netherlands using a cosm-based NOEC value (Posthuma-Doodeman, 2008). Risk characterization is how the risk of a chemical can be estimated based on the predicted or measured exposure concentration and based on the effect assessment data, including PNEC values. Thus, the risk characterization integrates the exposure and effect assessments to visualize the possible risks of a chemical on the ecosystem. It is often performed by evaluating 
risk quotients $(\mathrm{RQ})$, which is the ratio between predicted and/or measured environmental concentration of a chemical and a concentration at which acceptable effects occur (PNEC) and followed by its interpretation (van Leeuwen and Vermeire, 2007; Shea and Thorsen, 2012).

As a result of its several advantages, the use of ES concept is emerging in ERA (Maltby et al., 2018; Faber et al., 2019). For example, it can serve as a tool to communicate risk assessment results to users such as policy makers and the general public (Faber and Van Wensem, 2012; Forbes and Calow 2012). The concept also help showing how effects of chemicals on SPU (ecosystem functional groups) can be cascaded to ES and benefits to people. However, a mechanistic tool linking ecotoxicological endpoints to ES assessment is still lacking (Faber et al., 2019).

\subsection{General objectives of the thesis}

Lake Ziway is a freshwater lake located in the Central Ethiopian Rift Valley region, Ethiopia and faces pollution pressures from agricultural activities in its catchment area and surrounding its shoreline. Smallholder farmers of vegetables and fruits and large-scale floriculture farms use irrigation water from the lake. These agrochemical intensive agricultural activities have put the lake under the pressure of agrochemical contamination (Hengsdijk and Jansen 2006, Feyissa and Ranjan, 2012; Mengistie et al., 2017; Teklu et al., 2018). Furthermore, Lake Ziway is under threat of urban activities due to the adjacent fast-growing towns of Batu and Meki (Beneberu and Mengistou, 2009; Fetahi, 2019). Habitat destruction (e.g., destruction of wetland macrophytes) and over-abstraction of irrigation water are other challenges the ecosystem is encountering (Legesse and Ayenew, 2006; Desta et al., 2015). These multiple anthropogenic pressures may cause ecological deterioration such as decline in water quality, reduction of water level, and destruction of lake habitats that ultimately impair the capacity of Lake Ziway to provide its ecosystem goods and services directly affecting the livelihood and well-being of the population in the region. However, a comprehensive study that explicitly examines the ecological impacts of the pollution due to these human activities, mainly agriculture and urban-related activities, to the lake ecosystem is lacking. Furthermore, toxicological data of pesticides for local aquatic species is almost absent. Therefore, this study aimed to assess the ecological impacts of agricultural and urban driven contaminants on Lake Ziway and its consequences for ecosystem service delivery of the lake. 
The specific research objectives of the thesis are:

1. To review the status and the variability in water quality and biological resources of Lake Ziway.

2. To assess the ecosystem goods and services that Lake Ziway supplies to the different stakeholders, and evaluate the potential impacts to them due to the current use of pesticide by smallholder and large-scale farmers found surrounding the lake.

3. To assess microplastic pollution in sediment and fish of Lake Ziway.

4. To perform biological and chemical monitoring to assess the impacts of pesticide residues to the Lake Ziway ecosystem.

5. To generate pesticide toxicity data specifically for tropical aquatic fauna and derive a safe environmental concentration in comparison to established data for temperate climatic zones.

\subsection{Outline of the thesis}

In Chapter 2, the biological resources and water quality status of the Lake Ziway are reviewed and the spatio-temporal variability of water quality of the lake is evaluated. In the review, special focus is given to nutrients, trace metals and pesticides. In addition, other important variables such as water abstraction for irrigation use, sediment load and microplastic pollution are discussed. Finally, the chapter identifies important future research needs and outlook for policy interventions for the protection of the lake.

The study described in Chapter 3 provides information about the ES of Lake Ziway which local and international (e.g., through trade flow) communities harvest and benefit from. The chapter further presents data on safety in use and handling of pesticides by smallholder farmers and large-scale farms located at the shoreline of Lake Ziway. Environmental and human health issues in relation to the misuse of pesticide and poor management of its wastes are explored. Hazard (e.g., pesticide use of the farmers) and associated risk (e.g., environmental conditions) assessments are discussed. Moreover, the potential impacts of pesticide on ES of Lake Ziway are assessed using a conceptual approach which links pesticide pollution of the lake with biological components of the lake that are instrumental in the delivery of ES.

Chapter 4 discusses the outcomes of a biological and chemical monitoring programme on the ecological risks of pesticides in Lake Ziway. The results of the quantification of residual 
pesticides (insecticides and fungicides), physicochemical variables in water and sediment samples are described. The functional and structural effects of environmental stress variables are discussed by correlating the monitored biological organisms of the lake (fish and macroinvertebrates) to the stress variables. Moreover, ecological risks of the single compound and mixtures of pesticides quantified in sediment and water samples of Lake Ziway are presented and discussed.

Chapter 5 examines the pollution of Lake Ziway by plastic particles (micro- and small macro-plastics). The study elucidates plastic particles distribution in gastrointestinal tracts of four fish species, that are important resources for income and subsistence food to local communities. In addition, plastic particles pollution in shoreline sediments of the lake and their spatio-temporal variation are studied. Furthermore, polymer identification of plastic particles found in fish and shoreline sediments were evaluated, and the potential sources are identified.

In Chapter 6, the effect of imidacloprid on structural (macroinvertebrates, phytoplankton and zooplankton) and functional (physico-chemical parameters, organic matter decomposition) parameters of a tropical aquatic ecosystem are presented. Effect threshold values (e.g., LC50/EC50 and NOEC) are presented and discussed in comparison with reported values in other climatic regions (e.g., temperate, sub-tropic and Mediterranean climate). In this chapter, observations on the recovery of affected species are also presented and discussed.

Finally, in Chapter 7, the key findings of the thesis in consideration of its specific research objectives are summarised and discussed. Lessons learnt, recommendations for governmental and non-governmental actors that help improve protection of the lake and its ES through averting pollution and eutrophication problems, and some future research that strengthen risk assessments of chemicals in aquatic ecosystems of Ethiopia are presented in this chapter. 



\section{CHAPTER 2}

Trends in chemical pollution and ecological status of Lake Ziway, Ethiopia: A review focussing on nutrients, metals and pesticides

Lemessa B. Merga, Alemayehu A. Mengistie, Jack H. Faber, Paul J. van den Brink

This chapter has been published in African Journal of Aquatic Science 45:4, 386-400. DOI: 10.2989/16085914.2020.1735987 


\section{Abstract}

Aquatic ecosystems contribute to human wellbeing by delivering ecosystem services, but its protection has been given low priority in Africa. Lake Ziway is found in Ethiopian rift valley basin providing services including irrigation, drinking water and fish food in the region. This paper reviews the biological resources, and spatio-temporal variation of water quality of the lake focussing on nutrients, metals and pesticides. Lake Ziway is under increasing agricultural and urban pressure with deteriorating trends in several water quality and ecological parameters. Nutrients and trace metals including $\mathrm{PO}_{4}{ }^{3-}, \mathrm{NO}_{3}{ }^{-}, \mathrm{NH}_{4}{ }^{+}, \mathrm{Ca}^{2+}, \mathrm{Cu}$ and $\mathrm{Ni}$ of the lake have shown increasing temporal trends in concentration. Spatially, higher values of major parameters (e.g. $\mathrm{NO}_{3}{ }^{-}, \mathrm{NH}_{4}{ }^{+}, \mathrm{K}, \mathrm{Na}$ and electrical conductivity) were observed at shoreline sites near floriculture farming. The water quality of the lake exceeded guideline values for drinking water (alkalinity and $\mathrm{Fe}$ ) and for aquatic life $\left(\mathrm{NH}_{4}{ }^{+}, \mathrm{Fe}, \mathrm{Cr}, \mathrm{Cu}\right.$ and $\left.\mathrm{Se}\right)$. The recently reported pesticides in the lake possibly cause ecological and human health effect. Thus, agriculture and urbanization are affecting water quality of Lake Ziway, with likely effects on human health and the lake ecosystem unless appropriate interventions are taken. Our results may be an indicator for other African lakes subject to similar anthropogenic activities in their catchments. 


\subsection{Introduction}

Human wellbeing is largely dependent on ecosystem goods and services (ES). This is particularly the case for useable water, irrigation and food supplied by aquatic ecosystems (Baron et al., 2002; MEA, 2005; Maltby et al., 2018; Faber et al., 2019). However, stewardship of aquatic ecosystems through protection and restoration interventions has not been given enough attention, especially in less developed areas (Baron et al., 2002; Ansara-Ross et al., 2012). In many developing countries anthropogenic activities such as unsustainable land-use, discharge of untreated municipal and industrial wastes, and intensive use of agrochemicals are affecting the quality of natural water bodies (Van de Meutter et al., 2006; Beyene et al., 2009; Ansara-Ross et al., 2012; Abong'o et al., 2015; Teklu et al., 2016), and may impair the capacity of these ecosystems to deliver expected ES (Maltby, 2013; Maltby et al., 2018).

Ethiopia is one of the water resource richest African countries (Awulachew et al., 2007). Lake Ziway (Fig. 2.1), situated between $7^{\circ} 51^{\prime}$ to $8^{\circ} 07^{\prime} \mathrm{N}$ and $38^{\circ} 43^{\prime}$ to $38^{\circ} 56^{\prime} \mathrm{E}$ is located 160 $\mathrm{km}$ south of the capital, Addis Ababa, Ethiopia, at an altitude of $1636 \mathrm{~m}$ above sea level (Endebu and Girma, 2016). Surface area, shoreline length and total catchment area of the lake are $442 \mathrm{~km}^{2}, 137 \mathrm{~km}$ and $7380 \mathrm{~km}^{2}$, respectively (Lemma and Desta, 2016). The mean and maximum depth of Lake Ziway were reported in the range of $2.5-4 \mathrm{~m}$ and $7-9 \mathrm{~m}$, respectively (Desta et al., 2015; Erko et al., 2016; Teklu et al., 2018). The differences in reported depth of the lake by several authors seems to be partly explained by the remarkable seasonal rain fall variation (Tamire Mengistou, 2012) of the region. The lake has two inflowing perennial rivers (Meki river and Ketar river), and drained into Lake Abjata via Bulbula river (Ayenew, 2007; Ayenew and Legesse, 2007). It is one of the largest freshwater lake found in Ethiopian rift valley basin possessing high environmental, economic and social significance (Sissay, 2003). For instance, the lake is known by its very high biodiversity values, fish production, tourism, irrigation for agriculture, and a potable water supply for an increasing population in the catchment (Sissay, 2003).

Over the last two decades commercial floriculture companies and smallholder vegetable producing farmers have swiftly expanded on the shoreline of Lake Ziway, along its feeder rivers and outflow river (Feyissa and Ranjan, 2012; Teklu, 2016; Mengistie et al., 2017; Teklu et al., 2018). These intensive agricultural activities have put the lake under pressure of agrochemical contamination. Furthermore, Lake Ziway is under threats of increasing 
urbanization, as the lake is situated adjacent to fast growing towns of Batu at the south-west side and Meki (Fig. 2.1) at the north-west side (Zinabu et al., 2002; Beneberu and Mengistou, 2009). Changes in the hydrology of Lake Ziway due to climate change are also expected, though less substantial compared to other man-made impacts (Seyoum et al., 2015). These multiple anthropogenic impacts may lead to a decline in water quality, a reduction of water level and a destruction of lake habitats (Ayenew, 2004; Legesse and Ayenew, 2006).

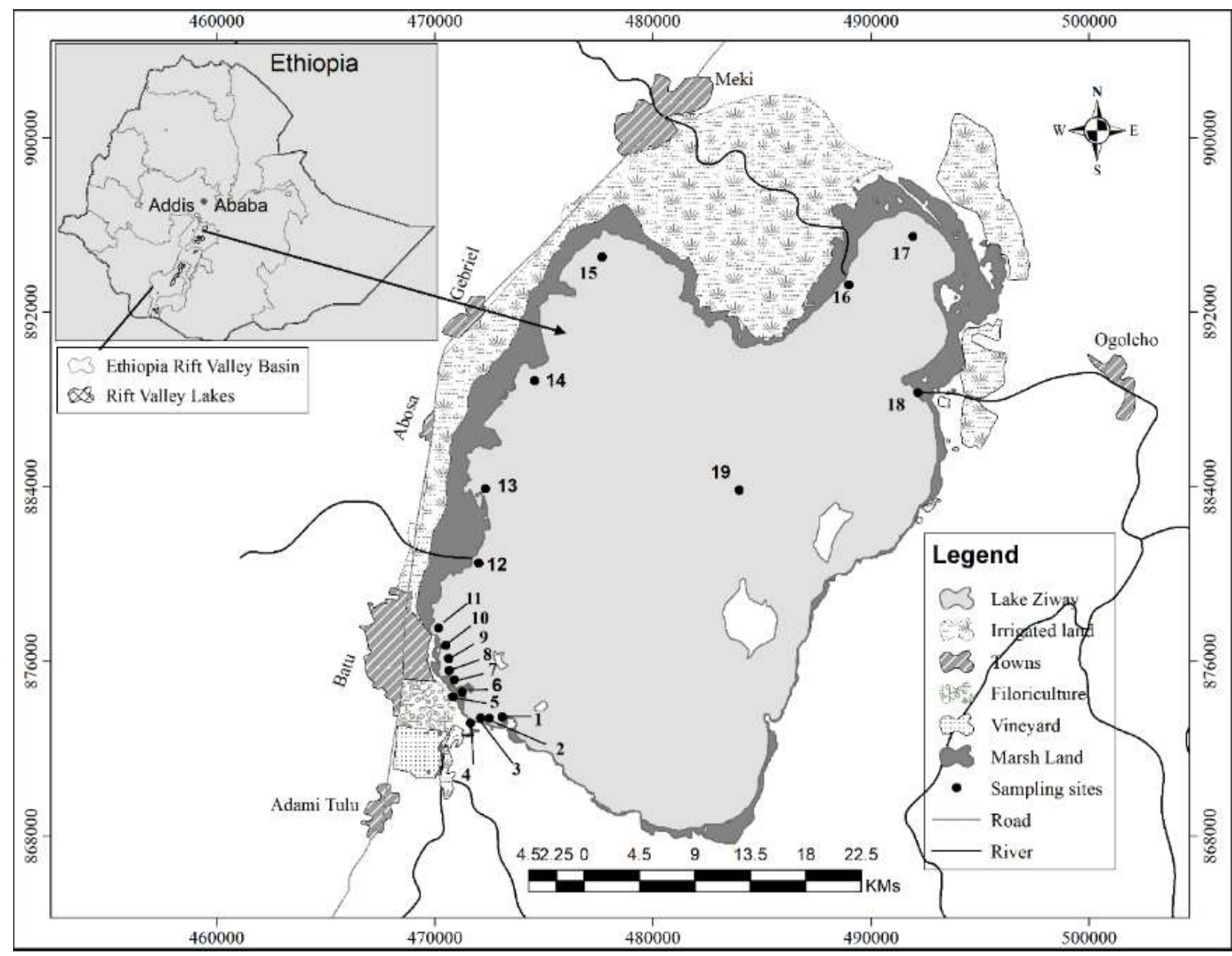

Fig. 2.1. Map of Lake Ziway, Ethiopia showing various shoreline human activities and sampling sites as evaluated by Teklu et al. (2018). The sampling sites are: Wamicha (1), Bochessa (2), Bulbula (3), Water Supply (4), Floriculture-2 (5), Floriculture-1(6), SEDA Nursery site (7), Fish production (8), Korokonch (9), Around lodges (10), Church (11), Edo-Kontola (12), Abosa (13), Gabriel (14), North western Lake (15), Meki River (16), Golbe North Eastern lake (17), Ketar River (18) and Lake centre (19). Source: Adopted from Teklu et al. (2018).

Several studies on physicochemical characteristics, pesticides contamination and trace metal levels of Lake Ziway have been reported (e.g., Wood and Talling, 1988; Zinabu et al., 2002; Zinabu and Pearce, 2003; Teklu et al., 2018). However, current status and temporal trends of water quality of the lake have not been reviewed systematically to inform research gaps and corrective management interventions. The main objective of this paper is to review the literature and reports on the status, temporal and spatial variability in water quality and 
biological resources of Lake Ziway with emphasis on nutrients, trace metals and pesticides. This review is also expected to assist in identifying pollution sources, designing monitoring programmes and contribute to the lake management decisions.

\subsection{Lake Ziway ecology}

In this section we review available reported data on species abundance, community composition, and current status and trends of the main biological components of the Lake Ziway ecosystem.

\subsubsection{Phytoplankton}

Kebede and Willen (1998) disclosed that Lake Ziway is the third richest lake in terms of phytoplankton species when compared to the other Ethiopian rift valley lakes with about 67 taxa reported. The identified taxa are mainly grouped into six classes including cyanophyceae, dinophyceae, diatomophyceae, chlorophyceae, euglenophyceae and charophyceae. Taxa from the cyanophyceae class were the dominant (48\%) and the species Anabaena cf. aphanizomenoides, Cylindrospermopsis africana, Planktolyng bya limnetica, Myxobactron spp. and Radiocystis geminata were found abundantly. Chlorophyceae and diatomophyceae taxa have also been reported as the second and third dominant phytoplankton groups of the lake, respectively (Kebede and Willen, 1998). Similarly, compared to the other Ethiopian rift valley lakes, the highest phytoplankton biovolume $\left(16 \mathrm{~mm}^{3} \mathrm{l}^{-1}\right)$ and biomass $(154 \mu \mathrm{g} / \mathrm{L})$ have been recorded in Lake Ziway whereas Cylindrospermopsis africana and Planktolyngbya limnetica, which belong to the cyanophyceae taxa, have been reported as major contributor (67\%) for the recorded phytoplankton biovolume (Kebede and Willen, 1998). However, there have been no repeat studies since Kebede and Willen (1998), so current status including spatial variability of the phytoplankton taxa of Lake Ziway are not clear.

\subsubsection{Zooplankton}

Lake Ziway has a diverse zooplankton species composition. In total 83 zooplankton taxa have been reported which include rotifers and crustaceans. The proportion of rotifers, copepod, cladocera and cyclopoid crustacea were $90 \%, 6.0 \%, 2.4 \%$ and $1.2 \%$ of the total zooplankton, respectively (Bryce, 1931; Cannicci and Almagia, 1947; Belay, 1988; Green, 1994; 
Dagne et al., 2008; Hailu, 2011). According to the recent study by Dagne et al. (2008), Anuraeopsis fissa, Brachionus angularis, Filinia novaezealandiae and Trichocerca ruttneri were numerically the most abundant rotifers of the lake, while Moina micrura and Diaphanosoma excisum were the two most dominant cladocera. Some rotifers, including Scaridium longicaudum, Mytilina mucronata, Lecane ungulata, Lecane curvicornis, Lecane flexilis, Lecane acus, Euchlanis dilatata, Diplois daviesiae, Brachionus plicatilis and Brachionus dimidiatus, were not recorded by recent study Dagne et al. (2008); but reported earlier by Bryce (1931). Moreover, Moina micrura and Daphnia barbata were reported in recent studies (Dagne et al., 2008; Hailu, 2011) but not by Bryce (1931). The ostracoda taxa Limnocythere thomasi, Gomphocythere angulata and Darwinula stevensoni were reported by Martens and Tudorancea (1991), but not recently reported. However, conclusions on the impacts of anthropogenic activities on the zooplankton community of the lake are difficult to determine.

\subsubsection{Fish}

Lake Ziway is the second most important fishery landing site of the country (Bekele and Hussien, 2015) with 3180 tons reported as being harvested in 1997 (LFDP, 1997) while empirical modelling estimated possible yields of 2500 to 6680 tons (Spliethoff et al., 2009). The fishery of the lake is a year-round source of subsistence food and income for many poor households in the region (Endebu et al., 2015). The lake is inhabited by fifteen fish species including Labeobarbus ethiopicus, Labeobarbus intermedius, Barbus paludinosus, Aplheilichthys aninorii, Lebias dispar, Oreochromis niloticus, Garra makiensis, Garra dembecha, Garra hirticeps, Garra quadrimaculata, Tilapia zillii, Carassius auratus, Carassius carassius, Cyprinus carpio and Clarias gariepinus. Of these fish species, L. ethiopicus and G. makiensis are endemic to the lake (Getahun and Stiassny, 1998; Golubtsov et al., 2002). The fishery of Lake Ziway is under threat due to anthropogenic activities (Hirpo, 2016). Recently, the annual fish yield of the lake dropped to almost a third from 3180 tons reported in 1997 by LFDP (1997) to 1157 tons reported in 2010 by Abera et al. (2018) accompanied by a shift in species composition (Fig. 2.2). For example, in 1994 the fish yield contributions of O. niloticus and C. carpio were $89 \%$ and $0.12 \%$, respectively. However, two decades later the contribution of $O$. niloticus decreased to $50 \%$, but the proportion of $C$. carpio increased to $28 \%$ (Endebu et al., 2015; Abera et al., 2018). 


\subsubsection{Macrophytes}

According to previous (Makin et al., 1976; Hughes and Hughes, 1992) and recent (Hailu, 2011; Tamire and Mengistou, 2012) studies, Lake Ziway supports about eighteen macrophyte species, including Pistia stratiotes, Nymphoides indica, Nymphaea lotus, Potamogeton schweinfurthii, Potamogeton lucens, Phragmites mauritianus, Cyperus papyrus, Cyperus articulatus, Echinochola colona, Arundo donax, Typha angustifolia, Typha latifolia, Typha domingensis, Schoenoplectus corymbosus, Echinochloa stagnina, Persicaria senegalensis, Ludwigia erecta and Ludwigia stolonifera. Of these species, $P$. stratiotes is a free-floating plant while the water-lilies $N$. indica and $N$. lotus are rooted with floating leaves. Potamogeton spp. are submerged, while the remainder are emergent macrophytes. We note that the freefloating adventive weed Eichhornia crassipes has also been reported in Lake Ziway (Stroud, 1994; Fishpool and Evans, 2001). These aquatic plants contribute invaluably to the functioning of the lake ecosystem, not only by provision of habitat and food for aquatic animal life, but also by producing oxygen, trapping sediment load and absorbing nutrients, and detoxifying organic pollutants (Dhir et al., 2009; Tamire and Mengistou, 2012). The recently observed increase in lake surface coverage by $P$. stratiotes and infestation of the exotic macrophyte, Eichhornia crassipes, in littoral parts of Lake Ziway in specific close to agricultural irrigations is probably a result of a high load of nutrients from the activities (Tamire and Mengistou, 2012).

The earlier studies by Makin et al. 1976, and Hughes and Hughes 1992 reported only the dominant macrophytes. Comparing earlier with recent reports, there is an indication of temporal change of macrophytes of Lake Ziway in composition and abundance. For instance, Cyperus papyrus, Phragmites mauritianus and T. domingensis were reported by Makin et al. (1976), and Hughes and Hughes (1992) as the dominant species in the lake, but this has been shifted to A. donax, E. colona and P. schweinfurthii according to the recent studies by Hailu (2011), and Tamire and Mengistou (2012). 


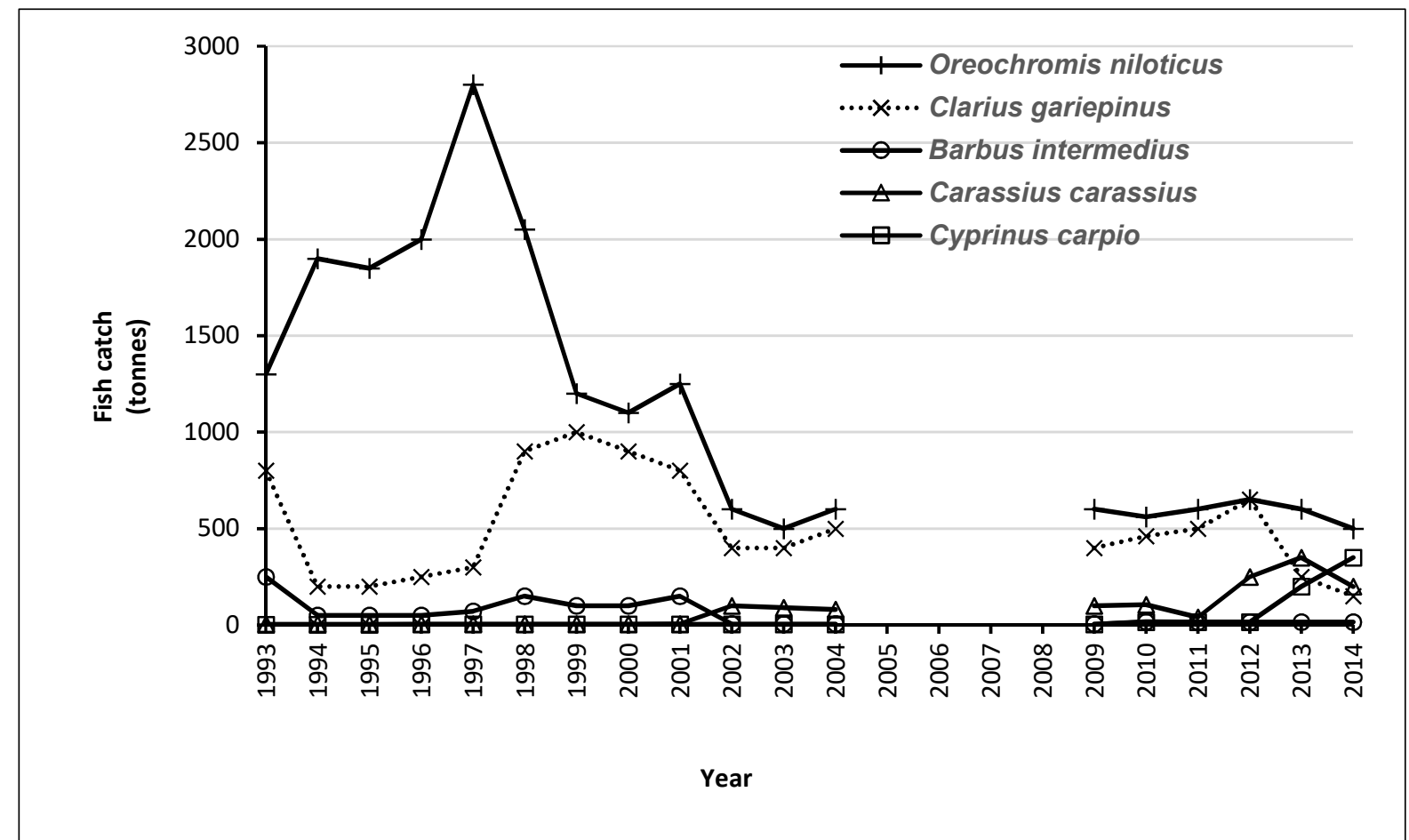

Fig. 2.2. Temporal trends of fish yield and fish catch species composition of Lake Ziway for the years 1993 to 2014, whereas data are missing for the year 2005 - 2008. Source Abera et al. (2018).

\subsubsection{Macroinvertebrates}

About 31 taxa belonging to diptera, oligochaeta, nematoda, ephemeroptera, gastropoda, hemiptera, odonata, lepidoptera and coleoptera were reported in Lake Ziway (Tudorancea et al., 1989; Hughes and Hughes, 1992; Hailu, 2011). Species from the orders diptera (29\%), gastropoda (29\%), nematoda (13\%) and ephemeroptera (10\%) were reported as the most abundant. These taxa are an important food source for fish and therefore the fishery (Macadam and Stockan, 2015). Macroinvertebrates are also a significant food source for the many species of water fowl (Covich et al., 1999), that in turn, are valued by eco-tourism ventures at Lake Ziway. The invertebrate fauna can also play a role in nutrient cycling and waste detoxification processes (Covich et al., 1999; Macadam and Stockan, 2015). Moreover, species such as beetles are useful as biological means to control disease causing organisms including malaria mosquitoes and snails that host the intermediate life cycle of schistosomiasis causing parasite (Sissay, 2003). Malaria and schistosomiasis are commonly observed in villages closer to Lake Ziway (Gari et al., 2016; Teklemariam et al., 2018). For instance, annual incidence of malaria in the region Lake Ziway found has been reported in the range of $5-25$ patients per 1000 individuals (Jima et al., 2012). 
Earlier studies by Tudorancea et al. (1989) and Hughes and Hughes (1992) were reported gastropoda taxa including Anisus natalensis, Biomphalaria sudanica, Bulinus forskalii, Bulinus truncatus, Melanoides tuberculata and Lymnaea natalensis as the most common macroinvertebrates of Lake Ziway. But, the recent study by Hailu (2011) were reported diptera taxa including Chironomidae spp., Microchironomus spp., Dicrotendipes spp. and Ceratopogonidae spp. as the most common macroinvertebrates of the lake. In addition, Hailu (2011) has reported macroinvertebrates taxa including ephemeroptera (Baetidae spp., Caenidae spp. and Potamanthidae spp.) hemiptera (Corixidae spp. and Pentatomidae spp.), odonata (Coenagrionidae spp.), lepidoptera (Psychodidae spp.), gastropoda (B. sudanica and M. tuberculata) and coleoptera (Elmidae spp.). Comparing earlier with recent reports, there is an indication of variation in abundance and composition of macroinvertebrates of Lake Ziway over time.

\subsubsection{Birds}

Lake Ziway is reported as the key bird site of the country (Urban, 1969; Spliethoff et al., 2009), seasonally supporting over thousands of birds. The lake ecosystem is of regional importance and is one of the 68 potential Ramsar Sites that Ethiopia owned (BLI, 2019). The most commonly observed bird species in the wetlands around the lake are Pelecanus onocrotalus, Leptoptilos crunemferus, Dendrocygna bicolor, Dendrocygna viduata, Thalassornis leuconotus, Larus cirrocephalus, Larus ridibundus, Chlidonias hybridus, and Chlidonias leucopterus (Urban, 1969; Lemma, 2005). The first bird inventory conducted in 1990s (Syvertsen, 1995; EWNHS, 1996) was indicated that Lake Ziway support more than 270 bird species (about 20000 individual birds). However, the most recent survey conducted in 2000 (Wondefrash, 2003) showed that the numbers have dropped to about 58 resident and migratory water-fowl species with a total population size of 1,855 individuals. The population decline of birds of the lake observed between 1990 and 2000 could be partly due to the destruction of habitats that serve the birds as roosting and stop-over sites. This habitat damage includes conversion of riverine woodlands, wet grasslands and marginal wetlands of the lake into agricultural irrigation and grazing lands (Mengesha et al., 2014). 


\subsubsection{Mammals}

Only one study (Lemma, 2005) has been published on wild mammals supported by the Lake Ziway ecosystem. According to that study, Phacochoerus africanus (warthog), Hippopotamus amphibius, Tragelaphus strepsiceros (greater kudu), Sylvicapra grimmia (common duiker) and Colobus guereza are the mammals that use riverine woodlands and marginal wetlands of the lake ecosystem as home and source of food. Because there have been no repeated survey studies after the most recent data by Lemma (2005), trends and current status of mammals of Lake Ziway are unknown.

\subsection{Physicochemical parameters}

In this section, temporal trends and spatial variation of physicochemical characteristics, and water quality status of Lake Ziway are presented and discussed. Parameter levels reported from 1960s to 2015 , water quality trends and water quality status are summarized in Table 2.1, Table 2.2a and Table 2.2b, respectively. In Table 2.1 only sites and parameters that have shown increasing or decreasing temporal trends were reported, but detailed summary for all sites and parameters is given in Table S12.1. To discuss trends and water quality exceedances of Lake Ziway in general, data from the centre of the lake (site 19) were used. Data set containing recent measurements, as this the only available data set without missing values (Table SI2.2), of several physicochemical parameters described by Teklu et al. (2018) was used to perform redundancy analysis (RDA) by including sampling dates and sites as explanatory variables (Fig. 3.3). Canoco for Windows package was used according to Ter Braak and Šmilauer, (2018) for the analysis. This RDA was used mainly to visualise the spatial variation in the parameters between thirteen sampling sites (Fig. 2.1) and at six dates between June 2013 and February 2015 (Teklu et al., 2018).

The water quality status of Lake Ziway for drinking water and for freshwater aquatic life are evaluated by reference to a guideline set by Ethiopian Drinking Water Guideline (EDWG) (MoH, 2011). But in case where values not found in EDWG other several international guidelines those set by the World Health Organization (WHO, 2011), the US Environmental Protection Agency (US-EPA, https://www.epa.gov/wqs-tech), the Canadian Council of Ministers of the Environment (CCME, https://www.ccme.ca/), the Australian and New Zealand Environment and Conservation Council (ANZECC) (ANZECC, 1992) and the European 
Communities (EU, 1998) were used. Only mean and the most recently reported values were compared with these guideline values to evaluate the water quality status of the lake.

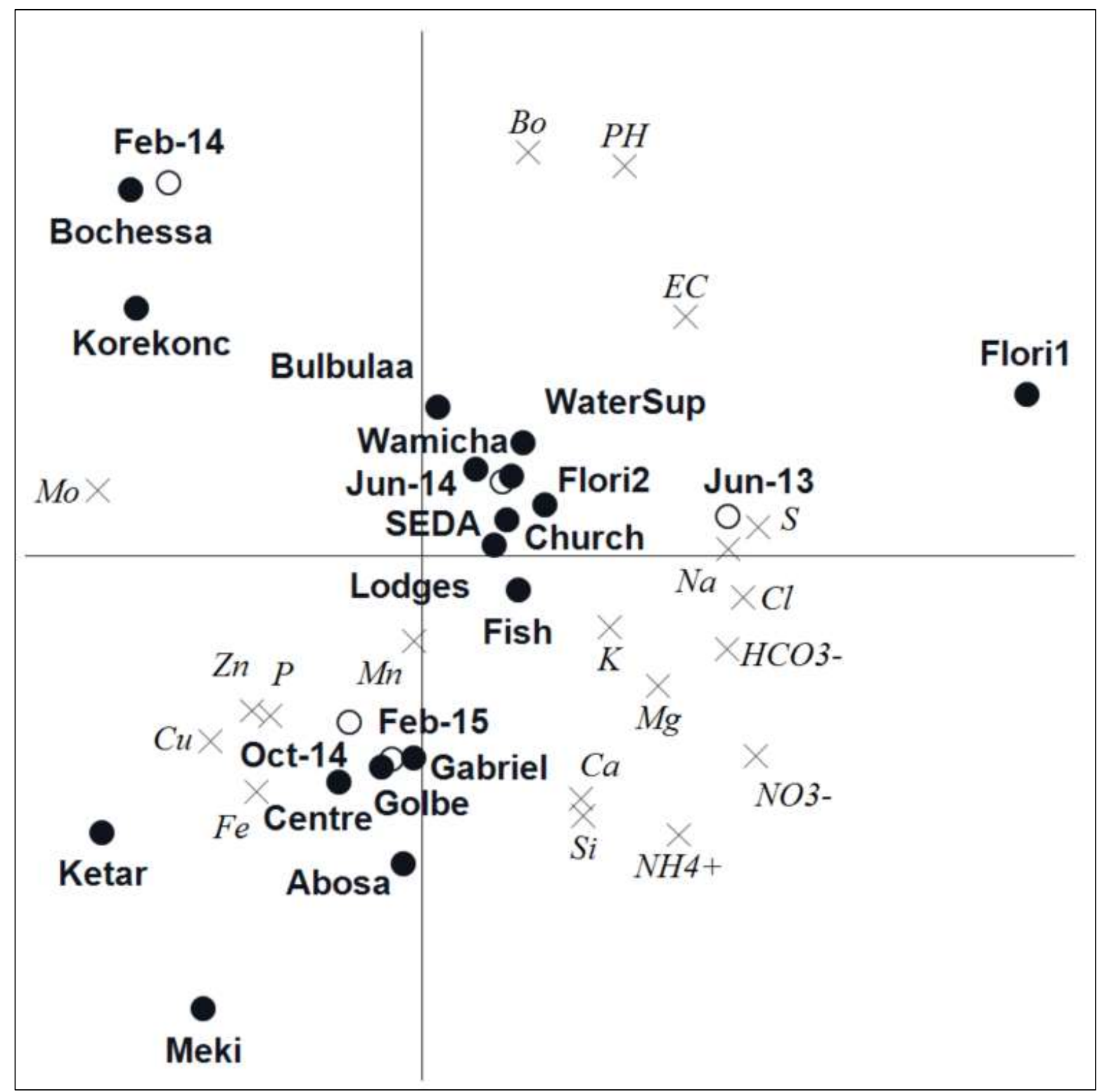

Fig. 2.3. RDA biplot showing the correlations between sampling date and site, and the physicochemical parameters. Sampling date and site explained a significant proportion of the variation in physicochemical parameter value $(42 \%$; $P=0.004)$ levels. Of this variation in physico-chemical parameters between sites and dates, $33 \%$ is displayed on the horizontal axis and another $25 \%$ on the vertical axis. For the location of the sites refer to Fig. 2.1. Abbreviated site names such as WaterSup, Flori2, Flori1, SEDA, Fish and Korokonc represent site number 4, 5, 6, 7, 8 and 9, respectively. The black solid, open circle and " $x$ " mark represent sampling site, sampling date and parameter, respectively.

\subsubsection{Spatio-temporal variation}

Generally water quality parameters of Lake Ziway including $\mathrm{Ca}^{2+}, \mathrm{NO}_{3}{ }^{-}$, alkalinity and $\mathrm{NH}_{4}{ }^{+}$ have shown increasing temporal trend, while $\mathrm{SO}_{4}{ }^{2-}, \mathrm{SiO}_{2}$, total phosphorus $(\mathrm{P})$ and $\mathrm{HCO}_{3}{ }^{-}$have exhibited decreasing trend (see sample site 19 in Table 2.1 and 2a). At shoreline sites, nutrients such as $\mathrm{NO}_{3}{ }^{-}$(at Bulbula, Fish production, Abosa, Meki river and Ketar river), and the 
$\mathrm{PO}_{4}{ }^{3-}$ (at Meki river) have shown increasing temporal trend (Table 2.1, Table 2.2a). The other sites are either have insufficient data or have no remarkable temporal trend (Table SI2.1). RDA analysis (Fig. 2.3) shows the variation in physicochemical parameter value levels between the sites of Lake Ziway. A significant part of the variation $(42 \%, p=0.004$; Monte Carlo permutation test) is explained by sampling date and sample location. At the site close to the floriculture farm (Floriculture-1) relatively higher levels of the majority of physicochemical including $\mathrm{EC}, \mathrm{Ca}^{2+}, \mathrm{Mg}^{2+}, \mathrm{Na}^{+}, \mathrm{K}^{+}, \mathrm{Cl}^{-}$, and $\mathrm{HCO}_{3}{ }^{-}, \mathrm{SO}_{4}{ }^{2-}$ and $\mathrm{NO}_{3}{ }^{-}$were observed resulting in the separation by the RDA of this site (Fig. 2.3). Similarly, at Meki and Ketar sites higher level of P and metals were found that also resulted in the RDA separating these sites (Fig. 2.3).

\subsubsection{Exceedance of water quality guideline values}

Generally, none of the reported parameters of Lake Ziway exceeded drinking water quality guideline value except alkalinity. The observed exceedance of alkalinity of the lake was likely not caused by anthropogenic activities, because the alkalinity of many other East African shallow lakes are naturally high (Ndungu et al., 2014). At various shoreline sites parameters such as $\mathrm{NO}_{3}{ }^{-}$(at Floriculture-1 and Golbe), pH (at Wamicha, Bochessa, Bulbula, Water Supply, Floriculture-1, SEDA Nursery and Church), and alkalinity (at Water Supply, Floriculture-2, SEDA Nursery, Fish production, Korokonch and Around lodges) were exceeded drinking water guideline values (Table 2.1, Table 2.2b and Table SI2.1). Generally, except $\mathrm{NH}_{4}{ }^{+}$no water quality parameter reported in Lake Ziway was found that exceeded ecological guideline values, while parameters including $\mathrm{NO}_{3}{ }^{-}$(at Water Supply, Floriculture-2, Floriculture-1, SEDA Nursery, Church, Abosa, Meki River, Golbe and Ketar River), P (at Meki River) and $\mathrm{NH}_{4}{ }^{+}$(at all sites) exceeded ecological guideline values at shoreline sites of the lake (Table 2.1, Table 2.2b and Table SI2.1). 
Table 2.1. Physicochemical properties of Lake Ziway reported by previous studies since 1961 for various sites of the lake. The data are presented as mean with standard deviation (SD) or with range or only mean value in case $\mathrm{SD} /$ range not reported. The values are expressed in $\mathrm{mg} / \mathrm{L}$ except for conductivity $(\mu \mathrm{S} / \mathrm{cm}), \mathrm{PO}{ }_{4}^{3-}(\mu \mathrm{g} / \mathrm{L})$ and alkalinity $(\mathrm{meq} / \mathrm{L})$. Values in parentheses () and in square brackets [ ] in the table headings indicate maximum permissible levels (MPL) according to standards for ecological quality and for drinking water, respectively. The guidelines used are indicated "A" for ANZECC, "E" for EU, "W" for WHO, "C" for CCME, "U" for USEPA and "ET" for EDWG. Values in bold are those above MPL in ecological quality and/or in drinking water. Numbers in the table refer to site numbers shown in Fig. 2.1.

\begin{tabular}{|c|c|c|c|c|c|c|c|c|c|}
\hline $\begin{array}{l}\text { Site } \\
\text { No. }\end{array}$ & Reported date & Reference & $\begin{array}{l}\mathrm{PO}_{4}{ }^{3-} \\
\text { (NA) } \\
\text { [NA] }\end{array}$ & $\begin{array}{r}P \\
(0.02) \mathrm{C} \\
{[\mathrm{NA}]}\end{array}$ & $\begin{array}{r}\mathrm{NH}_{4}{ }^{+} \\
(0.103) \mathrm{C} \\
{[2] \mathrm{ET}}\end{array}$ & $\begin{array}{r}\mathrm{NO}_{3}{ }^{-} \\
(13) \mathrm{C} \\
{[50] \mathrm{ET}}\end{array}$ & $\begin{array}{r}\text { Alkalinity } \\
(>0.4) U \\
{[4] \mathrm{ET}}\end{array}$ & $\begin{array}{r}\mathrm{HCO}_{3}^{-} \\
\text {(NA) } \\
\text { [NA] }\end{array}$ & $\begin{array}{r}\text { Conductivity } \\
(1500) \mathrm{A} \\
{[2500] \mathrm{E}}\end{array}$ \\
\hline 3 & Mar. - May 2010 and Oct. - Dec. 2010 & Tamire and Mengistou (2012) & $40.8 \pm 8.8$ & - & - & $0.07 \pm 0.02$ & - & - & $445 \pm 25$ \\
\hline 3 & Oct. 2012 - Sept. 2014 & Hirpho (2016) & $50.3 \pm 3.9$ & - & - & $0.031 \pm 0$ & - & - & $397 \pm 6$ \\
\hline 3 & June 2013 - Feb. 2015 & Teklu et al. (2018) & - & $0.005 \pm 0.002$ & $0.6 \pm 0.5$ & $9.5 \pm 6.5$ & $3.9 \pm 1.3$ & $257 \pm 26$ & $442 \pm 34$ \\
\hline 8 & Jan. 2001 - Dec. 2002 & Erko et al.(2006) & _ & - & _ & $2.3(0.8-4.7)$ & _ & _ & $435(378-472)$ \\
\hline 8 & Nov. 2003 - Aug. 2004 & Beneberu and Mengistou (2009) & $211(20-380)$ & _- & _ & $0.19(0.2-0.6)$ & _- & _ & _ \\
\hline 8 & Mar. - May 2010 and Oct - Dec 2010 & Tamire and Mengistou (2012) & $64.5 \pm 32$ & _ & _ & $0.09 \pm 0.03$ & - & _ & $432 \pm 12$ \\
\hline 8 & June 2013 - Feb. 2015 & Teklu et al. (2018) & _ & $0.005 \pm 0.002$ & $0.8 \pm 0.75$ & $12.7 \pm 6.1$ & $4.1 \pm 1.3$ & $269 \pm 22$ & $447 \pm 41$ \\
\hline 13 & Oct. 2012 - Sept. 2014 & Hirpho (2016) & $59.2 \pm 36$ & _ & _- & $0.04 \pm 0.0$ & _- & _ & $484 \pm 15$ \\
\hline 13 & Oct. 2014 - Feb. 2015 & Teklu et al. (2018) & _ & $0.005 \pm 0$ & $1.02 \pm 0.7$ & $16.7 \pm 3.7$ & _ & $250 \pm 29$ & $425 \pm 21$ \\
\hline 16 & Mar. - May 2010 and Oct - Dec 2010 & Tamire and Mengistou (2012) & $24.4 \pm 6.2$ & - & _- & $0.9 \pm 0.02$ & _- & _ & $451 \pm 13$ \\
\hline 16 & Oct. 2012 - Sept. 2014 & Hirpho (2016) & $42.6 \pm 4.1$ & _ & _- & $0.03 \pm 0.0$ & _- & _ & $405 \pm 26$ \\
\hline 16 & June 2013 - Feb. 2015 & Teklu et al. (2018) & - & $0.2 \pm 0.3$ & $0.8 \pm 1.2$ & $42.3 \pm 65.1$ & - & $166 \pm 73$ & $320 \pm 116$ \\
\hline 18 & Mar. - May 2010 and Oct. - Dec. 2010 & Tamire and Mengistou (2012) & $29.05 \pm 19$ & _ & _ & $0.03 \pm 0.01$ & _- & _ & $424 \pm 6$ \\
\hline 18 & Oct. 2012 - Sept. 2014 & Hirpho (2016) & $43.7 \pm 24.5$ & _ & _- & $0.03 \pm 0.0$ & _- & _ & $377 \pm 23$ \\
\hline 18 & June 2013 - Feb. 2015 & Teklu et al. (2018) & - & $0.05 \pm 0.1$ & $0.18 \pm 0.3$ & $56.6 \pm 117.4$ & - & _ & $450 \pm 633$ \\
\hline 19 & May 1961 & Talling \& Talling (1965) & - & 0.17 & - & - & 3.9 & _ & 370 \\
\hline 19 & March 1964 & Wood \& Talling (1988) & - & _ & - & _ & 3.3 & - & 361 \\
\hline 19 & January 1976 & Von Damm and Edmond (1984) & _ & _- & _ & _- & 3.2 & - & _ \\
\hline 19 & August 1988 & Gizaw (1996) & - & _ & - & _ & - & 367 & - \\
\hline 19 & March 1991 & Kebede et al. (1994) & $<1$ & $0.2 \overline{2}$ & $0 . \overline{4}$ & - & - & _ & 410 \\
\hline 19 & $1990-2000$ & Zinabu et al. (2002) & $34(2.5-220)$ & - & - & - & - & - & $388(295-468)$ \\
\hline 19 & Nov. 2003 - Aug. 2004 & Beneberu and Mengistou (2009) & $90(40-170)$ & - & - & $0.4(N D-0.8)$ & - & - & \\
\hline 19 & Jan. - Dec. 2005 & Tilahun and Ahlgren (2010) & $10.2 \pm 5.9$ & $0.069 \pm 0$ & $0.11 \pm 0.08$ & $0.0032 \pm 0.003$ & $4.9 \pm 0.8$ & - & $478 \pm 32.8$ \\
\hline 19 & January 2008 & Masresha et al. (2011) & - & - & _ & 0.05 & _ & 247 & 479 \\
\hline 19 & July 2009 & Masresha et al. (2011) & & & - & & - & 255 & 530 \\
\hline 19 & Mar. - May 2010 and Oct - Dec 2010 & Tamire and Mengistou (2012) & $25.6 \pm 8.4$ & _ & $0.15 \pm 0.02$ & $0.044 \pm 0.01$ & - & _ & $399 \pm 18$ \\
\hline 19 & Oct. 2012 - Sept. 2014 & Abera et al. (2018) & $38.2 \pm 19.1$ & _ & $0.13 \pm 0.0$ & $0.02 \pm 0.0$ & _ & _ & $367 \pm 2$ \\
\hline 19 & Oct. 2014 - Feb. 2015 & Teklu et al. (2018) & - & $<0.01$ & $0.86 \pm 0.63$ & $10.2 \pm 8.2$ & - & $237 \pm 23$ & $295 \pm 120$ \\
\hline
\end{tabular}

Note: NA = guideline value not available 


\begin{tabular}{|c|c|c|c|c|c|}
\hline Site No. & Reported date & Reference & $\begin{array}{r}\mathrm{Ca}^{2+} \\
\text { (NA) } \\
{[300] \mathrm{W}}\end{array}$ & $\begin{array}{r}\mathrm{SO}_{4}{ }^{2-} \\
\text { (NA) } \\
{[250] \mathrm{W}}\end{array}$ & $\begin{array}{l}\mathrm{SiO}_{2} \\
\text { (NA) } \\
\text { [NA] }\end{array}$ \\
\hline 19 & May 1961 & Talling \& Talling (1965) & 10 & 28.8 & 47 \\
\hline 19 & March 1964 & Wood \& Talling (1988) & 14 & 9.6 & 45 \\
\hline 19 & January 1976 & Von Damm and Edmond (1984) & 14 & 4.8 & _ \\
\hline 19 & August 1988 & Gizaw (1996) & 17.3 & 6 & _ \\
\hline 19 & March 1991 & Kebede et al. (1994) & 11.22 & 15.4 & 37 \\
\hline 19 & $1990-2000$ & Zinabu et al. (2002) & $16(11-23)$ & $4.8(1.9-15.4)$ & $21(13-37)$ \\
\hline 19 & Jan. - Dec. 2005 & Tilahun and Ahlgren (2010) & - & - & $23.9 \pm 9.2$ \\
\hline 19 & January 2008 & Masresha et al. (2011) & 21.3 & 6.7 & _- \\
\hline 19 & July 2009 & Masresha et al. (2011) & 12 & 7.8 & - \\
\hline 19 & Mar - May 2010 and Oct - Dec 2010 & Tamire and Mengistou (2012) & - & - & - \\
\hline 19 & Oct. 2012 - Sept. 2014 & Hirpo (2016) & - & - & _ \\
\hline 19 & Oct. 2014 - Feb. 2015 & Teklu et al. (2018) & $21 \pm 3$ & $2.3 \pm 0.4$ & $15.9 \pm 4.3$ \\
\hline
\end{tabular}

Note: $\mathbf{N A}=$ guideline value not available 
Table 2.2. Summary of water and sediment quality temporal trend, and exceedance of guidelines for various sites of Lake Ziway based on physicochemical and trace metals parameters. The arrows $(\rightarrow),(\uparrow)$ and $(\downarrow)$ indicate no remarkable change, increasing trend and decreasing trend, respectively. Sites with insufficient data for trend analysis and parameters for which guideline values not found were not reported in this table. Numbers in the table refer to site numbers shown in Fig. 2.1.

\begin{tabular}{|c|c|c|c|c|c|c|c|}
\hline \multicolumn{8}{|c|}{ a). Physico-chemical parameters and heavy metals: temporal trend observed for various sites (for water column) } \\
\hline \multirow[t]{2}{*}{ Parameter } & \multicolumn{3}{|c|}{ Temporal trend } & \multirow[t]{2}{*}{ Parameter } & \multicolumn{3}{|c|}{ Temporal trend } \\
\hline & $\rightarrow$ & $\uparrow$ & $\downarrow$ & & $\rightarrow$ & $\uparrow$ & $\downarrow$ \\
\hline Conductivity & $3,8,16,18,19$ & no site & 13 & Bicarbonate & no site & no site & 19 \\
\hline Potassium & 8,19 & no site & no site & Chlorophyll-a & 19 & no site & no site \\
\hline Sodium & 8,19 & no site & no site & Temperature & $3,16,18,19$ & no site & no site \\
\hline Calcium & 8 & 19 & no site & As & 19 & no site & no site \\
\hline Sulphate & no site & no site & 19 & $\mathrm{Zn}$ & no site & no site & 19 \\
\hline Silicate & no site & no site & 19 & $\mathrm{Cd}$ & 19 & no site & no site \\
\hline Nitrate & no site & $\begin{array}{r}3,8,13,16,18 \\
19\end{array}$ & no site & $\mathrm{Cu}$ & no site & 19 & no site \\
\hline $\mathrm{pH}$ & $\begin{array}{r}3,8,13,16,18 \\
19\end{array}$ & no site & no site & $\mathrm{Fe}$ & 19 & no site & no site \\
\hline Orthophosphate & $3,8,18,19$ & 16 & no site & $\mathrm{Cr}$ & 19 & no site & no site \\
\hline Total Alkalinity & no site & 19 & no site & $\mathrm{Mn}$ & 19 & no site & no site \\
\hline Total phosphate & no site & no site & 19 & $\mathrm{Ni}$ & no site & 19 & no site \\
\hline Magnesium & 19 & no site & no site & $\mathrm{Se}$ & no site & no site & 19 \\
\hline Chloride & 19 & no site & no site & Co & 19 & no site & no site \\
\hline Ammonia & no site & 19 & no site & $\mathrm{Pb}$ & 19 & no site & no site \\
\hline \multicolumn{8}{|c|}{ b). Physico-chemical parameters and heavy metals: ecological quality and drinking water exceedance } \\
\hline & \multicolumn{2}{|c|}{ Water column } & & \multicolumn{2}{|c|}{ Water column } & \multicolumn{2}{|l|}{ Sediment } \\
\hline Parameter & $\begin{array}{l}\text { Site(s) with } \\
\text { exceeded } \\
\text { value for } \\
\text { Ecological } \\
\text { quality }\end{array}$ & $\begin{array}{l}\text { Site(s) with } \\
\text { exceeded value } \\
\text { for drinking } \\
\text { water }\end{array}$ & Parameter & $\begin{array}{l}\text { Site(s) with } \\
\text { exceeded } \\
\text { value for } \\
\text { Ecological } \\
\text { quality }\end{array}$ & $\begin{array}{l}\text { Site(s) with } \\
\text { exceeded } \\
\text { value for } \\
\text { drinking } \\
\text { water }\end{array}$ & $\begin{array}{l}\text { Site(s) wi } \\
\text { exceeded } \\
\text { for sedime } \\
\text { quality }\end{array}$ & alue \\
\hline Conductivity & no site & no site & As & no site & no site & no site & \\
\hline Potassium & NA & no site & $\mathrm{Zn}$ & no site & no site & no site & \\
\hline Sodium & NA & no site & $\mathrm{Cd}$ & no site & no site & 10 & \\
\hline Calcium & NA & no site & $\mathrm{Cu}$ & all sites & no site & no site & \\
\hline Sulphate & NA & no site & $\mathrm{Fe}$ & all sites & all sites & NA & \\
\hline Nitrate & $\begin{array}{r}4,5,6,7,11,13 \\
16,17,18\end{array}$ & 6,17 & $\mathrm{Cr}$ & 19 & no site & no site & \\
\hline $\mathrm{pH}$ & no site & $1,2,3,4,6,7,11$ & $\mathrm{Mn}$ & NA & no site & NA & \\
\hline Total Alkalinity & no site & $\begin{array}{r}4,5,7,8,9,10 \\
19\end{array}$ & B & no site & $2,9,18$ & - & \\
\hline Total phosphate & 16 & NA & $\mathrm{Ni}$ & no site & no site & 19 & \\
\hline Chloride & no site & no site & Se & 19 & no site & NA & \\
\hline Ammonia & all sites & no site & $\mathrm{Pb}$ & 2,11 & 2,11 & no site & \\
\hline
\end{tabular}

Note: $\mathrm{NA}=$ no guideline value is available

\subsection{Trace metal contamination}

The aforementioned drinking water and ecological quality guidelines are also used to assess water quality status of the lake with respect to trace metals, while sediment quality guideline values set by the Canadian Council of Ministers of the Environment (https://www.ccme.ca/) was used to evaluate sediment quality status of the lake for aquatic life. General trends and quality exceedances of Lake Ziway were discussed using data from the centre of the lake (site number 19 of Table 2.3 and 2.4). Only mean and the most recently 
reported values were compared with standard guideline values to evaluate the quality status of the lake. Temporal trends and water quality guideline exceedances by trace metals in the lake are summarized in Table 2.2a and 2.2b, respectively. Trace metal concentrations in Lake Ziway reported by previous studies are summarised for water (Table 2.3) and sediment (Table 2.4).

\subsubsection{Spatio-temporal variation}

Generally, an increasing temporal trend was observed for copper and nickel, while zinc and selenium have shown decreasing trend for the water column of Lake Ziway (Table 2.2a; Table 2.3). Temporal trend for shoreline locations were not evaluated due to insufficient data (see Table 2.3). Spatial variability was also observed for water trace metals. High concentrations of $\mathrm{Zn}, \mathrm{Cu}, \mathrm{Fe}$ and $\mathrm{Mn}$ at Meki and Ketar sampling sites were measured (Fig. 2.3; Table 2.3). Sediment trace metal temporal trends were not evaluated because the sampling dates were missing from the reports (see Table 2.4). However, spatial variation along various sites of the lake has been observed (Table 2.4). Accordingly, highest values of sediment trace metals were measured at shoreline sites where intensive agricultural activities are practiced (at Floriculture-1 $\mathrm{Cu}$ and V), and sites that receive urban effluents (at Around lodges: Fe, $\mathrm{Zn}, \mathrm{Ag}$, $\mathrm{Cd}$ and $\mathrm{Sn}$, and Korokonch: $\mathrm{Cr}$ ). Comparing with the other sample sites, sediment from centre of the lake has also been reported with highest trace metal values of $\mathrm{Ni}, \mathrm{Mn}, \mathrm{As}$, Se and $\mathrm{Pb}$ (Table 2.4).

\subsubsection{Exceedance of water quality guideline values}

The level of Fe exceeded the drinking water maximum permissible level (MPL) in all sites, while at some shoreline sites trace metals including B (at Bochessa, Korokonch and Ketar River) and $\mathrm{Pb}$ (at Bochessa and Church) exceeded the guideline values (Table 2.3 and Table 2.2b). Metals including $\mathrm{Fe}, \mathrm{Cr}, \mathrm{Cu}$ and Se have also exceeded ecological quality guideline value at the centre of Lake Ziway, while at shoreline sites $\mathrm{Cu}$ and Fe (at all sites) and $\mathrm{Pb}$ (at Bochessa and Church) exceeded the guideline values (Table 2.3 and Table 2.2b). Sediment quality assessment for freshwater aquatic life indicates that the concentration of $\mathrm{Ni}$ at the centre of Lake Ziway (site number 19) and $\mathrm{Cd}$ at Around lodges shoreline site (site number 10) were exceeded ecological guideline value (Table $2.2 \mathrm{~b}$ and Table 2.4). Therefore, at current 
Chapter 2

concentrations these metals, $\mathrm{Ni}$ and $\mathrm{Cd}$, may pose risk for the ecological integrity of the Lake Ziway ecosystem. 
Table 2.3. Water column concentration of heavy metals in Lake Ziway reported by previous studies since 1996 for various sites of the lake. The data are presented as mean with standard deviation (SD) or only mean value in case SD not reported. The values are expressed in $\mu \mathrm{g} / \mathrm{L}$ except for $\mathrm{Fe}(\mathrm{mg} / \mathrm{L})$ and $B(\mathrm{mg} / \mathrm{L})$. Values in parentheses () and in square brackets [ ] in the table headings indicate maximum permissible levels (MPL) according to international standards for ecological quality and for drinking water, respectively. The guidelines used are indicated as "W" for WHO, "C" for CCME and "ET" for EDWG. Values in bold are those above MPL in ecological quality and/or in drinking water. Numbers in the table refer to site numbers shown in Fig. 2.1.

\begin{tabular}{|c|c|c|c|c|c|c|c|c|}
\hline $\begin{array}{l}\text { Site } \\
\text { No. }\end{array}$ & Reported date & Reference & $\begin{array}{r}\text { As } \\
(50) C \\
{[10] E T}\end{array}$ & $\begin{array}{r}\mathrm{Zn} \\
(30) \mathrm{C} \\
{[6000] \mathrm{ET}}\end{array}$ & $\begin{array}{r}\text { Cd } \\
(0.8) \mathrm{C} \\
{[3] \mathrm{ET}}\end{array}$ & $\begin{array}{r}\mathrm{Cu} \\
(2) \mathrm{C} \\
{[5000] \mathrm{ET}}\end{array}$ & $\begin{array}{r}\mathrm{Fe} \\
(0.3) \mathrm{C} \\
{[0.4] \mathrm{ET}}\end{array}$ & $\begin{array}{r}\mathrm{Cr} \\
(2) \mathrm{C} \\
{[50] \mathrm{W}}\end{array}$ \\
\hline 1 & June 2013 - Feb. 2015 & Teklu et al. (2018) & - & $5 \pm 2.4$ & - & $10 \pm 4.9$ & $1.3 \pm 0.6$ & _ \\
\hline 2 & not reported & Nigussie et al. (2010) & _ & $460 \pm 3$ & _ & - & - & _ \\
\hline 2 & June 2013 - Feb. 2015 & Teklu et al. (2018) & _ & $5 \pm 2.4$ & _ & $10 \pm 4.9$ & $2.8 \pm 3.6$ & _ \\
\hline 3 & June 2013 - Feb. 2015 & Teklu et al. (2018) & _ & $5 \pm 2.6$ & _ & $10 \pm 5.2$ & $1.1 \pm 0.9$ & _ \\
\hline 4 & June 2013 - Feb. 2015 & Teklu et al. (2018) & _ & $5 \pm 2.6$ & _ & $10 \pm 5.2$ & $1.2 \pm 0.9$ & _ \\
\hline 5 & June 2013 - Feb. 2015 & Teklu et al. (2018) & _ & $5 \pm 2.6$ & _ & $10 \pm 5.2$ & $1.7 \pm 1.2$ & _ \\
\hline 6 & June 2013 - Feb. 2015 & Teklu et al. (2018) & _ & $8.2 \pm 7.2$ & _ & $10 \pm 4.1$ & $0.5 \pm 0.5$ & _ \\
\hline 7 & June 2013 - Feb. 2015 & Teklu et al. (2018) & _ & $6.2 \pm 3.8$ & _ & $10 \pm 5.2$ & $1.7 \pm 1.3$ & _ \\
\hline 8 & June 2013 - Feb. 2015 & Teklu et al. (2018) & _ & $5 \pm 2.6$ & _ & $10 \pm 5.2$ & $1.8 \pm 1.4$ & _ \\
\hline 9 & June 2013 - Feb. 2015 & Teklu et al. (2018) & _ & $5 \pm 2.6$ & _- & $10 \pm 5.2$ & $3.7 \pm 4.2$ & _ \\
\hline 10 & June 2013 - Feb. 2015 & Teklu et al. (2018) & _ & $5 \pm 2.6$ & _ & $10 \pm 5.2$ & $5 \pm 8.6$ & _ \\
\hline 11 & not reported & Nigussie et al. (2010) & _ & $10 \pm 1$ & _ & - & _ & _ \\
\hline 11 & June 2013 - Feb. 2015 & Teklu et al. (2018) & _ & $5 \pm 2.6$ & _ & $10 \pm 5.2$ & $1.5 \pm 1.1$ & _ \\
\hline 13 & Oct. 2014 - Feb. 2015 & Teklu et al. (2018) & _ & $5 \pm 0$ & _- & $10 \pm 0$ & $2.8 \pm 1.1$ & _ \\
\hline 14 & Oct. 2014 - Feb. 2015 & Teklu et al. (2018) & _ & $5 \pm 0$ & - & $10 \pm 0$ & $2.0 \pm 2.2$ & - \\
\hline 15 & Oct. 2014 - Feb. 2015 & Teklu et al. (2018) & _ & $5 \pm 0$ & _ & $10 \pm 0$ & $2.5 \pm 2.3$ & _ \\
\hline 16 & June 2013 - Feb. 2015 & Teklu et al. (2018) & _ & $162 \pm 321$ & _ & $10 \pm 5.2$ & $7 \pm 10.9$ & - \\
\hline 17 & February 2015 & Teklu et al. (2018) & _ & 5 & _ & 10 & 3.2 & _ \\
\hline 18 & June 2013 - Feb. 2015 & Teklu et al. (2018) & _ & $8 \pm 6.8$ & _- & $10 \pm 5.2$ & $3.9 \pm 5.7$ & _ \\
\hline 19 & March 1996 & Zinabu \& Preace (2003) & 2.7 & 51 & ND & ND & ND & 1.4 \\
\hline 19 & February 2008 & Kassaye et al. (2016) & 2.5 & 25 & 0.02 & 4.7 & _ & 8.6 \\
\hline 19 & Jan./Feb. 2008 & Masresha et al. (2011) & 2.5 & 25.1 & 0.02 & 4.7 & 2.6 & 8.6 \\
\hline 19 & July/Sept. 2009 & Masresha et al. (2011) & 1.8 & 7 & 0.02 & 3.4 & 1.8 & 2.6 \\
\hline 19 & Oct. 2014 - Feb. 2015 & Teklu et al. (2018) & _- & $5 \pm 0$ & _ & $10 \pm 0$ & $2.3 \pm 1.8$ & _ \\
\hline Site & & & $M n$ & B & $\mathbf{N i}$ & Se & Co & $\mathrm{Pb}$ \\
\hline \multirow[t]{2}{*}{ No. } & Reported date & Reference & (NA) & (1.5)C & $(65) C$ & (1)C & (NA) & (2)C \\
\hline & & & [500]ET & [0.3]ET & [70]W & [10]ET & [NA] & [20]ET \\
\hline 1 & June 2013 - Feb. 2015 & Teklu et al. (2018) & $13 \pm 5.5$ & $0.1 \pm 0.05$ & _ & _ & _ & _ \\
\hline 2 & not reported & Nigussie et al. (2010) & $10 \pm 1$ & - & $<40$ & - & - & $110 \pm 13$ \\
\hline 2 & June 2013 - Feb. 2015 & Teklu et al. (2018) & $25 \pm 29.6$ & $1.5 \pm 2.1$ & _ & _ & _ & _ \\
\hline 3 & June 2013 - Feb. 2015 & Teklu et al. (2018) & $13.2 \pm 6$ & $0.1 \pm 0.05$ & _ & - & _ & _ \\
\hline 4 & June 2013 - Feb. 2015 & Teklu et al. (2018) & $13.6 \pm 6.2$ & $0.1 \pm 0.05$ & _ & - & - & _ \\
\hline 5 & June 2013 - Feb. 2015 & Teklu et al. (2018) & $14.2 \pm 4.9$ & $0.1 \pm 0.05$ & - & - & - & _ \\
\hline 6 & June 2013 - Feb. 2015 & Teklu et al. (2018) & $19 \pm 13.3$ & $0.3 \pm 0.1$ & - & - & - & - \\
\hline 7 & June 2013 - Feb. 2015 & Teklu et al. (2018) & $11.9 \pm 4$ & $0.1 \pm 0.05$ & - & - & - & - \\
\hline 8 & June 2013 - Feb. 2015 & Teklu et al. (2018) & $21.4 \pm 19$ & $0.1 \pm 0.05$ & _ & _- & - & _ \\
\hline 9 & June 2013 - Feb. 2015 & Teklu et al. (2018) & $35 \pm 38.3$ & $1.5 \pm 2.3$ & _ & _- & - & _ \\
\hline 10 & June 2013 - Feb. 2015 & Teklu et al. (2018) & $13.4 \pm 6$ & $0.1 \pm 0.05$ & _ & _ & _ & _ \\
\hline 11 & not reported & Nigussie et al. (2010) & $110 \pm 6$ & - & $<40$ & - & - & $470 \pm 1$ \\
\hline 11 & June 2013 - Feb. 2015 & Teklu et al. (2018) & $12.6 \pm 6.1$ & $0.1 \pm 0.05$ & _ & - & - & - \\
\hline 13 & Oct. 2014 - Feb. 2015 & Teklu et al. (2018) & $30 \pm 14.1$ & ND & _ & - & - & _ \\
\hline 14 & Oct. 2014 - Feb. 2015 & Teklu et al. (2018) & $35 \pm 21.2$ & ND & _ & - & - & _ \\
\hline 15 & Oct. 2014 - Feb. 2015 & Teklu et al. (2018) & $12 \pm 10.6$ & ND & - & - & - & _ \\
\hline 16 & June 2013 - Feb. 2015 & Teklu et al. (2018) & $178 \pm 353.8$ & $0.1 \pm 0.05$ & - & - & _ & _ \\
\hline 17 & February 2015 & Teklu et al. (2018) & 20 & ND & - & - & - & - \\
\hline 18 & June 2013 - Feb. 2015 & Teklu et al. (2018) & $46 \pm 51.4$ & $0.4 \pm 0.2$ & - & - & - & - \\
\hline 19 & March 1996 & Zinabu \& Preace (2003) & 4 & - & ND & 10.4 & ND & ND \\
\hline 19 & February 2008 & Kassaye et al. (2016) & 117 & _ & 7.8 & 0.83 & 1.3 & 2.2 \\
\hline 19 & Jan./Feb. 2008 & Masresha et al. (2011) & 117 & _ & 7.8 & 0.83 & 1.3 & 1.2 \\
\hline 19 & July/Sept. 2009 & Masresha et al. (2011) & 113 & _ & 3.1 & 1.2 & 0.7 & 0.02 \\
\hline 19 & Oct. 2014 - Feb. 2015 & Teklu et al. (2018) & $20 \pm 14.1$ & _ & _ & - & - & _ \\
\hline
\end{tabular}

Note: $\mathrm{ND}$ = not detected, NA = guideline value not available 
Table 2.4. Mean concentration of sediment trace metals (in $\mathrm{mg} / \mathrm{kg}$ dry weight) of Lake Ziway reported by previous studies since 2008. The data are presented as mean with standard deviation (SD) or only mean value in case SD not reported. Values in parentheses ( ) in the table headings indicate probable effect concentrations (PEL) above which adverse effects are expected to occur frequently according to CCME sediment quality for aquatic life guideline. Values in bold are those above PEL in ecological quality. Sampling dates were not reported except by Kassaye et al. (2016). Numbers in the table refer to site numbers shown in Fig. 2.1.

\begin{tabular}{|c|c|c|c|c|c|c|c|c|c|}
\hline Site No. & Reference & $\begin{array}{r}\mathrm{Cr} \\
(90)\end{array}$ & $\begin{array}{r}\mathrm{Mn} \\
\text { (NA) }\end{array}$ & $\begin{array}{r}\mathrm{Fe} \\
(\mathrm{NA})\end{array}$ & $\begin{array}{r}\text { Co } \\
\text { (NA) }\end{array}$ & $\begin{array}{r}\mathrm{Ni} \\
(48.6)\end{array}$ & $\begin{array}{r}\mathrm{Cu} \\
(197)\end{array}$ & $\begin{array}{r}\text { Zn } \\
(315)\end{array}$ & $\begin{array}{r}V \\
\text { (NA) }\end{array}$ \\
\hline 1 & Mekonnen et al. (2015) & 52.3 & 76900 & 1680 & 60.3 & 46.8 & 105 & 140 & 62.6 \\
\hline 2 & Nigussie et al. (2010) & _ & 117 & _ & _ & 15 & _ & 111 & _ \\
\hline 2 & Mekonnen et al. (2015) & 25.6 & 57000 & 1830 & 4.3 & 7.51 & 70.2 & 200 & 53.4 \\
\hline 4 & Mekonnen et al. (2015) & 40.8 & 44800 & 1070 & 5.52 & 14.1 & 59.2 & 140 & 79.3 \\
\hline 6 & Mekonnen et al. (2015) & 49.7 & 54700 & 2000 & 14.6 & 28 & 126.9 & 160 & 99.8 \\
\hline 9 & Mekonnen et al. (2015) & 63.4 & 49820 & 1570 & 16.8 & 27.6 & 76 & 170 & 59.5 \\
\hline 10 & Mekonnen et al. (2015) & 53.4 & 55700 & 2290 & 13.8 & 32.6 & 108.7 & 240 & 61.1 \\
\hline 11 & Nigussie et al. (2010) & _ & 171 & - & - & 24 & _ & 174 & - \\
\hline 11 & Mekonnen et al. (2015) & 23.8 & 60200 & 1320 & 31.1 & 41 & 97 & 170 & 76.6 \\
\hline 19 & Kassaye et al. (2016) & 21 & 1230 & _ & 5.5 & 15 & 12.8 & 166 & - \\
\hline 19 & Mekonnen et al. (2015) & 52.5 & 83500 & 860 & 37.8 & 68 & 92.9 & 110 & 62.1 \\
\hline Site No. & Reference & $\begin{array}{r}\text { As } \\
(17)\end{array}$ & $\begin{array}{r}\text { Se } \\
\text { (NA) }\end{array}$ & $\begin{array}{r}\mathrm{Ag} \\
\text { (NA) }\end{array}$ & $\begin{array}{r}C d \\
(3.5)\end{array}$ & $\begin{array}{r}\text { Sn } \\
\text { (NA) }\end{array}$ & $\begin{array}{r}\mathrm{Hg} \\
(0.49)\end{array}$ & $\begin{array}{r}\mathrm{Pb} \\
(91.3)\end{array}$ & \\
\hline 1 & Mekonnen et al. (2015) & $<0.00016$ & 0.0564 & 30.8 & 3.23 & 2.43 & 0.034 & 10.1 & \\
\hline 2 & Nigussie et al. (2010) & _ & _ & _ & _ & _ & _ & 8.5 & \\
\hline 2 & Mekonnen et al. (2015) & $<0.00016$ & 0.062 & 17.3 & 0.38 & 6.17 & 0.02 & 31.8 & \\
\hline 4 & Mekonnen et al. (2015) & $<0.00016$ & 0.067 & 28.6 & 0.39 & 4.01 & 0.059 & 15.8 & \\
\hline 6 & Mekonnen et al. (2015) & $<0.00016$ & 0.050 & 49.1 & 0.34 & 4.38 & 0.032 & 21.6 & \\
\hline 9 & Mekonnen et al. (2015) & $<0.00016$ & 0.073 & 39 & 0.67 & 5.57 & 0.033 & 30.6 & \\
\hline 10 & Mekonnen et al. (2015) & $<0.0002$ & 0.049 & 59.1 & 8.87 & 11.7 & 0.026 & 31.5 & \\
\hline 11 & Nigussie et al. (2010) & - & - & - & - & - & - & 20.2 & \\
\hline 11 & Mekonnen et al. (2015) & $<0.00016$ & 0.052 & 39 & 0.49 & 3.94 & 0.031 & 16.3 & \\
\hline 19 & Kassaye et al. (2016) & 2.8 & 0.61 & _ & 0.27 & _ & _ & 14.0 & \\
\hline 19 & Mekonnen et al. (2015) & $<0.00016$ & 0.0588 & 22.7 & 0.56 & 1.69 & 0.038 & 33.2 & \\
\hline
\end{tabular}

Note: NA = guideline value not available

\subsection{Pesticides pollution}

In this section pesticides contamination of Lake Ziway are discussed considering the spatiotemporal variability and water quality status of the lake. Reported pesticides based on use category depicted in Fig. 2.4, while measured concentration values of the pesticides are presented in Table SI2.3.

FAO pesticide statistical data has shown an increasing trend in annual pesticide consumption in Ethiopia (FAO, http://www.fao.org/faostat/en/\#data/RP/visualize). This trend is probably a result of the expansion of intensive large-scale and small-scale agricultural activities in the country including the Ethiopian rift valley area. Since 2011, about 54 kinds of pesticides with different concentration levels have been reported by Jansen and Harmsen (2011), and by Teklu et al. (2018) in water samples taken from Lake Ziway and its feeder rivers 
(see Table S12.3). The reported pesticides grouped into 26 chemical classes, where fungicides (40\%) and insecticides (28\%) were the predominantly identified pesticide types in Lake Ziway (see Table SI2.3 and Fig. 2.4). Evaluating pesticides' temporal trend of Lake Ziway is difficult, as insufficient monitoring data are available. However, spatial variability of the pesticides in Lake Ziway was observed, which was generally local in nature. Of the reported 54 pesticides $81.5 \%, 26 \%, 18.5 \%$ and $18.5 \%$, and $2 \%$ were observed in shoreline sites of the lake near commercial floriculture farms (Floriculture-1), near smallholder vegetable farming village (Edo-Kontola), at the inlets of inflow rivers (Meki and Ketar), at drinking water supply (Water Supply) and at the mouth of the lake (Bulbula), respectively (Table SI2.3). Based on the determined acute exposure toxicity ratio (ETR) as first tier risk assessment tool performed by Teklu et al. (2018), at the aforementioned shoreline sites pesticides including sulphur, spiroxamine, methomyl, endosulfan, deltamethrin and chlofentenzin are reported to pose high ecological risk.

Moreover, the levels of the detected pesticides at Bulbula (100\%), near floriculture farm (54.5\%), at Water Supply site (40\%), at the inlets of the Meki and Ketar rivers (30\%) and near Edo-Kontola villages (28.6\%) were exceeded the EU MPL $(0.1 \mu \mathrm{g} / \mathrm{L} ; \mathrm{EU}, 1998)$ for drinking water (See Table S12.3). According to the evaluated internationally estimated daily intake (IEDI) values by Teklu et al. (2018), the concentrations of pesticide including those of boscalid, methomyl, carbendazim and spiroxamine at sites near floriculture farming, metalaxyl and diazinon at sites near Edo-Kontola village, and dodemorph and spiroxamine at the inlets of the Meki and Ketar rivers may pose chronic human health risk. Furthermore, bio-magnifications of organochlorine pesticides (OCP), including banned pesticides like dichlorodiphenyltrichloroethane (DDT) and its metabolites, was reported in commercially important fish species of the lake by Deribe et al. (2013) and Yohannes et al. (2014), and the authors suggested present use of the pestcide. However, these obsolete OCP pesticides were not reported in a recent monitoring effort by Teklu et al. (2018). No data was found for sediment pesticides concentration levels in the lake, and it clearly needs to be addressed in any new monitoring proposals. 


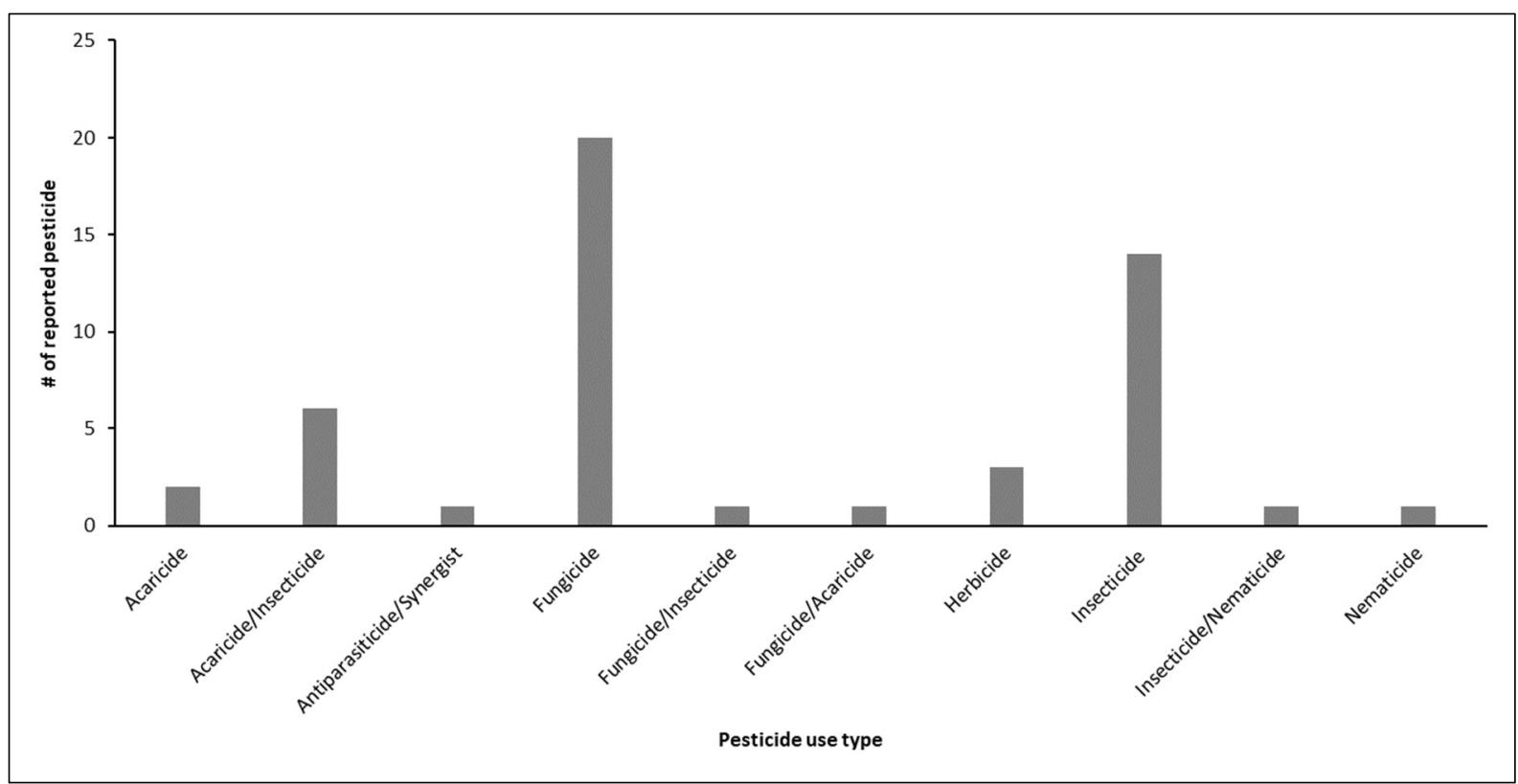

Fig. 2.4. Reported pesticides in Lake Ziway based on their use type classification. Source: Jansen and Harmsen (2011), and Teklu et al. (2018).

\subsection{Other anthropogenic stress factors}

\subsubsection{Water abstraction for irrigation}

Previous studies have reported a slight decline of the water level of Lake Ziway (Ayenew and Legesse, 2007). However, the recent irrigation based agricultural developments around the shoreline and along the feeder rivers can lead to further significant declines in lake water levels. According to the study by Ayenew (1998) the annual volume of water abstracted for irrigation and drinking water was 28 million $\mathrm{m}^{3}$ and 0.63 million $\mathrm{m}^{3}$, respectively. Almost a decade later, the annual water abstraction for irrigation increased by $5-8$ times, while the abstraction for drinking use and livestock watering seems to have remained constant (Eresso, 2010; Desta et al., 2015). The annual total water inflow and outflow (including abstraction) of Lake Ziway estimated 1052.4 million $\mathrm{m}^{3}$ and 1113.2 million $\mathrm{m}^{3}$, respectively with an overall negative water balance (i.e. -61 million $\mathrm{m}^{3}$ ). This apparent over-exploitation of the water resource from Lake Ziway may lead to lower water levels and a reduction in lake surface area that will have ecological impacts due to habitat destruction such as deterioration of marginal wetlands and seasonal grasslands (Ayenew and Legesse, 2007; Eresso, 2010). 


\subsubsection{Sediment load}

Due to rapid land use change, mainly conversion into agricultural lands, (Desta et al., 2015) at the watershed of Lake Ziway, annual sediment loads have increased significantly. This issue is likely to affect water clarity, salinity (through major ions enrichment, Ayenew, 2007), nutrient concentrations (Smith et al., 1999) and lake depth. Detailed information about sediment load to Lake Ziway is, however, sparse. According to Berhane (2014), annually about 9 tons/hectare of sediment was estimated to be yielded into Lake Ziway only from its western watershed. Similalry, the recent study by Aga et al. (2019) has reported that the annual sediment load into Lake Ziway from its catchment area was estimated about $2039.59 \times 10^{3}$ tons. Baseed on the sediment load estimation by Aga et al. (2019), annually sediment thickness of lake Ziway is increased by $3.8 \mathrm{~mm}$, which would amount about $3.8 \mathrm{~cm}$ decrease in lake depth per decade. This would be a serious deterioration in the lake ecosystem.

\subsubsection{Plastics pollution}

Plastics are synthetic polymers that widely found in the environment, as a result, it is an emerging environmental concern (Solomon and Palanisami, 2016; Koelmans et al., 2017). Plastics of various particle sizes may enter water ecosystems, for example, via drainage systems, aerial deposition and runoff (Castañeda et al., 2014; Free et al., 2014). Many recent studies have disclosed that microplastics (size $<5 \mathrm{~mm}$ ) are widely distributed in surface water and sediment, and are ingested by aquatic animals (Castañeda et al., 2014; Foekema et al., 2013; Besseling et al., 2015). In addition, recent studies have shown the ecological effects of microplastics in water ecosystem (Redondo-Hasselerharm et al., 2018). As plastic processing plants are absent around Lake Ziway, urban solid waste (Fig. 2.5) and wastewater effluents can be a potential source of plastics pollution to the lake ecosystem. Plastic ropes for plant support widely used by smallholder tomato growers, may exacerbate the pollution. However, we have found no quantitative studies on plastics pollution at Lake Ziway. 


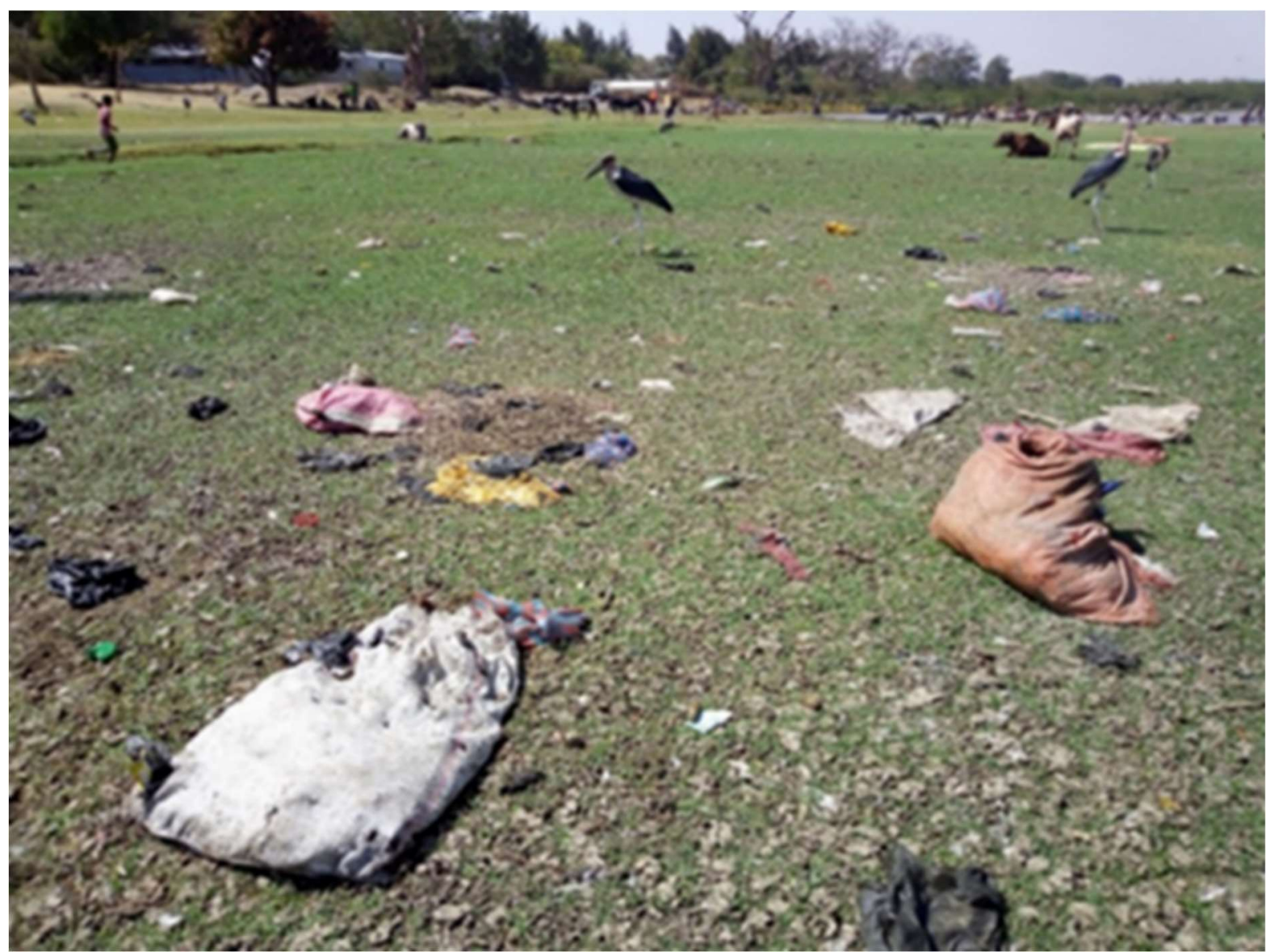

Fig. 2.5. Domestic waste dumped by Batu town inhabitants into wetlands of Lake Ziway (photo by Lemessa B. Merga, December 2017).

\subsection{Conclusions and outlook}

In populated regions such as central Ethiopian rift valley, installing protection and conservation programmes to manage the quality of surface water is challenging. Currently, contamination as a result of agricultural and urban effluents threaten Lake Ziway mainly shorelines. For example, the reported values of some nutrients and trace metals of the lake $\left(\mathrm{Ca}^{2+}, \mathrm{NO}_{3}{ }^{-}\right.$, alkalinity, $\mathrm{NH}_{4}{ }^{+}, \mathrm{Cu}$ and $\left.\mathrm{Ni}\right)$ and at shoreline spots $\left(\mathrm{NO}_{3}{ }^{-}\right.$and $\left.\mathrm{PO}_{4}{ }^{3-}\right)$ have shown an increasing temporal trend. Spatially, sites including Floriculture-1 (for major parameters), Meki river inlet (for $\mathrm{NO}_{3}{ }^{-}, \mathrm{P}, \mathrm{Zn}, \mathrm{Fe}$ and $\mathrm{Mn}$ ) and Ketar river inlet (for $\mathrm{P}, \mathrm{NO}_{3}{ }^{-}$and $\mathrm{Fe}$ ) were found as the impacted hotspot shorelines of Lake Ziway. Moreover, high sediment trace metal concentrations were observed at spots close to floriculture farming (Floriculture-1), at sites receiving urban effluents (Around lodges and Korokonch) and at the centre of the lake.

Water quality of the lake may be deemed as not suitable for drinking water on the basis of the guideline values for Fe and alkalinity. However, as mentioned earlier high alkalinity of the lake is likely natural as it is the case for most East African shallow freshwater lakes. Similarly, 
water quality of the lake (for $\mathrm{NH}_{4}{ }^{+}, \mathrm{Fe}, \mathrm{Cr}, \mathrm{Cu}$ and $\mathrm{Se}$ ) and sediment quality (for $\mathrm{Ni}$ ) were not fit ecological guideline values. Water quality parameters including $\mathrm{NO}_{3}{ }^{-}, \mathrm{pH}, \mathrm{P}, \mathrm{NH}_{4}{ }^{+}, \mathrm{B}, \mathrm{Fe}, \mathrm{Cu}$ and $\mathrm{Pb}$ were exceeded drinking water or/and ecological guideline values at some shoreline sites of Lake Ziway. Pesticide pollution was also observed recently in sites close to floriculture farms, vegetable producing villages and at inlets of the inflow rivers. Sulphur, spiroxamine, methomyl, chlofentenzin, endosulfan, deltamethrin, boscalid, methomyl, carbendazim, metalaxyl, dodemorph and diazinon pesticides have been reported to pose high ecological and human health risk. Sedimentation is also another threat of Lake Ziway as it remarkably decreases the depth (by ca. $0.38 \mathrm{~cm} /$ year) of the lake. Microplastics pollution and excessive use of water for irrigation are additional risks to the lake ecosystem, for which hardly data is available.

Future monitoring and research in Lake Ziway should focus on better identification of major pollution sources and impacted hotspots for endpoints including nutrients, microplastics, pesticides and trace metals considering water and sediment components. Furthermore, impact assessment of pesticides and microplastics in water, sediment and biota are needed. Collection of updated information on biological components of the lake is needed for evaluation of the state and trends of its ecosystem resource. Governmental agencies responsible for the management of Lake Ziway in collaboration with stakeholders should design and implement appropriate protection and conservation programmes to help improve its ecological quality, so that, the lake provides its key ecosystem services. In general, our review study provides a warning that other African freshwater lakes under pressure from agricultural intensification and urbanisation may not be immune from deterioration of their ecosystem services.

\section{Acknowledgements}

The study was financially supported by Netherlands fellowship programmes, NUFFIC/ PhD studies, grant NFP - PhD.16/0019, reference number WIMEK2015 02. We would also like to thank the anonymous reviewers for their valuable comments. 


\section{Appendix 2. Supplementary Informations (SI)}

Table SI2.1. Summary of physicochemical properties of Lake Ziway reported by previous studies since 1961 for various sites of the lake. The values are summarized as mean with standard deviation or range, except for values reported only mean or values with “*”, which are single time measurements. The values are in $\mathrm{mg} / \mathrm{L}$ except for conductivity ( $\mu \mathrm{S} / \mathrm{cm}$ ), $\mathrm{PO}{ }_{4}^{3-}(\mu \mathrm{g} / \mathrm{L}$ ), Alkalinity (meq/L), Chlorophyl-a $(\mu \mathrm{g} / \mathrm{L})$, Temperature $\left({ }^{\circ} \mathrm{C}\right)$ and $\mathrm{pH}(-)$. Values in parentheses () and in square brackets [ ] in the table headings indicate maximum permissible levels $(\mathrm{MPL})$ according to standards for ecological quality and for drinking water, respectively. The guidelines used are indicated as "A" for ANZECC, "E" for EU, "W" for WHO, “C" for CCME, "U" for USEPA and "ET" for EDWG. Values in bold are those above MPL in ecological quality and/or in drinking water. Numbers in the table refer to site numbers shown in Fig. 2.1.

\begin{tabular}{|c|c|c|c|c|c|c|c|c|}
\hline Site No. & Reported date & Reference & $\begin{array}{r}\text { Conductivity } \\
(1500) \mathrm{A} \\
{[2500] \mathrm{E}}\end{array}$ & $\begin{array}{r}\mathrm{K}^{+} \\
\text {(NA) } \\
\text { [NA] }\end{array}$ & $\begin{array}{r}\mathrm{Na}^{+} \\
\text {(NA) } \\
{[200] \mathrm{W}}\end{array}$ & $\begin{array}{r}\mathrm{Ca}^{2+} \\
\text { (NA) } \\
{[300] \mathrm{W}}\end{array}$ & $\begin{array}{r}\mathrm{SO}_{4}{ }^{2-} \\
\text { (NA) } \\
{[250] \mathrm{W}}\end{array}$ & $\begin{array}{l}\mathrm{SiO}_{2} \\
\text { (NA) } \\
\text { [NA] }\end{array}$ \\
\hline 1 & June 2013 to February 2015 & Teklu et al. (2018) & $440 \pm 45$ & $12.6 \pm 5.2$ & $67.5 \pm 8.8$ & $17.6 \pm 3.6$ & $2.7 \pm 1.1$ & $16.3 \pm 1.4$ \\
\hline 2 & June 2013 to February 2015 & Teklu et al. (2018) & $435 \pm 34$ & $9.9 \pm 6.3$ & $54.6 \pm 27$ & $13.9 \pm 7.4$ & $2.0 \pm 1.3$ & $12.7 \pm 6.8$ \\
\hline 3 & March-May 2010 \& Oct - Dec 2010 & Tamire and Mengistou (2012) & $445 \pm 25$ & _- & _- & _- & _- & - \\
\hline 3 & October 2012 to September 2014 & Hirpho (2016) & $397 \pm 6$ & _- & _- & _ & _- & - \\
\hline 3 & June 2013 to February 2015 & Teklu et al. (2018) & $442 \pm 34$ & $10.8 \pm 6.1$ & $59.2 \pm 24.2$ & $15.2 \pm 5.9$ & $2.3 \pm 1.4$ & $14.2 \pm 5.6$ \\
\hline 4 & June 2013 to February 2015 & Teklu et al. (2018) & $442 \pm 34$ & $12.6 \pm 5.2$ & $67.8 \pm 9$ & $17.9 \pm 3.6$ & $2.9 \pm 1.3$ & $14.1 \pm 6.1$ \\
\hline 5 & June 2013 to February 2015 & Teklu et al. (2018) & $467 \pm 53$ & $13.2 \pm 5.4$ & $72.8 \pm 8.4$ & $18.0 \pm 4.1$ & $3.3 \pm 1.4$ & $16.9 \pm 2.4$ \\
\hline 6 & June 2013 to February 2015 & Teklu et al. (2018) & $1068 \pm 286$ & $29 \pm 9.5$ & $200 \pm 69$ & $24 \pm 8.5$ & $16 \pm 2.2$ & $22.2 \pm 3.5$ \\
\hline 7 & June 2013 to February 2015 & Teklu et al. (2018) & $448 \pm 34$ & $12.6 \pm 5.2$ & $68.2 \pm 7.9$ & $14.6 \pm 7$ & $2.2 \pm 1.1$ & $17.2 \pm 1.9$ \\
\hline 8 & January 2001 - December 2002 & Erko et al. 2006 & $435(378-472)$ & $11(10.6-12)$ & $68(63-85)$ & $19(16-24)$ & - & - \\
\hline 8 & March-May 2010 \& Oct - Dec 2010 & Tamire and Mengistou (2012) & $432 \pm 12$ & - & - & - & - & - \\
\hline 8 & June 2013 to February 2015 & Teklu et al. (2018) & $447 \pm 41$ & $12.8 \pm 5.3$ & $68 \pm 8.7$ & $18.8 \pm 3.6$ & $2.2 \pm 1.2$ & $17.6 \pm 2.5$ \\
\hline 9 & June 2013 to February 2015 & Teklu et al. (2018) & $445 \pm 34$ & $10.3 \pm 6.5$ & $57 \pm 28$ & $15.1 \pm 8.2$ & $1.7 \pm 1.3$ & $14.9 \pm 7.3$ \\
\hline 10 & June 2013 to February 2015 & Teklu et al. (2018) & $443 \pm 33$ & $10 \pm 6.5$ & $68 \pm 7.8$ & $18.2 \pm 4.4$ & $2.2 \pm 1.1$ & $17.0 \pm 1.2$ \\
\hline 11 & June 2013 to February 2015 & Teklu et al. (2018) & $443 \pm 28$ & $12.6 \pm 5.1$ & $55 \pm 26$ & $17.5 \pm 3.9$ & $2.2 \pm 1.1$ & $16.6 \pm 1.0$ \\
\hline 13 & October 2012 to September 2014 & Hirpho (2016) & $484 \pm 15$ & - & - & - & - & - \\
\hline 13 & October 2014 to February 2015 & Teklu et al. (2018) & $425 \pm 21$ & $12 \pm 0.1$ & $61 \pm 0.3$ & $22.1 \pm 2.3$ & $2 \pm 0.04$ & $17.8 \pm 2.1$ \\
\hline 14 & October 2014 to February 2015 & Teklu et al. (2018) & $400 \pm 0$ & $12 \pm 0.1$ & $59.6 \pm 0.8$ & $22.0 \pm 2.1$ & $2.2 \pm 0.2$ & $15.8 \pm 4.9$ \\
\hline 15 & October 2014 to February 2015 & Teklu et al. (2018) & $405 \pm 7$ & $12 \pm 0.2$ & $58.4 \pm 1.1$ & $21.5 \pm 2.9$ & $2.2 \pm 0.2$ & $16.5 \pm 5.6$ \\
\hline 16 & March-May 2010 \& Oct - Dec 2010 & Tamire and Mengistou (2012) & $451 \pm 13$ & - & - & - & - & - \\
\hline 16 & October 2012 to September 2014 & Hirpho (2016) & $405 \pm 26$ & - & - & - & - & - \\
\hline 16 & June 2013 to February 2015 & Teklu et al. (2018) & $320 \pm 116$ & $15.4 \pm 16.5$ & $44.1 \pm 17$ & $22 \pm 5.6$ & $3.4 \pm 2$ & $32 \pm 24.6$ \\
\hline
\end{tabular}

Note: ND = not detected, NA = guideline value not available 


\begin{tabular}{|c|c|c|c|c|c|c|c|c|}
\hline Site No. & Reported date & Reference & $\begin{array}{r}\text { Conductivity } \\
(1500) \mathrm{A} \\
{[2500] \mathrm{E}}\end{array}$ & $\begin{array}{r}K^{+} \\
\text {(NA) } \\
\text { [NA] }\end{array}$ & $\begin{array}{r}\mathrm{Na}^{+} \\
\text {(NA) } \\
{[200] \mathrm{W}}\end{array}$ & $\begin{array}{r}\mathrm{Ca}^{2+} \\
\text { (NA) } \\
{[300] \mathrm{W}}\end{array}$ & $\begin{array}{r}\mathrm{SO}_{4}{ }^{2-} \\
\text { (NA) } \\
{[250] \mathrm{W}}\end{array}$ & $\begin{array}{l}\mathrm{SiO}_{2} \\
\text { (NA) } \\
\text { [NA] }\end{array}$ \\
\hline 17 & February 2015 & Teklu et al. (2018) & $410^{*}$ & $11.51^{*}$ & $58.4^{*}$ & $23.5^{*}$ & 2.03* & $17.9^{*}$ \\
\hline 18 & March-May 2010 \& Oct - Dec 2010 & Tamire and Mengistou (2012) & $424 \pm 6$ & _- & _- & _- & _ & _ \\
\hline 18 & October 2012 to September 2014 & Hirpo (2016) & $377 \pm 23$ & _- & _- & _- & _- & _ \\
\hline 18 & June 2013 - February 2015 & Teklu et al. (2018) & $450 \pm 633$ & $14.4 \pm 20.2$ & $69.7 \pm 131$ & $16.1 \pm 6.1$ & $6 \pm 12.1$ & $28 \pm 12.1$ \\
\hline 19 & May 1961 & Talling and Talling (1965) & 370 & 14 & 64.4 & 10 & 28.8 & 47 \\
\hline 19 & March 1964 & Von Wood and Talling (1988) & 361 & 11.7 & 48.3 & 14 & 9.6 & 45 \\
\hline 19 & January 1976 & Von Damm and Edmond (1984) & _- & 11.7 & 52.9 & 14 & 4.8 & _ \\
\hline 19 & August 1988 & Gizaw (1996) & - & 16 & 96 & 17.3 & 6 & _ \\
\hline 19 & March 1991 & Kebede et al. (1994) & 410 & 12.12 & 66.01 & 11.22 & 15.4 & 37 \\
\hline 19 & $1990-2000$ & Zinabu et al. (2002) & $388(295-468)$ & $12(8.2-13.6)$ & $64.4(53-78)$ & $16(11-23)$ & $4.8(1.9-15.4)$ & $21(13-37)$ \\
\hline 19 & January - December 2005 & Tilahun and Ahlgren (2010) & $478 \pm 32.8$ & & & & & $23.9 \pm 9.2$ \\
\hline 19 & January 2008 & Masresha et al. (2011) & 479 & 11.3 & 60.1 & 21.3 & 6.7 & _ \\
\hline 19 & July 2009 & Masresha et al. (2011) & 530 & 11 & 58 & 12 & 7.8 & - \\
\hline 19 & Mar - May 2010 and Oct - Dec 2010 & Tamire and Mengistou (2012) & $399 \pm 18$ & _- & _- & _- & _- & _ \\
\hline 19 & October 2012 to September 2014 & Hirpo (2016) & $367 \pm 2$ & - & - & - & - & - \\
\hline 19 & October 2014 - February 2015 & Teklu et al. (2018) & $295 \pm 120$ & $11.3 \pm 0.2$ & $57 \pm 1.3$ & $21 \pm 3$ & $2.3 \pm 0.4$ & $15.9 \pm 4.3$ \\
\hline Site No. & Reported Year & References & $\begin{array}{l}\mathrm{PO}_{4}^{3-} \\
\text { (NA) } \\
{[\mathrm{NA}]}\end{array}$ & $\begin{array}{r}\mathrm{NO}_{3}{ }^{-} \\
(13) \mathrm{C} \\
{[50] \mathrm{ET}}\end{array}$ & $\begin{array}{r}\mathrm{pH} \\
(6.5-9) \mathrm{U} \\
{[6.5-8.5] \mathrm{ET}}\end{array}$ & $\begin{array}{r}\text { Alkalinity } \\
(>0.4) U \\
{[4] E T}\end{array}$ & $\begin{array}{r}P \\
(0.02) \mathrm{C} \\
{[\mathrm{NA}]}\end{array}$ & $\begin{array}{l}\mathrm{Mg}^{2+} \\
\text { (NA) } \\
\text { [NA] }\end{array}$ \\
\hline 1 & June 2013 to February 2015 & Teklu et al. (2018) & - & $11.7 \pm 6.4$ & $8.7 \pm 0.2$ & $3.8 \pm 1.1$ & $0.005 \pm 0.002$ & $8.4 \pm 0.9$ \\
\hline 2 & June 2013 to February 2015 & Teklu et al. (2018) & - & $11.6 \pm 8.4$ & $8.6 \pm 0.2$ & $3.9 \pm 1.4$ & $0.005 \pm 0.002$ & $6.5 \pm 3.3$ \\
\hline 3 & March-May 2010 \& Oct - Dec 2010 & Tamire and Mengistou (2012) & $40.8 \pm 8.8$ & $0.07 \pm 0.02$ & $8.7 \pm 0.1$ & _- & _- & _ \\
\hline 3 & October 2012 to September 2014 & Hirpo (2016) & $50.3 \pm 3.9$ & $0.031 \pm 0$ & $8.2 \pm 0.1$ & - & - & - \\
\hline 3 & June 2013 to February 2015 & Teklu et al. (2018) & - & $9.5 \pm 6.5$ & $8.6 \pm 0.2$ & $3.9 \pm 1.3$ & $0.005 \pm 0.002$ & $7.3 \pm 3$ \\
\hline 4 & Nov. 2003 - Aug. 2004 & Beneberu and Mengistou (2009) & 134 (ND - 220) & $0.4(N D-0.95)$ & - & - & - & - \\
\hline 4 & June 2013 to February 2015 & Teklu et al. (2018) & _- & $14.8 \pm 7.6$ & $8.6 \pm 0.1$ & $4.1 \pm 1.5$ & $0.005 \pm 0.002$ & $8.4 \pm 0.1$ \\
\hline 5 & June 2013 to February 2015 & Teklu et al. (2018) & _ & $17.7 \pm 9.4$ & $8.5 \pm 0.2$ & $4.7 \pm 0.4$ & $0.005 \pm 0.002$ & $8.2 \pm 1.2$ \\
\hline
\end{tabular}




\begin{tabular}{|c|c|c|c|c|c|c|c|c|}
\hline Site No. & Reported date & Reference & $\begin{array}{l}\mathrm{PO}_{4}{ }^{3-} \\
\text { (NA) } \\
\text { [NA] }\end{array}$ & $\begin{array}{r}\mathrm{NO}_{3}{ }^{-} \\
(13) \mathrm{C} \\
{[50] \mathrm{ET}}\end{array}$ & $\begin{array}{r}\mathrm{pH} \\
(6.5-9) \mathrm{U} \\
{[6.5-8.5] \mathrm{ET}}\end{array}$ & $\begin{array}{r}\text { Alkalinity } \\
(>0.4) \mathrm{U} \\
{[4] \mathrm{ET}}\end{array}$ & $\begin{array}{r}P \\
(0.02) \mathrm{C} \\
{[\mathrm{NA}]}\end{array}$ & $\begin{array}{l}\mathrm{Mg}^{2+} \\
\text { (NA) } \\
\text { [NA] }\end{array}$ \\
\hline 6 & June 2013 - February 2015 & Teklu et al. (2018) & _ & $108.3 \pm 65.8$ & $8.6 \pm 0.1$ & & $0.005 \pm 0.002$ & $9.8 \pm 3.1$ \\
\hline 7 & June 2013 - February 2015 & Teklu et al. (2018) & _ & $13.9 \pm 7.0$ & $8.6 \pm 0.3$ & $4.1 \pm 1.2$ & $0.005 \pm 0.002$ & $8.4 \pm 0.8$ \\
\hline 8 & January 2001 - December 2002 & Erko et al.(2006) & _ & $2.3(0.8-4.7)$ & $7.5(7-8)$ & - & - & _ \\
\hline 8 & Nov. 2003 - Aug. 2004 & Beneberu and Mengistou (2009) & $211(20-380)$ & $0.19(0.2-0.6)$ & _ & _ & _ & _ \\
\hline 8 & Mar. - May 2010 and Oct - Dec 2010 & Tamire and Mengistou (2012) & $64.5 \pm 32$ & $0.09 \pm 0.03$ & $8.6 \pm 0.1$ & & & \\
\hline 8 & June 2013 - February 2015 & Teklu et al. (2018) & _ & $12.7 \pm 6.1$ & $8.4 \pm 0.2$ & $4.1 \pm 1.3$ & $0.005 \pm 0.002$ & $8.6 \pm 0.9$ \\
\hline 9 & June 2013 - February 2015 & Teklu et al. (2018) & _- & $11.7 \pm 8.3$ & $8.5 \pm 0.2$ & $4.1 \pm 1.6$ & $0.005 \pm 0.002$ & $7.0 \pm 3.4$ \\
\hline 10 & June 2013 - February 2015 & Teklu et al. (2018) & _- & $12.8 \pm 6.4$ & $8.5 \pm 0.3$ & $4.1 \pm 1.6$ & $0.005 \pm 0.002$ & $8.5 \pm 0.9$ \\
\hline 11 & June 2013 - February 2015 & Teklu et al. (2018) & _ & $13.1 \pm 6.2$ & $8.6 \pm 0.2$ & $3.9 \pm 1$ & $0.005 \pm 0.002$ & $8.4 \pm 0.9$ \\
\hline 13 & October 2012 to September 2014 & Hirpo (2016) & $59.2 \pm 36$ & $0.04 \pm 0.0$ & $8.0 \pm 0.2$ & _ & _ & _ \\
\hline 13 & October 2014 to February 2015 & Teklu et al. (2018) & - & $16.7 \pm 3.7$ & $8.2 \pm 0.2$ & - & $0.005 \pm 0$ & $8.3 \pm 0.6$ \\
\hline 14 & October 2014 to February 2015 & Teklu et al. (2018) & _- & $13.0 \pm 3.3$ & $8.4 \pm 0.1$ & _ & $0.005 \pm 0$ & $8.1 \pm 0.7$ \\
\hline 15 & October 2014 to February 2015 & Teklu et al. (2018) & _ & $12.5 \pm 3.6$ & $8.2 \pm 0.2$ & _- & $0.005 \pm 0$ & $8.0 \pm 1$ \\
\hline 16 & March-May 2010 \& Oct - Dec 2010 & Tamire and Mengistou (2012) & $24.4 \pm 6.2$ & $0.9 \pm 0.02$ & $7.9 \pm 0.2$ & _ & _- & _ \\
\hline 16 & October 2012 to September 2014 & Hirpo (2016) & $42.6 \pm 4.1$ & $0.03 \pm 0.0$ & $8.1 \pm 0.1$ & _ & _- & _ \\
\hline 16 & June 2013 to February 2015 & Teklu et al. (2018) & _- & $42.3 \pm 65.1$ & $8.2 \pm 0.3$ & _ & $0.2 \pm 0.3$ & $10 . \pm 9.5$ \\
\hline 17 & February 2015 & Teklu et al. (2018) & _ & $15.2^{*}$ & $8.6^{*}$ & _ & $0.005^{*}$ & $8.5^{*}$ \\
\hline 18 & March-May 2010 \& Oct - Dec 2010 & Tamire and Mengistou (2012) & $29.05 \pm 19$ & $0.03 \pm 0.01$ & $7.8 \pm 0.2$ & _- & _- & _ \\
\hline 18 & October 2012 to September 2014 & Hirpo (2016) & $43.7 \pm 24.5$ & $0.03 \pm 0.0$ & $8.3 \pm 0.3$ & _ & _ & _ \\
\hline 18 & June 2013 to February 2015 & Teklu et al. (2018) & _ & $56.6 \pm 117.4$ & $8.05 \pm 0.5$ & _ & $0.05 \pm 0.1$ & $5.5 \pm 3$ \\
\hline 19 & May 1961 & Talling and Talling (1965) & - & - & 8.9 & 3.9 & 0.17 & 9.8 \\
\hline 19 & March 1964 & Wood and Talling (1988) & _- & _ & 8.2 & 3.3 & _- & 7.29 \\
\hline 19 & January 1976 & Von Damm and Edmond (1984) & - & _ & 7.6 & 3.2 & _ & 7.29 \\
\hline 19 & August 1988 & Gizaw (1996) & _ & _ & 7.3 & _- & _ & 8.34 \\
\hline 19 & March 1991 & Kebede et al. (1994) & $<1$ & _ & 8.5 & 4 & 0.22 & 7.78 \\
\hline 19 & $1990-2000$ & Zinabu et al. (2002) & $34(2.5-220)$ & - & $8.5(7-9)$ & $4(3.3-4.4)$ & - & $8.5(6-10)$ \\
\hline 19 & Nov. 2003 - Aug. 2004 & Beneberu and Mengistou (2009) & $90(40-170)$ & $0.4(N D-0.8)$ & - & - & - & - \\
\hline 19 & January - December 2005 & Tilahun and Ahlgren (2010) & $10.2 \pm 5.9$ & $0.0032 \pm 0.003$ & $8.7 \pm 0.1$ & $4.9 \pm 0.8$ & $0.069 \pm 0.005$ & _ \\
\hline 19 & January 2008 & Masresha et al. (2011) & _ & 0.05 & 8.4 & _- & _- & 9 \\
\hline 19 & July 2009 & Masresha et al. (2011) & - & ND & 8.9 & - & - & 7.6 \\
\hline 19 & Mar. - May 2010 and Oct - Dec 2010 & Tamire and Mengistou (2012) & $25.6 \pm 8.4$ & $0.044 \pm 0.01$ & $8.5 \pm 0.1$ & _- & _- & _ \\
\hline 19 & October 2012 - September 2014 & Abera et al. (2018) & $38.2 \pm 19.1$ & $0.02 \pm 0.0$ & $8.4 \pm 0.1$ & - & - & - \\
\hline 19 & October 2014 - February 2015 & Teklu et al. (2018) & & $10.2 \pm 8.2$ & $8.5 \pm 0.1$ & _ & $<0.01$ & $7.8 \pm 0.9$ \\
\hline
\end{tabular}

Note: $\mathrm{ND}=$ not detected, $\mathrm{NA}=$ guideline value not available 


\begin{tabular}{|c|c|c|c|c|c|c|c|}
\hline Site No. & Reported date & Reference & $\begin{array}{r}\mathrm{Cl}^{-} \\
(120) \mathrm{C} \\
{[250] \mathrm{W}}\end{array}$ & $\begin{array}{r}\mathrm{NH}_{4}{ }^{+} \\
(0.103) \mathrm{C} \\
{[2] \mathrm{ET}}\end{array}$ & $\begin{array}{r}\mathrm{HCO}_{3}^{-} \\
\text {(NA) } \\
{[\mathrm{NA}]}\end{array}$ & $\begin{array}{r}\text { Chlorophyll-a } \\
\text { (NA) } \\
\text { [NA] }\end{array}$ & $\begin{array}{r}\text { Temperature } \\
\text { (NA) } \\
\text { [NA] }\end{array}$ \\
\hline 1 & June 2013 - February 2015 & Teklu et al. (2018) & $14.8 \pm 3.7$ & $0.54 \pm 0.4$ & $261 \pm 33$ & - & _ \\
\hline 2 & June 2013 - February 2015 & Teklu et al. (2018) & $13.9 \pm 7.7$ & $0.51 \pm 0.49$ & $214 \pm 106$ & - & _ \\
\hline 3 & Mar.- May 2010 and Oct - Dec 2010 & Tamire and Mengistou (2012) & _ & _ & _ & _- & $27.9 \pm 0.5$ \\
\hline 3 & October 2012 - September 2014 & Hirpo (2016) & _ & _- & _ & $54.5 \pm 2.3$ & $24.1 \pm 0.6$ \\
\hline 3 & June 2013 - February 2015 & Teklu et al. (2018) & $15.6 \pm 4.2$ & $0.6 \pm 0.5$ & $257 \pm 26$ & - & _ \\
\hline 4 & Nov. 2003 - Aug. 2004 & Beneberu and Mengistou (2009) & - & _- & _- & $34(26-45)$ & _ \\
\hline 4 & June 2013 - February 2015 & Teklu et al. (2018) & $15.6 \pm 4.2$ & $0.55 \pm 0.51$ & $258 \pm 30$ & _- & _ \\
\hline 5 & June 2013 - February 2015 & Teklu et al. (2018) & $15.3 \pm 3.7$ & $0.5 \pm 0.49$ & $264 \pm 34$ & _ & _ \\
\hline 6 & June 2013 - February 2015 & Teklu et al. (2018) & $28.2 \pm 6.9$ & $0.4 \pm 0.42$ & $503 \pm 143$ & _ & _ \\
\hline 7 & June 2013 - February 2015 & Teklu et al. (2018) & $15.6 \pm 3.6$ & $0.6 \pm 0.59$ & $256 \pm 24$ & _ & _ \\
\hline 8 & Nov. 2003 - Aug. 2004 & Beneberu and Mengistou (2009) & _ & _ & _ & $34(28-45)$ & \\
\hline 8 & Mar. - May 2010 and Oct - Dec 2010 & Tamire and Mengistou (2012) & _ & _ & _ & _ & $26.9 \pm 0.6$ \\
\hline 8 & June 2013 - February 2015 & Teklu et al. (2018) & $16.4 \pm 4.3$ & $0.8 \pm 0.75$ & $269 \pm 22$ & _ & _ \\
\hline 9 & June 2013 - February 2015 & Teklu et al. (2018) & $13.4 \pm 7.5$ & $0.68 \pm 0.63$ & $215 \pm 106$ & _ & _ \\
\hline 10 & June 2013 - February 2015 & Teklu et al. (2018) & $15.4 \pm 4.4$ & $0.64 \pm 0.59$ & $254 \pm 24$ & _ & _ \\
\hline 11 & June 2013 - February 2015 & Teklu et al. (2018) & $15.9 \pm 4.6$ & $0.6 \pm 0.45$ & $249 \pm 29$ & _ & _ \\
\hline 13 & October 2012 - September 2014 & Hirpo (2016) & _ & $0.124 \pm 0.001$ & _ & $50 \pm 0.9$ & $23.4 \pm 0.5$ \\
\hline 13 & October 2014 - February 2015 & Teklu et al. (2018) & $16.5 \pm 5.7$ & $1.02 \pm 0.7$ & $250 \pm 29$ & _ & _ \\
\hline 14 & October 2014 - February 2015 & Teklu et al. (2018) & $16.2 \pm 8.8$ & $1.05 \pm 0.9$ & $242 \pm 24$ & _ & _ \\
\hline 15 & October 2014 - February 2015 & Teklu et al. (2018) & $16.2 \pm 8.1$ & $1.1 \pm 0.85$ & $246 \pm 21$ & _ & _ \\
\hline 16 & Mar. - May 2010 and Oct - Dec 2010 & Tamire and Mengistou (2012) & _ & _ & _ & _ & $26.1 \pm 0.9$ \\
\hline 16 & October 2012 - September 2014 & Hirpo (2016) & _ & _ & _ & $37 \pm 6.4$ & $22.3 \pm 0.7$ \\
\hline 16 & June 2013 - February 2015 & Teklu et al. (2018) & $6.8 \pm 4$ & $0.8 \pm 1.2$ & $166 \pm 73$ & _ & _ \\
\hline
\end{tabular}

Note: $\mathrm{ND}=$ not detected, $\mathrm{NA}=$ guideline value not available 


\begin{tabular}{|c|c|c|c|c|c|c|c|}
\hline Site No. & Reported date & Reference & $\begin{array}{r}\mathrm{Cl}^{-} \\
(120) \mathrm{C} \\
{[250] \mathrm{W}}\end{array}$ & $\begin{array}{r}\mathrm{NH}_{4}{ }^{+} \\
(0.103) \mathrm{C} \\
{[2] \mathrm{ET}}\end{array}$ & $\begin{array}{l}\mathrm{HCO}_{3}^{-} \\
\text {(NA) } \\
\text { [NA] }\end{array}$ & $\begin{array}{r}\text { Chlorophyll-a } \\
\text { (NA) } \\
\text { [NA] }\end{array}$ & $\begin{array}{r}\text { Temperature } \\
\text { (NA) } \\
\text { [NA] }\end{array}$ \\
\hline 17 & February 2015 & Teklu et al. (2018) & $21.5^{*}$ & $0.21^{*}$ & $258.7^{*}$ & - & \\
\hline 18 & Mar. - May 2010 and Oct - Dec 2010 & Tamire and Mengistou (2012) & - & - & - & - & $23.9 \pm 1.2$ \\
\hline 18 & October 2012 - September 2014 & Hirpo (2016) & - & - & - & $42 \pm 7.9$ & $20.8 \pm 0.4$ \\
\hline 18 & June 2013 - February 2015 & Teklu et al. (2018) & $10.9 \pm 12.5$ & $0.18 \pm 0.3$ & $237 \pm 242$ & - & - \\
\hline 19 & May 1961 & Talling and Talling (1965) & 18 & - & - & - & - \\
\hline 19 & March 1964 & Wood and Talling (1988) & 7.1 & - & - & - & - \\
\hline 19 & Oct.1966 & Wood et al. (1979) & - & - & - & 7 & - \\
\hline 19 & January 1976 & Von Damm and Edmond (1984) & 10.6 & - & - & - & - \\
\hline 19 & Apr. 1980 & Belay and Wood (1984) & - & - & - & 91 & - \\
\hline 19 & August 1988 & Gizaw (1996) & 18 & - & 367 & - & 22 \\
\hline 19 & March 1991 & Kebede et al. (1994) & 11.4 & 0.4 & - & 154 & - \\
\hline 19 & $1990-2000$ & Zinabu et al. (2002) & $14.2(9.2-16.3)$ & - & - & $82(23-224)$ & - \\
\hline 19 & Nov. 2003 - Aug. 2004 & Beneberu and Mengistou (2009) & - & - & - & $44(30-58)$ & - \\
\hline 19 & January - December 2005 & Tilahun and Ahlgren (2010) & - & $0.11 \pm 0.08$ & - & $39 \pm 9.4$ & $22.4 \pm 2.2$ \\
\hline 19 & January 2008 & Masresha et al. (2011) & 13.5 & - & 247 & - & 27.5 \\
\hline 19 & July 2009 & Masresha et al. (2011) & 13.8 & - & 255 & - & 23.1 \\
\hline 19 & Mar. - May 2010 and Oct - Dec 2010 & Tamire and Mengistou (2012) & - & $0.15 \pm 0.02$ & - & - & $24.1 \pm 1$ \\
\hline 19 & October 2012 - September 2014 & Hirpo (2016) & - & $0.13 \pm 0.0$ & - & $44.5 \pm 5$ & $23.9 \pm 0.1$ \\
\hline 19 & October 2014 - February 2015 & Teklu et al. (2018) & $16.9 \pm 7$ & $0.86 \pm 0.63$ & $237 \pm 23$ & _- & _ \\
\hline
\end{tabular}

Note: ND = not detected, NA = guideline value not available , for site numbers refer to Fig. 2.1 
Table SI2.2. Nutrients and trace metals monitoring data in various sites of Lake Ziway used to preform RDA analysis (Fig. 2.3). Source: Teklu et al. (2018).

\begin{tabular}{|c|c|c|c|c|c|c|c|c|c|c|c|}
\hline Sampling date & Sampling site & EC & $\mathrm{pH}$ & $\begin{array}{l}\mathrm{NH}_{4}^{+} \\
(\mathrm{mg} / \mathrm{L})\end{array}$ & $\begin{array}{l}\mathrm{NO}_{3}{ }^{-} \\
(\mathrm{mg} / \mathrm{L})\end{array}$ & $\begin{array}{l}\mathrm{P} \\
(\mathrm{mg} / \mathrm{L})\end{array}$ & $\begin{array}{l}\text { Alkalinity } \\
\text { (meq/L) }\end{array}$ & $\begin{array}{l}\mathrm{K}^{+} \\
(\mathrm{mg} / \mathrm{L})\end{array}$ & $\begin{array}{l}\mathrm{Ca}^{2+} \\
(\mathrm{mg} / \mathrm{L})\end{array}$ & $\begin{array}{l}\mathrm{Mg}^{2+} \\
(\mathrm{mg} / \mathrm{L})\end{array}$ & $\begin{array}{l}\mathrm{Na}^{+} \\
(\mathrm{mg} / \mathrm{L})\end{array}$ \\
\hline June 2013 & Wamicha & 490 & 9 & 1.03 & 17.34 & 0 & 124 & 13.37 & 14.22 & 8.92 & 79.3 \\
\hline June 2013 & Bochessa & 480 & 9 & 0.97 & 16.87 & 0 & 116 & 13.21 & 13.98 & 8.77 & 78.05 \\
\hline June 2013 & Bulbulaa & 470 & 8.8 & 0.84 & 14.55 & 0 & 122 & 13.84 & 14.47 & 8.87 & 77.54 \\
\hline June 2013 & Water Supply & 480 & 8.8 & 0.93 & 19.09 & 0 & 124 & 13.37 & 14.77 & 8.83 & 78.59 \\
\hline June 2013 & Floriculture-2 & 440 & 8.7 & 0.74 & 23.35 & 0 & 224 & 12.28 & 13.16 & 6.81 & 73.56 \\
\hline June 2013 & SEDA Nursery site & 490 & 9 & 0.89 & 16.57 & 0 & 136 & 12.95 & 13.41 & 8.66 & 78.21 \\
\hline June 2013 & Fish production & 500 & 8.4 & 1.92 & 15.22 & 0 & 134 & 13.59 & 16.38 & 9.32 & 79.68 \\
\hline June 2013 & Korekonch & 490 & 8.7 & 1.37 & 14.16 & 0 & 118 & 12.98 & 14.58 & 8.91 & 77.93 \\
\hline June 2013 & Around lodges & 490 & 8.9 & 0.82 & 14.64 & 0 & 116 & 12.92 & 13.36 & 8.68 & 77.45 \\
\hline June 2013 & Kidanemihret Church & 470 & 8.9 & 0.79 & 16.19 & 0 & 140 & 13.18 & 13.82 & 8.78 & 77.39 \\
\hline June 2013 & Floriculture-1 & 1040 & 8.7 & 1.03 & 47.85 & 0 & not measured & 22.54 & 13.69 & 4.26 & 207.65 \\
\hline June 2013 & Meki River Outlet & 160 & 7.7 & 3.08 & 167.48 & 0.86 & not measured & 45.62 & 29.57 & 29.26 & 26.73 \\
\hline June 2013 & Ketar River Outlet & 140 & 7.8 & 0.9 & 18.13 & 0.22 & not measured & 5.63 & 13.1 & 4.39 & 12.03 \\
\hline February 2014 & Wamicha & 440 & 8.7 & 0.02 & 6.64 & 0.005 & 220 & 12.88 & 16.81 & 9.35 & 71.19 \\
\hline February 2014 & Bochessa & 440 & 8.8 & 0.005 & 0.06 & 0.005 & 234 & 0.33 & 0.43 & 0.38 & 3.15 \\
\hline February 2014 & Bulbulaa & 450 & 8.7 & 0.02 & 5.03 & 0.005 & 238 & 12.85 & 17.65 & 9.37 & 72.5 \\
\hline February 2014 & Water Supply & 440 & 8.7 & 0.005 & 7.18 & 0.005 & 233 & 12.72 & 18.12 & 9.39 & 71.84 \\
\hline February 2014 & Floriculture-2 & 500 & 8.7 & 0.01 & 7.23 & 0.005 & 255 & 13.97 & 19.13 & 9.41 & 81.18 \\
\hline February 2014 & SEDA Nursery site & 450 & 8.7 & 0.02 & 7.71 & 0.005 & 234 & 12.56 & 17.85 & 9.17 & 72.06 \\
\hline February 2014 & Fish production & 450 & 8.6 & 0.05 & 7.77 & 0.005 & 218 & 12.62 & 18.58 & 9.24 & 71.75 \\
\hline February 2014 & Korekonch & 460 & 8.6 & 0.005 & 0.16 & 0.005 & 237 & 0.33 & 0.47 & 0.38 & 3.16 \\
\hline February 2014 & Around lodges & 450 & 8.6 & 0.13 & 8.25 & 0.005 & 260 & 12.59 & 18.73 & 9.28 & 72.31 \\
\hline February 2014 & Kidanemihret Church & 450 & 8.7 & 0.28 & 9.86 & 0.005 & 229 & 12.47 & 17.73 & 9.22 & 70.97 \\
\hline February 2014 & Floriculture-1 & 540 & 8.5 & 0.01 & 17.9 & 0.005 & not measured & 15.11 & 38.84 & 11.22 & 65.38 \\
\hline February 2014 & Meki River Outlet & 210 & 8 & 0.17 & 3.96 & 0.005 & not measured & 4.27 & 18.46 & 5.44 & 19.77 \\
\hline February 2014 & Ketar River Outlet & 1740 & 9 & 0.04 & 296.08 & 0.005 & not measured & 53.06 & 26.36 & 11.51 & 337.08 \\
\hline June 2014 & Wamicha & 490 & 8.7 & 0.28 & 7.74 & 0.005 & 224.4 & 13.2 & 18.12 & 9.09 & 74.84 \\
\hline June 2014 & Bochessa & 470 & 8.8 & 0.08 & 7.1 & 0.005 & 244.8 & 13.19 & 16.95 & 9.11 & 74.92 \\
\hline June 2014 & Bulbulaa & 480 & 8.8 & 0.35 & 8.27 & 0.005 & 224.4 & 13.06 & 17.45 & 9.17 & 74.39 \\
\hline June 2014 & Water Supply & 480 & 8.7 & 0.18 & 11.58 & 0.005 & 265.2 & 13.21 & 17.89 & 9.21 & 76.13 \\
\hline June 2014 & Floriculture-2 & 530 & 8.7 & 0.2 & 14.79 & 0.005 & 224.4 & 14.15 & 17.34 & 9.33 & 83.51 \\
\hline June 2014 & SEDA Nursery site & 480 & 8.7 & 0.21 & 10.3 & 0.005 & 244.8 & 13.14 & 17.37 & 9.35 & 74.84 \\
\hline June 2014 & Fish production & 490 & 8.6 & 0.49 & 9.77 & 0.005 & 265.2 & 13.32 & 18.81 & 9.43 & 75.88 \\
\hline June 2014 & Korekonch & 470 & 8.8 & 0.23 & 8.27 & 0.005 & 265.2 & 13.22 & 16.99 & 9.25 & 78.86 \\
\hline June 2014 & Around lodges & 470 & 8.8 & 0.19 & 8.27 & 0.005 & 244.8 & 0.005 & 16.68 & 9.14 & 73.94 \\
\hline June 2014 & Kidanemihret Church & 470 & 8.9 & 0.36 & 8.91 & 0.005 & 224.4 & 13.09 & 16.2 & 9.13 & 5.01 \\
\hline June 2014 & Floriculture-1 & 1170 & 8.9 & 0.13 & 172.67 & 0.005 & not measured & 30.52 & 22.53 & 11.91 & 250.3 \\
\hline June 2014 & Meki River Outlet & 400 & 8.5 & 0.28 & 17.03 & 0.005 & not measured & 9.38 & 26.27 & 6.93 & 48.99 \\
\hline June 2014 & Ketar River Outlet & 200 & 8.1 & 0.03 & 6.25 & 0.005 & not measured & 3.71 & 16.81 & 4.72 & 16.21 \\
\hline
\end{tabular}




\begin{tabular}{|c|c|c|c|c|c|c|c|c|c|c|c|}
\hline Sampling date & Sampling site & $\mathrm{EC}$ & $\mathrm{pH}$ & $\begin{array}{l}\mathrm{NH}_{4}^{+} \\
(\mathrm{mg} / \mathrm{L})\end{array}$ & $\begin{array}{l}\mathrm{NO}_{3}^{-} \\
(\mathrm{mg} / \mathrm{L})\end{array}$ & $\begin{array}{l}\mathrm{P} \\
(\mathrm{mg} / \mathrm{L})\end{array}$ & $\begin{array}{l}\text { Alkalinity } \\
\text { (meq/L) }\end{array}$ & $\begin{array}{l}\mathrm{K}^{+} \\
(\mathrm{mg} / \mathrm{L})\end{array}$ & $\begin{array}{l}\mathrm{Ca}^{2+} \\
(\mathrm{mg} / \mathrm{L})\end{array}$ & $\begin{array}{l}\mathrm{Mg}^{2+} \\
(\mathrm{mg} / \mathrm{L})\end{array}$ & $\begin{array}{l}\mathrm{Na}^{+} \\
(\mathrm{mg} / \mathrm{L})\end{array}$ \\
\hline October 2014 & Wamicha & 380 & 8.5 & 0.97 & 10.71 & 0.005 & not measured & 11.97 & 19.83 & 7.68 & 61.54 \\
\hline October 2014 & Bochessa & 400 & 8.4 & 1.07 & 17.12 & 0.005 & not measured & 10.99 & 15.63 & 5.87 & 54.54 \\
\hline October 2014 & Bulbulaa & 400 & 8.4 & 1.36 & 3.23 & 0.005 & not measured & 2.48 & 5.01 & 1.46 & 12.26 \\
\hline October 2014 & Water Supply & 410 & 8.4 & 1.21 & 18.2 & 0.005 & not measured & 12.13 & 20.79 & 7.99 & 63.97 \\
\hline October 2014 & Floriculture-2 & 420 & 8.4 & 1.25 & 22.23 & 0.005 & not measured & 12.51 & 21 & 7.99 & 62.37 \\
\hline October 2014 & SEDA Nursery site & 420 & 8.3 & 1.49 & 17.05 & 0.005 & not measured & 12.85 & 2.03 & 8.17 & 63.46 \\
\hline October 2014 & Fish production & 430 & 8.2 & 1.17 & 14.17 & 0.005 & not measured & 12.88 & 21.75 & 8.27 & 62.99 \\
\hline October 2014 & Korekonch & 420 & 8.3 & 1.32 & 17.62 & 0.005 & not measured & 12.61 & 21.02 & 8.1 & 61.91 \\
\hline October 2014 & Around lodges & 430 & 8.3 & 1.58 & 16.66 & 0.005 & not measured & 12.56 & 21.65 & 8.14 & 63.16 \\
\hline October 2014 & Kidanemihret Church & 420 & 8.3 & 1.25 & 15.51 & 0.005 & not measured & 12.15 & 20.1 & 7.86 & 60.81 \\
\hline October 2014 & Floriculture-1 & 1320 & 8.6 & 0.66 & 181.2 & 0.005 & not measured & 43.23 & 25.17 & 12.23 & 247.21 \\
\hline October 2014 & Meki River Outlet & 300 & 8.3 & 0.26 & 7.26 & 0.005 & not measured & 6.51 & 17.79 & 5.17 & 46.33 \\
\hline October 2014 & Ketar River Outlet & 190 & 7.9 & 0.005 & 6.11 & 0.005 & not measured & 5.39 & 13.95 & 4.29 & 21.17 \\
\hline October 2014 & Abosa & 440 & 8.1 & 1.55 & 19.35 & 0.005 & not measured & 11.92 & 20.47 & 7.83 & 60.64 \\
\hline October 2014 & Gabriel & 400 & 8.3 & 1.68 & 10.71 & 0.005 & not measured & 11.76 & 20.53 & 7.55 & 60.19 \\
\hline October 2014 & North western of the lake & 400 & 8.1 & 1.68 & 9.98 & 0.005 & not measured & 11.51 & 19.43 & 7.32 & 57.69 \\
\hline October 2014 & Lake centre & 380 & 8.4 & 1.31 & 4.38 & 0.005 & not measured & 11.23 & 19.13 & 7.16 & 56.2 \\
\hline February 2015 & Wamicha & 440 & 8.6 & 0.38 & 16 & 0.005 & not measured & 11.75 & 23.15 & 8.25 & 59.73 \\
\hline February 2015 & Bochessa & 420 & 8.6 & 0.41 & 16.98 & 0.005 & not measured & 11.79 & 22.93 & 8.43 & 59.65 \\
\hline February 2015 & Bulbulaa & 450 & 8.6 & 0.39 & 16.36 & 0.005 & not measured & 11.74 & 22.94 & 8.23 & 60.06 \\
\hline February 2015 & Water Supply & 440 & 8.6 & 0.45 & 17.81 & 0.005 & not measured & 11.39 & 22.96 & 8.19 & 59.69 \\
\hline February 2015 & Floriculture-2 & 510 & 8.4 & 0.16 & 20.81 & 0.005 & not measured & 13.27 & 23.71 & 8.92 & 70.45 \\
\hline February 2015 & SEDA Nursery site & 450 & 8.6 & 0.22 & 17.91 & 0.005 & not measured & 11.6 & 23.05 & 8.35 & 59.29 \\
\hline February 2015 & Fish production & 410 & 8.5 & 0.23 & 16.41 & 0.005 & not measured & 11.61 & 23.72 & 8.35 & 60.4 \\
\hline February 2015 & Korekonch & 430 & 8.4 & 0.46 & 18.14 & 0.005 & not measured & 12.22 & 24.04 & 8.8 & 61.96 \\
\hline February 2015 & Around lodges & 420 & 8.3 & 0.49 & 15.99 & 0.005 & not measured & 11.94 & 24.63 & 8.76 & 62.07 \\
\hline February 2015 & Kidanemihret Church & 450 & 8.5 & 0.32 & 15.02 & 0.005 & not measured & 11.92 & 23.81 & 8.65 & 60.48 \\
\hline February 2015 & Floriculture-1 & 1040 & 8.7 & 0.19 & 126.48 & 0.005 & not measured & 31.81 & 26.43 & 11.29 & 199.24 \\
\hline February 2015 & Meki River Outlet & 450 & 8.5 & 0.1 & 15.81 & 0.005 & not measured & 11.33 & 23.95 & 8.34 & 59.65 \\
\hline February 2015 & Ketar River Outlet & 230 & 7.9 & 0.1 & 5.9 & 0.005 & not measured & 4.22 & 18.43 & 5.46 & 21.43 \\
\hline February 2015 & Abosa & 410 & 8.4 & 0.5 & 14.04 & 0.005 & not measured & 11.86 & 23.79 & 8.73 & 61.11 \\
\hline February 2015 & Gabriel & 400 & 8.5 & 0.42 & 15.34 & 0.005 & not measured & 11.8 & 23.5 & 8.59 & 59.09 \\
\hline February 2015 & North western of the lake & 410 & 8.4 & 0.47 & 15.02 & 0.005 & not measured & 11.82 & 23.66 & 8.74 & 59.21 \\
\hline February 2015 & Lake centre & 210 & 8.6 & 0.42 & 15.95 & 0.005 & not measured & 11.46 & 23.27 & 8.48 & 58.06 \\
\hline February 2015 & Golbe North Eastern of the lake & 410 & 8.6 & 0.21 & 15.2 & 0.005 & not measured & 11.51 & 23.51 & 8.52 & 58.38 \\
\hline
\end{tabular}




\begin{tabular}{|c|c|c|c|c|c|c|c|c|c|c|c|}
\hline Sampling date & Sampling site & $\begin{array}{l}\mathrm{So}_{4}{ }^{2-} \\
\text { (mg/L) }\end{array}$ & $\begin{array}{l}\mathrm{Cl}^{-} \\
(\mathrm{mg} / \mathrm{L})\end{array}$ & $\begin{array}{l}\mathrm{HCO}_{3}{ }^{-} \\
(\mathrm{mg} / \mathrm{L})\end{array}$ & $\begin{array}{l}\mathrm{SiO}_{2} \\
(\mathrm{mg} / \mathrm{L})\end{array}$ & $\begin{array}{l}\mathrm{Fe} \\
(\mathrm{mg} / \mathrm{L})\end{array}$ & $\begin{array}{l}\mathrm{Mn} \\
(\mathrm{mg} / \mathrm{L})\end{array}$ & $\begin{array}{l}\mathrm{Zn} \\
(\mathrm{mg} / \mathrm{L})\end{array}$ & $\begin{array}{l}\text { B } \\
(\mathrm{mg} / \mathrm{L})\end{array}$ & $\begin{array}{l}\mathrm{Cu} \\
(\mathrm{mg} / \mathrm{L})\end{array}$ & $\begin{array}{l}\text { Mo } \\
\text { (mg/L) }\end{array}$ \\
\hline June 2013 & Wamicha & 3.04 & 16.93 & 270.91 & 17.28 & 0.78 & 0.02 & 0 & 0.1 & 0 & 0 \\
\hline June 2013 & Bochessa & 3.02 & 18.92 & 276.4 & 16.67 & 0.61 & 0.01 & 0 & 0.1 & 0 & 0 \\
\hline June 2013 & Bulbulaa & 3.28 & 17.43 & 278.23 & 16.58 & 0.57 & 0.02 & 0 & 0.1 & 0 & 0 \\
\hline June 2013 & Water Supply & 3.11 & 16.43 & 291.66 & 16.09 & 0.56 & 0.02 & 0 & 0.1 & 0 & 0 \\
\hline June 2013 & Floriculture-2 & 3.69 & 14.44 & 234.3 & 12.93 & 0.43 & 0.02 & 0 & 0.1 & 0 & 0 \\
\hline June 2013 & SEDA Nursery site & 2.88 & 17.43 & 275.18 & 15.56 & 0.38 & 0.01 & 0 & 0.1 & 0 & 0 \\
\hline June 2013 & Fish production & 2.67 & 18.42 & 283.11 & 15.84 & 0.35 & 0.06 & 0 & 0.1 & 0 & 0 \\
\hline June 2013 & Korekonch & 2.75 & 17.92 & 272.13 & 15.79 & 0.39 & 0.04 & 0 & 0.1 & 0 & 0 \\
\hline June 2013 & Around lodges & 2.86 & 16.43 & 273.35 & 15.95 & 0.46 & 0.02 & 0 & 0.1 & 0 & 0 \\
\hline June 2013 & Kidanemihret Church & 2.84 & 20.91 & 272.74 & 15.88 & 0.38 & 0.02 & 0 & 0.1 & 0 & 0 \\
\hline June 2013 & Floriculture-1 & 13.89 & 20.41 & 446.03 & 18.17 & 0.31 & 0.03 & 0 & 0.3 & 0 & 0 \\
\hline June 2013 & Meki River Outlet & 3.34 & 3.98 & 61.02 & 81.47 & 29.3 & 0.9 & 0.79 & 0.1 & 0.07 & 0 \\
\hline June 2013 & Ketar River Outlet & 1.27 & 5.48 & 81.76 & 50.59 & 15.4 & 0.13 & 0.02 & 0 & 0 & 0 \\
\hline February 2014 & Wamicha & 2.81 & 11.97 & 297.76 & 16.24 & 0.71 & 0.01 & 0.005 & 0.1 & 0.01 & 0.01 \\
\hline February 2014 & Bochessa & 0.09 & 0.35 & 4.41 & 0.58 & 10.7 & 0.09 & 0.005 & 5.7 & 0.01 & 0.05 \\
\hline February 2014 & Bulbulaa & 2.86 & 15.96 & 258.1 & 15.94 & 0.69 & 0.01 & 0.005 & 0.1 & 0.01 & 0 \\
\hline February 2014 & Water Supply & 3.99 & 10.97 & 241.62 & 16.02 & 0.62 & 0.01 & 0.005 & 0.1 & 0.01 & 0.005 \\
\hline February 2014 & Floriculture-2 & 3.53 & 13.97 & 267.25 & 16.12 & 0.6 & 0.01 & 0.005 & 0.1 & 0.01 & 0.005 \\
\hline February 2014 & SEDA Nursery site & 2.8 & 12.47 & 236.74 & 15.77 & 0.6 & 0.01 & 0.005 & 0.1 & 0.01 & 0.005 \\
\hline February 2014 & Fish production & 3.35 & 13.47 & 276.74 & 16.77 & 0.81 & 0.01 & 0.005 & 0.1 & 0.01 & 0.01 \\
\hline February 2014 & Korekonch & 0.12 & 0.35 & 3.89 & 0.53 & 11.9 & 0.11 & 0.005 & 5.7 & 0.01 & 0.05 \\
\hline February 2014 & Around lodges & 2.79 & 11.97 & 235.52 & 16.39 & 0.7 & 0.01 & 0.005 & 0.1 & 0.01 & 0 \\
\hline February 2014 & Kidanemihret Church & 2.79 & 12.97 & 235.52 & 16.26 & 0.6 & 0.005 & 0.005 & 0.1 & 0.01 & 0.005 \\
\hline February 2014 & Floriculture-1 & 14.96 & 21.45 & 235.52 & 17.52 & 0.26 & 0.01 & 0.005 & 0 & 0.01 & 0.01 \\
\hline February 2014 & Meki River Outlet & 1.07 & 4.99 & 113.49 & 25 & 1.28 & 0.06 & 0.005 & 0 & 0.01 & 0.005 \\
\hline February 2014 & Ketar River Outlet & 30.9 & 33.42 & 704.12 & 32.35 & 0.06 & 0.03 & 0.005 & 0.4 & 0.01 & 0.01 \\
\hline June 2014 & Wamicha & 2.94 & 16.34 & 288.61 & 15.54 & 1.05 & 0.01 & 0.005 & 0.1 & 0.01 & 0.005 \\
\hline June 2014 & Bochessa & 2.9 & 17.33 & 284.94 & 15.45 & 1 & 0.01 & 0.005 & 0.1 & 0.01 & 0.005 \\
\hline June 2014 & Bulbulaa & 2.86 & 15.35 & 285.55 & 15.6 & 1.03 & 0.01 & 0.005 & 0.1 & 0.01 & 0.005 \\
\hline June 2014 & Water Supply & 2.85 & 18.33 & 291.66 & 15.95 & 1.15 & 0.01 & 0.005 & 0.1 & 0.01 & 0.005 \\
\hline June 2014 & Floriculture-2 & 3.57 & 16.84 & 308.13 & 16.01 & 0.99 & 0.01 & 0.005 & 0.1 & 0.01 & 0.005 \\
\hline June 2014 & SEDA Nursery site & 2.8 & 15.35 & 289.83 & 15.55 & 0.94 & 0.01 & 0.005 & 0.1 & 0.01 & 0.005 \\
\hline June 2014 & Fish production & 2.87 & 17.83 & 292.88 & 15.35 & 0.85 & 0.01 & 0.005 & 0.1 & 0.01 & 0.005 \\
\hline June 2014 & Korekonch & 2.87 & 15.85 & 286.77 & 15.66 & 1 & 0.01 & 0.005 & 0.1 & 0.01 & 0.005 \\
\hline June 2014 & Around lodges & 2.89 & 15.85 & 283.72 & 16.72 & 1.39 & 0.02 & 0.005 & 0.1 & 0.01 & 0.005 \\
\hline June 2014 & Kidanemihret Church & 2.9 & 16.34 & 283.11 & 15.22 & 0.88 & 0.01 & 0.005 & 0.1 & 0.01 & 0.005 \\
\hline June 2014 & Floriculture-1 & 15.87 & 28.23 & 611.99 & 25.53 & 0.27 & 0.04 & 0.005 & 0.3 & 0.01 & 0 \\
\hline June 2014 & Meki River Outlet & 7.08 & 11.39 & 210.5 & 25.8 & 3.01 & 0.03 & 0.005 & 0 & 0.01 & 0.005 \\
\hline June 2014 & Ketar River Outlet & 0.77 & 1.49 & 115.93 & 23.91 & 1.95 & 0.09 & 0.005 & 0 & 0.01 & 0.005 \\
\hline
\end{tabular}




\begin{tabular}{|c|c|c|c|c|c|c|c|c|c|c|c|}
\hline Sampling date & Sampling site & $\begin{array}{l}\mathrm{So}_{4}{ }^{2-} \\
(\mathrm{mg} / \mathrm{L})\end{array}$ & $\begin{array}{l}\mathrm{Cl}^{-} \\
(\mathrm{mg} / \mathrm{L})\end{array}$ & $\begin{array}{l}\mathrm{HCO}_{3}^{-} \\
(\mathrm{mg} / \mathrm{L}) \\
\end{array}$ & $\begin{array}{l}\mathrm{SiO}_{2} \\
(\mathrm{mg} / \mathrm{L})\end{array}$ & $\begin{array}{l}\mathrm{Fe} \\
(\mathrm{mg} / \mathrm{L})\end{array}$ & $\begin{array}{l}\mathrm{Mn} \\
(\mathrm{mg} / \mathrm{L})\end{array}$ & $\begin{array}{l}\mathrm{Zn} \\
(\mathrm{mg} / \mathrm{L})\end{array}$ & $\begin{array}{l}B \\
(\mathrm{mg} / \mathrm{L})\end{array}$ & $\begin{array}{l}\mathrm{Cu} \\
(\mathrm{mg} / \mathrm{L})\end{array}$ & $\begin{array}{l}\mathrm{Mo} \\
(\mathrm{mg} / \mathrm{L})\end{array}$ \\
\hline October 2014 & Wamicha & 2.36 & 10.99 & 228.81 & 14.29 & 1.1 & 0.005 & 0.005 & 0 & 0.01 & 0.005 \\
\hline October 2014 & Bochessa & 2 & 13.48 & 232.47 & 8.59 & 0.12 & 0.005 & 0.005 & 0 & 0.01 & 0.005 \\
\hline October 2014 & Bulbulaa & 0.27 & 11.49 & 234.91 & 2.92 & 0.11 & 0.005 & 0.005 & 0 & 0.01 & 0.005 \\
\hline October 2014 & Water Supply & 2.52 & 14.48 & 234.91 & 1.91 & 0.38 & 0.005 & 0.005 & 0 & 0.01 & 0.005 \\
\hline October 2014 & Floriculture-2 & 2.44 & 11.98 & 225.76 & 18.74 & 2.97 & 0.01 & 0.005 & 0 & 0.01 & 0.005 \\
\hline October 2014 & SEDA Nursery site & 2.42 & 13.98 & 230.03 & 20.26 & 3.47 & 0.01 & 0.01 & 0 & 0.01 & 0.005 \\
\hline October 2014 & Fish production & 2.38 & 12.98 & 262.37 & 21.55 & 3.86 & 0.01 & 0.005 & 0 & 0.01 & 0.005 \\
\hline October 2014 & Korekonch & 2.24 & 11.98 & 231.25 & 19.49 & 3.21 & 0.01 & 0.005 & 0 & 0.01 & 0.005 \\
\hline October 2014 & Around lodges & 2.26 & 12.48 & 234.3 & 16.88 & 22.4 & 0.005 & 0.005 & 0 & 0.01 & 0.005 \\
\hline October 2014 & Kidanemihret Church & 2.26 & 11.49 & 222.71 & 16.9 & 2.3 & 0.01 & 0.005 & 0 & 0.01 & 0.005 \\
\hline October 2014 & Floriculture-1 & 20.34 & 33.96 & 602.84 & 24.61 & 0.39 & 0.01 & 0.005 & 0.3 & 0.01 & 0.01 \\
\hline October 2014 & Meki River Outlet & 3.22 & 6.99 & 147.05 & 24.1 & 4.05 & 0.04 & 0.005 & 0 & 0.01 & 0.005 \\
\hline October 2014 & Ketar River Outlet & 1.06 & 2.5 & 86.64 & 18.44 & 3.19 & 0.01 & 0.005 & 0 & 0.01 & 0.005 \\
\hline October 2014 & Abosa & 2.09 & 12.48 & 230.03 & 16.35 & 2.02 & 0.04 & 0.005 & 0 & 0.01 & 0.005 \\
\hline October 2014 & Gabriel & 2.31 & 9.99 & 224.54 & 12.32 & 0.45 & 0.05 & 0.005 & 0 & 0.01 & 0.01 \\
\hline October 2014 & North western of the lake & 2.35 & 10.49 & 231.25 & 12.58 & 0.85 & 0.005 & 0.005 & 0 & 0.01 & 0.005 \\
\hline October 2014 & Lake centre & 2.62 & 11.98 & 220.27 & 12.92 & 1.04 & 0 & 0.005 & 0 & 0.01 & 0.005 \\
\hline February 2015 & Wamicha & 2.17 & 20.5 & 262.37 & 16.07 & 2.54 & 0.02 & 0.005 & 0 & 0.01 & 0.005 \\
\hline February 2015 & Bochessa & 2.19 & 22 & 265.42 & 17.81 & 3.12 & 0.02 & 0.005 & 0 & 0.01 & 0.005 \\
\hline February 2015 & Bulbulaa & 2.23 & 22.49 & 266.03 & 15.87 & 2.54 & 0.02 & 0.005 & 0 & 0.01 & 0.005 \\
\hline February 2015 & Water Supply & 2.12 & 22 & 265.42 & 15.77 & 2.54 & 0.02 & 0.005 & 0 & 0.01 & 0.005 \\
\hline February 2015 & Floriculture-2 & 3.28 & 22 & 300.2 & 18.97 & 3.22 & 0.02 & 0.005 & 0 & 0.01 & 0.005 \\
\hline February 2015 & SEDA Nursery site & 2.16 & 22 & 262.98 & 17.1 & 2.91 & 0.02 & 0.005 & 0 & 0.01 & 0.005 \\
\hline February 2015 & Fish production & 2.13 & 23.49 & 268.47 & 16.36 & 2.67 & 0.02 & 0.005 & 0 & 0.01 & 0.005 \\
\hline February 2015 & Korekonch & 2.32 & 22.49 & 267.25 & 17.7 & 2.97 & 0.02 & 0.005 & 0 & 0.01 & 0.005 \\
\hline February 2015 & Around lodges & 2.14 & 23.49 & 270.91 & 16.91 & 2.8 & 0.01 & 0.005 & 0 & 0.01 & 0.005 \\
\hline February 2015 & Kidanemihret Church & 2.19 & 22 & 264.81 & 17.93 & 3.12 & 0.02 & 0.005 & 0 & 0.01 & 0.005 \\
\hline February 2015 & Floriculture-1 & 16.94 & 37.99 & 568.67 & 24.55 & 1.49 & 0.02 & 0.005 & 0.2 & 0.01 & 0.01 \\
\hline February 2015 & Meki River Outlet & 2.08 & 2 & 261.15 & 14.94 & 2.42 & 0.02 & 0.005 & 0 & 0.01 & 0.005 \\
\hline February 2015 & Ketar River Outlet & 0.32 & 18 & 134.23 & 27.17 & 1.02 & 0.01 & 0.005 & 0 & 0.01 & 0.005 \\
\hline February 2015 & Abosa & 2.03 & 20.5 & 270.9 & 19.26 & 3.58 & 0.02 & 0.005 & 0 & 0.01 & 0.005 \\
\hline February 2015 & Gabriel & 2.08 & 22.49 & 258.71 & 19.21 & 3.63 & 0.02 & 0.005 & 0 & 0.01 & 0.005 \\
\hline February 2015 & North western of the lake & 2.07 & 22 & 260.54 & 20.45 & 4.12 & 0.02 & 0.005 & 0 & 0.01 & 0.005 \\
\hline February 2015 & Lake centre & 2.03 & 22 & 253.22 & 18.98 & 3.6 & 0.02 & 0.005 & 0 & 0.01 & 0.005 \\
\hline February 2015 & Golbe North Eastern of the lake & 2.03 & 21.5 & 258.71 & 17.91 & 3.24 & 0.02 & 0.005 & 0 & 0.01 & 0.005 \\
\hline
\end{tabular}


Table S12.3. Reported pesticides values in various shoreline parts of Lake Ziway. The values are summarized as mean with the range in parentheses ( ), except for values with "** that are single time measurement.

\begin{tabular}{|c|c|c|c|c|c|c|}
\hline $\begin{array}{l}\text { Sampling } \\
\text { Site }\end{array}$ & Sampling date & Pesticide & Use category & Chemical class & $\begin{array}{l}\text { Reported } \\
\text { con. }(\mu \mathrm{g} / \mathrm{L})\end{array}$ & Reference \\
\hline Bulbula & August 2014 & Spiroxamine & Fungicide & Morpholine & $6.9(-)^{*}$ & 2 \\
\hline Floriculture 1 & July 2009/July 2010 & Acetamiprid & Insecticide & Neonicotinoid & $7.6(-)^{*}$ & 1 \\
\hline Floriculture 1 & July 2009 \& July 2010 & Azoxystrobin & Fungicide & Strobilurin & $2.2(-)^{*}$ & 1 \\
\hline Floriculture 1 & July 2009 \& July 2010 & Boscalid & Fungicide & Carboxamide & $2.6(-)^{*}$ & 1 \\
\hline Floriculture 1 & July 2009 \& July 2010 & Bitertanol & Fungicide & Triazole & $0.45(0.11-0.8)$ & 1 \\
\hline Floriculture 1 & July 2009 \& July 2010 & Bupirimate & Fungicide & Pyrimidinol & $0.19(-)^{*}$ & 1 \\
\hline Floriculture 1 & July 2009 \& July 2010 & Carbendazim & Fungicide & Benzimidazole & $3.2(0.14-9.1)$ & 1 \\
\hline Floriculture 1 & July 2009 \& July 2010 & Cyprodinil & Fungicide & $\begin{array}{l}\text { Anilinopyrimidin } \\
\text { e }\end{array}$ & $0.13(0.05-0.19)$ & 1 \\
\hline Floriculture 1 & July 2009 \& July 2010 & Clofentezine & Acaricide & Tetrazine & $0.1(-)^{*}$ & 1 \\
\hline Floriculture 1 & July 2009 \& July 2010 & $\begin{array}{l}\text { Diethyltoluam } \\
\text { ide }\end{array}$ & Insecticide & Unclassified & $0.1(0.06-0.14)$ & 1 \\
\hline Floriculture 1 & July 2009 \& July 2010 & Dodemorf & Fungicide & Morpholine & $0.36(0.13-0.5)$ & 1 \\
\hline Floriculture 1 & July 2009 \& July 2010 & Dimethomorf & Fungicide & Morpholine & $0.43(0.09-0.77)$ & 1 \\
\hline Floriculture 1 & July 2009 \& July 2010 & $\begin{array}{l}\text { Endosulfan- } \\
\text { sulfate }\end{array}$ & $\begin{array}{l}\text { Insecticide- } \\
\text { metabolite }\end{array}$ & Organochlorine & $0.06(-)^{*}$ & 1 \\
\hline Floriculture 1 & July 2009 \& July 2010 & Ethirimol & Fungicide & Pyrimidinol & $0.05(0.01-0.09)$ & 1 \\
\hline Floriculture 1 & July 2009 \& July 2010 & Fenitrothion & Insecticide & $\begin{array}{l}\text { Organophosphat } \\
\text { e }\end{array}$ & $0.16(-)^{*}$ & 1 \\
\hline Floriculture 1 & July 2009 \& July 2010 & Fenamiphos & Nematicide & $\begin{array}{l}\text { Organophosphat } \\
\text { e }\end{array}$ & $0.08(-)^{*}$ & 1 \\
\hline Floriculture 1 & July 2009 \& July 2010 & Fenarimol & Fungicide & Pyrimidine & $0.4(-)^{*}$ & 1 \\
\hline Floriculture 1 & July 2009 \& July 2010 & Fludioxonil & Fungicide & Phenylpyrrole & $0.19(0.12-0.26)$ & 1 \\
\hline Floriculture 1 & July 2009 \& July 2010 & $\begin{array}{l}\text { Fenamiphos- } \\
\text { sulfone }\end{array}$ & metabolite & unkown & $0.01(-)^{*}$ & 1 \\
\hline Floriculture 1 & July 2009 \& July 2010 & $\begin{array}{l}\text { Fenamiphos- } \\
\text { sulfoxide }\end{array}$ & metabolite & unkown & $0.04(0.02-0.07)$ & 1 \\
\hline Floriculture 1 & July 2009 \& July 2010 & Fenhexamid & Fungicide & Hydroxyanilide & $0.08(-)^{*}$ & 1 \\
\hline Floriculture 1 & July 2009 \& July 2010 & Hexythiazox & Acaricide & Carboxamide & $0.09(-)^{*}$ & 1 \\
\hline Floriculture 1 & July 2009 \& July 2010 & Imidacloprid & Insecticide & Neonicotinoid & $0.16(0.04-0.3)$ & 1 \\
\hline Floriculture 1 & July 2009 \& July 2010 & Iprodione & Fungicide & Dicarboximide & $0.53(0.25-0.81)$ & 1 \\
\hline Floriculture 1 & July 2009 \& July 2010 & Iprovalicarb & Fungicide & Carbamate & $0.14(0.01-0.38)$ & 1 \\
\hline Floriculture 1 & July 2009 \& July 2010 & Linuron & Herbicide & Urea & $0.02(-)^{*}$ & 1 \\
\hline Floriculture 1 & July 2009 \& July 2010 & Linuron & Herbicide & Urea & $0.02(-)^{*}$ & 1 \\
\hline Floriculture 1 & July 2009 \& July 2010 & Lufenuron & $\begin{array}{l}\text { Insecticide/ } \\
\text { Acaricide/VS }\end{array}$ & Benzoylurea & $0.02(-)^{*}$ & 1 \\
\hline Floriculture 1 & July 2009 \& July 2010 & Metalaxyl & Fungicide & Phenylamide & $0.34(0.18-0.51)$ & 1 \\
\hline Floriculture 1 & July 2009 \& July 2010 & Methomyl & $\begin{array}{l}\text { Insecticide/ } \\
\text { Acaricide }\end{array}$ & Carbamate & $1.48(0.26-2.7)$ & 1 \\
\hline Floriculture 1 & July 2009 \& July 2010 & $\begin{array}{l}\text { Methoxyfenoz } \\
\text { ide }\end{array}$ & Insecticide & Diacylhydrazine & $0.25(0.01-0.5)$ & 1 \\
\hline Floriculture 1 & July 2009 \& July 2010 & Methiocarb & $\begin{array}{l}\text { Acaricide/ } \\
\text { Insecticide }\end{array}$ & Carbamate & $0.04(-)^{*}$ & 1 \\
\hline Floriculture 1 & July 2009 \& July 2010 & Oxamyl & $\begin{array}{l}\text { Insecticide/Nemati } \\
\text { cide/Acaricide }\end{array}$ & Carbamate & $0.01(-)^{*}$ & 1 \\
\hline Floriculture 1 & July 2009 \& July 2010 & $\begin{array}{l}\text { Piperonyl- } \\
\text { butoxide }\end{array}$ & $\begin{array}{l}\text { Antiparasiticide/ } \\
\text { Synergist }\end{array}$ & Unclassified & $0.02(-)^{*}$ & 1 \\
\hline Floriculture 1 & July 2009 \& July 2010 & Pyraclostrobin & Fungicide & Strobilurin & $0.09(0.03-0.15)$ & 1 \\
\hline Floriculture 1 & July 2009 \& July 2010 & Propamocarb & Fungicide & Carbamate & $0.6(0.32-1)$ & 1 \\
\hline Floriculture 1 & July 2009 \& July 2010 & Spiroxamine & Fungicide & Morpholine & $2.55(1.1-4)$ & 1 \\
\hline
\end{tabular}

Note: Reference 1 = Jansen and Harmsen (2011), and 2 = Teklu et al. (2018) 
Table SI2.3 ... cont'd

\begin{tabular}{|c|c|c|c|c|c|c|}
\hline $\begin{array}{l}\text { Sampling } \\
\text { Site }\end{array}$ & Sampling date & Pesticide & Use category & Chemical class & $\begin{array}{l}\text { Reported } \\
\text { con. }(\mu \mathrm{g} / L)\end{array}$ & Reference \\
\hline Floriculture 1 & July 2009 \& July 2010 & Triadimefol & Fungicide & Triazole & $0.1(-)^{*}$ & 1 \\
\hline Floriculture 1 & July 2009 \& July 2010 & Triadimefon & Fungicide & Triazole & $0.16(-)^{*}$ & 1 \\
\hline Floriculture 1 & August, 2014 & Teflubenzuron & Insecticide/VS & Benzoylurea & $0.05(-)^{*}$ & 2 \\
\hline Floriculture 1 & July 2009 \& July 2010 & Tebufenpyrad & $\begin{array}{l}\text { Acaricide/Inse } \\
\text { cticide }\end{array}$ & Pyrazolium & $0.1(0.09-0.11)$ & 1 \\
\hline Floriculture 1 & July 2009 \& July 2010 & $\begin{array}{l}\text { Thiophanate- } \\
\text { methyl }\end{array}$ & Fungicide & Benzimidazole & $0.05(-)^{*}$ & 1 \\
\hline Floriculture 1 & July 2009 \& July 2010 & Triforine & $\begin{array}{l}\text { Fungicide, } \\
\text { Insecticide }\end{array}$ & Piperazine & $0.25(0.1-0.4)$ & 1 \\
\hline Floriculture 1 & July 2009 \& July 2010 & Tetradifon & $\begin{array}{l}\text { Insecticide/Ac } \\
\text { aricide }\end{array}$ & $\begin{array}{l}\text { Bridged } \\
\text { diphenyl }\end{array}$ & $0.85(0.4-1.15)$ & 1 \\
\hline Floriculture 1 & July 2009 \& July 2010 & Trifloxystrobin & Fungicide & Strobilurin & $0.34(-)^{*}$ & 1 \\
\hline Water Supply & August, 2014 & Deltamethrin & Insecticide & Pyrethroid & $0.01(-)^{*}$ & 2 \\
\hline Water Supply & August, 2014 & Diazinon & Insecticide & $\begin{array}{l}\text { Organophospha } \\
\text { te }\end{array}$ & $0.41(-)^{*}$ & 2 \\
\hline Water Supply & August, 2014 & Endosulfan & Insecticide & Organochlorine & $0.1(-)^{*}$ & 2 \\
\hline Water Supply & July 2009 \& July 2010 & Isoproturon & Herbicide & Urea & $0.03(-)^{*}$ & 1 \\
\hline Water Supply & August, 2014 & Lufenuron & $\begin{array}{l}\text { Insecticide/Ac } \\
\text { aricide/VS }\end{array}$ & Benzoylurea & $0.02(-)^{*}$ & 2 \\
\hline Water Supply & July 2009 \& July 2010 & $\begin{array}{l}\text { Metsulfuron- } \\
\text { methyl }\end{array}$ & Herbicide & Sulfonylurea & $0.3(-)^{*}$ & 1 \\
\hline Water Supply & July 2009 \& July 2010 & Methomyl & $\begin{array}{l}\text { Insecticide/Ac } \\
\text { aricide }\end{array}$ & Carbamate & $0.02(-)^{*}$ & 1 \\
\hline Water Supply & March 2015 & Pyraclostrobin & Fungicide & Strobilurin & $0.06(-)^{*}$ & 2 \\
\hline Water Supply & July 2009 \& July 2010 & Sulphur & $\begin{array}{l}\text { Fungicide/ } \\
\text { Acaricide }\end{array}$ & $\begin{array}{l}\text { Inorganic } \\
\text { substance }\end{array}$ & $10(-)^{*}$ & 1 \\
\hline Water Supply & August, 2014 & Teflubenzuron & Insecticide/VS & Benzoylurea & $0.08(-)^{*}$ & 2 \\
\hline Edo-Kontola & July 2009 \& July 2010 & Carbaryl & Insecticide & Carbamate & $0.05(-)^{*}$ & 1 \\
\hline Edo-Kontola & August, 2014 & $\begin{array}{l}\text { Dodemorf/Do } \\
\text { demorph }\end{array}$ & Fungicide & Morpholine & $32(-)^{*}$ & 2 \\
\hline Edo-Kontola & July 2009 \& July 2010 & Diazinon & Insecticide & $\begin{array}{l}\text { Organophospha } \\
\text { te }\end{array}$ & $0.09(-)^{*}$ & 1 \\
\hline Edo-Kontola & August, 2014 & Diazinon & Insecticide & $\begin{array}{l}\text { Organophospha } \\
\text { te }\end{array}$ & $0.28(-)^{*}$ & 2 \\
\hline Edo-Kontola & July 2009 \& July 2010 & Hexaflumuron & Insecticide & Benzoylurea & $0.01(-)^{*}$ & 1 \\
\hline Edo-Kontola & August, 2014 & Lufenuron & $\begin{array}{l}\text { Insecticide/Ac } \\
\text { aricide/VS }\end{array}$ & Benzoylurea & $0.08(-)^{*}$ & 2 \\
\hline Edo-Kontola & July 2009 \& July 2010 & Metalaxyl & Fungicide & Phenylamide & $0.09(-)^{*}$ & 1 \\
\hline Edo-Kontola & July 2009 \& July 2010 & $\begin{array}{l}\text { Metsulfuron- } \\
\text { methyl }\end{array}$ & Herbicide & Sulfonylurea & $\begin{array}{r}0.07(0.06- \\
0.08)\end{array}$ & 1 \\
\hline Edo-Kontola & July 2009 \& July 2010 & Sulphur & $\begin{array}{l}\text { Fungicide, } \\
\text { Acaricide }\end{array}$ & $\begin{array}{l}\text { Inorganic } \\
\text { substance }\end{array}$ & $2(1-3)$ & 1 \\
\hline Edo-Kontola & August, 2014 & Spiroxamine & Fungicide & Morpholine & $57(-)^{*}$ & 2 \\
\hline Edo-Kontola & July 2009 \& July 2010 & Triadimefol & Fungicide & Triazole & $0.02(-)^{*}$ & 1 \\
\hline Edo-Kontola & July 2009 \& July 2010 & Triadimefon & Fungicide & Triazole & $0.02(-)^{*}$ & 1 \\
\hline Edo-Kontola & August, 2014 & Teflubenzuron & Insecticide/VS & Benzoylurea & $0.03(-)^{*}$ & 2 \\
\hline Edo-Kontola & July 2009 \& July 2010 & Thiametoxam & Insecticide & Neonicotinoid & $0.01(-)^{*}$ & 1 \\
\hline
\end{tabular}

Note: VS veterinary substance, Reference 1 = Jansen and Harmsen (2011), and 2 = Teklu et al. (2018) 
Table SI2.3 ... cont'd

\begin{tabular}{|c|c|c|c|c|c|c|}
\hline Sampling Site & Sampling date & Pesticide & Use category & $\begin{array}{l}\text { Chemical } \\
\text { class }\end{array}$ & $\begin{array}{l}\text { Reported } \\
\text { con. }(\mu \mathrm{g} / \mathrm{L})\end{array}$ & $\begin{array}{l}\text { Referenc } \\
\text { e }\end{array}$ \\
\hline $\begin{array}{l}\text { Meki and Ketar } \\
\text { rivers }\end{array}$ & July 2009 \& July 2010 & $\sum \mathrm{DDT}$ & Insecticide & $\begin{array}{l}\text { Organochlo } \\
\text { rine }\end{array}$ & $0.04(-)^{*}$ & 1 \\
\hline $\begin{array}{l}\text { Meki and Ketar } \\
\text { rivers }\end{array}$ & July 2009 \& July 2010 & Dimethoate & $\begin{array}{l}\text { Acaricide/Inse } \\
\text { cticide }\end{array}$ & $\begin{array}{l}\text { Organophos } \\
\text { phate }\end{array}$ & $0.03(-)^{*}$ & 1 \\
\hline $\begin{array}{l}\text { Meki and Ketar } \\
\text { rivers }\end{array}$ & August, 2014 & Endosulfan & Insecticide & $\begin{array}{l}\text { Organochlo } \\
\text { rine }\end{array}$ & $0.14(-)^{*}$ & 2 \\
\hline $\begin{array}{l}\text { Meki and Ketar } \\
\text { rivers }\end{array}$ & July 2009 \& July 2010 & Fenitrothion & Insecticide & $\begin{array}{l}\text { Organophos } \\
\text { phate }\end{array}$ & $0.08(-)^{*}$ & 1 \\
\hline $\begin{array}{l}\text { Meki and Ketar } \\
\text { rivers }\end{array}$ & July 2009 \& July 2010 & Metalaxyl & Fungicide & $\begin{array}{l}\text { Phenylamid } \\
\text { e }\end{array}$ & $0.11(-)^{*}$ & 1 \\
\hline $\begin{array}{l}\text { Meki and Ketar } \\
\text { rivers }\end{array}$ & July 2009 \& July 2010 & $\begin{array}{l}\text { Metsulfuron- } \\
\text { methyl }\end{array}$ & Herbicide & $\begin{array}{l}\text { Sulfonylure } \\
\text { a }\end{array}$ & $0.04(-)^{*}$ & 1 \\
\hline $\begin{array}{l}\text { Meki and Ketar } \\
\text { rivers }\end{array}$ & July 2009 \& July 2010 & $\begin{array}{l}\text { Piperonyl- } \\
\text { butoxide }\end{array}$ & $\begin{array}{l}\text { Antiparasitici } \\
\text { de/Synergist }\end{array}$ & Unclassified & $0.02(-)^{*}$ & 1 \\
\hline $\begin{array}{l}\text { Meki and Ketar } \\
\text { rivers }\end{array}$ & July 2009 \& July 2010 & Sulphur & $\begin{array}{l}\text { Fungicide, } \\
\text { Acaricide }\end{array}$ & $\begin{array}{l}\text { Inorganic } \\
\text { substance }\end{array}$ & $7(-)^{*}$ & 1 \\
\hline $\begin{array}{l}\text { Meki and Ketar } \\
\text { rivers }\end{array}$ & July 2009 \& July 2010 & Triadimefol & Fungicide & Triazole & $0.05(-)^{*}$ & 1 \\
\hline $\begin{array}{l}\text { Meki and Ketar } \\
\text { rivers }\end{array}$ & July 2009 \& July 2010 & Triadimefon & Fungicide & Triazole & $0.04(-)^{*}$ & 1 \\
\hline
\end{tabular}




\section{CHAPTER 3}

Ecosystem services provided by the freshwater Lake Ziway in Ethiopia and the potential impact of pesticide use in local agriculture Lemessa B. Merga, Jack H. Faber, Paul J. van den Brink

Manuscript for submission is under preparation 


\section{Abstract}

Freshwater ecosystems supply multiple ecosystem goods and services (ES) that contribute to human wellbeing. However, pesticide pollution may affect the ecosystem and its capacity to provide these services. Here, we investigate the ES provided by Lake Ziway, a freshwater lake in Ethiopia, and the potential impact of pesticides on the ES as a result of unsustainable use and handling practices of the compounds by smallholder farmers and floriculture farms found along the shoreline of the lake. Data were collected from smallholder farmers, tourists, largescale farms and different governmental offices using a semi-structured questionnaire, field observations and interviews. The results showed that Lake Ziway supplies twenty-four ES types, with the provision of drinking water, fish food and irrigation water being the most important services for the local communities. Furthermore, the study indicated that smallholder farmers misuse and inappropriately handle pesticides. Improper storage, overdosage, too frequent applications ignoring recommended interval periods, mixing pesticides near water canals, and dumping pesticide wastes into the surrounding environment were among the commonly reported malpractices by farmers. Use of protective materials during pesticide spraying was low, thus human health may also be at risk. Furthermore, the effluents from five floriculture farms are released into Lake Ziway without adequate pre-treatment. This indicates that the agricultural crop production systems practiced by the smallholder vegetable and floriculture farmers are unsustainable and likely expose Lake Ziway to pesticide contamination resulting in effects on aquatic organisms. By affecting the biological components of Lake Ziway, pesticides may limit the capacity of the lake ecosystem to supply ES. Effective implementation of the present legislation on pesticide registration and control is urgent to reduce the impacts of pesticides on Lake Ziway and its ES. Training for famers and local pesticide shops on safe use and handling of pesticides, pest diagnosis and other pest control options are advocated. 


\subsection{Introduction}

Human society is nature dependent, as ecosystems support human life by delivering multiple ecosystem goods and services (ES). ES are benefits like food, drinking water and climate regulation which are directly or indirectly obtained by people from an ecosystem thus contributing to key components of human well-being, such as security, basic material for good life and health and good social relations (Baron et al., 2002; MEA, 2005; Boyd and Banzhaf, 2007; Braat and Groot, 2012; Busch et al., 2012; Haines-Young and Potschin, 2013; Allan et al., 2015). According to Haines-Young and Potschin (2013), ES can be classified into provisioning, regulating and maintenance, and cultural services, while supporting services are considered as part of the underlying structures, process and functions of an ecosystem, thus treated as intermediary services.

Freshwater lakes provide ES that include drinking water, food, flood control, climate regulation, waste detoxification and recreation (MEA, 2005; MEA, 2007; Schallenberg et al., 2013; Grizzetti et al., 2015). However, as a result of anthropogenic activities degradation of their ES has occurred in the past few decades in different parts of the world (MEA, 2005; Maltby, 2013). Specifically in developing countries human activities such as watershed forest clearance for the purpose of agricultural land expansion, poor use and handling practices of agrochemicals, excessive use of irrigation water and discharge of untreated wastes are prevailing pressures towards freshwater lakes ecosystem (Roggeri, 1995; Laurance et al., 2014; Mengistie et al., 2017). These human practices, as reported by many authors (Foley et al., 2005; de Meutter et al., 2006; Holland et al., 2011; Schäfer, 2012), have induced disturbances to ecosystem structure and function that reduce the capacity of aquatic ecosystems to deliver ES. As a consequence, the degradation of ES has directly or indirectly contributed to poverty and social conflict (MEA, 2005; Vanbergen, 2013; Xu et al., 2016).

Agricultural land and intensification practices have significantly expanded in Ethiopia over the past three decades (Garedew et al., 2009). The expansion is anticipated to continue at a fast rate to fulfil the future food demand of the rapidly growing population in the country (Garedew et al., 2009; Laurance et al., 2014). In particular, following the agricultural development strategy announced in 1995 (updated in 2010) by the Ethiopian government, intensive agricultural irrigation schemes have been swiftly expanded by commercial floriculture and viticulture companies, and smallholder vegetable farmers around the 
freshwater lake, Lake Ziway (Fig. 3.1) (Gebreselassie, 2006; MoFED 2010; Mengistie et al., 2017).

Lake Ziway is situated in Central Ethiopian Rift Valley (CERV) region of Ethiopia, between geographic coordinates of $7^{\circ} 51^{\prime}$ to $8^{\circ} 07^{\prime} \mathrm{N}$ and $38^{\circ} 43^{\prime}$ to $38^{\circ} 56^{\prime} \mathrm{E}$ at about $160 \mathrm{~km}$ to the south of the capital Addis Ababa. Its surface area is $442 \mathrm{~km}^{2}$ with an altitude of $1636 \mathrm{~m}$ above sea level. Two rivers, Katar and Meki, from central highland parts of the country feed the lake perennially, while it drains through the river Bulbula into Lake Abjata (Kebede and Willen, 1998; Ayenew, 2002; Lemma and Desta, 2016). As discussed in the aforementioned, due to the agricultural activities in the catchment area huge volumes of irrigation water (about 223 million $\mathrm{m}^{3}$ annually) are withdrawn from the lake as well as from its feeder rivers (Desta et al., 2015; Merga et al., 2020b). This excessive withdrawal of irrigation water is aggravated by a poor water use efficiency of smallholder vegetable farmers (Halsema et al., 2011; Ulsido and Alemu, 2014). Apart from water abstraction agricultural expansion activities can pollute the lake ecosystem by pesticides (Merga et al., 2020b) in which misuse and improper handling of the chemicals and poor managment of its waste by the farmers may exacerbate the contamination. Pesticides contamination may impact biological components that support the delivery of ES of Lake Ziway by affecting the underlaying ecological structures, processes and functions of the lake ecosystem. In this study these biological components are referred to as service providing units (SPUs) (Luck et al., 2003; Andersson et al., 2015).Impact to these SPUs may lead to loss of regionally relevant ES as observed elsewhere, for example, in North American streams (Sweeney et al., 2004).

To our knowledge, there is no available study that identifies the ES provided by Lake Ziway, while their assessment may help prioritising the protection of the lake ecosystem in regional environmental policymaking and management. Furthermore, information on use and safe management of pesticides and related wastes by smallholder vegetable farmers and by largescale commercial farms in the vicinity of Lake Ziway is scarce (Mengistie et al., 2017). To this end, our study aimed to: 1) identify the ES that Lake Ziway provides for local communities, 2) investigate use and handling of pesticides and related wastes by small- and large-scale farms found proximate to the lake, and 3) conceptualize the potential impacts of pesticides on ES of Lake Ziway. With these objectives our study combines aspects of hazard assessment and risk assessment, as addressed by pesticides use survey, and the environmental observations and ES survey, respectively. 


\subsection{Materials and Methods}

\subsubsection{Study design, sample selection and data collection}

\subsubsection{ES identification and assessment of pesticides use}

Prior to taking the semi-structured questionnaire (i.e., consists of open and closed questions), field observations and interviews, a one day workshop was organized for key stakeholders, in Batu town (Fig. SI 1). Representatives of large-scale horticulture companies did not attended the workshop, although invited. The workshop aimed to introduce the project and to get feedback on its objectives, in order to bring it into accordance with stakeholder interests and to improve the survey questionnaires. Immediately after the workshop, a semi-structured questionnaire (see Supplementary Information (SI), section 3A and $3 \mathrm{~B}$ ) and interviews (see SI, Section $3 \mathrm{C}$ ) were performed with various stakeholders. These included local households residing in three districts, tourists, fishery cooperatives, culture and tourism offices, a drinking water supply and sewerage enterprise, and commercial floriculture and viticulture companies.

Households survey: To sample representative farmers for the household survey, a two steps selection technique was employed. First, 11 villages (Table SI3.1) were selected from the three districts bordering Lake Ziway (Fig. 3.1), namely Adami Tulu Jido Kombolcha (ATJK, 4 villages), Dugda (4) and Ziway-dugda (3). Offices of the districts including land and environmental protection, irrigation, and fishery and livestock were consulted in this selection process, to assure that the selected villages were among the main users of a wide range of ES that Lake Ziway provides. Second, the households sample size was determined according to Israel (2013), where the proportional sampling method, with 95\% confidence interval and 7\% precision level was used (Table SI3.1). In total 202 households were included in the survey. Participating households were randomly selected from a list of households obtained from the office of the manager of each village. 


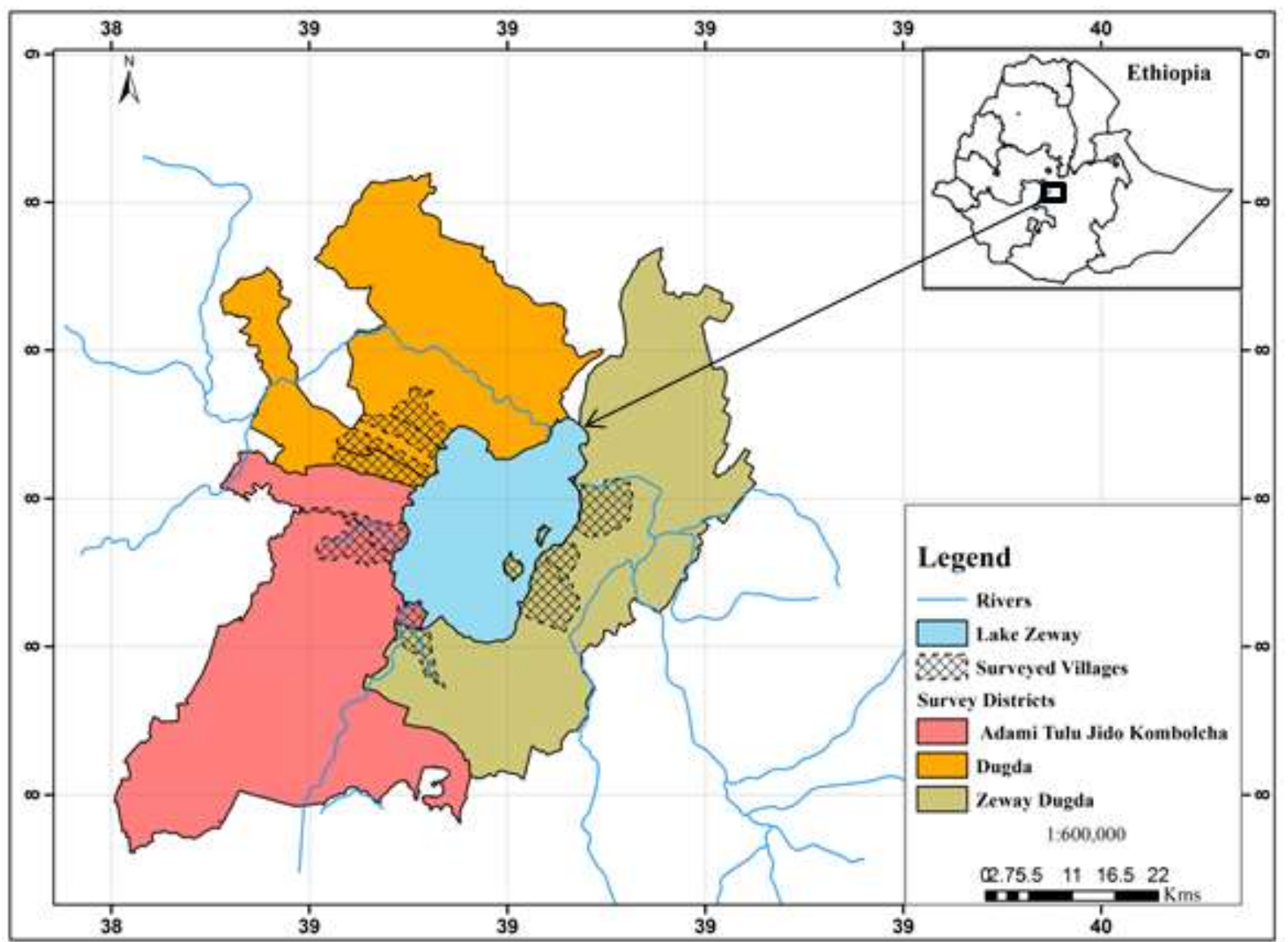

Fig. 3.1. Map of Lake Ziway, and surveyed districts and villages.

Before starting data collection the questionnaire was pre-tested by three farmers from the ATJK district. Minor revisions of the content were made, based on their observations and reflections. The data was collected by visiting the house of selected farmers via face-to-face interviews with the head of households between 20 February and 19 April 2017. During the interview, in addition to the demographic and socioeconomic profile of the farmers (e.g., age, gender, year of stay in the village, family size), the sample farmers were asked questions including benefits the farmers obtain from Lake Ziway, their understanding on status of the ES of the lake and existing challenges that can damage the services, their understanding on potential causes for the existing challenges and other related issues.

Moreover, information about pesticides type, use practices and safety issues was also collected during household surveys in face-to-face interviews with smallholder vegetable farmers who use the lake water for irrigation. Consequently, various information was collected including irrigation farm size, irrigation water use technique, vegetables produced, pesticide types used, application frequency, dosage, pesticide handling and storage and trainings received on pesticide use and human and environmental safety. In addition, empty 
pesticide containers and respective leaflets were collected from the farmers to verify information provided on the pesticide types used.

Culture and tourism survey: Having the aim to assess the current tourism and recreational activities of Lake Ziway, a survey was conducted with tourists visiting the lake between 14 21 March 2017. Only those visitors who spoke English and aged $\geq 18$ years old were selected to answer a self-administered survey (See SI, Section 3B). In total 51 visitors participated. The questionnaire was pre-tested with three visitors from the local community and modified according to feedback. The collected information included country of origin, purpose of visit, recreational activities, attractive lake features, and related questions.

Interviews were also conducted with Batu Culture and Tourism Office, and Adami Tulu Jido Kombolcha Culture and Tourism Office. Information on cultural, religious, recreational and tourism related ES of the lake and existing challenges to the services as perceived by the offices were collected using a pre-organized list of questions (see SI, Section $3 \mathrm{C}$ ). In order to correctly interpret the responses during the interview, voice recording was used in consent of the interviewee.

Drinking water supply, fishery, horticulture survey: Batu Town Drinking Water Supply and Sewerage Enterprise and 12 fishery cooperatives were interviewed with the help of preorganized questions ( $\mathrm{SI}$, Section $3 \mathrm{C}$ ). Challenges related to drinking water supply from the lake and pollution (Batu Town Drinking Water Supply and Sewerage Enterprise), and status and challenges of fishery in the lake (fishery cooperatives) were investigated through interviews.

Furthermore, interviews were performed with farm managers of all the five floriculture companies, and one viticulture company, which located proximate to Lake Ziway and use the lake as source of irrigation water. In addition to interviews with farm managers, farm observations were also conducted. During the interview and farm observations information was collected about the amount of irrigation water used annually, pesticides use, wastewater drainage facilities and wastewater treatment technologies. Voice recording was used in consent of the interviewee.

\subsubsection{Ranking of ecosystem goods and services}

To rank the listed ES of Lake Ziway based on their relative importance for the local communities, cardinal scoring was used, adopted from Sheil and Liswanti (2006). The classification of ES used in this study was adopted from Haines-Young and Potschin (2013). 
Two villages from each districts were selected for the ranking activity (i.e. ATJK (Bochessa and Edo-Kontola villages), Dugda (Tepho-Choroke and Tuchi-Dembel villages) and ZiwayDugda (Herera and Bashira-Chafa villages)). In each village a group of 7 individuals was assembled. To include young and elderly people alike, individuals with age 20 - 35 years (as representative of young people) and $>35$ years (as representative of elders) were invited. $A$ picture symbolizing each service was drawn on a flipchart (Fig. SI 2) and the participants were given a presentation about the services and overall scoring processes. After clarifying the procedure and discussing questions raised by the group members, a demonstration on how to score the ES using 100 pebbles was given twice by facilitators to make the scoring more clear. Following the demonstration, 100 pebbles were handed to the group to be allocated as a team over the pictures symbolizing the services. The distribution was to be made in proportion to the relative importance the services have for their community. The scoring was made after the group reached agreement. There was no intervention by the researcher or facilitator during the discussions and disagreements, unless the group needed more clarification on the pictures. Average scores were calculated for each districts separately. The six villages scorings were pooled together as replicates, and the overall average score was calculated to overall prioritize the ES of the lake.

Each member of the group received three bars of soap to acknowledge their time expenditure and contribution.

\subsubsection{Data analysis}

Analysis of survey data was performed using SPSS (version 23). Pearson Chi-square test was used to evaluate differences between study districts based on the responses of the farmers in each district for both ES and pesticide use survey.

\subsection{Results and discussion}

\subsubsection{Profiles of the sample farmers and tourists}

Farmer respondence in the households survey was from ATJK $(n=74)$, Dugda $(n=42)$, and Ziway-Dugda $(n=86)$ districts (Table SI3.1). The average age $( \pm$ STD) of the respondent farmers was 41 ( \pm 10 years), thus it is supposed that they owned good knowledge about the use and benefits Lake Ziway provides for the community. The majority of farmers (96\%) in the sample 
survey were male, while $4 \%$ was female (Table SI3.2). Most farmers were married (96\%), few were single (1.5\%), widower (1.5\%), or divorced (1\%). The reported average family size (6.9 \pm 3.6) of the respondent farmers was in the range of large household sizes according to UN (2017). The educational status of the majority of the respondent farmers (85\%) were at primary (grade $1-8$ ) to high (grade $9-12$ ) school education levels (see Table SI3.2).

The respondent tourists $(n=51)$ visited Lake Ziway were from eight countries of 3 continents: France (27\%), Ethiopia (23\%), Italy (20\%), Netherlands (12\%), Eritrea (10\%), UK (4\%), USA (2\%) and Canada (2\%). The average age of the visitors was $40 \pm 14$ years, and 63\% were male and $37 \%$ were female (Table SI3.3).

\subsubsection{Ecosystem goods and services of Lake Ziway}

Based on the households survey, workshop and interview results a total of 24 ES types, according to the classification by Haines-Young and Potschin (2013), were identified for the Lake Ziway ecosystem that benefit the local communities, encompassing 15 provisioning services, 3 regulation and maintenance services, and 6 cultural services (Table 3.1; Table SI3.2). The classification by Haines-Young and Potschin (2013) was used because it is an internationally agreed standard for ES classification.

Animal food: aquatic animals (e.g., fish, molluscs) are an important source of nutrition for human beings (Haines-Young and Potschin, 2013; Schallenberg et al., 2013). Our study found that wild fish is one of the key harvestable ecosystem goods for local communities provided by Lake Ziway. From 202 farmer respondents, 52\% (106 farmers) replied that they harvest fish from the lake, and the majority $(83 \%)$ of these farmers $(n=106)$ use the catch as a source of subsistence food or income (Table SI3.2). Similarly, Endebu et al. (2015) reported that the livelihoods of $>4000$ people ( $1 \%$ of the total population of the three districts) of the local communities lived in districts bordering Lake Ziway (total population 383, 676 people (CSA 2013)) directly depend on fish from the lake. There was significant spatial association between wild fish harvesting and location of farmers $(p<0.001)$, where relatively high number of respondent farmers in Ziway-Dugda district harvested wild fish compared to the other two districts (Table 3.3 b; Fig. 3.1). This is likely due to the scarcity of agricultural land in the surveyed villages of Ziway-Dugda district as most of the respondent farmers in this district live on the islands such as Tulu Gudo, Tsedacha and Funduro (Table 3.3 a). 
Farmers and fishery cooperatives mentioned different important fish species of Lake Ziway that provide food for local communities, including Koroso (Oreochromis niloticus and Tillapia zilli), Dubbee (Carassius carassius), Ambaazzaa (Clarias gariepinus) Bilcaa/Minici (Barbus ethiopicus) and Jappee (Cyprinus carpio) in local (scientific) names (Table SI3.2). However, they reported a substantial drop in fish yields of Lake Ziway since 1990s, which has also been described by Abera et al. (2018) stating the declining of catch yield in 2014 (1157 tons) by 64\% compared to the yield recorded in 1997 (3180 tons) (Fig. 3.3 f). This period coincided with the expansion of agricultural activities in the region by smallholder vegetable producing farmers (Fig. 3.3 c) and large-scale floriculture and viticulture farms (Gebreselassie, 2006; Mengistie et al., 2017). Furthermore, farmers and fishery cooperatives reported decreasing trends in annual catches of the species $O$. niloticus, C. carassius, $C$. gariepinus, $T$. zilli and B. ethiopicus, while $77 \%$ of the farmers reported an increasing trend at the same time for $C$. carpio (Table SI3.2). Farmers and the fishery cooperatives have suggested various human activities as a cause for the observed changes. According to the respondents the main causes were the use of illegal fishnets, overfishing, chemical pollution by agricultural activities, destruction of shoreline and wetland vegetation, overexploitation of water for irrigation, and inappropriate fishing (e.g., using small fish to catch bigger fish). Previous studies (Endebu et al., 2015; Abera et al., 2018) listed similar potential causes for the observed fish yield declines and composition changes in Lake Ziway.

Plant food: Lake ecosystems provide plant based nutrition ES (Haines-Young and Potschin, 2013). About $87 \%$ of the respondent farmers harvest plants from Lake Ziway for food (Table SI3.2). Our results show that about $100 \%, 77 \%$ and $64 \%$ of farmers harvested the plants locally (and scientifically) named as Fiilaa/Awwaaree (Typha lotifolia), Kesem (Arundo donex) and Mochee (Nymphaea lotus) (Table SI3.2). No data is available showing the amounts of annually harvestable plant food from the lake. Farmers mainly harvest during droughts, when arable crop production is low. Plant harvesting for food differed between districts $(p=0.036)$, with significantly large household farmers in ATJK and Dugda districts use the service (Table $3.3 \mathrm{~b}$; Fig. 3.1). The plants are mainly supported by the wetland and floodplain parts of Lake Ziway where these parts are relatively larger in size from the side of ATJK and Dugda districts (personal observation). This could explain for the differences observed between the districts.

Potable water: Supply of drinking water is another important ES of aquatic ecosystems (Baron et al., 2002; Haines-Young and Potschin, 2013; Schallenberg et al., 2013). As a 
freshwater lake, Lake Ziway also provides this service to a large extend. Even while about 97\% of the respondent farmers reported that the water quality of Lake Ziway has deteriorated for drinking water use, still a considerable (45\%) of the local farmers use the lake as a source of drinking water without any pre-treatment (Table SI3.2). This indicates that the local communities have no access to good quality drinking water, which can be due to several reasons such as financial limitations to drill ground water sources, and the seasonality of other water sources like springs and ponds in the area. In rural parts of Ethiopia the lack of access to good quality/safe drinking water is among the key causes for transmittable diseases (Teshome, 2013; Usman et al., 2019). There was a significant difference between farmer districts in the amounts of potable water used $(p<0.001)$ where the service is used most in Dugda district (Table 3.3 b; Fig. 3.1). Half the farmers (54\%) reported to have alternative source(s) for drinking water. Boreholes and springs were the main other sources for drinking water as reported by $68 \%$ and $8 \%$ of the respondent farmers, respectively (Table SI3.2).

Furthermore, according to an expert from Batu Town Drinking Water Supply and Sewerage Enterprise, the drinking water supplies for Batu town (population about 70,436 people (CSA, 2013)) originate from Lake Ziway. The expert stated that the current water consumption (i.e., based on the data of the year 2016) from the lake by Batu has reached about 1.3 million $\mathrm{m}^{3}$ per year, which is a 5 times increase over two decades $\left(0.24\right.$ million $\mathrm{m}^{3}$ per year in 1998) (Fig. 3.3 a) . According to the expert, increasing amounts $(\mathrm{kg})$ of chemicals (e.g., $\mathrm{Ca}_{3}(\mathrm{OCl})_{2}$, polyelectrolyte and $\mathrm{Al}_{2} \mathrm{SO}_{4}$ ) were used in recent years (e.g., 2016) to treat raw water from Lake Ziway. For instance, the amount of chemicals used per volume of raw water in 2016 was 4 times higher than in 2002 (Fig. 3.3 e). The expert mentioned the deterioration of lake water quality due to agricultural activities as the major cause for the additional costs for water purification by the enterprise.

Water for other uses: as abiotic material, water resource (e.g., for the purpose of livestock watering, irrigation water, water for bathing and domestic uses) is an important ES from which people benefit from freshwater lakes (Alahuhta et al., 2013; Haines-Young and Potschin, 2013). Water resources from Lake Ziway also provide multiple provisioning services that benefit local communities. About $96 \%$ of the farmer respondents use the lake as a source for livestock watering, and $91 \%$ of the farmers consider the water quality to this purpose good enough. The water supply of the lake for livestock consumption was estimated to be 0.59 million $\mathrm{m}^{3} /$ year (Eresso, 2010). As temporarily alternative sources of livestock watering, 
springs, boreholes and ponds were reported by $8.2 \%, 3.6 \%$ and $1.5 \%$ of the farmers, respectively (Table SI3.2).

Lake Ziway also provides irrigation water for smallholder vegetable producing farmers and large scale farms in the region (Halsema et al., 2011; Ulsido and Alemu, 2014; Desta et al., 2015; Merga et al., 2020b). Expansion of vegetable agriculture by smallholder farmers along the shoreline and catchment of the lake was reported by irrigation offices in the three surveyed districts. According to the offices, a total of about 8,537 hectare of land was irrigated in the 2016-2017 cropping season where ATJK, Dudga and Ziway-Dugda districts contributed $66 \%, 28 \%$ and $5.8 \%$ for the total irrigation land size, respectively (Table 3.3 a). The irrigated land size in these districts increased by $70 \%$ relative to the land size reported a decade earlier by Jansen et al. (2007) (Fig. 3.3 c). This has caused an increasing temporal trend of water withdrawal from Lake Ziway by smallholder farmers (Fig. 3.3 b).

Our results showed that the majority (76\%) farmers use Lake Ziway as a source of irrigation water to produce vegetables including tomato, onion, green bean, green pepper and cabbage (Table SI3.2). The estimated amount of irrigation water abstraction by the smallholder farmers from the lake in 2010 was 117 million $\mathrm{m}^{3}$ /year (Eresso, 2010) which is 4 times high compared to the volume (28 million $\mathrm{m}^{3} /$ year) reported for 1998 (Ayenew and Legesse, 2007) (Fig. 3.3 b). Significant association between irrigation water use and location of the respondent farmers was also observed $(P=0.009)$ where farmers in ATJK and Dugda districts were the main users of irrigation water from the lake (Table $3.3 \mathrm{c}$ ). In agreement with this result, 8,537 hectare of land was irrigated in the 2016-2017 cropping season, with 66\% (5672 ha) of the irrigated area being located in ATJK, 28\% (2367 ha) in Dugda and the remaining 6\% (489 ha) in Ziway-Dugda (Table 3.3 a). Quality of irrigation water is an important factor for crop production (Reddy and Behera, 2006). According to the majority (95\%) of smallholder vegetable farmers, the water quality of the lake is considered good enough for the production of vegetables, and none of the farmers use other water sources (Table SI3.2). Furthermore, our interviews with farm managers of the large-scale farms showed that Lake Ziway provides irrigation water for six large-scale horticulture companies, and these farms exploit about 12 million $\mathrm{m}^{3} /$ year of water (Table 3.4).

In Ethiopia the majority (about 70\%) of the rural population has no access to good quality water from improved sources for sanitation and domestic use (Anthonj et al., 2018). Lake Ziway is used as a source water for sanitation purposes such as laundry washing and bathing 
by local communities, as reported by the majority (73\%) of the respondent farmers (Table SI3.2). Water for other domestic use such as cooking is another service that water from Lake Ziway provides to local communities as reported by $57 \%$ of the farmers (Table SI3.2). However, farmers think that the water quality of the lake has deteriorated for these purposes. As optional sources $68 \%, 8.4 \%$ and $1.5 \%$ of the farmers reported the alternative use of a borehole, a spring or a pond, respectively (Table SI3.2). However, the farmers still need the lake as a primary source of water for the above mentioned uses, despite they think that the water quality is too poor. This can be related to various factors including the inaccessibility of borehole waters and the limited availability of spring and pond waters as these sources are quite temporary in this region due to erratic rainfall. It was also observed that water use for laundry washing, bathing water and other domestic use differed significantly between the districts of sample farmers $(p<0.001)$ where farmer respondents in Dugda district were the main users of these services (Table 3.3 b; Fig. 3.1).

Ornamental resources: Supplying biomaterials (e.g., plants, shells) with ornamental uses are ES of freshwater ecosystem (Alahuhta et al., 2013; Haines-Young and Potschin, 2013). The study by Ciftcioglu et al. (2019) reported the contribution of ornamental plants based ES to two components of human wellbeing including security and contact with nature. As decorative bio-material Ketemaa (Cyperus articulatus) were harvested from Lake Ziway by the majority (98\%) of the farmer respondents (Table SI3.2). This aquatic plant is often used by the local communities to decorate the coffee ceremony, which is part of Ethiopian culture. In addition, the farmers use the plant to decorate their house during national and religious festivals, and wedding ceremonies. Decorative use of aquatic macrophytes has likewise been reported by Meena and Rout (2016) for India.

Aquatic plant biomass: Freshwater ecosystem, particularly the transitional systems such as wetlands and floodplains, supply harvestable biomass with a broad array of use (Harrison et al., 2010; Alahuhta et al., 2013). Lake Ziway supports provisioning of various important plant species that the local communities harvest for a range of purposes such as livestock fodder, roof thatching, fence construction, boat construction, chair construction, house roof making, and fuel wood. The macrophytes such as Kesem (A. donex), Fiilaa/Awwaaree (Typha latifolia), and Ketemaa (Cyperus papyrus and C. articulatus) were reported by the respondent farmers (100\%) as livestock fodder (Table SI3.2). Similarly, the use of aquatic macrophytes species (e.g., Ceratophyllum demersum, C. platyphyllus and C. tenuispica) as livestock fodder was 
reported in India (Meena and Rout, 2016). The macrophytes T. latifolia and C. papyrus were also used by the majority of farmers (72\%) for house roof thatching. A few farmers (7.9\%) reported fence construction as a service by T. latifolia (Table SI3.2). Another use of $C$. papyrus reported by some of the respondent farmers (20\%) was for boat construction (Table SI3.2). Utilization of reeds (e.g., for house fencing and combustibles) and Cyperus sp. (e.g., for roof thatching) were also reported for farmers in Kano floodplain, Kenya (Ondiek et al., 2016). Our result further shows that the local communities harvest the locally named Bofoffee (Aeschynomene elaphroxylon) biomass from marshland (floodplain) part of the lake for multiple uses. About $29 \%$ of the farmers reported boat construction, fence construction, chair making, roof making and firewood uses of $A$. elaphroxylon (Table SI3.2). This indicated that plant biomass has broad applications in the livelihood of the local people, as also reported in other African countries such as in Ghana (Abobi et al., 2015). Abobi et al. (2015) reported the uses of aquatic macrophytes for communities in Northern Region of Ghana including fodder for livestock, for making goods (hats, mats and necklaces), to treat disease (stomach ulcer, rheumatism and malaria) and food source for human consumption.

Water flow regulation and transportation: Lake ecosystems can regulate the catchment and downstream water flow regimes, thus attenuate extreme runoffs and support transportation (Alahuhta et al., 2013; Haines-Young and Potschin, 2013; Schallenberg et al., 2013). In particular, wetland parts of lake ecosystems largely contribute to flood attenuation, (Daigneault et al., 2012). These ES (transportation and flood attenuation) are also provided by Lake Ziway ecosystem as reported by the majority (71\%) of the farmers (Table SI3.2). The utilization of the services also significantly differed between districts $(p<0.001)$ where most farmers in Ziway-Dugda were using the transportation service, as many of the respondent farmers in this district (e.g., from Herara and Bashira Chafa villages) live on the Islands (e.g., Tulu Gudo, Tsedacha and Funduro) of Lake Ziway (Table 3.3 a and b; Fig. 3.1). The farmers in ATJK were key beneficiaries of the flood protection service, as some of the sampled farmers of the district (e.g., Bochessa and Dodicha villages) live downstream of the lake. About $69 \%$ of sampled farmers from villages upstream of the lake consider their area more prone to extreme flooding than downstream villages (Table SI3.2). The majority of the farmers (73\%) remember the recent flooding of upstream villages in 2005 and 2008 resulting in severe damage to crops, houses and livestock, whilst the downstream villages (e.g., Dodicha, Bochessa) were spared. 
Habitat and breeding ground for aquatic life: Lake Ziway is home for different plants and animals, supporting the species breeding ground for nursery populations and habitat (Merga et al., 2020b), as also has been reported for European freshwater ecosystems (Alahuhta et al., 2013; Haines-Young and Potschin, 2013). For instance, Lake Ziway seasonally supports over thousands of birds, and is one of the 68 potential Ramsar Sites in Ethiopia (BLI, 2019; Merga et al., 2020b). According to the participants of the stakeholders' workshop, Lake Ziway supports diverse aquatic flora and fauna with a home to inhabit and breed as also described by Merga et al. (2020b). Similarly, experts from Batu Culture and Tourism Office and Adami Tulu Jido Kombolcha Culture and Tourism Office disclosed that the lake supports over 260 aquatic bird species. However, recent studies showed declines in bird species due to the destruction of shoreline vegetation that serve as roosting and stopover sites (Mengesha et al., 2014; Merga et al., 2020b).

Recreation and community activities: Boating, sport fishing, swimming, ice-skating and hunting of waterfowl are among the ES provided by aquatic ecosystems, which is grouped under the service group of recreational and community activities (Haines-Young and Potschin, 2013). The majority (55\%) of the interviewed farmers visit Lake Ziway weekly (Table SI3.2). Bird watching, enjoying the landscape, swimming, boating, riverine walking, enjoying the water-tide, and enjoying fresh air were the recreational activities reported by the farmers. The use of the ES was significant different between the districts of the farmers, where farmers from ATJK and Dugda districts were using these services more $(p<0.001)$ (Table $3.3 \mathrm{~b}$; Fig. 3.1). The observed differences may be due to reduced accessibility of infrastructure in ZiwayDugda (e.g., road, boat and availability of restaurants) that hampers the delivery of this service in this district (Table 3.3 a). The result of tourist survey also disclosed that $53 \%$ of the respondent tourists were inspired by the outstanding landscape of Lake Ziway (Table SI3.3), indicating aesthetic value of its landscape. Boating (55\%), bird watching (49\%), hippo watching (33\%), riverine walking (12\%) were identified by the tourists as the most enjoying recreational activities during their visit (Table SI3.3). Furthermore, according to the data collected from Batu Culture and Tourism Office the average revenues generated from tourists visiting Lake Ziway over the last five years (2013 to 2017) was 198,381 USD per year. For the trend of revenue generated in the year 2013 to 2017 from the service see Fig. 3.3 d. This amount is likely underestimated as hotels and lodges are reluctant to reveal their precise income. During the field observation, the researchers personally noticed that Lake Ziway has a huge potential 
for this ES, if more attention were given by the responsible bodies. For instance, bird watching, boating to islands and hiking, hippo watching and visiting the monasteries on the Islands are among the potential recreational activities of Lake Ziway that can attract tourists.

Heritage, spiritual and religious services: Cultural related ecosystem services can be important non-material benefits people obtain from water bodies (MEA, 2005; Knoll et al., 2019). Wetland parts of African surface waters play a key role in providing these services for local communities. For example, in Ombeyi natural wetland of Kenya local community conduct spiritual and religious activities such as water baptism, spiritual cleansing and exorcising evil spirits into the wetland (Ondiek et al., 2016). Lake Ziway also provides spiritual and religious services to local people. According to the interviews with experts from Adami Tulu Jido Kombolcha Culture and Tourism Office, and Batu Culture and Tourism Office, the local community (from Oromo ethnic group) living in the districts bordering the lake has religious and ritual gatherings called "IRREECHAA MALKAA TAAJOO ROOBAA", which is celebrated yearly in January. The ceremony is mainly dedicated to thank God for the blessings and mercies of the previous year, and to welcome the new year. This religious ceremony is celebrated at sacred grounds, viz. at two wetlands called "Malkaa Taajo" and "Chaffaa Jila". The experts from the culture and tourism offices additionally disclosed that the historical Orthodox churches and monastery found on the islands of Lake Ziway (Gelila, Tulu-Gudo, Tsedacha and Funduro) have significant cultural, spiritual and religious services for their followers. There are claims that the monastery found in Tulu-Gudo island housed the $9^{\text {th }}$ century Ark of the Covenant (Lemma and Desta, 2016), indicating its cultural heritage. Moreover, according to the culture and tourism offices the reported cultural, religious and spiritual services of the lake also remarkably contribute to the tourism activity, as every year many visitors attend these ceremonies.

\subsubsection{Ranking Lake Ziway Ecosystem goods and Services}

Knowledge of ES preferences and valuation by local communities can inform policy makers and spatial development planners, helping them to come to decisions for effective ecosystem management (Paudyal et al., 2018; Keeler et al., 2019). Our ES prioritisation results indicate that provisioning services including drinking water (overall average score $(O A S)=11.5$ ), fish food $(\mathrm{OAS}=9.7)$ and irrigation water (OAS $=7.3$ ) were the three most important ES for the 
local communities (Table 3.1). These services are highly prioritized by local people for protection, and it is the expectation of the communities that the lake ecosystem will provide these ES.

Table 3.1. Relative ranking of ES (\%) as perceived by local communities in ATJK (Bochessa (1) and Edo-Kontola (2) villages), Dugda (Tepho-Choroke (3) and Tuchi-Dembel (4) villages) and Ziway-Dugda (Herera (5) and Bashira-Chafa (6) villages) districts.

\begin{tabular}{|c|c|c|c|c|c|c|c|c|c|c|}
\hline \multirow{2}{*}{ Ecosystem goods and services } & \multicolumn{2}{|c|}{ Village } & \multirow{2}{*}{$\begin{array}{l}\begin{array}{l}\text { Averaged } \\
\text { score }\end{array} \\
1 \text { and } 2\end{array}$} & \multicolumn{2}{|c|}{ Village } & \multirow{2}{*}{$\begin{array}{l}\text { Averaged } \\
\text { score }\end{array}$} & \multicolumn{2}{|c|}{ Village } & \multirow{2}{*}{$\begin{array}{l}\begin{array}{l}\text { Averaged } \\
\text { score }\end{array} \\
5 \text { and } 6\end{array}$} & \multirow{2}{*}{$\begin{array}{l}\begin{array}{l}\text { Overall average } \\
\text { score (OAS) }\end{array} \\
1,2,3,4,5 \text { and } 6\end{array}$} \\
\hline & 1 & 2 & & 3 & 4 & & 5 & 6 & & \\
\hline Drinking water & 14 & 15 & 14.5 & 11 & 12 & 11.5 & 5 & 12 & 8.5 & 11.5 \\
\hline Fish food & 10 & 10 & 10 & 8 & 7 & 7.5 & 13 & 10 & 11.5 & 9.7 \\
\hline Irrigation water & 6 & 6 & 6 & 9 & 5 & 7 & 10 & 8 & 9 & 7.3 \\
\hline Livestock watering & 4 & 4 & 4 & 6 & 10 & 8 & 7 & 8 & 7.5 & 6.5 \\
\hline Fodder for livestock & 6 & 6 & 6 & 8 & 9 & 8.5 & 5 & 4 & 4.5 & 6.3 \\
\hline Spiritual and religion & 5 & 3 & 4 & 4 & 6 & 5 & 7 & 9 & 8 & 5.7 \\
\hline Roof thatching & 3 & 10 & 6.5 & 5 & 8 & 6.5 & 3 & 4 & 3.5 & 5.5 \\
\hline Transportation & 4 & 6 & 5 & 4 & 4 & 4 & 7 & 5 & 6 & 5.0 \\
\hline Domestic water (for cooking) & 3 & 5 & 4 & 5 & 7 & 6 & 4 & 5 & 4.5 & 4.8 \\
\hline $\begin{array}{l}\text { Habitat and maintenance } \\
\text { ground for aquatic life }\end{array}$ & 8 & 4 & 6 & 6 & 4 & 5 & 4 & 3 & 3.5 & 4.8 \\
\hline Recreation and eco-tourism & 5 & 6 & 5.5 & 3 & 4 & 3.5 & 5 & 4 & 4.5 & 4.5 \\
\hline Attractive landscape & 7 & 3 & 5 & 3 & 2 & 2.5 & 7 & 5 & 6 & 4.5 \\
\hline Bathing and cloth washing water & 3 & 4 & 3.5 & 4 & 4 & 4 & 6 & 4 & 5 & 4.2 \\
\hline Boat construction & 4 & 3 & 3.5 & 4 & 3 & 3.5 & 4 & 4 & 4 & 3.7 \\
\hline Fuel wood & 3 & 4 & 3.5 & 4 & 2 & 3 & 3 & 2 & 2.5 & 3.0 \\
\hline House roof construction & 2 & 1 & 1.5 & 3 & 3 & 3 & 3 & 4 & 3.5 & 2.7 \\
\hline Decorative use & 2 & 3 & 2.5 & 4 & 2 & 3 & 2 & 2 & 2 & 2.5 \\
\hline Flood attenuation & 7 & 1 & 4 & 2 & 1 & 1.5 & 1 & 1 & 1 & 2.2 \\
\hline Chair making & 1 & 2 & 1.5 & 3 & 2 & 2.5 & 2 & 2 & 2 & 2.0 \\
\hline Food from wild plants & 2 & 2 & 2 & 2 & 3 & 2.5 & 1 & 2 & 1.5 & 2.0 \\
\hline Fence construction & 1 & 2 & 1.5 & 2 & 2 & 2 & 1 & 2 & 1.5 & 1.7 \\
\hline
\end{tabular}

Note: From twenty-four (24) ES types identified only 21 ES were listed for ranking, because the other three cultural services (wilderness, Boating, and Bird/Hippo watching) were majorly reported by tourists.

\subsubsection{Pesticide use by smallholder vegetable farmers}

\subsubsection{1. pesticides use and supply}

Of the 202 interviewed farmers, 153 were involved in production of horticulture crops (vegetables and fruits) and used irrigation water from Lake Ziway. These smallholder vegetable farmers $(n=153)$ filled in the questionnaires related to their pesticides use. Our results show that the farm size of the majority farmers (80\%) were $<1$ hectare, while few (20\%) farmers had $\geq 1$ hectare (Table SI3.4). Similarly, Mengistie et al. (2017) reported an average farm size of 0.75 ha for smallholder vegetable farmers in CERV region, Ethiopia. As mentioned earlier, tomato, green beans, cabbage, onion, pepper and potato are crops that were widely produced using furrow irrigation by the sample smallholder farmers. About $92 \%$ 
of the respondent farmers considered pesticides as necessary input for their production, and they expect to use more in the future (Table SI3.4). This can be due to high prevalence of pests and diseases, and expansion of agricultural land area in the region (Fig. 3.3 c) (Ngowi et al., 2007; Mengistie et al., 2017). Furthermore, promoting pesticides as the dominant means to control pests and diseases, and the lack of effective and inexpensive pest management alternatives also contributes to increasing usage anticipated for Africa in the future (Williamson et al., 2008). Local pesticide shops were reported by majority farmers (95\%) as key supplier of the chemicals, as is also the case in other African countries (Ngowi et al., 2007; Oluwole and Cheke, 2009). However, a few farmers reported buying pesticides from open market (3.3\%) or cooperatives (1.3\%) (Table SI3.4). Buying pesticides from an open market is often done by low-income farmers, as open market venders dispense pesticides into smaller amounts and sell broad spectrum compounds at low prices (Mengistie et al., 2017). In 2013/14 cropping seasons the consumption of insecticide and fungicide by smallholder vegetable farmers in ATJK and Dugda districts were estimated to be 53,044 L (liquid) and 50,957 kg (powder) of formulation, respectively (Mengistie et al., 2017), but data is not available for Ziway-Dugda district. Although no sufficient data are available, the pesticide consumption of the region is assumed to increase. Because, as discussed earlier, the water abstraction for irrigation and irrigated land size in these districts showed remarkable increases in recent years compared to the land size reported 10 year back (Fig. $3.3 \mathrm{~b}$ and c). This is an opposite trend to annual fish catch yield of Lake Ziway (Fig. $3.3 \mathrm{f}$ ), but similar trend with the expenditure of cost to treat raw water from the lake by Batu Town Drinking Water Supply and Sewerage Enterprise to supply drinking water for Batu town (Fig. 3.3 e; section 3.3.2).

\subsubsection{Types of pesticides used by smallholder vegetable farmers}

In Africa, large amounts and different types of pesticides are used in unsustainable ways that violate product recommendations (de Bon et al., 2014; Oesterlund et al., 2014; Okonya et al., 2019; Onwona-Kwakye et al., 2020). We identified 59 different pesticides, based on their trade names, with a composition of 36 active ingredients (Table 3.2), which is higher than the result (41 types and 20 active ingredients) reported by Mengistie et al. (2017) also for the CERV region, Ethiopia. The types of pesticides identified during the household survey included insecticides (63\%), fungicides (34\%), and an acaricide (3\%) (Table 3.2). When comparing the farmers' actual use practice of pesticides with the recommendations given on leaflets and 
product labelling, frequent misuse was found. For instance, the majority of the identified pesticides (63\%) were sprayed on vegetable and/or fruits for which they are not recommended (Table 3.2). In line with this result, Mengistie et al. (2017) also reported the use of endosulfan (prescribed for cotton) on vegetables by smallholder farmers in this region.

Assuming higher doses can eradicate pests and diseases more quickly and effectively, farmers will often apply dosages of pesticides exceeding product recommendations (Mengistie et al., 2017). Our study showed overdosing (i.e., application above the recommended dose as stated on the leaflet) by farmers for $5 \%$ of the identified pesticides (Table 3.2). Furthermore, $90 \%$ of the reported pesticides were sprayed at a higher frequency than recommended, and violation of recommended application interval (days) was also identified for $39 \%$ of the pesticide products in use (Table 3.2). Similar results have been reported for the smallholder farmers in CERV region, Ethiopia (Teklu et al., 2016a; Mengistie et al., 2017), in Tanzania (Ngowi et al., 2007; Stadlinger et al., 2011) and in Ghana (OnwonaKwakye et al., 2019; Onwona-Kwakye et al., 2020). The factors that contribute for the observed violations in this study include the lack of knowledge by the farmers, ineffectiveness of pesticides (e.g., due to wrong pesticide for the pest and spraying expired chemicals), pest resistance, and climatic conditions that favour pests and diseases (Ngowi et al., 2007; Mengistie et al., 2017).

\subsubsection{Pesticides management, usage skills and safety practices by smallholder farmers}

Proper storage of pesticides is key in safe chemicals management, needed to protect human health and the environment (de Bon et al., 2014; Loha et al., 2018). The majority of the farmers sampled in our study store pesticides inadequately, i.e. $37 \%$ of the farmers stored the pesticides anywhere in the living house within reach of children, and $32 \%$ in the living house away from reach of children (Table SI3.4). Mengistie et al. (2017) reported similar results, mentioning that about 32\% of the farmers in CERV region, Ethiopia stored pesticides unsafely in their homes. Similar improper pesticide storage practices were also reported for smallholder farmers in Tanzania (Ngowi et al., 2007), Nigeria (Oluwole and Cheke, 2009) and Ghana (Onwona-Kwakye et al., 2019). In our study, only few respondents (25\%) mentioned a separate and protected room as a place to store pesticides (Table SI3.4). This poor practice of pesticide storage can increase the risk of accidental poisoning of family members (e.g., children), as the chemicals can be easily accessed. For pesticides usage information, $69 \%$ of 
the farmers read the leaflet that is provided with each package (Table SI3.4). Contrary to our results, Mengistie et al. (2017) reported that the majority of the farmers in CERV region, Ethiopia did not read or understand pesticide leaflets, as these are written in English or Swahili. During our field survey we observed that leaflets written in English or Swahili, nowadays also included local Amharic language.

We observed that farmers did not use the information on the leaflet exhaustively. The majority of farmers used the leaflet to understand how to mix the pesticides (water to formulation proportion) and amount required per hectare (94\%), and to know the expire date (55\%) (Table SI3.4). But, only one-third of the farmers (34\%) were concerned about the hazard class of the pesticides they use (Table SI3.4). This indicates the limited awareness about the potential impact of pesticides on human health and the environment, as was also reported by Mengistie et al. (2017) and by Teklu et al. (2016a) for smallholder farmers in the region.

Lack of crucial leaflet and product label information were also identified by the farmers in the region. About $48 \%$ of farmers which had read the leaflets, reported their experiences where they encountered problems such as the leaflets and/or product label written in a language that they do not understand, or leaflets not specifying an expire date (Table SI3.4). Such shortcomings can worsen inappropriate usage. In addition to the description given on leaflet, the respondent farmers consult with neighbours (62\%), local pesticide shops (41\%), rely on their own experience (40\%), or development agents (15\%) as a source of information about pesticide usage (Table SI3.4). This indicates that neighbours and local pesticides shops are key sources of information. Stadlinger et al. (2011) also reported neighbour farmers as a chief source of information regarding how to use pesticides for smallholder rice farmers in Tanzania. Moreover, our results show that the support from government via development agents is effectively negligible, as has also been reported by Mengistie et al. (2017). Developing knowledge and awareness of farmers and local pesticide shops through capacity training and onsite support (e.g., by development agents) can be helpful to improve a safer use of pesticides by farmers. No statistically significant difference $(p=0.169)$ was observed between the districts regarding their sources of information on pesticide usage. 
Table 3.2. Types of pesticides used by vegetable farmers in villages bordering Lake Ziway for 2016/17 cropping season and their use practices compared with recommended usage description.

\begin{tabular}{|c|c|c|c|c|c|c|c|c|c|c|c|}
\hline Trade name & Active ingredient & Type & $\begin{array}{l}\text { Physic } \\
\text { al } \\
\text { State }\end{array}$ & $\begin{array}{l}\text { Crops } \\
\text { sprayed } \\
\text { by farmers }\end{array}$ & $\begin{array}{l}\text { Rec. } \\
\text { crops }\end{array}$ & $\begin{array}{l}\text { Farmers' } \\
\text { dosage } \\
\left(\mathrm{L} / \mathrm{kgha}^{-1}\right)\end{array}$ & $\begin{array}{l}\text { Rec. } \\
\text { dosage } \\
\left(\text { L/kgha-1 }^{-1}\right)\end{array}$ & $\begin{array}{l}\text { Appl. interval } \\
\text { by farmers } \\
\text { (days) }\end{array}$ & $\begin{array}{l}\text { Rec. appl. } \\
\text { interval } \\
\text { (days) }\end{array}$ & $\begin{array}{l}\text { No. of appl. } \\
\text { by farmers }\end{array}$ & $\begin{array}{l}\text { Rec. \# of } \\
\text { appl. }\end{array}$ \\
\hline Agro-Lambacin & Profenfos $30 \%+$ & I & Liquid & $\mathrm{GB}^{*}$ & Co & 0.4 & 0.4 & $4 *-15$ & 5 & $2-6^{*}$ times & 2 times \\
\hline Super 315 EC & Lambda-Cyhalothrin 1.5\% & & & $C^{*}, O^{*}$ & & & & & & & \\
\hline Agro-Thoate $40 \%$ EC & Dimethoate $400 \mathrm{~g} / \mathrm{L}$ & 1 & & $\mathrm{~T}, \mathrm{C}, \mathrm{GP} *$ & $\mathrm{~B}, \mathrm{~T}, \mathrm{C}, \mathrm{P}$ & 1 & $1-2$ & $4 *-10$ & $7-10$ & 4 - 10 times* & 2 times \\
\hline Ampligo $150 \mathrm{ZC}$ & $\begin{array}{l}\text { Chlorantrniliprole } 100 \mathrm{~g} / \mathrm{L}+ \\
\text { Lambda-cyhalothrin } 50 \mathrm{~g} / \mathrm{L}\end{array}$ & I & Liquid & $\mathrm{T}$ & $\mathrm{T}$ & 0.1 & 0.1 & $7^{*}$ & $14-21$ & $3-5^{*}$ times & 3 times \\
\hline Avaunt $150 \mathrm{SC}$ & Indoxacarb $150 \mathrm{~g} / \mathrm{L}$ & I & Liquid & $\mathrm{T}^{*}, \mathrm{M}$ & M & 0.2 & 0.2 & 7 & 5 & 6 - 8 times* & 2 times \\
\hline Akrimactin $1.8 \mathrm{EC}$ & Abmectin $18 \mathrm{~g} / \mathrm{L}$ & I & Liquid & $\mathrm{GB}$ & $\mathrm{Co}, \mathrm{V}, \mathrm{Fi}$ & $0.5^{*}$ & 0.025 & 10 & 4 & 4 - 8 times* & 2 times \\
\hline Alligator & Emamectin & $\mathrm{F}$ & Liquid & $\mathrm{T}$ & v & 1 & $0.6-1$ & $4^{*}$ & 7 & 3 - 8 times* & 2 times \\
\hline Belt SC 480 & Flubendiamide $480 \mathrm{~g} / \mathrm{L}$ & I & Liquid & $\mathrm{T}$ & $\mathrm{T}$ & 0.12 & 0.12 & 7 & 5 & 3 - 5 times* & 2 times \\
\hline Coragen 200 SC & Chlorantraniliprole $200 \mathrm{~g} / \mathrm{L}$ & I & Liquid & $\mathrm{T}$ & Co, $\mathrm{T}$ & 0.2 & $0.125-0.2$ & 7 & $7-14$ & 4 - 7 times* & 2 times \\
\hline Decis EC 025 & Deltamethrin $25 \mathrm{~g} / \mathrm{L}$ & I & Liquid & $\mathrm{T}^{*}, \mathrm{O}^{*}$ & $\mathrm{~F}$ & 0.5 & $0.5-0.6$ & 7 & 5 & 3 - 5 times* & 2 times \\
\hline Diazinon $60 \% \mathrm{EC}$ & Diazinon $600 \mathrm{~g} / \mathrm{L}$ & I & Liquid & $\mathrm{O}, \mathrm{C}^{*}$ & $\mathrm{~F}, \mathrm{O}$ & 1.5 & $1-1.5$ & $5-7^{*}$ & $10-14$ & $2-10^{*}$ times & 2 times \\
\hline Dursban $48 \%$ EC & Chlorpyrifos $480 \mathrm{~g} / \mathrm{L}$ & I & Liquid & $\mathrm{O}, \mathrm{C}, \mathrm{T}$ & $\mathrm{v}$ & 2 & 2 & 14 & 5 & 3 - 5 times* & 2 times \\
\hline Dynamec 1.8 EC & Abamectin $18 \mathrm{~g} / \mathrm{L}$ & 1 & Liquid & $\mathrm{T}^{*}$ & $\mathrm{~F}$ & 0.025 & 0.025 & 14 & 7 & $2-4^{*}$ times & 2 times \\
\hline Ethiosulfan $35 \%$ EC & Endosulfan $350 \mathrm{~g} / \mathrm{L}$ & I & Liquid & $\mathrm{O}^{*}, \mathrm{C}^{*}, \mathrm{~T}^{*}$ & Co & $1.5-2$ & $2-2.5$ & $7-14$ & 7 & $2-10 *$ times & 2 times \\
\hline Ethiolathion $50 \%$ EC & $500 \mathrm{~g} / \mathrm{L}$ Malathion & I & Liquid & $\mathrm{C}$ & $\mathrm{T}, \mathrm{B}, \mathrm{C}, \mathrm{O}$ & $1-2$ & $1.1-2.75$ & 7 & 7 & $3-5^{*}$ times & $1-4$ times \\
\hline Ethiotrothion $50 \% \mathrm{EC}$ & $50 \%$ Fenitrothion & I & Liquid & $\mathrm{O}^{*}, \mathrm{P}, \mathrm{T}^{*}, \mathrm{GP} *$ & $\mathrm{SP}$ & 0.5 & 0.5 & 14 & 5 & 4 - 6 times* & 2 times \\
\hline Fastac $100 \mathrm{~g} / \mathrm{L} \mathrm{EC}$ & Alphacypermetrin $100 \mathrm{~g} / \mathrm{L}$ & I & Liquid & $\mathrm{O}^{*}, \mathrm{~T}^{*}$ & $\mathrm{~F}$ & 0.15 & $0.15-0.3$ & 21 & $7-10$ & 3 - 4 times* & 2 times \\
\hline Gain $20 \mathrm{SL}$ & $200 \mathrm{~g} / \mathrm{L}$ Imidacloprid & I & Liquid & $\mathrm{O}^{*}, \mathrm{P}$ & $\mathrm{P}$ & 0.11 & 0.11 & 7 & $5-10$ & $2-3 *$ times & 2 times \\
\hline Highway 50 EC & Lambda-cyhalothrin & I & Liquid & $\mathrm{O}^{*}, \mathrm{~T}^{*}, \mathrm{C}^{*}$ & $\mathrm{CP}$ & 0.4 & 0.4 & $4^{*}$ & $5-7$ & 5 - 7 times* & 2 times \\
\hline Helerat 50 EC & Lambda-cyhalothrin & I & Liquid & $\mathrm{O}^{*}$ & Co & 0.4 & 0.4 & $7^{*}$ & 10 & $6-7$ times* & 2 times \\
\hline Karate $5 \mathrm{EC}$ & $50 \mathrm{~g} / \mathrm{L}$ lambda-cyhalothrin & I & Liquid & $\mathrm{GB}^{*}, \mathrm{~T}, \mathrm{GP}, \mathrm{O}$ & v & 0.4 & $0.25-0.4$ & $4 *-21$ & 10 & 2 - 3 times & RAR \\
\hline Lifothoate $40 \mathrm{EC}$ & 40\% Dimethoate & 1 & Liquid & $\mathrm{T}^{*}, \mathrm{C}^{*}, \mathrm{GP}^{*}$ & Co & 1 & 1 & 7 & 7 & $4-8$ times & RAR \\
\hline Lamdex 5\% EC & Lambda-cyhalothrin 5\% EC & 1 & Liquid & $\mathrm{GB}^{*}, \mathrm{C}^{*}$ & $M, F$ & 0.4 & 0.4 & 14 & $7-10$ & 4 - 5 times* & 2 times \\
\hline Mitigan $18.5 \mathrm{EC}$ & dicofol & A & Liquid & $0^{*}$ & Co & $2-4^{*}$ & $2.4-3.2$ & 7 & 7 & $5-10$ times* & 2 times \\
\hline Nativo & $\begin{array}{l}\text { Trifloxystorbin + } \\
\text { Tebuconazole }\end{array}$ & $\mathrm{F}$ & Liquid & 0 & $\mathrm{~T}, \mathrm{O}$ & 1 & $0.5-1$ & 7 & 7 & $2-6 *$ times & 2 times \\
\hline Mitac $20 \mathrm{EC}$ & amitraz $200 \mathrm{~g} / \mathrm{L}$ & I & Liquid & GP* & Co & $2-2.5$ & $2-2.5$ & 7 & 7 & 4- 6 times* & 2 times \\
\hline
\end{tabular}

Note: “*” Indicates mismatch between recommended and farmers' practice, $\mathrm{NA}-$ not available. $\mathrm{O}=$ onion, $\mathrm{T}=$ tomato, $\mathrm{C}=$ cabbage, $\mathrm{GP}=$ green pepper, $\mathrm{P}=$ potato, $\mathrm{M}=$ maize, $\mathrm{GB}=\mathrm{Green}$ Beans, $\mathrm{F}=$ flowers, $\mathrm{CP}=$

Chickpea, $\mathrm{B}=$ Beans, $\mathrm{V}=$ vegetables, $\mathrm{Fi}=$ Fruits, $\mathrm{SP}=$ Sweet potato, $\mathrm{Co}=$ cotton, $\mathrm{S}=$ sorghum, $\mathrm{SC}=$ Sugarcane, $\mathrm{W}=$ wheat, $\mathrm{Ba}=\mathrm{Barley}, \mathrm{Ce}=\mathrm{Cereal}$ and $\mathrm{RAR}=$ repeated as required. $\mathrm{I}=$ insecticide, $\mathrm{F}=\mathrm{fungicide} ; \mathrm{A}=$

Acaricide 


\begin{tabular}{|c|c|c|c|c|c|c|c|c|c|c|c|}
\hline Trade name & Active ingredient & Type & $\begin{array}{l}\text { Physical } \\
\text { State }\end{array}$ & $\begin{array}{l}\text { Crops sprayed } \\
\text { by farmers }\end{array}$ & $\begin{array}{l}\text { Rec. } \\
\text { crops }\end{array}$ & $\begin{array}{l}\text { Farmers' } \\
\text { dosage } \\
\text { Practice } \\
\left(\mathrm{L} / \mathrm{kgha}^{-1}\right)\end{array}$ & $\begin{array}{l}\text { Rec. dosage } \\
\left(\text { L/kgha }^{-1}\right)\end{array}$ & $\begin{array}{l}\text { Appl. } \\
\text { interval } \\
\text { by farmers } \\
\text { (days) }\end{array}$ & $\begin{array}{l}\text { Rec. appl. } \\
\text { interval } \\
\text { (days) }\end{array}$ & $\begin{array}{l}\text { No. of appl. } \\
\text { by farmers }\end{array}$ & $\begin{array}{l}\text { Rec. \# of } \\
\text { appl. }\end{array}$ \\
\hline Natura $250 \mathrm{EW}$ & $250 \mathrm{~g} / \mathrm{L}$ Tebuconazole & $\mathrm{F}$ & liquid & $\mathrm{T}, \mathrm{GP}$ & $\mathrm{V}$ & 0.5 & 0.5 & 21 & $5-10$ & $3-5$ times $*$ & 2 times \\
\hline Nimbicidine & Azadirachtin A & 1 & & $\mathrm{O}, \mathrm{T}$ & $\mathrm{O}$ & 0.5 & 0.5 & 14 & $7-10$ & $3-5$ times $*$ & 2 times \\
\hline Ortiva 250 SC & Azoxystrobin $250 \mathrm{~g} / \mathrm{l}$ & $\mathrm{F}$ & liquid & $\mathrm{T}^{*}$ & $\mathrm{~F}$ & 0.5 & 0.5 & 7 & $7-10$ & $3-6$ times* & 2 times \\
\hline Profit $72 \%$ & Profenofos $720 \mathrm{~g} / \mathrm{L}$ & 1 & liquid & $\mathrm{O}, \mathrm{T}^{*}, \mathrm{M}^{*}$ & $\mathrm{CP}, \mathrm{O}$ & 1 & $0.5-1.4$ & $4^{*}-21$ & $7-10$ & $2-9 *$ times & 2 times \\
\hline Prove $1.92 \mathrm{EC}$ & $\begin{array}{l}\text { Emamectin Benzoate } 19.2 \\
\mathrm{~g} / \mathrm{L}\end{array}$ & I & liquid & $\mathrm{T}^{*}$ & $\mathrm{~F}, \mathrm{~B}$ & $0.4-0.6$ & $0.4-0.6$ & $4^{*}-10$ & $7-14$ & 5 - 9 times & RAR \\
\hline Pyrinex & Chlorpyrifos $48 \%$ EC & I & liquid & $C^{*}, \mathrm{GP}$ & GP & 0.1 & 0.1 & 14 & $7-10$ & $2-4^{*}$ times & 2 times \\
\hline Radiant 120 SC & Spinetoram $120 \mathrm{~g} / \mathrm{L}$ & I & liquid & $\mathrm{T}$ & $\mathrm{T}, \mathrm{O}$ & 0.13 & $0.13-0.15$ & 7 & $5-7$ & 3 - 7 times* & 2 times \\
\hline $\begin{array}{l}\text { Runnertm } 240 \\
\text { SC }\end{array}$ & $240 \mathrm{~g} / \mathrm{L}$ Methoxyfenozide & 1 & liquid & $\mathrm{T}, \mathrm{C}, \mathrm{GP} *$ & $\mathrm{~T}, \mathrm{C}$ & 0.5 & 0.5 & 7 & 7 & 3 - 6 times* & 2 times \\
\hline Selecron 720 EC & Profenofos $720 \mathrm{~g} / \mathrm{L}$ & 1 & liquid & $\mathrm{O}, \mathrm{C}^{*}, \mathrm{~T}^{*}$ & $\mathrm{M}, \mathrm{O}, \mathrm{S}$ & 1 & $0.5-1$ & $4^{*}-10$ & 10 & 4 - 12 times* & 3 times \\
\hline Secure $36 \%$ SC & Chlorfenapyr & I & liquid & $\mathrm{T}, \mathrm{O}^{*}, \mathrm{C}^{*}, \mathrm{GP}^{*}$ & $\mathrm{~F}, \mathrm{~T}$ & 0.4 & 0.4 & $4 *-7$ & $5-7$ & 5 - 6 times* & 2 times \\
\hline Tricel & $48 \%$ Chlorpyriphos & । & liquid & $\mathrm{T}^{*}, \mathrm{GP}$ & GP & 2 & 2 & $7^{*}$ & 30 & $2-10 *$ times & 2 times \\
\hline Tilt 250 EC & Propiconazole & $\mathrm{F}$ & liquid & $\mathrm{O}^{*}, \mathrm{~T}^{*}$ & $\mathrm{~W}, \mathrm{Ba}$ & $0.6-1$ & $0.6-1$ & 21 & 14 & 3 - 4 times* & 2 times \\
\hline Tracer $480 \mathrm{SC}$ & Spinosad $48 \mathrm{~g} / \mathrm{L}$ & 1 & liquid & $\mathrm{T}$ & $\begin{array}{l}\text { T, Co, C, } \\
\text { GP, O, M }\end{array}$ & 0.3 & $0.25-0.3$ & 7 & $5-7$ & $3-8^{*}$ times & $\begin{array}{l}2-3 \\
\text { times }\end{array}$ \\
\hline Thionex 35\% EC & $350 \mathrm{~g} / \mathrm{L}$ Endosulfan & 1 & liquid & $\begin{array}{l}\mathrm{O}, \mathrm{T}, \mathrm{C} \\
\mathrm{GP}, \mathrm{M}\end{array}$ & & $1.5-2.5$ & $1.25-2.5$ & $4-21$ & 7 & 3 - 12 times* & 2 times \\
\hline $\begin{array}{l}\text { Agro-Laxyl MZ } \\
63.5 \text { WP }\end{array}$ & $\begin{array}{l}560 \mathrm{~g} / \mathrm{kg} \text { Mancozeb + } \\
75 \mathrm{~g} / \mathrm{Kg} \text { metalaxyl }\end{array}$ & $\mathrm{F}$ & solid & O* & $\mathrm{T}$ & 3 & 3 & $7-14$ & $7-14$ & $2-4^{*}$ times & 2 times \\
\hline Bayleton 25 WP & $250 \mathrm{~g} / \mathrm{Kg}$ Triadimefon & $\mathrm{F}$ & solid & $\mathrm{T}$ & v & 0.35 & $0.25-0.35$ & $7^{*}$ & $10-14$ & 2 - 3 times & $\begin{array}{l}2-3 \\
\text { times }\end{array}$ \\
\hline Bacticide & 772 g/L Copper Hydroxide & $\mathrm{F}$ & solid & $\mathrm{O}^{*}, \mathrm{~T}$ & $\mathrm{~T}$ & 3 & 3.4 & $4-7^{*}$ & 14 & $2-5^{*}$ times & 2 times \\
\hline Curzate R WP & $\begin{array}{l}42 \% \text { Cymoxanil + } \\
397 \% \text { copper oxychloride }\end{array}$ & $\mathrm{F}$ & solid & $\mathrm{T}, \mathrm{GP}$ & $\mathrm{V}, \mathrm{Fi}$ & 2.5 & 2.5 & $4^{*}-15$ & $10-14$ & $6-10^{*}$ times & 4-6 times \\
\hline
\end{tabular}

Note: "**" Indicates mismatch between recommended and farmers' practice, $\mathrm{NA}-$ not available. $\mathrm{O}=$ onion, $\mathrm{T}=$ tomato, $\mathrm{C}=$ cabbage, $\mathrm{GP}=$ green pepper, $\mathrm{P}=$ potato, $\mathrm{M}=$ maize, $\mathrm{GB}=\mathrm{Green}$ Beans, $\mathrm{F}=$ flowers, $\mathrm{CP}=$ Chickpea, $\mathrm{B}=$ Beans, $\mathrm{V}=$ vegetables, $\mathrm{Fi}=$ Fruits, $\mathrm{SP}=$ Sweet potato, $\mathrm{Co}=$ cotton, $\mathrm{S}=$ sorghum, $\mathrm{SC}=$ Sugarcane, $\mathrm{W}=$ wheat, $\mathrm{Ba}=\mathrm{Barley}, \mathrm{Ce}=\mathrm{Cereal}$ and $\mathrm{RAR}=$ repeated as required. $\mathrm{I}=$ insecticide, $\mathrm{F}=$ fungicide; $\mathrm{A}=$

Acaricide 


\section{Table 3.2 continued}

\begin{tabular}{|c|c|c|c|c|c|c|c|c|c|c|c|}
\hline Trade name & Active ingredient & Type & $\begin{array}{l}\text { Physical } \\
\text { State }\end{array}$ & $\begin{array}{l}\text { Crops sprayed } \\
\text { by farmers }\end{array}$ & $\begin{array}{l}\text { Rec. } \\
\text { crops }\end{array}$ & $\begin{array}{l}\text { Farmers' } \\
\text { dosage } \\
\text { Practice } \\
\left(\text { L/kgha }{ }^{-1}\right)\end{array}$ & $\begin{array}{l}\text { Rec. } \\
\text { dosage } \\
\left(\mathrm{L} / \mathrm{kgha}^{-1}\right)\end{array}$ & $\begin{array}{l}\text { Appl. } \\
\text { interval } \\
\text { by farmers } \\
\text { (days) }\end{array}$ & $\begin{array}{l}\text { Rec. appl. } \\
\text { interval } \\
\text { (days) }\end{array}$ & $\begin{array}{l}\text { No. of appl. } \\
\text { by farmers }\end{array}$ & $\begin{array}{l}\text { Rec. \# of } \\
\text { appl. }\end{array}$ \\
\hline Champion & $\begin{array}{l}\text { Copper Hydroxide } 770 \\
\mathrm{gm} / \mathrm{kg}\end{array}$ & $\mathrm{F}$ & solid & $T$ & $\bar{T}$ & 2.5 & 2.5 & 7 & $5-7$ & $2-4^{*}$ times & 2 times \\
\hline Ethiozeb $80 \%$ WP & Mancozeb & $\mathrm{F}$ & solid & $\mathrm{O}^{*}, \mathrm{C}^{*}, \mathrm{~GB}^{*}, \mathrm{~T}$ & $\mathrm{~T}$ & 2 & $2-3$ & $4 *-7$ & $7-14$ & $2-3^{*}$ times & 2 times \\
\hline Fungozeb 80 WP & Mancozeb & $\mathrm{F}$ & solid & $\mathrm{O}^{*}, \mathrm{C}^{*}, \mathrm{~GB}^{*}, \mathrm{~T}^{*}$ & $P$ & 2 & $2-3$ & $4-7^{*}$ & $8-10$ & $2-6^{*}$ times & 2 times \\
\hline Kocide101 & Copperhydroxide $77 \%$ & $\mathrm{~F}$ & solid & $\mathrm{O}^{*}, \mathrm{C}^{*}, \mathrm{GP}$ & GP & 2.5 & 2.5 & $5^{*}-7$ & 7 & 6 - 8 times* & 5 times \\
\hline Mancolaxyl 72\% WP & $\begin{array}{l}\text { Mancozeb 64\%+ } \\
\text { metalaxyl } 8 \%\end{array}$ & $\mathrm{~F}$ & solid & $\mathrm{C}^{*}, \mathrm{O}^{*}, \mathrm{~T}, \mathrm{GP} *$ & $T$ & 1.5 & 1.5 & $4 *-10$ & $7-10$ & 8 - 9 times* & 2 times \\
\hline $\begin{array}{l}\text { Ridomil Gold MZ } 68 \\
\text { WG }\end{array}$ & $\begin{array}{l}4 \% \text { Metalaxyl-M + } \\
64 \% \text { Mancozeb }\end{array}$ & $\mathrm{F}$ & solid & $\mathrm{O}, \mathrm{C}, \mathrm{GB}, \mathrm{T}$ & $\begin{array}{l}T, O, C \\
G P, B\end{array}$ & 2.5 & $2.5-4$ & $4^{*}-21$ & $7-14$ & $2-10^{*}$ times & 2 times \\
\hline Sevin 85\% WP & Carbaryl & I & solid & $\mathrm{T}^{*}, \mathrm{M}$ & $\mathrm{Ce}$ & $2^{*}$ & 1 & 14 & NA & $6-7$ times & NA \\
\hline Sabozeb $80 \%$ WP & $800 \mathrm{~g} / \mathrm{Kg}$ Mancozeb & $\mathrm{F}$ & solid & $\mathrm{T}, \mathrm{O}$ & $\begin{array}{l}B<T, O \\
G P\end{array}$ & 2 & 2 & 21 & 14 & 5 - 9 times & RAR \\
\hline Saboxyl $72 \%$ wp & $\begin{array}{l}640 \text { g/Kg Mancozeb + } \\
80 \text { Metalxyl }\end{array}$ & $\mathrm{F}$ & solid & $\mathrm{T}$ & $\begin{array}{l}\mathrm{T}, \mathrm{O}, \\
\mathrm{GP}, \mathrm{C}, \\
\mathrm{GB}\end{array}$ & $2.5-4$ & $2.5-4$ & 7 & 7 & 3- $6 *$ times & 3 times \\
\hline $\begin{array}{l}\text { Trust-Cymocop } \\
439.5 \text { WP }\end{array}$ & $\begin{array}{l}397.5 \mathrm{~g} / \mathrm{Kg} \text { Copper } \\
\text { oxychloride }+ \\
42 \mathrm{~g} / \mathrm{Kg} \text { Cymoxanil }\end{array}$ & $\mathrm{F}$ & solid & $\mathrm{T}$ & $T$ & 1.5 & 1.5 & 7 & $7-14$ & 7 - 8 times* & 2 times \\
\hline Unizeb $80 \%$ WP & $800 \mathrm{~g} / \mathrm{Kg}$ Mancozeb & $\mathrm{F}$ & solid & $\mathrm{T}, \mathrm{O}$ & $\mathrm{T}, \mathrm{O}$ & 1.5 & $1.5-2$ & $7 *$ & $10-15$ & $4-12$ times* & $\begin{array}{l}2-3 \\
\text { times }\end{array}$ \\
\hline Victory 72 WP & $\begin{array}{l}\text { Metalaxyl } 80 \mathrm{~g} / \mathrm{kg}+ \\
\text { Mancozeb } 640 \mathrm{gm} / \mathrm{kg}\end{array}$ & $\mathrm{F}$ & solid & $\mathrm{T}, \mathrm{O}^{*}$ & $\mathrm{~F}, \mathrm{P}, \mathrm{T}$ & 2.5 & 2.5 & 14 & $7-10$ & $4-7$ times* & 2 times \\
\hline
\end{tabular}


The attendance of any training regarding pesticide usage, handling and safety issues was also investigated during the survey. One-third of the farmers (31\%) replied that they had attended a training, but the majority (69\%) had never attended one (Table SI3.4). Similarly, Mengistie et al. (2017) reported about 78\% of the sample farmers in this region had not received formal training in pesticides use and safety. This stresses the necessity for basic training to outreach to the majority of farmers. There was a significant difference in percentage of trained farmers between the different districts, with more farmers in ATJK and Ziway-Dugda having had training on pesticide related issues $(p=0.01)$ (Table 3.3 c; Fig. 3.1). The substantial expansion of irrigation land by the smallholder vegetable farmers in ATJK compared to the other districts may attract the training organizers (Table $3.3 \mathrm{a}$ ), and can partially explain the differences observed between districts. The main themes of trainings according to the respondent farmers were skills on how to mix pesticides (92\%), spraying techniques (90\%), human health safety issues (67\%), environmental safety issues (12\%), and disposal methods of obsolete pesticides and empty pesticide containers (12\%) (Table SI3.4). Environmental safety of pesticides and safe disposal of waste were given low attention, as only a few farmers mentioned they had received training in these aspects (Table SI3.4).

In Africa, the lack of knowledge and concern by smallholder farmers about pesticide related safety are key factors causing impacts on human health and the environment (Oluwole and Cheke, 2009; Mengistie et al., 2017; Loha et al., 2018; Onwona-Kwakye et al., 2019; Okonya et al., 2019). Environmental safety related behaviour of the farmers was also further assessed during the survey by asking about their actual practices, for example, during pesticide mixing and spraying activities. In line with the reported results for Ethiopia (Teklu et al., 2016a; Mengistie et al., 2017) and in Ghana (Onwona-Kwakye et al., 2019), our results showed that the majority $(73 \%)$ of the farmers mix pesticides near water sources such as tributary and canals to Lake Ziway (Table SI3.4). This indicates that pesticide contamination of water of Lake Ziway may occur during spray mixture preparation by the farmers which may cause effects on the biological components of the lake that underlie the ecological functions and processes to deliver ES (Fig. 3.2). Significant differences in mixing practices were found between the different districts $(p=0.001)$, the practice was more common among farmers in the ATJK and Dugda district relative to the farmers in Ziway-Dugda district despite significantly large number of farmers in ATJK district had training on pesticide compared to farmers in Dugda (Table $3.3 \mathrm{c}$ ). 
Contrary to the smallholder vegetable farmers in Rwanda and Burundi (Okonya et al., 2019), the majority of the sampled farmers (93\%) know and understand the undesired impacts of pesticides on aquatic life if the chemicals enter the aquatic ecosystem (Table SI3.4). The level of knowledge and understanding was significantly different between the farmers in the three districts, with farmers in the ATJK district having relatively better understanding about the impact of pesticides on aquatic ecosystem $(p=0.002)$ (Table $3.3 c)$. Regardless of farmers' understanding on the possible impact of pesticides on aquatic ecosystems, more than half (57\%) of the sampled farmers replied that they did not take any environmental safety measure(s) during chemical spraying to protect Lake Ziway or other water bodies from contamination (Table SI3.4). There is a mismatch between the farmers' knowledge and understanding on the environmental impacts of pesticides, and their actual practices. This is likely due to a lack of awareness about how pesticides enter water bodies (Teklu et al., 2016a) and the low concern for their environment (Mengistie et al., 2017).

However, almost half of the farmers (43\%) replied that they took various measures to protect Lake Ziway from contamination by pesticides during their mixing and spraying activities (Table SI3.4). They indicated to mix the pesticides away from water canal, consider the wind direction, do not dump pesticide wastes such as empty containers into the lake, built buffer zones between irrigated farm land and the lake, and only spray on dry days, as measures to reduce pesticides inputs to the nearby waters (e.g., Lake Ziway) (Table SI3.4). The differences between districts on the number of farmers taking measures to protect Lake Ziway from pesticides pollution was significant $(P=0.019)$, with more farmers in Ziway-Dugda taking safety measures (Table $3.3 \mathrm{c}$ ). As discussed, this can be due to the impact of training the farmers in Ziway-Dugda had in the past (Table $3.3 \mathrm{c}$ ).

Inappropriate dumping of wastes of pesticides including empty pesticide containers can be another source of pesticide contamination to the environment (Briassoulis et al., 2014). In agreement with the observation by Mengistie et al. (2017) in this region, our result showed that majority (63\%) of the respondent farmers threw pesticide related wastes into their surrounding environment, indicating an inappropriate management of the waste of pesticides by the farmers (Table SI3.4). Residual pesticides from the wastes may be released into Lake Ziway, and pose risks to the lake ecosystem and its important ES such as fish food and drinking water (Fig. 3.2). Similar improper waste disposal practices by smallholders farmers were reported in other African countries (Ntow et al., 2006; Onwona-Kwakye et al., 2019). 
Moreover, the use of pesticide containers as household equipment and the selling of containers were reported by $14 \%$ and $0.7 \%$ of the respondent farmers, respectively (Table SI3.4), which may again impose risks to the human health (Oluwole and Cheke, 2009). Similarly, Oluwole and Cheke (2009) reported the use of empty plastic pesticide containers for storing drinking water and food by the smallholder farmers in Nigeria. Burying $(27 \%)$ and burning $(15 \%)$ of empty containers of pesticides were among the other disposal practices reported by the sample farmers (Table SI3.4). The majority of the farmers (71\%) denied any contribution of their pesticide use and handling practices to the possible contamination of Lake Ziway by the compounds (Table SI3.4).

Human health related safety-in-use issues were also key points investigated in this study. African farmers often spray pesticides without wearing appropriate protective clothing and devices (Oesterlund et al., 2014; Mengistie et al., 2017; Onwona-Kwakye et al., 2019; Okonya et al., 2019). Farmers' practices of considering wind direction and owning separate clothing for spraying to minimise the occupational exposure, were reported by $67 \%$ and $52 \%$ the sample farmers, respectively (Table SI3.4). The use of protective gloves and closed boots was negligible in the region, as also reported by Mengistie et al. (2017). A few farmers reported the use of hats (9\%) or boots (8\%) during pesticide spraying (Table SI3.4). This indicates that, human health safety measures taken by the farmers during spraying were limited to the use of a few safety materials, which are inadequate to fully protect from exposure. Lack of protective materials or their partial use was also reported by vegetables producing farmers in Ghana (Ntow et al., 2006; Onwona-Kwakye et al., 2019), in Uganda (Oesterlund et al., 2014), in Nigeria (Oluwole and Cheke, 2009) and rice producing farmers in Tanzania (Stadlinger et al., 2011). This can be due to a lack of knowledge or a lack of protective materials at affordable costs on the local market (Oluwole and Cheke, 2009). The hot weather condition of the CERV region can also be a reason why the sprayers are unwilling to wear protective materials (Mengistie et al., 2017). 
Table 3.3. General profile of the sample farmers, and the ecosystem goods and services and pesticide use practices of the farmers for which significant differences observed between the districts.

\begin{tabular}{|c|c|c|c|c|}
\hline $\begin{array}{l}\text { a. General Profile of the respondent } \\
\text { farmers and the districts }\end{array}$ & ATJK & Dugda & Ziway-Dudga & \\
\hline Number of sample households (n(\%)) & $74(36.6)$ & $42(20.8)$ & $86(42.6)$ & \\
\hline Age in year (average ( \pm standard deviation)) & $40 \pm 10$ & $42 \pm 7$ & $40 \pm 12$ & \\
\hline Household family size (average \pm SD) & $6.2 \pm 2.6$ & $7.9 \pm 2.4$ & $6.9 \pm 3.7$ & \\
\hline \multicolumn{5}{|l|}{ Educational level (n (\%)) } \\
\hline $\begin{array}{l}\text { Not read and write (did not attend any } \\
\text { formal school) }\end{array}$ & $11(14.9)$ & $4(9.5)$ & $15(17.4)$ & \\
\hline Grade 1 to 8 & $51(68.9)$ & $34(81)$ & $54(62.8)$ & \\
\hline High school (Grade 9 - 12) & $12(16.2)$ & $4(9.5)$ & $16(18.6)$ & \\
\hline Collage/University (Above Grade 12) & $0(0)$ & $0(0)$ & $1(1.2)$ & \\
\hline $\begin{array}{l}\text { Villages encompassing farmers live on the } \\
\text { islands of the lake }\end{array}$ & No & No & $\begin{array}{l}\text { Herara and Bashira } \\
\text { Chafa }\end{array}$ & \\
\hline $\begin{array}{l}\text { Infrastructure development around the lake } \\
\text { for recreational activities (e.g., road, and boat) } \\
\text { (personal observation) }\end{array}$ & Relatively good & Relatively good & Relatively low & \\
\hline $\begin{array}{l}\text { Wetland and floodplains parts (personal } \\
\text { observation) }\end{array}$ & Relatively large & Relatively large & Relatively low & \\
\hline Irrigation land size of the districts (ha) & 5672 & 2367 & 489 & \\
\hline b. Ecosystem services and goods harvested & $\begin{array}{l}\text { Pearson Chi- } \\
\text { square } \\
\text { test P-value }\end{array}$ & ATJK (n (\%)) & Dugda (n (\%)) & $\begin{array}{l}\text { Ziway- } \\
\text { Dudga (n } \\
\text { (\%)) }\end{array}$ \\
\hline Fish food harvest & $p<0.001$ & $27(36.5)$ & $21(50)$ & $58(67.4)^{*}$ \\
\hline Plants food harvest & $p=0.036$ & $65(87.8)^{*}$ & $41(97.6)^{*}$ & $70(81.4)$ \\
\hline Drinking water & $p<0.001$ & $21(28.4)$ & $40(95.2)^{*}$ & $31(36)$ \\
\hline Cloth washing and bathing & $p<0.001$ & $43(58.1)$ & $42(100)$ & $62(72.1)$ \\
\hline Irrigation water & $P=0.009$ & $61(82.4)^{*}$ & $36(85.7)^{*}$ & $56(65.1)$ \\
\hline Other domestic use like for cooking use & $p<0.001$ & $26(35.1)$ & $42(100)^{*}$ & $47(54.7)$ \\
\hline Transportation & $p<0.001$ & $38(51.4)$ & $30(71.4)$ & $75(87.2)^{*}$ \\
\hline Recreation and community activities & $p<0.001$ & $46(62.2)^{*}$ & $24(57.1)^{*}$ & $41(47.7)$ \\
\hline $\begin{array}{l}\text { c. Pesticide use practices of the respondent } \\
\text { farmers }\end{array}$ & $\begin{array}{l}\text { Pearson Chi- } \\
\text { square } \\
\text { test P-value }\end{array}$ & ATJK (n (\%)) & Dugda (n (\%)) & $\begin{array}{l}\text { Ziway- } \\
\text { Dudga (n } \\
\text { (\%)) }\end{array}$ \\
\hline $\begin{array}{l}\text { Training regarding pesticide usage, handling } \\
\text { and safety issues }\end{array}$ & $p=0.01$ & $24(39.3)^{*}$ & $4(11.1)$ & $20(35.7)^{*}$ \\
\hline $\begin{array}{l}\text { Understand the undesired impacts of } \\
\text { pesticides on aquatic organisms }\end{array}$ & $p=0.002$ & $61(100)^{*}$ & $30(83.3)$ & 52 (92.9) \\
\hline $\begin{array}{l}\text { Take safety measures to protect Lake Ziway } \\
\text { and other nearby waters }\end{array}$ & $P=0.019$ & $12(19.7)$ & $13(36.1)$ & $31(55.4)^{*}$ \\
\hline Not mix pesticides near water sources & $p=0.001$ & $11(18)$ & $4(11.1)$ & $29(51.8)^{*}$ \\
\hline
\end{tabular}

Note: * indicates significance difference $(p<0.05) ;$ ATJK = Adami Tulu Jido Kombolcha district

\subsubsection{Pesticide use by large-scale companies}

\subsubsection{Usage and type of pesticides}

Five floriculture and one viticulture large-scale companies, located at the south-west part of Lake Ziway, were interviewed during our field survey to assess the types of pesticides used 
and their practical usage. The floriculture farms withdraw irrigation water from Lake Ziway, while the viticulture farm uses the Bulbula River (outflow of Lake Ziway) and boreholes as a source of water (Table 3.4). According to the farm managers of the companies, the total volume of water abstracted from the lake and its outflow river are about 11 million $\mathrm{m}^{3} /$ year and 1 million $\mathrm{m}^{3} /$ year, respectively (Table 3.4). This indicates that the farms entirely rely on Lake Ziway and on its outflow river for their irrigation water requirement. The total farm size of the floriculture companies was about 500 ha, while 453 ha was irrigated by the viticulture company (Table 3.4).

Horticulture, viticulture and floriculture farms use large amounts and a wide range of pesticides to control pests and diseases (Lacasaña et al., 2010; Schilmann et al., 2010). Our survey showed that three of the five floriculture farms have employed Integrated Pest Management (IPM) technology to control spider mites and use different types of pesticides for other pests (Table 3.4). However, two of the five farms totally relied on the use of pesticides to protect their flowers from pests (Table 3.4). According to the viticulture farm manager, different types of fungicides were used on farm to suppress fungal diseases like mildew. Both floriculture and viticulture companies did not allow access to the names and types (i.e., chemical class) of pesticides used, nor the volumes consumed (Table 3.4). Such denial to access information hamper a scientific evaluation of the environmental and human health risks and reduces the transparency between stakeholders at the lakeside. However, a survey by Teklu et al. (2016a) reported about 34 pesticide types (based on their common name) containing 35 active ingredients used by the large-scale flower farms found in CERV region of Ethiopia near Debire Zeit, which is $83 \mathrm{~km}$ North of Lake Ziway. The authors (Teklu et al., 2016a) also reported that the flower farms use the pesticides in accordance with the product recommendations.

\subsubsection{Drainage facilities and wastewater treatment by large-scale farms}

Our study found that the floriculture companies released their wastewater effluent into Lake Ziway (Table 3.5). During our visit, the different sections of the farms such as greenhouses, postharvest/packaging house, chemicals mix and sprayers' bathrooms were identified as the main sources of wastewater effluent from floriculture farms (Table 3.5), as was also reported by Teklu et al. (2016a) for flower farms found in Debre Zeit, Ethiopia. During the farm observation it was noticed that the four floriculture companies (15 greenhouses 
established on 143 hectares) had implemented Wastewater Treatment Technology (WWTT) such as wetland plates, soak away pits (e.g., to treat wastewater from chemical mix house), and silo recycling (Table 3.5). However, one floriculture company with 27 greenhouses, built on 357 ha of land (64\% of the total floricultures farm size), did not permit visitation, stating that wetland plates were under construction (Table 3.5). However, the researchers did not observe any construction around the greenhouses owned by the farm, or any other measures (personal observation). Our search on Google maps (map data 2020) also did not show any recently constructed wetlands. This suggests that at the time of visit, wastewater from the majority of the floriculture farm land (64\%) may have been released into Lake Ziway without adequate treatment, which may cause pesticides and residuals to enter the lake ecosystem.

Furthermore, the managers of the farms having constructed WWTT were interviewed whether they had regular chemical monitoring programme to check the efficiency of the constructed technologies. Two out of five floriculture farms reported that they had a regular chemical monitoring programme in place, but were unable to provide the data or were not willing to show it to the researchers (Table 3.5). Therefore, the sufficiency and efficiency of the constructed WWTT to treat the effluent of the farms remains questionable, needing further clarification.

From the viticulture farm there was no wastewater released into Lake Ziway nor into its outlet river, Bulbula from any point source. However, there was wastewater effluent discharge into a fenced and protected stabilization pond from its wine making factory. During the visit it was observed that the wastewater stabilization pond was almost full (Table 3.5). This showed that residual pesticides may enter into Bulbula River from the viticulture farm through surface runoff, and perhaps from the stabilization pond in times of high precipitation causing overflow and due to infiltration.

Better management of other pesticides related solid wastes by the large-scale farms was observed. The farms reported that they employed compositing, incineration and recycling methods to remove organic wastes, empty pesticide containers and other pesticide packaging materials (i.e., carton boxes), respectively (Table 3.5). These good practices and experiences of the large-scale farms could be shared with smallholder farmers in the region thus helping the farmers to dispose of pesticide related solid wastes. 
Table 3.4. Background information including farm type, farm size, number of green house, year of establishment, number of employees per year, source of water, and technology in use to protect the farms from pest and disease of five large-scale private-owned farms around Lake Ziway (surveyed in 2017).

\begin{tabular}{|c|c|c|c|c|c|c|c|c|}
\hline Farm name & $\begin{array}{l}\text { Farm } \\
\text { type }\end{array}$ & $\begin{array}{l}\text { Farm } \\
\text { size (ha) }\end{array}$ & $\begin{array}{l}\text { No. of green } \\
\text { houses }\end{array}$ & $\begin{array}{l}\text { Founding } \\
\text { Year }\end{array}$ & $\begin{array}{l}\text { No. of } \\
\text { yearly } \\
\text { employees }\end{array}$ & $\begin{array}{l}\text { Source of } \\
\text { irrigation water }\end{array}$ & $\begin{array}{l}\text { water consumption } \\
(* 1000000 \\
\left.\mathrm{m}^{3} / \text { year }\right)\end{array}$ & $\begin{array}{l}\text { Pest control } \\
\text { method }\end{array}$ \\
\hline Farm1 & $\mathrm{GH}$ & 39 & 4 & 2006 & 1100 & LZ & 0.8541 & IPM + Pesticides \\
\hline Farm2 & $\mathrm{GH}$ & 22 & 2 & 2009 & 700 & LZ & 0.3212 & IPM + Pesticides \\
\hline Farm3 & $\mathrm{GH}$ & 40 & 4 & 2006 & 1100 & LZ & 0.876 & pesticides \\
\hline Farm4 & $\mathrm{GH}$ & 42 & 5 & 2005 & 1300 & LZ & 0.9198 & pesticides \\
\hline Farm5 & $\mathrm{GH}$ & 357 & 27 & 2005 & 11000 & LZ & 7.8183 & IPM + Pesticides \\
\hline Farm6 & OP & 453 & - & 2008 & 1000 & $\mathrm{BR}+\mathrm{BH}$ & 0.96 & Fungicides \\
\hline
\end{tabular}

Note: IPM = integrated pest management, $\mathrm{LZ}=$ Lake Ziway, $\mathrm{BR}=$ Bulbula River, $\mathrm{BH}=$ borehole, $\mathrm{GH}=$ produce in green house, OF = produce in open field. The name of farms are known by the authors.

Table 3.5. Main sources of wastewater and solid wastes, drainage facilities and waste management technologies employed by large-scale floriculture and viticulture companies found around Lake Ziway.

\begin{tabular}{|c|c|c|c|c|c|c|c|c|c|}
\hline \multirow[t]{2}{*}{ Company name } & \multirow{2}{*}{$\begin{array}{l}\text { Farm } \\
\text { observa } \\
\text { tion }\end{array}$} & \multirow[t]{2}{*}{$\begin{array}{l}\text { Main origin of } \\
\text { wastewater }\end{array}$} & \multirow{2}{*}{$\begin{array}{c}\text { Wastewater } \\
\text { Treatment } \\
\text { technology } \\
\text { (WWTT) in use }\end{array}$} & \multicolumn{3}{|c|}{$\begin{array}{l}\text { Solid waste treatment technology (SWTT) } \\
\text { in use }\end{array}$} & \multirow{2}{*}{$\begin{array}{l}\text { Regular chemical } \\
\text { monitoring } \\
\text { Programme to check } \\
\text { the efficiency of WWTT }\end{array}$} & \multirow{2}{*}{$\begin{array}{l}\text { Accessed to } \\
\text { WWTT efficiency } \\
\text { supporting } \\
\text { data }\end{array}$} & \multirow{2}{*}{$\begin{array}{c}\text { Ecosystem into } \\
\text { which effluent } \\
\text { released }\end{array}$} \\
\hline & & & & Composting & Incineration & Recycling & & & \\
\hline Farm1 & Yes & $\begin{array}{l}\text { GH, PH, PMH, } \\
\text { FMH, SBR }\end{array}$ & $\begin{array}{l}\text { wetland plates, } \\
\text { Soak away pits }\end{array}$ & $\begin{array}{l}\text { Organic } \\
\text { wastes }\end{array}$ & $\begin{array}{l}\text { empty } \\
\text { containers }\end{array}$ & $\begin{array}{l}\text { Carton } \\
\text { boxes }\end{array}$ & once per year & No & Lake Ziway \\
\hline Farm2 & Yes & $\begin{array}{l}\mathrm{GH}, \mathrm{PH}, \mathrm{PMH}, \\
\mathrm{FMH}, \mathrm{SBR}\end{array}$ & $\begin{array}{l}\text { wetland plates, } \\
\text { Silo recycling }\end{array}$ & $\begin{array}{l}\text { Organic } \\
\text { wastes }\end{array}$ & $\begin{array}{l}\text { empty } \\
\text { containers }\end{array}$ & - & Not implemented & - & Lake Ziway \\
\hline Farm3 & yes & $\begin{array}{l}\mathrm{GH}, \mathrm{PH}, \mathrm{PMH} \\
\mathrm{FMH}, \mathrm{SBR}\end{array}$ & $\begin{array}{l}\text { wetland plates, } \\
\text { Soak away pits }\end{array}$ & $\begin{array}{l}\text { Organic } \\
\text { wastes }\end{array}$ & $\begin{array}{l}\text { empty } \\
\text { containers }\end{array}$ & - & $\begin{array}{l}\text { once per three } \\
\text { months }\end{array}$ & No & Lake Ziway \\
\hline Farm4 & yes & $\begin{array}{c}\mathrm{GH}, \mathrm{PH}, \mathrm{PMH}, \\
\mathrm{FMH}, \mathrm{SBR}\end{array}$ & $\begin{array}{l}\text { wetland plates } \\
\text { (under } \\
\text { construction) }\end{array}$ & $\begin{array}{l}\text { Organic } \\
\text { wastes }\end{array}$ & $\begin{array}{c}\text { empty } \\
\text { containers }\end{array}$ & $\begin{array}{l}\text { Carton } \\
\text { boxes }\end{array}$ & Not implemented & - & Lake Ziway \\
\hline Farm5 & No & NFO & NFO & $\begin{array}{l}\text { Organic } \\
\text { wastes }\end{array}$ & $\begin{array}{l}\text { empty } \\
\text { containers }\end{array}$ & $\begin{array}{l}\text { Carton } \\
\text { boxes }\end{array}$ & Not implemented & - & Lake Ziway \\
\hline Farm6 & yes & Wine factory & $\begin{array}{c}\text { wastewater } \\
\text { stabilization pond }\end{array}$ & $\begin{array}{l}\text { Organic } \\
\text { wastes }\end{array}$ & $\begin{array}{l}\text { empty } \\
\text { containers }\end{array}$ & $\begin{array}{l}\text { Carton } \\
\text { boxes }\end{array}$ & Not implemented & - & $\begin{array}{l}\text { basin } \\
\text { infiltration }\end{array}$ \\
\hline
\end{tabular}

Note: Greenhouse (GH), Package house (PH), pesticides mix house (PMH), Fertilizers mix house (FMH) and sprayers bathing room (SBR). 


\subsubsection{Potential impact of pesticides on Lake Ziway ES}

As discussed, this study identified several ES that Lake Ziway provides to the local communities. A sustainable supply of the services is dependent on a continued good ecological condition of the lake ecosystem, supporting the well-being of the SPUs (Luck et al., 2003; EFSA 2010; Grizzetti et al. 2015). Pesticides adversely affects aquatic organisms (e.g., fish, primary producers and invertebrates) and ecological functions and processes (e.g., DO production, organic matter decomposition rate and pH level) (Brock et al., 2000a; Brock et al., 2000b; Fleeger et al. 2003; Maltby et al., 2009; McMahon et al., 2012; Schäfer et al., 2012; Bundschuh et al. 2019).

Other studies in Ethiopia have indicated the risks of pesticides to aquatic organisms (Teklu, 2016). Teklu et al. (2016a) studied the risks of pesticides used by the smallholder vegetable farmers in CERV region around Debre Zeit area, Ethiopia with the use of PRIMET model (Ethiopian version) to estimate the exposure concentrations to aquatic organisms. The authors, (Teklu et al., 2016a), reported that the use of $\lambda$-cyhalothrin, profenofos and malathion by farmers posed risks to daphnia and fish, and that endosulfan, propiconazole and diazinon posed risks to fish, algae and daphnia, respectively. Moreover, the result of a monitoring study made in 2014 by Teklu et al. (2018) in Lake Ziway, Ethiopia demonstrated the presence of 13 pesticides in the lake water, where the observed concentrations of the fungicide spiroxamine and the insecticides deltamethrin and endosulfan pesticides posed acute risks to aquatic organisms, and the fungicide spiroxamine was found in a concentration risky to human health upon chronic exposure via drinking water (Fig. 3.2).

Our monitoring studies in 2017 (Merga et al., 2020a) further showed that the water and sediment compartments of Lake Ziway are contaminated by different types of pesticides (Fig. 3.2). The majority of the pesticides (78\%) found and quantified in water and sediment of Lake Ziway (Teklu et al., 2018; Merga et al., 2020a) are reported to be used by the smallholder vegetables farmers. Furthermore, the pesticides metalaxyl, propamocarb, iprovalicarb, deltamethrin and ethoprophos quantified in Lake Ziway by Merga et al. (2020a) was reported by Teklu et al. (2016a) to be used by the floriculture farms found in the central Ethiopian rift valley region, near Debre Zeit, Ethiopia. According to the authors (Merga et al., 2020a), the water concentration levels of dimethoate, carbaryl and malathion, diazinon, fenitrothion and endosulfan, chlorpyrifos, spiroxamine, $\lambda$-cyhalothrin and $\alpha$-cypermethrin posed ecological 
risks. In the sediment, deltamethrin, dimethoate, chlorpyrifos, fenitrothion, endosulfan, $\lambda$ cyhalothrin and $\alpha$-cypermethrin posed risks to aquatic organisms (Merga et al., 2020a) (Fig. 3.2). The study (Merga et al., 2020a) also demonstrated a negative correlation of macroinvertebrate and fish abundances with concentration levels of the pesticides in the lake.

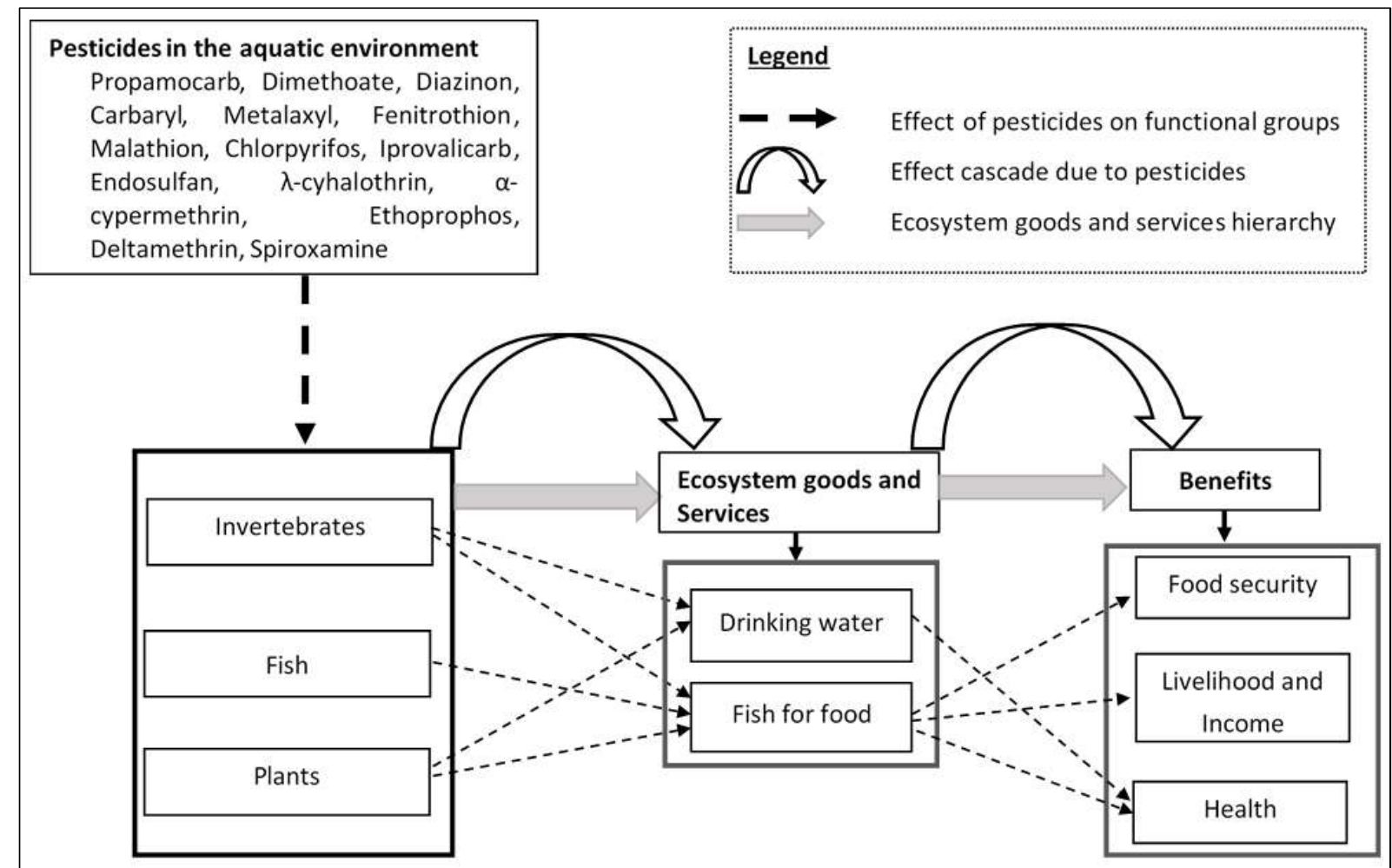

Figure 3.2. Conceptual framework showing the linkages between pesticides used in agriculture potentially affecting biological components in the aquatic ecosystem and the vulnerable ecosystem goods and services that are most valued by stakeholders in the region around Lake Ziway. The bold broken arrow indicates effects on aquatic groups functionally important in the provision of associated ES and benefits (thin broken arrows). The bended arrows illustrate subsequent potential cascading effects from these service providing functional groups via ecosystem dysfunction to impaired provision of ecosystem goods and services, reducing social and economic benefits or avoided costs. Presence of the pesticides listed has consistently been demonstrated in lake water and sediments (Teklu et al. 2018; Merga et al., 2020a) at concentrations above known effect thresholds for the relevant aquatic organisms, and declines in the provision of Ecosystem goods and services have also been suggested (this study).

The results of our current study showed that unsustainable crop production practices were employed by the smallholder vegetable farmers and the large-scale floriculture farms in the vicinity of Lake Ziway. The malpractices by the smallholder farmers to handle and use pesticides, and wastewater effluent released into Lake Ziway from the floriculture farms are expected to be the major cause for the reported pesticide pollution of the lake and associated ecological risks. Because, as discussed earlier, the pesticides found in the lake and posed risks to aquatic organisms (Teklu et al., 2018; Merga et al.,2020a) are used by smallholder farmers and floriculture farms in the region. This could be a threat to the continued provision of Lake 
Ziway ES by affecting the biological components that are functionally important in the provision of the ES and benefits. In Fig. 3.2 we demonstrated how effects of pesticide on aquatic functional groups cascaded to associated ES of Lake Ziway and benefits obtained by local communities. Effects of pesticides on invertebrates and plants may impair drinking water provision by affecting the organisms functioning in water purification processes such as nutrient cycling and removal and detoxification of pollutants, which further affects human health due to poor quality of water. Adverse effects of the pesticides on invertebrates (e.g., serve as food for fish), plants (e.g., used as nursery and maintenance ground and sources of food) and fish can also affect provisioning of fish for human consumption by the lake. This effect limits the contribution of harvestable fish food for food security, livelihood and income and health of the local people.

Furthermore, Fig. 3.3 showed that water abstraction from Lake Ziway (for drinking water supply for the nearby town (Batu) and for irrigation by smallholder farmers) and irrigated land size for vegetable production by smallholders in the catchment area of the lake showed an increasing temporal trend, while fish yield of the lake showed a substantial declining trend. Likely as a result of water quality deterioration of the lake, treatment cost per volume of raw water to supply drinking water for Batu town also showed a substantial increasing temporal trend. The trends (Fig. 3.3) suggest the association between the increasing temporal trends of agricultural activities (irrigation land size and water abstraction for irrigation) in the catchment area of Lake Ziway and the deterioration of water quality that affects drinking water supply and declining of harvestable fish food of the lake over time as discussed earlier using the conceptual framework in Fig. 3.2. 


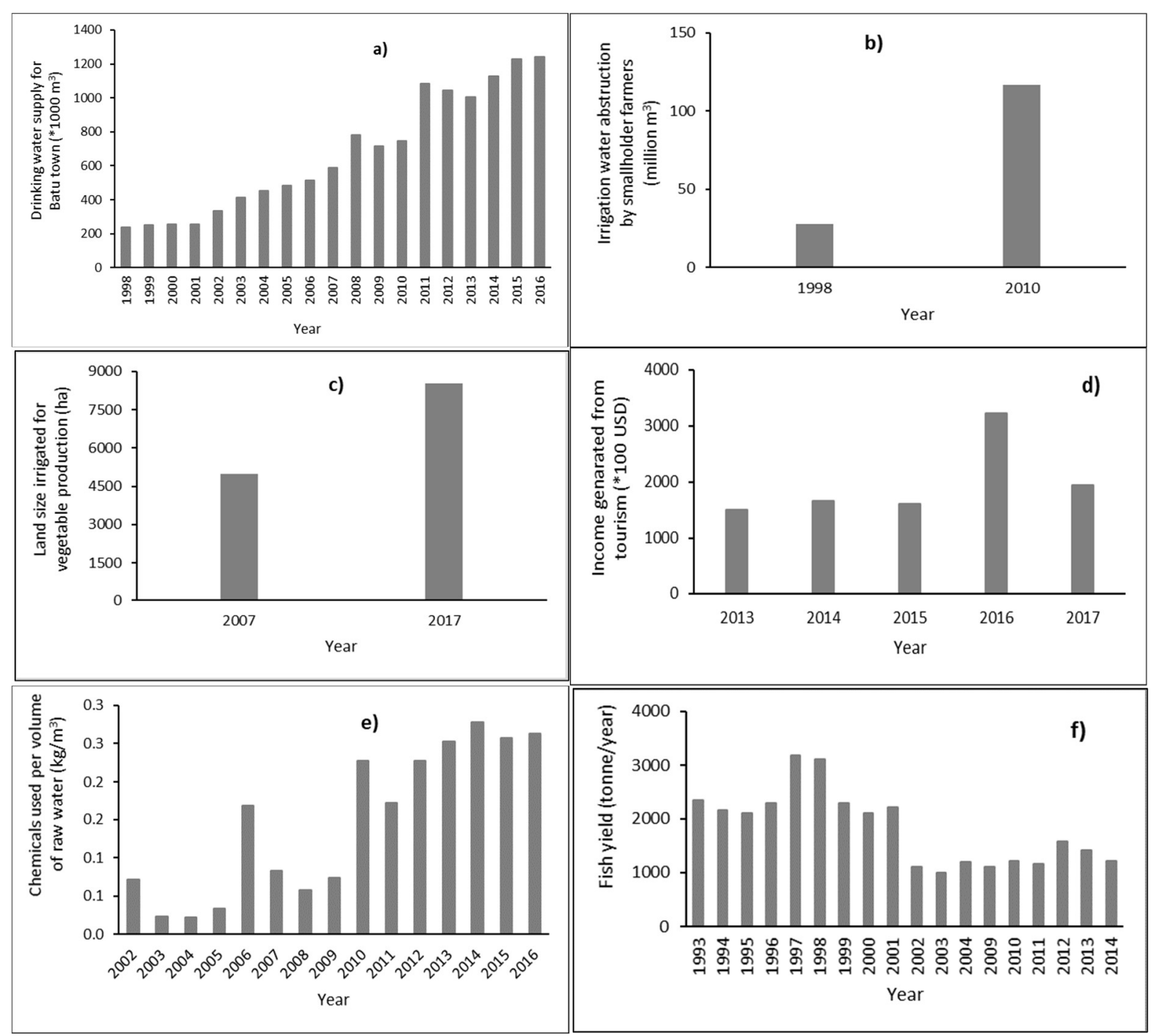

Fig. 3.3. Trends of drinking water supply for Batu town from Lake Ziway (a), irrigation water abstraction by smallholder farmers (b), irrigated land size (c), income generated from tourism activity (d), chemical use by drinking water supplying enterprise for Batu town (e) and fish catch yield of Lake Ziway (f). No data was found for the year range $1999-2009$ (b), $2008-2016$ (c) and 2005 - 2008 (f). Sources: a: (our interview with drinking water supplying enterprise for Batu town); b: (Ayenew and Legesse, 2007; Eresso 2010); c: (Jansen et al., 2007; our interview with agricultural offices of the interviewed districts); $d$ : (our interview with cultural office of Batu town); e: (our interview with water supplying enterprise for Batu town); f: (Abera et al., 2018).

\subsection{Conclusions and recommendations}

Lake Ziway is a multifunctional ecosystem that provides a wide range of provisioning, cultural, and regulation and maintenance ES benefiting the local communities. Drinking water and fish food are the most important ES of the lake in the region. However, the use of pesticides in local agriculture may pose risks to the current and future delivery of ES by Lake Ziway due to increased environmental concentrations as a consequence of the use and misuse of pesticides by smallholder farmers and lack of proper management of wastewater effluents from floriculture farms. To reduce these environmental risks of pesticides it is recommended 
to build capacity of farmers and local pesticide shops through training on safe use of pesticide and scouting of disease and pest, promote use of alternative methods for pest control that help reduce pesticide consumption (e.g., IPM), and implement environmental auditing of effluents from floriculture farms, for example, through regular monitoring of its chemical constituents. Moreover, enhancing the effective implementation of the available legislation on pesticide registration and control by overcoming the key barriers for their implementation (e.g., poor information availability to state and non-state actors, low motivation of state actors to implement the policies, and insufficient financial and human resources to implement) (Mengistie et al., 2015) is also crucial to avert pesticide related risks to Lake Ziway ecosystem and to its ES.

\section{Acknowledgments}

The study was financially supported by Netherlands fellowship programmes, NUFFIC/ PhD studies, grant NFP - PhD.16/0019, reference number WIMEK2015 02. The authors are most indebted to Batu Fishery and Other Aquatic Life Research Centre for logistic support, Mr. Alemu Lema for his contribution in data collection, and the farmers, tourists and offices for their kind cooperation. 
Appendix 3: Supplementary information (SI)

\section{Section 3A: questionnaire used for household survey}

\section{Dear participant,}

This survey study is part of my PhD research in Wageningen University, The Netherlands. The aim of the study is to assess ecosystem goods and services provided by the Ziway lake ecosystem, and to evaluate pesticides use by smallholder vegetable farmers in the region. You have been selected for the survey, because you and the community in this village/kebele are considered as the main beneficiaries of ecosystem goods and services supplied by the lake. You therefore are resourceful for the survey. I highly appreciate your help by filling the questionnaire. Your genuine responses will have a direct impact on quality of the study. The survey is only used for research purposes and it will be kept confidential. The survey takes about $\mathbf{5 0}$ minutes to fill in. Thank you most sincerely for your collaboration and patience in advance to fill the questionnaire.

If you have any questions contact at: lemessa.merga@wur.nl

Cell phone: $+251-931556873$

Regards,

Lemessa Benti Merga

\begin{tabular}{|l|l|l|c|}
\hline Name of data collector & Signature & Researcher & Signature \\
\hline & & & \\
\hline
\end{tabular}

\section{PART 1. Preliminary questions}

A. General Information

\begin{tabular}{|l|l|}
\hline Name of District: & Date: \\
\hline Name of Peasant Association: & Time: \\
\hline
\end{tabular}

B. Demographic characteristics of the respondent

\begin{tabular}{|l|l|}
\hline Respondent name/Code: & Age: \\
\hline Main Occupation: & Gender: \\
\hline Marital Status: $\square$ Married $\square$ Fingle $\square$ Divorce $\square$ Widow & years you stay here: \\
\hline Role in the family: & Family size: \\
\hline $\begin{array}{l}\text { Educational level: } \\
\square \text { Illiterate (not went to school, not read and not write) } \\
\square \text { Primary level (grade 1-8) } \\
\square \text { Secondary and high school level (Grade 9 - 12) } \\
\square \text { College and university level }\end{array}$ \\
\end{tabular}


C. Socio-economic characteristics of the respondent

\begin{tabular}{|l|l|l|l|l|l|l|}
\hline No. of cattle & No. of Goats & No. of Sheep & No. of Horse & No. of Mule & Donkey & Total livestock \\
\hline & & & & & & \\
\hline
\end{tabular}

\section{PART 2. Ecosystem Services Assessment}

Direction: Lakes are important ecosystem that provide different ecosystem goods and services for human beings. Below, various services are listed which may be provided by Lake Ziway ecosystem to you and your community. You are requested to choose the benefits you obtain from the lake and kindly asked to give your genuine answer also for related questions.

\section{A. Provisioning goods and services: You can select more than one answer when necessary}

1. Do you harvest/catch wild fish from the lake? $\square$ Yes $\square$ No

1.1. If yes, indicate the use type through which fishery contributes for your livelihood.

Subsistence

Commercial

1. 2. Are you a member of fishery cooperative? $\square$ Yes $\square$ No

1.2.1. If yes, please specify the name of your cooperative:

1.3. Have you noticed unexpected change in amount of fish catches in the past few years? $\square$ Yes $\square$ No

1.3.1. If yes, what change did you observe per species?

\begin{tabular}{|l|c|c|c|c|c|}
\hline Fish species/local name & $\begin{array}{c}\text { Increase } \\
\text { (amount of } \\
\text { catch/supply) }\end{array}$ & $\begin{array}{c}\text { Decrease } \\
\text { (amount of } \\
\text { catch/supply } \\
\text { ) }\end{array}$ & $\begin{array}{c}\text { Remain } \\
\text { unchanged }\end{array}$ & $\begin{array}{c}\text { No } \\
\text { consistent } \\
\text { change } \\
\text { have } \\
\text { no } \\
\text { idea }\end{array}$ \\
\hline & $\square$ & $\square$ & $\square$ & $\square$ & $\square$ \\
\hline$\square$ & $\square$ & $\square$ & $\square$ & $\square$ \\
\hline$\square$ & $\square$ & $\square$ & $\square$ \\
\hline$\square$ & $\square$ & $\square$ & $\square$ \\
\hline
\end{tabular}

1.3.1.1. If observed, what do you think about the cause(s) for the unexpected changes for the past few years?
$\square$ Over fishing $\square$ Chemical pollution
$\square$ Destruction of shoreline vegetation of the lake
$\square$ Overexploitation of water by irrigation
$\square$ Destruction of wetland part of the lake
Inappropriate fishing (use of illegal fish net) $\square$ Fishing at near spawning/vegetation zone
$\square$ Catching older fish using younger fish
$\square$ Other, specify:

1.4. If your answer for $Q \# 1$ is NO, what is/are the reason for not fishing?
Because the lake has no fish stock
Because fish stock has declined in recent times
Because the sector is less profitable compared with other sectors

Because I have no experience of eating fish 
Because I have no experience in catching fish

Other, specify:

2. Is there any other food sources you harvest other than wild fish from the lake? $\quad \square$ Yes $\quad \square$ No

2.1. If Yes, please mention them by filling the following table

\begin{tabular}{|l|l|c|}
\hline S/N & Name of the species (plant/animal) & Remark/tick it \\
\hline & & $\square$ \\
\hline & & $\square$ \\
\hline
\end{tabular}

3. For which purposes do you use water from the lake?

Drinking water

Livestock watering
Washing clothes \& bathing

$\square$ Irrigation water
Other domestic uses

$\square$ Industrial use (e.g. for construction)

3.1. What do you think about the quality of the lake's water for the aforementioned (Q\#3) use types.

\begin{tabular}{|l|l|l|l|l|}
\hline Use type & Good & $\begin{array}{l}\text { Recently } \\
\text { becoming } \\
\text { poor }\end{array}$ & $\begin{array}{l}\text { Remark (any observation if } \\
\text { “becoming poor"): any } \\
\text { indicators like color, odor, } \\
\text { fish kill, health problem... }\end{array}$ & $\begin{array}{l}\text { What do you think about } \\
\text { the cause for poor } \\
\text { quality? }\end{array}$ \\
\hline Drinking water & $\square$ & $\square$ & & \\
\hline Irrigation water & $\square$ & $\square$ & & \\
\hline Livestock water & $\square$ & $\square$ & & \\
\hline Washing clothes \& bathing & $\square$ & $\square$ & & \\
\hline Industrial use & $\square$ & $\square$ & & \\
\hline Other domestic uses & $\square$ & $\square$ & & \\
\hline
\end{tabular}

3.2. If you have optional water sources please tick the source type.

\begin{tabular}{|c|c|c|c|c|c|}
\hline \multirow[b]{2}{*}{ Water Uses } & \multicolumn{4}{|c|}{ optional Sources } & \multirow[b]{2}{*}{$\begin{array}{l}\text { Remark (during what time you use } \\
\text { and why you look for optional water } \\
\text { sources) }\end{array}$} \\
\hline & $\begin{array}{l}\text { Pipe water } \\
\text { from other } \\
\text { water source }\end{array}$ & $\begin{array}{l}\text { Pond } \\
\text { water }\end{array}$ & $\begin{array}{l}\text { Spring } \\
\text { water }\end{array}$ & $\begin{array}{l}\text { Deep } \\
\text { well }\end{array}$ & \\
\hline Drinking water & $\square$ & $\square$ & $\square$ & $\square$ & \\
\hline $\begin{array}{l}\text { Washing clothes \& } \\
\text { bathing }\end{array}$ & $\square$ & $\square$ & $\square$ & $\square$ & \\
\hline $\begin{array}{l}\text { Domestic uses like } \\
\text { cooking }\end{array}$ & $\square$ & $\square$ & $\square$ & $\square$ & \\
\hline Livestock watering & $\square$ & $\square$ & $\square$ & $\square$ & \\
\hline Irrigation water & $\square$ & $\square$ & $\square$ & $\square$ & \\
\hline
\end{tabular}

4. Is there any animal species, plant species or other material that you use from the lake as decorative materials?

$\square$ Yes

No 
4.1. If yes, please specify the name of the species and/or materials

\begin{tabular}{|l|l|l|l|}
\hline S/N & $\begin{array}{l}\text { Plant species (bulbs, cut } \\
\text { flowers) }\end{array}$ & Animal species & $\begin{array}{l}\text { Other material (shells, feathers, stone, } \\
\text { etc) }\end{array}$ \\
\hline 1 & $\square$ Ketema & & \\
\hline 2 & & & \\
\hline
\end{tabular}

5. Do you harvest bio-materials from the wetland and riparian part of the lake for different uses?

$$
\square \text { Yes } \square \text { No }
$$

5.1. If yes, please would you specify the materials per their use by filling this table?

\begin{tabular}{|c|c|c|c|c|c|c|c|c|c|}
\hline \multirow{3}{*}{ S/N } & \multirow{2}{*}{$\begin{array}{l}\text { Local name/Species } \\
\text { name (biomaterials) }\end{array}$} & $\begin{array}{l}\text { Livestock } \\
\text { fodder }\end{array}$ & $\begin{array}{l}\text { Roof } \\
\text { thatching }\end{array}$ & Fence & $\begin{array}{l}\text { Boat } \\
\text { making }\end{array}$ & $\begin{array}{l}\text { Chair } \\
\text { makin } \\
\text { gan }\end{array}$ & $\begin{array}{l}\text { Traditiona } \\
\text { I medicine }\end{array}$ & $\begin{array}{l}\text { Biomateri } \\
\text { al for feul }\end{array}$ & $\begin{array}{l}\text { Other, } \\
\text { specif } \\
\text { y }\end{array}$ \\
\hline & & $\square$ & $\square$ & $\square$ & $\square$ & $\square$ & $\square$ & $\square$ & \\
\hline & & $\square$ & $\square$ & $\square$ & $\square$ & $\square$ & $\square$ & $\square$ & \\
\hline
\end{tabular}

6. Do you harvest sand for construction from the lake? $\square$ Yes $\square$ No

7. Do you use the lake for transportation use? $\square$ Yes $\square$ No

\section{B. Cultural services: You can select more than one answer when necessary}

8. How often do you visit the lake when you have spare time?
daily
$\square$ weekly
$\square$ monthly
once per year

8.1. What activity makes you relax or enjoy during your visit?

$\begin{array}{lll}\square \text { Brid watching } & \square \text { Enjoying the landscape } & \square \text { Swimming }\end{array}$

9. Does the lake or species in the lake ecosystem considered by your community as a cultural heritage or sacred by the local society? $\quad$ Yes $\square \quad$ No

9.1. If yes, please describe the historical background

\begin{tabular}{|l|l|}
\hline Name of the Lake/river/species & Background history why it is considered as a cultural heritage/why sacred \\
\hline & \\
\hline & \\
\hline
\end{tabular}

10. Does your community has any cultural gatherings, religious festivals and ceremonies in which you go to lake Ziway to celebrate the occasion? $\square$ Yes $\square$ No

10.1. If yes, please would you provide detail information about the name of the gatherings/festivals, and when

\begin{tabular}{|l|l|l|}
\hline Lake & Name of gatherings/religious festival etc. & How often annually and when? \\
\hline & & \\
\hline & & \\
\hline
\end{tabular}

11. Is there any species in the lake (fish species, bird..) that your community see as symbolic or iconic/charismatic species? $\quad \square$ Yes $\square$ No 
11.1. If any, please would you provide the name of the species and respective historical background to be seen as symbolic or iconic or charismatic species?

\begin{tabular}{|l|l|l|l|}
\hline Name of the species as & $\begin{array}{l}\text { Background } \\
\text { symbolic/iconic }\end{array}$ & $\begin{array}{l}\text { Background } \\
\text { charismatic species }\end{array}$ & \\
\hline & & & \\
\hline & & & \\
\hline
\end{tabular}

12. Any bio/abiotic-material from the lake or the wetland of the lake used as traditional medicine

\begin{tabular}{|l|l|l|c|c|}
\hline S/N & Name of bio/abiotic-material & $\begin{array}{l}\text { Disease to protect/cure/local name of the } \\
\text { disease }\end{array}$ & Human & livestock disease \\
\hline 1 & & & $\square$ & $\square$ \\
\hline 2 & & & $\square$ & $\square$ \\
\hline
\end{tabular}

\section{Regulation and maintenance: You can select more than one answer when it necessary}

13. Do you think that your area (village/cropland) is prone to flooding? $\quad \square$ Yes $\quad \square$ No (remark by enumerator: $\square$ upstream village $\square$ downstream village)

13.1. Do you remember when upstream villages were flooded but not downstream villages of the lake?

$\square$ Yes $\square$ No

13.1.1. If Yes, when

13.1.2. What was damaged in the upstream villages?

$\square$ House $\quad \square$ health/life $\square$ livestock $\square$ crops $\square$ Other, Specify:

PART 3: Questionnaire for smallholder irrigation farmers to assess agrochemicals usage, handling, safety and effect. Only those farmers involved on irrigation farming to produce vegetables were filled this part

A. Characteristics of irrigation farm

\begin{tabular}{|c|c|c|}
\hline Irrigation farm size & Irrigation method & Vegetable use category \\
\hline & $\begin{array}{c}\square \text { Furrow } \\
\square \text { Drip/trickle } \\
\square \text { Sprinkler } \\
\text { Other specify : }\end{array}$ & $\begin{array}{l}\square \text { Subsistance } \\
\square \text { Commercial }\end{array}$ \\
\hline
\end{tabular}

\section{B. Pesticide supply and usage assessment}

1. How do you rank the importance of pesticides input for your vegetables production?

Highly important and use it always

Moderately important and use it sometimes

Not important and I do not use pesticides in vegetable production 
2. Who supply the pesticides to you?
Government
Local retailer/shop
Farmers' cooperatives
Buy from open market
other specify:

3. Specification of pesticides used by smallholder vegetable farmers

\begin{tabular}{|l|l|l|l|l|l|l|l|l|l|}
\hline S/N & $\begin{array}{l}\text { Vege } \\
\text { table }\end{array}$ & $\begin{array}{l}\text { Croppin } \\
\text { g per } \\
\text { year }\end{array}$ & $\begin{array}{l}\text { Pests to } \\
\text { protect (use } \\
\text { category: } \\
\text { Insecticide, } \\
\text { herbicide, } \\
\text { fungicide...) }\end{array}$ & $\begin{array}{l}\text { Pesticide in } \\
\text { use } \\
\text { (brand/local } \\
\text { name and } \\
\text { chemical) }\end{array}$ & $\begin{array}{l}\text { State of } \\
\text { formulation } \\
\text { (Liquid/pow } \\
\text { der/granule } \\
\text { ) }\end{array}$ & $\begin{array}{l}\text { Mode of } \\
\text { applicatio } \\
\mathbf{n} \\
\text { (spraying } \\
\text { /foliar) }\end{array}$ & $\begin{array}{l}\text { Amount } \\
\text { of } \\
\text { applicatio } \\
\text { (kg or } \\
\text { L/hectare) }\end{array}$ & $\begin{array}{l}\text { \# of } \\
\text { applicatio } \\
\text { n/croppin } \\
\text { g } \\
\text { season/cr } \\
\text { op }\end{array}$ & $\begin{array}{l}\text { Application } \\
\text { interval for } \\
\text { multiple } \\
\text { application } \\
\text { (day) }\end{array}$ \\
\hline 1 & & & & & & & & & \\
\hline 2 & & & & & & & & \\
\hline
\end{tabular}

4. From your past experience, what do you think about your future pesticides consumption trend?
Increasing
decreasing
$\square$ remain unchanged

\section{Pesticides handling, health, environmental safety and effect assessment}
5. Do you had any training on pesticide handling and use?
$\square$ Yes
No

5.1. If yes, who organized the training and when?

5.2. What were the themes of the training?

$\square$ How to mix and use $\square$ Spraying techniques $\square$ Environmental and health safety issues

$\square$ Disposal method for obsolete pesticides and pesticide containers

$\square$ Others, specify

\section{Where do you store pesticides?}

$\square$ In the kitchen $\quad \square$ Anywhere in the house $\quad \square$ In a separate and protected place
$\square$ Others, please specify:

7. Do you read the label on the container of pesticides? $\square$ Yes $\square$ No

7.1. If yes, on which information you usually focus/concentrate?
Expire Date
Hazard class
Usage description
Other, specify

7.2. Is there any problem you encountered with labels of pesticides? $\quad \square$ Yes $\quad \square$ No

\subsubsection{If yes, what problem(s) you observed/encountered?}

No label on pesticide container

$\square$ It was written in other foreign language which I do not understand

It lacks information such as:

Other, specify: 
8. From whom you get advice for dosage of pesticides?

$\square$ Local retailer/vendor $\quad \square$ Development Agents $\quad \square$ Own past experience

According to the description on label $\square$ Other farmer experience (neighbor)

Other Specify

9. What protective materials do you use upon spraying?

$\square$ None $\quad \square$ Glove $\quad \square$ Boots $\quad \square$ Eye goggles $\square$ Hat

Separate clothes for spraying only $\quad \square$ Others, specify

10. Do you consider wind direction during pesticide spraying? $\square$ Yes $\quad \square$ No

11. Where do you usually mix pesticides for spraying?

Near water source/canal: specify the name of the water body

In vegetable farm/field $\square$ At home

12. Do you think that pesticides may cause some undesired effect on the water system? $\square$ Yes $\square$ No

12.1. If yes, would you give any effect you think and/or any observation you made so far?

12.2. What measures do you often take not to pollute nearby lake/any water body during pesticides spraying?

None

Spray only on sunny days

Consider the direction of wind (not spray when the wind blows to the direction of water body)

Make buffer between the water body and my vegetable farm

Mix pesticides far from water body

Not dump any pesticides related waste to water body

Other, specify

13. Do you think that the lake is stressed by chemicals sourced from similar irrigation activities in the region?

Yes $\square$ No

13.1. If yes, would you tell us any evidence you observed?

14. What do you do with empty pesticide container?

Throw it outside $\square$ Burn it

Buried underground $\square$ Use it as house equipment $\square$ Sell it 


\section{Section 3B: Survey questionniare for tourists}

Dear participants,

This survey study is part of my PhD research in Wageningen University, The Netherlands. The aim of the study is to assess ecosystem goods and services provided by the lake. You have been selected for the survey, because you are considered as the main beneficiaries of ecosystem services supplied by this lake. You therefore are resourceful for the survey. I highly appreciate your help by filling the questionnaire. Your genuine responses will have a direct impact on quality of the study. The survey is only used for research purposes and it will be kept confidential. The survey takes about 10 minutes to fill in. Thank you most sincerely for your collaboration and patience in advance to fill the questionnaire.

If you have any questions contact at: lemessa.merga@wur.nl

Phone number: $+251-931556873$

Regards,

Lemessa B. Merga

PART 1. General information

\begin{tabular}{|l|l|l|l|}
\hline $\begin{array}{l}\text { Name of visitor/tourist } \\
\text { (optional) }\end{array}$ & $-\begin{array}{l}\text { Country of origin (for } \\
\text { foreigner) }\end{array}$ & - \\
\hline Age & $-\begin{array}{l}\text { Number of days you } \\
\text { stay visiting the lake }\end{array}$ & - \\
\hline Gender & $\square \mathrm{M} \square \mathrm{F}$ & & \\
\hline \multirow{2}{*}{$\begin{array}{l}\square \text { Foreigner (non-Ethiopian citizen) } \\
\square \text { Ethiopian citizen } \\
\square \text { Local visitor (Ethiopian, but from local community) }\end{array}$} & \\
\hline
\end{tabular}

\section{PART 2. Ecosystem service survey questions}

Direction: Please provide your answer by ticking the boxes for each question. More than one answer is possible when needed.

1. Do you indicate the purpose of your visit?
$\square$ Recreational/touring
$\square$ Research
Meeting
$\square$ Other, specify:

2. How did you hear about the lake? (only for tourists)
$\square$ Tour guide
$\square$ Online Media like TV, internet ..
$\square$ Brochure
$\square$ Tourism office
$\square$ Friend

If others, specify:

3. What inspires you more about the lake?

$\square$ Its attractive landscape

$\square$ Its diversified aquatic species such as unique water birds and Hippos

$\square$ Its historic islands including churches and monastery on the island Tulu Gudo

$\square$ Its sensational water tide

$\square$ Its cultural heritage

$\square$ Its Wilderness

If others, specify: 
4. How do you enjoy during your stay visiting lake Ziway?

$\square$ Swimming

$\square$ Boating

$\square$ Watching waterfowls/bird watching

$\square$ Watching aquatic mammals like Hippos

$\square$ Angling (fish angling)

$\square$ Silent walk in the shoreline of the lake

If others, specify:

5. Is it your first time to visit/tour the lake? $\square$ Yes $\quad \square$ No

5.1. If No, how many times you visited the lake in the past?

5.2. If Yes, do you think you will come again to tour/visit the lake? $\square$ Yes $\quad \square$ No

6. Indicate the most memorable/unforgettable feature(s) of the lake

$\square$ The scenery of the landscape of the lake

$\square$ The aquatic bird species of the lake

$\square$ The sandy beach of the lake

$\square$ The water tide is unforgotten

$\square$ If others, please specify:

7. How do you rank the recreational value of the lake?

$\square$ High $\square$ Moderate $\square$ Low

Questions from \#8 to \#11 are only answered by visitors coming for research purpose and are researchers

8. From which research institute or university you are?

9. What is the title of your project?

10. When did you start the project?

11. Why you interested to this particular lake? 
Section 3C: Lists of interview questions for stakeholders including A) Batu Drinking Water Supply and Sewerage Service Enterprise, B) Batu Culture and Tourism Office (ВСТO) and Adami Tulu Jido Kombolcha Culture and Tourism Office (ATJK-TCO), C) fishery cooperatives and D) Large-scale floriculture and viticulture farms.

A. Interview Questions for Batu Drinking Water Supply and Sewerage Service Enterprise (BDWSSSE)

I. General information about the respondent

\begin{tabular}{|l|l|}
\hline Name of your organization & \\
\hline Name of the Respondent & \\
\hline Position/Responsibility & \\
\hline Gender & $\square$ Male $\square$ Female \\
\hline
\end{tabular}

\section{List of Interview Questions}

1. Background of the water supply enterprise? Year of establishment?

2. Why Lake Ziway is important source of drinking water supply for Batu town?

3. What is the annual water volume supplied from the lake for drinking use?

4. What about its current supply coverage (\%) for the town water need? If any plan to increase the supply from the lake?

5. Does the town has optional drinking water supply?

6. What concern the enterprise has on water quality and quantity of lake Ziway?

7. What look likes your production cost, for example, per liter for the last 5 years? Is there any increasing or decreasing in production cost due to changes in water quality of the lake? May be due to pollution?

8. What interest the enterprise has and in what way your organization contribute for the management and sustainable use of the lake?

B. Interview questions for Batu Culture and Tourism Office (ВСТO) and Adami Tulu Jido Kombolcha Culture and Tourism Office (ATJK-TCO)

I. Introduce myself and my project including highlights of its objective

II. General information about the respondent

\begin{tabular}{|l|l|}
\hline Name of your organization & \\
\hline Zone/District & \\
\hline Name of the Respondent & \\
\hline Position/Responsibility & \\
\hline Academic rank and field of expert & $\square$ Male $\square$ Female \\
\hline Gender & $\square$ \\
\hline
\end{tabular}

\section{B. List of interview questions}

1. Background of the offices, role and responsibilities?

2. What are the potential and currently existing recreational and eco-tourism activities of Lake Ziway?

3. What are unique features of the lake that attract tourists/visitors? 
4. What cultural values the lake have? Any historical sites?

5. What are the popular recreational activities in the lake?

6. If you have data showing number of visitors/tourists visited the lake for the last five years?

7. What contributions the lake have in eco-tourism sector? Any income data on generated from the sector?

8. How many individuals from local community involve in the eco-tourism sector for example as tour guide/boat services providers for tourists? If any related statistical data?

9. What environmental bottlenecks observed for recreation and eco-tourism services of the lake?

10. How your office see the impact of the current agricultural expansion near the shoreline of the lake on recreational and tourism activities of the lake? Do you think this development affect the services?

11. What are the interest and contribution of your office in protection of the lake and sustainable use of the resource?

\section{Interview questions for fishery cooperatives}

I. General information

\begin{tabular}{|l|l|}
\hline Name of the Respondent & \\
\hline Position/Responsibility & \\
\hline Age & \\
\hline Gender & $\square$ Male $\square$ Female \\
\hline
\end{tabular}

\section{List of Interview Questions}

1. Background of the cooperatives? Name of the cooperative, total members, year of establishment, landing site(s)?

2. What are the most commercially important fish species of the lake?

3. What market outlet the cooperative uses to supply the fish meet?

4. How do you explain the livelihood dependency of the members of the cooperatives on this sector?

5. Have you observed and environmental bottlenecks to fishery? In the past few years have you noticed any unexpected change deviated from normal trend in amount of fish catches? Any change in fish composition? Would you explain per species?

6. What do you think about the causes for the observed change in fish yield meet and species composition? Would you mention it?

7. What are the interest and contribution of your cooperative in protecting the lake and sustainable use of the resource?

D. Interview questions for Horticulture companies (floriculture and viticulture)

\section{General information about the respondent}

\begin{tabular}{|l|c|}
\hline Name of the Respondent & \\
\hline Name of the farm & $\square$ State owned $\square$ Local Private (Ethiopian) \\
\hline Farm ownership & \begin{tabular}{l}
$\square$ Private (non-Ethiopian) $\square$ Joint venture (Gov.-private/Gov.) \\
\hline Lake (source of irrigation water)
\end{tabular} \\
\hline Farm size & $\square$ Open \\
\hline Farm type & $\square$ closed/green house \\
\hline
\end{tabular}


Chapter 3

\begin{tabular}{|l|l|}
\hline Position/Responsibility & \\
\hline Sex & $\square$ Male $\square$ Female \\
\hline Year of establishment & \\
\hline
\end{tabular}

\section{List of interview questions}

1. Background of the company? When established?, What types of flower/fruits your company produces?, Number of employees?

2. What is the annul water consumption of your farm in $\mathrm{m}^{3} /$ Year?

3. Do you treat wastewater that discharged from your farm before released to Lake Ziway? What technology(ies) you have implemented? Do you monitor the efficiency of the applied wastewater treatment technology?

4. Do you tell me the practice of your company to properly dispose solid wastes including wastes from flowers, empty pesticide bottles, and expired agrochemicals?

5. Do you provide environmental and human safety trainings for your employees? How often? How do you monitor the safety practices of your employees in your greenhouses?

6. The lake (Ziway) provides multiple services for different stakeholders. Thus, sometimes there might be interest conflicts between these stakeholders. How do you treat if any conflict arise? Do you have discussion platform with other stakeholders particularly with local communities?

7. Is your company permits me for sampling you wastewater for chemical monitoring?

8. Do you undergo legal registration in importing your agrochemicals? Would you provide me your legal procedure, if possible? Do you provide me your chemical lists you are currently in use?

9. Your Pesticides application pattern? Kg or L/hectare or? \# of application/spraying per cropping season?

10. Do you permit me to visit your farm and take photographs? 
Table SI3.1. District, name of villages, population and sample size considered for the household survey.

\begin{tabular}{|c|c|c|c|c|c|}
\hline \multirow[b]{2}{*}{ District } & \multirow[b]{2}{*}{ Villages } & \multirow[b]{2}{*}{ Male } & \multirow[b]{2}{*}{ Female } & \multirow[b]{2}{*}{ Total } & \multirow[b]{2}{*}{$\begin{array}{l}\text { Where, } \mathrm{e}=7 \% \text { precision leve } \\
\text { and } 95 \% \mathrm{CL} \text { and } \mathrm{P}=0.5\end{array}$} \\
\hline & & & & & \\
\hline & Abine Garmama & 512 & 195 & 707 & 16 \\
\hline Adami Tulu Jido & Dodicha & 333 & 128 & 461 & 10 \\
\hline \multirow[t]{4}{*}{ Kombolcha } & Bochessa & 869 & 395 & 1264 & 29 \\
\hline & Edo-Kontola & 640 & 224 & 864 & 19 \\
\hline & Tepho-Choroke & 420 & 86 & 506 & 12 \\
\hline & Tuchi Dambel & 253 & 64 & 317 & 8 \\
\hline \multirow[t]{3}{*}{ Dugda } & Wayo Gabriel & 463 & 81 & 544 & 12 \\
\hline & Dodota Dambel & 356 & 87 & 443 & 10 \\
\hline & Sanbaro & 1749 & 267 & 2016 & 45 \\
\hline \multirow[t]{3}{*}{ Ziway Dugda } & Herara & 612 & 87 & 699 & 16 \\
\hline & Bashira Chafa & 947 & 145 & 1092 & 25 \\
\hline & & \multicolumn{2}{|c|}{ Total household } & 8913 & Sample size $(n)=202$ \\
\hline
\end{tabular}

Note: A/T/J/K - Adami Tulu Jido Kombolcha 
Table SI3.2. Household survey results for identification of ecosystem goods and services of Lake Ziway.

\begin{tabular}{|c|c|c|c|c|c|c|c|c|}
\hline \multirow{2}{*}{$\begin{array}{l}\text { General background of the respondent farmers } \\
\text { Age in year (average ( } \pm \text { Standard deviation)) }\end{array}$} & \multirow{2}{*}{$\frac{\text { ATJK district }}{39.8 \pm 10.4}$} & \multicolumn{2}{|l|}{ Dugda district } & \multicolumn{2}{|c|}{ Ziway-Dugda district } & \multicolumn{3}{|l|}{ Total } \\
\hline & & \multicolumn{2}{|l|}{$41.9 \pm 6.9$} & \multicolumn{2}{|l|}{$40.5 \pm$} & \multicolumn{3}{|l|}{$40.5 \pm$} \\
\hline & & & & \multicolumn{2}{|l|}{11.9} & \multicolumn{3}{|l|}{10.4} \\
\hline Household family size & $6.2 \pm 2.6$ & $7.9 \pm 2.4$ & & $6.9 \pm 3.7$ & & $6.9 \pm 3.6$ & & \\
\hline \multicolumn{9}{|l|}{ Gender of the respondent farmers } \\
\hline Male & 68 (91.9) & \multicolumn{2}{|l|}{$41(97.6)$} & \multicolumn{2}{|l|}{$85(98.8)$} & \multicolumn{3}{|l|}{$194(96.0)$} \\
\hline Female & $6(8.1)$ & \multicolumn{2}{|l|}{$1(2.4)$} & \multicolumn{2}{|l|}{$1(1.2)$} & \multicolumn{3}{|l|}{$8(4)$} \\
\hline \multicolumn{9}{|l|}{ Educational level } \\
\hline Not read and write (not attend any formal school) & $11(14.9)$ & \multicolumn{2}{|l|}{$4(9.5)$} & \multicolumn{2}{|l|}{$15(17.4)$} & \multicolumn{3}{|l|}{$30(14.9)$} \\
\hline Grade 1 to 8 & $51(68.9)$ & \multicolumn{2}{|l|}{$34(81)$} & \multicolumn{2}{|l|}{$54(62.8)$} & \multicolumn{3}{|l|}{$139(68.8)$} \\
\hline High school (Grade 9 - 12) & $12(16.2)$ & \multicolumn{2}{|l|}{$4(9.5)$} & \multicolumn{2}{|l|}{$16(18.6)$} & \multicolumn{3}{|l|}{$32(15.8)$} \\
\hline Collage/University (Above Grade 12) & $0(0)$ & \multicolumn{2}{|l|}{$0(0)$} & \multicolumn{2}{|l|}{$1(1.2)$} & \multicolumn{3}{|l|}{$1(0.5)$} \\
\hline \multicolumn{9}{|l|}{ Marital status of the sample farmers } \\
\hline Married & 68 (91.9) & $41(97.6)$ & & $85(98.8)$ & & $194(96)$ & & \\
\hline Single & $1(1,4)$ & $1(2.4)$ & & $1(1.2)$ & & $3(1.5)$ & & \\
\hline Divorce & $2(2,7)$ & $0(0)$ & & $0(0)$ & & $2(1)$ & & \\
\hline Widow & $3(4.1)$ & $0(0)$ & & $0(0)$ & & $3(1.5)$ & & \\
\hline & ATJK & istrict & Dugda & istrict & Ziway-Dı & gda district & & \\
\hline Ecosystem services related questions/items & Yes = N (\%) & No $=N(\%)$ & Yes $=\mathbf{N}(\%)$ & No = N (\%) & $\begin{array}{l}\text { Yes = N } \\
(\%)\end{array}$ & No $=\mathbf{N}(\%)$ & Yes = N (\%) & No $=\mathbf{N}(\%)$ \\
\hline Fish food harvest & $27(36.5)$ & $47(63.5)$ & $21(50)$ & $21(50)$ & $58(67.4)$ & $28(32.6)$ & $106(52.5)$ & $96(47.5)$ \\
\hline Use the fish: Sources of income and subsistence food & $20(74.1)$ & $7(25.9)$ & $21(100)$ & $0(0)$ & $47(81)$ & $11(19)$ & $88(83)$ & $18(17)$ \\
\hline Trends in annual yield for Koroso (Oreochromis niloticus & & & & & & & & \\
\hline Decreasing trend & $27(100)$ & $0(0)$ & $21(100)$ & $0(0)$ & $58(100)$ & $0(0)$ & $106(100)$ & $0(0)$ \\
\hline Trends in annual yield for Dubbee (Carassius carassius) & & & & & & & & \\
\hline Increasing trend & $2(7.4)$ & $25(92.6)$ & $21(100)$ & $0(0)$ & $36(62.1)$ & $22(37.9)$ & $59(55.6)$ & $47(44.4)$ \\
\hline Decreasing trend & $25(92.6)$ & $2(7.4)$ & $0(0)$ & $0(0)$ & $20(34.5)$ & $38(65.5)$ & $45(42.5)$ & $61(57.4)$ \\
\hline Remain unchanged & $0(0)$ & $0(0)$ & $0(0)$ & $0(0)$ & $2(3.4)$ & $65(96.6)$ & $2(1.9)$ & $104(98.1)$ \\
\hline
\end{tabular}




\begin{tabular}{|c|c|c|c|c|c|c|c|c|}
\hline \multirow[b]{2}{*}{ Ecosystem services related questions/items } & \multicolumn{2}{|c|}{ ATJK district } & \multicolumn{2}{|c|}{ Dugda district } & \multicolumn{2}{|c|}{ Ziway-Dugda district } & \multicolumn{2}{|c|}{ Total } \\
\hline & $\begin{array}{l}\text { Yes = N } \\
(\%)\end{array}$ & No $=\mathbf{N}(\%)$ & $\begin{array}{l}\text { Yes = N } \\
(\%)\end{array}$ & $\begin{array}{l}\text { No = N } \\
(\%)\end{array}$ & $\begin{array}{l}\text { Yes = N } \\
(\%)\end{array}$ & $\begin{array}{l}\text { No = N } \\
(\%)\end{array}$ & $\begin{array}{l}\text { Yes = N } \\
(\%)\end{array}$ & No $=\mathbf{N}(\%)$ \\
\hline \multicolumn{9}{|c|}{ Trends in annual yield for Ambaazzaa (Clarias gariepinus) } \\
\hline Increasing trend & $10(37)$ & $17(63)$ & $12(57.1)$ & 9 (42.9) & $13(22.4)$ & $45(77.6)$ & $35(33)$ & $71(67)$ \\
\hline Decreasing trend & $17(63)$ & $10(37)$ & $9(42.9)$ & $12(57.1)$ & $35(60.3)$ & $23(39.7)$ & $61(57.5)$ & $45(42.5)$ \\
\hline Remain unchanged & $0(0)$ & $0(0)$ & $0(0)$ & $0(0)$ & $8(13.8)$ & $50(86.2)$ & $8(7.5)$ & $98(92.5)$ \\
\hline I have no idea & $0(0)$ & $0(0)$ & $0(0)$ & $0(0)$ & $2(3.4)$ & $56(96.6)$ & $2(1.9)$ & $104(98.1)$ \\
\hline \multicolumn{9}{|l|}{ Trends in annual yield for Jappee (Cyprinus carpio) } \\
\hline Increasing trend & $24(88.9)$ & $3(11.1)$ & $18(85.7)$ & $3(14.3)$ & $40(69)$ & $18(31)$ & $82(77.4)$ & $24(22.6)$ \\
\hline Decreasing trend & $1(3.7)$ & $26(96.3)$ & $3(14.3)$ & $18(85.7)$ & $8(13.8)$ & $50(86.2)$ & $12(11.3)$ & $94(88.7)$ \\
\hline Remain unchanged & $2(7.4)$ & $25(92.6)$ & $0(0)$ & $0(0)$ & $6(10.3)$ & $52(89.7)$ & $8(7.5)$ & $98(92.5)$ \\
\hline I have no idea & $0(0)$ & $0(0)$ & $0(0)$ & $0(0)$ & $3(5.2)$ & $55(94.8)$ & $3(2.8)$ & $103(97.2)$ \\
\hline No consistent change/trend & $0(0)$ & $0(0)$ & $0(0)$ & $0(0)$ & $1(1.7)$ & $57(98.3)$ & $1(0.9)$ & $105(99.1)$ \\
\hline \multicolumn{9}{|l|}{ Trends in annual yield for Koroso (Tillapia Zilli) } \\
\hline Decreasing trend & $27(100)$ & $0(0)$ & $19(90.4)$ & $2(9.6)$ & $35(60.3)$ & $23(39.7)$ & $81(76.4)$ & $25(23.6)$ \\
\hline I have no idea & $0(0)$ & $0(0)$ & $1(4.8)$ & $20(95.2)$ & $15(25.9)$ & $43(74.1)$ & $16(14.2)$ & $90(84.9)$ \\
\hline No consistent change/trend & $0(0)$ & $0(0)$ & $1(4.8)$ & $20(95.2)$ & $8(13.8)$ & $50(86.2)$ & $9(8.5)$ & $97(91.5)$ \\
\hline \multicolumn{9}{|c|}{ Trends in annual yield for Bilcaa/Minici (Barbus ethiopicus) } \\
\hline Decreasing trend & $26(96.3)$ & $1(3.7)$ & $21(100)$ & $0(0)$ & $42(72.4)$ & $16(27.6)$ & $89(84)$ & $17(16)$ \\
\hline Remain unchanged & $0(0)$ & $0(0)$ & $0(0)$ & $0(0)$ & $1(1.7)$ & $57(98.3)$ & $1(0.9)$ & $105(99.1)$ \\
\hline I have no idea & $1(3.7)$ & $26(96.3)$ & $0(0)$ & $0(0)$ & $7(12.1)$ & $51(87.9)$ & $8(7.5)$ & $98(92.5)$ \\
\hline No consistent change/trend & $0(0)$ & $0(0)$ & $0(0)$ & $0(0)$ & $8(13.8)$ & $50(86.2)$ & $8(7.5)$ & $98(92.5)$ \\
\hline Harvest water plants for food & $65(87.8)$ & $9(12.2)$ & $41(97.6)$ & $1(2.4)$ & $70(81.4)$ & $16(18.6)$ & $176(87.1)$ & $26(12.9)$ \\
\hline Typha latifolia (Fiilaa) & $65(100)$ & $0(0)$ & $41(100)$ & $0(0)$ & $70(100)$ & $0(0)$ & $176(100)$ & $0(0)$ \\
\hline Arundo donax (Kesem) & 50 (76.9) & $15(23.1)$ & $33(80.5)$ & $8(19.5)$ & $52(74.3)$ & $18(25.7)$ & $135(76.7)$ & $41(23.3)$ \\
\hline Nymphaea lotus (Mochee) & $32(49.2)$ & $33(50.8)$ & $36(87.8)$ & $5(12.2)$ & $44(62.9)$ & $26(37.1)$ & $112(63.6)$ & $64(36.4)$ \\
\hline
\end{tabular}




\begin{tabular}{|c|c|c|c|c|c|c|c|c|}
\hline \multirow[b]{2}{*}{ Ecosystem services related questions/items } & \multicolumn{2}{|c|}{ ATJK district } & \multicolumn{2}{|c|}{ Dugda district } & \multicolumn{2}{|c|}{ Ziway-Dugda district } & \multicolumn{2}{|c|}{ Total } \\
\hline & $\begin{array}{l}\text { Yes = N } \\
(\%)\end{array}$ & $\begin{array}{l}\text { No }=\mathrm{N} \\
(\%)\end{array}$ & $\begin{array}{l}\text { Yes = N } \\
(\%)\end{array}$ & $\begin{array}{l}\text { No }=\mathbf{N} \\
(\%)\end{array}$ & $\begin{array}{l}\text { Yes = N } \\
(\%)\end{array}$ & $\begin{array}{l}\text { No }=\mathrm{N} \\
(\%)\end{array}$ & $\begin{array}{l}\text { Yes = N } \\
(\%)\end{array}$ & No $=\mathbf{N}(\%)$ \\
\hline Drinking water & $21(28.4)$ & $53(71.6)$ & $40(95.2)$ & $2(4.8)$ & $31(36)$ & $55(64)$ & $92(45.5)$ & $110(54.5)$ \\
\hline \multicolumn{9}{|l|}{ Other sources of drinking water } \\
\hline Pipe water & $1(1.4)$ & $73(98.6)$ & $0(0)$ & $42(100)$ & $0(0)$ & $86(100)$ & $1(0.5)$ & $201(99.5)$ \\
\hline Pond & $0(0)$ & $74(100)$ & $0(0)$ & $42(100)$ & $3(3.5)$ & $83(96.5)$ & $3(1.5)$ & $199(98.5)$ \\
\hline Spring & $0(0)$ & $74(100)$ & $0(0)$ & $42(100)$ & $17(19.8)$ & $69(80.2)$ & $17(8.4)$ & $184(91.6)$ \\
\hline Borehole & $67(90.5)$ & $7(9.5)$ & $13(31)$ & $29(69)$ & $57(66.3)$ & $29(33.7)$ & $137(67.8)$ & $65(32.2)$ \\
\hline Cloth washing and bathing (Sanitation use) & $43(58.1)$ & $31(41.9)$ & $42(100)$ & $0(0)$ & $62(72.1)$ & $24(27.9)$ & $147(72.8)$ & $55(27.2)$ \\
\hline Other domestic use like for cooking use & $26(35.1)$ & $48(64.9)$ & $42(100)$ & $0(0)$ & $47(54.7)$ & $39(45.3)$ & $115(56.9)$ & $87(43.1)$ \\
\hline Do you think good water quality for domestic and sanitation uses? & $7(9.5)$ & $67(90.5)$ & $11(26.2)$ & $31(73.8)$ & $24(27.9)$ & $62(72.1)$ & $42(20.8)$ & $160(79.2)$ \\
\hline \multicolumn{9}{|l|}{ Other sources of water for domestic and sanitation uses } \\
\hline Pond & $0(0)$ & $74(100)$ & $0(0)$ & $42(100)$ & $3(3.5)$ & $83(96.5)$ & $3(1.5)$ & $199(98.5)$ \\
\hline Spring & $0(0)$ & $74(100)$ & $0(0)$ & $42(100)$ & $17(19.8)$ & $69(80.2)$ & $17(8.4)$ & $184(91.6)$ \\
\hline Borehole & $67(90.5)$ & $7(9.5)$ & $13(31)$ & $29(69)$ & $57(66.3)$ & $29(33.7)$ & $137(67.8)$ & $65(32.2)$ \\
\hline Livestock watering & $70(94.6)$ & $4(5.4)$ & $40(95.2)$ & $2(4.8)$ & $85(98.8)$ & $1(1.2)$ & $195(96.5)$ & $7(3.5)$ \\
\hline Do you think good water quality for livestock watering? & $73(98.6)$ & $1(1.4)$ & $40(95.2)$ & $2(4.8)$ & $70(81.4)$ & $16(18.6)$ & $183(90.6)$ & $19(9.4)$ \\
\hline \multicolumn{9}{|l|}{ What other sources of water do you have for livestock watering? } \\
\hline Pond & $0(0)$ & $70(100)$ & $0(0)$ & $40(100)$ & $3(3.5)$ & $82(96.5)$ & $3(1.5)$ & $192(98.5)$ \\
\hline Spring & $0(0)$ & $70(100)$ & $0(0)$ & $40(100)$ & $16(18.8)$ & $69(81.2)$ & $16(8.2)$ & $179(91.2)$ \\
\hline Borehole & $0(0)$ & $70(100)$ & $0(0)$ & $40(100)$ & $7(8.2)$ & $78(91.8)$ & $7(3.6)$ & $188(96.4)$ \\
\hline Irrigation water & $61(82.4)$ & $13(17.6)$ & $36(85.7)$ & $6(14.3)$ & $56(65.1)$ & 30 (34.9) & $153(75.7)$ & $49(24.3)$ \\
\hline Do you think good water quality for irrigation? & $74(100)$ & $0(0)$ & $41(97.6)$ & $1(2.4)$ & $76(88.4)$ & $10(11.6)$ & $191(94.6)$ & $11(5.4)$ \\
\hline Do you have other sources of water for irrigation? & $0(0)$ & $61(100)$ & $0(0)$ & $36(100)$ & $0(0)$ & $56(100)$ & $0(0)$ & $153(100)$ \\
\hline Decorative plant material (Cyprus articulatus) & $74(100)$ & $0(0)$ & $42(100)$ & $0(0)$ & $82(95.3)$ & $4(4.7)$ & $198(98)$ & $4(2)$ \\
\hline $\begin{array}{l}\text { Biomaterial for livestock fodder (T. latifolia, A. donax, C. articulatus } \\
\text { and Cyprus papyrus) }\end{array}$ & $74(100)$ & $0(0)$ & $42(100)$ & $0(0)$ & $86(100)$ & $0(0)$ & $202(100)$ & $0(0)$ \\
\hline Biomaterial for roof thatching (T. latifolia and C. papyrus) & $50(67.6)$ & $24(32.4)$ & $37(88.1)$ & 5 (11.9) & $59(68.6)$ & $27(31.4)$ & $146(72.3)$ & $56(27.7)$ \\
\hline Biomaterial for fence construction (T. latifoli) & $15(20.3)$ & $59(79.7)$ & $0(0)$ & $42(100)$ & $1(1.2)$ & $85(98.8)$ & $16(7.9)$ & $186(92.1)$ \\
\hline
\end{tabular}




\begin{tabular}{|c|c|c|c|c|c|c|c|c|}
\hline \multirow[b]{2}{*}{ Ecosystem services related questions/items } & \multicolumn{2}{|c|}{ ATJK district } & \multicolumn{2}{|c|}{ Dugda district } & \multicolumn{2}{|c|}{ Ziway-Dugda district } & \multicolumn{2}{|c|}{ Total } \\
\hline & $\begin{array}{l}\text { Yes }=\mathbf{N} \\
(\%)\end{array}$ & $\begin{array}{l}\text { No }=N \\
(\%)\end{array}$ & $\begin{array}{l}\text { Yes }=\mathbf{N} \\
(\%)\end{array}$ & $\begin{array}{l}\text { No }=\mathbf{N} \\
(\%)\end{array}$ & $\begin{array}{l}\text { Yes = N } \\
(\%)\end{array}$ & $\begin{array}{l}\text { No }=\mathbf{N} \\
(\%)\end{array}$ & Yes = N (\%) & No $=\mathbf{N}(\%)$ \\
\hline Biomaterial for boat thatching (C. papyrus) & $16(21.6)$ & $58(78.4)$ & $10(23.8)$ & $32(76.2)$ & $14(16.3)$ & $72(83.7)$ & $40(19.8)$ & $162(80.2)$ \\
\hline $\begin{array}{l}\text { Biomaterial for contrcution of fence, chair, boat and roof, } \\
\text { and fuelwood (Aeschynomene elaphroxylon) }\end{array}$ & $8(10.8)$ & $66(89.2)$ & $15(35.7)$ & $27(64.3)$ & $36(41.9)$ & $50(58.1)$ & $59(29.2)$ & $143(70.8)$ \\
\hline Transportation and flood attenuation & $38(51.4)$ & $36(48.6)$ & $30(71.4)$ & $12(28.6)$ & $75(87.2)$ & $11(12.8)$ & $143(70.8)$ & $59(29.2)$ \\
\hline $\begin{array}{l}\text { Any incident when upstream villages were flooded but not } \\
\text { downstream villages of the lakes? }\end{array}$ & $47(63.5)$ & $27(36.5)$ & $36(85.7)$ & $6(14.3)$ & $64(74.4)$ & $22(25.6)$ & $147(73.1)$ & $55(26.9)$ \\
\hline Do you visit the lake weekly when you have spare time? & $46(62.2)$ & $28(37.8)$ & $24(57.1)$ & $18(42.9)$ & $41(47.7)$ & $45(52.3)$ & $111(55)$ & $91(45)$ \\
\hline Activities of farmers when visit Lake Ziway & & & & & & & & \\
\hline Bird watching & $34(47.9)$ & $37(52.1)$ & $3(8.3)$ & $33(91.7)$ & $17(20.2)$ & $67(79.8)$ & $54(28.3)$ & $137(71.7)$ \\
\hline Enjoy Landscape & $45(63.4)$ & $26(36.6)$ & $10(28.6)$ & $25(71.4)$ & $40(47.6)$ & $44(52.4)$ & $95(50)$ & $95(50)$ \\
\hline Swimming & $42(59.2)$ & $29(40.8)$ & $30(85.7)$ & $5(14.3)$ & $62(73.8)$ & $22(26.2)$ & $134(70.5)$ & $56(29.5)$ \\
\hline Boating & 39 (54.9) & $32(45.1)$ & $18(51.4)$ & $17(48.6)$ & $48(57.1)$ & $36(42.9)$ & $105(55.3)$ & $85(44.7)$ \\
\hline Riverine walk & $32(45.1)$ & 39 (54.9) & $1(2.9)$ & $34(97.1)$ & $21(25)$ & $63(75)$ & $54(28.4)$ & $136(71.6)$ \\
\hline Enjoying the water tide & $0(0)$ & $71(100)$ & $1(2.9)$ & 34 (97.1) & $4(4.8)$ & $80(95.2)$ & $5(2.6)$ & $185(97.4)$ \\
\hline Enjoy fresh air & $0(0)$ & $71(100)$ & $0(0)$ & $35(100)$ & $4(4.8)$ & $80(95.2)$ & $4(2.1)$ & $186(97.9)$ \\
\hline
\end{tabular}


Table SI3.3. Tourist survey results for identification of ecosystem goods and services of Lake Ziway.

\begin{tabular}{|c|c|c|}
\hline General information of the respondent tourists $(n=51)$ & Result & \\
\hline Age (Year): Average (minimum - Maximum) & $40.5(18-75)$ & \\
\hline \multicolumn{3}{|l|}{ Gender (n (\%)) } \\
\hline Male & $32(62.7)$ & \\
\hline Female & $19(37.3)$ & \\
\hline \multicolumn{3}{|l|}{ Country of origin ( $\mathrm{n}(\%))$} \\
\hline France & $14(27.5)$ & \\
\hline Ethiopia & $12(23.5)$ & \\
\hline Italy & $10(19.6)$ & \\
\hline The Netherlands & $6(11.8)$ & \\
\hline Eritrea & $5(9.8)$ & \\
\hline United Kingdom (UK) & $2(3.9)$ & \\
\hline United State of America (USA) & $1(2)$ & \\
\hline Canada & $1(2)$ & \\
\hline Recreation and community activities related items (questions) & Yes $=\mathbf{N}(\%)$ & No $=\mathbf{N}(\%)$ \\
\hline Do you inspired by the attractive landscape of the lake? & $27(52.9)$ & $24(47.1)$ \\
\hline Do you enjoy with watching hippos during your stay visiting the lake? & $17(33.3)$ & $34(66.7)$ \\
\hline Do you inspired by wilderness of the lake? & $6(11.8)$ & $45(88.2)$ \\
\hline Do you enjoy with boating during your stay visiting the lake? & 28 (54.9) & $23(45.1)$ \\
\hline Do you enjoy with watching waterfowls during your stay visiting the lake? & $25(49)$ & $26(51)$ \\
\hline Do you enjoy with silent walking along the shoreline of the lake? & $6(11.8)$ & $45(88.2)$ \\
\hline Do you think that the scenery of the landscape of the lake is memorable? & $21(41.2)$ & $30(58.8)$ \\
\hline Do you think that the aquatic bird species of the lake is memorable? & $39(76.5)$ & $12(23.5)$ \\
\hline
\end{tabular}


Table SI3.4. Survey results of pesticide use of smallholder vegetable and fruit farmers in Adami Tulu Jido Kombolcha (ATJK), Dugda and Ziway-Dugda districts.

\begin{tabular}{|c|c|c|c|c|c|c|c|c|}
\hline \multirow[b]{2}{*}{ Items/questions related to pesticide use of smallholder farmers } & \multicolumn{2}{|c|}{ ATJK district } & \multicolumn{2}{|c|}{ Dugda district } & \multicolumn{2}{|c|}{ Ziway-Dugda district } & \multicolumn{2}{|c|}{ Total } \\
\hline & $\begin{array}{l}\text { Yes = N } \\
(\%)\end{array}$ & $\begin{array}{l}\text { No }=\mathbf{N} \\
(\%)\end{array}$ & $\begin{array}{l}\text { Yes = N } \\
(\%)\end{array}$ & $\begin{array}{l}\text { No }=\mathbf{N} \\
(\%)\end{array}$ & $\begin{array}{l}\text { Yes = N } \\
(\%)\end{array}$ & $\begin{array}{l}\text { No }=\mathbf{N} \\
(\%)\end{array}$ & Yes $=\mathbf{N}(\%)$ & No $=\mathbf{N}(\%)$ \\
\hline \multicolumn{9}{|l|}{ Irrigation farm size (hectare) } \\
\hline Above 1 hectare & $16(26.2)$ & $45(73.8)$ & $4(11.1)$ & 32 (88.9) & $11(20.3)$ & $45(79.7)$ & $31(19.7)$ & $122(80.3)$ \\
\hline Less than 1 hectare & $45(73.8)$ & $16(26.2)$ & $32(88.9)$ & $4(11.1)$ & $45(79.7)$ & $11(20.3)$ & $122(80.3)$ & $31(19.7)$ \\
\hline \multicolumn{9}{|l|}{ Irrigation methods } \\
\hline Furrow & $61(100)$ & $0(0)$ & $36(100)$ & $0(0)$ & $36(100)$ & $0(0)$ & $153(100)$ & $0(0)$ \\
\hline $\begin{array}{l}\text { Is use of pesticide compulsory for vegetables and fruits } \\
\text { production? }\end{array}$ & $61(100)$ & $0(0)$ & $28(77.8)$ & $8(22.2)$ & $52(92.9)$ & $4(7.1)$ & $141(92.2)$ & $12(7.8)$ \\
\hline Do you think pesticide consumption will increase in the future? & $61(100)$ & $0(0)$ & $36(100)$ & $0(0)$ & $56(100)$ & $0(0)$ & $153(100)$ & $0(0)$ \\
\hline \multicolumn{9}{|l|}{ Pesticides supply for the farmers } \\
\hline Local pesticide shops/retailers & $61(100)$ & $0(0)$ & $32(88.9)$ & $4(11.1)$ & $53(94.6)$ & $3(5.4)$ & $146(95.4)$ & $7(4.6)$ \\
\hline Farmers' cooperative & $0(0)$ & $61(100)$ & $0(0)$ & $36(100)$ & $2(3.6)$ & $54(96.4)$ & $2(1.3)$ & $151(98.7)$ \\
\hline Open markets & $0(0)$ & $61(100)$ & $4(11.1)$ & $32(88.9)$ & $1(1.8)$ & $55(98.2)$ & $5(3.3)$ & $148(96.7)$ \\
\hline \multicolumn{9}{|l|}{ Pesticide storage practices of the farmers } \\
\hline Anywhere in the living house within reach of children & $19(31.1)$ & $42(68.9)$ & $18(50)$ & $18(50)$ & 19 (33.9) & $37(66.1)$ & $56(36.6)$ & $97(63.4)$ \\
\hline In the living house, but away from reach of children & $35(57.4)$ & $26(42.6)$ & $0(0)$ & $36(100)$ & $14(25)$ & $42(75)$ & $49(32)$ & $104(68)$ \\
\hline In the kitchen & $3(4.9)$ & $58(98.1)$ & $3(8.3)$ & $33(91.7)$ & $1(1.8)$ & $55(98.2)$ & $7(4.6)$ & $146(95.4)$ \\
\hline In a separate and protected place & $1(1.6)$ & $60(98.4)$ & $15(41.7)$ & $21(58.3)$ & $22(39.3)$ & $34(60.7)$ & $38(24.8)$ & $115(75.2)$ \\
\hline Buried in the ground till use & $3(4.9)$ & $58(98.1)$ & $0(0)$ & $36(100)$ & $0(0)$ & $56(100)$ & $3(2)$ & $150(98)$ \\
\hline Do you read the label and leaflet on the container of pesticides? & $38(62.3)$ & $23(37.7)$ & $29(80.6)$ & $7(19.4)$ & $39(69.6)$ & $17(30.4)$ & $106(69.3)$ & $47(30.7)$ \\
\hline I use leaflet to know expire date & $22(57.9)$ & $16(42.1)$ & $17(58.6)$ & $12(41.4)$ & $19(48.7)$ & $20(51.3)$ & $58(54.7)$ & $48(45.3)$ \\
\hline I use leaflet to know the hazard class of the pesticide & $17(44.7)$ & $21(55.3)$ & $2(6.9)$ & $27(93.1)$ & $17(43.6)$ & $22(56.4)$ & $36(34)$ & $70(66)$ \\
\hline $\begin{array}{l}\text { I use leaflet to know usage description like how to mix and } \\
\text { amount per hectare }\end{array}$ & $37(97.4)$ & $1(2.6)$ & $28(96.6)$ & $1(3.4)$ & $35(89.7)$ & $4(10.3)$ & $100(94.3)$ & $6(5.7)$ \\
\hline $\begin{array}{l}\text { Do you have an experience when you encountered problems } \\
\text { with leaflets of pesticides? }\end{array}$ & $8(21.1)$ & $30(78.9)$ & $21(72.4)$ & $8(27.6)$ & $22(56.4)$ & $17(43.6)$ & $51(48.1)$ & $55(51.9)$ \\
\hline Languages that I don't understand & $8(100)$ & $0(0)$ & $21(100)$ & $0(0)$ & $21(95.5)$ & $0(0)$ & $50(98)$ & $0(0)$ \\
\hline No expire date on the label & $0(0)$ & $0(0)$ & $0(0)$ & $0(0)$ & $1(4.5)$ & $0(0)$ & $1(2)$ & $0(0)$ \\
\hline
\end{tabular}




\begin{tabular}{|c|c|c|c|c|c|c|c|c|}
\hline \multirow[b]{2}{*}{ Items/questions related to pesticide use of smallholder farmers } & \multicolumn{2}{|c|}{ ATJK district } & \multicolumn{2}{|c|}{ Dugda district } & \multicolumn{2}{|c|}{ Ziway-Dugda district } & \multicolumn{2}{|c|}{ Total } \\
\hline & $\begin{array}{l}\text { Yes = N } \\
(\%)\end{array}$ & $\begin{array}{l}\text { No }=N \\
(\%)\end{array}$ & $\begin{array}{l}\text { Yes = N } \\
(\%)\end{array}$ & $\begin{array}{l}\text { No = N } \\
(\%)\end{array}$ & $\begin{array}{l}\text { Yes = N } \\
(\%)\end{array}$ & $\begin{array}{l}\text { No = N } \\
(\%)\end{array}$ & $\begin{array}{l}\text { Yes = N } \\
(\%)\end{array}$ & No $=\mathbf{N}(\%)$ \\
\hline \multicolumn{9}{|l|}{ Main source of information for farmers on pesticide use } \\
\hline Local pesticide shops/retailers & $43(70.5)$ & $18(29.5)$ & $9(25)$ & $27(75)$ & $11(19.6)$ & $45(80.4)$ & $63(41.2)$ & $90(58.8)$ \\
\hline Development agents (Das)/extension workers & $5(8.2)$ & $56(91.8)$ & $6(16.7)$ & $30(83.3)$ & $12(21.4)$ & $44(78.6)$ & $23(15)$ & $130(85)$ \\
\hline Own past experience & $26(42.6)$ & $35(57.4)$ & $13(36.1)$ & $23(63.9)$ & $23(41.1)$ & $33(58.9)$ & $62(40.5)$ & $91(59.5)$ \\
\hline Leaflet available with pesticide package & $37(60.7)$ & $24(39.3)$ & $28(77.8)$ & $8(22.2)$ & $35(62.5)$ & $21(37.5)$ & $100(65.4)$ & $53(34.6)$ \\
\hline Neighbour farmer & $37(60.7)$ & $24(39.3)$ & $21(58.3)$ & $15(41.7)$ & $37(66.1)$ & $19(33.9)$ & $95(62.1)$ & $58(37.9)$ \\
\hline Have you received any training on pesticide handling and use? & $24(39.3)$ & $37(60.7)$ & $4(11.1)$ & $32(88.9)$ & $20(35.7)$ & $36(64.3)$ & $48(31.4)$ & $105(68.6)$ \\
\hline Had training on how to mix and use & $23(95.8)$ & $1(4.2)$ & $4(100)$ & $0(0)$ & $17(85)$ & $3(15)$ & $44(91.7)$ & $4(8.3)$ \\
\hline Had training on spraying techniques & $24(100)$ & $0(0)$ & $4(100)$ & $0(0)$ & $15(75)$ & $5(25)$ & $43(89.6)$ & $5(10.4)$ \\
\hline Had training on human health safety issue & $15(62.5)$ & 9 (37.5) & $3(75)$ & $1(25)$ & $14(70)$ & $6(30)$ & $32(66.7)$ & $153(3.3)$ \\
\hline Had training on environmental health safety issues & $0(0)$ & $24(100)$ & $1(25)$ & $3(75)$ & $5(25)$ & $15(75)$ & $6(12.5)$ & $42(87.5)$ \\
\hline $\begin{array}{l}\text { Had training on disposal methods of obsolete pesticides and } \\
\text { pesticide containers }\end{array}$ & $0(0)$ & $24(100)$ & $1(25)$ & $3(75)$ & $5(25)$ & $15(75)$ & $6(12.5)$ & $42(87.5)$ \\
\hline \multicolumn{9}{|l|}{ Where do you usually mix pesticides for spraying? } \\
\hline Near water source/canals mainly from Lake Ziway & 50 (81.9) & $11(18)$ & 32 (88.9) & $4(11.1)$ & $29(51.8)$ & $27(48.2)$ & $112(73.2)$ & $41(26.8)$ \\
\hline In vegetable farm/field away from waters & $11(18)$ & $50(81.9)$ & $4(11.1)$ & $32(88.9)$ & $26(46.4)$ & $30(53.6)$ & $41(26.8)$ & $112(73.2)$ \\
\hline At home & $0(0)$ & $61(100)$ & $0(0)$ & $36(100)$ & $1(1.8)$ & $55(98.2)$ & $1(0.7)$ & $152(99.3)$ \\
\hline $\begin{array}{l}\text { Do you think that pesticides may cause undesired effect on the } \\
\text { water system? }\end{array}$ & $61(100)$ & $0(0)$ & $30(83.3)$ & $6(16.7)$ & $52(92.9)$ & $4(7.1)$ & $143(93.5)$ & $10(6.5)$ \\
\hline Do you often take measures to protect waters while spraying? & $12(19.7)$ & $49(80.3)$ & $13(36.1)$ & $23(63.9)$ & $31(55.4)$ & $25(44.6)$ & $66(43.1)$ & $87(56.9)$ \\
\hline \multicolumn{9}{|l|}{ Measure reported by farmers to protect nearby waters } \\
\hline Spray only on sunny days to avoid runoff to waters & $0(0)$ & $12(100)$ & $0(0)$ & $23(100)$ & $2(6.5)$ & $29(93.5)$ & $2(3)$ & $64(97)$ \\
\hline Spray considering wind direction to reduce drift to waters & $0(0)$ & $12(100)$ & $4(17.4)$ & $19(82.6)$ & $12(38.7)$ & $19(61.3)$ & $16(24.2)$ & $50(75.8)$ \\
\hline Built buffer between farm and the water body & $0(0)$ & $12(100)$ & $4(17.4)$ & $19(82.6)$ & $3(9.7)$ & $28(90.3)$ & $7(10.6)$ & $59(89.4)$ \\
\hline Mix pesticides away from water bodies & $8(66.7)$ & $4(33.3)$ & $19(82.6)$ & $4(17.4)$ & $27(87.1)$ & 4 (12.9) & $54(81.8)$ & $12(18.2)$ \\
\hline Do not dump pesticide containers and others to waters & $6(50)$ & $6(50)$ & $0(0)$ & $23(100)$ & $8(25.8)$ & $23(74.2)$ & $14(21.2)$ & $52(78.8)$ \\
\hline
\end{tabular}




\begin{tabular}{|c|c|c|c|c|c|c|c|c|}
\hline \multirow[b]{2}{*}{$\begin{array}{l}\text { Items/questions related to pesticide use of smallholder } \\
\text { farmers }\end{array}$} & \multicolumn{2}{|c|}{ ATJK district } & \multicolumn{2}{|c|}{ Dugda district } & \multicolumn{2}{|c|}{ Ziway-Dugda district } & \multicolumn{2}{|c|}{ Total } \\
\hline & $\begin{array}{l}\text { Yes }=N \\
(\%)\end{array}$ & $\begin{array}{l}\text { No }=N \\
(\%)\end{array}$ & $\begin{array}{l}\text { Yes = N } \\
(\%)\end{array}$ & $\begin{array}{l}\text { No = N } \\
(\%)\end{array}$ & $\begin{array}{l}\text { Yes = N } \\
(\%)\end{array}$ & $\begin{array}{l}\text { No = N } \\
(\%)\end{array}$ & $\begin{array}{l}\text { Yes = N } \\
(\%)\end{array}$ & No $=\mathbf{N}(\%)$ \\
\hline \multicolumn{9}{|l|}{ Practices of farmers with empty pesticide containers } \\
\hline Throw to outside/the environment & $47(77)$ & $14(23)$ & $23(63.9)$ & $13(36.1)$ & $26(46.4)$ & $30(53.6)$ & $96(62.7)$ & $57(37.3)$ \\
\hline Buried in the ground & $11(18)$ & $50(82)$ & $8(22.2)$ & $28(77.8)$ & $22(39.3)$ & $34(60.7)$ & $41(26.8)$ & $112(73.2)$ \\
\hline Burn & $6(9.8)$ & $55(90.2)$ & $6(16.7)$ & $30(83.3)$ & $11(19.6)$ & $45(80.4)$ & $23(15)$ & $130(85)$ \\
\hline Use as house equipment & $10(16.4)$ & $51(83.6)$ & $0(0)$ & $36(100)$ & $12(21.4)$ & $44(78.6)$ & $22(14.4)$ & $131(85.6)$ \\
\hline Sell it to others & $1(1.6)$ & $60(98.4)$ & $0(0)$ & $36(100)$ & $0(0)$ & $56(100)$ & $1(0.7)$ & $152(99.3)$ \\
\hline $\begin{array}{l}\text { Do you think that Lake Ziway is stressed by pesticides } \\
\text { sourced from your irrigation activity? }\end{array}$ & $3(4.9)$ & $58(95.1)$ & $16(44.4)$ & $20(55.6)$ & $26(46.4)$ & $30(53.6)$ & $45(29.4)$ & $108(70.6)$ \\
\hline \multicolumn{9}{|l|}{$\begin{array}{l}\text { Protective measures taken by the farmers to protect } \\
\text { human health during spraying }\end{array}$} \\
\hline Consider wind direction during pesticide spraying & $31(50.8)$ & $30(49.2)$ & $29(80.6)$ & $7(19.4)$ & $42(75)$ & $14(25)$ & $102(66.7)$ & $51(33.3)$ \\
\hline $\begin{array}{l}\text { Own separate clothes (coveralls/brooms) for pesticide } \\
\text { spraying }\end{array}$ & $40(65.6)$ & $21(34.4)$ & $6(12.5)$ & $30(83.3)$ & $33(58.9)$ & $23(41.1)$ & $79(51.6)$ & $74(48.4)$ \\
\hline Use hat during pesticide spraying & $1(1.6)$ & $60(98.4)$ & $6(16.7)$ & $30(83.3)$ & $9(16.1)$ & 47 (83.9) & $14(9.2)$ & $139(90.8)$ \\
\hline $\begin{array}{l}\text { Use chemical splash goggles to protect your face during } \\
\text { spraying? }\end{array}$ & $0(0)$ & $61(100)$ & $0(0)$ & $36(100)$ & $0(0)$ & $56(100)$ & $0(0)$ & $153(100)$ \\
\hline Use glove during pesticide spraying & $0(0.0 \%)$ & $61(100)$ & $0(0)$ & $36(100)$ & $0(0)$ & $56(100)$ & $0(0)$ & $153(100)$ \\
\hline Use eye goggles during pesticide spraying? & $0(0.0 \%)$ & $61(100)$ & $0(0)$ & $36(100)$ & $0(0)$ & $56(100)$ & $0(0)$ & $153(100)$ \\
\hline
\end{tabular}


Chapter 3
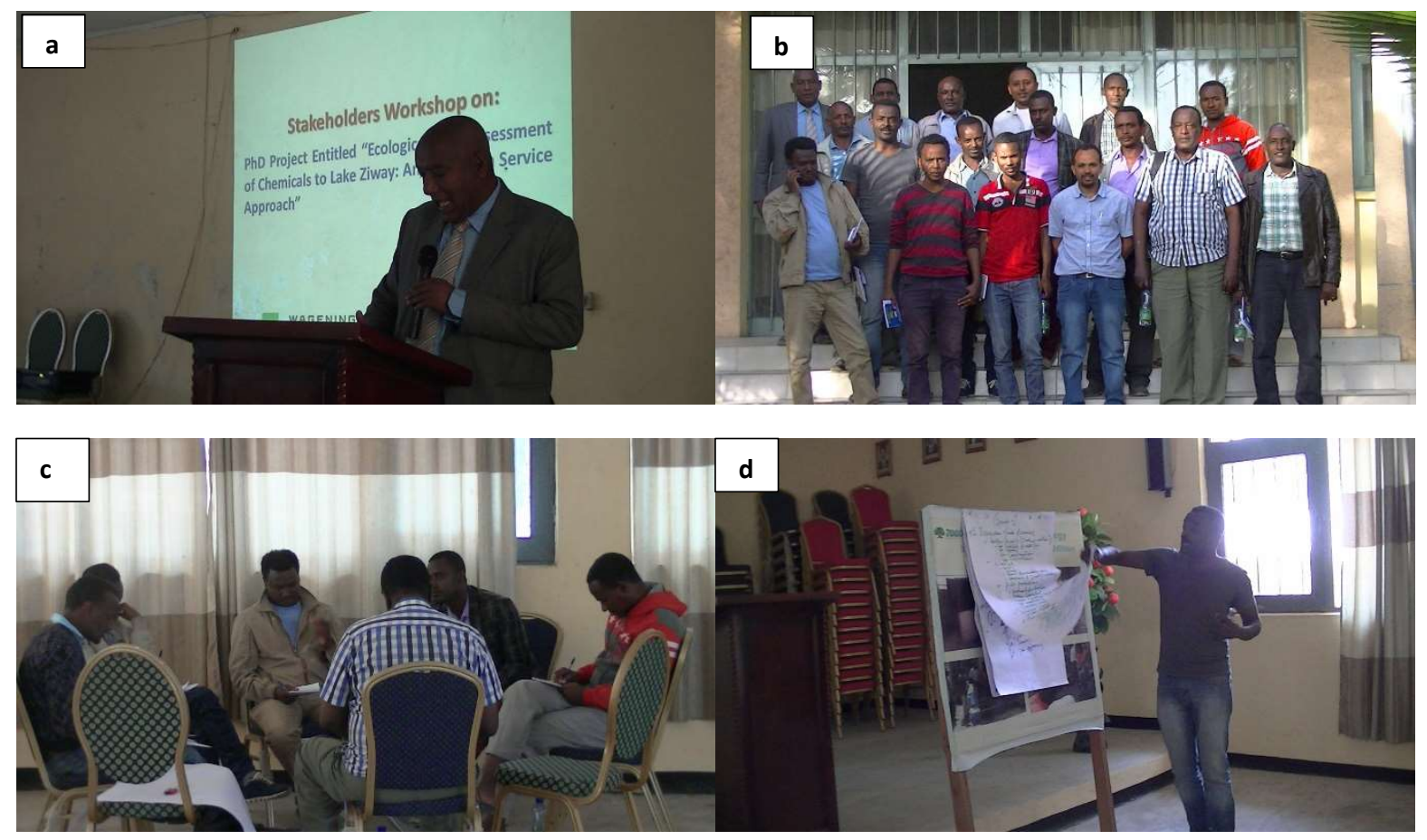

Fig. S13.1. Pictures taken during stakeholders workshop (12 January 2017). The pictures indicate a) opening speech given by home supervisor of the project, b) participants of the workshop, c) group discussion and d) presentations by each group. 
Chapter 3
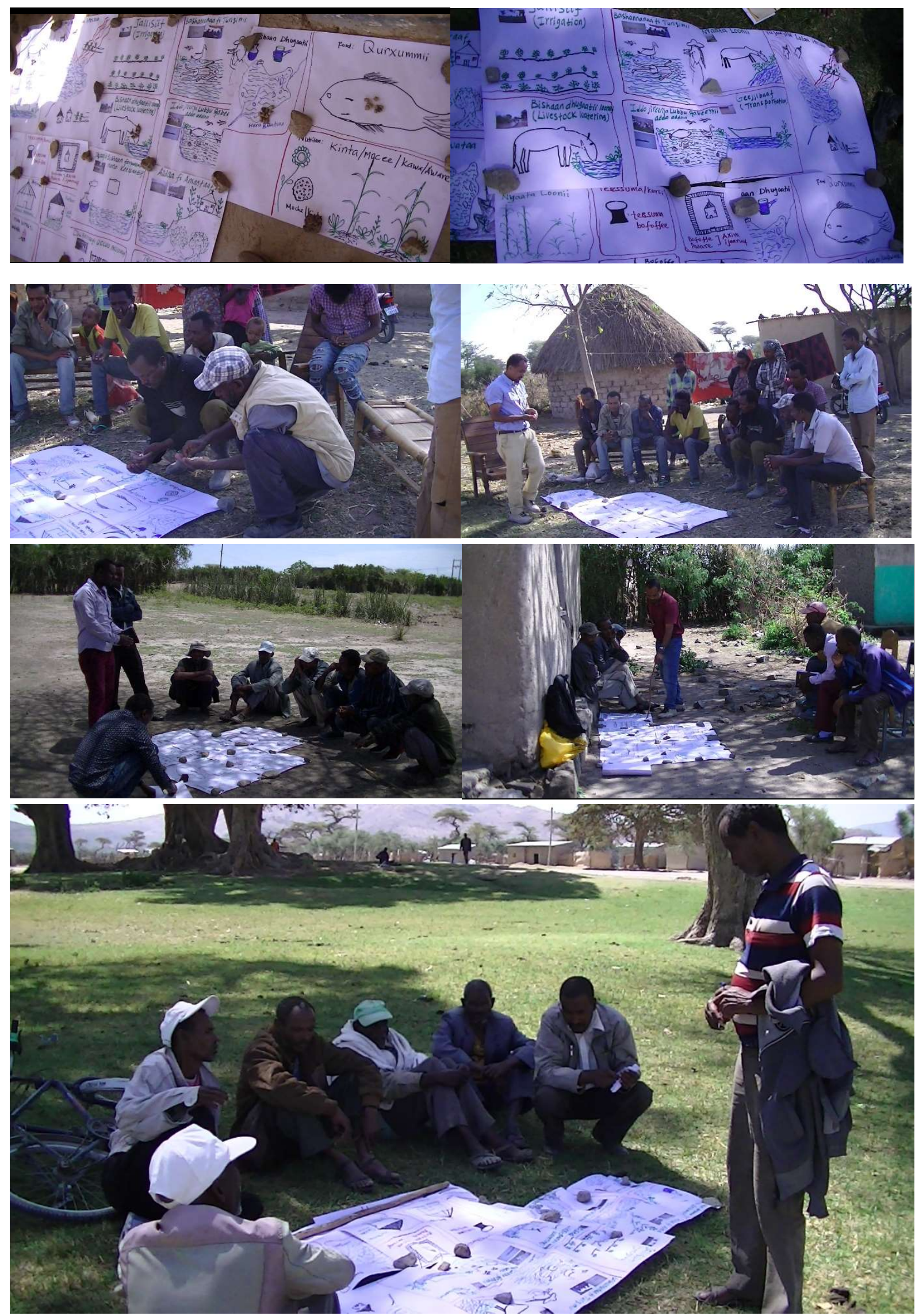

Fig. S13.2. Ranking of ecosystem services and goods of Lake Ziway using pebble distribution method by local community. 


\section{CHAPTER 4}

Biological and chemical monitoring, and ecological risk assessment of residual pesticides in Lake Ziway, Ethiopia

Lemessa B. Merga, Alemayehu A. Mengistie, Miresa T. Alemu, Paul J. Van den Brink

This chapter has been accepted for publication in Chemosphere: https://doi.org/10.1016/i.chemosphere.2020.129214 


\section{Abstract}

Lake Ziway, a freshwater lake located in Ethiopia, is under the pressure of pesticide and nutrient pollution due to agricultural activity and urbanization. This study has analysed concentrations of insecticides, fungicides and nutrients in water and sediment samples of Lake Ziway taken in the wet and dry season at 13 sites expected to be under different environmental stress and assessed their expected ecological impacts. Malathion, dimethoate, metalaxyl, diazinon, chlorpyrifos, fenitrothion and endosulfan were detected in more than half of the water samples, while diazinon, $\alpha$-cypermethrin and endosulfan were frequently detected (> 25\%) in sediment samples. Higher levels of physicochemical parameters were observed at sample locations proximate to agricultural and urban activities. Risk quotients

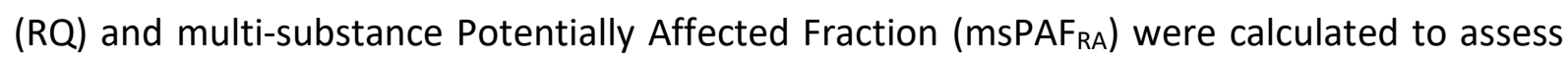
the ecological risk of individual and mixture of pesticides, respectively. The majority of the pesticides detected in the water of the lake showed a potential acute risk ( $R Q>1)$, specifically the insecticides chlorpyrifos, $\lambda$-cyhalothrin and $\alpha$-cypermethrin for which high potential acute risks were calculated using a $2^{\text {nd }}$ tier risk assessment. Levels of pesticides in sediment showed low ecological risks. Arthropods and fishes are expected to be highly affected by mixtures of pesticides $\left(\operatorname{msPAF}_{\mathrm{RA}} \leq 1-80 \%\right)$ detected at locations that are proximate to smallholders' farms, and receive largescale farms' wastewater and at sites where inflow rivers join the lake. Macroinvertebrates based redundancy analysis showed the effectiveness of EPT richness to assess ecological status of the lake. Training for smallholder farmers on pesticides safety and usage, and implementation of improved effluent management mechanisms by floriculture farms are urgently needed intervention measures to reduce the pollution. 


\subsection{Introduction}

The agricultural sector of Ethiopia has recorded a significant growth, where the total crop yield grew from 142 million tonnes in 2004/05 to 320 million tonnes in 2014/15 (Bachewe et al., 2018). The growth is mainly due to the expansion of agriculture to new lands and the intensification of the use of agrochemicals (Pretty, 2011; Bachewe et al., 2018). For instance, the agricultural use of pesticides and fertilizers in Ethiopia in 2017 were 4,128 tonnes (active ingredient (a.i.)) and 320,035 tonnes, respectively (FAO, 2019). Compared to 2002, the country's 2017 fertilizer consumption increased by 91\%, while pesticide consumption was 20 times higher than the consumption in 1993 (FAO, 2019). As a result, nutrients and toxic (in)organic chemicals released from agricultural activities has continued to pose environmental concerns in the country (Laurance et al., 2014; Teklu et al., 2018). This pollution may compromise the ecological integrity of the water ecosystem as observed in many subSaharan African lakes and reservoirs (Fetahi, 2019; Nyenje et al., 2010; Wenaty et al., 2019).

In the central rift valley (CRV) region of Ethiopia, particularly around Lake Ziway and its catchment, smallholders and commercial farmers have been practicing intensive agricultural activities (Merga et al., 2020b; Teklu et al., 2018). Data obtained from irrigation offices of the three districts that border Lake Ziway showed that a total of 8,537 hectare of land was irrigated in the 2016/17 cropping season to produce vegetables by smallholder farmers (Chapter 3). However, only 5,000 ha of irrigated land was reported for a decade earlier (Jansen et al., 2007), showing the expansion of irrigated land by 71\%. Moreover, about 950 ha of land proximate to Lake Ziway is in use by horticulture companies (Fig. 4.1). Residuals of pesticides from these farms may contaminate Lake Ziway via various routes such as drainage, runoff, and airborne deposition during spraying (Teklu et al., 2016a; Teklu et al., 2018).

Monitoring studies of toxic pollutants are important to assess their distribution and concentration levels in order to evaluate their risk to non-target organisms (Añasco et al., 2010; Ccanccapa et al., 2016). Monitoring studies of pesticides in Ethiopian surface waters are rare as only a few studies are available (Deribe et al., 2013; Teklu et al., 2016a; Teklu et al., 2018). The majority of previous studies in Lake Ziway focused on physicochemical variables (Merga et al., 2020b). Recently, Teklu et al. (2018) studied the distribution and impacts of pesticides as well as nutrients and trace metals in the lake. But, the levels of pesticides have never been evaluated in sediments, nor in combination with biological sampling, despite their 
high importance for environmental risk assessment as biological communities disclose historical anthropogenic disturbances that further strengthen the risk assessment of the present pollution (Aazami et al., 2015; Abbasi and Abbasi, 2011; Ccanccapa et al., 2016; Kebede et al., 2020).

To address these issues, the objectives of the present study were to 1) assess the concentrations of insecticides and fungicides in water and sediment samples, and the levels of physicochemical parameters in water samples of Lake Ziway, 2) perform a risk assessment for the insecticide and fungicide concentrations measured in both matrixes 3) correlate the abundance of biological organisms (macroinvertebrates and fish) to monitored pesticide concentrations and levels of physicochemical parameters and 4) evaluate the correlation between macroinvertebrate based biotic indices and the monitored pesticide concentrations and levels of physicochemical parameters. This with the aim to assess the risks posed by pesticides to aquatic, non-target (macroinvertebrates and fish) organisms in Lake Ziway and to select appropriate biological indices to assess future changes in biological water quality.

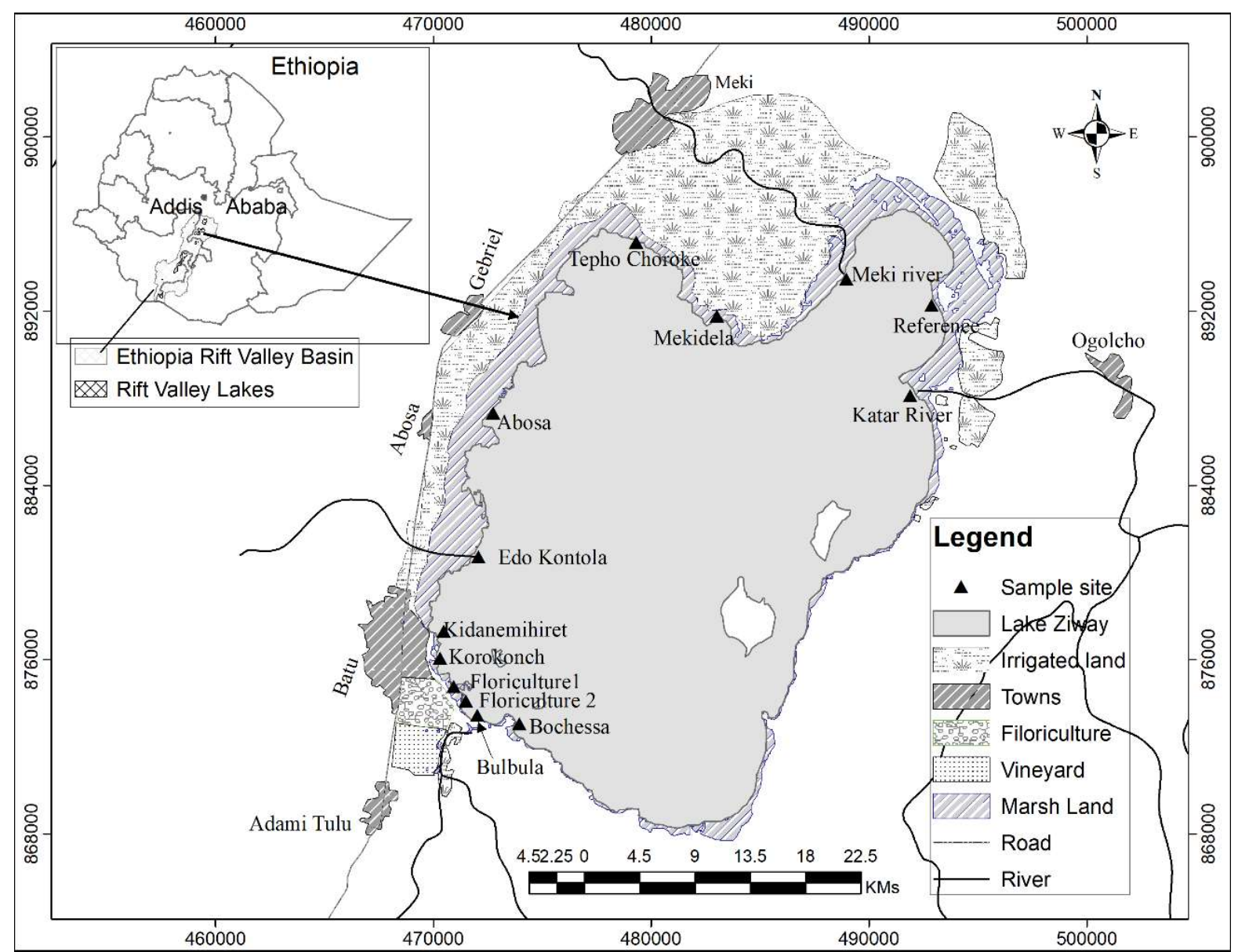

Fig. 4.1. Map of Lake Ziway showing shoreline human activities and sampling sites from where water, sediment and biological samples were collected. Smallholder farmers are mainly found on the area labelled as "Irrigated land" in the Legend section of the figure. 


\subsection{Materials and methods}

\subsubsection{Lake Ziway}

Lake Ziway (Fig. 4.1), is situated between $7^{\circ} 51^{\prime}$ to $8^{\circ} 07^{\prime} \mathrm{N}$ and $38^{\circ} 43^{\prime}$ to $38^{\circ} 56^{\prime} \mathrm{E}$ with an altitude of $1636 \mathrm{~m}$ above sea level located about $160 \mathrm{~km}$ to the south of Addis Ababa, Ethiopia. The lake covers a surface area of $442 \mathrm{~km}^{2}$ with a catchment area of $7380 \mathrm{~km}^{2}$. It is a shallow freshwater lake with average and maximum depths ranging between $2.5-4 \mathrm{~m}$ and $7-9 \mathrm{~m}$, respectively. The depth variations are partially explained by seasonal rain fall differences (Merga et al., 2020b). The perennial Meki River and Katar River flow into the lake, and as an exorheic lake, Lake Ziway outflows into Lake Abjata via Bulbula River (Ayenew, 2007; Teklu et al., 2018).

\subsubsection{Water and sediment samples}

Water and sediment samples were collected during the dry season (between 17 - 25 May 2017) and the wet season (between 13 - 21 November 2017) at 13 selected shoreline sites of Lake Ziway (Fig. 4.1) to assess the levels of physicochemical parameters and residuals of pesticides. Simultaneously, macroinvertebrates and fishes were sampled to assess the abundance and distribution of the species along the selected shoreline sites of the lake.

The sites were selected based on their proximity and vulnerability to shoreline human activities as depicted in Fig. 4.1. Floriculture1 and Floriculture2 sites receive wastewater from floriculture farms. Kidanemihiret and Korokonch sites receive urban waste from Batu town. Locations at Edo-Kontola, Abosa, Tepho-Choroke and Mekidela are proximate to vast smallholder vegetable farms. Bochessa and Bulbula locations are also close to smallholder farms, but the farms along these sites were not as large as in the case of the other sites. MekiRiver and Ketar-River locations receive inflow rivers from the upper catchment of the lake. At the Reference sampling site, the agricultural and urban activities are minimal (Fig. 4.1).

\subsubsection{Water sample collection and analysis}

For physicochemical analysis, water samples were collected into pre-cleaned $1 \mathrm{~L}$ polyethylene bottles, and transported to the laboratory using an ice-box and stored at $4{ }^{\circ} \mathrm{C}$ until analysis. Parameters, including $\mathrm{pH}$, temperature, conductivity, dissolved oxygen (DO) and total dissolved solids, were measured in-situ, while nitrate, phosphate, sulphate, ammonia, 
alkalinity, chemical oxygen demand, chlorophyll-a and turbidity were measured according to methods described by US-EPA (1983).

Nineteen (19) pesticides (15 insecticides and 4 fungicides; see Table SI4.1 for names and physicochemical properties) were selected to be monitored, because these pesticides are widely used by farmers in the vicinity of Lake Ziway based on a survey we carried out in 2017 (Chapter 3). For the analysis, water samples were collected into cleaned $1 \mathrm{~L}$ amber glass bottles and transported to laboratory using a cooled ice-box. In the laboratory, $5 \mathrm{~mL}$ of $2 \mathrm{~N} \mathrm{H}_{2} \mathrm{SO}_{4}$ and $10 \mathrm{~mL}$ methanol were added to the sample which was again stored at $4{ }^{\circ} \mathrm{C}$ while the pesticide extraction was performed within a week. The extraction protocol was adopted after Quintana et al. (2001) with a small modification. The solid-phase extraction (SPE) method using BAKERBOND spe ${ }^{\mathrm{TM}}$ and styrene divinylbenzene copolymer (SDB) as sorbent was employed. Pesticide quantification was carried out using Clarus-600 gas chromatography coupled to Clarus-600T mass spectrometer detector. Quantification of residual pesticides was performed using an internal standard based response factor approach as described by Hladik et al. (2009). For detailed information see Supplementary Information (SI), section 4A.

\subsubsection{Sediment sample collection and analysis}

Sediment samples $(0-5 \mathrm{~cm})$ were collected using an Ekman grab sampler, wrapped into aluminium foil and kept in zipped polyethylene bags. The samples were transported to the laboratory using a cooled ice-box which was kept in a freezer at $-20^{\circ} \mathrm{C}$. Total organic matter (TOM\%) and fraction of organic carbon ( $\left.f_{\text {oc }}\right)$ were analysed using the dichromate method (Ryan et al., 2001).

Pesticides extraction from sediment was performed using methanol-water (in 4:1 v/v ratio) solvent as described by Vega et al. (2005). For clean-up and quantification of the residual pesticides, similar procedures used for the water samples were fully employed. More detailed information is given in $\mathrm{SI}$, section $4 \mathrm{~B}$.

\subsubsection{Method validation, quality assurance and quality control for pesticides determination}

To validate the analytical method, we performed various validation procedures including the plotting of calibration curves and recovery analysis (Vega et al., 2005). The obtained $r^{2}$ values for calibration graphs ranged from 0.9668 to 0.9995 (Table SI4.2). The recoveries 
ranged from $79.8 \%$ - $94.1 \%$ for water and $75.3 \%$ - 99.5\% for sediment (Table SI4.2). For detailed information, see SI, section 4C.

A signal-to-noise ratio (Saadati et al., 2013) based calculation of the limit of detection (LOD) and limit of quantification (LOQ) were performed for each pesticide using water and sediment samples collected from an unpolluted temporary pond. For the results of the LOD and LOQ calculations, see Table SI4.2.

\subsubsection{Biological samples and biotic indices}

Macroinvertebrates were monitored according to the protocol by the Ontario Benthos Biomonitoring Network (Jones et al., 2007) in the littoral part of Lake Ziway using a D-shaped net (500 $\mu \mathrm{m}$ mesh). Sorting was done in the laboratory. Taxonomic identification was performed to the family level using expert knowledge and guide books by Kriska (2014). Nylon made beach seine net (40 $\mathrm{mm}$ mesh) was used to sample live fishes following the suggestions by Portt et al. (2006) and EPP (2009). Length (cm) and weight (g) were measured, and taxonomic identification was performed. Afterwards, the fish were released back into the lake, for more information see SI, section 4D.

Macroinvertebrate based indices were computed to evaluate the applicability of the indices to discriminate the sampling sites according to their level of pesticide and nutrient impacts due to shoreline activities. Fifteen indices were calculated, including Biological Monitoring Working Party index (BMWP score$_{\text {) }}$ and the BMWP based Average Score Per Taxa

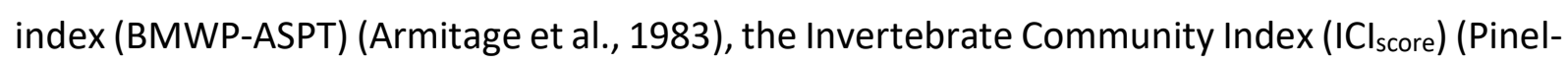
Alloul et al., 1996), the South African Scoring System index (SASS score$_{\text {) }}$ and SASS-ASPT index (Dickens and Graham, 2002), diversity indices (Shannon Weiner and Simpson indices), species richness indices (Margalef's and Menhinick's indices), and an evenness index (Pielou evenness) (Magurran, 1988). In addition, abundance and compositional indices including total number of individual (\#Totalabun), the total number of Ephemeroptera, Plecoptera and Trichoptera (\#EPT abun), the total number of taxa (\#Total $\left.\right|_{\text {taxa }}$ ), number of EPT taxa (\#EPT taxa), and percentage of EPT taxa (\%EPT taxa) were included. 


\subsubsection{Data Analysis}

\subsubsection{Risk assessment}

Assessment of the ecological risks of the insecticides and fungicides was performed by computing acute tier-1 and tier-2 based risk quotients (RQ) as described by Van Wijngaarden et al. (2015) and Rico et al. (2019), respectively. As triplicate samples ( $n=3$ ) of water and sediment were collected from each sampling site, the geometric mean values were calculated and used as exposure concentrations. The minimum and maximum measured exposure concentrations of the pesticides at all sites in the lake were included in the RQ calculation, hereby providing a range of RQs possible with the highest $R Q$ representing the worst-case risk scenario. As toxicity data is very scarce for sediments, the pore water concentration $\left(C_{\text {pow }}\right)$ was assumed to be the bioavailable concentration and used for risk assessment of the sediment concentrations of the pesticides (Diepens et al., 2017). The pore water concentrations were calculated according to Eq. 1 (Ccanccapa et al., 2016). For pesticides detected with a maximum concentration of $\leq \mathrm{LOQ}$, the pore water concentration was calculated using $0.5 * \mathrm{LOQ}$ as sediment concentration.

$C_{\text {pow }}=\frac{C_{\text {sed }}}{K_{d}}$

Eq. 1

Where $C_{\text {sed }}$ is sediment pesticides concentration and $K_{d}$ is the partitioning coefficient which was calculated using the organic carbon-water partitioning coefficient $\left(\mathrm{K}_{\mathrm{oc}}\right)$ and the fraction of organic carbon ( $\left.f_{\text {oc }}\right)$ using Eq. 2.

$\mathrm{K}_{\mathrm{d}}=\mathrm{K}_{\mathrm{oc}} * \mathrm{f}_{\mathrm{oc}}$

The $\mathrm{K}_{\mathrm{oc}}$ was calculated using the octanol-water portioning coefficient $\left(\mathrm{K}_{\mathrm{ow}}\right)$ as stated in Eq. 3 (Schwarzenbach and Westall, 1981).

$\log K_{\text {oc }}=0.72\left(\operatorname{LogK}_{\text {ow }}\right)+0.49$

Eq. 3

For the acute tier-1 insecticides risk assessment, toxicity data for Daphnia magna (48-h $\mathrm{EC}_{50}$; immobility), Americamysis bahia (96-h $\mathrm{LC}_{50}$; survival) and lowest toxicity value of Chironomus sp. (i.e. Chironomus riparius, Chironomus dilutus/tentans or Chironomus yoshimitsui; 96-h LC 50 survival), were collected from existing toxicity databases including Pesticide Properties DataBase (PPDB) of University of Hertfordshire: (https://sitem.herts.ac.uk/aeru/ppdb/en/index.htm) and US-EPA ecotoxicological database: 
ECOTOX (https://cfpub.epa.gov/ecotox/). For fungicides, toxicity values for D. magna (48-h $\mathrm{EC}_{50}$; immobility), Oncorhynchus mykiss (96-h $\mathrm{LC}_{50}$, survival) and the lowest toxicity value of the algal species Raphidocelis subcapitata and Desmodesmus subspicatus (72-h/96-h EC50; growth) were collected from the same databases (Rico et al., 2019). When more than one toxicity value with similar exposure time and effect endpoint were observed for a species, the geometric mean of these values was calculated.

The obtained $L(E) C_{50}$ values were divided by an assessment factor (AF) of 100 to calculate the acute tier-1 Predicted No Effect Concentration (PNEC) for insecticides (Van Wijngaarden et al., 2015). For fungicides the $L(E) C_{50}$ of $D$. magna and $O$. mykiss were divided by an $A F$ of 100 , and the $\mathrm{EC}_{50}$ value of algae (R. subcapitata or D. subspicatus) was divided by AF 10 (Rico et al., 2019). The lowest PNECs (Table SI4.3) were selected for the RQs calculation. For the tier-2 acute risk assessment, additional toxicity values for arthropods for insecticides and all species (fishes, arthropods and algae) for fungicides were collected, with a $1-4$ days test duration and evaluating immobility, growth or mortality as effect endpoints (Maltby et al., 2005; Maltby et al., 2009) from the same data bases stated above. To calculate the tier- 2 PNEC, the species sensitivity distribution (SSD) approach was employed (Van Wijngaarden et al., 2015). An SSD was constructed using the ETX 2.1 software (Van Vlaardingen et al., 2003). The tier-2 PNEC (Table SI4.3) was calculated by dividing the median $\mathrm{HC}_{5}$ (hazardous concentration protective for $95 \%$ of the population) by an AF of 6 (Van Wijngaarden et al., 2015).

Chronic tier-1 RQs were calculated using the selected chronic toxicity values for $D$. magna

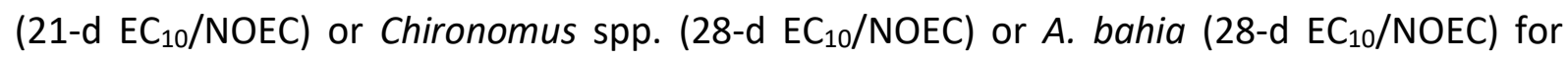
insecticides (Brock et al., 2016), and for D. magna (21-d NOEC/EC 10 ) or O. mykiss (28-d NOEC/EC 10 ) or algae (72-h/96-h EC 50 ) for fungicides (Rico et al., 2019). The toxicity values were divided by an AF of 10 to obtain chronic tier-1 PNECs and the lowest PNEC values (Table SI4.3) were used for RQs calculations (Brock et al., 2016; Rico et al., 2019). The tier-1 and tier-2 RQs were calculated by dividing the measured environmental concentrations of the pesticides by their the tier-1 and tier-2 PNEC values, respectively. Risk characterization categories were made as: $\mathrm{RQ}<1=$ no risk, $1-10=$ low risk, $10-100=$ high risk and $>100=$ very high risk.

Site-specific impacts of mixtures of pesticides to aquatic organisms via water and sediment exposures were also evaluated. Two freshwater community groups, arthropods and fishes, were considered for the impact assessment of the measured mixtures of the insecticides and 
fungicides, as they are expected to be more sensitive than primary producers and nonarthropod invertebrates (Maltby et al., 2005; Maltby et al., 2009). As aforementioned for individual pesticide risk assessment, the geometric mean values of the three samples taken at each location were calculated and used as exposure concentrations. For the detected pesticides with a concentration of $<\mathrm{LOQ}$ the exposure concentration was set at $0.5 *$ LOQ.

The mixture risk assessment was performed by applying mixture toxicity mixed-models (Posthuma et al., 2002). First, the pesticides were classified according to their toxicological mode of action (TMOA) with the help of that database of the Insecticide resistance Action Committee (https://www.irac-online.org/modes-of-action//) for insecticides and the Fungicide Resistance Action Committee (https://www.frac.info/publications/downloads) for fungicides (Table SI4.4). Secondly, for each pesticide, toxicity values with $1-4$ days test duration using immobility, growth or mortality as effect endpoints for fish and arthropods were collected from the aforementioned toxicity database and were log transformed, while the median $(\mu)$ and standard deviation $(\delta)$ were estimated for arthropods and fishes separately (Table SI4.4). Hazard units (HU) for each pesticide were computed per site by dividing the exposure pesticide concentration by $10^{\mu i}$, where $\mu \mathrm{i}$ is the log-transformed median of acute toxicity values of the respective pesticide. Thirdly, the concentration addition model was implemented to calculated multi-substance potentially affected fraction based on concentration addition ( $\mathrm{MSPAF}_{\mathrm{CA}}$ ) values for pesticides with a similar TMoA by employing the function NORM.DISAT(Log10 $\left(\Sigma \mathrm{HU}_{\mathrm{TMOA}}\right), 0$, Average $\left.\left(\delta_{\mathrm{TMOA}}\right), 1\right)$, where Average $\left(\delta_{T M o A}\right)$ and $\Sigma \mathrm{HU}_{\mathrm{TMOA}}$ are the average of the standard deviations $(\delta)$ and the summation of $\mathrm{HU}$ for pesticides with similar TMoA, respectively (Posthuma et al., 2002). Lastly, the multi-substance Potentially Affected Fraction based on response addition ( $\mathrm{mSPAF}_{\mathrm{RA}}$ ) was estimated using: $\operatorname{msPAF}_{R A}=1-\Pi\left(1-\operatorname{msPAF}_{C A i}\right)$, where $\operatorname{msPAF}_{C A}$ is the $\operatorname{msPAF}_{C A}$ for a group of pesticides $i$ with the same TMoA. The model assumes that there is no effect interactions between the existing group of pesticides with a dissimilar mode of action. For detailed information regarding the calculations and the application of the method one can have a look at Munz et al. (2017), Rämö et al. (2018) and Silva et al. (2015) as examples. The contribution of each pesticide to the msPAF $_{\text {RA }}$ was also evaluated as described by Rämö et al. (2018). For risk characterization, classifications were made based on the calculated \%msPAF ${ }_{R A}$ values. Accordingly, $\% m s P A F_{R A}$ $\leq 5 \%, 5-25 \%, 25-50 \%$ and $>50 \%$ were interpreted as a low, moderate, high and very high contribution, respectively. 


\subsubsection{Redundancy analysis}

To assess the significance of the variation in species composition and abundance (see Table SI4.5) between the sites explained by the different physicochemical parameters and pesticides, redundancy analyses (RDA) were performed using Canoco 5 (Ter Braak and Šmilauer, 2018). First, the physicochemical parameters (Table SI4.6) and pesticide concentrations in the water and sediment (Table SI4.7; Table SI4.8) were $\operatorname{Ln}(\mathrm{x})$ transformed when no 0 values are present and $\operatorname{Ln}(a x+1)$ transformed when 0 values were present. In the formula, the value of $a$ was calculated for each parameter separately with ax yields 2 with $\mathrm{x}$ being the lowest number above 0 (Van den Brink et al., 2000). An RDA using physicochemical parameters as species and sampling date and site as explanatory variables was performed to get an overview of the differences in parameter values between sampling dates and sites. In order to make all parameters equally important in the analysis their value were centred and standardised.

The significance of each environmental parameter with respect to the differences in species composition between the different samples was tested by an RDA introducing all environmental variables as explanatory variables and sampling date as covariable. Besides the simple effects also the conditional effects were tested. The resulting RDA biplot shows the correlations between the species and the environmental variables. After that an RDA was performed including the environmental variables which were significant in the simple and conditional effects as explanatory variables, and sampling date and sample site as passive explanatory variables. This yields a triplot showing the correlations between species, sites, sampling date and the environmental variables, which are represented by a limited set as selected by the conditional effects. The same analysis was performed for the biotic indices (Table SI4.9), which played the role of the species, but their values were centred and standardized within the analysis in order to make them equally important within the analysis (Ter Braak and Šmilauer, 2018). Pearson correlations between species abundance and $\mathrm{mSPAF}_{\mathrm{RA}}$, and between biotic indices and $\mathrm{mSPAF}_{\mathrm{RA}}$ were calculated to evaluate the contribution of the $\mathrm{MSPAF}_{\mathrm{RA}}$ to the variation observed in species abundance and composition, and biotic indices between sampling sites. 


\subsection{Results and discussion}

\subsubsection{Physicochemical parameters}

Turbidity, temperature and alkalinity was higher in the samples taken in the dry season (May) compared to the wet season (November), which showed higher $\mathrm{SO}_{4}{ }^{2-}$ concentrations. The sites receiving waste water effluent from the floriculture farms showed higher chlorophyll-a, EC, TDS, $\mathrm{COD}$ and $\mathrm{NO}_{3}{ }^{-}$levels, compared to the sites influenced by agriculture and urban settlements, but were the lowest at the reference site, which also showed the highest DO and pH levels (Table SI4.6; Fig. SI4.1). In line with Merga et al. (2020b) and Teklu et al. (2018), our result indicates that physicochemical properties of Lake Ziway may be affected by floriculture, agricultural and urban activities in the catchment area of the lake ecosystem. It is difficult to causally link the stressors imposed by floriculture, agriculture and urban activities to the water quality as the number of sampled sites is very limited, not allowing a statistical evaluation. For instance, only 1 reference site has been sampled while for different stressor categories 2-4 sites were selected. The result of the redundancy analyses (see below), though, provide some justification of the causality of stressor-water quality correlations as multivariate analysis analyses the whole data set in one assessment. Furthermore, all samples are taken in the same lake and are, although the lake is very large, not compeletely independant from each other. These limitations account for the data set as a whole, including the biological and the pesticide endpoints.

\subsubsection{Residual of pesticides in water samples}

A total of 19 pesticides were monitored and the majority (63\%) of them were detected in water samples of the studied lake. During both sampling seasons (dry season and wet season), malathion, dimethoate, metalaxyl, fenitrothion, diazinon, chlorpyrifos and endosulfan were frequently detected in water samples (detection frequency (DF) $>60 \%$ ) (Table 4.1). The distribution of pesticides in aquatic ecosystems is affected by the physicochemical properties of the active ingredient (Weber, 1995). The ubiquitous presence of malathion, dimethoate and metalaxyl pesticides can be explained by their low $\log \mathrm{K}_{\mathrm{ow}}$, and high aqueous hydrolysis and photolysis half-life ( DT $_{50}$ ) values (Table SI4.1). As reported by Teklu et al. (2016a), the low detections of $\lambda$-cyhalothrin and $\alpha$-cypermethrin are likely due to their high $\log \mathrm{K}_{\text {ow }}$ and low 
aqueous photolysis $\mathrm{DT}_{50}$ values (Table SI4.1). Higher mean and maximum concentrations were observed for the majority of pesticides in the wet season compared to the dry season (Table 4.1). Runoff from agricultural lands in the wet season is an important transportation route for pesticides to surface waters (Otieno et al., 2012; Papadakis et al., 2015) and likely explains the observed seasonal variation in this study.

Endosulfan, diazinon and deltamethrin were reported with mean concentrations of 0.1 , 0.345 and $0.01 \mu \mathrm{g} / \mathrm{L}$, respectively in Lake Ziway by Teklu et al. (2018). Similarly, Jansen and Harmsen (2011) reported metalaxyl, iprovalicarb, propamocarb, carbaryl, and fenitrothion, with mean values of $0.215,0.14,0.6,0.05$ and $0.16 \mu \mathrm{g} / \mathrm{L}$, respectively in the lake. These values are lower than the values measured in this study, except for deltamethrin. This suggests increasing concentration levels of the pesticides in the water column of the lake over time, to which a year-to-year expansion of smallholder irrigation lands and large-scale farms may have a major contribution.

Compered to our results, Mekonen et al. (2016) measured higher mean values of malathion $(7.7 \mu \mathrm{g} / \mathrm{L})$ and diazinon $(5.6 \mu \mathrm{g} / \mathrm{L})$ in water samples collected from rivers surrounded by agricultural fields close to Jimma, Ethiopia, located $200 \mathrm{~km}$ to the east of Lake Ziway. These values indicate that rivers and streams surrounded by agricultural fields are likely to have higher pesticides concentrations, and may serve as transport routes of pesticides to the receiving downstream waters.

Internationally banned organochlorine pesticides including endosulfan and DDT have been widely studied in surface waters of other African countries (Taiwo, 2019), while a few reports on other pesticides' classes. Abong'o et al. (2018), Wenaty et al. (2019) and Okoya et al. (2013) have reported mean concentrations of endosulfan for Nyando River of Kenya (0.64 $\mu \mathrm{g} / \mathrm{L})$, Lake Victoria of Tanzania $(0.134 \mu \mathrm{g} / \mathrm{L})$ and Agoo River of Nigeria $(1.65 \mu \mathrm{g} / \mathrm{L})$, respectively, which are quite similar to the concentrations measured in the current study (Table 4.1). According to the authors, endosulfan is widely used by subsistence farmers producing vegetables, fruits and sugarcane in the catchment of the studied waters. Similarly, the smallholder farmers in the catchment of Lake Ziway widely use the pesticide to protect onion, cabbage and tomato from bollworm (Mengistie et al., 2017; Teklu et al., 2016a).

Other chemical classes of pesticides were also detected in African surface waters, which are under similar agricultural pressure as Lake Ziway. Malathion was detected in the Sebeya River of Rwanda (Houbraken et al., 2017), and in the Ankobra River Basin of Ghana (Affum et 
al., 2018) with mean values of $0.19 \mu \mathrm{g} / \mathrm{L}$ and $0.13 \mu \mathrm{g} / \mathrm{L}$, respectively, which are lower than the concentrations found in the current study. Cypermethrin $(0.186$ (ND - 0.925) $\mu \mathrm{g} / \mathrm{L})$ and deltamethrin (0.020 (ND - 0.020) $\mu \mathrm{g} / \mathrm{L}$ ) were detected in the Ankobra River Basin, Ghana (Affum et al., 2018). In the current study we found much higher levels for cypermethrin in the wet season, while its dry season concentrations and the dry and wet season concentrations of deltamethrin are difficult to compare since the LOD of cypermethrin and deltamethrin in the current study were relatively high i.e. 0.19 and $0.15 \mu \mathrm{g} / \mathrm{L}$, respectively (Table SI4.2). Chlorpyrifos was detected in the Lake Naivasha, Kenya (Otieno et al., 2012) and in the Ankobra River Basin, Ghana (Affum et al., 2018) with mean values of $12 \mu \mathrm{g} / \mathrm{L}$ and $0.34 \mu \mathrm{g} / \mathrm{L}$, respectively, the latter being comparable to levels found in the current study. Furthermore, metalaxyl was detected in the Lake Kivu, Rwanda (Houbraken et al., 2017) and fenitrothion in the Ankobra River, Ghana (Affum et al., 2018) with mean concentrations of $2.44 \mu \mathrm{g} / \mathrm{L}$ and $0.035 \mu \mathrm{g} / \mathrm{L}$, respectively, which are higher and lower than the concentrations reported in Table 4.1, respectively. Agricultural activity related differences in types and quantities of pesticides use likely to contribute to these variations, although the concentrations of many pesticides do correspond.

The composition and detection frequency of pesticides were spatially variable in Lake Ziway. The majority of the pesticides $(>50 \%)$ were detected in waters sampled from locations proximate to smallholder farms and receiving the inflow from the rivers (Table SI4.10). Those sites receiving wastewater from floriculture farms also detected a considerable number of pesticides (30-50\%) (Table SI4.10). Similar to earlier reports (Mengistie et al., 2017; Teklu et al., 2016a), our survey in 2017 (Chapter 3) showed that the pesticides included in our monitoring programme were intensively used in CRV region by subsistence vegetable farmers and large-scale flower farmers. Therefore, the observed ubiquitous of the pesticides at the aforementioned locations is likely to be related to these activities.

\subsubsection{Residual of pesticides in sediment samples}

Only $3(16 \%)$ and $9(47 \%)$ of the monitored pesticides $(n=19)$ were detected in sediment samples collected in dry season and in wet season, respectively (Table 4.1). In the dry season, diazinon was the most frequently detected pesticide (39\% DF) and its concentrations ranged from $<0.36-0.53 \mu \mathrm{g} / \mathrm{kg}-\mathrm{dw}$ (Table 4.1). In the wet season diazinon, chlorpyrifos, endosulfan 
and $\alpha$-cypermethrin were frequently detected (DF >30\%) and their concentrations ranged from $<0.36-2.95 \mu \mathrm{g} / \mathrm{kg}-\mathrm{dw}$ (Table 4.1). Their high hydrophobicity $\left(\log _{\mathrm{kow}}>3\right.$; Table SI4.1) can explain the accumulation of the pesticides in the sediment of the lake (Ccanccapa et al., 2016; Teklu et al., 2016a). Similar to the observation for water samples, the wet season sediment samples were more contaminated compared to the dry season samples (Table 4.1) indicating seasonal variations. Similarly, Otieno et al. (2012) reported the wide distributed and high level of chlorpyrifos in wet season sediment samples compared to the lower levels found in the dry season in the Lake Naivasha, Kenya.

This study is the first to report the concentrations of pesticides in the sediment of Ethiopian surface waters. Few studies reported pesticides in other African surface waters mainly for obsolete organochlorine pesticides as discussed earlier. Endosulfan concentrations ranged from 3.75 - $14.40 \mu \mathrm{g} / \mathrm{kg}$-dw (Darko et al., 2008) and 0.03 - $9.67 \mu \mathrm{g} / \mathrm{kg}-\mathrm{dw}$ (Wasswa et al., 2011) in sediments of Lake Bosomtwi (Ghana) and Lake Victoria (Uganda), respectively. These values are higher than the values measured in our study (maximum concentration $=2.95 \mu \mathrm{g} / \mathrm{kg}-\mathrm{dw}$; Table 4.1). Moreover, diazinon (0.56-1.08 $\mu \mathrm{g} / \mathrm{kg}-\mathrm{dw})$ and dimethoate $(0.02-0.29 \mu \mathrm{g} / \mathrm{kg}-\mathrm{dw})$ in Nyando-Sondu-Miriu River of Kenya (Musa et al., 2011a), malathion (<0.01 $\mu \mathrm{g} / \mathrm{kg}-\mathrm{dw}$ ) in Yala-Nzoia River of Kenya (Musa et al., 2011b) and chlorpyrifos (4.7-30.1 $\mathrm{\mu g} / \mathrm{kg}-\mathrm{dw}$ ) in Lake Naivasha of Kenya (Otieno et al., 2012) have been reported. In the current study, similar values were reported for diazinon and dimethoate, while higher and lower values were reported for malathion and chlorpyrifos, respectively (Table 4.1). According to the authors, the studied surface waters received pesticides residual from smallholder vegetables, sugarcane and fruits farms in their catchment (Otieno et al., 2012; Wasswa et al., 2011), which are comparable sources of pesticides as in the current study on Lake Ziway. As mentioned earlier, regional source differences of pesticides likely contribute to the differences in chlorpyrifos concentrations.

Pesticides were detected in sediment samples collected from the majority (85\%) of locations (Table SI4.10), but their composition and DF varied between the sampling sites. The differences are likely due to differences in the types and application intensity of pesticides used in the areas closer to the sampling sites. The highest DF in the dry season was $16 \%$ and observed at the inflow where Meki River joins the lake. In the wet season large numbers of pesticides (DF >20\%) were detected in the sediments at locations near to smallholder farms, the point of effluent from the floriculture and the point of inflow of the rivers (Table SI4.10). 
This indicates that the sediment of the lake are probably contaminated with pesticides released from the surrounding agricultural and floricultural activities. The observed high concentrations and number of pesticides in the wet season sediment samples is likely a result of the high load of pesticides adsorbed to sediments via runoff (Papadakis et al., 2015) from agricultural area in the catchment of the studied lake. 
Table 4.1. Mean, minimum ( $\min$. ) and maximum (max.) concentrations, and detection frequencies of the studied pesticides in water samples (a) in sediment samples (b) of Lake Ziway. The samples were collected during May 2017 (dry season) and November (Nov.) 2017 (wet season).

\begin{tabular}{|c|c|c|c|c|c|c|c|c|c|c|c|c|c|c|c|c|}
\hline \multirow[b]{4}{*}{ Pesticides } & \multicolumn{8}{|c|}{ Water sample } & \multicolumn{8}{|c|}{ Sediment sample } \\
\hline & \multirow{2}{*}{\multicolumn{2}{|c|}{$\begin{array}{l}\text { Detection } \\
\#(\% D F)\end{array}$}} & \multicolumn{6}{|c|}{ Concentration $(\mu \mathrm{g} / \mathrm{L}) ; \mathrm{n}=3$} & \multirow{2}{*}{\multicolumn{2}{|c|}{$\begin{array}{l}\text { Detection frequency } \\
\#(\% D F)\end{array}$}} & \multicolumn{6}{|c|}{ Concentration $\left(\mu \mathrm{g} / \mathrm{Kg} \_\mathrm{dw}\right) ; \mathrm{n}=3$} \\
\hline & & & \multicolumn{3}{|c|}{ Dry season } & \multicolumn{3}{|c|}{ Wet season } & & & \multicolumn{3}{|c|}{ Dry season } & \multicolumn{3}{|c|}{ Wet season } \\
\hline & $\begin{array}{l}\text { Dry } \\
\text { season }\end{array}$ & $\begin{array}{l}\text { Wet } \\
\text { season }\end{array}$ & Mean & Min. & Max. & Mean & Min. & Max. & $\begin{array}{l}\text { Dry } \\
\text { season }\end{array}$ & $\begin{array}{l}\text { Wet } \\
\text { season }\end{array}$ & Mean & Min. & Max. & Mean & Min. & Max. \\
\hline Propamocarb & $5(38.5)$ & $3(23.1)$ & 0.72 & $<0.13$ & 0.91 & 0.503 & 0.41 & 0.62 & nd & nd & - & - & - & - & - & - \\
\hline Acephate & nd & nd & - & - & - & - & - & - & nd & nd & - & - & - & - & - & - \\
\hline Ethoprophos & nd & nd & - & - & - & - & - & - & nd & $2(15.4 \%)$ & - & - & - & 0.48 & 0.35 & 0.61 \\
\hline Dimethoate & $10(76.9)$ & $11(84.6)$ & 0.54 & $<0.05$ & 0.88 & 0.63 & $<0.05$ & 0.99 & nd & $1(7.7 \%)$ & - & - & - & 0.32 & 0.32 & 0.32 \\
\hline Diazinon & $9(69.2)$ & $9(69.2)$ & 0.42 & $<0.08$ & 0.74 & 0.51 & $<0.08$ & 0.88 & $5(38.5 \%)$ & $6(46.1 \%)$ & 0.44 & $<0.36$ & 0.53 & 0.42 & $<0.36$ & 0.74 \\
\hline Chlorothalonil & nd & nd & - & - & - & - & - & - & nd & nd & - & - & - & - & - & - \\
\hline Carbaryl & $4(30.8)$ & $4(30.8)$ & 0.18 & 0.02 & 0.36 & 0.23 & $<0.02$ & 0.38 & nd & nd & - & - & - & - & - & - \\
\hline Metalaxyl & $9(69.2)$ & 10(76.9) & 0.72 & $<0.1$ & 1.9 & 0.75 & 0.14 & 1.41 & nd & nd & - & - & - & - & - & - \\
\hline Fenitrothion & 10(76.9) & $8(61.5)$ & 0.38 & $<0.08$ & 0.69 & 0.48 & 0.19 & 0.74 & nd & $3(23.1 \%)$ & - & - & - & 0.91 & 0.89 & 0.94 \\
\hline Malathion & $12(92.3)$ & 10(76.9) & 0.38 & $<0.07$ & 0.85 & 0.42 & $<0.07$ & 0.55 & nd & nd & - & - & - & - & - & - \\
\hline Chlorpyrifos & 10(76.9) & $8(61.5)$ & 0.55 & $<0.15$ & 0.87 & 0.58 & 0.31 & 0.88 & nd & $4(30.8 \%)$ & - & - & - & 0.79 & 0.71 & 0.88 \\
\hline Profenofos & nd & nd & - & - & - & - & - & - & nd & nd & - & - & - & - & - & - \\
\hline Iprovalicarb & $6(46.1)$ & $5(38.5)$ & 0.57 & $<0.17$ & 0.93 & 0.59 & 0.38 & 0.88 & nd & nd & - & - & - & - & - & - \\
\hline Endosulfan & $9(69.2)$ & $8(61.5)$ & 0.76 & $<0.42$ & 1.01 & 1.11 & $<0.42$ & 1.85 & $3(23.1 \%)$ & $4(30.8 \%)$ & 2.1 & $<0.63$ & 2.22 & 2.69 & $<0.63$ & 2.95 \\
\hline Dicofol & nd & nd & - & - & - & - & - & - & nd & nd & - & - & - & - & - & - \\
\hline$\lambda$-cyhalothrin & $3(23.1)$ & $3(23.1)$ & - & $<0.45$ & $<0.45$ & - & $<0.45$ & $<0.45$ & nd & $3(23.1 \%)$ & - & - & - & 1.98 & 1.88 & 2.08 \\
\hline Acrinathrin & nd & nd & - & - & - & - & - & - & nd & nd & - & - & - & - & - & - \\
\hline$\alpha$-cypermethrin & $3(23.1)$ & $5(38.5)$ & - & $<0.61$ & $<0.61$ & 0.75 & $<0.61$ & 0.81 & $2(15.4 \%)$ & $6(46.1 \%)$ & - & $<0.71$ & $<0.71$ & 1.75 & 1.58 & 1.97 \\
\hline Deltamethrin & nd & nd & - & - & - & - & - & - & nd & $2(15.4 \%)$ & - & - & - & - & $<0.54$ & $<0.54$ \\
\hline
\end{tabular}

Note: $\mathrm{nd}=$ not detected 


\subsubsection{Role of farmers' pesticide use practices for pesticide pollution of Lake Ziway}

Poor management of pesticides by African smallholder farmers is one of the major cause of pesticide pollution in surface waters (Loha et al., 2018; Onwona-Kwakye et al., 2019; Stadlinger et al., 2011). Studies (Mengistie et al., 2017; Teklu et al., 2016a) have reported the mismanagement and malpractices of pesticide use by smallholder farmers in the Ethiopian CRV region. According to Teklu et al. (2016a), the majority of farmers in CRV region lack adequate knowledge about routes through which pesticides enter into water bodies and its ecological impacts. Over use (e.g., too high application rate) and misuse (e.g., spraying on crops for which a pesticide is not prescribed) are also major problems (Mengistie et al., 2017; Teklu et al., 2016a). Mixing pesticides close to waterbodies, washing pesticides' containers into surface waters/canal, and disposing of pesticides' containers and expired pesticides to the environment are also the commonly observed malpractices in the region (Mengistie et al., 2017; Teklu et al., 2016a). Furthermore, Adami Tulu Pesticide Processing factory located in CRV, formulates a variety of pesticides including malathion, endosulfan, diazinon, fenitrothion, deltamethrin and dimethoate (Bremmer et al., 2014; PMI, 2009) so the pesticides are easily available in the pesticide shops for the farmers in the region. This may be also contribute to their presence in the water and sediment of Lake Ziway.

\subsubsection{Tier-1 and tier-2 risk quotients based ecological risk assessment}

For the majority of the pesticide concentrations measured in water samples a RQ higher than 1 was calculated, indicating a potential ecological risk (Table 4.2). Based on the acute tier-1 RQ, diazinon, malathion, chlorpyrifos, $\lambda$-cyhalothrin and $\alpha$-cypermethrin pose a very high acute ecological risk $(R Q>100)$ in both seasons. Dimethoate and fenitrothion pose a high acute risk ( $R Q=10-100 ;$ Table 4.2). For endosulfan high (dry season) to very high (wet season) acute ecological risks were calculated. According to the acute tier-2 RQs, chlorpyrifos, $\lambda$ cyhalothrin and $\alpha$-cypermethrin were expected to pose very high acute risks (Table 4.2). Diazinon measured in the wet season, and fenitrothion and endosulfan measured in both seasons pose high acute ecological risks (acute tier2 RQ >10; Table 4.2). Furthermore, chronic tier-1 RQ indicated that water concentrations of malathion (dry season), $\lambda$-cyhalothrin and $\alpha$ cypermethrin pose very high chronic risks (Table 4.2). The ecological risks calculated from the sediment concentrations in the lake were low compared to risks of pesticides from water 
exposure (Table 4.3). The tier-1 acute RQ indicates that in the wet season dimethoate, chlorpyrifos, $\lambda$-cyhalothrin, $\alpha$-cypermethrin and deltamethrin pesticides pose high acute ecological risks (Table 4.3). According to its acute tier-2 RQ, $\lambda$-cyhalothrin (in the wet season) poses a high acute risk (Table 4.3). Moreover, chronic tier-1 RQ values showed that deltamethrin poses a very high chronic risk whereas fenitrothion and $\lambda$-cyhalothrin pose a high chronic ecological risks in the wet season (Table 4.3).

Higher RQ values were calculated for pesticides measured in the wet season samples compared to the dry season for both water and sediment samples (Table 4.2; Table 4.3), indicating that wet season pesticides exposure may pose higher ecological risks than the dry season exposure. Moreover, for the majority of the pesticides ( $>55 \%)$ found in water and in sediment the \%RQ $>1$ were above 50\% (Table 4.2; Table 4.3), indicating that the pesticides can pose an acute and chronic risks at the majority of the sampling locations where they were detected.

Generally, as expected, the acute tier-1 RQ values were higher than the acute tier-2 RQ values (Table 4.2; Table 4.3). Based on tier-1 RQ values, the majority of the pesticides pose a high to very high acute ecological risk to the lake ecosystem, but pose no risk to low risk according to tier-2 RQ values (Table 4.2; Table 4.3). This shows that the lower tier is more conservative risk assessment tools than the second tier, which should be the case in a functioning tiered risk assessment (Brock et al., 2011). For the majority of the detected pesticides ( $71 \%$ in water, $44 \%$ in sediment), the acute tier- 2 RQ values are $>1$, thus expected to pose ecological risks by affecting the ecological integrity and health (Ccanccapa et al., 2016) of the studied lake. Teklu et al. (2018) reported only for two pesticides (endosulfan and deltamethrin) tier-2 $R Q>1$ for Lake Ziway, but only 8 pesticides were detected in this study. This indicated that pesticide contamination of the lake may be increasing over time. Similar to our results, Onwona-Kwakye et al. (2020) reported that dimethoate, chlorpyrifos, $\lambda$ cyhalothrin and $\alpha$-cypermethrin pose risks to aquatic ecosystems in Ghana by estimating an acute tier-2 RQ values for these pesticides using the PRIMET model. 
Table 4.2. Pesticides detected in water samples of Lake Ziway and their calculated acute tier-1, chronic tier-1 and acute tier-2 risk quotients (RQs), and percentage of the RQ values above 1 .

\begin{tabular}{|c|c|c|c|c|c|c|c|c|c|}
\hline \multirow[b]{2}{*}{ Pesticides } & \multicolumn{3}{|c|}{ Acute Tier-1 RQ range and $\%$ of $R Q>1$} & \multicolumn{3}{|c|}{ Chronic Tier-1 RQ range and \% of RQ > 1} & \multicolumn{3}{|c|}{ Acute Tier-2 RQ range and $\%$ of $R Q>1$} \\
\hline & Dry season & Wet Season & $\% R Q>1$ & Dry season & Wet Season & $\% R Q>1$ & Dry season & Wet Season & $\% R Q>1$ \\
\hline Propamocarb & $<0.01$ & $<0.01$ & 0 & $<0.01$ & $<0.01$ & 0 & $<0.01$ & $<0.01$ & 0 \\
\hline Dimethoate & $1.93-68$ & $2-77$ & 100 & $0.26-9$ & $0.3-11$ & 67 & $0.09-3$ & $0.09-3$ & 67 \\
\hline Diazinon & $7-130$ & $7-155$ & 100 & $0.71-13$ & $0.71-16$ & 67 & $0.52-9$ & $0.5-12$ & 67 \\
\hline Carbaryl & $0.21-4$ & $0.10-4$ & 50 & $<0.01-0.014$ & $<0.01-0.01$ & 0 & $0.05-0.9$ & $0.03-1.01$ & 12 \\
\hline Metalaxyl & $<0.01-0.01$ & $<0.01-0.01$ & 0 & $<0.01$ & $<0.01$ & 0 & $<0.01-0.01$ & $<0.01$ & 0 \\
\hline Fenitrothion & $1-18$ & $5-19$ & 100 & $5-79$ & $22-85$ & 100 & $0.6-11$ & $3-12$ & 94 \\
\hline Malathion & $9-212$ & $9-137$ & 100 & $6-142$ & $6-92$ & 100 & $0.4-9$ & $0.4-6$ & 52 \\
\hline Chlorpyrifos & $187-2175$ & 775 - 2200 & 100 & $7.5-87$ & $31-88$ & 100 & $9-102$ & $36-101$ & 100 \\
\hline Iprovalicarb & $<0.01$ & $<0.01$ & 0 & $<0.01$ & $<0.01$ & - & - & - & - \\
\hline Endosulfan & $17-80$ & $17-146$ & 100 & - & - & - & $9-43$ & $9-78$ & 100 \\
\hline$\lambda$-cyhalothrin & $1906-1906$ & 1907 - 1907 & 100 & 1022 - 1022 & 1022 - 1022 & 100 & $595-595$ & $595-595$ & 100 \\
\hline a-cypermethrin & $2346-2346$ & $2346-6230$ & 100 & $101-101$ & $101-270$ & 100 & $227-228$ & $227-604$ & 100 \\
\hline
\end{tabular}

Table 4.3. Pesticides detected in sediment samples of Lake Ziway and their calculated acute tier-1, chronic tier-1 and acute tier-2 risk quotients (RQs), and percentage of the $R Q$ values $>1$.

\begin{tabular}{|c|c|c|c|c|c|c|c|c|c|}
\hline \multirow[b]{2}{*}{ Pesticides } & \multicolumn{3}{|c|}{ Acute Tier-1 RQ range and $\%$ of $R Q>1$} & \multicolumn{3}{|c|}{ Chronic Tier-1 RQ range and \% of RQ > 1} & \multicolumn{3}{|c|}{ Acute Tier- $2 \mathrm{RQ}$ range and $\%$ of $R Q>1$} \\
\hline & Dry season & Wet Season & $\% R Q>1$ & Dry season & Wet Season & $\% R Q>1$ & Dry season & Wet Season & $\% \mathrm{RQ}>1$ \\
\hline Ethoprophos & - & $0.4-1.01$ & 50 & - & $1.1-2.6$ & 100 & - & $0.33-0.83$ & 0 \\
\hline Dimethoate & - & 66. -66 & 100 & - & $9.1-9.1$ & 100 & - & $3.0-3.0$ & 100 \\
\hline Diazinon & $0.75-5.9$ & $0.7-8.4$ & 45 & $0.076-0.6$ & $0.1-0.8$ & 0 & $0.06-0.45$ & $0.06-0.64$ & 0 \\
\hline Fenitrothion & - & $1.2-5.8$ & 100 & - & $5.5-26$ & 100 & - & $0.76-3.5$ & 33 \\
\hline Chlorpyrifos & - & $7.6-52$ & 100 & - & $0.3-2.1$ & 25 & - & $0.4-2.4$ & 50 \\
\hline Endosulfan & $0.13-1.9$ & $0.1-2.5$ & 57 & - & - & - & $0.07-1.01$ & $0.05-1.4$ & 42 \\
\hline$\lambda$-cyhalothrin & - & $24-51$ & 100 & - & $13-27$ & 100 & - & $7.6-16$ & 100 \\
\hline$\alpha$-cypermethrin & $4.7-5.2$ & $7.1-27$ & 100 & $0.21-0.23$ & $0.31-1.2$ & 37 & $0.46-0.51$ & $0.7-2.6$ & 50 \\
\hline Deltamethrin & - & $62-73$ & 100 & - & $1000-1176$ & 100 & - & $6.4-7.5$ & 100 \\
\hline
\end{tabular}




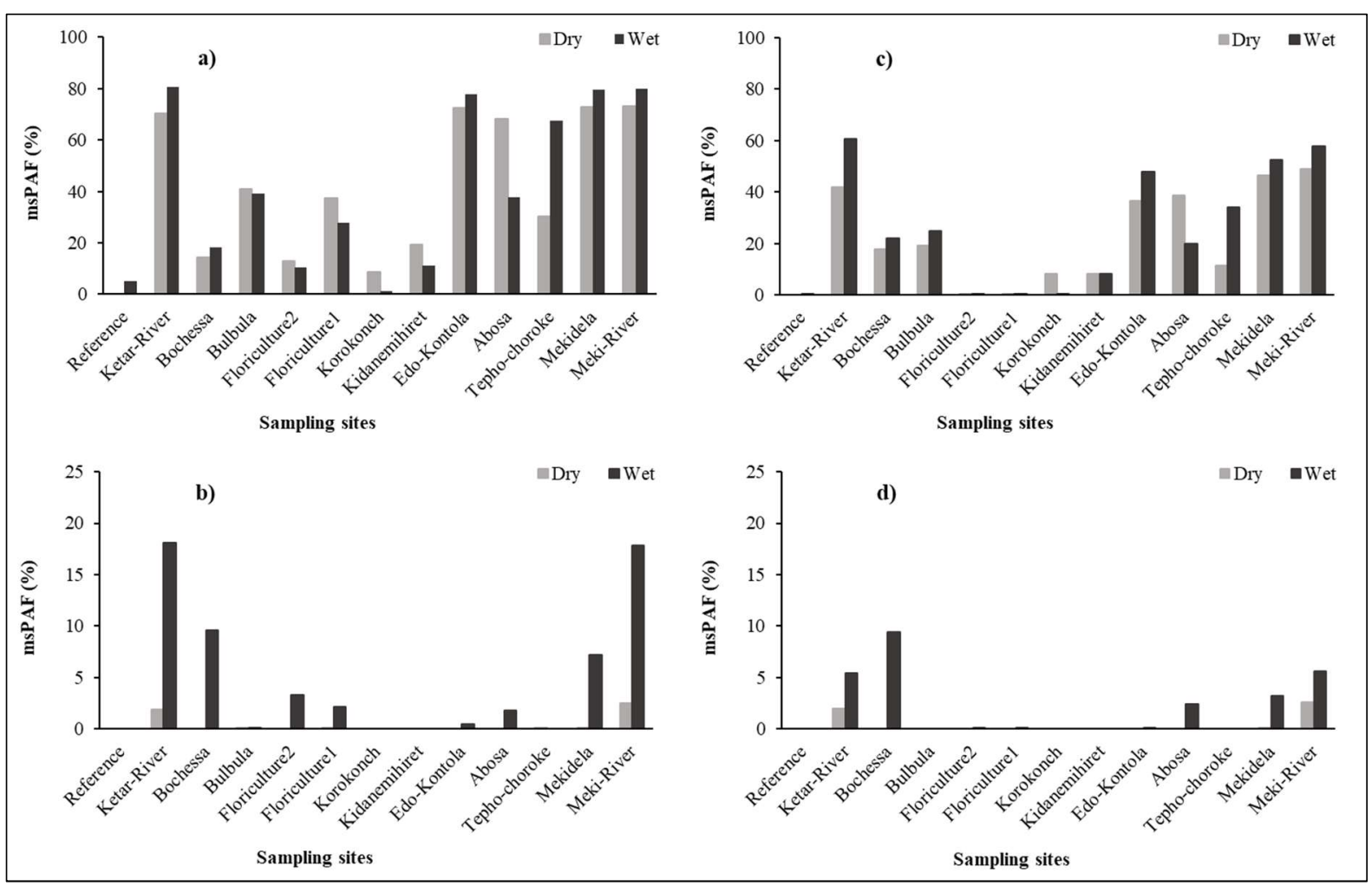

Fig. 4.2. Percentage of multi-substance potentially affected fraction (msPAF $(\%)$ ) of arthropods ( $a$ and $b$ ) and fishes ( $c$ and $d$ ) for mixture of pesticides observed in water ( $a$ and $c$ ) and sediment ( $b$ and $d$ ) samples collected from 13 locations of Lake Ziway in May 2017 (Dry) and in November 2017 (Wet).

\subsubsection{Site specific risk assessment for arthropods and fishes}

Most risk assessment tools evaluate individual pesticides for regulatory purposes. But, in reality, aquatic ecosystems are often exposed to a mixture of pesticides (Silva et al., 2015). The calculated acute toxicity data based $\mathrm{mSPAF}_{\mathrm{RA}}$ to evaluate the site specific risk of the mixture of measured pesticides in Lake Ziway to arthropods and fish are summarized in Fig. 4.2 and Table SI4.10.

Our results based on water concentrations at all sites, indicate that arthropods (median msPAF $_{R A}=37 \%$ ) are more affected compared to the fish community (median msPAF $F_{R A}=20 \%$ ). At the majority of sample locations, the $\mathrm{mSPAF}_{\mathrm{RA}}$ values for arthropods from water exposure were $>5 \%$ (i.e. higher than the acceptable threshold value in risk assessment) (Brock et al., 2011). In both sampling seasons, at sites of the lake close to smallholder farms, sites which receive floriculture farm's wastewater and those receiving inflow from rivers, pesticide mixtures pose high to very high acute risks to arthropods $\left(\mathrm{msPAF}_{\mathrm{RA}}>25 \%\right)$ through water exposure (Fig. 4.2a). During both seasons, fishes were under high to very high acute risks $\left(\right.$ msPAF $\left._{\mathrm{RA}}>25 \%\right)$ due to water exposure to pesticide mixtures at locations nearby smallholder farms and those receiving the inflow from rivers (Fig. 4.2c). The maximum $\mathrm{msPAF}_{\mathrm{RA}}$ values 
found in this study for arthropods (80\%) and fishes (60\%) from water exposure are higher than the values reported by Rämö et al. (2018) for arthropods (25\%) and fishes (0.2\%) in Madre de Dios River, Costa Rica. Silva et al. (2015) reported for Sado, Tejo and Mondego river basins $\mathrm{msPAF}_{\mathrm{RA}}$ values of $72 \%$ for Sado, $43 \%$ for Tejo and 39\% for Mondego for arthropods and 35\% for Sado, $25 \%$ for Tejo and $18 \%$ for Mondego for fishes. This shows that both communities were under higher risks due to exposure to pesticide mixtures in these river basins, like also is the case for Lake Ziway.

The risks of exposure to mixtures of pesticides through exposure by the sediment were low for arthropods and fishes. At most of the locations the sediment $\mathrm{mSPAF}_{\mathrm{RA}}$ values were $<1 \%$, indicating negligible risks (Fig. 4.2b and d; Table SI4.10).

Furthermore, our results indicate that the risk of the pesticides mixtures was not determined by an individual pesticide. The mixture of fenitrothion, malathion, chlorpyrifos, endosulfan, $\lambda$-cyhalothrin and $\alpha$-cypermethrin pesticides contributed to $75-100 \%$ of the mSPAFA $_{R A}$ for both community groups due to water exposures (Table SI4.11). Similarly, 88 $100 \%$ of arthropods $\mathrm{msPF}_{\mathrm{RA}}$ from sediment exposure was determined by a mixture of dimethoate, diazinon, fenitrothion, chlorpyrifos, $\lambda$-cyhalothrin, $\alpha$-cypermethrin and deltamethrin (Table SI4.12a). Moreover, the mixture of ethoprophos, diazinon, endosulfan, $\lambda$ cyhalothrin and $\alpha$-cypermethrin contributed to $75-100 \%$ of the fish msPAFRA due to sediment exposure (Table SI4.12b). Similarly, Rämö et al. (2018) reported that the mixture of chlorpyrifos, diazinon, ethoprophos, difenoconazole and carbaryl explained about $90 \%$ of the msPAF $_{R A}$ for arthropods and fish in the River Madre de Dios, Costa Rica. However, a high contribution of a single pesticide to the $\mathrm{mSPAF}_{\mathrm{RA}}$ for arthropods (chlorfenvinphos) and fish (endosulfan) was reported by Silva et al. (2015) for Mondego and Sado rivers, while high contribution of mixture of chlorfenvinphos and chlorpyrifos was reported for the Tejo river.

Our results indicate that evaluating mixtures of pesticides instead of individual pesticides in the ecological risk assessment using the msPAF model is important to avoid underestimation of overall risks as it also reported by Rämö et al. (2018). The approach can be applied for regulatory purposes as it may support a decision regarding further risk quantification, intervention actions, or approval of the ecological status of an ecosystem (Faggiano et al., 2010; Rämö et al., 2018). As this study only evaluated the risks of insecticides and fungicides, we recommend future studies focussing on the risks of herbicides, although 
their use is expected to be lower compared to insecticides and fungicides (Merga et al., 2020b).

\subsubsection{Effects on measured functional and structural parameters}

The RDA analysis showed that $97 \%$ of the variation in species composition and abundance between the sampling locations (Table SI4.13) was explained by the monitored environmental variables (Fig. 4.3; Fig. SI4.2). Fourteen environmental variables (Table SI4.13) that explain a significant part of the variation between the sites were identified using Monte Carlo permutation tests with simple term effects. But, the variables were reduced to four (metalaxyl, $\mathrm{NO}_{3}{ }^{-}$, carbaryl and diazinon) based on the conditional term effects (Fig. 4.3). These four variables explained $55 \%$ of the variation, where $68 \%$ of the variation was displayed on the first two axes.

The abundance of the majority of the macroinvertebrates species was negatively correlated with higher values of the environmental variables (Fig. 4.3; Fig. SI4.2). The EPT taxa (e.g., Polymitarcyidae, Caenidae, Baetidae, Limnephilidae and Taeniopterygidae) and Odonata (e.g. Coenagrionidae) showed a strong negative correlation to high levels of nutrients and pesticides (Fig. 4.3). This indicates that these taxa might be sensitive to water pollution. Similarly, many studies (Beyene et al., 2009; Costas et al., 2018; Getachew et al., 2012; Mereta et al., 2013) reported the sensitivity of EPT taxa and some Odonata species to water quality disturbances. Studies reported the tolerance of Chrionomidae to water pollution (Beyene et al., 2009; Kebede et al., 2020). We also found that Chironomidae, Corixidae, Notonectidae taxa were positively correlated to sites with higher levels of nutrients and pesticides (Fig. 4.3).

The Pearson correlation test between species abundance and $\operatorname{msPA}_{R A}$ showed a significant negative correlation with species from Polymitarcyidae, Baetidae, Caenidae, Taeniopterygida, Limnephilidae and Glossiphoniidae families $\left(r^{2}=0.389-0.583\right)$, and a significant positive correlation with species from Chironomidae, Psychodidae, Hydrophilidae, Noteridae, Gerridae and Pisauridae families $\left(r^{2}=0.399-0.641\right)$. But, for the majority of the species, the correlations were not significant, indicating the insensitivity of these taxa for the studied stressors or a contribution of other stressors including higher levels of nutrients.

Concentration levels of pesticides and physicochemical variables explained a significant (99\%) part of the variation observed in the values of biotic indices between sampling locations 
(Fig. 4.4; Fig. SI4.3). Metalaxyl, $\mathrm{NO}_{3}{ }^{-}, \mathrm{SO}_{4}{ }^{2-}$, endosulfan (sediment) and carbaryl were identified as significant using Monte Carlo permutation test with conditional term effects, and explained $62 \%$ of the variation (Table S14.14). Although significant in the conditional effects, TDS was not included as it did not explain a significant part when tested individually. The RDA triplot result (Fig. 4.4) shows that biotic indices are negatively correlated to high levels of nutrients and pesticides. $\mathrm{ICl}_{\text {score, }} \mathrm{BMWP}_{\text {score, }} \# \mathrm{EPT}_{\text {taxa, }} \# \mathrm{EPT}_{\text {abun }}$ and \%EPT taxa indices were highly associated to the sites with low values of nutrients and pesticides (e.g., Bochessa and Reference) (Fig. 4.4). The indices were negatively correlated to the disturbed locations i.e. locations correlated with high values of variables (Fig. 4.3; Fig. 4.4).

Pearson correlation result showed a negative correlation between biotic indices and msPAF $_{R A}$ values. Significant correlations were observed for \#EPT abun, \#EPT taxa, \%EPT tax and $\mathrm{ICl}_{\text {score }}$ indices $\left(r^{2}=0.565-0.723\right)$. However, the correlations were not significant for the majority (73\%) of biotic indices, showing that the effect of pesticides does not fully explain the variations observed in community composition between locations of the lake.

Furthermore, our result showed the sensitivity and applicability of biotic indices to monitor the water quality status of the studied lake. Some indices (e.g. based on EPT data) effectively distinguished pesticide impacted sites from sites with minimal disturbance (Fig. 4.4). As many studies (Aazami et al., 2015; Beyene et al., 2009; Mereta et al., 2013) recommended for surface waters affected by agricultural, industrial and urbanization activities, this study also showed the suitability of \#EPT taxa, \#EPT abun and \%EPT $T_{\text {taxa }}$ indices for water quality monitoring of Lake Ziway. The indices are easy and sensitive compared to conventional methods such as monitoring of physical and chemical variables (Abbasi and Abbasi, 2011). Similarly, Odume et al. (2012) have indicated that EPT richness index has the power to discriminate impacted from less impacted sites of Swartkops River, South Africa. Hamid and Rawi (2017) applied EPT richness tool on three Malaysian rivers (Tupah, Batu Hampar and Teroi), and reported the effectiveness of the tool, and recommended its application for surface water quality assessment. It should, however, be noted that these indices show the general water quality, not specifically water quality degradation due to pesticides (Schuwirth et al., 2015). 


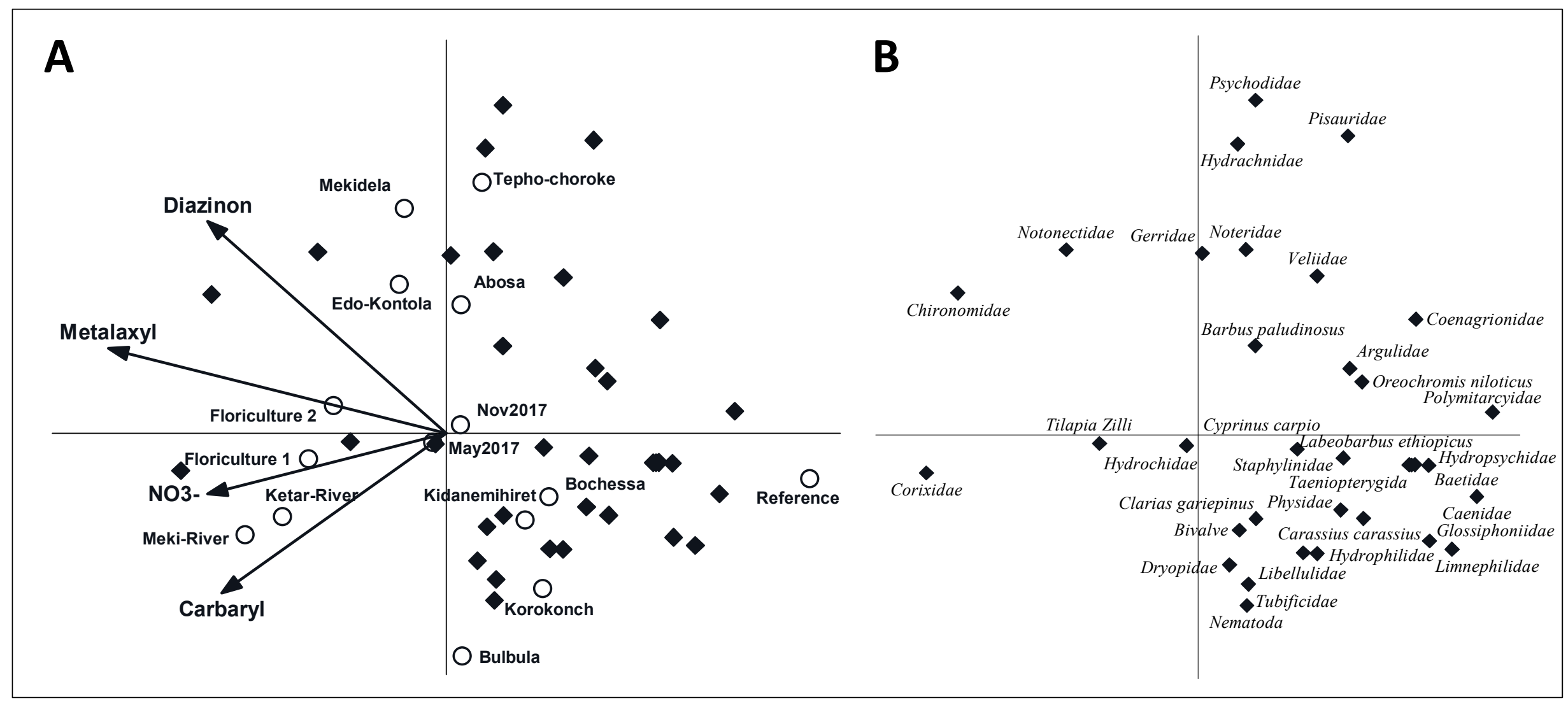

Fig. 4.3. RDA triplot (A: sample sites and environmental variables; B: species) showing the correlations between species abundance, environmental variables which explain a significant part of the variation in species composition using conditional effects (Table S14.2), sample sites and sampling date. The environmental variables explain 55\% of the variation in species composition of which $36 \%$ is displayed on the horizontal axis and another $32 \%$ on the vertical axis. 


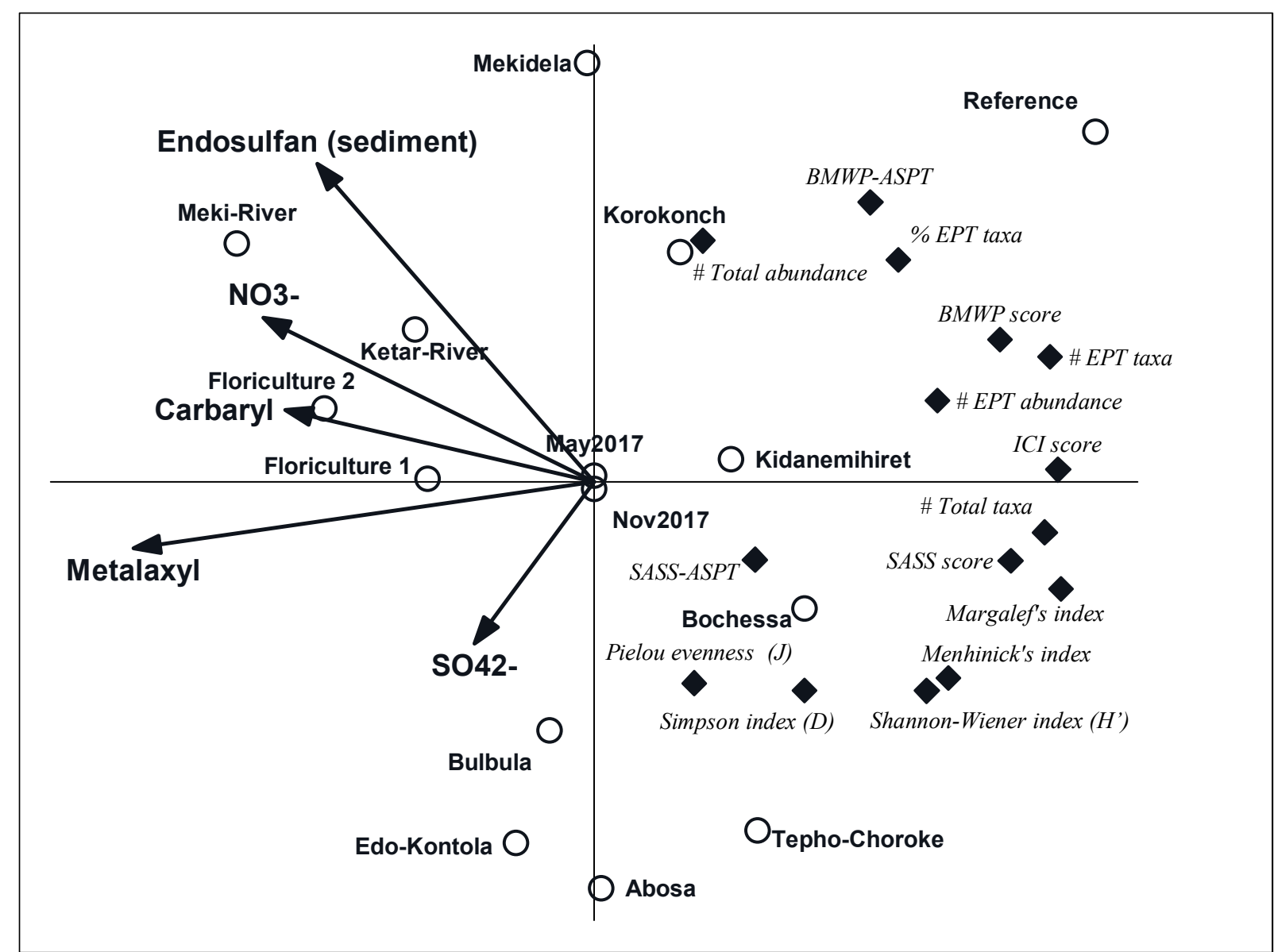

Fig. 4.4. RDA triplot showing the correlations between biotic indices values, environmental variables which explain a significant part of the variation in biotic indices values using conditional effects (Table SI4.4), sample sites and sampling date. The environmental variables explain $62 \%$ of the variation in biotic indices values of which $69 \%$ is displayed on the horizontal axis and another $16 \%$ on the vertical axis.

\subsection{Conclusions}

Pesticides released from small- and large-scale agricultural activities are posing ecological risks to biological communities in Lake Ziway. High contamination of pesticides was observed in water samples compared to sediment samples of the lake. Organophosphates and pyrethroids were the most ubiquitous pesticides in both matrixes. Compared to the previous reported values (Jansen and Harmsen, 2011; Teklu et al., 2018) an increasing trend in water concentration levels of many pesticides was observed, indicating lack of effective management of pesticides waste from agricultural activities. Our study was more comprehensive compared to Jansen and Harmsen (2011) and Teklu et al. (2018) in the sense that also biological endpoints were assessed and that the risk assessment went beyond the RQ method to calculate PAF values which also enable the evaluation of mixtures. The study shows the added value of this approach as more weight of evidence is obtained to link 
stressors with calculated risks as well to evaluate the risks posed by mixtures of pesticides instead of individual ones.

The levels of the majority of the pesticides exceeded $1^{\text {st }}$ and $2^{\text {nd }}$ tier PNECs, thus can cause detrimental effects on structural and functional characteristics of the lake. Intervention measures including smallholder farmers' training on pesticides safe management and use, strict monitoring of floriculture effluent and encouraging large-scale farmers to implement integrated pest management programmes (Mengistie, 2016) are urgently needed to avert the pollution and related risks. Management of urban waste from the nearby towns required attention. Assessing of ecological status of the lake with a simple and cheap tool e.g., EPT richness, is crucial for regulatory purposes.

\section{Acknowledgments}

The study was financially supported by Netherlands fellowship programmes, NUFFIC/ PhD studies, grant NFP - PhD.16/0019, reference number WIMEK2015 02. Special thanks to Batu Fishery and Other Aquatic Life Research Centre for the cooperation during monitoring programme. We declare that there are no conflicts of interest. 


\section{Appendix 4. Supplementary Information (SI)}

Section 4A. Complementary information about water sample collection, and physical and chemical analysis

Water samples were collected using Van Dorn sampler (HYDRO-BIOS, Germany) into precleaned $1 \mathrm{~L}$ volume polyethylene bottles. The samples were transported to laboratory using ice-box and stored at $4{ }^{\circ} \mathrm{C}$ until analysis. In-situ parameters $(\mathrm{pH}$, temperature, conductivity and dissolved oxygen; DO) were measured using portable multi-meter (HQ40d, HACH) and total dissolved solids (TDS) was determined using TDS meter (HI96301, HANNA). Other parameters such as nitrate, phosphate, sulphate, ammonia, alkalinity and chemical oxygen demand were measured according to methods described by (US-EPA, 1983). Chlorophyll-a was measured using spectrophotometric technique. Turbidity was measured using turbidimeter (WGZ-200-Biocotek, China).

Water samples for pesticide analysis were collected into, pre-cleaned (i.e. with detergent, acetone and distilled water), amber $1 \mathrm{~L}$ glass bottles (Van Dorn, Germany). The samples were transported to laboratory using cooled ice-box. In laboratory $5 \mathrm{~mL}$ of $2 \mathrm{~N} \mathrm{H}_{2} \mathrm{SO}_{4}$ and $10 \mathrm{~mL}$ methanol were added and stored at $4{ }^{\circ} \mathrm{C}$ and extraction were carried out within a week. The extraction protocol was adopted after Quintana et al. (2001) with small modification. Shortly, a pre-filtered (Whatman GF/A) $1 \mathrm{~L}$ water sample was passed over the conditioned BAKERBOND spe ${ }^{\mathrm{TM}}$, styrene divinylbenzene copolymer (SDB), sorbent (conditioning protocol: $3 \mathrm{ml}$ of ethyl acetate, $3 \mathrm{ml}$ of methanol and $6 \mathrm{ml}$ of water) at a flow-rate of $4 \mathrm{ml} / \mathrm{min}$. The sorbent was afterwards dried under nitrogen for $20 \mathrm{~min}$. Immediately, elution was performed by soaking the cartridge with $5 \mathrm{ml}$ of ethyl acetate twice at a flow-rate of $0.8 \mathrm{ml} / \mathrm{min}$ into an amber glass vial with top screw containing $0.5 \mathrm{ml}$ of isooctane. The eluted analyte was then dried under a gentle stream of nitrogen gas to $0.45 \mathrm{ml}$. The volume was precisely adjusted to $0.5 \mathrm{ml}$ of isooctane. Finally, $20 \mu \mathrm{l}$ of internal standard solution (Triphenyl Phosphate with concentration of $5 \mu \mathrm{g} / \mathrm{mL}$ ) was added to the extract and stored frozen at $-20^{\circ} \mathrm{C}$ until analysis.

Pesticides quantification were carried out using Clarus-600 gas chromatography (GC) coupled to Clarus-600T mass spectrometer (MS) detector (PerkinElmer, USA). A Restek Rtx ${ }^{\circledR}$ $5 \mathrm{MS}$ (cross-bond with 5\% diphenyl - 95\% dimethyl polyslloxane) capillary column (30 m length, $0.32 \mathrm{~mm}$ internal diameter and $0.25 \mu \mathrm{m}$ film thickness) was used for separation with helium (purity $=99.999 \%$ ) as carrier gas at a flow rate of $1.5 \mathrm{~mL} /$ minute. The GC column condition 
was programmed at $100{ }^{\circ} \mathrm{C}$ hold for $1 \mathrm{~min}$, then raise to $200{ }^{\circ} \mathrm{C}$ at $10^{\circ} \mathrm{C} \mathrm{min}-1$ rate and hold for 4 minutes, again up to $250{ }^{\circ} \mathrm{C}$ at $30{ }^{\circ} \mathrm{C} \mathrm{min}-1$ rate and hold for 2.33 minutes, and finally increased to $280^{\circ} \mathrm{C}$ at a rate of $30^{\circ} \mathrm{C} \mathrm{min}^{-1}$ and hold for 5 minutes. The total run time was 25 minutes. The injector temperature was set at $270{ }^{\circ} \mathrm{C}$, while the split/splitless injector was operated in splitless mode. A sample volume of $1 \mu \mathrm{L}$ was injected. The MS detector was operated in positive ionization mode $\left(\mathrm{El}^{+}\right)$where its ion source and transfer line temperature, and electron energy was adjusted at $270{ }^{\circ} \mathrm{C}$ and $74 \mathrm{ev}$, respectively. The filament emission current of the detector was $2.71 \mathrm{~A}$. Samples analysis were performed with the use of selected ion recording (SIR) mode in which each target compound was dwelled for a time of 0.5 second (see Table SI4.1). The monitored ions and retention time of each target compounds that have been used during samples analysis with SIR mode was identified by injecting individual pesticide standard in full scan mode using mass to charge ratio in the range of $50-500 \mathrm{~m} / \mathrm{z}$. For more detailed information see Table S14.1. Pesticide residue quantification was performed using internal standard based response factor (RF) approach following the quantification method described by Hladik et al. (2009).

\section{Section 4B. Complementary information about sediment sample collection, extraction and chemical analysis}

Sediment samples $(0-5 \mathrm{~cm})$ collected using Ekman grab sampler into aluminium foil and wrapped, and kept in zipped polyethylene bags. The samples were transported to laboratory using cooled ice-box and kept in freezer at $-20^{\circ} \mathrm{C}$. Total organic matter (TOM\%) and fraction of organic carbon ( $\left.f_{o c}\right)$ were analysed using dichromate method (Ryan et al., 2001) and used to calculate pore water concentrations of pesticides in sediment.

The extraction protocol for sediment pesticides was adopted after Vega et al. (2005) with little modification. Pesticides were extracted from homogenized and air dried $30 \pm 0.0001 \mathrm{~g}$ sediment sample with $70 \mathrm{~mL}$ of methanol-water (4:1 v/v) by shaking for 45 minutes with orbit shaker (VRN-480, GEMMY, Taiwan) at a speed of $273 \mathrm{rpm}$ followed by sonication for 20 minutes through digital ultrasonic water bath (CD-4820, Jeken $\left.{ }^{\circledR}, \mathrm{China}\right)$. The sonicated sample then subjected to filtration using GF/A filter followed by removal of organic solvent using vacuum rotary evaporator (RE-52A, Lanphan Henan, China) at $50{ }^{\circ} \mathrm{C}$ for 45 minutes and the residual analyte was made up to $1000 \mathrm{~mL}$ volume with distilled water. For clean-up, extraction 
of pesticides from the residual water and quantification of the residual pesticides similar procedures used for water sample were fully employed.

Section 4C. Complementary information about method validation, quality assurance and quality control for pesticides determination

To validate our analytical method we have performed various validation parameters. To check sensitivity and linearity of the response of the instrument (Vega et al., 2005), calibration curves were plotted. For each targeted compounds calibration curves were plotting using the peak area against the concentration of the corresponding calibration standards at five calibration concentration levels ranging between $0.1-250 \mu \mathrm{g} / \mathrm{L}$. The obtained $\mathrm{r}^{2}$ values were range from 0.9668 - 0.9995 (Table SI4.1). To validate the extraction efficiency of the employed method (Vega et al., 2005), recovery analysis were performed by spiking known concentration levels of each target pesticide compound to water and sediment samples (taken as blank samples) collected from unpolluted temporary pond found nearby Ambo University, Ethiopia (coordinate: $8^{\circ} 59^{\prime} 29.9868^{\prime \prime} \mathrm{N}, 37^{\circ} 50^{\prime} 24.0108^{\prime \prime} \mathrm{E}$ ). The recoveries observed was ranged from $79.8-94.1 \%$ for water and $75.3-99.5 \%$ for sediment, and the relative standard deviation (\%RSD) was ranged from 1.8 - 15.9 and 1.9 - 14.8 for water and sediment, respectively (Table SI4.1).

\section{Section 4D. Complementary information about biological samples and biotic indices}

In short, macroinvertebrates were collected from the littoral part of the lake by a D-shaped net $(50 \times 50 \mathrm{~cm} ; 500 \mu \mathrm{m}$ mesh) using the traveling kick and sweep sampling technique by transecting the sampling area. Each sampling used a standardized sampling time (10 minutes), habitat (littoral vegetation) and sampling area (50 m x $1.5 \mathrm{~m}=75 \mathrm{~m}^{2}$ ) as recommended by Meutter et al. (2006) and Beyene et al. (2009). From each sampling site triplicate samples were collected separately, but latter composited into one bucket. Sorting was done in laboratory. Taxonomic identification was performed to family level using expert and guide books by Kriska (2014).

Nylon made beach seine net (length $60 \mathrm{~m}$, depth $8 \mathrm{~m}$ and mesh size of $40 \mathrm{~mm}$ ) was used to sample live fishes the suggestions by Portt et al. (2006) and EPP (2017) into consideration. To better ensure comparability of the results among sites, maximum care was taken by employing similar sampling efforts at each sites. Triplicate samples were collected per site but 
caught fishes were pooled to a single water filled bucket. Length $(\mathrm{cm})$ and weight $(\mathrm{g})$ were measure, and taxonomic identification were performed. The fish were released back into the lake.

Table S14.1. Physicochemical properties (LogKow, water solubility and half-life (DT50)) of the studied pesticides in water and sediment of Lake Ziway.

\begin{tabular}{lrrrrrr} 
Pesticides & LogKow & $\begin{array}{c}\text { Water } \\
\text { Solubility } \\
\text { (mg/L) }\end{array}$ & $\begin{array}{c}\text { Aqueous } \\
\text { hydrolysis } \\
\text { DT }_{\text {50 }}\end{array}$ & $\begin{array}{c}\text { Aqueous } \\
\text { photolysis } \\
\text { DT }_{\mathbf{5 0}}\end{array}$ & $\begin{array}{c}\text { Water- } \\
\text { sediment } \\
\text { DT }_{\mathbf{5 0}}\end{array}$ & $\begin{array}{c}\text { Soil } \\
\text { degradation } \\
\text { DT }_{\mathbf{5 0}}\end{array}$ \\
\hline Propamocarb & 0.84 & 900000 & na & na & na & 14 \\
Acephate & -0.85 & 790000 & 50 day & 2 day & na & 3 \\
Ethoprophos & 2.99 & 1300 & stable & stable & 83 & 1.3 \\
Dimethoate & 0.704 & 25900 & 68 & 175 & 15.5 & 7.2 \\
Diazinon & 3.69 & 60 & 138 & 50 & 10.4 & 18.4 \\
Chlorothalonil & 2.94 & 0.81 & 29.6 & 0.72 & 0.57 & 17.9 \\
Carbaryl & 2.36 & 9.1 & 12 & 10 & 5.8 & 16 \\
Metalaxyl & 1.75 & 8400 & 106 & stable & 56 & 38.7 \\
Fenitrothion & 3.32 & 19 & 183 & 3.5 & 1.57 & 2.7 \\
Malathion & 2.75 & 148 & 6.2 & 98 & 0.4 & 1 \\
Chlorpyrifos & 4.7 & 1.05 & 53.5 & 29.6 & 36.5 & 27.6 \\
Profenofos & 1.7 & 28 & stable & na & na & 7 \\
Iprovalicarb & 3.2 & 17.8 & stable & stable & 181 & 15.5 \\
Endosulfan & 4.75 & 0.32 & 20 & na & na & 86 \\
Dicofol & 4.3 & 0.8 & 3.3 & 26 & 29 & 80 \\
$\lambda$-cyhalothrin & 5.5 & 0.005 & stable & 40 & 15.1 & 26.9 \\
Acrinathrin & 6.3 & 0.0022 & stable & 2.3 & 18.6 & 22 \\
$\alpha$-cypermethrin & 5.5 & 0.004 & 70 & 6.3 & 21 & 42.6 \\
Deltamethrin & 4.6 & 0.0002 & stable & na & 65 & 21 \\
\hline
\end{tabular}

Source: Pesticide Properties DataBase (PPDB) of University of Hertfordshire:

(https://sitem.herts.ac.uk/aeru/ppdb/en/index.htm), na = not available 
Table SI4.2. Targeted pesticide compound, selected ion recording (SIR) ions (mass/charge ratio) with SIR retention time range ( $R_{t}$ in minutes) used for mass spectrometer (MS) detector, linear concentration range used to plot calibration curve, calibration equation obtained with respective $r^{2}$, recoveries with its percent relative standard deviation (\%RSD), and limit of quantifications (LOQ) and limit of detections (LOD) for each pesticides monitored in water and sediment samples collected from shoreline sites of Lake Ziway. The SIR values in bold are base peak of MS spectrum for each pesticide.

\begin{tabular}{|c|c|c|c|c|c|c|c|c|c|c|c|c|c|}
\hline \multirow[b]{2}{*}{ Pesticide } & \multirow[b]{2}{*}{$\begin{array}{c}\text { SIR } \\
(\mathrm{m} / \mathrm{z})\end{array}$} & \multirow{2}{*}{$\begin{array}{c}\text { SIR } \\
\mathrm{R}_{\mathrm{t}} \text { range } \\
\text { (min) }\end{array}$} & \multirow[b]{2}{*}{$\begin{array}{l}\text { Linear range } \\
\quad(\mu \mathrm{g} / \mathrm{L})\end{array}$} & \multirow[b]{2}{*}{ Calibration equation } & \multirow[b]{2}{*}{$r^{2}$} & \multicolumn{4}{|c|}{ Water } & \multicolumn{4}{|c|}{ Sediment } \\
\hline & & & & & & $\begin{array}{l}\text { LOD } \\
(\mu \mathrm{g} / \mathrm{L})\end{array}$ & $\begin{array}{c}\text { LOQ } \\
(\mu \mathrm{g} / \mathrm{L})\end{array}$ & $\begin{array}{c}\text { Recovery } \\
\text { (\%) }\end{array}$ & $\begin{array}{l}\text { RSD } \\
\text { (\%) }\end{array}$ & $\begin{array}{c}\text { LOD } \\
(\mu \mathrm{g} / \mathrm{Kg}- \\
\mathrm{dw})\end{array}$ & $\begin{array}{c}\text { LOQ } \\
(\mu \mathrm{g} / \mathrm{Kg} \\
-\mathrm{dw})\end{array}$ & $\begin{array}{c}\text { Recovery } \\
\text { (\%) }\end{array}$ & $\begin{array}{l}\text { RSD } \\
\text { (\%) }\end{array}$ \\
\hline Propamocarb & $58,72,129,188$ & $6.0-6.40$ & $0.2-150$ & $y=16.098 x+1443.1$ & 0.9774 & 0.039 & 0.125 & 89.92 & 14.29 & 0.14 & 0.47 & 93.85 & 4.64 \\
\hline Acephate & $136,142,94,183$ & $6.40-7.74$ & $1.0-250$ & $y=4.0633 x+366.22$ & 0.9909 & 0.270 & 0.858 & 79.80 & 9.07 & 0.28 & 0.89 & 97.72 & 7.83 \\
\hline Ethoprophos & $158,97,139,242$ & $7.75-8.85$ & $0.2-150$ & $y=5.8978 x+410.96$ & 0.9885 & 0.033 & 0.105 & 81.38 & 7.60 & 0.11 & 0.35 & 99.50 & 12.16 \\
\hline Dimethoate & $87,125,143,229$ & $8.85-9.91$ & $0.1-100$ & $y=13.864 x+312.95$ & 0.9901 & 0.017 & 0.053 & 88.90 & 14.68 & 0.09 & 0.30 & 80.52 & 10.34 \\
\hline Diazinon & $137,179,152,304$ & $9.91-10.59$ & $0.1-100$ & $y=14.103 x+194.32$ & 0.9911 & 0.026 & 0.083 & 94.12 & 9.73 & 0.11 & 0.36 & 78.69 & 13.12 \\
\hline Chlorothalonil & $266,264,268$ & $10.59-10.84$ & $0.1-100$ & $y=9.0427 x+94.5$ & 0.9919 & 0.001 & 0.003 & 90.89 & 9.47 & 0.06 & 0.20 & 94.79 & 1.90 \\
\hline Carbaryl & 144, 115, 116, 201 & $10.84-11.65$ & $0.1-100$ & $y=14.273 x+381.8$ & 0.9931 & 0.008 & 0.025 & 85.83 & 4.52 & 0.10 & 0.35 & 86.24 & 7.80 \\
\hline Metalaxyl & 206, 160, 146, 279 & $11.65-11.86$ & $0.2-150$ & $y=4.6399 x+170.67$ & 0.9948 & 0.032 & 0.102 & 91.40 & 8.53 & 0.37 & 1.23 & 92.30 & 3.81 \\
\hline Fenitrothion & $125,109,277,260$ & $11.87-12.18$ & $0.1-100$ & $y=10.234 x+322.3$ & 0.9957 & 0.024 & 0.077 & 89.95 & 8.19 & 0.21 & 0.69 & 94.79 & 4.23 \\
\hline Malathion & $127,125,173,330$ & $12.18-12.48$ & $0.1-100$ & $y=13.813 x+252$ & 0.9984 & 0.021 & 0.068 & 89.73 & 6.39 & 0.16 & 0.55 & 95.45 & 8.94 \\
\hline Chlorpyrifos & $97,199,258,350$ & $12.48-12.76$ & $0.2-150$ & $y=9.6452 x+476.98$ & 0.9933 & 0.046 & 0.148 & 93.25 & 5.74 & 0.20 & 0.66 & 92.08 & 8.28 \\
\hline Profenofos & $139,206,207,364$ & $15.15-15.79$ & $1.0-200$ & $y=238.5 x+22189$ & 0.9957 & 0.293 & 0.933 & 92.33 & 4.67 & 0.313 & 0.995 & 75.33 & 4.58 \\
\hline Iprovalicarb & $116,119,134,320$ & $15.79-16.05$ & $0.2-150$ & $y=7.4816 x+766.33$ & 0.9908 & 0.054 & 0.171 & 89.03 & 15.90 & 0.041 & 0.129 & 88.04 & 4.47 \\
\hline Endosulfan & $195,161,160,407$ & $16.21-16.60$ & $0.5-200$ & $y=10.55 x+347.05$ & 0.9939 & 0.13 & 0.42 & 90.28 & 5.32 & 0.20 & 0.63 & 79.91 & 14.37 \\
\hline Dicofol & $139,251,111,370$ & $17.62-18.41$ & $0.2-150$ & $y=14.138 x+856.5$ & 0.9995 & 0.050 & 0.159 & 84.20 & 7.40 & 0.23 & 0.76 & 84.36 & 8.44 \\
\hline$\lambda$-cyhalothrin & $181,197,208,450$ & $18.42-19.41$ & $0.5-200$ & $y=226.68 x+19192$ & 0.9921 & 0.14 & 0.45 & 85.69 & 7.41 & 0.14 & 0.46 & 78.30 & 14.84 \\
\hline Acrinathrin & $181,208,289$ & $19.42-19.80$ & $1.0-250$ & $y=300.83 x+28421$ & 0.9841 & 0.20 & 0.64 & 80.09 & 5.16 & 0.21 & 0.68 & 87.48 & 3.59 \\
\hline$\alpha$-cypermethrin & $181,163,165,416$ & $20.50-22.00$ & $1.0-250$ & $y=332.04 x+25207$ & 0.9668 & 0.19 & 0.61 & 87.27 & 1.80 & 0.22 & 0.71 & 87.28 & 3.98 \\
\hline Deltamethrin & $181,253,209,77$ & $22.35-22.90$ & $0.5-200$ & $y=1145.8 x+118013$ & 0.9849 & 0.15 & 0.48 & 86.60 & 9.87 & 0.17 & 0.54 & 86.78 & 9.25 \\
\hline
\end{tabular}


Table S14.3. Acute tier 1 PNEC, chronic tier 1 PNEC and acute tier 2 PNEC values used for risk assessment of the pesticides measured in Lake Ziway, Ethiopia.

\begin{tabular}{lrrr}
\hline Pesticides & $\begin{array}{c}\text { Acute tier-1 } \\
\text { PNEC }\end{array}$ & $\begin{array}{c}\text { Chronic tier-1 } \\
\text { PNEC }\end{array}$ & $\begin{array}{r}\text { Acute tier-2 } \\
\text { PNEC }\end{array}$ \\
\hline Propamocarb & 968 & 30100 & 7950 \\
Acephate & 73 & 4300 & 80 \\
Ethoprophos & 0.15 & 0.057 & 0.18 \\
Dimethoate & 0.013 & 0.093 & 0.28 \\
Diazinon & 0.0057 & 0.056 & 0.075 \\
Chlorothalonil & 0.35 & 0.096 & 2.2 \\
Carbaryl & 0.094 & 25 & 0.37 \\
Metalaxyl & 235 & 372 & 321 \\
Fenitrothion & 0.038 & 0.0087 & 0.063 \\
Malathion & 0.004 & 0.006 & 0.093 \\
Chlorpyrifos & 0.0004 & 0.01 & 0.0085 \\
Profenofos & 0.019 & na & 0.029 \\
Iprovalicarb & $>198$ & 189 & na \\
Endosulfan & 0.013 & na & 0.024 \\
Dicofol & 0.6 & 12500 & 8.5 \\
Lambda-cyhalothrin & 0.00022 & na \\
Acrinathrin & 0.00012 & 0.00032 & 0.0013 \\
Alphacypermethrin & 0.003 & 0.00053 \\
Deltamethrin & 0.00013 & 0.0000034 & 0.0038 \\
\hline NB: & 0.00055 & & \\
\hline
\end{tabular}

NB: na = sufficient data was not available to calculate the PNEC

Table S14.4. Pesticides quantified in water and sediments of Lake Ziway with their respective Toxicological Mode of Action, and median $(\mu)$ and standard deviation $(\delta)$ of the log-transformed acute toxicity values for arthropods and fish. For pesticides with "na", no sufficient acute toxicity data was found to calculate the median and standard deviation values.

\begin{tabular}{l|l|l|rr|rr}
\hline \multirow{2}{*}{ Pesticides } & \multicolumn{2}{c}{ Toxic Mode of Action } & \multicolumn{2}{c|}{ Arthropods } & \multicolumn{2}{c}{ Fish } \\
\cline { 2 - 7 } & Arthropods & Fish & median $(\boldsymbol{\mu})$ & STD $(\boldsymbol{\delta})$ & median $(\boldsymbol{\mu})$ & STD $(\boldsymbol{\delta})$ \\
\hline Propamocarb & Not known & Not known & 5.02 & 0.0038 & 5.28 & 0.42 \\
Ethoprophos & AChE-Inhibitor & AChE-Inhibitor & 1.17 & 0.88 & 2.83 & 0.99 \\
Dimethoate & AChE-Inhibitor & AChE-Inhibitor & 2.90 & 1.27 & 3.89 & 0.94 \\
Diazinon & AChE-Inhibitor & AChE-Inhibitor & 1.38 & 1.02 & 3.50 & 0.74 \\
Carbaryl & AChE-Inhibitor & AChE-Inhibitor & 1.87 & 1.19 & 3.67 & 0.45 \\
Fenitrothion & AChE-Inhibitor & AChE-Inhibitor & 1.08 & 1.13 & 3.44 & 0.84 \\
Malathion & AChE-Inhibitor & AChE-Inhibitor & 1.65 & 1.22 & 2.99 & 0.85 \\
Chlorpyrifos & AChE-Inhibitor & AChE-Inhibitor & 0.32 & 1.09 & 2.35 & 1.07 \\
Metalaxyl & Not known & Not known & 4.11 & 1.06 & 5.37 & 0.34 \\
Iprovalicarb & Not known & Not known & na & na & na & na \\
Endosulfan & GABA-Blocker & GABA-Blocker & 1.12 & 1.28 & 0.52 & 0.86 \\
$\lambda$-cyhalothrin & SCh-modulator & SCh-modulator & -0.64 & 1.30 & 0.53 & 1.26 \\
$\alpha$-cypermethrin & SCh-modulator & SCh-modulator & -0.36 & 1.12 & 0.57 & 1.82 \\
Deltamethrin & SCh-modulator & SCh-modulator & -0.95 & 1.08 & 1.60 & 1.49 \\
\hline
\end{tabular}

NB: AChE-inhibitor = Acetylcholinesterase (AChE) inhibitors, GABA-Blocker = gamma-aminobutyric acid (GABA)-gated chloride channel blockers and SCh-modulator $=$ Sodium channel(SCh) modulators 
Table SI4.5. Abundance (\#) of biological organisms (fishes and macroinvertebrates) monitored at thirteen shoreline sites of Lake Ziway during May 2017 and November 2017.

\begin{tabular}{|c|c|c|c|c|c|c|c|c|c|c|c|c|c|c|c|c|}
\hline Sampling date & Sample site & On & $\mathrm{Cg}$ & Сус & Cc & $\mathrm{Bp}$ & $\mathrm{Tz}$ & Le & Po & $\mathrm{Ba}$ & $\mathrm{Ca}$ & Hydrop & Limn & Taen & Arg & Chiro \\
\hline May 2017 & 1 & 14 & 1 & 0 & 1 & 0 & 0 & 0 & 44 & 46 & 16 & 0 & 2 & 0 & 3 & 17 \\
\hline May 2017 & 2 & 9 & 0 & 2 & 0 & 2 & 0 & 0 & 2 & 129 & 0 & 0 & 0 & 0 & 7 & 2 \\
\hline May 2017 & 3 & 0 & 1 & 0 & 0 & 0 & 0 & 0 & 8 & 62 & 0 & 0 & 0 & 0 & 11 & 340 \\
\hline May 2017 & 4 & 5 & 0 & 0 & 0 & 0 & 1 & 0 & 0 & 50 & 0 & 0 & 0 & 0 & 2 & 351 \\
\hline May 2017 & 5 & 7 & 0 & 0 & 0 & 0 & 0 & 0 & 54 & 468 & 247 & 0 & 70 & 0 & 4 & 48 \\
\hline May 2017 & 6 & 1 & 0 & 1 & 0 & 0 & 0 & 0 & 5 & 503 & 168 & 0 & 26 & 0 & 0 & 160 \\
\hline May 2017 & 7 & 4 & 0 & 0 & 0 & 0 & 0 & 0 & 0 & 72 & 0 & 0 & 0 & 0 & 2 & 295 \\
\hline May 2017 & 8 & 35 & 1 & 0 & 2 & 1 & 0 & 0 & 44 & 516 & 0 & 0 & 4 & 0 & 3 & 215 \\
\hline May 2017 & 9 & 68 & 0 & 0 & 0 & 1 & 0 & 0 & 4 & 8 & 3 & 0 & 0 & 0 & 2 & 77 \\
\hline May 2017 & 10 & 12 & 0 & 2 & 0 & 2 & 0 & 0 & 5 & 49 & 2 & 0 & 0 & 0 & 6 & 693 \\
\hline May 2017 & 11 & 2 & 0 & 0 & 1 & 1 & 0 & 0 & 0 & 7 & 0 & 0 & 0 & 0 & 0 & 361 \\
\hline May 2017 & 12 & 61 & 8 & 4 & 0 & 2 & 0 & 0 & 184 & 980 & 724 & 6 & 49 & 32 & 37 & 53 \\
\hline May 2017 & 13 & 19 & 4 & 0 & 0 & 5 & 0 & 0 & 0 & 6 & 4 & 0 & 2 & 0 & 3 & 659 \\
\hline Nov. 2017 & 1 & 9 & 0 & 0 & 2 & 10 & 0 & 0 & 100 & 27 & 60 & 0 & 5 & 0 & 8 & 43 \\
\hline Nov. 2017 & 2 & 56 & 0 & 27 & 5 & 1 & 0 & 0 & 59 & 24 & 0 & 0 & 0 & 0 & 9 & 7 \\
\hline Nov. 2017 & 3 & 1 & 0 & 2 & 0 & 3 & 0 & 0 & 28 & 76 & 0 & 0 & 0 & 0 & 6 & 322 \\
\hline Nov. 2017 & 4 & 17 & 0 & 0 & 0 & 2 & 0 & 0 & 8 & 7 & 0 & 0 & 0 & 0 & 9 & 319 \\
\hline Nov. 2017 & 5 & 25 & 0 & 1 & 0 & 0 & 0 & 0 & 4 & 406 & 196 & 0 & 29 & 0 & 8 & 90 \\
\hline Nov. 2017 & 6 & 10 & 0 & 1 & 0 & 0 & 0 & 0 & 42 & 465 & 123 & 0 & 12 & 0 & 0 & 254 \\
\hline Nov. 2017 & 7 & 27 & 0 & 8 & 0 & 2 & 0 & 0 & 22 & 119 & 0 & 0 & 0 & 0 & 44 & 271 \\
\hline Nov. 2017 & 8 & 14 & 0 & 5 & 0 & 2 & 0 & 0 & 18 & 30 & 0 & 0 & 0 & 0 & 26 & 150 \\
\hline Nov. 2017 & 9 & 6 & 0 & 0 & 0 & 8 & 0 & 0 & 11 & 46 & 22 & 0 & 2 & 0 & 43 & 121 \\
\hline Nov. 2017 & 10 & 7 & 0 & 3 & 0 & 1 & 0 & 0 & 15 & 76 & 3 & 0 & 0 & 0 & 0 & 410 \\
\hline Nov. 2017 & 11 & 8 & 1 & 0 & 0 & 1 & 0 & 0 & 4 & 10 & 0 & 0 & 0 & 0 & 4 & 341 \\
\hline Nov. 2017 & 12 & 90 & 3 & 23 & 6 & 5 & 0 & 6 & 430 & 1212 & 540 & 14 & 32 & 20 & 29 & 31 \\
\hline Nov. 2017 & 13 & 12 & 4 & 3 & 0 & 2 & 0 & 0 & 0 & 11 & 0 & 0 & 0 & 0 & 2 & 317 \\
\hline
\end{tabular}

Note: 1 = Bochessa, 2 = Bulbula, $3=$ Floriculture2, $4=$ Floriculture1, $5=$ Korokonch, $6=$ Kidanemihiret, $7=$ Edo-Kontola, $8=$ Abosa, $9=$ Tepho-Choroke, $10=$ Mekidela, $11=$ Meki-River, $12=$ Reference and $13=$ Ketar-River. On = Oreochromis niloticus, $\mathrm{Cg}=$ Clarias gariepinus, $\mathrm{Cyc}=$ Cyprinus carpio, $\mathrm{Cc}=$ Carassius carassius, $\mathrm{Bp}=$ Barbus paludinosus, Tz = Tilapia Zilli, Le = Labeobarbus ethiopicus, $\mathrm{Po}=$ Polymitarcyidae, $\mathrm{Ba}=$ Baetidae, $\mathrm{Ca}=$ Caenidae, Hydrop $=$ Hydropsychidae, Limn $=$ Limnephilidae, Taen $=$ Taeniopterygidae, Arg $=$ Argulidae, Chiro $=$ Chironomidae 
Table S14.5. ...cont'd.

\begin{tabular}{|c|c|c|c|c|c|c|c|c|c|c|c|c|c|c|c|c|c|c|c|c|}
\hline Sampling date & Sample site & Hydroch & Psych & Sta & Dry & Hyd & Not & Con & Libe & Pis & Vel & Gerr & Hydra & Noto & Cori & $\mathrm{Bi}$ & Phys & Tub & Nem & Glo \\
\hline May 2017 & 1 & 0 & 0 & 0 & 0 & 2 & 29 & 19 & 4 & 6 & 2 & 0 & 0 & 170 & 20 & 0 & 0 & 0 & 0 & 1 \\
\hline May 2017 & 2 & 0 & 0 & 0 & 398 & 0 & 5 & 2 & 62 & 0 & 4 & 0 & 0 & 3 & 50 & 0 & 27 & 4 & 4 & 0 \\
\hline May 2017 & 3 & 0 & 10 & 0 & 0 & 0 & 5 & 28 & 3 & 0 & 0 & 0 & 17 & 188 & 432 & 0 & 0 & 0 & 0 & 0 \\
\hline May 2017 & 4 & 0 & 0 & 0 & 0 & 0 & 21 & 18 & 0 & 0 & 20 & 0 & 0 & 700 & 202 & 0 & 0 & 0 & 18 & 0 \\
\hline May 2017 & 5 & 0 & 0 & 0 & 0 & 0 & 4 & 5 & 0 & 0 & 0 & 0 & 4 & 117 & 14 & 0 & 0 & 12 & 15 & 0 \\
\hline May 2017 & 6 & 0 & 0 & 0 & 0 & 0 & 8 & 15 & 0 & 5 & 0 & 0 & 4 & 160 & 124 & 4 & 0 & 0 & 7 & 2 \\
\hline May 2017 & 7 & 0 & 21 & 0 & 0 & 0 & 23 & 3 & 6 & 60 & 59 & 0 & 20 & 222 & 179 & 0 & 0 & 0 & 0 & 0 \\
\hline May 2017 & 8 & 0 & 14 & 0 & 0 & 0 & 21 & 9 & 0 & 31 & 34 & 0 & 16 & 106 & 52 & 0 & 3 & 5 & 0 & 0 \\
\hline May 2017 & 9 & 0 & 34 & 0 & 0 & 0 & 8 & 25 & 0 & 25 & 26 & 98 & 59 & 183 & 29 & 0 & 0 & 0 & 0 & 0 \\
\hline May 2017 & 10 & 0 & 124 & 0 & 0 & 0 & 37 & 2 & 4 & 44 & 0 & 45 & 33 & 624 & 87 & 0 & 0 & 0 & 0 & 0 \\
\hline May 2017 & 11 & 0 & 0 & 0 & 0 & 0 & 0 & 1 & 2 & 0 & 0 & 0 & 0 & 567 & 296 & 0 & 0 & 9 & 0 & 0 \\
\hline May 2017 & 12 & 0 & 6 & 2 & 0 & 4 & 12 & 29 & 20 & 7 & 17 & 5 & 4 & 106 & 80 & 0 & 6 & 9 & 12 & 11 \\
\hline May 2017 & 13 & 0 & 0 & 0 & 0 & 11 & 23 & 0 & 4 & 0 & 0 & 97 & 0 & 100 & 494 & 0 & 0 & 42 & 0 & 0 \\
\hline Nov. 2017 & 1 & 0 & 0 & 0 & 0 & 7 & 7 & 288 & 5 & 5 & 6 & 0 & 0 & 85 & 20 & 0 & 0 & 0 & 0 & 0 \\
\hline Nov. 2017 & 2 & 0 & 0 & 0 & 365 & 0 & 4 & 3 & 164 & 0 & 5 & 0 & 0 & 5 & 161 & 0 & 21 & 3 & 2 & 3 \\
\hline Nov. 2017 & 3 & 0 & 7 & 0 & 0 & 0 & 3 & 48 & 0 & 0 & 0 & 0 & 14 & 304 & 365 & 0 & 0 & 0 & 0 & 0 \\
\hline Nov. 2017 & 4 & 0 & 0 & 0 & 0 & 0 & 4 & 19 & 0 & 0 & 39 & 0 & 3 & 733 & 179 & 0 & 0 & 0 & 4 & 0 \\
\hline Nov. 2017 & 5 & 0 & 0 & 0 & 0 & 0 & 0 & 12 & 0 & 0 & 0 & 0 & 2 & 344 & 25 & 2 & 0 & 0 & 12 & 0 \\
\hline Nov. 2017 & 6 & 3 & 0 & 0 & 0 & 0 & 17 & 30 & 0 & 2 & 0 & 0 & 11 & 161 & 27 & 2 & 0 & 0 & 11 & 4 \\
\hline Nov. 2017 & 7 & 0 & 8 & 0 & 0 & 0 & 9 & 12 & 0 & 27 & 262 & 0 & 4 & 169 & 98 & 0 & 0 & 0 & 3 & 0 \\
\hline Nov. 2017 & 8 & 0 & 13 & 0 & 0 & 0 & 20 & 13 & 0 & 16 & 66 & 0 & 5 & 149 & 48 & 0 & 2 & 0 & 0 & 0 \\
\hline Nov. 2017 & 9 & 0 & 36 & 0 & 0 & 0 & 22 & 81 & 0 & 59 & 78 & 100 & 39 & 410 & 67 & 0 & 0 & 0 & 0 & 0 \\
\hline Nov. 2017 & 10 & 0 & 154 & 0 & 0 & 0 & 35 & 23 & 3 & 47 & 0 & 30 & 46 & 1864 & 117 & 0 & 0 & 0 & 0 & 0 \\
\hline Nov. 2017 & 11 & 0 & 0 & 0 & 0 & 0 & 3 & 4 & 0 & 0 & 0 & 0 & 0 & 505 & 144 & 0 & 0 & 0 & 0 & 0 \\
\hline Nov. 2017 & 12 & 0 & 7 & 5 & & 3 & 8 & 31 & 13 & 6 & 34 & 7 & 0 & 130 & 14 & & 5 & 6 & 7 & 9 \\
\hline Nov. 2017 & 13 & 0 & 0 & 0 & 0 & 7 & 25 & 0 & 2 & 0 & 0 & 121 & 0 & 112 & 403 & 0 & 0 & 0 & 15 & 0 \\
\hline
\end{tabular}

Note: 1 = Bochessa, 2 = Bulbula 3 = Floriculture2, 4 = Floriculture1, 5 = Korokonch, 6 = Kidanemihiret, 7 = Edo-Kontola, $8=$ Abosa, $9=$ Tepho-Choroke, $10=$ Mekidela, $11=$ Meki-River, $12=$ Reference and $13=$ Ketar-River. Hydroch $=$ Hydrochidae, Psych $=$ Psychodidae, Sta $=$ Staphylinidae, Dry $=$ Dryopidae, Hyd $=$ Hydrophilidae, Not $=$ Noteridae, Con $=$ Coenagrionidae, Libe $=$ Libellulidae, Pis $=$ Pisauridae, Vel $=$ Veliidae, Gerr $=$ Gerridae, Hydra $=$ Hydrachnidae, Noto $=$ Notonectidae, Cori $=$ Corixidae, Bi $=$ Bivalve, Phys $=$ Physidae, Tub $=$ Tubificidae, Nem $=$ Nematoda and Glo $=$ Glossiphoniidae 


\begin{tabular}{|c|c|c|c|c|c|c|c|c|c|c|c|c|c|c|}
\hline $\begin{array}{l}\text { Sampling } \\
\text { date }\end{array}$ & Sample site & $\begin{array}{l}\text { DO } \\
(\mathrm{mg} / \mathrm{L})\end{array}$ & $\begin{array}{l}\text { Temp. } \\
\left({ }^{\circ} \mathrm{C}\right)\end{array}$ & $\begin{array}{l}\text { EC } \\
(\mu S / \mathrm{cm})\end{array}$ & $\mathrm{pH}$ & $\begin{array}{l}\text { TDS } \\
\text { (mg/L) }\end{array}$ & $\begin{array}{l}\text { Turbidity } \\
\text { (NTU) }\end{array}$ & $\begin{array}{l}\mathrm{NO}_{3}^{-} \\
(\mathrm{mg} / \mathrm{L})\end{array}$ & $\begin{array}{l}\mathrm{NH}_{4}{ }^{+} \\
(\mathrm{mg} / \mathrm{L})\end{array}$ & $\begin{array}{l}\mathrm{PO}_{4}{ }^{3-} \\
(\mathrm{mg} / \mathrm{L})\end{array}$ & $\begin{array}{l}\mathrm{SO}_{4}{ }^{2-} \\
(\mathrm{mg} / \mathrm{L})\end{array}$ & $\begin{array}{l}\text { Chl-a } \\
(\mu \mathrm{g} / \mathrm{L})\end{array}$ & $\begin{array}{l}\text { COD } \\
(\mathrm{mg} / \mathrm{L})\end{array}$ & $\begin{array}{l}\text { Alkalinity } \\
\text { (meq/L) }\end{array}$ \\
\hline May 2017 & Bochessa & 6.46 & 23.6 & 498.0 & 8.7 & 326.7 & 213.0 & 0.29 & 0.35 & 0.005 & 5.70 & 53.40 & 51.3 & 4.93 \\
\hline May 2017 & Bulbula & 6.92 & 23.1 & 493.7 & 8.6 & 323.3 & 192.7 & 0.23 & 0.43 & 0.013 & 9.13 & 65.68 & 76.0 & 4.88 \\
\hline May 2017 & Floriculture2 & 6.65 & 23.5 & 501.0 & 8.5 & 336.7 & 193.7 & 0.76 & 0.40 & 0.091 & 5.74 & 78.50 & 80.0 & 4.99 \\
\hline May 2017 & Floriculture1 & 3.89 & 23.6 & 509.7 & 8.8 & 350.0 & 198.7 & 1.35 & 0.54 & 0.635 & 4.84 & 124.96 & 70.0 & 5.02 \\
\hline May 2017 & Korokonch & 7.49 & 23.9 & 500.7 & 8.6 & 346.7 & 177.5 & 0.74 & 0.87 & 0.098 & 7.34 & 108.77 & 47.1 & 5.28 \\
\hline May 2017 & Kidanemihiret & 7.24 & 23.2 & 500.0 & 9.3 & 330.0 & 182.5 & 0.82 & 0.76 & 0.091 & 7.68 & 117.19 & 38.7 & 5.28 \\
\hline May 2017 & Edo-Kontola & 6.49 & 23.3 & 500.3 & 9.4 & 323.3 & 193.5 & 0.28 & 0.63 & 0.019 & 10.27 & 60.34 & 44.4 & 4.93 \\
\hline May 2017 & Abosa & 6.36 & 23.8 & 497.3 & 9.3 & 320.0 & 201.3 & 0.27 & 0.75 & 0.023 & 6.35 & 80.10 & 38.8 & 5.11 \\
\hline May 2017 & Tepho-Choroke & 7.05 & 23.9 & 495.0 & 9.4 & 316.7 & 242.2 & 0.30 & 0.61 & 0.019 & 9.00 & 59.81 & 36.1 & 4.95 \\
\hline May 2017 & Mekidela & 6.00 & 23.9 & 499.0 & 9.2 & 336.7 & 316.0 & 0.42 & 0.54 & 0.053 & 4.79 & 116.41 & 77.2 & 4.95 \\
\hline May 2017 & Meki-River & 7.16 & 23.5 & 358.0 & 9.1 & 253.3 & 423.0 & 0.63 & 0.33 & 0.077 & 6.02 & 119.12 & 54.5 & 4.80 \\
\hline May 2017 & Reference & 7.56 & 23.3 & 451.3 & 9.4 & 296.7 & 339.5 & 0.11 & 0.21 & 0.005 & 3.12 & 50.73 & 36.3 & 4.49 \\
\hline May 2017 & Ketar-River & 8.04 & 22.4 & 472.0 & 9.4 & 266.7 & 353.5 & 0.43 & 0.35 & 0.085 & 10.34 & 144.71 & 46.9 & 4.66 \\
\hline Nov. 2017 & Bochessa & 6.6 & 18.2 & 462.0 & 9.4 & 306.7 & 117.7 & 0.23 & 0.45 & 0.033 & 18.27 & 70.49 & 30.0 & 4.28 \\
\hline Nov. 2017 & Bulbula & 6.7 & 21.2 & 434.7 & 9.4 & 286.7 & 101.7 & 0.14 & 0.42 & 0.037 & 14.59 & 72.09 & 38.0 & 4.09 \\
\hline Nov. 2017 & Floriculture2 & 6.0 & 21.0 & 469.7 & 9.3 & 316.7 & 108.7 & 0.67 & 0.53 & 0.374 & 15.22 & 74.76 & 59.3 & 4.02 \\
\hline Nov. 2017 & Floriculture1 & 4.6 & 20.1 & 515.7 & 8.9 & 353.3 & 119.0 & 0.95 & 0.42 & 0.594 & 16.69 & 80.10 & 72.7 & 4.52 \\
\hline Nov. 2017 & Korokonch & 4.9 & 20.6 & 478.3 & 8.8 & 323.3 & 137.3 & 1.00 & 0.56 & 0.163 & 15.16 & 91.70 & 76.0 & 4.65 \\
\hline Nov. 2017 & Kidanemihiret & 5.6 & 20.7 & 465.0 & 9.0 & 303.3 & 143.3 & 0.84 & 0.56 & 0.146 & 18.44 & 90.10 & 86.0 & 4.62 \\
\hline Nov. 2017 & Edo-Kontola & 5.9 & 19.7 & 462.7 & 8.8 & 296.7 & 114.0 & 0.34 & 0.19 & 0.037 & 15.04 & 63.55 & 36.7 & 4.26 \\
\hline Nov. 2017 & Abosa & 5.6 & 21.3 & 436.7 & 9.0 & 286.7 & 146.7 & 0.40 & 0.14 & 0.037 & 16.25 & 60.88 & 47.3 & 3.88 \\
\hline Nov. 2017 & Tepho-Choroke & 6.0 & 20.5 & 425.3 & 9.1 & 276.7 & 115.3 & 0.16 & 0.46 & 0.037 & 17.87 & 66.75 & 28.7 & 3.79 \\
\hline Nov. 2017 & Mekidela & 4.5 & 18.9 & 434.0 & 9.2 & 290.0 & 174.0 & 0.46 & 0.48 & 0.072 & 14.95 & 76.90 & 34.0 & 4.20 \\
\hline Nov. 2017 & Meki-River & 7.5 & 20.9 & 438.3 & 9.2 & 286.7 & 175.0 & 0.51 & 0.51 & 0.190 & 16.15 & 79.03 & 66.0 & 4.28 \\
\hline Nov. 2017 & Reference & 7.0 & 19.5 & 438.3 & 9.1 & 283.3 & 103.3 & 0.14 & 0.13 & 0.025 & 7.74 & 53.93 & 20.0 & 4.15 \\
\hline Nov. 2017 & Ketar-River & 5.8 & 20.2 & 347.0 & 8.7 & 233.3 & 131.7 & 0.49 & 0.53 & 0.156 & 17.54 & 74.76 & 52.0 & 2.51 \\
\hline
\end{tabular}


Table SI4.7. Measured concentration values (in $\mu \mathrm{g} / \mathrm{L}$ ) of pesticides in water samples collected thirteen shoreline sites of Lake Ziway during May 2017 and November 2017.

\begin{tabular}{|c|c|c|c|c|c|c|c|c|c|c|c|c|c|c|c|c|c|c|c|c|}
\hline 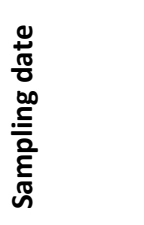 & 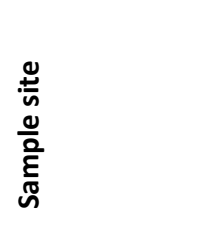 & $\begin{array}{l}\text { 은 } \\
\frac{\mathbb{Z}}{0} \\
\frac{0}{8} \\
\frac{1}{0} \\
\frac{0}{0} \\
\frac{1}{2}\end{array}$ & 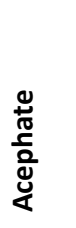 & 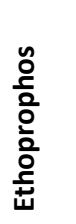 & 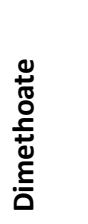 & 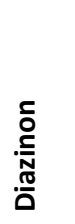 & $\begin{array}{l}\overline{\bar{c}} \\
\frac{0}{\pi} \\
\frac{\pi}{\tilde{t}} \\
\frac{0}{0} \\
\frac{0}{c}\end{array}$ & $\begin{array}{l}\overline{\frac{\pi}{\pi}} \\
\frac{\pi}{0} \\
\frac{0}{\pi} \\
\text { J̃ }\end{array}$ & $\begin{array}{l}\overline{\mathbb{x}} \\
\frac{\pi}{\pi} \\
\frac{d}{\tilde{d}} \\
\sum\end{array}$ & 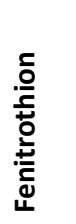 & $\begin{array}{l}\frac{\sigma}{0} \\
\frac{0}{1} \\
\frac{\pi}{\pi} \\
\Sigma\end{array}$ & 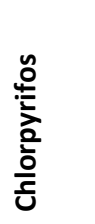 & 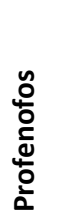 & 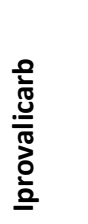 & 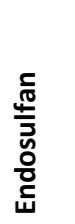 & $\begin{array}{l}\overline{0} \\
\frac{0}{0}\end{array}$ & 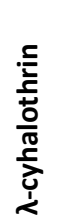 & 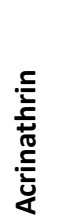 & 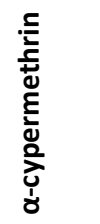 & 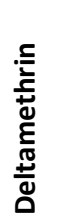 \\
\hline May 2017 & Bochessa & ND & ND & ND & ND & ND & ND & ND & ND & ND & 0.035 & ND & ND & 0.22 & 0.53 & ND & ND & ND & ND & ND \\
\hline May 2017 & Bulbula & 0.430 & ND & ND & 0.025 & 0.04 & ND & 0.08 & 0.40 & 0.04 & 0.035 & 0.590 & ND & 0.085 & 0.59 & ND & ND & ND & ND & ND \\
\hline May 2017 & Floriculture2 & 0.860 & ND & ND & 0.45 & 0.04 & ND & ND & 0.62 & 0.13 & 0.035 & 0.075 & ND & 0.93 & ND & ND & ND & ND & ND & ND \\
\hline May 2017 & Floriculture1 & 0.910 & ND & ND & 0.48 & 0.04 & ND & ND & 1.25 & 0.68 & 0.035 & 0.370 & ND & 0.84 & ND & ND & ND & ND & ND & ND \\
\hline May 2017 & Korokonch & ND & ND & ND & 0.08 & ND & ND & ND & ND & ND & 0.035 & 0.00 & ND & ND & 0.21 & ND & ND & ND & ND & ND \\
\hline May 2017 & Kidanemihiret & ND & ND & ND & 0.06 & ND & ND & ND & ND & 0.08 & 0.035 & 0.075 & ND & ND 0 & 0.21 & ND & ND & ND & ND & ND \\
\hline May 2017 & Edo-Kontola & ND & ND & ND & 0.63 & 0.14 & ND & 0.02 & 0.34 & 0.15 & 0.85 & 0.640 & ND & 0.52 & 0.77 & ND & ND & ND & ND & ND \\
\hline May 2017 & Abosa & ND & ND & ND & 0.60 & 0.13 & ND & $\mathrm{ND}$ & 0.31 & 0.39 & 0.09 & 0.200 & ND & $\mathrm{ND}$ & 0.91 & ND & ND & ND & ND & ND \\
\hline May 2017 & Tepho-Choroke & ND & ND & ND & ND & 0.50 & ND & ND & 0.05 & 0.08 & 0.035 & 0.500 & ND & ND & ND & ND & ND & ND & ND & ND \\
\hline May 2017 & Mekidela & 0.700 & ND & ND & 0.78 & 0.59 & ND & ND & 0.42 & 0.69 & 0.38 & 0.870 & ND & 0.34 & 0.92 & ND & ND & ND & ND & ND \\
\hline May 2017 & Meki-River & ND & ND & ND & 0.86 & 0.74 & ND & 0.36 & 1.90 & 0.57 & 0.23 & 0.075 & ND & ND & 1.01 & ND & ND & ND & ND & ND \\
\hline May 2017 & Reference & ND & ND & ND & ND & ND & ND & ND & ND & ND & ND & ND & ND & ND & ND & ND & ND & ND & ND & ND \\
\hline May 2017 & Ketar-River & 0.065 & ND & ND & 0.88 & 0.40 & ND & 0.25 & 0.56 & 0.64 & 0.34 & 0.710 & ND & ND & 0.60 & ND & ND & ND & 0.305 & ND \\
\hline Nov. 2017 & Bochessa & ND & ND & ND & ND & ND & ND & ND & ND & ND & 0.21 & ND & ND & 0.42 & 0.71 & ND & ND & ND & ND & ND \\
\hline Nov. 2017 & Bulbula & 0.410 & ND & ND & 0.025 & ND & ND & 0.04 & 0.29 & 0.19 & ND & 0.61 & ND & ND & 0.86 & ND & ND & ND & ND & ND \\
\hline Nov. 2017 & Floriculture2 & 0.480 & ND & ND & 0.76 & ND & ND & ND & 0.37 & 0.21 & 0.55 & ND & ND & 0.88 & ND & ND & ND & ND & ND & ND \\
\hline Nov. 2017 & Floriculture1 & 0.620 & ND & ND & 0.79 & 0.04 & ND & ND & 0.98 & 0.74 & 0.035 & 0.54 & ND & 0.73 & ND & ND & ND & ND & ND & ND \\
\hline Nov. 2017 & Korokonch & ND & ND & ND & 0.06 & 0.04 & ND & ND & ND & ND & 0.035 & ND & ND & ND & ND & ND & ND & ND & ND & ND \\
\hline Nov. 2017 & Kidanemihiret & ND & ND & ND & 0.06 & 0.04 & ND & ND & 0.14 & ND & 0.28 & ND & ND & ND & 0.21 & ND & ND & ND & ND & ND \\
\hline Nov. 2017 & Edo-Kontola & ND & ND & ND & 0.78 & 0.17 & ND & 0.013 & 0.87 & 0.21 & 0.45 & 0.760 & ND & 0.54 & 0.93 & ND & 0.23 & ND & 0.305 & ND \\
\hline Nov. 2017 & Abosa & ND & ND & ND & 0.96 & 0.19 & ND & ND & 1.04 & 0.49 & ND & 0.360 & ND & ND & 0.62 & ND & ND & ND & ND & ND \\
\hline Nov. 2017 & Tepho-Choroke & ND & ND & ND & 0.07 & 0.62 & ND & ND & 0.16 & ND & 0.28 & 0.51 & ND & ND & ND & ND & ND & ND & 0.67 & ND \\
\hline Nov. 2017 & Mekidela & ND & ND & ND & 0.99 & 0.65 & ND & ND & 0.85 & 0.80 & 0.45 & 0.880 & ND & 0.38 & 1.33 & ND & ND & ND & 0.305 & ND \\
\hline Nov. 2017 & Meki-River & ND & ND & ND & 0.95 & 0.88 & ND & 0.38 & 1.41 & 0.71 & 0.62 & 0.310 & ND & ND & 1.48 & ND & ND & ND & 0.77 & ND \\
\hline Nov. 2017 & Reference & ND & ND & ND & ND & ND & ND & ND & ND & ND & 0.035 & ND & ND & ND & ND & ND & ND & ND & ND & ND \\
\hline Nov. 2017 & Ketar-River & ND & ND & ND & 0.83 & 0.52 & ND & 0.26 & 1.36 & 0.48 & 0.52 & 0.700 & ND & ND & 1.85 & ND & ND & ND & 0.81 & ND \\
\hline
\end{tabular}


Table SI4.8. Measured concentration values (in $\mu \mathrm{g} / \mathrm{kg}-\mathrm{dw}$ ) of pesticides in sediment samples collected thirteen shoreline sites of Lake Ziway during May 2017 and November 2017.

\begin{tabular}{|c|c|c|c|c|c|c|c|c|c|c|c|c|c|c|c|c|c|c|c|c|}
\hline Sampling date & Sample site & 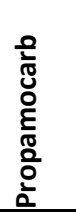 & 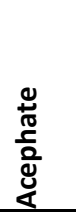 & 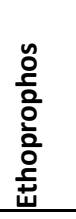 & 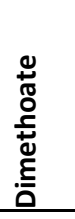 & 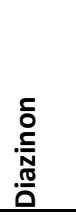 & 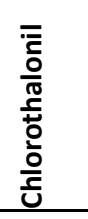 & $\begin{array}{l}\bar{Z} \\
\frac{1}{0} \\
\frac{0}{2} \\
0 \\
\end{array}$ & 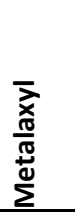 & 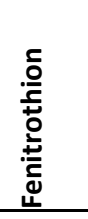 & 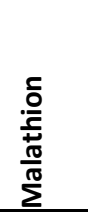 & $\begin{array}{l}\stackrel{\text { o }}{\frac{0}{z}} \\
\frac{2}{2} \\
\frac{0}{5}\end{array}$ & 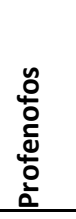 & 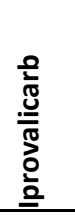 & 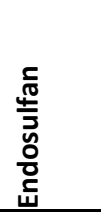 & $\begin{array}{l}\overline{0} \\
\stackrel{0}{0} \\
\dot{0}\end{array}$ & 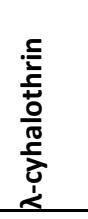 & 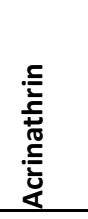 & 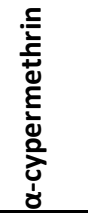 & 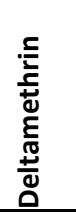 \\
\hline May 2017 & Bochessa & ND & $\mathrm{ND}$ & ND & ND & ND & ND & ND & ND & ND & ND & ND & ND & ND & ND & ND & ND & ND & ND & ND \\
\hline May 2017 & Bulbula & ND & ND & ND & ND & 0.18 & 0.00 & ND & ND & ND & ND & ND & ND & ND & ND & ND & ND & ND & ND & ND \\
\hline May 2017 & Floriculture2 & ND & ND & ND & ND & ND & ND & ND & ND & ND & ND & ND & ND & ND & ND & ND & ND & ND & ND & ND \\
\hline May 2017 & Floriculture1 & ND & ND & ND & ND & 0.18 & ND & ND & ND & ND & ND & ND & ND & ND & ND & ND & ND & ND & ND & ND \\
\hline May 2017 & Korokonch & ND & ND & ND & ND & ND & ND & ND & ND & ND & ND & ND & ND & ND & ND & ND & ND & ND & ND & ND \\
\hline May 2017 & Kidanemihiret & ND & ND & ND & ND & ND & ND & ND & ND & ND & ND & ND & ND & ND & ND & ND & ND & ND & ND & ND \\
\hline May 2017 & Edo-Kontola & ND & ND & ND & ND & ND & ND & ND & ND & ND & ND & ND & ND & ND & ND & ND & ND & ND & ND & ND \\
\hline May 2017 & Abosa & ND & ND & ND & ND & ND & ND & ND & ND & ND & ND & ND & ND & ND & ND & ND & ND & ND & ND & ND \\
\hline May 2017 & Tepho-Choroke & ND & ND & ND & ND & 0.4 & ND & ND & ND & ND & ND & ND & ND & ND & ND & ND & ND & ND & ND & ND \\
\hline May 2017 & Mekidela & ND & ND & ND & ND & 0.18 & ND & ND & ND & ND & ND & ND & ND & ND & 0.315 & ND & ND & ND & ND & ND \\
\hline May 2017 & Meki-River & ND & ND & ND & ND & 0.5 & ND & ND & ND & ND & ND & ND & ND & ND & 2.22 & ND & ND & ND & 0.36 & ND \\
\hline May 2017 & Reference & ND & ND & ND & ND & ND & ND & ND & ND & ND & ND & ND & ND & ND & ND & ND & ND & ND & ND & ND \\
\hline May 2017 & Ketar-River & ND & ND & ND & ND & ND & ND & ND & ND & ND & ND & ND & ND & ND & 1.98 & ND & ND & ND & 0.36 & 0.00 \\
\hline Nov. 2017 & Bochessa & ND & ND & ND & ND & ND & ND & ND & ND & ND & ND & ND & ND & ND & ND & ND & ND & ND & 1.80 & 0.00 \\
\hline Nov. 2017 & Bulbula & ND & ND & ND & ND & 0.18 & ND & ND & ND & ND & ND & ND & ND & ND & ND & ND & ND & ND & ND & ND \\
\hline Nov. 2017 & Floriculture2 & ND & ND & 0.4 & ND & ND & ND & ND & ND & 0.90 & ND & 0.830 & ND & ND & ND & ND & ND & ND & ND & ND \\
\hline Nov. 2017 & Floriculture1 & ND & ND & 0.6 & ND & 0.18 & ND & ND & ND & 0.94 & ND & 0.750 & ND & ND & ND & ND & ND & ND & ND & ND \\
\hline Nov. 2017 & Korokonch & ND & ND & ND & ND & ND & ND & ND & ND & ND & ND & ND & ND & ND & ND & ND & ND & ND & ND & ND \\
\hline Nov. 2017 & Kidanemihiret & ND & ND & ND & ND & ND & ND & ND & ND & ND & ND & ND & ND & ND & ND & ND & ND & ND & 1.62 & ND \\
\hline Nov. 2017 & Edo-Kontola & ND & ND & ND & ND & 0.65 & ND & ND & ND & ND & ND & 0.710 & ND & ND & 0.315 & ND & ND & ND & ND & ND \\
\hline Nov. 2017 & Abosa & ND & ND & ND & 0.32 & ND & ND & ND & ND & ND & ND & ND & ND & ND & ND & ND & ND & ND & 1.58 & ND \\
\hline Nov. 2017 & Tepho-Choroke & ND & ND & ND & ND & ND & ND & ND & ND & ND & ND & ND & ND & ND & ND & ND & ND & ND & ND & ND \\
\hline Nov. 2017 & Mekidela & ND & ND & ND & ND & 0.40 & ND & ND & ND & 0.89 & ND & ND & ND & ND & 2.22 & ND & 1.98 & ND & 1.73 & ND \\
\hline Nov. 2017 & Meki-River & ND & ND & ND & ND & 0.74 & ND & ND & ND & ND & ND & ND & ND & ND & 2.95 & ND & 1.88 & ND & 1.83 & 0.27 \\
\hline Nov. 2017 & Reference & ND & ND & ND & ND & ND & ND & ND & ND & ND & ND & ND & ND & ND & ND & ND & ND & ND & ND & ND \\
\hline Nov. 2017 & Ketar-River & ND & ND & ND & ND & 0.50 & ND & ND & ND & ND & ND & 0.880 & ND & ND & 2.90 & ND & 2.08 & ND & 1.97 & 0.27 \\
\hline
\end{tabular}


Table S14.9. Fifteen biotic indices calculated based on abundance (\#) of macroinvertebrates collected from thirteen shoreline sites of Lake Ziway during May 2017 and November 2017.

\begin{tabular}{|c|c|c|c|c|c|c|c|c|c|c|c|c|c|c|c|c|}
\hline Sampling date & Sampling site & 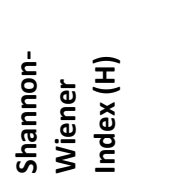 & 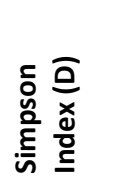 & 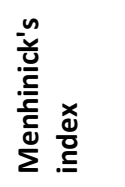 & 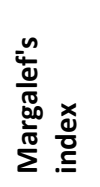 & 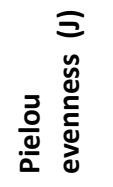 & $\begin{array}{l}\frac{c}{0} \\
\frac{0}{\pi} \\
\mathbb{D} \\
\frac{0}{0} \\
\#\end{array}$ & 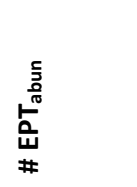 & 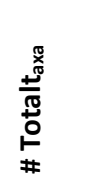 & 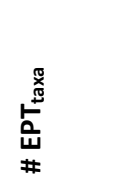 & 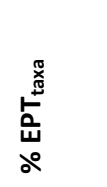 & $\sum_{\infty}^{0}$ & 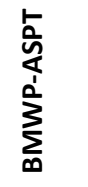 & & 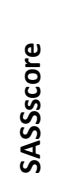 & 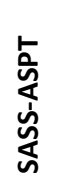 \\
\hline May 2017 & Bochessa & 1.89 & 0.76 & 0.768 & 2.36 & 0.70 & 381 & 108 & 15 & 4 & 26.7 & 52 & 5.2 & 26 & 56 & 4.7 \\
\hline May 2017 & Bulbula & 1.41 & 0.63 & 0.530 & 1.98 & 0.53 & 699 & 131.0 & 14 & 2 & 14.3 & 37 & 4.1 & 22 & 57 & 4.4 \\
\hline May 2017 & Floriculture2 & 1.52 & 0.72 & 0.331 & 1.43 & 0.63 & 1104 & 70.0 & 11 & 2 & 18.2 & 30 & 5.0 & 22 & 36 & 4.0 \\
\hline May 2017 & Floriculture1 & 1.34 & 0.66 & 0.242 & 1.11 & 0.61 & 1382 & 50.0 & 9 & 1 & 11.1 & 22 & 4.4 & 16 & 31 & 3.9 \\
\hline May 2017 & Korokonch & 1.67 & 0.73 & 0.399 & 1.72 & 0.65 & 1062 & 839.0 & 13 & 4 & 30.8 & 37 & 5.3 & 32 & 41 & 4.6 \\
\hline May 2017 & Kidanemihiret & 1.71 & 0.75 & 0.406 & 1.84 & 0.65 & 1191 & 702.0 & 14 & 4 & 28.6 & 39 & 4.9 & 30 & 55 & 4.6 \\
\hline May 2017 & Edo-Kontola & 1.87 & 0.80 & 0.387 & 1.60 & 0.75 & 962 & 72.0 & 12 & 1 & 8.3 & 30 & 5.0 & 20 & 41 & 4.1 \\
\hline May 2017 & Abosa & 1.71 & 0.71 & 0.458 & 2.01 & 0.63 & 1073 & 564.0 & 15 & 3 & 20.0 & 33 & 4.1 & 26 & 51 & 4.3 \\
\hline May 2017 & Tepho-Choroke & 2.09 & 0.83 & 0.581 & 2.04 & 0.79 & 581 & 15.0 & 14 & 3 & 21.4 & 34 & 4.9 & 22 & 58 & 4.8 \\
\hline May 2017 & Mekidela & 1.58 & 0.71 & 0.334 & 1.74 & 0.60 & 1755 & 56.0 & 14 & 3 & 21.4 & 42 & 5.3 & 22 & 57 & 4.8 \\
\hline May 2017 & Meki-River & 1.14 & 0.65 & 0.199 & 0.84 & 0.59 & 1243 & 7.0 & 7 & 1 & 14.3 & 31 & 4.4 & 12 & 23 & 3.3 \\
\hline May 2017 & Reference & 1.79 & 0.73 & 0.490 & 2.96 & 0.56 & 2395 & 1975.0 & 24 & 6 & 25.0 & 75 & 5.0 & 38 & 81 & 4.3 \\
\hline May 2017 & Ketar-River & 1.37 & 0.67 & 0.316 & 1.51 & 0.55 & 1445 & 12.0 & 12 & 3 & 25.0 & 49 & 4.9 & 14 & 40 & 4.0 \\
\hline Nov. 2017 & Bochessa & 1.84 & 0.76 & 0.542 & 2.00 & 0.70 & 666 & 192.0 & 14 & 4 & 28.6 & 49 & 5.4 & 26 & 53 & 4.8 \\
\hline Nov. 2017 & Bulbula & 1.63 & 0.73 & 0.519 & 2.08 & 0.60 & 835 & 83 & 15 & 2 & 13.3 & 37 & 4.1 & 22 & 60 & 4.3 \\
\hline Nov. 2017 & Floriculture2 & 1.59 & 0.75 & 0.292 & 1.27 & 0.69 & 1173 & 104 & 10 & 2 & 20.0 & 22 & 4.4 & 22 & 32 & 4.0 \\
\hline Nov. 2017 & Floriculture1 & 1.25 & 0.62 & 0.302 & 1.39 & 0.52 & 1324 & 15 & 11 & 2 & 18.2 & 22 & 4.4 & 16 & 49 & 5.4 \\
\hline Nov. 2017 & Korokonch & 1.59 & 0.74 & 0.357 & 1.56 & 0.64 & 1130 & 635 & 12 & 4 & 33.3 & 36 & 5.1 & 30 & 38 & 4.2 \\
\hline Nov. 2017 & Kidanemihiret & 1.77 & 0.76 & 0.440 & 1.98 & 0.65 & 1164 & 642 & 15 & 4 & 26.7 & 39 & 4.9 & 26 & 56 & 4.7 \\
\hline Nov. 2017 & Edo-Kontola & 1.93 & 0.82 & 0.402 & 1.73 & 0.75 & 1048 & 141 & 13 & 2 & 15.4 & 22 & 4.4 & 22 & 50 & 4.5 \\
\hline Nov. 2017 & Abosa & 2.04 & 0.83 & 0.551 & 1.90 & 0.80 & 556 & 48 & 13 & 2 & 15.4 & 25 & 4.2 & 22 & 50 & 4.5 \\
\hline Nov. 2017 & Tepho-Choroke & 2.20 & 0.83 & 0.445 & 1.99 & 0.81 & 1137 & 81 & 15 & 4 & 26.7 & 41 & 5.1 & 28 & 58 & 4.8 \\
\hline Nov. 2017 & Mekidela & 1.26 & 0.54 & 0.245 & 1.51 & 0.49 & 2823 & 94 & 13 & 3 & 23.1 & 42 & 5.3 & 24 & 57 & 4.8 \\
\hline Nov. 2017 & Meki-River & 1.12 & 0.62 & 0.251 & 1.01 & 0.54 & 1015 & 14 & 8 & 2 & 25.0 & 22 & 4.4 & 16 & 33 & 4.7 \\
\hline Nov. 2017 & Reference & 1.66 & 0.71 & 0.452 & 2.80 & 0.53 & 2593 & 2248 & 23 & 6 & 26.1 & 75 & 5.0 & 34 & 73 & 4.1 \\
\hline Nov. 2017 & Ketar-River & 1.49 & 0.72 & 0.314 & 1.30 & 0.65 & 1015 & 11 & 10 & 1 & 10.0 & 34 & 4.9 & 14 & 38 & 3.8 \\
\hline
\end{tabular}


Table S14.10. Detection frequency per sample site, and arthropod and fish based multi-substance potentially affected fraction in percentage $\left(\% \mathrm{msPF}_{\mathrm{RA}}\right)$ for the pesticides observed in water and sediment samples collected from shoreline sites of Lake Ziway in May 2017 (dry) and in November 2017 (wet).

\begin{tabular}{|c|c|c|c|c|c|c|c|c|c|c|c|c|}
\hline \multirow{3}{*}{$\begin{array}{l}\text { Sampling } \\
\text { site }\end{array}$} & \multirow{2}{*}{\multicolumn{2}{|c|}{$\begin{array}{l}\text { Water detection } \\
\text { frequency \#(\%DF) }\end{array}$}} & \multirow{2}{*}{\multicolumn{2}{|c|}{$\begin{array}{l}\text { Sediment detection } \\
\text { frequency \#(\%DF) }\end{array}$}} & \multicolumn{4}{|c|}{$\begin{array}{l}\text { Arthropod based } \\
\text { \%msPAF }_{\mathrm{RA}}\end{array}$} & \multicolumn{4}{|c|}{$\begin{array}{l}\text { Fish based } \\
\%_{\mathrm{msPAF}}\end{array}$} \\
\hline & & & & & \multicolumn{2}{|c|}{ Water } & \multicolumn{2}{|c|}{ Sediment } & \multicolumn{2}{|c|}{ Water } & \multicolumn{2}{|c|}{ Sediment } \\
\hline & Dry & Wet & Dry & Wet & Dry & Wet & Dry & Wet & Dry & Wet & Dry & Wet \\
\hline Bochessa & $3(15)$ & $3(16)$ & $0(0)$ & $1(5.3)$ & 14 & 18 & $<1$ & 9.6 & 18 & 22 & $<1$ & 9.4 \\
\hline Bulbula & $10(53)$ & $7(37)$ & $1(5.3)$ & $1(5.3)$ & 41 & 39 & $<1$ & $<1$ & 19 & 25 & $<1$ & $<1$ \\
\hline Floriculture2 & $8(42)$ & $6(32)$ & $0(0)$ & $3(16)$ & 13 & 11 & $<1$ & 3.3 & $<1$ & $<1$ & $<1$ & $<1$ \\
\hline Floriculture1 & $8(42)$ & $8(42)$ & $1(5.3)$ & $4(21)$ & 37 & 28 & $<1$ & 2.2 & $<1$ & $<1$ & $<1$ & $<1$ \\
\hline Korokonch & $3(16)$ & $3(16)$ & $0(0)$ & $0(0)$ & 8.6 & 1.3 & $<1$ & $<1$ & 8.2 & $<1$ & $<1$ & $<1$ \\
\hline Kidanemihiret & $5(26)$ & $5(26)$ & $0(0)$ & $1(5.3)$ & 19 & 11 & $<1$ & $<1$ & 8.2 & 8.2 & $<1$ & $<1$ \\
\hline Edo-Kontola & $10(53)$ & $11(58)$ & $0(0)$ & $3(16)$ & 72 & 78 & $<1$ & $<1$ & 37 & 48 & $<1$ & $<1$ \\
\hline Abosa & $8(42)$ & $6(32)$ & $0(0)$ & $2(10)$ & 68 & 38 & $<1$ & 1.8 & 39 & 20 & $<1$ & 2.4 \\
\hline $\begin{array}{l}\text { Tepho- } \\
\text { Choroke }\end{array}$ & $5(26)$ & $6(32)$ & $1(5.3)$ & $0(0)$ & 30 & 68 & $<1$ & $<1$ & 11 & 34 & $<1$ & $<1$ \\
\hline Mekidela & $10(53)$ & $10(53)$ & $2(10)$ & $5(26)$ & 73 & 79 & $<1$ & 7.2 & 46 & 52 & $<1$ & 3.2 \\
\hline Meki-River & $10(53)$ & $10(53)$ & $3(16)$ & $5(26)$ & 73 & 80 & 2.5 & 18 & 49 & 58 & 2.6 & 5.6 \\
\hline Reference & $0(0)$ & $1(5)$ & $0(0)$ & $0(0)$ & $<1$ & 5.2 & $<1$ & $<1$ & $<1$ & $<1$ & $<1$ & $<1$ \\
\hline Ketar-River & $10(53)$ & $9(47)$ & $2(10)$ & $6(32)$ & 70 & 80 & 1.9 & 18 & 42 & 60 & 2.0 & 5.4 \\
\hline
\end{tabular}




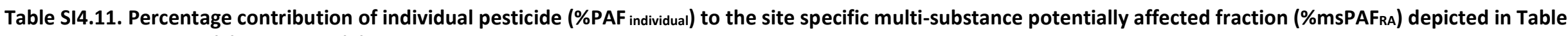
SI 4.10 for arthropods (a) and fishes (b) from water exposure.

\begin{tabular}{|c|c|c|c|c|c|c|c|c|c|c|c|c|c|}
\hline \multicolumn{14}{|c|}{ a. Arthropods community } \\
\hline \multirow[t]{2}{*}{ Pesticides } & Bochessa & Bulbula & Flori-2 & Flori-1 & Korokonch & $\begin{array}{l}\text { Kidane } \\
\text { mihiret }\end{array}$ & $\begin{array}{l}\text { Edo- } \\
\text { Kontola }\end{array}$ & Abosa & $\begin{array}{l}\text { Tepho- } \\
\text { Choroke }\end{array}$ & Mekidela & $\begin{array}{l}\text { Meki- } \\
\text { River }\end{array}$ & Reference & $\begin{array}{l}\text { Ketar- } \\
\text { River }\end{array}$ \\
\hline & $\% \mathrm{PAF}_{\text {in }}$ & $\% \mathrm{PAF}_{\text {in }}$ & $\% \mathrm{PAF}_{\text {in }}$ & $\% \mathrm{PAF}_{\text {in }}$ & \%PAF in & $\% \mathrm{PAF}_{\text {in }}$ & \%PAF ${ }_{\text {in }}$ & $\% \mathrm{PAF}_{\text {in }}$ & \%PAF in & $\% \mathrm{PAF}_{\text {in }}$ & \% $\mathrm{PAF}_{\text {in }}$ & $\% \mathrm{PAF}_{\text {in }}$ & \%PAF in \\
\hline Propamocarb & - & - & $<0.001$ & $<0.001$ & - & - & - & - & - & $<0.001$ & - & - & $<0.001$ \\
\hline Dimethoate & - & 0.06 & 6.9 & 2.2 & 6.4 & 0.85 & 0.68 & 1.0 & 0.12 & 1.00 & 0.96 & - & 1.1 \\
\hline Diazinon & - & 1.4 & 3.4 & 2.7 & 15 & 4.4 & 3.0 & 4.9 & 10 & 5.9 & 7.4 & - & 5.6 \\
\hline Carbaryl & - & 0.38 & - & - & - & - & 0.06 & - & - & - & 1.1 & - & 1.1 \\
\hline Fenitrothion & - & 8.7 & 36 & 30 & - & 12 & 5.1 & 7.7 & 2.8 & 7.7 & 6.7 & - & 8.9 \\
\hline Malathion & 33 & 0.68 & 21 & 1.3 & 23 & 14 & 3.9 & 1.1 & 3.5 & 3.4 & 1.2 & - & 3 \\
\hline Chlorpyrifos & - & 62 & 33 & 64 & - & 37 & 27 & 35 & 43 & 26 & 13 & 100 & 28 \\
\hline Metalaxyl & - & $<0.01$ & $<0.001$ & $<0.001$ & - & $<0.01$ & $<0.01$ & $<0.01$ & $<0.01$ & $<0.01$ & $<0.01$ & - & $<0.01$ \\
\hline Iprovalicarb & NC & $\mathrm{NC}$ & NC & NC & NC & $\mathrm{NC}$ & $\mathrm{NC}$ & NC & $\mathrm{NC}$ & NC & NC & NC & NC \\
\hline Endosulfan & 67 & 27 & - & - & 55 & 32 & 11 & 20 & - & 12 & 11 & - & 13 \\
\hline$\lambda$-cyhalothrin & - & - & - & - & - & - & 32 & 31 & - & 14 & 27 & - & - \\
\hline$\alpha$-cypermethrin & - & - & - & - & - & - & 16 & - & 40 & 29 & 32 & - & 39 \\
\hline \multicolumn{14}{|c|}{ b. Fish community } \\
\hline Propamocarb & - & - & $<0.001$ & $<0.001$ & - & - & - & - & - & $<0.001$ & - & - & $<0.001$ \\
\hline Dimethoate & - & $<0.001$ & 0.36 & 1.5 & $<0.001$ & $<0.001$ & $<0.001$ & $<0.001$ & $<0.001$ & $<0.001$ & $<0.001$ & - & $<0.001$ \\
\hline Diazinon & - & $<0.001$ & $<0.001$ & 0.009 & $<0.001$ & $<0.001$ & $<0.001$ & $<0.001$ & 25 & $<0.001$ & $<0.001$ & - & $<0.001$ \\
\hline Carbaryl & - & $<0.001$ & - & - & - & - & $<0.001$ & - & - & - & $<0.001$ & - & $<0.001$ \\
\hline Fenitrothion & - & $<0.001$ & 0.95 & 35 & - & $<0.001$ & $<0.001$ & 0.0019 & $<0.001$ & $<0.001$ & 0.0028 & - & 0.0034 \\
\hline Malathion & - & $<0.001$ & 0.71 & 58 & - & 0.0016 & $<0.001$ & 0.0043 & $<0.001$ & $<0.001$ & $<0.001$ & - & $<0.001$ \\
\hline Chlorpyrifos & 0.47 & $<0.001$ & 98 & 5.2 & 0.084 & 0.46 & 0.11 & 0.0098 & 0.10 & 0.082 & 0.0056 & 100 & 0.026 \\
\hline Metalaxyl & - & $<0.01$ & $<0.001$ & $<0.001$ & - & $<0.001$ & $<0.001$ & $<0.001$ & $<0.001$ & $<0.001$ & $<0.001$ & - & $<0.001$ \\
\hline Iprovalicarb & NC & $\mathrm{NC}$ & NC & NC & NC & NC & NC & NC & NC & NC & NC & NC & NC \\
\hline Endosulfan & 99 & 99.9 & - & - & 99.9 & 99.5 & 36 & 65 & - & 37 & 32 & - & 41 \\
\hline$\lambda$-cyhalothrin & - & - & - & - & - & - & 40 & 34 & - & 19 & 30 & - & - \\
\hline$\alpha$-cypermethrin & - & - & - & - & - & - & 24 & - & 75 & 43 & 38 & - & 59 \\
\hline
\end{tabular}

Flori-2 = Floriculture2, Flori-1 = Floriculture1, value with " -“ indicate for pesticide not detected, NC = not calculated as no sufficient toxicity data was found the compute the $\%$ msPAFA $_{\text {RA }}$ 


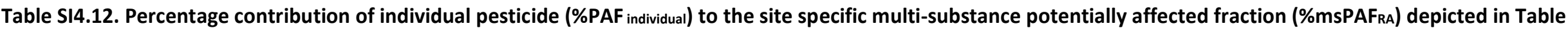
SI 4.10 for arthropods (a) and fishes (b) from sediment exposure.

\begin{tabular}{|c|c|c|c|c|c|c|c|c|c|c|c|c|c|}
\hline & Bochessa & Bulbula & Flori-2 & Flori-1 & Korokonch & $\begin{array}{l}\text { Kidane } \\
\text { mihiret }\end{array}$ & $\begin{array}{l}\text { Edo- } \\
\text { Kontola } \\
\end{array}$ & Abosa & $\begin{array}{l}\text { Tepho- } \\
\text { Choroke }\end{array}$ & Mekidela & $\begin{array}{l}\text { Meki- } \\
\text { River }\end{array}$ & Reference & $\begin{array}{l}\text { Ketar- } \\
\text { River }\end{array}$ \\
\hline Pesticides & $\% \mathrm{PAF}_{\text {in }}$ & $\% \mathrm{PAF}_{\text {in }}$ & $\% \mathrm{PAF}_{\text {in }}$ & $\% \mathrm{PAF}_{\text {in }}$ & \%PAF in & $\% \mathrm{PAF}_{\text {in }}$ & ${ }^{2} \mathrm{PAF}_{\text {in }}$ & \%PAF in & $\% \mathrm{PAF}_{\text {in }}$ & $\% \mathrm{PAF}_{\text {in }}$ & ${ }^{2} \mathrm{PAF}_{\text {in }}$ & $\% \mathrm{PAF}_{\text {in }}$ & $\% \mathrm{PAF}_{\text {in }}$ \\
\hline Ethoprophos & - & - & 9.4 & 39 & - & - & - & - & - & - & - & - & - \\
\hline Dimethoate & - & - & - & - & - & - & - & 62 & - & - & - & - & - \\
\hline Diazinon & - & 100 & - & 1.2 & - & - & 4.5 & - & 100 & 1.5 & 1.1 & - & 0.4 \\
\hline Fenitrothion & - & - & 45 & 38 & - & - & - & - & - & 16 & - & - & - \\
\hline Chlorpyrifos & - & - & 46 & 22 & - & - & 88 & - & - & - & - & - & 7.3 \\
\hline Endosulfan & - & - & - & - & - & - & 7.7 & - & - & 11 & 11 & - & 9.1 \\
\hline$\lambda$-cyhalothrin & - & - & - & - & - & - & - & - & - & 49 & 20 & - & 20 \\
\hline$\alpha$-cypermethrin & 100 & - & - & - & - & - & - & 38 & - & 22 & 13 & - & 12 \\
\hline Deltamethrin & - & - & - & - & - & - & - & - & - & - & 55 & - & 51 \\
\hline \multicolumn{14}{|c|}{ b. Fishes community } \\
\hline Ethoprophos & - & - & 79 & 97 & - & - & - & - & - & - & - & - & - \\
\hline Dimethoate & - & - & - & - & - & - & - & 0.04 & - & - & - & - & - \\
\hline Diazinon & - & 100 & - & $<0.001$ & - & - & 0.06 & - & 100 & $<0.001$ & $<0.001$ & - & $<0.001$ \\
\hline Fenitrothion & - & - & 7.8 & 1.2 & - & - & - & - & - & $<0.001$ & - & - & \\
\hline Chlorpyrifos & - & - & 13 & 1.6 & - & - & 0.05 & - & - & - & - & - & $<0.001$ \\
\hline Endosulfan & - & - & - & - & - & - & 99.8 & - & - & 2.2 & 8.9 & - & 4.9 \\
\hline$\lambda$-cyhalothrin & - & - & - & - & - & - & - & - & - & 61 & 40 & - & 44 \\
\hline$\alpha$-cypermethrin & 100 & - & - & - & - & - & - & 99.9 & - & 37 & 49 & - & 49 \\
\hline Deltamethrin & - & - & - & - & - & - & - & - & - & - & 2.1 & - & 2.1 \\
\hline
\end{tabular}

Flori-2 = Floriculture2, Flori-1 = Floriculture1, value with “ -“ indicate for pesticide not detected 
Table S14.13. Results of the Monte Carlo permutation tests using simple and conditional effects for the macroinvertebrate composition data set. The bold environmental variables were used in RDA analysis depicted on Fig. 4.3. The correlations between all environmental variables and the macroinvertebrate taxa abundance is provided in

\section{Fig. SI4.2.}

\begin{tabular}{|c|c|c|c|c|c|c|c|c|c|}
\hline Simple Term Effects: & & & & & Conditional Term Effects: & & & & \\
\hline Name & Explains \% & pseudo-F & $\mathrm{P}$ & $P($ adj) & Name & Explains \% & pseudo-F & $\mathrm{P}$ & $P($ adj) \\
\hline Metalaxyl & 19.6 & 5.6 & 0.002 & 0.00971 & Metalaxyl & 19.6 & 5.6 & 0.002 & 0.017 \\
\hline Fenitrothion & 17.1 & 4.7 & 0.002 & 0.00971 & NO3- & 13.4 & 4.4 & 0.002 & 0.017 \\
\hline Dimethoate & 16.8 & 4.6 & 0.002 & 0.00971 & Carbaryl & 11.8 & 4.5 & 0.002 & 0.017 \\
\hline Chlorpyrifos & 15.9 & 4.3 & 0.002 & 0.00971 & Diazinon & 12 & 5.5 & 0.002 & 0.017 \\
\hline Diazinon & 15.2 & 4.1 & 0.002 & 0.00971 & SO42- & 4.6 & 2.3 & 0.012 & 0.0816 \\
\hline NO3- & 15 & 4.1 & 0.002 & 0.00971 & $\lambda$-cyhalothrin & 3.8 & 2 & 0.018 & 0.08743 \\
\hline Carbaryl & 13.6 & 3.6 & 0.004 & 0.017 & S_Endosulfan & 4 & 2.2 & 0.016 & 0.08743 \\
\hline PO43- & 13 & 3.4 & 0.002 & 0.00971 & Iprovalicarb & 3 & 1.7 & 0.06 & 0.204 \\
\hline S_Endosulfan & 11 & 2.8 & 0.01 & 0.03091 & Propamocarb & 3 & 1.8 & 0.078 & 0.221 \\
\hline COD & 10.9 & 2.8 & 0.008 & 0.0272 & Chlorpyrifos & 3.1 & 2 & 0.038 & 0.14356 \\
\hline Chl-a & 9.8 & 2.5 & 0.006 & 0.02267 & PO43- & 2.9 & 2 & 0.022 & 0.0935 \\
\hline Malathion & 9.8 & 2.5 & 0.018 & 0.04371 & Malathion & 2.4 & 1.8 & 0.066 & 0.204 \\
\hline$\alpha$-cypermethrin & 9.5 & 2.4 & 0.018 & 0.04371 & Fenitrothion & 1.9 & 1.5 & 0.174 & 0.34 \\
\hline S_Diazinon & 9.1 & 2.3 & 0.016 & 0.04371 & $\alpha$-cypermethrin & 1.9 & 1.5 & 0.122 & 0.27653 \\
\hline SO42- & 8.4 & 2.1 & 0.05 & 0.11333 & Dimethoate & 2 & 1.8 & 0.1 & 0.26154 \\
\hline $\mathrm{NH} 4+$ & 6.9 & 1.7 & 0.112 & 0.20042 & $\mathrm{EC}$ & 1.7 & 1.6 & 0.108 & 0.26229 \\
\hline Propamocarb & 6.9 & 1.7 & 0.108 & 0.20042 & Chl-a & 1.4 & 1.4 & 0.19 & 0.34 \\
\hline Iprovalicarb & 6.9 & 1.7 & 0.108 & 0.20042 & $\mathrm{pH}$ & 1.6 & 1.7 & 0.17 & 0.34 \\
\hline Alkalinity & 6.5 & 1.6 & 0.122 & 0.20709 & S_Chlorpyrifos & 1.4 & 1.7 & 0.182 & 0.34 \\
\hline Endosulfan & 6.4 & 1.6 & 0.134 & 0.20709 & S_Dimethoate & 1.2 & 1.5 & 0.232 & 0.3944 \\
\hline TDS & 6.4 & 1.6 & 0.128 & 0.20709 & $\mathrm{NH} 4+$ & 0.9 & 1.3 & 0.312 & 0.50514 \\
\hline S_Deltamethrin & 6.3 & 1.6 & 0.148 & 0.21878 & S_Lambda-cyhalothrin & 0.9 & 1.4 & 0.356 & 0.55018 \\
\hline S_Lambda-cyhalothrin & 6.2 & 1.5 & 0.108 & 0.20042 & S_Fenitrothion & 0.7 & 1.1 & 0.466 & 0.68887 \\
\hline$\lambda$-cyhalothrin & 5.7 & 1.4 & 0.21 & 0.2856 & S_Deltamethrin & 0.6 & $<0.1$ & 1 & 1 \\
\hline DO & 5.6 & 1.4 & 0.196 & 0.27767 & & & & & \\
\hline Turbidity & 5.2 & 1.3 & 0.266 & 0.34729 & & & & & \\
\hline S_Alpha-cypermethrin & 4.8 & 1.2 & 0.286 & 0.34729 & & & & & \\
\hline $\mathrm{EC}$ & 4.7 & 1.1 & 0.284 & 0.34729 & & & & & \\
\hline S_Chlorpyrifos & 4.7 & 1.1 & 0.306 & 0.35876 & & & & & \\
\hline S_Fenitrothion & 3.8 & 0.9 & 0.562 & 0.61639 & & & & & \\
\hline $\mathrm{pH}$ & 3.7 & 0.9 & 0.558 & 0.61639 & & & & & \\
\hline S_Ethoprophos & 3 & 0.7 & 0.684 & 0.72675 & & & & & \\
\hline Temp & 3 & 0.7 & 0.724 & 0.74594 & & & & & \\
\hline S_Dimethoate & 2 & 0.5 & 1 & 1 & & & & & \\
\hline
\end{tabular}


Table SI4.14. Results of the Monte Carlo permutation tests using simple and conditional effects for the macroinvertebrate composition based biotic indices data set. The bold environmental variables were used in RDA analysis depicted on Fig. 4.4. The correlations between all environmental variables and the macroinvertebrate composition based biotic indices is provided in Fig. SI4.3.

\begin{tabular}{|c|c|c|c|c|c|c|c|c|c|}
\hline Simple Term Effects: & & & & & Conditional Term Effects: & & & & \\
\hline Name & Explains \% & pseudo-F & $P$ & $P(\operatorname{adj})$ & Name & Explains \% & pseudo-F & $P$ & $P($ adj $)$ \\
\hline Metalaxyl & 34.6 & 12.2 & 0.002 & 0.017 & Metalaxyl & 34.6 & 12.2 & 0.002 & 0.051 \\
\hline Dimethoate & 29.6 & 9.7 & 0.002 & 0.017 & NO3- & 10.8 & 4.4 & 0.006 & 0.051 \\
\hline Fenitrothion & 29.5 & 9.6 & 0.002 & 0.017 & SO42- & 9 & 4.2 & 0.01 & 0.05667 \\
\hline PO43- & 24.8 & 7.6 & 0.002 & 0.017 & S_Endosulfan & 7.4 & 3.9 & 0.01 & 0.05667 \\
\hline NO3- & 20.2 & 5.8 & 0.004 & 0.01943 & Carbaryl & 5.4 & 3.1 & 0.012 & 0.05829 \\
\hline S_Endosulfan & 16.6 & 4.6 & 0.01 & 0.034 & TDS & 5 & 3.3 & 0.004 & 0.051 \\
\hline Carbaryl & 16.6 & 4.6 & 0.004 & 0.01943 & S_Fenitrothion & 2.9 & 2 & 0.094 & 0.29055 \\
\hline Chl-a & 16.5 & 4.5 & 0.008 & 0.03022 & Iprovalicarb & 3.2 & 2.4 & 0.032 & 0.136 \\
\hline COD & 16 & 4.4 & 0.004 & 0.01943 & Temp & 4.6 & 4.1 & 0.006 & 0.051 \\
\hline S_Diazinon & 15.9 & 4.3 & 0.008 & 0.03022 & COD & 2 & 1.9 & 0.088 & 0.29055 \\
\hline SO42- & 14.6 & 3.9 & 0.016 & 0.04533 & Malathion & 1.8 & 1.8 & 0.126 & 0.3128 \\
\hline Chlorpyrifos & 13.8 & 3.7 & 0.016 & 0.04533 & S_Ethoprophos & 1.9 & 2 & 0.042 & 0.15867 \\
\hline Diazinon & 11.3 & 2.9 & 0.042 & 0.10985 & PO43- & 1.4 & 1.6 & 0.154 & 0.3128 \\
\hline Malathion & 10 & 2.6 & 0.048 & 0.11657 & EC & 1.3 & 1.6 & 0.172 & 0.3128 \\
\hline S_Lambda-cyhalothrin & 9.2 & 2.3 & 0.064 & 0.14507 & Chlorpyrifos & 1.2 & 1.5 & 0.236 & 0.3821 \\
\hline Propamocarb & 9 & 2.3 & 0.072 & 0.153 & $\alpha$-cypermethrin & 0.9 & 1.1 & 0.336 & 0.51927 \\
\hline$\alpha$-cypermethrin & 7.7 & 1.9 & 0.118 & 0.21018 & Dimethoate & 0.9 & 1.2 & 0.374 & 0.55287 \\
\hline $\mathrm{NH} 4+$ & 7.5 & 1.9 & 0.122 & 0.21018 & Fenitrothion & 1.3 & 1.8 & 0.184 & 0.3128 \\
\hline S_Chlorpyrifos & 7.3 & 1.8 & 0.102 & 0.204 & S_Diazinon & 1.2 & 1.9 & 0.15 & 0.3128 \\
\hline S_Deltamethrin & 7.1 & 1.8 & 0.136 & 0.21018 & Diazinon & 1.2 & 2.5 & 0.108 & 0.306 \\
\hline$\lambda$-cyhalothrin & 6.9 & 1.7 & 0.128 & 0.21018 & Endosulfan & 0.8 & 2 & 0.17 & 0.3128 \\
\hline S_Fenitrothion & 6.9 & 1.7 & 0.134 & 0.21018 & S_Lambda-cyhalothrin & 0.6 & 2.2 & 0.184 & 0.3128 \\
\hline Endosulfan & 6.3 & 1.5 & 0.192 & 0.28383 & S_Alpha-cypermethrin & 0.4 & 3.1 & 0.148 & 0.3128 \\
\hline Temp & 5.9 & 1.4 & 0.21 & 0.2856 & Chl-a & 0.1 & $<0.1$ & 1 & 1 \\
\hline Iprovalicarb & 5.9 & 1.4 & 0.22 & 0.28769 & & & & & \\
\hline DO & 5.8 & 1.4 & 0.21 & 0.2856 & & & & & \\
\hline Turbidity & 5.4 & 1.3 & 0.252 & 0.306 & & & & & \\
\hline EC & 5.4 & 1.3 & 0.252 & 0.306 & & & & & \\
\hline S_Ethoprophos & 4.4 & 1.1 & 0.348 & 0.39893 & & & & & \\
\hline S_Alpha-cypermethrin & 4.2 & 1 & 0.352 & 0.39893 & & & & & \\
\hline S_Dimethoate & 4 & 1 & 0.368 & 0.40361 & & & & & \\
\hline TDS & 3.7 & 0.9 & 0.448 & 0.46158 & & & & & \\
\hline Alkalinity & 3.7 & 0.9 & 0.396 & 0.42075 & & & & & \\
\hline $\mathrm{pH}$ & 3 & 0.7 & 0.59 & 0.59 & & & & & \\
\hline
\end{tabular}




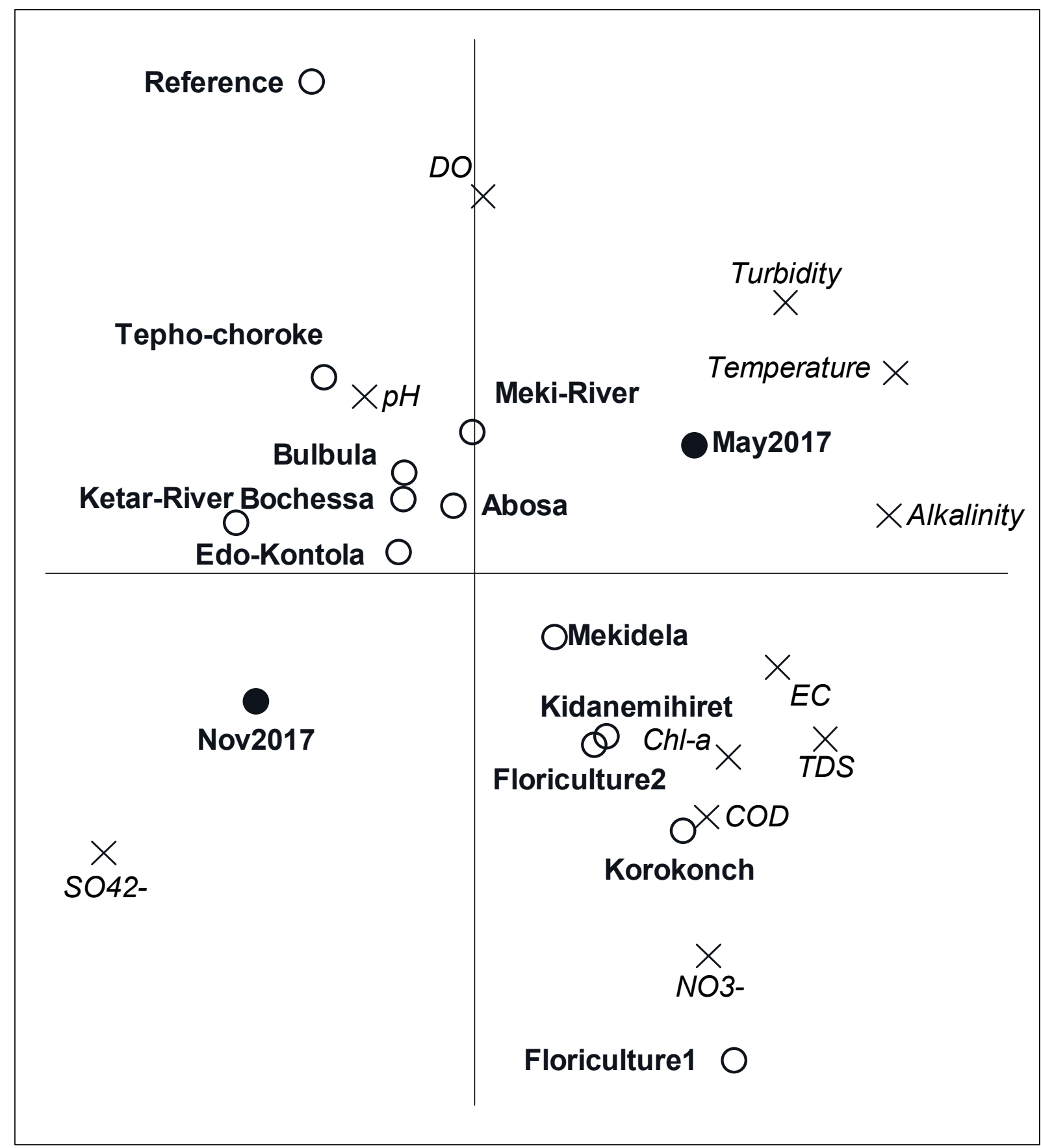

Fig. S14.1. RDA biplot showing the correlations between the physicochemical parameters and the sampling dates and sites. The explanatory variables explained $77 \%$ of all variation in physicochemical parameter values of which $43 \%$ is displayed on the horizontal axis and another $18 \%$ on the vertical axis. 


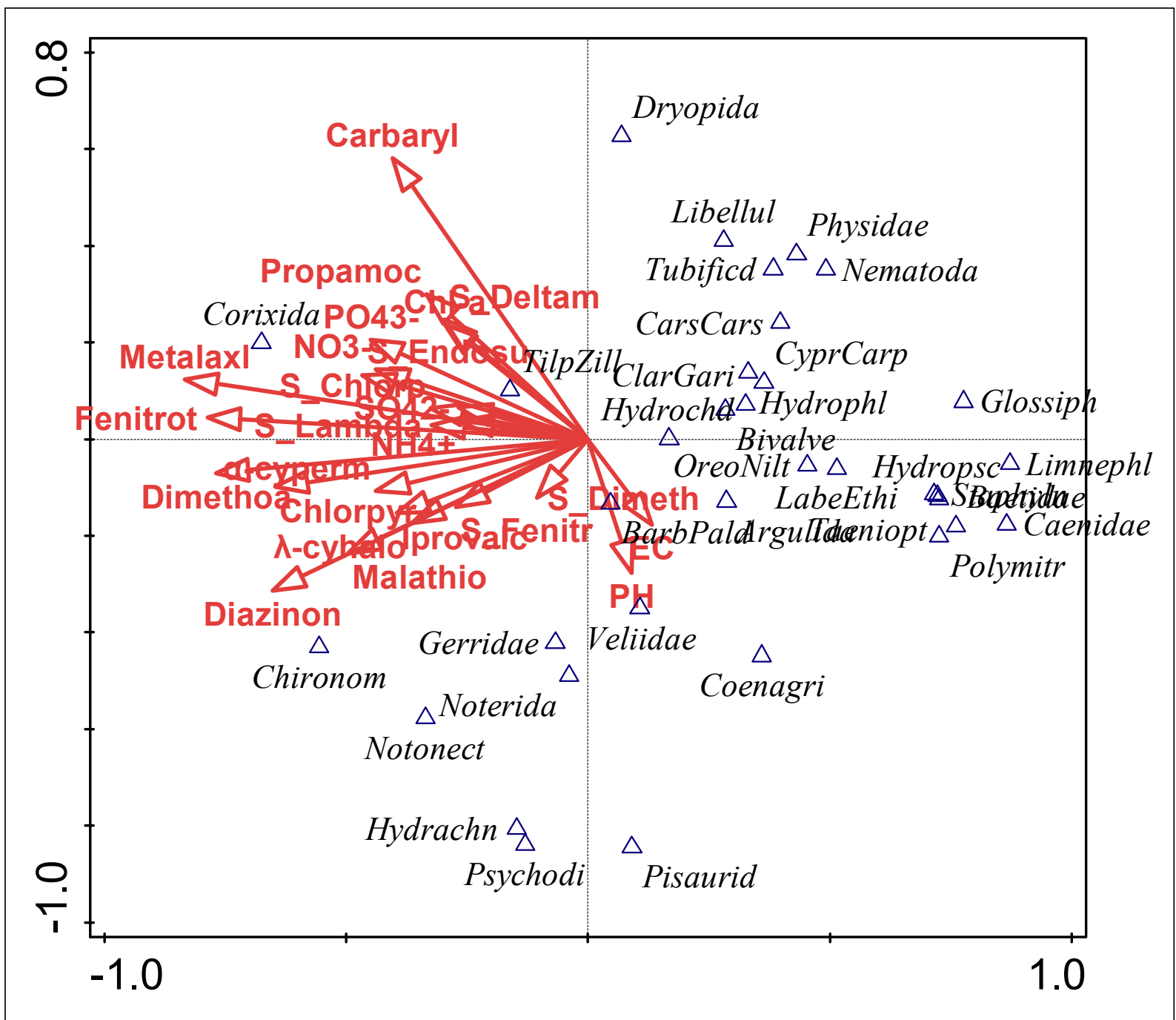

Fig. S14.2. RDA biplot showing the correlations between species abundance and all environmental variables. Sampling date explained $3 \%$ of the variation in species composition, which was excluded from the analysis. The environmental variables explain $100 \%$ of the remaining variation in species composition of which $26 \%$ is displayed on the horizontal axis and another $20 \%$ on the vertical axis. As $100 \%$ of the variation in species composition is explained by the environmental variables, the analysis is in fact a PCA with supplementary environmental variables. 


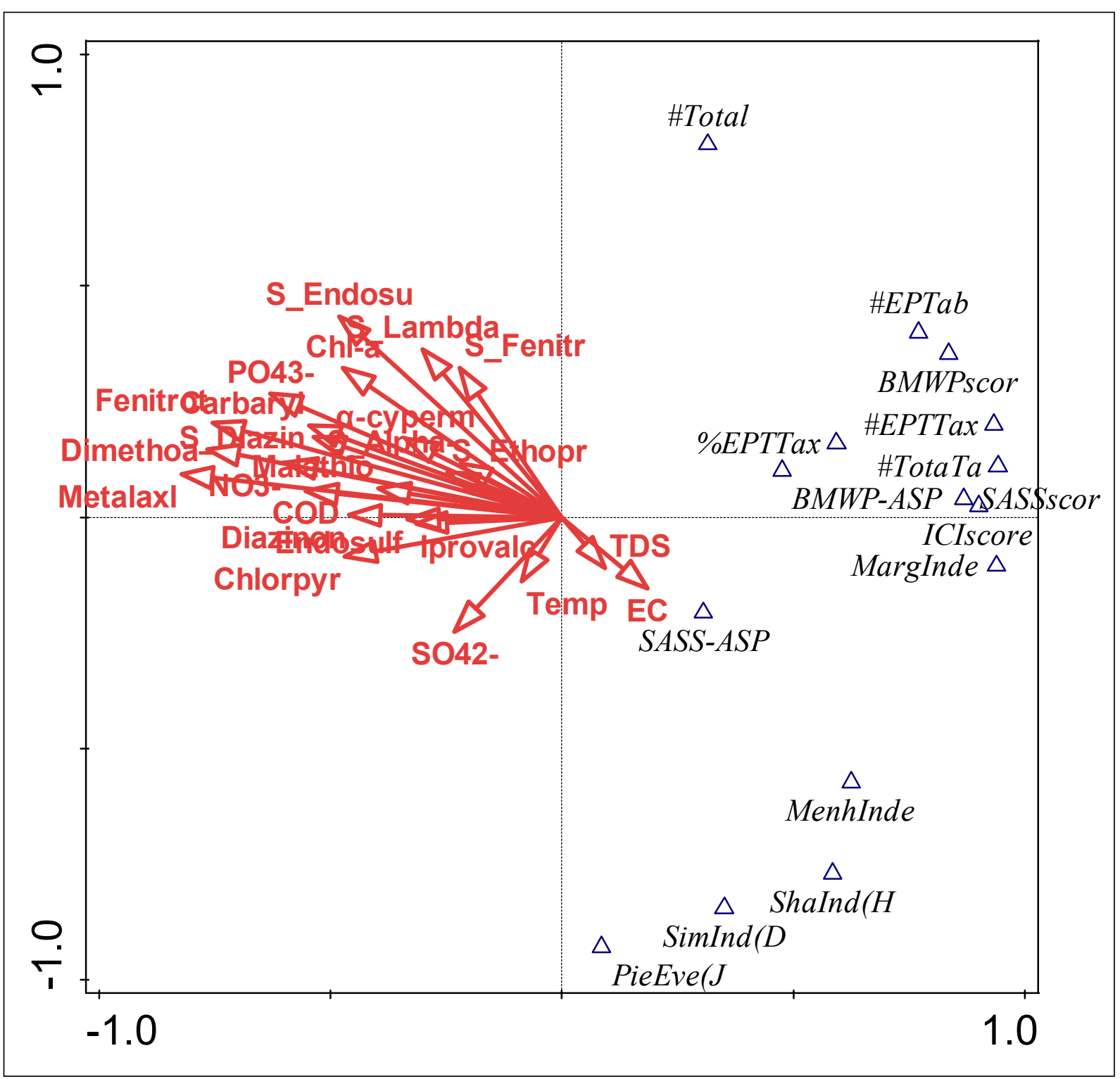

Fig. SI4.3. RDA biplot showing the correlations between the biotic indices values and all environmental variables. Sampling date explained $1 \%$ of the variation in species composition, which was excluded from the analysis. The environmental variables explain $100 \%$ of the remaining variation in biotic indices values of which $48 \%$ is displayed on the horizontal axis and another $24 \%$ on the vertical axis. As $100 \%$ of the variation in species composition is explained by the environmental variables, the analysis is in fact a PCA with supplementary environmental variables. 



\section{CHAPTER 5}

\section{Distribution of microplastics across four fish species and sediment in an} African lake

Lemessa B. Merga, Paula E. Redondo-Hasselerharm, Paul J. Van den Brink, Albert A. Koelmans

This chapter has been published in Science of The Total Environment (2020), 741, 140527: https://doi.org/10.1016/j.scitotenv.2020.140527. 


\section{Abstract}

Pollution with microplastics has become an environmental concern worldwide. Yet, little information is available on the distribution of microplastics in lakes. Lake Ziway is one of the largest lakes in Ethiopia and is known for its fishing and drinking water supply. This study aims to examine the distribution of plastic particles, of all sizes (micro- and small macro-plastics) in four of the major fish species of the lake and in its shoreline sediment. The gastrointestinal tracts analysis showed that $35 \%$ of the sampled fishes ingested plastic particles. The median number of particles per fish was 4 (range 1 - 26). Benthic (Clarias gariepinus) and benthopelagic (Cyprinus carpio and Carassius carassius) fish species were found to contain a significantly higher number of plastic particles in comparison to the planktivorous fish species (Oreochromis niloticus). More fishes ingested plastic particles in the wet compared to the dry season. The maximum plastic size (40 $\mathrm{mm}$ fibre) was found in C. carpio. Estimated median mass of plastic particles in fish was 0.07 (0.0002 - 385.2) mg/kg_ww. Fish and sediment samples close to known potential sources of plastic particles had a higher plastic ingestion frequency (52\% of the fish) and higher plastic concentration compared to the other parts of the lake. The median count and mass of plastic particles measured in sediment of the lake were 30000 (400 -124000) particles/m³ and 764 (0.05 - 36233) mg/kg_dw, respectively, the upper limits of which exceed known effect thresholds. Attenuated total reflection (ATR) - Fourier-transform infrared (FTIR) spectroscopy showed that polypropylene, polyethylene and alkyd-varnish were the dominant polymers in fishes and in sediment. The plastic particles size distributions were Log-linear and were identical for plastic particles found in fish and in sediment, suggesting strong benthic-pelagic coupling of plastic particles transfer. 


\subsection{Introduction}

Because of unsustainable use and inappropriate management of industrial as well as domestic plastic wastes, plastic debris is widely found in the environment and recently its pollution became an emerging environmental concern all over the globe (SAPEA, 2019; Edo et al., 2020). Once released into the environment, plastic waste generally is persistent and therefore stays for many years (SAPEA, 2019). Its fragmentation and degradation mostly are driven by UV-B radiation, physical stress and microbial action (Galgani et al., 2015; Kooi et al., 2017; SAPEA, 2019), which may enhance sinking of the buoyant polymers (Koelmans et al., 2017). UV radiation and microbially mediated degradation are highly dependent on the chemical constituents of the material and environmental variables such as temperature (Galgani et al., 2015). Depending on size, plastic debris is classified generally as nanoplastic (< $1 \mu \mathrm{m}$ ), microplastic (MP, $1 \mu \mathrm{m}-5 \mathrm{~mm}$ ), and macroplastic (> $5 \mathrm{~mm}$ ) (SAPEA, 2019).

Surface water MP pollution and related impacts on aquatic fauna are a rapidly evolving research issue (O'Connor et al., 2019). Many field observations have demonstrated the occurrence of MP in surface waters (Castañeda et al., 2014; Mintenig et al., 2020) and in sediment (Thompson et al., 2004; Imhof et al., 2013; Haave et al., 2019; Lorenz et al., 2019). Ingestion of MP by aquatic fauna including fish (Lusher et al., 2013; Rummel et al., 2016), mammals (Besseling et al., 2015), and invertebrates (Scherer et al., 2017; Nel et al., 2018) is also documented. Concerns have been raised regarding the potential impacts of MP ingestion by aquatic life, such as internal blockages and disruption of digestion (Cannon et al., 2016), or exposure of organisms to plastic-associated chemicals (O'Connor et al., 2019; Schrank et al., 2019). The implications of trophic transfer of MP through the food web for ecological and human health risks is of additional concern (Carbery et al., 2018; Nel et al., 2018). Empirical data showing impacts of MP on aquatic fauna in situ are scarce (Anderson et al., 2016). Recently, a few experimental studies have illustrated the effect of MP on physiological and behavioural traits including feeding (Cole et al., 2015; Ogonowski et al., 2016), fitness (Ogonowski et al., 2016; Schrank et al., 2019), growth (Redondo-Hasselerharm et al., 2018) and community composition (Redondo-Hasselerharm et al., 2020) of aquatic organisms.

Only little information is available on MP pollution in African lakes (Ryan, 1988; Madzena and Lasiak, 1997; Ngupula et al., 2014; Biginagwa et al., 2016; Nel et al., 2018), whereas sets of field data across species and compartments generally are scarce (Khan et al., 2018). Lake 
Ziway (Fig. SI5.1) is one of the largest lakes in Ethiopia, situated between $7^{\circ} 51^{\prime}$ to $8^{\circ} 07^{\prime} \mathrm{N}$ and $38^{\circ} 43^{\prime}$ to $38^{\circ} 56^{\prime} E$ at about $160 \mathrm{~km}$ to the south of the capital, Addis Ababa, Ethiopia. Its surface area is $442 \mathrm{~km}^{2}$ with a shoreline length of $137 \mathrm{~km}$. It is a shallow freshwater lake with average and maximum depths of 2.5-4 m and 7-9 m, respectively. The depth variation of the lake is partially explained by differences in the amount of rain fall between seasons (Merga et al., 2020b). Lake Ziway is known by its ecosystem goods and services including fish food and irrigation water supply (Lemma and Desta, 2016; Teklu et al., 2018). The lake is also a source of drinking water for the Batu town population (about 70, 436 inhabitants). As a result of urbanization and agricultural activities (Fig. SI5.1), MP pollution is a potential threat to Lake Ziway and to the ecosystem services the lake provides.

The present study aims to examine the occurrence of plastic particles in the gastrointestinal tracts of four major fish species and in shoreline sediment of a large freshwater lake (Lake Ziway). Data on all sizes of plastic particles found were recorded, i.e. including those larger than $5 \mathrm{~mm}$ in size. Therefore, we refer to the particles as plastic particles rather than MPs, which is usually defined as plastic with a size smaller than $5 \mathrm{~mm}$ only.

\subsection{Materials and Methods}

\subsubsection{Fish sample collection and gastrointestinal tract analysis}

\subsubsection{Sample collection}

First, the lake was clustered broadly into three zones (zone 1 to 3 ) based on the expected level of exposure of the sites to potential sources of plastic particles like urbanization and agricultural activities (Fig.SI5.1). Zone 1 was expected to be influenced by wastes generated from small- and large-scale agricultural activities, and urban areas (e.g. Batu town). Subsistence farms and Meki town (through Meki River) were expected to be the main sources of plastic particles at zone 2. At zone 3 shoreline agricultural activities were rare, thus, urban wastes from Ogolcho town via the inflow Katar River could be the main sources of plastic pollution. Fishes used for plastic particle analysis were obtained from active fishery cooperatives in these zones. Fishes were sampled on 24 - 25 May 2017 and 20 - 21 November 2017, to include the dry and the wet seasons, respectively.

During each sampling season, 15 individuals per species per zone, i.e. 180 specimens of four commercially important fish species (Oreochromis niloticus, Clarias gariepinus, Cyprinus 
carpio and Carassius carassius), were collected. A total of 360 individual fishes were sampled for analysis over the two seasons. The fish species were selected because they are sources of income for fishermen and widely used for home consumption by the local farmers (Endebu et al., 2015). Therefore, impact to the fish has not only ecological but also economic and possibly human health implications. If plastic particles are in the gastrointestinal tract, the smaller size factions (e.g. $<3 \mu \mathrm{m}$ ) can be translocated into edible fish tissues (Akoueson et al., 2020; Zitouni et al., 2020). The collected fishes were immediately transported in an icebox to the laboratory of Batu Fishery and Other Aquatic Life Research Centre (BFOALRC), located at the western shore of the lake, and stored at $-20^{\circ} \mathrm{C}$ until further analysis.

\subsubsection{Fish gastrointestinal tract analysis}

Fish gastrointestinal tracts (GIT) were analysed according to Foekema et al. (2013) with slight modifications. Briefly, in the laboratory, the length and wet weight of fish samples were measured. The entire content of the esophagus, stomach and intestines were collected into clean glass jars using ethanol cleaned scissor and forceps. Each jar was filled with $10 \% \mathrm{KOH}$ solution (Analytical grade, UNI-CHEM ${ }^{\circledR}$ ) in a volume ratio of 3:1 of $\mathrm{KOH}$ to biological material. Jars were stored in separate and cleaned cupboards for one month at room temperature to facilitate a complete digestion of the fish GIT matrix. During the process, shaking of the jars was avoided to minimize the damage of the plastic particles due to possible physical scratches by shells and other silica materials. The digested GIT was carefully sieved using a $0.1 \mathrm{~mm}$ sieve (i.e. $0.1 \mathrm{~mm}$ is the detection limit) and the residue was transferred into a clean glass bottle. Then, plastic particles were visually identified with the help of a 40x stereomicroscope (Premiere SMZ-05, USA) and following previously published procedures (Cannon et al., 2016; Lusher et al., 2016). Criteria included physical characteristics such as unnatural appearance (e.g. shiny particles without visible cellular or organic structures) as described by Lusher et al. (2016), shape of the particles (e.g., fibre, fragment) and colour. Malleability of the particles was checked by squashing with a laboratory stainless dissect needle (micro tip diameter) as stated by Cannon et al. (2016). The number of identified plastic particles was counted per individual fish. The length of the identified plastic particles was measured as the largest crosssection using an ocular micrometer fixed to the eyepiece of the microscope. Colour and shape (fibre, fragment, foam and pellet) were also recorded. 
The weight of the plastic particles was estimated using the average density of environmental MP $\left(1.04 \mathrm{~g} / \mathrm{cm}^{3}\right.$ ) (Redondo-Hasselerharm et al., 2018) and the estimated volume of each of the plastic particles. Following Besseling et al. (2019), for fragments, each particle was assumed to have a volume half of the volume of a sphere, with sphere radius taken as half of the measured length of the particles. For fibre plastic particles, the volume was calculated from length and a standard cross-sectional diameter $(20 \mu \mathrm{m})$, as fibres usually are assumed to have cylindrical shape (Kooi and Koelmans, 2019). The $20 \mu \mathrm{m}$ diameter estimate was obtained by taking the median of ten values reported in the literature (Frias et al., 2010; Cole et al., 2014; Cole, 2016; Napper and Thompson, 2016; Cincinelli et al., 2017; Falco et al., 2018; Absher et al., 2019; Wolff et al., 2019; Edo et al., 2020) (Table SI5.3). This diameter is within the range of the environmentally realistic diameter for fibres $(10-28 \mu \mathrm{m})$ as reported by Cole (2016). With these assumptions, weights of fragment and fibre plastics were estimated using equation 1 and 2 , respectively.

$$
\begin{aligned}
& \text { Weight of fragment }(g)=\rho^{*} \frac{1}{2}\left(\frac{4}{3} * \pi^{*} \frac{L^{3}}{8}\right) \ldots \ldots \ldots \text { equation } 1 \\
& \text { Weight of fibre }(g)=\rho^{*}\left(\pi^{*} \frac{d^{2}}{4} * L\right) \ldots \ldots \ldots \ldots \text { equation } 2
\end{aligned}
$$

Where " $\rho$ " is average density of MP $\left(\mathrm{g} / \mathrm{cm}^{3}\right)$, "L" length of the plastic particles $(\mathrm{cm})$ and " $d$ " is the cross sectional diameter of fibres $(\mathrm{cm})$.

Subsequently, using the weight of the plastic particles and the wet weight (ww) of fish, the mass concentration of plastic particles in fish (mg/kg_ww) was calculated. To evaluate the field based bio-accumulation of plastic particles through the food chain, Bio-accumulation Factors (BAF) were calculated by dividing the concentration of plastic particles in fish (mg/kg_ww) to concentration of plastic particles in sediment $(\mathrm{mg} / \mathrm{kg}$ _dry weight $(\mathrm{dw})$ of sediment) (Sue et al., 2016). Note that this BAF is calculated without gut defaecation, because for plastics the GIT is the target organ and thus drives spreading of the particles across the food web.

To reduce air borne contamination, each step during sample preparation and analysis was performed in a laminar flow hood, which was thoroughly cleaned using ethanol as suggested by Foekema et al. (2013) and Hermsen et al. (2018). Plastic made equipment was avoided during the analysis and counting processes. After every sample analysis, all used equipment 
was scrubbed with ethanol. Furthermore, gloves and cotton lab coats were worn during sample processes and analysis.

\subsubsection{Sediment sample collection and analysis}

\subsubsection{Sample collection, transportation and storage}

Sediment samples were collected from zone 1 ( 7 sites), zone 2 ( 3 sites) and zone 3 ( 3 sites) regions of Lake Ziway. In total, 13 shoreline sites were investigated (Fig. SI5.1). In addition to the earlier mentioned human activities generating plastic waste, their accessibility was also considered when selecting the sample sites. Surface sediment $(0-2 \mathrm{~cm})$ was collected using an Ekman grab sampler (HYDRO-BIOS, surface area $=0.0225 \mathrm{~m}^{2}$ ) from the selected shoreline sites. Samples were wrapped with aluminium foil and kept in clean wide mouth glass bottles. Three replicates $(n=3)$ were collected in each of the selected sampling sites. Immediately after collection, samples were transported carefully to BFOALRC using an icebox and stored at $4{ }^{\circ} \mathrm{C}$ till analysis.

\subsubsection{Sediment analysis}

A density separation technique was used to separate plastic particles from sediment samples following Thompson et al. (2004) with modifications. In brief, $250 \mathrm{~mL}$ of wet sediment was dried at $50^{\circ} \mathrm{C}$ for 72 hours in an oven. The dry weight ( $\mathrm{dw}$ ) of the sediment was measured and the sediment was subsequently added to a glass beaker containing $500 \mathrm{~mL}$ saturated $\mathrm{NaCl}$ solution ( $354 \mathrm{~g} / \mathrm{L}$, sieved by a $0.1 \mathrm{~mm}$ sieve). The solution was stirred slowly for 15 minutes to avoid damage to the plastic particles. The stirred sample was left to settle for $3 \mathrm{hrs}$ to enhance the separation of plastic particles from fine mineral particles, followed by careful filtration using a $0.1 \mathrm{~mm}$ sieve. The residue was transferred into a clean glass bottle (wide mouth) and examined for plastic particles applying the same procedure used for the fish GIT analysis. Concentrations were expressed as numbers of plastic particles per sediment volume (particles $/ \mathrm{m}^{3}$ ) and per dry weight of sediment (particles/kg_dw), and weight of plastic particles per dry weight of sediment $\left(\mathrm{mg} / \mathrm{kg} \_\mathrm{dw}\right)$. Furthermore, the numerical abundance of plastic particles per surface area (particles $/ \mathrm{m}^{2}$ ) was calculated by dividing the number of plastic particles counted by the area of sediment sampled by the Ekman grab sampler 0.0225 $\mathrm{m}^{2}$ ). Colour and shape of the identified plastic particles were recorded. To avoid airborne fibre contamination, the same practice mentioned earlier for GIT analysis was applied. 


\subsubsection{Characterization of the plastics}

Attenuated Total Reflectance (ATR) - Fourier Transform Infrared (FTIR) spectroscopy was used to characterize the polymer identity of the plastic particles detected in the sediment and in the GIT of the fishes. The analysis was performed at Wageningen University and Research. A total of $4.4 \%$ of the particles extracted from sediment and $3.2 \%$ of the particles from fishes were examined. The particles were analysed with a Scimitar series 1000 ATR-FTIR spectroscope (Varian, Agilent technologies INc., USA) as described by Hermsen et al. (2018). Polymer identification was performed by comparing the measured spectra $\left(650-4000 \mathrm{~cm}^{-1}\right)$ with the reference spectra. A reference database and free software developed by Aalborg University, Denmark and Alfred Wegener Institute, Germany (SiMPle; https://simpleplastics.eu/index.html) was used for comparison.

\subsubsection{Data analysis}

The non-parametric Wilcoxon test was used to assess significant differences in the concentration of plastic particles in sediment (particles $/ \mathrm{m}^{3}$ ) and percent of fish (\%) that ingested plastic particles between the dry and wet seasons. Furthermore, Chi-Squared test (Roch et al., 2019) was employed to test the significance differences between the four fishes in burden of plastic particles and between the three zones of the lake in frequency of fish (\%) that found with plastic particles.

To estimate plastic particles size distribution below the limit of detection (i.e. $0.1 \mathrm{~mm}$ ) of this study, we performed a particle size distribution analysis according to Roch et al. (2019). The plastic particles were grouped into 47 size bins ranging from 1 to $52169 \mu \mathrm{m}$ where the size of each next bin was increased by a factor of 1.26. Various parameters were calculated including size bin boundaries $\left(l_{i}, l_{i+1}\right)$, size of each particle size bin $\left(\Delta l_{i}\right)$, volume equivalent diameter $\left(l_{i^{*}}\right)$, size of each particle size bin to volume equivalent diameter ratio $\left(\Delta \mathrm{l}_{\mathrm{i}} / \mathrm{l}_{\mathrm{i}^{*}}\right)$, number of plastic particles per size bin $\left(\Delta N_{i}\right)$ and particle frequency per size bin $\left(\Delta N_{i} / \Delta l_{i}\right)$. A linearized (log-log) graph of volume equivalent diameter $\left(l_{i^{*}}\right)$ versus particle frequency per size bin $\left(\Delta \mathrm{N}_{\mathrm{i}} / \Delta \mathrm{l}_{\mathrm{i}}\right)$ were plotted. To extrapolate particle frequency for sizes $<200 \mu \mathrm{m}$ the regression function obtained from the linearized log-log graph was used.

Analysis of covariance model was used to test the significance of differences between the calculated linear regressions for size distributions of fish plastic particles and sediment plastic 
particles. Condition index (K) was calculated for fishes with and without plastic particles using a length-weight relationship equation $\left(K=100 *\left(W / L^{3}\right)\right.$ as described by Foekema et al. (2013), where $W$ is wet weight $(\mathrm{g})$ and $\mathrm{L}$ is total length $(\mathrm{cm})$ of fish. A Mann-Whitney test was used to test the significance of the difference between the condition index of fish with and without plastic particles. All analyses were performed using SPSS software package version 25 (IBM Corp., NY) and a critical $p$-value $<0.05$ was selected.

\subsection{Results}

\subsubsection{Occurrence of plastic particles in GIT of fishes and sediments}

The mean length and wet weight of the studied fish species were $20.1 \pm 4.5 \mathrm{~cm}$ and 163 $\pm 96.2 \mathrm{~g}$ (O. niloticus), $36.4 \pm 7.8 \mathrm{~cm}$ and $352 \pm 190 \mathrm{~g}$ (C. gariepinus), $27.4 \pm 7.1 \mathrm{~cm}$ and $338 \pm$ $206 \mathrm{~g}$ (C. carassius), and $34.4 \pm 7.3 \mathrm{~cm}$ and $504 \pm 288 \mathrm{~g}$ (C. carpio), respectively. From the 360 examined individual fishes, plastic particles were found in the GIT of 125 (35\%) individuals (Table SI5.1). All four species were found with plastic particles in their GIT. The fish species with the highest percentage of individuals with ingested plastics was C. gariepinus (41\%) and the lowest was O. niloticus (22\%). For C. carpio and C. carassius, plastics were found in $39 \%$ and $37 \%$ of the individual species, respectively. The number of fishes (70) that contained plastic particles in their GIT was significantly higher during the wet season than in the dry season (55) (Wilcoxon test; $p=0.042$ ).

Table 5.1. Plastic particles mean, minimum (min.) and maximum (max.) concentrations in fish (a) and sediment (b) samples of Lake Ziway.

\begin{tabular}{|c|c|c|c|c|c|c|c|c|}
\hline \multicolumn{5}{|c|}{ Fish sample } & \multicolumn{4}{|c|}{ b. Sediment sample } \\
\hline \multirow{2}{*}{$\begin{array}{l}\text { Sample } \\
\text { location }\end{array}$} & \multirow[b]{2}{*}{ Fish species } & \multicolumn{3}{|c|}{ Concentration (mg/kg_ww) } & \multirow[b]{2}{*}{ Sampling site } & \multicolumn{3}{|c|}{ Concentration (mg/kg_dw) } \\
\hline & & Mean & Min. & Max. & & Mean & Min. & Max. \\
\hline Zone 1 & O. niloticus & 1.1 & 0.001 & 6.4 & Bochesa & 226.1 & 0.046 & 446.2 \\
\hline Zone 1 & C. carassius & 3.8 & 0.001 & 51.4 & Bulbula & 543.7 & 116.4 & 1296.6 \\
\hline Zone 1 & C. gariepinus & 34.1 & 0.0007 & 170.7 & Floriculture 2 & 849.1 & 89.4 & 2552.7 \\
\hline Zone 1 & C. carpio & 56.3 & 0.0005 & 385.2 & Floriculture 1 & 3895.2 & 452.7 & 11892.6 \\
\hline Zone 2 & O. niloticus & 1.3 & 0.004 & 9.7 & Korekonch & 4957.5 & 198.6 & 13309.2 \\
\hline Zone 2 & C. gariepinus & 5.4 & 0.004 & 34.1 & Kidanemihiret & 12294.0 & 915.9 & 36233.2 \\
\hline Zone 2 & C. carassius & 8.3 & 0.013 & 35.1 & Edo-Kontola & 2509.0 & 324.2 & 9732.7 \\
\hline Zone 2 & C. carpio & 11.2 & 0.0002 & 51.3 & Abosa & 2644.0 & 88.6 & 5528.8 \\
\hline Zone 3 & O. niloticus & 3.9 & 0.01 & 15.5 & Tepho-Choroke & 1354.1 & 556.0 & 3380.0 \\
\hline Zone 3 & C. gariepinus & 23.9 & 0.003 & 106.2 & Mekidela & 3181.8 & 126.2 & 9613.6 \\
\hline Zone 3 & C. carassius & 2.4 & 0.0005 & 19.1 & Meki-River & 1269.0 & 36.0 & 5142.3 \\
\hline \multirow[t]{2}{*}{ Zone 3} & C. carpio & 3.0 & 0.005 & 21.0 & Reference & 66.5 & 0.26 & 152.5 \\
\hline & & & & & Katar-River & 4200.6 & 289.1 & 11525.3 \\
\hline
\end{tabular}


As for spatial variability, the fish GIT analysis indicated that a significantly (Chi-Squared test; $p<0.001$ ) higher frequency of fish with ingested plastic particles was collected from the western part (zone $1=52 \%$ ) compared to the northern (zone $2=29 \%$ ) and south-eastern (zone $3=23 \%$ ) parts of Lake Ziway. Moreover, of the 560 quantified plastic particles in the GIT of 125 fishes, a significantly (Chi-Squared test; $P<0.001$ ) higher proportion (68\%) of the particles was identified in fishes collected from the zone 1 sampling site, while fishes collected from zone 2 and zone 3 contributed only for $20 \%$ and 12\% particles, respectively (Fig. 5.2a).

C. carpio and C. gariepinus contained significantly more plastic particles than $O$. niloticus and $C$. carassius (Chi-Squared test; $P<0.001$ ). The count based median concentrations of plastic particles in fish was 4 (1 - 26) (particles/fish) (Fig. 5.2b), but the burden value is increased to 6.3 when the number of extrapolated MP included. The weight based median concentrations of plastic particles in fish were $0.07(0.0002-385.2) \mathrm{mg} / \mathrm{kg} \_w w$ (Table 5.1a). The highest number of plastic particles was quantified in C. carpio (benthopelagic), sampled from zone 1. The calculated weight based average BAF was $0.0048( \pm 0.0051)$ and ranged from 0.00027 - 0.0152. Furthermore, we found no significant differences between the condition factors of fishes with and without plastic particles $(p>0.05)$.

Plastic particles were detected in all sediment samples taken at the shoreline sites of Lake Ziway (Fig. SI5.1; Table SI5.2). In the total of 78 sediment samples collected from the 13 sites during the dry and wet seasons, 649 plastic particles were counted. Contrary to the seasonality of the numbers of plastic particles in fish, a significantly higher (Wilcoxon test; $p$ $<0.001$ ) number of plastic particles was observed for the dry season sediment (427 plastic particles) compared to the wet season samples (222 plastic particles). The count and weight based median of plastic particle concentrations in sediment of the lake were 30000 (400 124000) particles $/ \mathrm{m}^{3}$ and $764(0.05$ - 36233) mg/kg_dw, respectively. Higher plastic particle concentrations were observed at sampling sites found at the western and northern parts of the lake (Fig. 5.1; Table 5.1b). Particularly, sediments collected from Kidanemihiret (Dry = $74667 \pm 29029$ particles/m³, $12294(915.9-36233.2)$ mg/kg_dw), Korekonch (57333 \pm 29139 particles $/ \mathrm{m}^{3}, 4957.5(198.6$ - 13309.2) mg/kg_dw) and Meki-River (Dry = $48667 \pm 14841$ particles $/ \mathrm{m}^{3}, 1269(36-5142.3) \mathrm{mg} / \mathrm{kg}$ _dw) sampling sites were found with the highest plastic particle concentrations (Fig. 5.1; Table 5.1b; Table SI5.2). The lowest concentrations 
were quantified at the Reference sampling location $\left(6000 \pm 3347\right.$ particles $/ \mathrm{m}^{3}, 66.5(0.26-$ 152.5) $\left.\mathrm{mg} / \mathrm{kg} \_\mathrm{dw}\right)$.

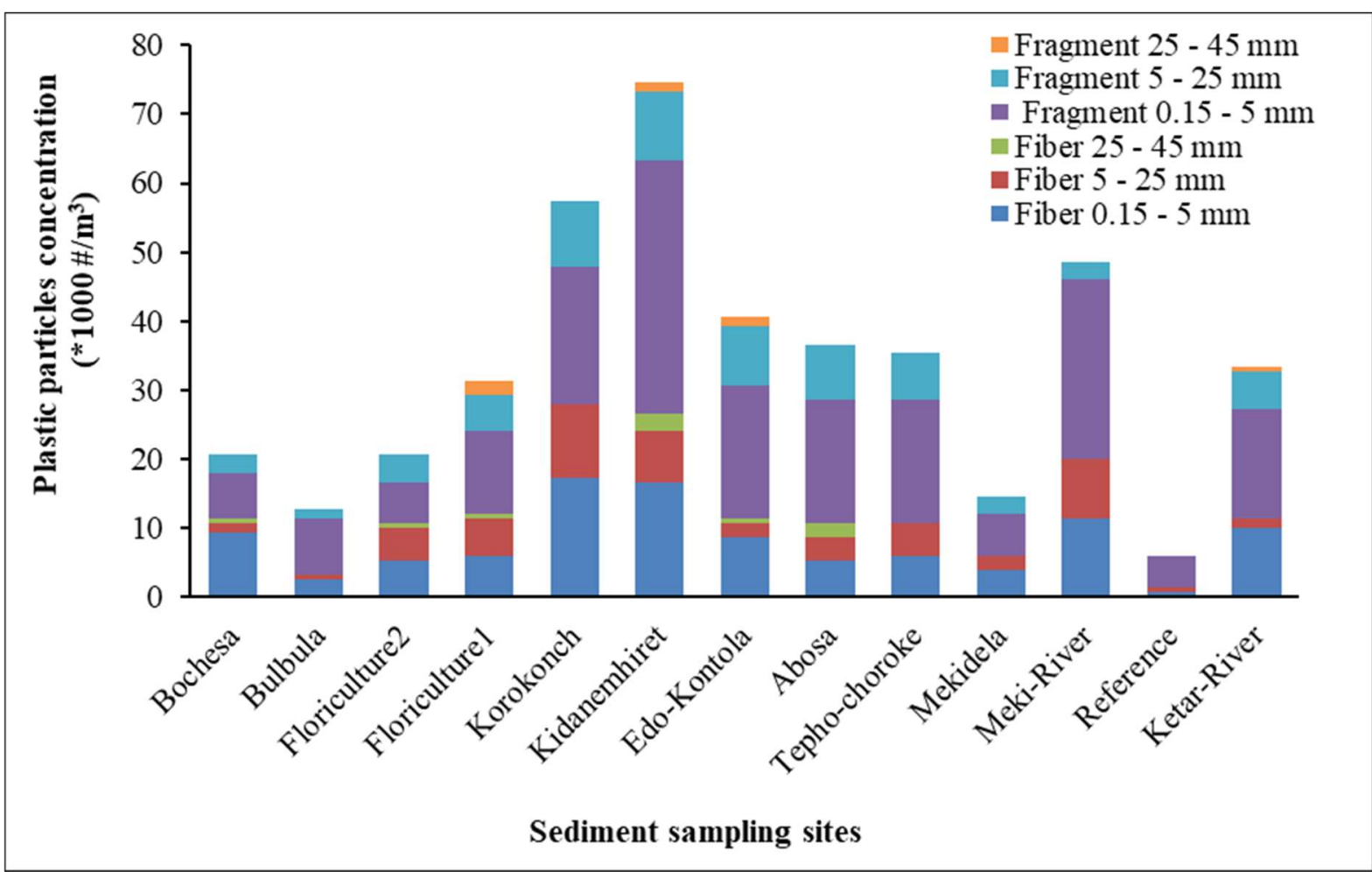

Fig. 5.1. Plastic particle concentrations (particles $/ \mathrm{m}^{3}$ ) in sediment samples collected from different shoreline sites of Lake Ziway. The particles are grouped according to shape and size.

\subsubsection{Size, shape and colour of plastic particles}

The minimum and maximum sizes of the quantified plastic particles in the GIT of the studied fishes were $0.2 \mathrm{~mm}$ and $40 \mathrm{~mm}$, respectively, with highest abundance at lower sizes (Fig. 5.3).The longest size ( $40 \mathrm{~mm}$ ) was measured for a fibre, observed in C. carpio sampled during the wet season at zone 1. The observed median and mean length values were $3.3 \mathrm{~mm}$ and $4.9 \mathrm{~mm}$, respectively. Of the 560 quantified plastic particles, the majority (74\%) were found to be in the MP particle size range of $0.2-5 \mathrm{~mm}$ (Fig. 5.4a), with 146 particles being larger than $5 \mathrm{~mm}$. The MP percentage was increased to $83 \%$ when the extrapolated number of $\mathrm{MP}<0.2 \mathrm{~mm}$ included (Fig. 5.3). MP abundances per species (plastics $<5 \mathrm{~mm}$ ) were $77 \%$, $61 \%, 71 \%$ and $69 \%$ in 0 . niloticus, C. carassius, C. gariepinus and C. carpio, respectively. No significant differences were observed between the four species with respect to the size of the ingested plastic particles (Fig. SI5.2). However, we found differences in the longest size of ingested plastic particles between $O$. niloticus $(15 \mathrm{~mm})$, C. carassius $(35 \mathrm{~mm})$, C. gariepinus $(31.5 \mathrm{~mm})$ and C. carpio $(40 \mathrm{~mm})$. However, in general, no strong correlation was observed 
between the size of the plastic particles and length of fish for each species where the plastic particles size-fish length $R^{2}$ ranged from $0.0001-0.0372$ (Fig. SI5.3). The plastic particles were dominated by fragments (57.5\%), followed by fibres (42.5\%). Plastic particles with blue (37\%) and transparent white (36\%) colours were dominant in the GIT of the fishes. Red, green, black and pink coloured plastic particles were also quantified in the range of $3.9-6.6 \%$.

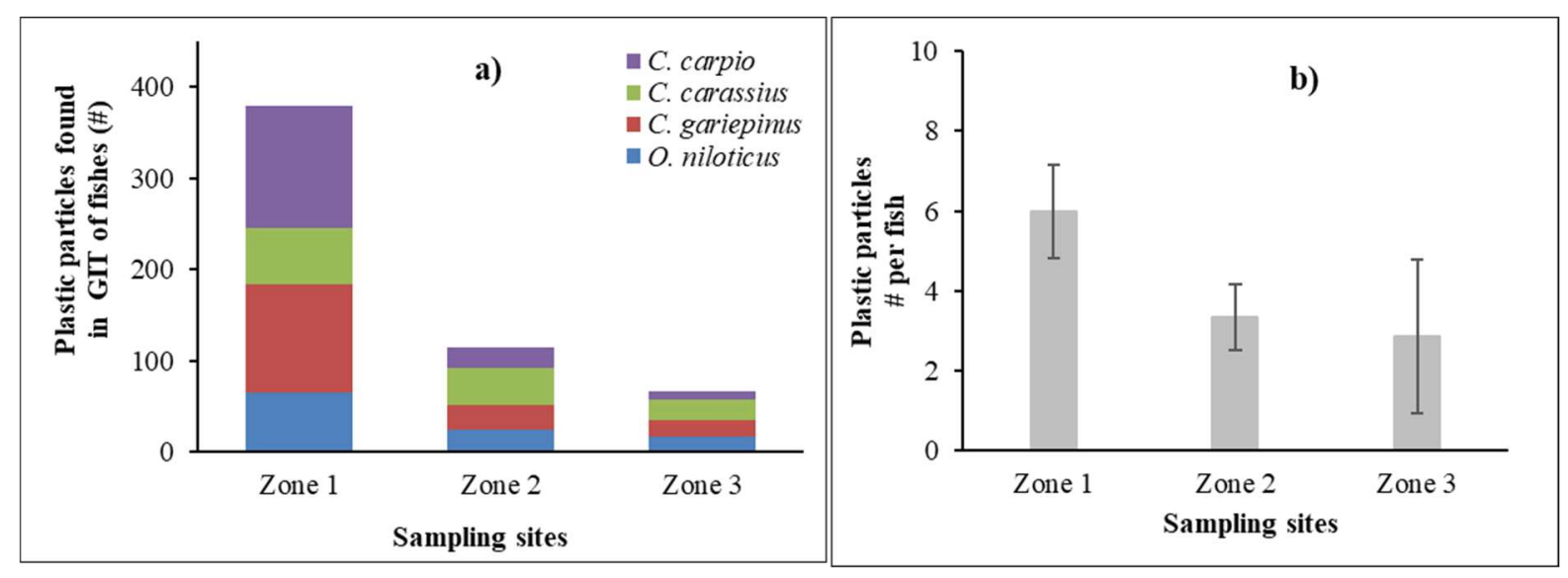

Fig. 5.2. Total number of plastic particles counted in GIT of fishes (a) and average number of plastic particles per fish that ingested the particles (b).

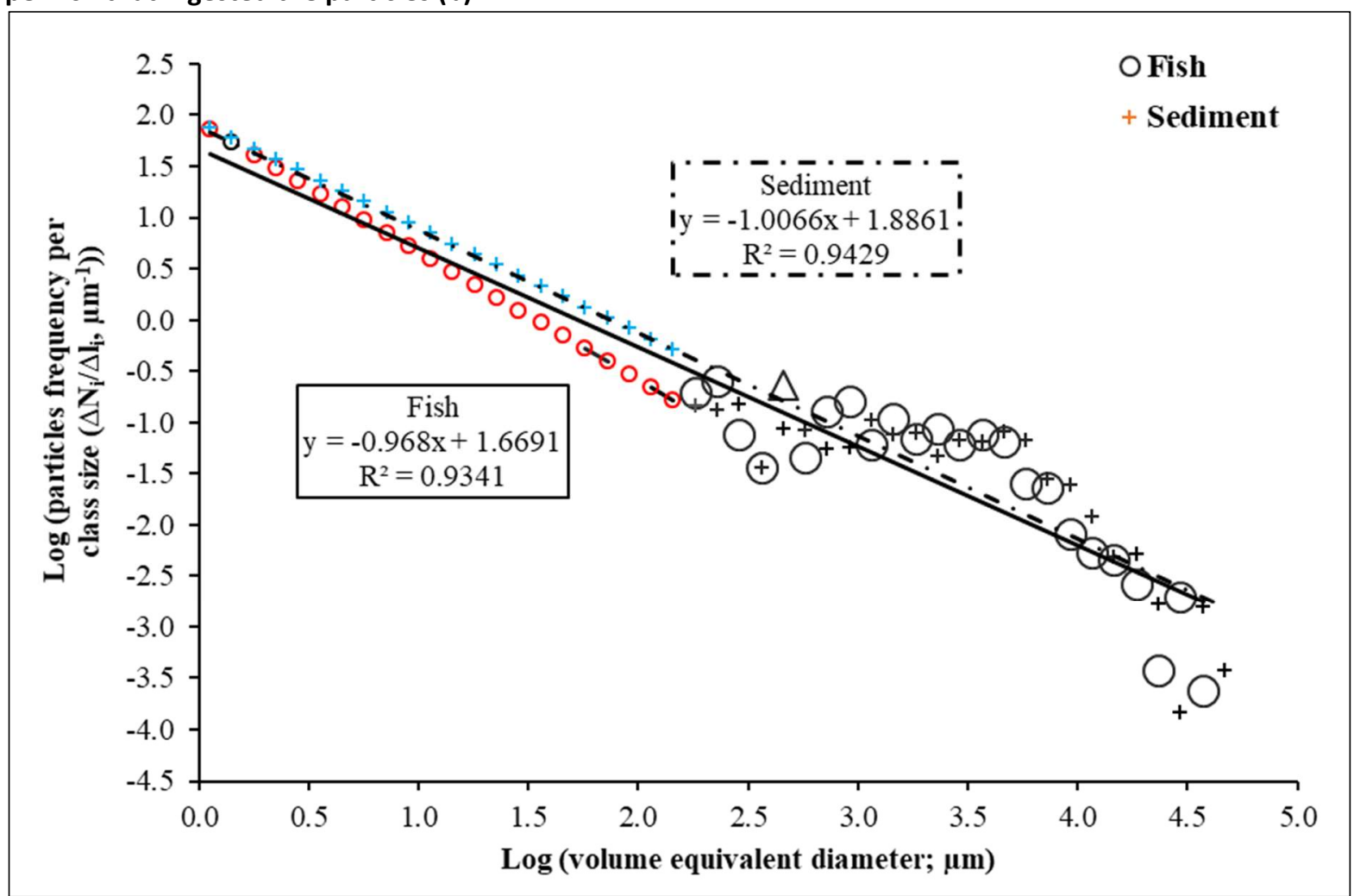

Fig. 5.3. Particle size distribution analysis of plastic particles in sediment and fish. The values in red and blue colours are for the extrapolated microplastics $<0.1 \mathrm{~mm}$.

The minimum and maximum sizes of plastic particles quantified in sediment samples were $0.15 \mathrm{~mm}$ and $45 \mathrm{~mm}$, respectively with highest abundance at lower sizes (Fig. 5.3). The largest size $(45 \mathrm{~mm})$ of fibre plastic particle was found in a sediment sample collected from the 
Floriculture site during the wet season. The plastic particle size distribution observed in sediment was not significantly different from the size distribution measured in GIT of the fishes $(p=0.233)$. The observed median and mean size values of sediment plastic particles were $3.8 \mathrm{~mm}$ and $5.3 \mathrm{~mm}$, respectively. And 70\% (46\% fragment and 24\% fibre) of plastic particles quantified in sediment had a size in the range of $0.15-5 \mathrm{~mm}$ (Fig. 5.1; Fig. 5.4a). But, when the extrapolated size $(<0.15 \mathrm{~mm})$ included, the percentage of MP in sediment rise to $80 \%$. Similar to the plastic particles found in the GIT of the fish species, the dominant shape and colours in sediment samples of Lake Ziway were fragments (62\%), and transparent white $(43 \%)$ and blue (36\%). Plastics with red, green, black and pink colours were also found, but their percentage was low, ranging from 3.6 to $9.1 \%$.

\subsubsection{Polymer identity of the sorted plastic particles}

ATR-FTIR analysis revealed that 93\% (27 pieces) of the particles sorted from sediments were plastics, while 2 of them were non-plastic organic matter particles. Similarly, 94\% (17 pieces) of the particles sorted from the GIT of the fishes were confirmed to be plastics. Synthetic and semi-synthetic polymers such as polyethylene (PE), polypropylene (PP) and alkyd-varnish (AV) were predominantly found in both fish and sediment samples (Fig. 5.4b). Polyethylene terephthalate (PET), ethylene-propylene rubber (EPR) and polyurethane_acrylic_rasin (PUAR) were identified in sediment in lower quantities only, as shown in Fig. 5.4b.

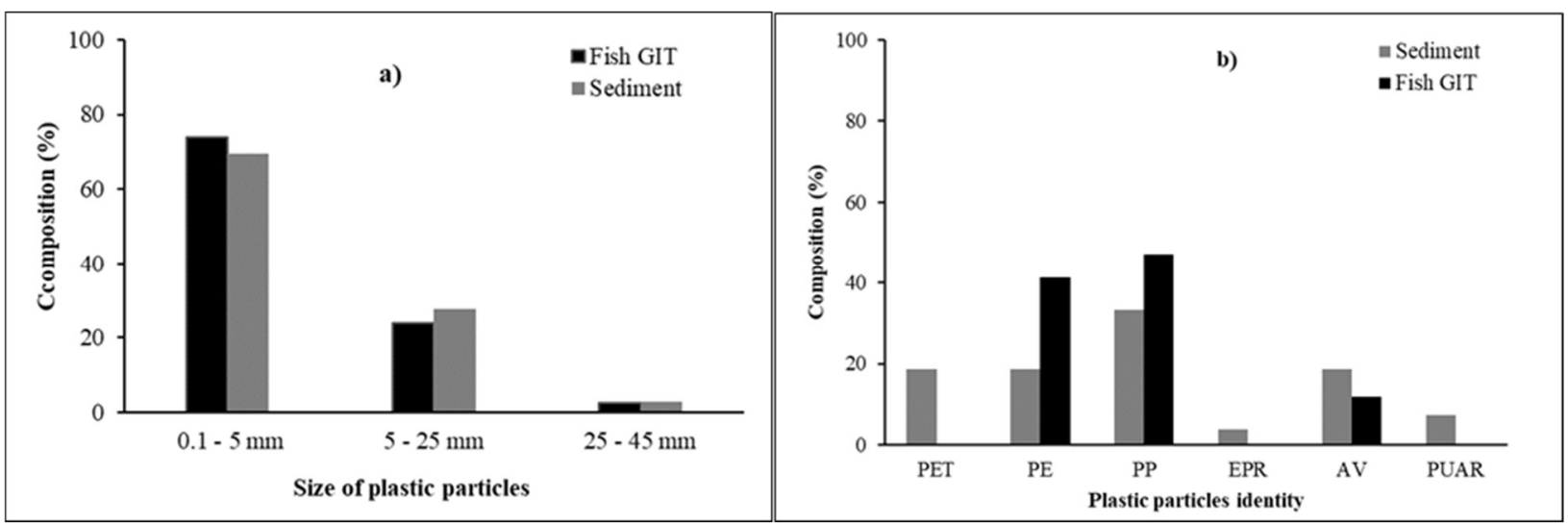

Fig. 5.4. Percent composition of plastic particles according to their size class in fish and in sediment samples of Lake Ziway (a). Identity and percent composition of plastic particles collected from GIT of fish and from sediment samples (b). 


\subsection{Discussion}

\subsubsection{Ingestion of plastics by fishes of Lake Ziway}

This study shows that four fish species of Lake Ziway were contaminated by plastic particles of various polymer types and sizes (Table SI5.1; Fig. 5.4). As the species are commercially important and are the subsistence food source for many people in the region (Endebu et al., 2015), the contamination with plastic may pose a risk on human health due to possible translocation of plastic particles into edible tissues of fish as observed by Collard et al. (2018) in freshwater Squalius cephalus species from Marne and Seine Rivers, France.

It is difficult to make comparisons across MP studies due to the differences in methods (Markic et al., 2019) and in the level of quality control/quality assurance used by researchers (Hermsen et al., 2018). Still it is useful to reflect on the present data in the light of earlier work. The observed percentage of fish containing plastic particles (35\%) was similar to previously reported values for marine fishes from the North Pacific Central Gyre (Boerger et al., 2010) and the English Channel, UK (Lusher et al., 2013) as depicted in Table 5.2. The reported value (20\%) by Biginagwa et al. (2016) for O. niloticus fish species sampled from the southern part of Lake Victoria (Africa), was also comparable with our result (22\%) for the same species (Table 5.2). Our results appear to be higher than the values reported for fishes in freshwater French rivers (Sanchez et al., 2014; Collard et al., 2018), in the North Atlantic (Lusher et al., 2016) and in the North Sea (Foekema et al., 2013; Hermsen et al., 2018) (Table 5.2). Differences in studied fish species and in regional sources of plastics may also contribute to this variation.

Our results (Table SI5.1) showed that a larger number of benthic (C. gariepinus) and benthopelagic ( $C$. carpio and $C$. carassius) fishes ingested plastic particles compared to the surface feeding planktivorous $O$. niloticus species. Furthermore, a significantly larger number of plastic particles was found in the GIT of $C$. carpio and $C$. gariepinus compared to the other two species. This shows that species mainly feeding on sediment can be exposed to plastic particles to a higher extent than surface feeding planktivorous fish species, which was also reported by Jabeen et al. (2017) for fishes sampled from Lake Taihu (China). Thus, feeding behaviour and feeding habitat are important factors in plastic particle studies in aquatic biota.

The differences observed in the frequency of fish that ingested plastic particles between various locations of Lake Ziway can possibly be explained from shoreline human activities, 
particularly urban influence (Peters and Bratton, 2016). A significantly higher number of fish containing plastic particles was observed at zone 1 , which is close to Batu town.

The average number of plastic particles per fish measured in our study $(4.4 \pm 3.6)$ was comparable to the results recorded for fish from the North Pacific Central Gyre $(2.1 \pm 5.78)$ (Boerger et al., 2010), the Lake Taihu and Yangtze estuary of China (3.7 \pm 1.5$)$ (Jabeen et al., 2017) and the Balearic Islands of Spain (3.75 \pm 0.25$)$ (Nadal et al., 2016). But, there are differences in measured size windows between these literature data and our study. Jabeen et al. (2017) and Nadal et al. (2016) considered plastic particles $\geq 0.005 \mathrm{~mm}$ and $0.001-5 \mathrm{~mm}$, respectively, whereas in the present study plastics $\geq 0.1 \mathrm{~mm}$ were counted. This shows that plastics with lower sizes $(<0.1 \mathrm{~mm}$ ), which have a profound contribution (e.g. up to $95 \%$ ) in sediment samples (Haave et al., 2019), were not quantified in our study. This was indicated in our extrapolation result (Fig. 5.3) for plastic particle size $<0.1 \mathrm{~mm}$.

Studies have reported that fishes may prey intentionally on plastic particles that possess colour (e.g. transparent white, blue and green) similar to their natural food items such as planktons (Boerger et al., 2010; Nadal et al., 2016). These colours, particularly transparent white (36\%) and blue (37\%) plastic particles, were found dominantly in the GIT of the studied fishes. However, our results do not suggest the intentional preying of plastic particles by the studied fishes as the colours were also similarly abundant in sediment samples (transparent white $(43 \%)$ and blue (37\%)). Unintentional ingestion of the particles attached to their food (Nadal et al., 2016) and secondary ingestion via prey items (Cannon et al., 2016) are the possible major sources of the plastic particles we found in the GIT of the fishes.

A recent allometric study (Jâms et al., 2020) showed a positive correlation between body length of organisms and size of ingested plastic particles, however in our data no strong relationship was observed for the studied fishes (Fig. SI5.3). Furthermore, the size distribution of plastic particles measured in fishes and in sediment samples (Fig. 5.3) were comparable and the difference was not significantly different $(p=0.233)$. This suggest that plastic particles found in the GIT of fishes just reflect the plastic particle characteristics of those detected in the sediment. 
Table 5.2. Reported literature values of frequency of fish ingested plastic particles (\%), number of ingested plastic particles per fish (mean \pm SD), concentration of plastic particles in fish ( $\left.\mathrm{mg} / \mathrm{kg} \_w w\right)$, size of ingested plastic particles $(\mathrm{mm})$, and dominant identity and shapes of the plastics for various surface waters around the world.

\begin{tabular}{|c|c|c|c|c|c|c|c|c|}
\hline $\begin{array}{l}\text { Water body from where the } \\
\text { studied fishes collected }\end{array}$ & $\begin{array}{l}\text { Analysed } \\
\text { matrix }\end{array}$ & $\begin{array}{l}\text { Fish ingested } \\
\text { plastics (\%) }\end{array}$ & $\begin{array}{l}\text { particles per fish } \\
\text { (mean } \pm \text { SD) }\end{array}$ & $\begin{array}{l}\text { Concentration } \\
\text { (mg/kg_ww) }\end{array}$ & $\begin{array}{l}\text { Ingested size } \\
(\mathrm{mm})\end{array}$ & $\begin{array}{l}\text { Dominant } \\
\text { polymer }\end{array}$ & $\begin{array}{l}\text { Major } \\
\text { shape }\end{array}$ & References \\
\hline North Pacific Central Gyre & SC & $35 \%$ & $2.1 \pm 5.78$ & NR & $1-2.79$ & Not reported & fragments & Boerger et al. (2010) \\
\hline Goiana Estuary, Brazil & SC & $23 \%$ & NR & NR & NR & Nylon & fragments & Possatto et al. (2011) \\
\hline English Channel, UK & GIT & $36.5 \%$ & $1.9 \pm 0.1$ & NR & $0.13-14.3$ & PA, Rayon, PES & fibres & Lusher et al. (2013) \\
\hline $\begin{array}{l}\text { Northern and southern } \\
\text { parts of North Sea }\end{array}$ & GIT & $2.6 \%$ & NR & NR & $0.04-4.8$ & PE, PP, PET, SA & NR & Foekema et al. (2013) \\
\hline French rivers, France & DT & $12 \%$ & NR & NR & NR & not reported & NR & Sanchez et al. (2014) \\
\hline North Sea and Baltic Sea & SC & $18.2 \%$ & $1.3( \pm 0.2)$ & $0.002-93.9$ & $0.63-164.5$ & Not reported & fragments & Romeo et al. (2015) \\
\hline Southern shore of Lake Victoria & GIT & $20 \%$ & NR & NR & NR & $\begin{array}{l}\text { PE, PUR, PES, } \\
\text { PE/PP cop, SR }\end{array}$ & NR & Biginagwa et al. (2016) \\
\hline Balearic Islands, Spain & GIT & $68 \%$ & $3.75 \pm 0.25$ & NR & $<5$ & Not reported & fibres & Nadal et al. (2016) \\
\hline Brazos River Basin, USA & SC & $45 \%$ & NR & NR & NR & Not reported & fibres & Peters and Bratton (2016) \\
\hline Southern Hemisphere & GIT & $5.5 \%$ & $1.4( \pm 0.5)$ & NR & $0.18-500$ & $P E, P P, P A$ & fragments & Rummel et al. (2016) \\
\hline North Sea and Baltic Sea & GIT & $0.3 \%$ & $2(-)$ & 0.0031 & $0.58-0.84$ & ACR & fragments & Cannon et al. (2016) \\
\hline Tokyo Bay, Japan & DT & $77 \%$ & $2.3(1-15)$ & NR & $0.1-7$ & $\mathrm{PP}, \mathrm{PE}$ & fragments & Tanaka and Takada (2016) \\
\hline North Atlantic & DT & $11 \%$ & $1.2 \pm 0.54$ & NR & $0.5-11.7$ & NR & fibres & Lusher et al. (2016) \\
\hline Northeast Atlantic, Scotland & GIT & $47.7 \%$ & $1.8( \pm 1.7)$ & NR & $0.1-15$ & PA & fibres & Murphy et al. (2017) \\
\hline $\begin{array}{l}\text { Lake Taihu and } \\
\text { Yangtze Estuary, China }\end{array}$ & GIT & $98 \%$ & $3.7 \pm 1.5$ & NR & $0.04-24.8$ & $\mathrm{CPH}, \mathrm{PET}, \mathrm{PES}$ & fibres & Jabeen et al. (2017) \\
\hline Southern part of North Sea & GIT & $0.25 \%$ & NR & NR & 0.4 & PMMA & spherical & Hermsen et al. (2018) \\
\hline Marne and Seine Rivers, France & SC & $15 \%$ & NR & NR & $0.39-7.38$ & $\mathrm{PP}, \mathrm{PE}$ & Fibres & Collard et al. (2018) \\
\hline Lake Ziway, Ethiopia & GIT & $35 \%$ & $4.4 \pm 3.6$ & $17.8 \pm 46.8$ & $0.2-40$ & PE and PP & fragments & This study \\
\hline
\end{tabular}

Abbreviations: polypropylene (PP), Polyethylene (PE), polyurethane (PUR), polyester (PES), Polyethylene/polypropylene copolymer (PE/PP cop), silicone rubber (SR), Polyethylene terephthalate (PET), styrene acrylate (SA), polymethylmethacrylate (PMMA), Polyamide (PA), Cellophane (CPH), acrylic resin (ACR), stomach contents (SC), gastrointestinal tracts (GIT), digestive tract (DT) and not reported (NR) 
Similar to some other studies (Possatto et al., 2011; Romeo et al., 2015; Cannon et al., 2016; Rummel et al., 2016), fragments were the dominant (57.5\%) shape of the plastic particles found in GIT of fishes of Lake Ziway (Table 5.2), with $42.5 \%$ being fibres. This indicates that fragmentation of larger plastic debris into smaller pieces (Rummel et al., 2016) may be the key source of the particles in the lake, rather than other sources including effluents from wastewater treatment plants and laundry machines that mainly generate fibre plastic particles (Fischer et al., 2016; Falco et al., 2018; Edo et al., 2020). However, our result differs to the result reported by Peters and Bratton (2016), who found fibres to be dominant (96\%) in the stomach of Lepomis macrochirus and Lepomis megalotis fishes. Peters and Bratton (2016) suggested that these fish species may reject fragments as the plastic particles do not easily adhere into organic food items while fibres plastic particles do. Therefore, differences in investigated fish species and in exposure concentrations of plastic particles with different shape may explain the variation.

\subsubsection{Concentration and distribution of plastic particles in shore sediments}

There was variation in the concentration of plastic particles in sediment between the sample locations (Fig. 5.1; Table 5.1; Table SI5.2). As evidenced by several previous studies (Castañeda et al., 2014; Fischer et al., 2016), the abundance of plastic particles in shoreline sediment of surface waters, was mainly explained by urban activities. For Lake Ziway, wastewater drainages (e.g. from Batu town), rivers which cross towns (e.g. Meki River and Katar River), and surface runoffs upon heavy rain are likely the main routes through which plastic particles enter the lake. The recorded high concentrations of plastic particles in sediment samples collected from Korekonch and Kidanemihiret (receiving urban waste from Batu town), and Meki-River (receiving Meki town's litter through the inflow Meki River) sites are indicative for the entry pathways and major origins of the particles in the lake (Fig. 5.1; Table 5.1).

Fishing and tourism activities are also sources of plastic litter to aquatic ecosystems (Karthik et al., 2018). Recreation related activities such as boating, restaurants, resorts and fishing (commercial and subsistence use) are among the possible key contributors for the observed high concentration of plastic particles in sediment samples collected from Korekonch, Kidanemihiret and Tepho-Choroke shoreline sites. Rivers are another important 
entry route transporting plastic debris from a catchment area into receiving water bodies such as lakes, estuaries and marines (Karthik et al., 2018; Constant et al., 2020). The observed sediment plastic particles concentration at the mouths of Meki River and Katar River reflect the contributions of the inflowing rivers. The rivers transport plastics from the catchment area originating from towns and agricultural areas that the rivers pass through.

Surface runoff from agricultural lands provides another flux of plastic particles to surface waters (Sanchez et al., 2014; Fischer et al., 2016; Zhang, 2017). The smallholder vegetable farmers in the central rift valley region widely use polypropylene made plastic ropes to support tomato plants (Merga et al., 2020b). These ropes may constitute a major source of plastic particles for the sediments collected from Abosa and Edo-Kontola sampling sites. Plastic particle concentrations in sediment samples at Floriculture1 and Floriculture2 sites indicate the contribution of the proximate flower farms, but relatively low compared to the aforementioned sources. At the north-eastern part of the lake (i.e. the Reference site), where agricultural and urban influence was minimal, we have observed the lowest concentration of plastic particles in sediment.

The plastic particle number concentrations measured in sediment in this study (33282 (5333 - 97333) particles $/ \mathrm{m}^{3}$ ) were comparable to values reported for freshwater lakes (Imhof et al., 2013; Su et al., 2016), freshwater rivers (Di and Wang, 2018; Nel et al., 2018) and marine sediment (Browne et al., 2010) (Table 5.3); and sometimes lower than other values reported (Castañeda et al., 2014; Klein et al., 2015; Leslie et al., 2017; Wang et al., 2017) (Table 5.3). However, mass concentrations of plastic particles in the present study are higher than those reported by Klein et al. (2015), which is one of the few studies reporting mass concentrations of plastic particles in sediment. This difference might be due to the larger particles included in our data. Differences in targeted size window applied for plastic particle quantification is a major cause of variation between results of studies (Koelmans et al., 2019; Lorenz et al., 2019; Mintenig et al., 2020). In addition to differences in regional sources of plastic particles, the variations we observed between our result and results of other studies is likely due to differences in targeted size window for detection. In our present study only plastic particles with $\geq 0.1 \mathrm{~mm}$ size were investigated in sediment. The studies by Leslie et al. (2017), Fischer et al. (2016) and Klein et al. (2015) included smaller size plastic particles (<0.1 mm).

Differences in used quality assurance/quality control are also a cause for the results variability (Hermsen et al., 2018; Koelmans et al., 2019; Mintenig et al., 2020). Given this fact, 
comparison between studies is difficult. As this has been addressed already by several authors (Hermsen et al., 2018; Koelmans et al., 2019; Markic et al., 2019), the problem requires the establishment of standard sampling, extraction, identification and quality control protocols for different environmental matrixes. 
Table 5.3. Reported literature values of numerical abundance over an area (particles $/ \mathrm{m}^{2}$ ), concentrations (particles $/ \mathrm{kg}$ _dw, particles $/ \mathrm{L}$, particles $/ \mathrm{m}^{3}$ and $\mathrm{mg} / \mathrm{kg}$ _dw), and dominant polymers and shapes documented in studied sediments of various surface waters around the world. The $*$ indicates the concentration is reported as particles/kg_wet weight.

\begin{tabular}{|c|c|c|c|c|c|c|c|c|}
\hline $\begin{array}{l}\text { Source of studied } \\
\text { sediment sample }\end{array}$ & $\begin{array}{l}\text { Abundance } \\
\text { (particles/m²) }\end{array}$ & $\begin{array}{l}\text { Con.(particles } \\
\text { /L) }\end{array}$ & $\begin{array}{l}\text { Con.(particles/Kg_d } \\
\text { w) }\end{array}$ & Con.(particles $/ \mathrm{m}^{3}$ ) & $\begin{array}{l}\text { Con. } \\
\text { (mg/kg_dw) }\end{array}$ & $\begin{array}{l}\text { Dominant } \\
\text { polymer }\end{array}$ & $\begin{array}{l}\text { Dominant } \\
\text { shape }\end{array}$ & References \\
\hline Tamar Estuary, UK & NR & $<60-160$ & NR & NR & NR & $\begin{array}{l}\text { PVC, PES, } \\
\text { PA }\end{array}$ & fibres & Browne et al. (2010) \\
\hline Lake Garda, Italy & $8.3-1108$ & NR & NR & NR & NR & PS, PE, PP & fragments & Imhof et al. (2013) \\
\hline Lake Erie, North America & $1.5(0.36-3.7)$ & - & NR & NR & NR & $P E, P P$ & fragments & Zbyszewski et al. (2014) \\
\hline Lake St. Clair, North America & $1.7(0.18-8.38)$ & - & NR & NR & NR & $P E, P P$ & fragments & Zbyszewski et al. (2014) \\
\hline Lake Huron, North America & $9.5(0-34)$ & - & NR & NR & NR & PE & pellets & Zbyszewski et al. (2014) \\
\hline St. Lawrence River, Canada & $13832(0-136926)$ & NR & NR & NR & NR & $\mathrm{PE}$ & beads & Castañeda et al. (2014) \\
\hline Rhine-Main rivers, Germany & $1800-30000$ & NR & $228-3763$ & NR & $21.8-932$ & $P P, P E, P S$ & fragments & Klein et al. (2015) \\
\hline Lake Bolsena, Italy & $1922(1903-1941)$ & NR & $112(109-117)$ & NR & NR & NR & fibres & Fischer et al. (2016) \\
\hline Lake Chiusi, Italy & $2117(1772-2462)$ & NR & $234(205-266)$ & NR & NR & NR & fibres & Fischer et al. (2016) \\
\hline Taihu Lake, China & NR & NR & $11-234.6$ & NR & NR & $\mathrm{CPH}, \mathrm{PET}$ & fibres & Su et al. (2016) \\
\hline $\begin{array}{l}\text { Amsterdam canal, } \\
\text { Netherlands }\end{array}$ & NR & NR & $2071(<68-10,500)$ & NR & NR & NR & fibres & Leslie et al. (2017) \\
\hline $\begin{array}{l}\text { Dutch North Sea coast, } \\
\text { Netherlands }\end{array}$ & NR & NR & $100-3600$ & NR & NR & NR & fibres & Leslie et al. (2017) \\
\hline Beijiang River, China & NR & NR & $312.5(178-544)$ & NR & NR & $P E, P P$ & fibres & Wang et al. (2017) \\
\hline Bloukrans River, South Africa & NR & NR & $13.3-563.8$ & NR & NR & NR & NR & Nel et al. (2018) \\
\hline Yangtze River, China & NR & NR & $82(25-300)^{*}$ & NR & NR & $P S, P P, P E$ & fibres & Di and Wang (2018) \\
\hline Lake Ziway, Ethiopia & $378(59-1081)$ & $33(5-97)$ & $40(6.3-115.9)$ & $\begin{array}{l}33282(5333- \\
97333)\end{array}$ & $\begin{array}{l}764(0.05- \\
36233)\end{array}$ & $\begin{array}{l}\text { PE, PP, AV, } \\
\text { PET }\end{array}$ & fragments & This study \\
\hline
\end{tabular}

Abbreviations: polyester (PES), acrylic resin (ACR), polypropylene (PP), polyethylene (PE), polystyrene (PS), cellophane (CPH), polyethylene terephthalate (PET), polyvinylchloride (PVC), polyamide (PA), Alkyd-Varnish (AV) and not reported (NR) 
Furthermore, we have observed a large mean size $(5.3 \pm 6.0 \mathrm{~mm})$ of plastic particles and a low faction (70\%) of MP (size $<5 \mathrm{~mm}$ ) compared to other studies. For example, in sediment samples from the St. Lawrence River of Canada (Castañeda et al., 2014), the southern North Sea (Lorenz et al., 2019), the Rhine River of Germany (Mani et al., 2019) and the Byfjorden coast of Norway (Haave et al., 2019) plastic particles < $5 \mathrm{~mm}(100 \%),<0.5 \mathrm{~mm}(99.96 \%),<$ $0.075 \mathrm{~mm}(96 \%)$ and $<0.1 \mathrm{~mm}$ (95\%) were reported, respectively. Being able to detect plastic particles in environmental samples depends on the targeted size range and on the sample volume (amount) (Koelmans et al., 2019). The above mentioned studies used high amounts $(1.2-2 \mathrm{~kg})$ of sediment and reported a small maximum size window $(\leq 5.033 \mathrm{~mm})$. The present study analysed comparably large sample quantities (e.g. $630 \mathrm{~g}$ ) and used a large maximum size window $(45 \mathrm{~mm})$. We hypothesize that the larger sample sizes enabled us to find larger particles that occur at a lower frequency.

Remarkably, the highest mass concentration measured in sediment of the studied lake was $36233 \mathrm{mg} / \mathrm{kg}$ _dw, i.e. $3.62 \%$ on a dry weight basis. To our knowledge, this is the highest plastic particle mass concentrations in sediment reported to date (Redondo-Hasselerharm et al., 2020; Schell et al., 2020). Redondo-Hasselerharm et al. (2018) found an $28-d E_{10}$ of $1.07 \%$ and an $\mathrm{EC}_{50}$ of $3.57 \%$ for the growth of Gammarus pulex, and a long term (15 month) benthic community effect LOEC of 5\% (Redondo-Hasselerharm et al., 2020). Effects on emergence and on body weight of Chironomus riparius upon chronic exposure (28 day) to a concentration of $2 \%$ of microplastic were observed by Scherer et al. (2020). Furthermore, effects on larval growth $(10-d$ LOEC $=0.25 \%)$ and on imagoes emergence $(10-d$ LOEC $=0.15 \%)$ of $C$. riparius were reported by Silva et al. (2019). These imply that the highest mass concentration measured in sediment samples from the lake exceed the currently known effect thresholds for MP in sediment, thus indicating that long term in situ benthic community effects cannot be excluded.

The possible reason for the observed significantly lower number of plastic particles in sediment samples collected during the wet season compared to the dry season samples (Table SI5.1) could be a result of the resuspension of plastic particles from bottom sediment due to heavy rain and runoff (Fischer et al., 2016; Mintenig et al., 2020).Plastic particles are likely to reside in the overlying water for considerable time as plastic particles only slowly settle from the water column to the bottom sediment (Nel et al., 2018). The identified polymer types in sediment samples were mainly PP and PE (Fig. 5.4b). These polymers generally have low 
densities that also enhance the resuspension of the particles from bottom sediment upon heavy rain during wet season. Though plastic particles in the water column were not quantified in our study, we hypothesise that the concentration of the particles in overlying water of the lake could be higher in the wet season than the dry season, as in the rainy season plastic particles enter into the lake via runoff from terrestrial ecosystem (Zhang, 2017).

\subsubsection{Identity and potential sources of the plastic particles}

We have identified different type of polymers (Fig. 5.4b). Similar to previous studies reporting polymer types for sediments (Wang et al., 2017; Karthik et al., 2018; Lorenz et al., 2019) and for fishes (Biginagwa et al., 2016; Rummel et al., 2016; Karthik et al., 2018), PP and PE were the most frequently found polymers in sediment and in the GIT of fishes of Lake Ziway (Table 5.2; Table 5.3). The percentage of PET and AV found in sediment samples was also high (18.5\%) compared to polyurethane-acrylic resin (7.4\%) and ethylene-propylene rubber (3\%). The contribution of alkyd-varnish (AV) in both fish (11.8\%) and sediment (18.5\%) was also considerable (Fig. 5.4b). These polymers are likely present in the lake due to urban wastes including plastic bags, packaging materials and disposable bottles that end up in the lake through various entry pathways including wastewater drainages, town crossing inflowing rivers, and heavy rain causing urban and agricultural land runoff. Similarly, the quantified EPR in sediment samples was likely originates from water hoses or electrical insulation waste (Haave et al., 2019). As reported by Wang et al. (2017) for sediment of the Beijiang River of China, and by Haave et al. (2019) for sediment at the Byfjorden coast of Norway, the identified synthetic resins such as polyurethane-acrylic resin and alkyd-varnish in sediment and fishes samples of this study were potentially originating from workshop wastes (e.g. wood and metal) and paint of boats.

\subsection{Conclusion}

To our knowledge this is the first study to report plastic particle abundance and characteristics both in the GIT of fishes and in sediment for an African shallow freshwater lake. Our results indicate that fishes and shoreline sediments sampled near to towns were more contaminated with plastic particles, compared to the samples taken from shore sites with a lower urban and agriculture activities, and exceed currently known threshold effect 
concentrations. In addition, there was a significant difference between the wet and dry seasons with respect to the frequency of fishes found with ingested plastic particles, as well as the plastic particle concentration in the sediment of the lake. The studied fish species have a significant economic and ecological roles in the region (Endebu et al., 2015). Because of their role as ecosystem engineers as well as ecosystem service providing units, it is important to study the impact of ingestion of plastic particles on these species. Furthermore, assessment of human health impacts caused by consumption of plastic particles contaminated fishes (Carbery et al., 2018) as well as drinking water (WHO, 2019) is needed. As confirmed by ATRFTIR, mainly urban related domestic waste was among the major sources for the plastic pollution in the studied lake. Mitigation measures such as implementing proper domestic waste management practices (Khan et al., 2018) by municipalities of the nearby towns and encouraging tomato producing farmers to use natural fibres made of degradable ropes instead of using plastic ropes are highly recommended to abate the problem.

\section{Acknowledgments}

The study was financially supported by Netherlands fellowship programmes, NUFFIC/ PhD studies, grant NFP - PhD.16/0019, reference number WIMEK2015 02. The authors would like to thank Batu Fishery and Other Aquatic Life Research Centre for permitting us to access the laboratory facilities of the centre, Mr. Mathewos Hailu for his technical support during the quantification of microplastics, Dr. Edwin T.H.M. Peeters for helping with the statistical analysis and Guus Frissen for his assistance during the ATR-FTIR analysis. We state that there are no conflicts of interest. 


\section{Appendix 5. Supplementary Information (SI)}

Table SI5.1. Sampling site, fish species, sample size, fish average length and weight, average length of plastic particles found in fish guts, and the percentage of individual fish species found with ingested plastics.

\begin{tabular}{|c|c|c|c|c|c|c|c|c|c|c|}
\hline \multirow[t]{2}{*}{ Site } & \multirow{2}{*}{$\begin{array}{l}\text { Fish } \\
\text { Species }\end{array}$} & \multirow{2}{*}{$\begin{array}{l}\text { Sample } \\
\text { size (n) }\end{array}$} & \multicolumn{2}{|c|}{ Fish length $(\mathrm{cm})$} & \multicolumn{2}{|c|}{ Fish weight (g) } & \multicolumn{2}{|l|}{$\begin{array}{l}\text { plastic } \\
\text { size }(\mathrm{mm})\end{array}$} & \multicolumn{2}{|c|}{$\begin{array}{l}\% \text { fish ingested } \\
\text { plastics }\end{array}$} \\
\hline & & & Wet & Dry & Wet & Dry & Wet & Dry & Wet & Dry \\
\hline \multirow{4}{*}{ 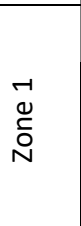 } & On & 15 & $17.7 \pm 3.9$ & $20.9 \pm 3.2$ & $110 \pm 57$ & $162 \pm 47$ & $2.9 \pm 2.6$ & $3.8 \pm 3.5$ & 40 & 33 \\
\hline & $\mathrm{Cg}$ & 15 & $31.4 \pm 4.1$ & $39.3 \pm 6.7$ & $224 \pm 91$ & $450 \pm 166$ & $5.5 \pm 6.7$ & $4.1 \pm 3.5$ & 67 & 53 \\
\hline & Cc & 15 & $20.9 \pm 9.5$ & $28.2 \pm 5.3$ & $188 \pm 187$ & $373 \pm 114$ & $4.6 \pm 5.1$ & $8 \pm 8.5$ & 40 & 53 \\
\hline & Сус & 15 & $29.8 \pm 3.9$ & $35.3 \pm 4.5$ & $315 \pm 128$ & $565 \pm 142$ & $4.3 \pm 3.5$ & $4.5 \pm 6.4$ & 60 & 67 \\
\hline \multirow{4}{*}{ 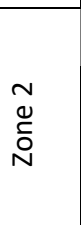 } & On & 15 & $17.4 \pm 4.2$ & $25.4 \pm 3.6$ & $104 \pm 62$ & $315 \pm 106$ & $2.4 \pm 1.9$ & $2.3 \pm 1.3$ & 27 & 13 \\
\hline & $\mathrm{Cg}$ & 15 & $37.2 \pm 5.3$ & $43.3 \pm 10$ & $348 \pm 129$ & $526 \pm 267$ & $4.3 \pm 3.0$ & $6.1 \pm 7.3$ & 40 & 27 \\
\hline & Cc & 15 & $29.6 \pm 8.1$ & $29.4 \pm 5$ & $339 \pm 196$ & $412 \pm 270$ & $5.3 \pm 7.3$ & $5.2 \pm 6.3$ & 33 & 33 \\
\hline & Cyc & 15 & $35.8 \pm 6.1$ & $38.9 \pm 8.2$ & $551 \pm 245$ & $778 \pm 402$ & $4.8 \pm 4.7$ & $5.9 \pm 5.8$ & 47 & 13 \\
\hline \multirow{4}{*}{$\begin{array}{l}m \\
\stackrel{d}{ } \\
\stackrel{0}{N} \\
\text { N }\end{array}$} & On & 15 & $19.8 \pm 2.8$ & $19.5 \pm 4.0$ & $133 \pm 29$ & $153 \pm 64$ & $4.4 \pm 3.0$ & $4.7 \pm 4.8$ & 13 & 7 \\
\hline & $\mathrm{Cg}$ & 15 & $30.9 \pm 3.8$ & $36.3 \pm 7.5$ & $200 \pm 66$ & $365 \pm 126$ & $8.4 \pm 9.8$ & $4.2 \pm 2.6$ & 33 & 27 \\
\hline & Cc & 15 & $26.0 \pm 4.0$ & $26.3 \pm 5.8$ & $286 \pm 157$ & $293 \pm 103$ & $5.9 \pm 3.8$ & $4.5 \pm 6.4$ & 33 & 27 \\
\hline & Сус & 15 & $28.8 \pm 6.7$ & $37.4 \pm 7.9$ & $303 \pm 221$ & $518 \pm 223$ & $13.5 \pm 12$ & $4.2 \pm 3.1$ & 33 & 13 \\
\hline
\end{tabular}

Abbreviations: O. niloticus (On), C. gariepinus (Cg), C. carassius (Cc) and C. carpio (Cyc) 
Table SI5.2. Average particles count (mean \pm SD), average size and range $(\mathrm{mm})$, numerical abundance over an area (particles/ $\mathrm{m}^{2}$ ) and average concentrations (particles/kg_dw and particles/ $\mathrm{m}^{3}$ ) of plastic particles observed in sediment samples $(\mathrm{n}=3)$ collected from different shoreline sites of Lake Ziway during the dry and wet seasons.

\begin{tabular}{|c|c|c|c|c|c|c|c|c|c|c|}
\hline \multirow[t]{2}{*}{ Sampling site } & \multicolumn{2}{|c|}{$\begin{array}{l}\text { Number of plastic } \\
\text { particles (mean } \pm s d \text { ) }\end{array}$} & \multicolumn{2}{|c|}{$\begin{array}{c}\text { Size }(\mathrm{mm}) \\
\text { mean (minimum - maximum) }\end{array}$} & \multicolumn{2}{|c|}{$\begin{array}{l}\text { Plastic particles abundance } \\
\text { (mean } \pm \text { sd; particles } / m^{2} \text { ) }\end{array}$} & \multicolumn{2}{|c|}{$\begin{array}{l}\text { Concentration in sediment } \\
\qquad \text { (mean } \pm \mathrm{sd} \text {; } \\
\text { particles } / \mathbf{k g} \mathbf{d w} \text { ) }\end{array}$} & \multicolumn{2}{|c|}{$\begin{array}{l}\text { Concentration in sediment } \\
\text { (mean } \pm \mathrm{sd} ; \text { particles } / \mathrm{m}^{3} \text { ) }\end{array}$} \\
\hline & Dry & Wet & Dry & Wet & Dry & Wet & Dry & Wet & Dry & Wet \\
\hline Bochessa & $8 \pm 1$ & $2.3 \pm 1.2$ & $4.2(0.3-29.6)$ & $3.8(0.45-7)$ & $356 \pm 44$ & $104 \pm 51$ & $38 \pm 5$ & $11 \pm 5$ & $32000 \pm 4000$ & $9333 \pm 4619$ \\
\hline Bulbula & $4.3 \pm 2.1$ & $2 \pm 2$ & $2.4(0.15-10)$ & $5.5(3.2-9)$ & $193 \pm 92$ & $89 \pm 89$ & $21 \pm 10$ & $9 \pm 9$ & $17333 \pm 8327$ & $8000 \pm 8000$ \\
\hline Floriculture2 & $7.3 \pm 3.5$ & $3 \pm 1$ & $\begin{array}{c}5.8(0.19- \\
26.3)\end{array}$ & $7.1(2.15-14.3)$ & $326 \pm 156$ & $133 \pm 44$ & $35 \pm 16$ & $14 \pm 5$ & $29333 \pm 14047$ & $12000 \pm 4000$ \\
\hline Floriculture1 & $10.3 \pm 0.6$ & $5.3 \pm 1.2$ & $\begin{array}{c}6.6(0.34- \\
31.6)\end{array}$ & $10.0(1.5-45)$ & $459 \pm 26$ & $237 \pm 51$ & $49 \pm 3$ & $25 \pm 5$ & $41333 \pm 2309$ & $21333 \pm 4619$ \\
\hline Korokonch & $20.3 \pm 4.9$ & $8.3 \pm 0.6$ & $\begin{array}{c}5.8(0.31- \\
23.4)\end{array}$ & $3.9(0.85-15)$ & $904 \pm 219$ & $370 \pm 26$ & $97 \pm 23$ & $40 \pm 3$ & $81333 \pm 19731$ & $33333 \pm 2309$ \\
\hline Kidanemihiret & $24.3 \pm 5.9$ & $13 \pm 1$ & $5.3(0.2-29.1)$ & $6.7(0.85-31.5)$ & $1081 \pm 260$ & $578 \pm 44$ & $116 \pm 28$ & $62 \pm 5$ & $97333 \pm 23438$ & $52000 \pm 4000$ \\
\hline Edo-Kontola & $13 \pm 3.6$ & $7.3 \pm 0.6$ & $5.5(0.2-34.6)$ & $6.6(0.15-40.1)$ & $578 \pm 160$ & $326 \pm 26$ & $62 \pm 17$ & $35 \pm 3$ & $52000 \pm 14422$ & $29333 \pm 2309$ \\
\hline Abosa & $10.7 \pm 2.9$ & $7.7 \pm 2.5$ & $\begin{array}{c}5.4(0.21- \\
27.5)\end{array}$ & $7.2(0.16-43.5)$ & $474 \pm 128$ & $341 \pm 112$ & $51 \pm 14$ & $36 \pm 12$ & $42667 \pm 11547$ & $30667 \pm 10066$ \\
\hline Tepho-Choroke & $13.3 \pm 2.1$ & $4.3 \pm 1.5$ & $3.9(0.15-8.9)$ & $4.8(0.65-13.1)$ & $593 \pm 92$ & $193 \pm 68$ & $69 \pm 10$ & $21 \pm 7$ & $53333 \pm 8327$ & $17333 \pm 6110$ \\
\hline Mekidela & $4.3 \pm 2.1$ & $3 \pm 1$ & $6.3(0.4-19.5)$ & $4.1(0.75-12.3)$ & $193 \pm 92$ & $133 \pm 44$ & $21 \pm 10$ & $14 \pm 5$ & $17333 \pm 8327$ & $12000 \pm 4000$ \\
\hline Meki-river & $15.3 \pm 0.6$ & $9 \pm 2$ & $3.7(0.2-14.9)$ & $3.3(0.2-14.9)$ & $681 \pm 26$ & $400 \pm 89$ & $73 \pm 3$ & $43 \pm 9$ & $61333 \pm 2309$ & $36000 \pm 8000$ \\
\hline Reference & $1.7 \pm 0.6$ & $1.3 \pm 1.2$ & $3.5(0.57-6.7)$ & $3.4(1.65-4.9)$ & $74 \pm 26$ & $59 \pm 51$ & $8 \pm 3$ & $6 \pm 5$ & $6667 \pm 2309$ & $5333 \pm 4619$ \\
\hline Katar-river & $9.3 \pm 2.5$ & $7.3 \pm 1.5$ & $3.7(0.6-14.3)$ & $6.5(0.5-36.4)$ & $415 \pm 112$ & $326 \pm 68$ & $44 \pm 12$ & $35 \pm 7$ & $37333 \pm 10066$ & $29333 \pm 6110$ \\
\hline
\end{tabular}


Table SI5.3. Reported cross-sectional diameter of fibres. Only the bolded diameter values were considered to calculate median value used for estimation of mass of fibre plastic particles.

\begin{tabular}{|c|c|c|c|}
\hline Sources of the fibres & Sample & diameter $(\mu \mathrm{m})$ & References \\
\hline Ross Sea, Antarctica & surface water & 30 & Cincinelli et al. (2017) \\
\hline Western English Channel (UK) & surface water & $28(6-175)$ & Cole et al. (2014) \\
\hline Gulf of Maine (USA) & surface water & $24(5-593)$ & Cole (2016) \\
\hline Sewage from washing machine & Synthetic fabrics - Plain weave polyester & $14 \pm 3$ & Falco et al. (2018) \\
\hline Sewage from washing machine & Synthetic fabrics - Double knit jersey polyester & $20 \pm 6$ & Falco et al. (2018) \\
\hline Sewage from washing machine & Synthetic fabrics - polypropylene & $19 \pm 6$ & Falco et al. (2018) \\
\hline Domestic laundry machine effluent & fabric types -Polyester cotton blend & 17.74 & Napper and Thompson (2016) \\
\hline Domestic laundry machine effluent & fabric type - polyester & 11.91 & Napper and Thompson (2016) \\
\hline Domestic laundry machine effluent & fabric type - acrylic & 14.05 & Napper and Thompson (2016) \\
\hline Admiralty Bay, Antarctica & surface water & $10-22$ & Absher et al. (2019) \\
\hline Primary effluents of WWTP, Near Madrid, Spain & Wastewater effluents & $5-34$ & Edo et al. (2020) \\
\hline Secondary effluents of WWTP, Near Madrid, Spain & Wastewater effluents & $8-89$ & Edo et al. (2020) \\
\hline Wet sludge of WWTP (used in soil amendment) & Sludge from WWTP & $5-34$ & Edo et al. (2020) \\
\hline Heat dried sludge of WWTP (soil amendment use) & Sludge from WWTP & $7-58$ & Edo et al. (2020) \\
\hline Cresmina and Fonte da Telha beachs, Portugal & Sediment & $1-5$ & Frias et al. (2010) \\
\hline MWWTP effluent (secondary, Rüsselsheim/Raunheim Germany & effluent & $2-180$ & Wolff et al. (2019) \\
\hline
\end{tabular}

NB: WWTP - wastewater treatment plant 


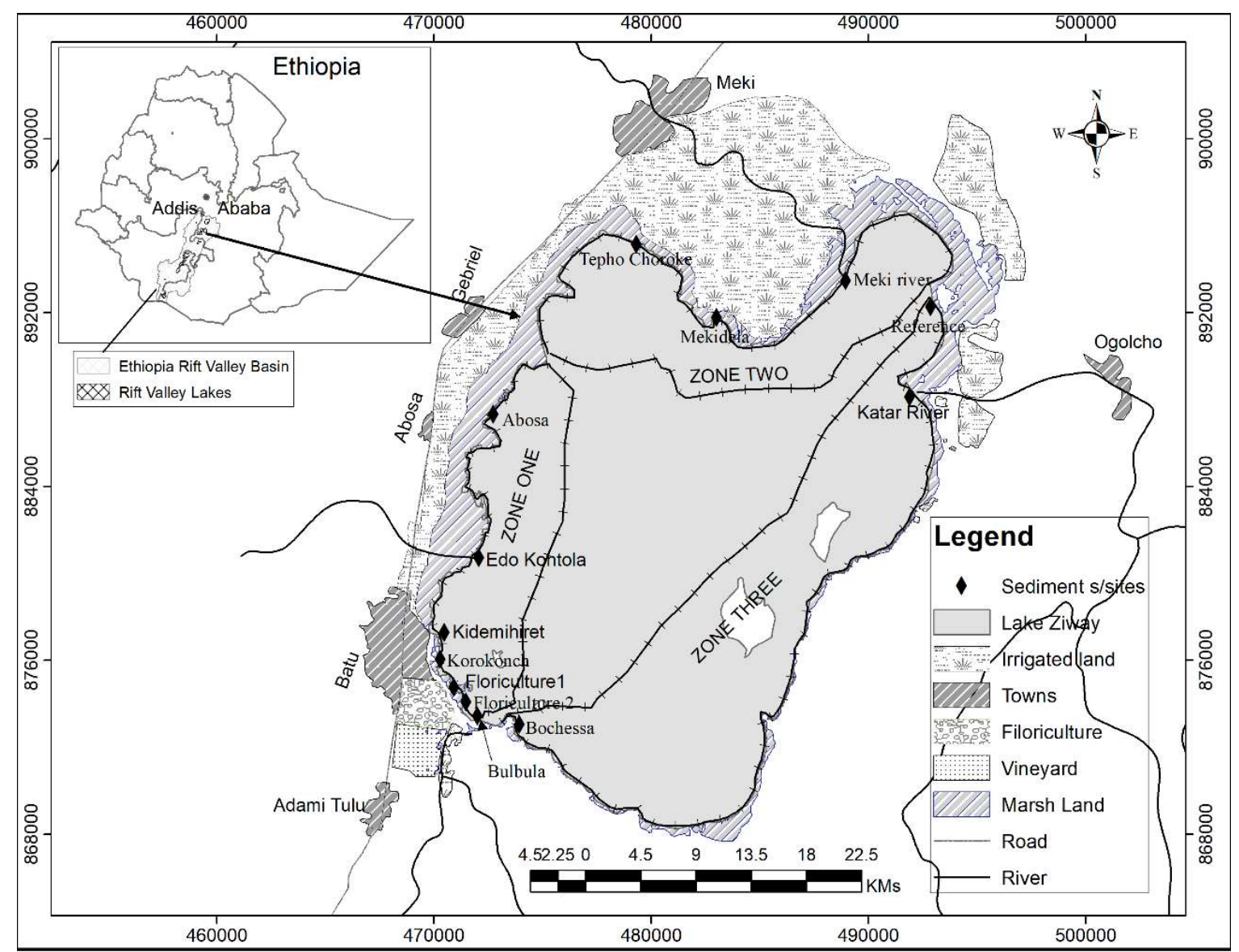

Fig. SI5.1. Map of Lake Ziway, Ethiopia showing various shoreline human activities and sampling sites from where shoreline sediment samples and fishes were collected for this study.

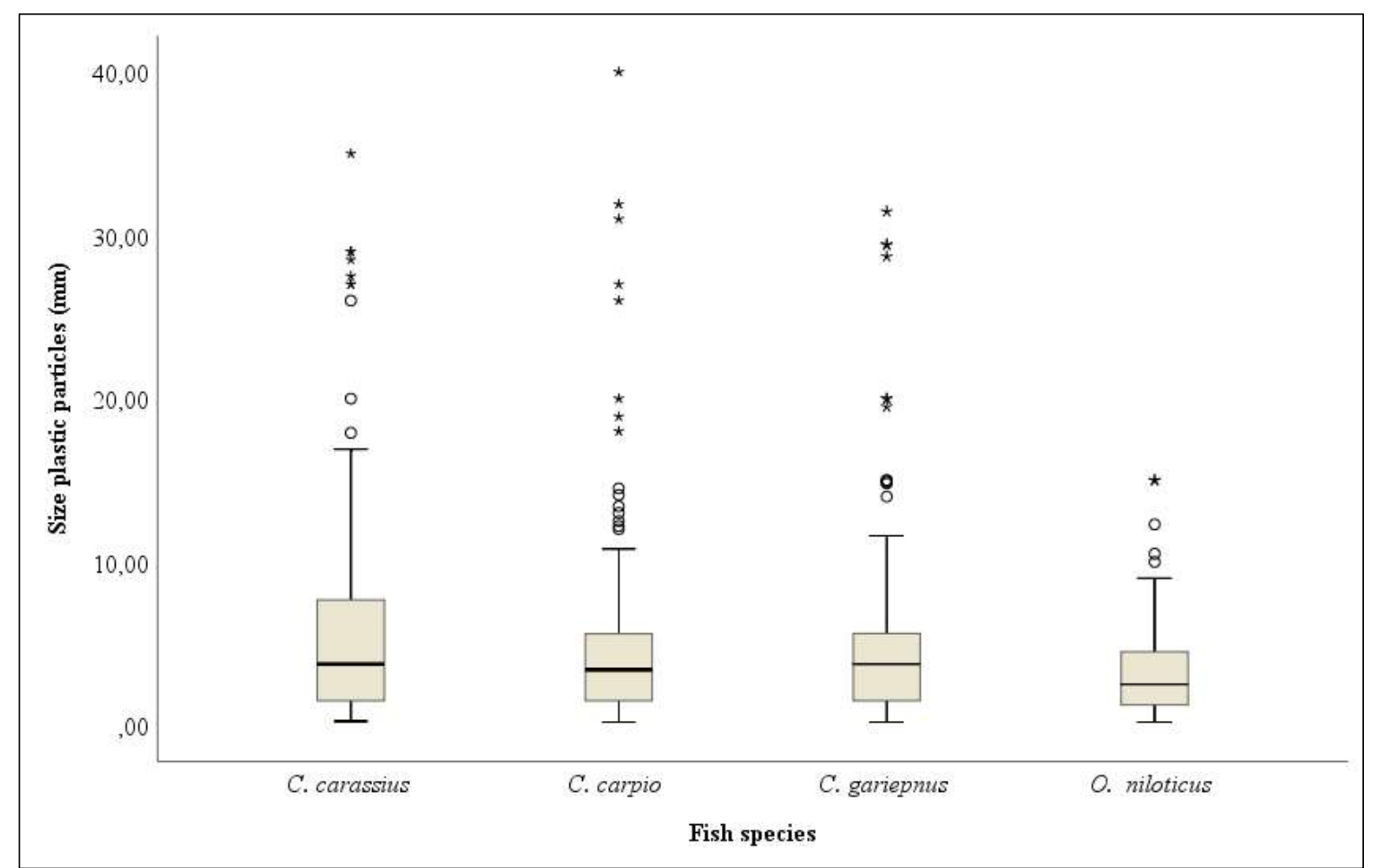

Fig. S15.2. Particle size boxplot of Plastic particles counted in GIT of four fishes from Lake Ziway of Ethiopia. 


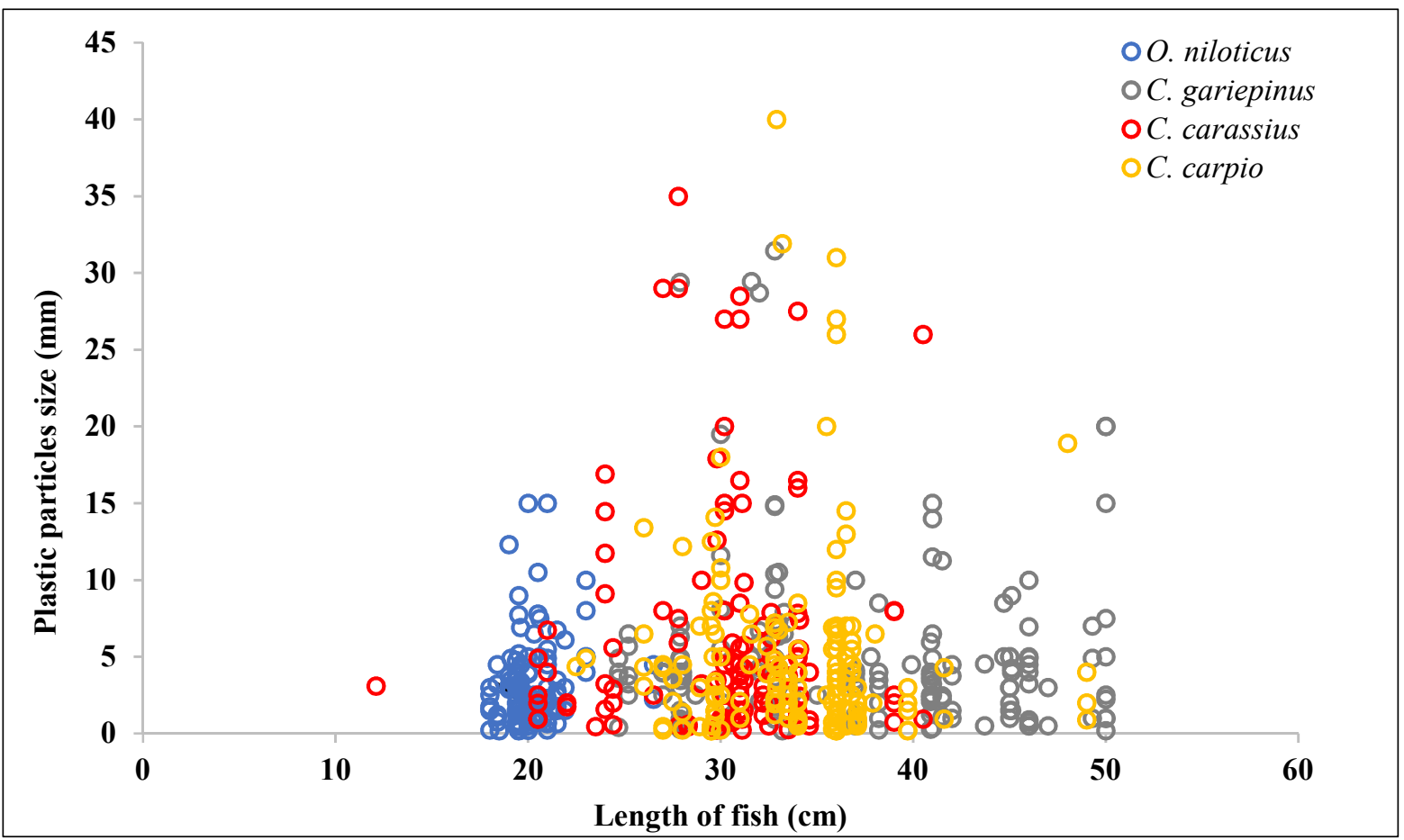

Fig. S15.3. Relationship between size of ingested plastic particles and fish length per species. 


\section{CHAPTER 6}

Ecological effects of imidacloprid on a tropical freshwater ecosystem and its recovery dynamics

Lemessa B. Merga, Paul J. van den Brink

Manuscript for submission is under preparation 


\section{Abstract}

Imidacloprid is a systemic neonicotinoid pesticide and widely used for various applications including agricultural use to control pests such as sucking insects and domestic use to control cockroaches, termites and fleas. The pesticide is also used in Ethiopia to control crop pests mainly by small-holder vegetable farmers in the central Ethiopian rift valley region. This study aimed to investigate the effect of imidacloprid on structural (invertebrates and primary producers) and functional (organic matter decomposition and physicochemical parameters) characteristics of tropical freshwater using acute single species and mesocosm studies performed in Ethiopia. The recovery of affected endpoints was also studied by using a study period of 21 weeks. Our acute toxicity test showed that Cloeon dipterum (96-h LC50 = $2.7 \mu \mathrm{g} / \mathrm{L}$ ) and Caenis horaria $(96-\mathrm{h} \mathrm{LC} 50=3.4 \mu \mathrm{g} / \mathrm{L})$ are relatively sensitive arthropods to imidacloprid. The mesocosm experiment evaluated the effects of four applications of imidacloprid with a weekly interval and the results showed that the macroinvertebrate and zooplankton communities declined significantly due to imidacloprid contamination at concentrations $\geq$ $0.01 \mu \mathrm{g} / \mathrm{L}$. The largest responses were found for C. dipterum, C. horaria, Brachionus sp. and Filinia sp.. Chlorophyll-a concentrations of periphyton and phytoplankton significantly increased in the treated mesocosms with concentrations $\geq 0.1 \mu \mathrm{g} / \mathrm{L}$ which is an indirect effect as a result of the release of grazing pressure. A significant decrease of organic matter decomposition rate was observed in mesocosms treated with concentrations $\geq 0.1 \mu \mathrm{g} / \mathrm{L}$. No recovery was observed for the macroinvertebrates community during the study period of 21 weeks, but zooplankton recovered after 9 weeks. Overall, using temperate toxicity data for the risk assessment of imidacloprid for tropical aquatic ecosystems is not recommended as we observed spatio-temporal related toxicity differences between tropical and temperate aquatic species, with tropical species being generally more sensitive. 


\subsection{Introduction}

Fulfilling the food demand of the growing world population is the key driver for the intensive use of agrochemicals by the agricultural sector (Sánchez-Bayo, 2010; Schäfer et al., 2010). The annual use of pesticides in agriculture has remarkably increased over the years. For example, the data by Food and Agriculture Organization of the United Nations (FAO, 2019) showed that the agriculture global use of the pesticides in 2017 (5.9 million tonnes of active ingredient (a.i.)) was increased by 92\% compared to the usage in 1991 (3.1 million tonnes, a.i.).

Imidacloprid, 1-(6-chloro-3- pyridylmethyl)-N-nitroimidazolidin-2-ylideneamine, is a neonicotinoid class of insecticide introduced into the market in 1990s by Bayer CropScience (Anderson et al., 2015). It is a systemic pesticide with agonistic effect to the acetylcholine receptor. Imidacloprid poses effects on target pests and non-target species such as insects that possess the receptor through contact and stomach action (Capowiez and Berard, 2006; Rico et al., 2018). Of the neonicotinoid insecticides, which have a share of $24 \%$ of the global insecticide market, imidacloprid has been reported as the most widely used insecticide around the world in various sectors including agriculture to control pests such as sucking insects (Anderson et al., 2015; Cavallaro et al., 2018; Rico et al., 2018). Its high toxicity to target pests and low toxicity to mammals compared to other insecticides increased the acceptance of imidacloprid among users (Capowiez and Berard, 2006; Colombo et al., 2013). Its applications include seed dressing, soil treatment, and foliar treatment in a variety of crops and orchards (Capowiez and Berard, 2006). Moreover, imidacloprid has domestic uses such as the control of cockroaches, termites and pets' fleas, and to care garden and lawn (Capowiez and Berard, 2006; Duchet et al., 2018). Currently the use of imidacloprid is highly controversial due to its effects on non-target species like bees and aquatic organisms, leading to a ban on outdoor use in Europe in 2018 (European Commission, 2018).

Although imidacloprid is not intentionally applied to aquatic ecosystems, it can enter water bodies through airborne (e.g. spray drift during aerial application) and waterborne (e.g. runoff from agricultural during precipitation, leaching and irrigation) pathways (Schäfer et al., 2010; Rico et al., 2018). Its high solubility in water $\left(0.610 \mathrm{mg} / \mathrm{L}\right.$ at $1 \mathrm{~atm}$ and $\left.25^{\circ} \mathrm{C}\right)$ and persistence in soil (soil half-live $=9-1250$ days) increases the widespread occurrence of imidacloprid in surface waters (Anderson et al., 2015; Morrissey et al., 2015; Duchet et al., 2018). 
Only a few monitoring studies are available showing surface water residual concentration of imidacloprid in Africa, probably due to a lack of available analytical facilities. Imidacloprid was reported in agricultural river watersheds (Krom River, Berg River and Hex River) of South Africa (Curchod et al., 2020), and in the surface water of Lake Ziway of Ethiopia (Jansen and Harmsen, 2011) with detectable water concentrations (mean and range) of 2.3 (0.73- 7.2 ) $\mu \mathrm{g} / \mathrm{L}$ and $0.16(0.04-0.3) \mu \mathrm{g} / \mathrm{L}$, respectively. The mean concentration levels of imidacloprid ranging from $<0.002-16 \mu \mathrm{g} / \mathrm{L}$ were also reported in surface waters with agricultural land use in developed countries such as USA, Japan, Canada, Sweden and Australia (Morrissey et al., 2015). Our survey about farmers' pesticide use performed in 2017 (Chapter 3) indicated that imidacloprid formulation with Gain 20 SL trade name is widely used by smallholder vegetable farmers in the central Ethiopian rift valley region of Ethiopia where Lake Ziway is located. Similarly, Negatu et al. (2016) reported the use of the neonicotinoid insecticides thiamethoxam and imidacloprid in this region. Imidacloprid is also among the recommended pesticides to control thrips in Ethiopia, particularly in the central Ethiopian rift valley region (Negash et al., 2020). Furthermore, Jansen and Harmsen (2011) reported mean concentrations for the neonicotinoid insecticides acetamiprid and imidacloprid of 7.6 and 0.16 $\mu \mathrm{g} / \mathrm{L}$ (see above) in water samples of Lake Ziway, respectively. Thus, the aquatic ecosystems in Ethiopia, particularly those found in the central Ethiopian rift valley region (e.g., Lake Ziway), is contaminated by residual levels of the neonicotinoid pesticides, of which imidacloprid is mostly used and detected.

Many single species toxicity tests ( Roessink et al., 2013; Morrissey et al., 2015; Van den Brink et al., 2016; Sumon et al., 2018; Bartlett et al., 2019) and cosm studies (Pestana et al., 2009; Colombo et al., 2013; Cavallaro et al., 2018; Rico et al., 2018; Sumon et al., 2018) have demonstrated impacts of imidacloprid on aquatic organisms, particularly on arthropods, at field relevant concentrations. The majority of the studies are from temperate climatic conditions with Sumon et al. (2018) and Rico et al. (2018) with exceptions from (sub-)tropical and Mediterranean regions, respectively.

Geographical origin may possibly affect species sensitivity to chemicals (Kwok et al., 2007; Diepens et al., 2014). Rico et al. (2018) and Sumon et al. (2018) have reported differences in toxicity of imidacloprid to freshwater arthropods between temperate, Mediterranean and (sub)-tropical species, where (sub)-tropical and Mediterranean aquatic arthropods were more sensitive than temperate species. Therefore, it is worthy to further investigate the effects of 
the insecticide (imidacloprid) to aquatic life under tropical conditions such as in Ethiopia to strengthen the reported result variations between climatic conditions. Furthermore, microcosm and mesocosm studies performed with imidacloprid studying the recovery of affected populations are scarce (Hayasaka et al., 2012; Cavallaro et al., 2018; Rico et al., 2018), despite the importance of studying recovery as part of ecological risk assessment to evaluate the acceptability of observed effects (Gergs et al., 2016). Recovery studies are important to evaluate how fast an ecosystem can return to a state comparable to an untreated control once contamination by a chemical is terminated (Van den Brink et al. 1996; Brock et al. 2000b; Beketov et al., 2008; Gergs et al. 2016), while they can also enable evaluation of delayed effects (Hayasaka et al., 2012).

Given these data gaps, the objectives of this study were: by using outdoor mesocosms to 1) assess the effects of imidacloprid on structural and functional endpoints of aquatic ecosystems under tropical conditions; 2) investigate post exposure recovery of aquatic communities and ecosystem function.

\subsection{Materials and Methods}

\subsubsection{Acute toxicity tests}

Acute toxicity tests to evaluate the single species toxicity of imidacloprid were performed with Cloeon dipterum, Caenis horaria, Plea minutissima and Corixidae sp. The species were collected from uncontaminated streams proximate to Ambo University, Ambo, Ethiopia and transferred into a bucket containing 50\% pre-conditioned test water and 50\% stream water. The species were acclimated for three days to laboratory conditions at room temperature prior to the experiment with aeration and feeding using substrates collected from the stream. The tests were carried out between 04-04-2019 and 12-05-2019. The experimental setup was established according to Roessink et al. (2013) with minor modifications. Shortly, $1 \mathrm{~L}$ jars filled with $900 \mathrm{~mL}$ pre-conditioned test water were used as test systems and 10 individuals and a stainless steel mesh were introduced into each replicate with the mesh serving as additional surface for the animals to minimize additional stress. Including control, seven treatments $(0$, 0.1, 0.3, 1, 3, 10, $30 \mu \mathrm{g} / \mathrm{L}$ for C. dipterum C. horaria and Corixidae sp., and 0, 1, 3, 10, 30, 100, $300 \mu \mathrm{g} / \mathrm{L}$ for $P$. minutissima) were used, with three replicates per treatment. The test jars were placed in a water bath, which has continuous water in- and out-flow to regulate the 
temperature of the test systems and a photoperiod of 12:12 hours (h) dark-light was employed to mimic the photoperiod of the region (Fig. SI6.1 c and d). Imidacloprid formulation (CONFIDENCE, China) containing $350 \mathrm{~g}$ imidacloprid a.i./L was used to prepared $90 \mathrm{mg} / \mathrm{L}, 9 \mathrm{mg} / \mathrm{L}$, $0.9 \mathrm{mg} / \mathrm{L}$ and $0.09 \mathrm{mg} / \mathrm{L}$ stock solutions. Appropriate volume that ranged from $1 \mathrm{ml}$ to $3 \mathrm{ml}$ from the appropriate stock were spiked into the system using a micropipette. No aeration of the system and feeding of the test animals were present during the 96-h experimental period. After 24-h, 48-h, 72-h and 96-h of imidacloprid exposure time in each test system the morality and immobility of individual animals was assessed. The toxicity test was considered as invalid when control immobility exceeded $15 \%$ (OECD, 2011). Water quality parameters including $\mathrm{pH}$, dissolved oxygen (DO), temperature and electrical conductivity (EC) were measured daily from the start till the end of the experiment in all test systems.

\subsubsection{Mesocosm experiment}

\subsubsection{Experimental setup}

The mesocosm study was conducted at Ambo University, Ambo, Ethiopia ( $8^{\circ} 58^{\prime} 57.48^{\prime \prime} \mathrm{N}$ and $\left.37^{\circ} 50^{\prime} 44.54 " \mathrm{E}\right)$. The experimental area was fenced, and roofed using transparent plastic sheets used for greenhouse roofing (Fig. SI6.1 a and b ). Locally available cylindrical polyvinyl chloride (PVC) containers (height: $85 \mathrm{~cm}$ and diameter: $110 \mathrm{~cm}$ ) were used to establish the mesocosm ponds. Twelve (12) PVC containers were buried (about $60 \mathrm{~cm}$ of its height) into the ground to minimize temperature fluctuations between day and night (Daam and Van den Brink, 2011) (Fig. SI6.1 a). The cosms were filled with natural sediment to about $15 \mathrm{~cm}$ height, which was collected from an unpolluted pond water nearby Ambo University. Subsequently, $600 \mathrm{~L}$ pre-conditioned water from which the residual chlorine was removed, was added to each container. After one week of water addition to the systems, the cosms were stocked with macroinvertebrate species and concentrated plankton, which were collected from natural and unpolluted ponds and streams located near to the experimental sites. Following invertebrates and planktons stocking, but prior to the application of imidacloprid, the system were left for seven months to enhance the establishment of biological communities. During the colonization time, reduction of water volume of the cosms due to evaporation was compensated by adding pre-conditioned water. During this establishment time (7 months) 20 $\%$ of the water (volume) was exchanged between the cosms every two weeks to promote the 
homogeneity among the systems (Sumon et al., 2018). During the whole experimental period nitrogen (1.4 mg/L nitrogen, urea) and phosphorus $(0.18 \mathrm{mg} / \mathrm{L} \mathrm{P}$, trisodium phosphate) were added every three weeks to the systems (Rico et al., 2014; Sumon et al., 2018). After the establishment time of seven months (30-05-2019) the model ecosystems were weekly dosed for four weeks with four treatment levels (0 (control), 0.01, 0.1 and $1 \mu \mathrm{g} / \mathrm{L}$ ) with three replicates each, using freshly prepared dosage imidacloprid solutions from imidacloprid formulation containing $350 \mathrm{~g}$ a.i./L. The cosms with $0.01 \mu \mathrm{g} / \mathrm{L}, 0.1 \mu \mathrm{g} / \mathrm{L}$ and $1 \mu \mathrm{g} / \mathrm{L}$ nominal concentrations were dosed with $10 \mathrm{ml}$ of $0.6 \mathrm{mg} / \mathrm{L}, 6 \mathrm{mg} / \mathrm{L}$ and $60 \mathrm{mg} / \mathrm{L}$ stock solutions, respectively.

\subsubsection{Phytoplankton, periphyton, and zooplankton}

Phytoplankton samples were collected at 7 and 1 day (d) before the first pesticide application and 2, 9, 16, 23, 30, 44, 58, 86, 114 and $142 \mathrm{~d}$ post first application. To measure the phytoplankton chlorophyll- $a$, water samples $(100 \mathrm{~mL})$ were collected from each cosm at a depth of $30 \mathrm{~cm}$ and filtered using a GF/C glass-fibre filter. The GF/C glass-fibre filter were warped in aluminium foil and stored till analysis at $-20{ }^{\circ} \mathrm{C}$. Periphyton chlorophyll- $a$ was assessed by introducing three glass slides (surface area $=37.5 \mathrm{~cm}^{2}$ ) into each cosm at $30 \mathrm{~cm}$ depth below water surface 7 days before the first application of imidacloprid. All the slides from each cosm were retrieved on $0 \mathrm{~d}$ (before pesticide application) and 7, 14, 21, 28, 42, 56, 84, 112 and $140 \mathrm{~d}$ after the first imidacloprid application. At each sampling date the attached periphyton was scrapped into a glass beaker containing $100 \mathrm{~mL}$ tap water and filtered using a GF/C glass-fibre filter and also stored till analysis at $-20^{\circ} \mathrm{C}$. After that the glass slides were put back in the cosms in their original position. Chlorophyll- $a$ of periphyton and phytoplankton was quantified using ultraviolet-visible (UV-VIS) spectrophotometric technique (Rico et al., 2014) after extraction of the chlorophyll-a from the GF/C glass-fibre filter using acetone solvent. The periphyton and phytoplankton chlorophyll-a concentrations were expressed in $\mathrm{mg} / \mathrm{m}^{2}$ and $\mu \mathrm{g} / \mathrm{L}$, respectively.

For zooplankton sampling, a depth-integrated water sample of $5 \mathrm{~L}$ was collected from each cosm and passed through a $55 \mu \mathrm{m}$ mesh plankton net and concentrated to $50 \mathrm{~mL}$. The samples were collected on 7 and $1 \mathrm{~d}$ pre-treatment and on 2, 9, 16, 23, 30, 44, 58, 86, 114, and $142 \mathrm{~d}$ after the first imidacloprid application. The zooplankton samples were treated with $10 \%$ buffer formalin solution and stored at $4{ }^{\circ} \mathrm{C}$ till further analysis. A binocular microscope was used for 
taxa identification and assessment of the abundance of the zooplankton taxa from $1 \mathrm{~mL}$ subsample. Macrozooplankton species were not found in our cosms. Back calculation was employed to obtain the number of zooplankton per volume of water (\#/L).

\subsubsection{Macroinvertebrates}

Two pebble baskets (volume $=0.0123 \mathrm{~m}^{3}$ ) that served as artificial substrates were introduced into each cosm and put on the brick two weeks before the first imidacloprid application. The baskets were sampled alternatively on 7 and $1 \mathrm{~d}$ pre-treatment and on 7,14 , $21,28,42,56,84,112,140$ and $168 \mathrm{~d}$ after the first application of imidacloprid. During the sampling, one of the pebble baskets was gently emerged from the brick and directly enveloped with a net (500 $\mu \mathrm{m}$ mesh net). Macroinvertebrates were carefully collected from the substrate and the net into a white tray after which the pebble basket was returned to the cosm to its original position. To collect free swimming invertebrates, the $500 \mu \mathrm{m}$ mesh net was passed through water column and one-fourth of the walls surface (Sumon et al., 2018). On each sampling date Chironomid larvae were collected from the sediment using a polyvinyl chloride (PVC) pipe (about $4 \mathrm{~cm}$ internal diameter). The collected macroinvertebrates were taxonomically identified to family level except for C. dipterum, C. horaria and P. minutissima, and counted. The alive macroinvertebrates were released back to their original cosms (Rico et al., 2014; Sumon et al., 2018).

\subsubsection{Organic matter decomposition}

Nylon litter bags ( $300 \mu \mathrm{m}$ mesh size) were used to investigate whether imidacloprid affects the microorganism community by assessing the organic matter decomposition rate. Banana leaves were leached in pre-conditioned tap water for 48-h to remove easily leachable humic substances (Sumon et al., 2018). Then the conditioned leaves were dried at $70{ }^{\circ} \mathrm{C}$ for $48-\mathrm{h}$ in an oven. About $2 \mathrm{~g}$ of the dried banana leaves was introduced into a litter bag. Eight bags were introduced into each cosm $1 \mathrm{~d}$ before the first imidacloprid application. The litter bags were placed at a depth of approximately $30 \mathrm{~cm}$ below the water surface. One of the 8 litter bags was retrieved on $2,16,28,42,56,70,84$ and $98 \mathrm{~d}$ after the first imidacloprid application. The remaining leaf material from the retrieved bag was carefully collected into clean glass petridish and dried at $70^{\circ} \mathrm{C}$ for $48 \mathrm{~h}$ and its weight was measured. The percentage of weight loss per day was calculated and recorded as the organic matter decomposition rate. 


\subsubsection{Physicochemical parameters}

Water quality variables including DO, $\mathrm{pH}, \mathrm{EC}$ and temperature were measured in-situ using a portable multi-meter ( $\mathrm{HQ40d}, \mathrm{HACH})$. For the variables total hardness, alkalinity, ammonia, nitrate and phosphate concentrations, water samples of about $500 \mathrm{~mL}$ were collected from each cosm and analysed in the laboratory according to USEPA (1983). Water quality measurements were performed on 7 and 1 d pre-treatment, and $0,7,14,21,28,42,56,84$, 112,140 and $168 \mathrm{~d}$ after the first application of imidacloprid.

\subsubsection{Concentration verification of imidacloprid exposure}

As discussed, an imidacloprid formulation (trade name: CON-FIDENCE, China) containing $350 \mathrm{~g}$ imidacloprid a.i./L was used to prepared dosage solutions, which are $90 \mathrm{mg} / \mathrm{L}, 9 \mathrm{mg} / \mathrm{L}$, $0.9 \mathrm{mg} / \mathrm{L}$ and $0.09 \mathrm{mg} / \mathrm{L}$ for single species toxicity tests, and $60 \mathrm{mg} / \mathrm{L}, 6 \mathrm{mg} / \mathrm{L}$ and $0.6 \mathrm{mg} / \mathrm{L}$ for mesocosm study. Samples $(10 \mathrm{ml})$ from the stock solutions were collected into amber glass for verification purpose and stored at $4{ }^{\circ} \mathrm{C}$ till analysis. Imidacloprid quantification was performed using liquid chromatography-tandem mass spectrometry (LC-MS) as described in Roessink et al. (2013).

\subsubsection{Data Analysis}

The acute toxicity test results of imidacloprid for $C$. dipterum, C. horaria, $P$. minutissima and Corixidae sp. were used to calculate lethal concentrations (LC) and effect concentrations (EC) at which $10 \%, 50 \%$ and $90 \%$ of the tested species were affected. Log-logistic regression as programmed in the software GenStat $11^{\text {th }}$ (VSN International Ltd., Oxford, UK) according to Rubach et al. (2011) was used to calculate the LC10, LC50 and LC90, and EC10, EC50 and EC90 values.

The Williams test (Williams, 1972), as available in the Community Analysis computer program, version 4.3.05 (Hommen et al. 1994), was used to calculate no-observed-effectconcentration (NOEC) values for the mesocosm variables including water quality parameters, chlorophyll-a levels of phytoplankton and periphyton, abundance of zooplankton and macroinvertebrate taxa and organic matter decomposition rates. Prior to the analysis, the abundance data of zooplankton and macroinvertebrates were $\ln (A x+1)$ transformed. Detailed 
information about the determination of $A$ and the rationale behind this transformation is available in Van den Brink et al. (2000).

Data sets of zooplankton and macroinvertebrates were analysed by the principal response curve (PRC) method using the CANOCO Software package, version 5 (Van den Brink and Ter Braak, 1999; Ter Braak and Smilauer, 2012). The PRC method is a specific type of redundancy analysis (RDA) that is able to extract the variation in community composition which can be attributed to the stressor from the total variation by including the treatment regime and its interaction with time as explanatory variables, and the sampling date as covariables. The overall significance of the effect of imidacloprid treatment on the variation in community composition ( $p \leq 0.05$ ) was tested by performing Monte Carlo permutations (Van den Brink and Ter Braak, 1999). As the amount of replication was not enough to test each treatment against the control for each sampling date using Monte Carlo permutation tests under the RDA option, the community data was reduced to a single number per cosm for each sampling date using principal component analysis (PCA). The PCA coordinates were subsequently analysed by the Williams test in order to calculate a NOECcommunity for each sampling date (Van den Brink et al., 1996).

\subsection{Results and discussion}

\subsubsection{Acute single species toxicity tests}

The average concentration of imidacloprid measured in the dosing stock solutions used for single species toxicity test was $105(91.3-123) \%$ of the intended concentrations. This indicates that each treatment in the acute tests received an appropriate amount of imidacloprid.

Van den Brink et al. (2016) reported a recovery of $86-94 \%$ of the intended concentration of imidacloprid after 4 days of acute toxicity experiment performed under 12:12 photoperiod and $18 \pm 1^{\circ} \mathrm{C}$. Low recovery (47\%) was reported by Sumon et al. (2018) after 4 days of acute exposure under high temperatures $\left(27.4 \pm 0.6^{\circ} \mathrm{C}\right)$. The photoperiod was not specified by Sumon et al. (2018), but they described it as a high intensity. The photoperiod reported by Van den Brink et al. (2016) is similar to the one used in our acute experimental setup, but the temperature we measured $(21 \pm 0.5)$ was slightly higher. As degradation of imidacloprid in water is mainly by photolysis (Bonmatin et al., 2015; Lu et al., 2015), the dissipation of 
imidacloprid in our acute experiment is likely to be comparable to the results reported by Van den Brink et al. (2016). We, therefore, used the nominal concentrations for the data analysis.

No significant increasing or decreasing trend in the levels of the monitored water quality variables (DO, EC, $\mathrm{pH}$ and temperature) were observed during the experimental period of the acute single species tests. As also reported by Roessink et al. (2013), a concentration dependent slight increase in EC value was observed in this study, most probably a direct result of the addition of the test substance. The observed value range of the parameters were 6.67 $-8.91 \mathrm{mg} / \mathrm{L}, 19.5-22.4{ }^{\circ} \mathrm{C}, 215-238 \mu \mathrm{s} / \mathrm{cm}, 7.42-8.04$ for DO, temperature, EC and $\mathrm{pH}$, respectively (Table SI6.1).

During the acute tests, a low control immobility ranging from 3.3 to $6.7 \%$ was observed in tests with $C$. dipterum, $C$. horaria and $P$. minutissima after $96-\mathrm{h}$ of exposure (Table 6.1). The highest control immobility $(16.7 \%$ at $96-h)$ was observed for the test with Corixidae sp., which slightly higher than the accepted threshold value (15\%) according to OECD (2011) for standard test organism (Chironomus sp.) with 48-h exposure time. But, the 48-h control immobility for Corixidae sp. was $3.3 \%$, so significantly lower than the aforementioned threshold value.

Table 6.1. Results of single species acute toxicity studies of imidacloprid to four freshwater arthropods. Effect concentrations are expressed as $96-\mathrm{h} \mathrm{L}(\mathrm{E}) \mathrm{C50}$ and $96-\mathrm{h} \mathrm{L}(\mathrm{E}) \mathrm{C10}$ values in $\mu \mathrm{g} / \mathrm{L}$.

\begin{tabular}{|c|c|c|c|c|c|}
\hline \multirow{2}{*}{ Test species } & \multicolumn{2}{|c|}{ Mortality } & \multicolumn{2}{|c|}{ Immobility } & \multirow{2}{*}{$\begin{array}{l}\text { Control } \\
\text { Mortality/ } \\
\text { Immobility } \\
\text { (\%) }\end{array}$} \\
\hline & 96-h LC10 & 96-h LC50 & 96-h EC10 & 96-h EC50 & \\
\hline Cloeon dipterum & $0.54(0.2-1.4)$ & $2.7(1.7-4.3)$ & $0.3(0.11-0.83)$ & $1.5(0.96-2.4)$ & 6.7 \\
\hline Caenis horaria & $1.4(0.81-2.4)$ & $3.4(2.5-4.5)$ & $1.2(0.65-2.2)$ & $1.9(1.4-2.7)$ & 6.7 \\
\hline Corixidae sp. & $1.5(0.59-4.0)$ & $6.8(4.3-11)$ & $0.96(0.4-2.2)$ & $3.6(2.4-5.6)$ & 16.7 \\
\hline Plea minutissima & $15(5.9-40)$ & $68(43-107)$ & $9.6(4.1-22)$ & $36(24-56)$ & 3.3 \\
\hline
\end{tabular}

LC50 = median lethal concentration; $\mathrm{Cl}$ = confidence interval; LC10 = lethal concentration for 10\%; EC50 = median effective concentration; $\mathrm{EC} 10$ = effective concentration for $10 \%$.

Our acute toxicity results showed that $C$. dipterum $(96-\mathrm{h} \mathrm{LC50}=2.7 \mu \mathrm{g} / \mathrm{L} ; \mathrm{EC} 50=1.5 \mu \mathrm{g} / \mathrm{L})$ is the most sensitive species, followed by $C$. horaria (96-h LC50 $=3.4 \mu \mathrm{g} / \mathrm{L} ; \mathrm{EC} 50=1.9 \mu \mathrm{g} / \mathrm{L}$ ), Corixidae sp. (96-h LC50 = $6.8 \mu \mathrm{g} / \mathrm{L} ; \mathrm{EC} 50=3.6 \mu \mathrm{g} / \mathrm{L})$ and P. minutissima $(96-\mathrm{h} \mathrm{LC50}=68 \mu \mathrm{g} / \mathrm{L}$; EC50 $=36 \mu \mathrm{g} / \mathrm{L})$ (Table 6.1). P. minutissima was found to be the most tolerant species compared to the other tested arthropods with 96-h LC50 and EC50 values being $23-25$ times higher than the effect values calculated for the most sensitive species, $C$. dipterum. The detailed effect concentrations for 24-h to 96-h exposure days and the raw toxicity datasets are presented in Table SI6.2 and Table SI6.3, respectively. 
The 96-h LC50 values we observed for $C$. dipterum were lower by a factor of 10 and 13 compared to the values reported for the temperate population in summer (Roessink et al., 2013) and winter generations (Van den Brink et al., 2016), respectively (Table SI6.4). The 96-h EC50 (immobility) of the species (C. dipterum) calculated in this study was also lower by a factor of 17 compared to the temperate winter generation (Van den Brink et al., 2016), but equivalent with the value reported by Roessink et al. (2013) for the summer generation. Moreover, compared to the effect values (96-h LC50 = $1152 \mu \mathrm{g} / \mathrm{L}$ and 96-h EC50 = $23.1 \mu \mathrm{g} / \mathrm{L}$ ) reported for overwintered Cloeon sp. generation sampled in early spring (May) in Canada (Raby et al., 2018), our results are lower by a factor of 427 for LC50 and 15 for EC50 (Table SI6.4). Similarly, Sumon et al. (2018) reported lower effect values (96-h LC50 $=0.024 \mu \mathrm{g} / \mathrm{L}$ and $\mathrm{EC50}=0.0055 \mu \mathrm{g} / \mathrm{L}$ ) for Cloeon sp. from the sub-tropical climate in Bangladesh compared to temperate species (Table SI6.4).

The 96-h lethal (LC50) and immobility (EC50) toxicity values we estimated for $C$. horaria and $P$. minutissima were lower than the values reported for temperate winter populations tested under temperate conditions (Van den Brink et al., 2016) by a factor ranging from 4.2 8.2 and $3.2-5.2$, respectively. Our results for these species are comparable with the values reported by Roessink et al. (2013) for the temperate summer generations of the same species. Furthermore, our 96-h LC50 and EC50 values for Corixidae sp. were lower by a factor of 4.1 and 3 compared to the effect values of summer generation of Micronecta sp. (Roessink et al., 2013) and by a factor of 66.2 and 17.5 relative to the values reported for winter generation Trichocorixa sp. (Raby et al., 2018), respectively (Table SI6.4). Both Micronecta sp. and Trichocorixa sp. are from Corixidae family.

These differences in sensitivity between summer and winter generations, and temperate and tropical populations (see discussions below in section 6.3.3) could point towards an effect of metabolic state on the sensitivity of species (e.g., Cloeon sp.), as a result of differences in toxicokinetics, e.g. increased uptake (Van den Brink et al., 2016). But further experiments are needed to find the mechanistic links causing the differences in sensitivity and spatio-temporal backgrounds of the tested populations. 


\subsubsection{Mesocosm experiment}

\subsubsection{Verification of imidacloprid concentrations}

The measured average concentration of imidacloprid in the dosing stock solutions used for mesocosm experiment was $118(110-128) \%$ of the intended concentrations. Therefore, based on the amount spiked from dosing solution and the test volume, the result showed that each cosm treatment received the appropriate amount of imidacloprid, and the nominal concentrations were used for the data analysis.

Light and temperature are important environmental conditions affecting the dissipation of imidacloprid in aquatic ecosystem (Lu et al., 2015; Hayasaka et al., 2019). Therefore, relative fast dissipation of the compound is expected in (sub)-tropical climates. Indeed, fast dissipation of imidacloprid has been reported for a pond microcosm (half-life $=28 \pm 8 \mathrm{~h}$; cosm temperature $=10-24^{\circ} \mathrm{C}$ ) exposed to high levels of ultraviolet radiation (Colombo et al., 2013), as well as for experimental rice paddies (half-life $0.9-3$ days; rice mesocosm temperature $=$ $20-31^{\circ} \mathrm{C}$ ) established in summer (July) in Portugal (Daam et al., 2013; Pereira et al. 2017). However, the presence of suspended particulate matter, e.g. due to a high abundance of algae and macrophytes, can reduce the dissipation of imidacloprid by photolysis. For instance, in an outdoor microcosm study under the sub-tropical climatic conditions in Bangladesh a dissipation of about $47-55 \%$ of the compound after 7 days was reported, with an average cosm temperature of $28 \pm 2{ }^{\circ} \mathrm{C}$ under sunny experimental days with the sunlight filtered by a transparent plastic slate (Sumon et al., 2018). Under Mediterranean climatic conditions with a cosm temperature ranging from 16 to $25^{\circ} \mathrm{C}$ a half-life of 10 days was reported by Rico et al. (2018) in a mesocosm study performed between April and June. In both studies (i.e., by Rico et al., 2018; Sumon et al., 2018) the authors stated the presence of particulate matter, continuous growth of algae and macrophytes as mitigating factors for the observed low dissipation of imidacloprid in cosms they established.

The mesocosm experiment established in this study was roofed with transparent plastic slates similar to the cosms used by Sumon et al. (2018) and the temperature range (16.6 - 20.9 ${ }^{\circ} \mathrm{C}$ ) of our cosms overlaps with the range reported by Rico et al. (2018). However, imidacloprid was applied in the wet season (June - July) in our study, while the experiments by Sumon et al. (2018) and Rico et al. (2018) were performed during sunny periods. Thus based on the similarities and differences in experimental setup and climatic conditions between our cosm 
experiment and the aforementioned cosm studies (Rico et al., 2018; Sumon et al., 2018), we hypothesized that the half-life of imidacloprid in our mesocosm study would have been $\geq 10$ days. Therefore, a build-up of the concentration is to be expected, meaning that the maximum concentration after 4 applications on day 21 could have been between a factor of 2 (DT50 = $10 \mathrm{~d}$ ) and $4($ DT50 $=\infty$ ) higher than the concentration after the first application.

\subsubsection{Invertebrates response}

Overall, our cosm results showed that the effect threshold values for invertebrates seem to be lower than the reported values in temperate region. Such variations can be due higher temperature in tropical experiments (Kwok et al., 2007; Macaulay et al., 2020) and due to differences in life cycle of the test species (Van den Brink et al., 2016). The sensitivity differences observed between the studies are discussed in a separate section 6.3.3.

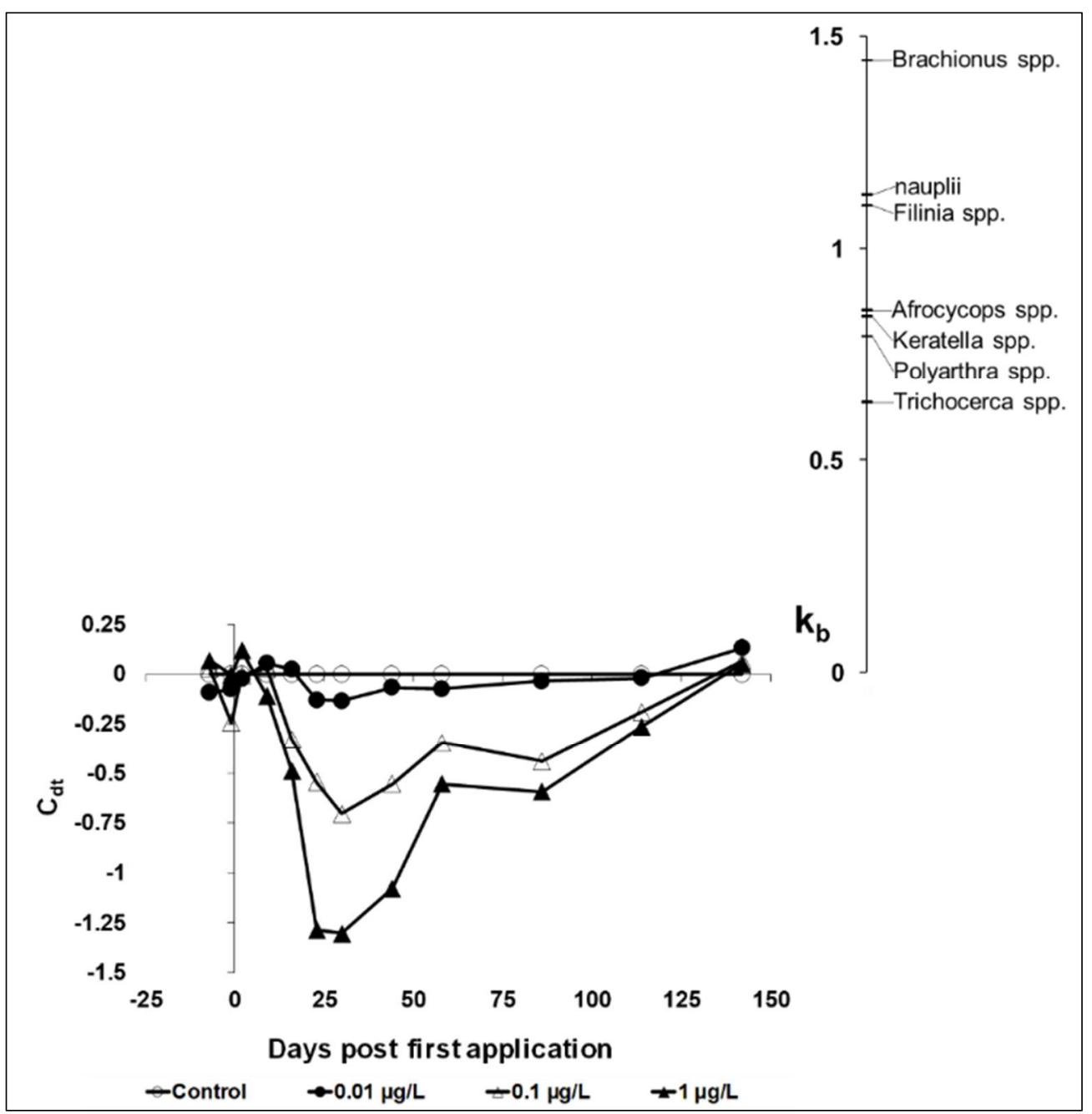

Fig. 6.1. Principal Response Curve (PRC) depicting the effect of imidacloprid contamination on zooplankton community over the course of experimental period. The sample weights $\left(C_{\mathrm{dt}}\right)$ indicate differences between the treatments and the control at the different sampling dates. The affinity of each taxon of the community with the response indicated by the PRC is provided by the species weight $\left(k_{b}\right)$. 
Table 6.2. The No Observed Effect Concentration (NOEC) values ( $\mu \mathrm{g} / \mathrm{L}$ ) for water quality and periphyton (a), and zooplankton and phytoplankton (b) variables. The arrow between brackets indicate an imidacloprid treatment related significant increase ( $\uparrow$ ) or decrease ( $\downarrow$ ) of a variable (Williams test; $p<0.05)$. The NOEC values greater than $1 \mathrm{\mu g} / \mathrm{L}$ is marked by > symbol. The shed with light grey indicates the application period of imidacloprid, while the -7 and -1 are pre-application and $>21$ are post application periods. An - indicates that the endpoint was not evaluated on that sampling date.

\begin{tabular}{|c|c|c|c|c|c|c|c|c|c|c|c|c|c|}
\hline \multirow{2}{*}{$\begin{array}{l}\text { a. Monitored } \\
\text { variables }\end{array}$} & \multicolumn{13}{|c|}{ Treatment time (day) } \\
\hline & -7 & -1 & 0 & 7 & 14 & 21 & 28 & 42 & 56 & 84 & 112 & 140 & 168 \\
\hline \multicolumn{14}{|l|}{ Water Quality } \\
\hline Dissolved oxygen & $>$ & $>$ & $>$ & $>$ & $>$ & $>$ & $>$ & $>$ & $0.01(\downarrow)$ & $>$ & $>$ & $0.1(\uparrow)$ & $>$ \\
\hline Conductivity & $>$ & $>$ & $>$ & $>$ & $>$ & $>$ & $>$ & $>$ & $>$ & $>$ & $>$ & $0.1(\downarrow)$ & $>$ \\
\hline Temperature & $>$ & $>$ & $>$ & $>$ & $>$ & $>$ & $>$ & $>$ & $0.01(\downarrow)$ & $>$ & $>$ & $<0.01(\downarrow)$ & $>$ \\
\hline $\mathrm{pH}$ & $>$ & $>$ & $>$ & $>$ & $>$ & $>$ & $>$ & $>$ & $>$ & $>$ & $>$ & $>$ & $>$ \\
\hline Alkalinity & $>$ & $>$ & $>$ & $>$ & $>$ & $0.1(\uparrow)$ & $>$ & $>$ & $>$ & $0.1(\downarrow)$ & $>$ & $0.1(\uparrow)$ & $>$ \\
\hline Total hardness & $>$ & $>$ & $>$ & $>$ & $>$ & $>$ & $>$ & $>$ & $>$ & $>$ & $>$ & $0.01(\uparrow)$ & $>$ \\
\hline Ammonia & $>$ & $>$ & $>$ & $>$ & $>$ & $>$ & $>$ & $>$ & $>$ & $>$ & $>$ & $>$ & $>$ \\
\hline Nitrate & $0.1(\uparrow)$ & $0.1(\uparrow)$ & $>$ & $>$ & $>$ & $>$ & $>$ & $0.1(\uparrow)$ & $>$ & $>$ & $>$ & $>$ & $>$ \\
\hline Phosphate & $>$ & $>$ & $>$ & $>$ & $>$ & $>$ & $>$ & $0.1(\downarrow)$ & $>$ & $>$ & $>$ & $>$ & $>$ \\
\hline \multicolumn{14}{|l|}{ Periphyton } \\
\hline Chlorophyll-a & - & - & $>$ & $0.1(\uparrow)$ & $0.01(\uparrow)$ & $0.01(\uparrow)$ & $>$ & $0.01(\uparrow)$ & $0.01(\uparrow)$ & $<0.01(\uparrow)$ & $0.1(\downarrow)$ & $>$ & - \\
\hline b. Monitored & \multicolumn{13}{|c|}{ Treatment time (day) } \\
\hline variables & -7 & -1 & 2 & 9 & 16 & 23 & 30 & 44 & 58 & 86 & 114 & 142 & \\
\hline \multicolumn{14}{|l|}{ Zooplankton } \\
\hline Community & $>$ & $>$ & $>$ & $>$ & 0.01 & $<0.01$ & $<0.01$ & 0.01 & 0.01 & $>$ & $>$ & $>$ & \\
\hline Brachionus sp. & $>$ & $>$ & $>$ & $>$ & $0.01(\downarrow)$ & $<0.01(\downarrow)$ & $0.01(\downarrow)$ & $0.01(\downarrow)$ & $0.1(\downarrow)$ & $0.1(\downarrow)$ & $0.1(\downarrow)$ & $>$ & \\
\hline Filinia sp. & $>$ & $>$ & $>$ & $>$ & $0.1(\downarrow)$ & $0.01(\downarrow)$ & $0.01(\downarrow)$ & $0.01(\downarrow)$ & $<0.01(\downarrow)$ & $0.01(\downarrow)$ & $>$ & $>$ & \\
\hline Nauplii & $>$ & $>$ & $>$ & $>$ & $0.01(\downarrow)$ & $<0.01(\downarrow)$ & $0.01(\downarrow)$ & $0.01(\downarrow)$ & $0.01(\downarrow)$ & $0.01(\downarrow)$ & $>$ & $>$ & \\
\hline Keratella sp. & $>$ & $>$ & $0.1(\uparrow)$ & $>$ & $0.1(\downarrow)$ & $0.01(\downarrow)$ & $0.01(\downarrow)$ & $0.01(\downarrow)$ & $>$ & $>$ & $>$ & $>$ & \\
\hline Afrocyclops sp. & $>$ & $>$ & $>$ & $>$ & $0.01(\downarrow)$ & $0.01(\downarrow)$ & $<0.01(\downarrow)$ & $<0.01(\downarrow)$ & $0.01(\downarrow)$ & $0.01(\downarrow)$ & $>$ & $>$ & \\
\hline Trichocerca sp. & $>$ & $>$ & $>$ & $>$ & $>$ & $<0.01(\downarrow)$ & $0.01(\downarrow)$ & $0.01(\downarrow)$ & $0.1(\downarrow)$ & $>$ & $>$ & $>$ & \\
\hline Polyarthra sp. & $>$ & $>$ & $>$ & $<0.01(\downarrow)$ & $0.01(\downarrow)$ & $0.01(\downarrow)$ & $0.01(\downarrow)$ & $0.01(\downarrow)$ & $0.01(\downarrow)$ & $>$ & $>$ & $>$ & \\
\hline \multicolumn{14}{|l|}{ Phytoplankton } \\
\hline Chlorophyll- $a$ & $>$ & $>$ & $>$ & $>$ & $0.01(\uparrow)$ & $0.01(\uparrow)$ & $0.1(\uparrow)$ & $0.1(\uparrow)$ & $>$ & $<0.01(\uparrow)$ & $>$ & $>$ & \\
\hline
\end{tabular}




\subsection{Zooplankton}

Our pond mesocosms were dominated by Rotifera (5 taxa) and Copepoda (2 taxa). Cladocerans were not found during the whole experimental period in any of the cosms. The PRC shows that the imidacloprid treatment explained a significant $(P-$ value $=0.002)$ part of the variation in the zooplankton community composition between the different treatments during the experimental time (Fig. 6.1). For some taxa (e.g. Afrocycops sp.) the effect of imidacloprid increased till 44/58 days after the pesticide first application (Table 6.2), indicating chronic toxicity of the compound. The maximum effect of imidacloprid on the zooplankton community was observed on 23 day and 30 day after the first imidacloprid application (NOECcommunity < $0.01 \mu \mathrm{g} / \mathrm{L}$ ), coinciding with the last application (Table 6.2).

According to the estimated species weight $\left(k_{b}\right)$, the rotifer Brachionus sp. showed the largest response to the imidacloprid treatments followed by nauplii and Filinia sp., while Trichocerca sp. showed small response compared to the other species (Fig. 6.1). For all zooplankton species, except Keratella sp. and Polyarthra sp., we found consistent significant treatment related effects on their abundance in all imidacloprid treatments (i.e., consistent means at least on two consecutive samplings) (Table 6.2). Consistent effects for Keratella sp. and Polyarthra sp. were found for the $0.1 \mu \mathrm{g} / \mathrm{L}$ and $1 \mu \mathrm{g} / \mathrm{L}$ treatments (Table 6.2). Imidacloprid treatment related responses of rotifers and copepods were reported in cosm studies performed in Bangladesh (Sumon et al., 2018) and in Spain (Rico et al., 2018). The NOEC values reported by Sumon et al. (2018) in Bangladesh for the rotifers Keratella sp., Polyarthra sp., Brachionus sp., Filinia sp. and Trichocerca sp. were $<0.03$ (23-d), $<0.03$ (16-d), 0.03 (28-d), 0.3 (23-d) and $0.3(23-d) \mu g / L$, respectively. The values were comparable to our results for the rotifer species (see Table 6.2; Table SI6.6), except for Filinia sp. and Trichocerca sp. where our results are lower by about one order of magnitude. Rico et al. (2018), were also reported a NOEC value of $1 \mu \mathrm{g} / \mathrm{L}$ for the rotifer Keratella quadrata, which is about 100 times higher than the NOEC value (44-d, $0.01 \mu \mathrm{g} / \mathrm{L}$ ) estimated in this study. Sumon et al. (2018) reported $<0.03$ (28-d), 0.03 (9-d) and 0.3 (9-d) $\mu \mathrm{g} / \mathrm{L}$ NOEC values for the copepods Diaptomus sp., nauplius and Cyclops sp., respectively, which are comparable with our results for Afrocyclops sp. (44-d NOEC $<0.01 \mu \mathrm{g} / \mathrm{L}$ ) and nauplii (23-d NOEC <0.01 $\mu \mathrm{g} / \mathrm{L}$ ) (Table SI6.6; Table SI6.7). But compared to the NOEC values reported by Rico et al. (2018) for Cyclopoida (17-d NOEC = $1 \mu \mathrm{g} / \mathrm{L}$ ), and nauplii (3-d NOEC $=5 \mu \mathrm{g} / \mathrm{L}$ ), our results for copepods are lower by about two orders of magnitude. This indicates that the abundance of rotifers and copepods were severely affected 
by imidacloprid upon chronic exposure to environmentally relevant low concentrations. The toxicity of imidacloprid to Diaptomus sp. (copepod) was demonstrated by Sumon et al. (2018) in the sub-tropical region of Bangladesh (96-h LC50 $=6.5 \mu \mathrm{g} / \mathrm{L} ; \mathrm{EC50}=0.0386 \mu \mathrm{g} / \mathrm{L}$ ). This suggests that the effect observed on copepods in our cosm study is likely due to direct effect of imidacloprid to the species.

Toxicity studies of imidacloprid to rotifers species are not available in the literature to evaluate whether the effects observed in our results are due to direct effect of the insecticide or indirect, except for the rotifer Brachionus calyciflorus for which high effect values (i.e., 24$\mathrm{h} \mathrm{NOEC}$ (mortality) $=17500 \mu \mathrm{g} / \mathrm{L} ; 10-\mathrm{d}$ NOEC (population growth) $=6220 \mu \mathrm{g} / \mathrm{L}$ ) were reported (Gharaei et al., 2020) indicating the insensitivity of the species to the compound. Similarly, Finnegan et al. (2017) reported high effect values for the species (Brachionus calyciflorus; 24h LC50 > $100000 \mu \mathrm{g} / \mathrm{L}$ ) for the neonicotinoid thiamethoxam insecticide. But, similar to our cosm result, Brachionus sp. proved to show a response to imidacloprid treatments in the study of Sumon et al. (2018) in Bangladesh. As only scarce data is available on the toxicity of imidacloprid to rotifers, it is difficult to draw a conclusive statement for the observed treatment related decline in abundance of Rotifera taxa in this study and other cosm studies from Mediterranean (Rico et al., 2018) and sub-tropical (Sumon et al., 2018) regions. This needs further clarifications to prove whether the cosm response was due to the direct toxic effect of imidacloprid. Thus, to mechanistically validate these effects as direct effects, single species tests with tropical rotifer species should be performed.

The effect-size on the zooplankton community decreased after 30 days after the first application and showed a full recovery after 86 days, although some species were not recovered yet at the population level (Table 6.2). For mesocosm ponds treated with a single dose of $\leq 25 \mu \mathrm{g} / \mathrm{L}$ imidacloprid, Rico et al. (2018) reported a recovery time of 56 days for the zooplankton community, which is quick compared to our result (86 days for cosms repeatedly treated with $\leq 1 \mu \mathrm{g} / \mathrm{L}$ ) (Table S16.5). This suggests that for tropical aquatic ecosystems repeatedly exposed to environmentally relevant low concentrations of imidacloprid the zooplankton community can be affected for a long period of time before the group returns to its untreated condition. However, a long recovery period (16 weeks) was reported by Hayasaka et al. (2012) for the zooplankton community (ostracods, Cladocerans and copepods) of a mesocosm paddy that was designed to mimic rice field in Japan and treated with $49 \mu \mathrm{g} / \mathrm{L}$ of imidacloprid which quickly (i.e., in 3 days) declined to $1 \mu \mathrm{g} / \mathrm{L}$ (Table SI6.5). The longer 
recovery period reported by Hayasaka et al. (2012) compared to our result may be due to the high initial exposure concentration of imidacloprid, and variations in species composition and differences in cosm setup as the authors (Hayasaka et al., 2012) performed the experiment in rice paddies.

\subsection{Macroinvertebrate}

Eleven taxa of macroinvertebrates were identified in our mesocosm ponds. The taxa included Ephemeroptera (C. dipterum and C. horaria), Diptera (Culicidae sp. and Chironomidae sp.), Hemiptera (Corixidae sp., Pleidae sp., Gerridae sp. and Notonectidae sp.), Coleoptera (Dytiscidae sp.) and Gastropoda (Planorbidae sp. and Physidae sp.). In abundance, the gastropods were the dominant taxa during the whole course of the experimental period. The PRC (Fig. 6.2) indicates that the macroinvertebrate community composition was significantly $(P$-value $=0.01)$ altered by the imidacloprid treatments, as is also reported in many other cosm studies (Table SI6.5; Table SI6.6) (Alexander et al., 2008; Pestana et al., 2009; Pereira et al., 2017; Rico et al., 2018; Sumon et al., 2018). The estimated no observed effect concentration for the macroinvertebrate community (NOECcommunity) was $0.01 \mu \mathrm{g} / \mathrm{L}$ (Table 6.3), indicating that the two highest imidacloprid concentrations significant changed the community composition of the macroinvertebrate community.

In this study, C. dipterum (14-d NOEC $<0.01 \mu \mathrm{g} / \mathrm{L}$ ), C. horaria (14-d and 21-d NOEC $<0.01$ $\mu \mathrm{g} / \mathrm{L}$ ) and Culicidae sp. (21-d and 28-d NOEC $=0.01 \mu \mathrm{g} / \mathrm{L}$ ) showed the largest response to the imidacloprid treatments (i.e., higher species weight, $\mathrm{k}_{b}$ values) (Fig. 6.2) relative to the others macroinvertebrates. Our NOEC value for $C$. dipterum was in agreement with the effect values reported in the cosm studies performed in Spain (Rico et al., 2018; 28-d NOEC < $0.09 \mu \mathrm{g} / \mathrm{L}$ for C. dipterum) and Bangladesh (Sumon et al., 2018; 9-d NOEC < $0.03 \mu \mathrm{g} / \mathrm{L}$ for Cloeon sp.) (Table S16.6). But compared to the chronic 28-d EC10 values for $C$. dipterum $(0.033 \mu \mathrm{g} / \mathrm{L})$ and $C$. horaria $(0.024 \mu \mathrm{g} / \mathrm{L})$ reported for temperate populations (Roessink et al., 2013) our NOEC values are low as is also supported by our acute toxicity results (Table SI6.6). Moreover, in a stream mesocosm study under temperate conditions with continuous imidacloprid application, Alexander et al. (2008) also reported a higher effect threshold value (20-d NOEC $=0.3 \mu \mathrm{g} / \mathrm{L}$ ) for Epeorus sp. nymphs relative to our values for mayflies (i.e., $C$. dipterum and $C$. horaria) (Table SI6.6). 
The consistent NOEC values estimated in our study for the dipteran Chironomidae sp. and Culicidae sp. of $0.01 \mu \mathrm{g} / \mathrm{L}$ are comparable with the cosm 10-d NOEC value ( $<0.2 \mu \mathrm{g} / \mathrm{L}$ ) reported for Chironomini in the Mediterranean cosm experiment (Rico et al., 2018). But, relative to the sensitivity of dipteran species from the temperate region such as Chironomus dilutus (14-d $\mathrm{LC20}=0.47 \mu \mathrm{g} / \mathrm{L})$ (Cavallaro et al., 2017) and Chironomus riparius (10-d LC10 = $1.64 \mu \mathrm{g} / \mathrm{L}$ ) (Chandran et al., 2018) our observed NOEC values are low (Table SI6.6). This variation could be partly explained by the higher temperature in tropical region relative to temperate. See section 6.3.3 for more discussion for the sensitivity differences between studies.

For the Hemipteran taxa of Gerridae sp. and Corixidae sp. the largest significant effect was observed after the $3^{\text {rd }}$ application of imidacloprid with $28-\mathrm{d}$ NOECs of $<0.01 \mu \mathrm{g} / \mathrm{L}$ (Table 6.3). Similarly, the largest effects on the abundances of Notonectidae sp. (28-d NOEC $=0.01 \mu \mathrm{g} / \mathrm{L}$ ) and $P$. minutissima $(42-\mathrm{d}$ NOEC $=0.01 \mu \mathrm{g} / \mathrm{L})$ were observed in the two highest treatments on 28 days and 42 days after the first application of imidacloprid, respectively (Table 6.3). For Gerris sp. and Notonecata sp., Sumon et al. (2018) reported a $16-\mathrm{d}$ NOEC value of $0.03 \mu \mathrm{g} / \mathrm{L}$ in sub-tropical cosms, which is comparable to our results in Ethiopia. Rico et al. (2018) also reported a NOEC value of $0.2 \mu \mathrm{g} / \mathrm{L}$ for Notonetidae sp. from a mesocosm study performed in Mediterranean climatic conditions (Table SI6.6). But, for Gerris latiabdominis (Hayasaka et al., 2012) and Notonecta tiguttata (Kobashi et al., 2017) no significant effects of imidacloprid (at $49 \mu \mathrm{g} / \mathrm{L}$ for $\mathrm{G}$. latiabdominis and at $157 \mu \mathrm{g} / \mathrm{L}$ for $N$. tiguttata) were reported in a mesocosm study using rice paddies in Japan. Furthermore, the $28-\mathrm{d}$ EC10 value $(2.03 \mu \mathrm{g} / \mathrm{L})$ reported for P. minutissima reported by Roessink et al. (2013) for the temperate population is 203 times higher compared to the NOEC value $(42-\mathrm{d}$ NOEC $=0.01 \mu \mathrm{g} / \mathrm{L})$ measured in our study for the species in Ethiopia (Table SI6.6). These indicate location based sensitivity variations between population of the tested Hemipteran species. See section 6.3.3 for more discussion.

Pereira et al. (2017) demonstrated significant effects of imidacloprid (applied once at 60 $\mu \mathrm{g} / \mathrm{L}$ which quickly dissipated with half-life of 2.7 days) on Hydaticus sp. (Coleoptera, Dytiscidae family) using rice mesocosms with Mediterranean climatic condition. This is in line with our pond mesocosms result for Dytiscidae sp. $(28-\mathrm{d}$ NOEC $<0.01 \mu \mathrm{g} / \mathrm{L}$ ) in Ethiopia (Table SI6.6), although we tested much lower concentrations with repeated application.

The snails (i.e., Physidae sp. and Planorbidae sp.) showed the smallest response to the imidacloprid treatments compared to other macroinvertebrates. For both species a 28-d NOEC value of $0.1 \mu \mathrm{g} / \mathrm{L}$ was calculated (Fig. 6.2; Table 6.3). There are studies from the 
temperate region indicated that imidacloprid is toxic to aquatic snails (e.g., Planorbella pilsbryi, Lymnaea stagnalis). Prosser et al. (2016) reported a 28-d EC10 (on growth), EC50 (on growth), LC10 and LC50 effect values of 15.4, 39.4, 45.7 and $646 \mu \mathrm{g} / \mathrm{L}$, respectively for the freshwater snail P. pilsbryi. Tufi et al. (2015) also reported sublethal toxicity of imidacloprid to the freshwater snail L. stagnalis. Tufi et al. (2015) demonstrated significant changes in the levels of several amino acids (e.g., tryptophan, proline, phenylalanine) in L. stagnalis which were exposed to 0.1 and $1 \mu \mathrm{g} / \mathrm{L}$ of imidacloprid for 10 days. The choline/acetylcholine ratio in the snail (L. stagnalis) was also significantly increased at exposure concentration of $1 \mu \mathrm{g} / \mathrm{L}$ imidacloprid (10-d NOEC $=0.1 \mu \mathrm{g} / \mathrm{L}$ ) (Tufi et al., 2015). These results indicate that the effects observed on abundance of the Physidae sp. and Planorbidae sp. snails in this study are likely due to direct toxicity of imidacloprid, although the NOEC values we measured for both species in this study are low compared to the $28-\mathrm{d} \mathrm{EC10} \mathrm{value}(15.4 \mu \mathrm{g} / \mathrm{L})$ reported by Prosser et al. (2016) for the temperate freshwater snail Planorbella pilsbryi (Table SI6.6). See section 6.3.3 for discussion related to the sensitivity differences between studies.

Full recovery of the macroinvertebrates community was not demonstrated during the 21 weeks of the recovery period (Table 6.3), while the differences in community composition between the treatment and the control decreased after 42 days (Fig. 6.2). Compared to the zooplankton community, we found that the macroinvertebrates community required a longer recovery period, which is probably due to the longer generation times of macroinvertebrate taxa compared to zooplankton taxa which have a relatively short life cycle (Beketov et al., 2008; Rico and Van den Brink, 2015). This indicates that for tropical aquatic ecosystems which are continuously exposed to imidacloprid with residual concentration of $\geq 0.1 \mu \mathrm{g} / \mathrm{L}$, the full recovery of the macroinvertebrates community, especially of mayflies and mosquitos, will take more than five months. Comparing the recovery of the populations of individual species, except for the most sensitive species (C. dipterum, $C$. horaria and Culicidae sp.), all other species were recovered (i.e., no significant differences between treatments and control) after 24 weeks of the first application (Table 6.3). Similar delayed recovery results were reported by Beketov et al. (2008) for the neonicotinoid thiacloprid insecticide studied using mesocosms that was designed to mimic temperate streams under single time dosing. The authors (Beketov et al.,2008) reported that recovery of the macroinvertebrate community exposed to $3.2 \mu \mathrm{g} / \mathrm{L}$ was not observed after 27 weeks. In contrary, in a mesocosm study by Rico et al. (2018) a shorter recovery period (56 days) was reported for macroinvertebrate community 
which contaminated to single application of $\leq 250 \mu \mathrm{g} / \mathrm{L}$ of imidacloprid. This result variation may be explained partly due to differences in species composition as our cosm contains $82 \%$ insects ( 9 taxa) and 18\% molluscs ( 2 taxa), while the pond cosms established by Rico et al. (2018) contain more diverse species in which 69\% insects (9 taxa), 15\% molluscs ( 2 taxa) and $8 \%$ each from Arachnida ( 1 taxon) and Crustacea (1 taxon). The differences in exposure scenario between our study (chronic) and Rico et al. (2018) (acute) can be also one of the factors for the recovery result variations. In addition to life cycle characteristics, aerial recolonization of the treated cosms from an external sources for mobile species (e.g., insects) is reported as an important route for the quick recovery of species (Beketov et al., 2008; Kattwinkel et al., 2012; Gergs et al., 2016). However, as our experiment was carried out during the rainy season we hypothesis that heavy rain likely inhibited the possible aerial recolonization from nearby water bodies as heavy rain affects the emergence of aquatic insects (Lake, 2000, Malison and Baxter, 2010).

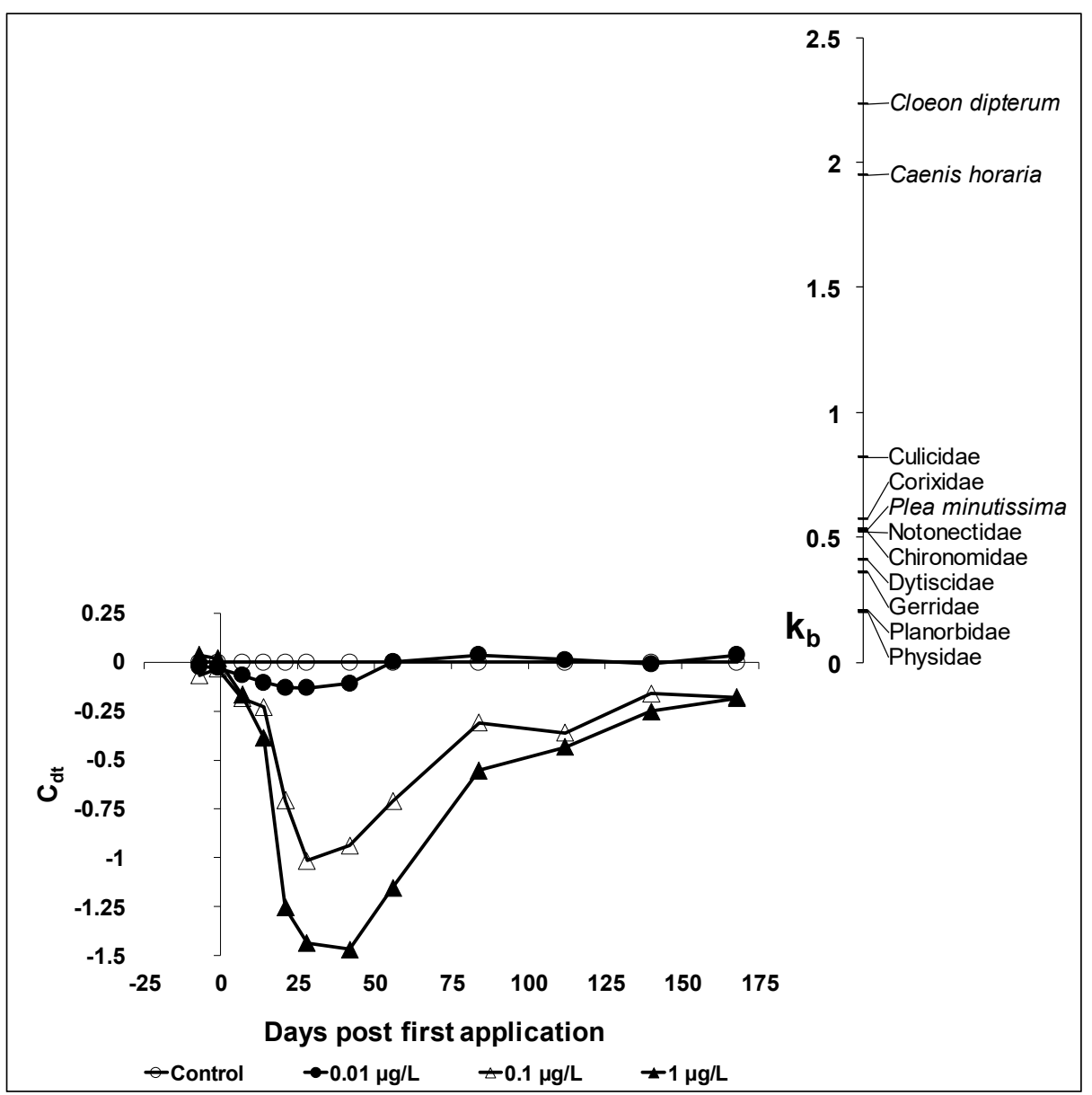

Fig. 6.2. Principal Response Curve (PRC) depicting the effect of imidacloprid contamination on the macroinvertebrate community over the course of experimental period. The sample weights $\left(C_{d t}\right)$ indicate differences between the treated macroinvertebrate community and the control in the different sampling dates. The affinity of each taxon of the community with the PRC is indicated by the species weight (Kb). 
Table 6.3. The No Observed Effect Concentration (NOEC) values ( $\mu \mathrm{g} / \mathrm{L}$ ) for macroinvertebrates and organic matter decomposition parameters. The arrow between brackets indicate an imidacloprid treatment related significant increase ( $\uparrow$ ) or decrease $(\downarrow)$ of a variable (Williams test; $p<0.05)$. The NOEC values greater than $1 \mu \mathrm{g} / \mathrm{L}$ is marked as $>$. The shed with light grey indicates the application period of imidacloprid, while the $-\mathbf{7}$ and -1 are pre-application and $>21$ are post application periods. An - indicates that the endpoint was not evaluated on that sampling date.

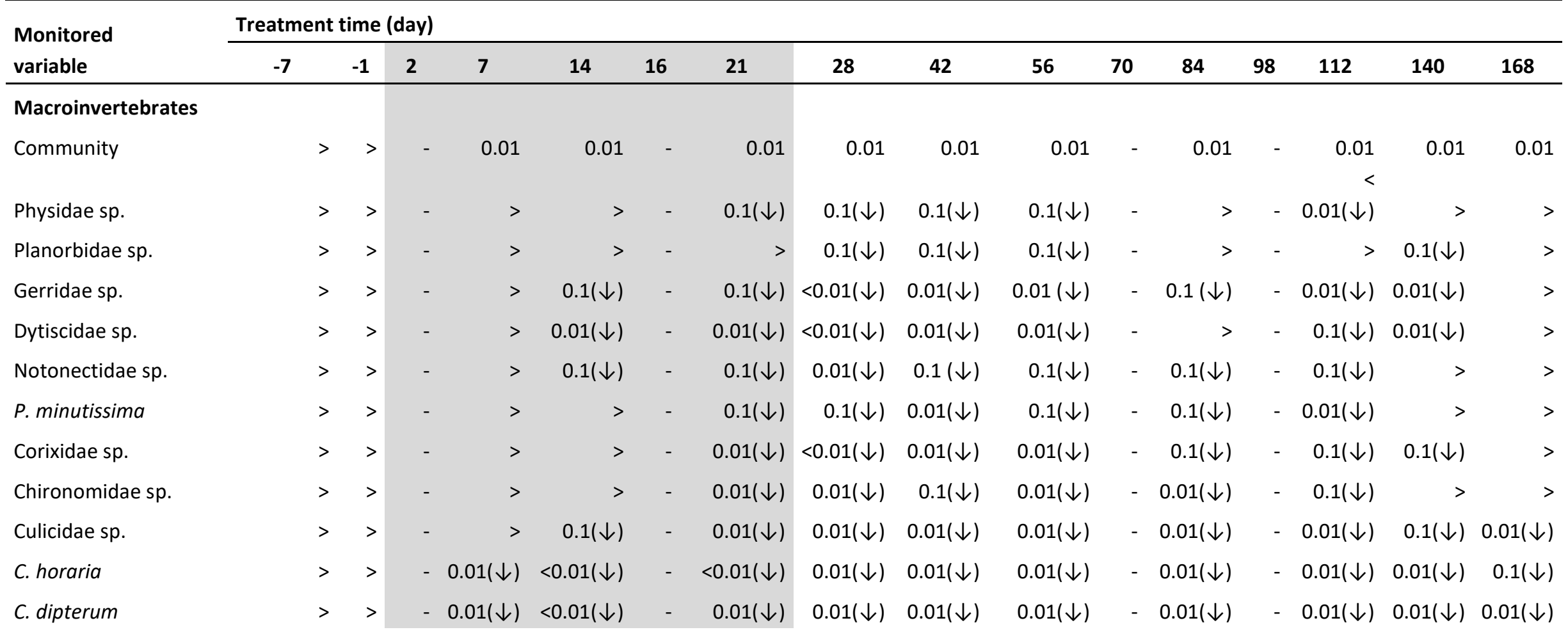

Organic matter decomposition

$\%$ weight loss

$-\quad-$

$0.1(\downarrow) \quad 0.01(\downarrow)$ 


\subsubsection{Periphyton and phytoplankton}

Chlorophyll- $a$ was measured to proximate the effect of imidacloprid on phytoplankton and periphyton communities. The mean values of chlorophyll- $a$ were $608 \pm 170 \mu \mathrm{g} / \mathrm{L}, 577 \pm 164$ $\mu \mathrm{g} / \mathrm{L}, 632 \pm 175 \mu \mathrm{g} / \mathrm{L}$ and $654 \pm 184 \mu \mathrm{g} / \mathrm{L}$ for phytoplankton, and $2.3 \pm 2.9 \mu \mathrm{g} / \mathrm{cm}^{2}, 2.8 \pm 3.4$ $\mu \mathrm{g} / \mathrm{cm}^{2}, 3.3 \pm 3.1 \mu \mathrm{g} / \mathrm{cm}^{2}$ and $3.0 \pm 2.6 \mu \mathrm{g} / \mathrm{cm}^{2}$ for periphyton in the control, $0.01,0.1$ and 1 $\mu \mathrm{g} / \mathrm{L}$ imidacloprid treatments, respectively (Fig. S16.3). Our result showed that the concentration levels of chlorophyll-a for both phytoplankton and periphyton were significantly higher in the two highest imidacloprid test concentrations (23-d NOEC of 0.01 $\mu \mathrm{g} / \mathrm{L}$ ) compared to the control and lowest treatment (Table 6.2; Fig. S16.3). The effects remained till 86 days and 84 days for phytoplankton and periphyton, respectively (Table 6.2). This can be explained by an indirect effect of imidacloprid on algae, due to a loss of grazing pressure as a result of the decrease in invertebrates (see below section 6.3.2.7).

\subsubsection{Physicochemical parameters}

Water quality variables showed no consistent effects (significant on at least two consecutive samplings), nor a consistent increasing or decreasing trend in time, except for temperature (Table 6.2; Fig. S16.2). The temperature of the cosms decreased from a mean value of $20.4{ }^{\circ} \mathrm{C}$ on day 0 of the first imidacloprid application to a mean value of $16.9{ }^{\circ} \mathrm{C}$ measured on day 140 . This trend is a result of the seasonal variation during the experimental period, as after the day 0 (31-05-2019) the wet season started which ended in September. After the wet season stopped the temperature increased to $18.6{ }^{\circ} \mathrm{C}$ on day 168 (Fig. SI6.2). The observed ranges of values for the water quality variables during the experimental period were for temperature 16.6 till $20.9^{\circ} \mathrm{C}$, DO 5.5 till $9.0 \mathrm{mg} / \mathrm{L}$, EC 215 till $331 \mu \mathrm{S} / \mathrm{cm}$, pH 7.1 till 8.7, alkalinity 1.4 till $2.1 \mathrm{meq} / \mathrm{L}$, total hardness 32 till $52 \mathrm{mg} / \mathrm{L} \mathrm{NH}_{4}{ }^{+} 0.14$ till $0.42 \mathrm{mg} / \mathrm{L} \mathrm{NO}_{3}{ }^{-}$ 0.24 till $1.04 \mathrm{mg} / \mathrm{L}$ and $\mathrm{PO}_{4}{ }^{3-} 0.01$ till $0.1 \mathrm{mg} / \mathrm{L}$ (Table SI6.7).

\subsubsection{Organic matter decomposition}

The mean (and range) values of organic matter decomposition rate (\%loss/day) were 0.63 (0.48 - 0.95), 0.60 (0.47 - 0.92), 0.59 (0.48 - 0.89) and 0.58 (0.48 - 0.91) for the control, 0.01, 0.1 and $1 \mu \mathrm{g} / \mathrm{L}$ treatment levels, respectively (see Table SI6.8). The Williams test showed that decomposition rate was significantly decreased in the highest treatment on day 28 and 42 (Table 6.3; Fig. S16.4), indicating direct or indirect effects on microbial activity of the ponds 
treated with $1 \mu \mathrm{g} / \mathrm{L}$. A single species toxicity test performed in central Europe, Slovenia (Tišler et al. 2009) evaluated the toxic effect of imidacloprid (both analytical grade and Confidor SL 200 formulation) to bacteria (Vibrio fischeri) and reported a $30 \mathrm{~min} \mathrm{IC20} \mathrm{of} 11200 \mu \mathrm{g} / \mathrm{L}$ with luminescence inhibition as endpoint. In contrast to our observation, many studies (Kreutzweiser et al., 2007; Pestana et al., 2009; Sumon et al., 2018) reported no significant effect of imidacloprid on organic matter decomposition rate and microbial activity. Our result should be validated conducting toxicity tests for the insecticide to microorganisms at climatic conditions relevant to tropical aquatic ecosystem. Recovery of the functional endpoint was observed on day 56 after the first application.

\subsubsection{Overall effect chain}

The effects of imidacloprid on structural and functional endpoints as observed in the highest treatment are summarized and depicted in Fig. 6.3. Significant direct effects of imidacloprid were measured on the abundance of several invertebrates taxa in the cosms with the highest two treatment concentration levels $(0.1$ and $1 \mu \mathrm{g} / \mathrm{L})$. The effect observed on rotifers requires further sensitivity testing to evaluate whether the observed effects should be classified as direct or indirect effect of the imidacloprid. The largest responses to the imidacloprid exposure were observed for the macroinvertebrate species $C$. dipterum, $C$. horaria and Culicidae sp. and the zooplankton taxa Brachionus sp., Filinia sp. and nauplii. The study showed an increase of chlorophyll-a concentrations of periphyton and phytoplankton in the 0.1 and $1 \mu \mathrm{g} / \mathrm{L}$ treatments, likely a indirect effect (Fleeger et al., 2003) resulting from the decrease in abundance of grazers (e.g., C. dipterum and Brachionus sp.) and scrapers (e.g., Physidae sp. and Planorbidae sp.) resulting from the direct effect of the insecticide.

Moreover, a significant effect of imidacloprid on the microbial activity was found in this study as the organic matter decomposition rate was significantly lower in the 0.1 and $1 \mu \mathrm{g} / \mathrm{L}$ treatments. So imidacloprid may affect key ecological functions (litter decomposition) mediated by microorganisms, which in turn can pose impact on nutrient cycling and energy flow in aquatic ecosystem. However, as discussed earlier, many studies (Kreutzweiser et al., 2007; Sumon et al., 2018) reported no effect of imidacloprid on microbial activity in aquatic ecosystems. Thus, further studies are needed to confirm whether our finding is a direct effect of imidacloprid or an indirect effect. 


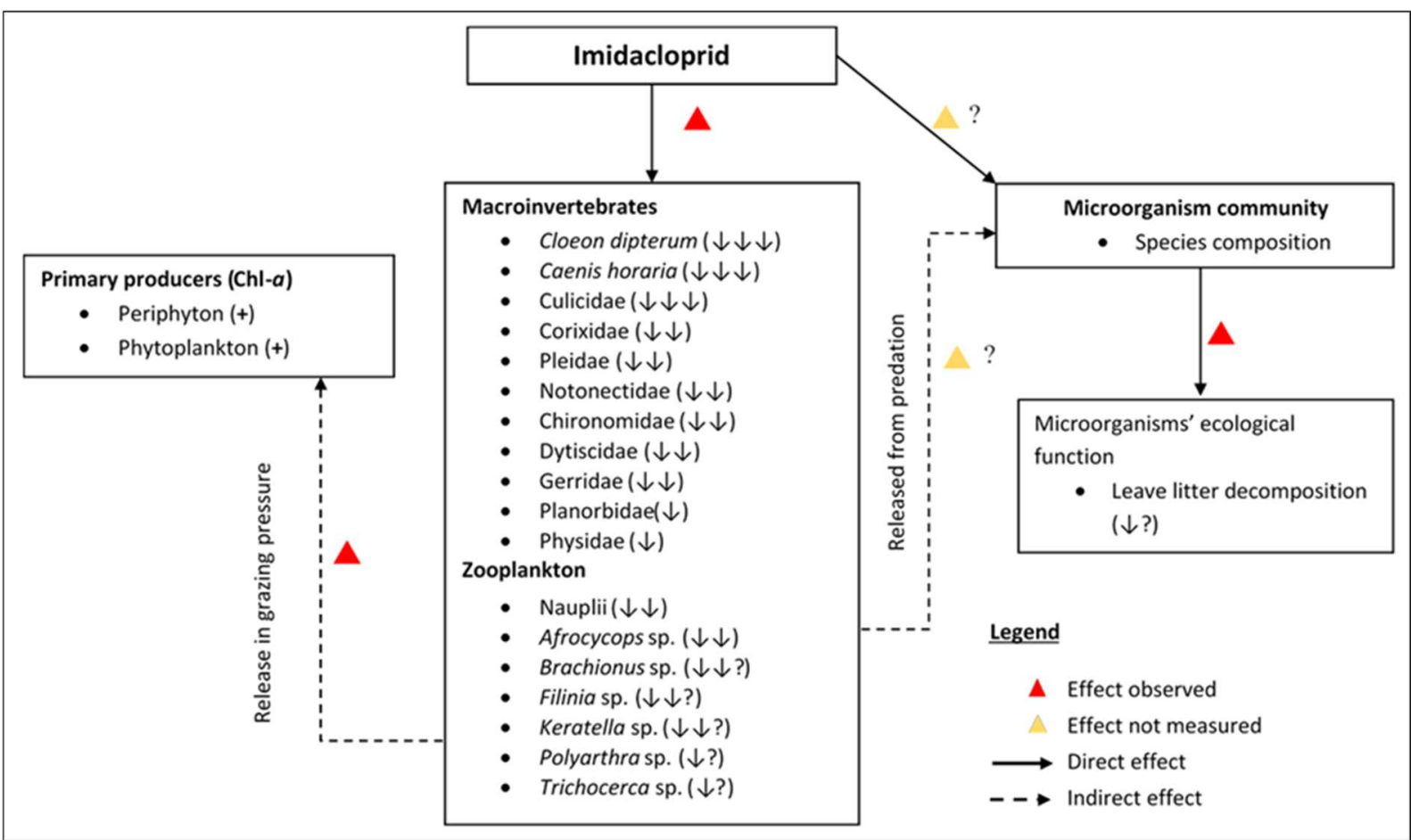

Fig. 6.3. The effect chain diagram showing the structural and functional effects of imidacloprid on structural and functional characteristics of mesocosm ecosystem established in tropical climatic condition in Ethiopia. The symbol $(\downarrow),(\downarrow ?)$ and (+) represent: decrease due to direct effect, decrease but it is unclear whether it is due to direct or indirect effects and increase, respectively.

\subsubsection{Sensitivity differences between tropical and temperate aquatic species}

In general, we observed lower effect threshold values of imidacloprid for the tropical macroinvertebrates and zooplankton communities compared to the results from temperate climatic conditions. Similar findings were reported by Sumon et al. (2018) for sub-tropical communities in Bangladesh and by Rico et al. (2018) for aquatic species from the Mediterranean climatic region. These differences in sensitivity can be a result of multiple factors.

First, the difference in temperature between tropical and temperate region can be one of the factors contributing for the differences, as water solubility of chemicals increases with temperature (thereby also increasing exposure), and increases the rate of uptake and circulation of the chemicals in the test organisms (Castillo et al., 1997; Kwok et al., 2007; Camp and Buchwalter, 2016). For example, Van den Brink et al. (2016) reported that the mortality and immobility of $C$. dipterum acutely (96-h) exposed to imidacloprid was increased by a factor of 4.2 and 1.7, respectively when the temperature of the test system was increased from 10 ${ }^{\circ} \mathrm{C}$ to $18{ }^{\circ} \mathrm{C}$ (at $10{ }^{\circ} \mathrm{C} \mathrm{LC50}=154 \mu \mathrm{g} / \mathrm{L}, \mathrm{EC} 50=31 \mu \mathrm{g} / \mathrm{L}$; at $18{ }^{\circ} \mathrm{C} \mathrm{LC} 50=37 \mu \mathrm{g} / \mathrm{L}, \mathrm{EC} 50=18 \mu \mathrm{g} / \mathrm{L}$ ). Camp and Buchwalter (2016) also reported that increasing the test temperature from $15^{\circ} \mathrm{C}$ to 
$24{ }^{\circ} \mathrm{C}$ decreased the time-to-effect (immobility endpoint) of imidacloprid by about a factor of 3 for the mayfly Isonychia bicolor. Furthermore, Macaulay et al. (2020) demonstrated synergistic effects of temperature-imidacloprid interactions on survivorship, mobility and moulting frequency of the freshwater mayflies Deleatidium sp. and Coloburiscus humeralis. The authors (Macaulay et al., 2020) reported that increasing the test water temperature from $9{ }^{\circ} \mathrm{C}$ to $15{ }^{\circ} \mathrm{C}$ reduced the mobility of the mayfly $\mathrm{C}$. humeralis by $100 \%$ when exposed for 96 hours to $12.5 \mu \mathrm{g} / \mathrm{L}$ of imidacloprid. Secondly, Van den Brink et al. (2016) reported the higher sensitivity of the reproducing summer generations of freshwater arthropods to imidacloprid compared to the overwintering generations. As most tropical aquatic arthropods reproduce continuously (Brittain, 1982; Sumon et al., 2018), this may contribute to the relatively high vulnerability of aquatic populations in the tropics, although the mechanistic pathway remains to be revealed.

Factors not related to geographical variation such as differences in formulations used can also contribute to observed differences in the field, as mixture co-formulants can increase the bioavailability of the active substance imidacloprid enhancing toxicity to aquatic species (Jemec et al., 2007; Stoughton et al., 2008; Tišler et al., 2009; Malev et al., 2012).

\subsection{Overall conclusions}

This study is the first to investigate the effect of imidacloprid on structural and functional characteristics of tropical aquatic ecosystems using single species acute toxicity tests and outdoor mesocosms. The concentrations used in our cosm studies are within the concentration range $(0.04-7.2 \mu \mathrm{g} / \mathrm{L})$ of imidacloprid previously reported for African aquatic ecosystems (Jansen and Harmsen, 2011; Curchod et al., 2020). Our results suggest that imidacloprid can pose significant adverse effects on invertebrates and organic matter decomposition in water ecosystems repeatedly exposed to $\geq 0.01 \mu \mathrm{g} / \mathrm{L}$. The study further showed that a long-term alteration of the structure of macroinvertebrate community, especially concerning mayflies and mosquitos can occur in water bodies where imidacloprid reached $\geq 0.1 \mu \mathrm{g} / \mathrm{L}$. Further to previous studies under sub-tropical (Sumon et al., 2018) and Mediterranean (Rico et al., 2018; Sumon et al., 2018) conditions our results highlight elevated sensitivity of tropical aquatic species to imidacloprid relative to their temperate counterparts. Considering our NOECcommunity values for invertebrate communities, the current water 
quality standard for imidacloprid for European waters $(0.0083 \mu \mathrm{g} / \mathrm{L})$ (Smit et al., 2015) is not likely to be protective for tropical aquatic ecosystems.

\section{Acknowledgments}

The study was financially supported by Netherlands fellowship programmes, NUFFIC/ PhD studies, grant NFP - PhD.16/0019, reference number WIMEK2015 02. Special thanks to Ambo University, Ethiopia for accessing us laboratories during the experiments. This study was cofunded by the GETREAL (Incorporating spatial and seasonal variability in community sensitivity into chemical risk assessment) project, which was funded by the European Chemical Industry Council long-range research initiative (CEFIC-LRi project ECO 50). 


\section{Appendix 6. Supplementary Information (SI)}

Table SI6.1. Water quality values (mean \pm standard deviation) for dissolved oxygen, temperature, electrical conductivity and pH parameters measured during acute single species toxicity experiment.

\begin{tabular}{|c|c|c|c|c|c|c|c|c|c|c|c|c|}
\hline \multirow[t]{2}{*}{ Species } & \multicolumn{3}{|c|}{$\mathrm{DO}$ (mg/L) } & \multicolumn{3}{|c|}{ Temperature $\left({ }^{\circ} \mathrm{C}\right)$} & \multicolumn{3}{|c|}{ Conductivity $(\mu \mathrm{s} / \mathrm{cm})$} & \multicolumn{3}{|c|}{$\mathrm{pH}$} \\
\hline & Mean \pm SD & Min. & Max. & Mean \pm SD & Min. & Max. & Mean \pm SD & Min. & Max. & Mean \pm SD & Min. & Max. \\
\hline Cloeon dipterum & $7.7 \pm 0.6$ & 6.69 & 8.73 & $20.8 \pm 0.7$ & 19.5 & 21.9 & $217.9 \pm 1.3$ & 215 & 221 & $7.4 \pm 0.2$ & 7.42 & 8.03 \\
\hline Caenis horaria & $7.9 \pm 0.6$ & 6.67 & 8.73 & $20.7 \pm 0.6$ & 19.5 & 21.8 & $217.9 \pm 1.1$ & 215 & 220 & $7.7 \pm 0.1$ & 7.51 & 7.98 \\
\hline Corixidae spp. & $8.2 \pm 0.4$ & 7.42 & 8.84 & $21.3 \pm 0.4$ & 20.4 & 21.9 & $221.8 \pm 0.9$ & 218.9 & 223 & $7.8 \pm 0.1$ & 7.61 & 7.9 \\
\hline Plea minutissima & $8.4 \pm 0.4$ & 7.51 & 8.91 & $21.9 \pm 0.2$ & 21.5 & 22.4 & $236.0 \pm 1.3$ & 233 & 238.3 & $7.8 \pm 0.1$ & 7.61 & 8.04 \\
\hline
\end{tabular}


Table S16.2. Acute toxicity effect concentration values for Cloeon dipterum, Caenis horaria, Corixidae sp. and Plea minutissima species. Lethal (a) and immobility (b) effect concentrations affecting $10 \%, 50 \%$ and $90 \%$ of the species were depicted in the table.

a. Survival, $\mathrm{LCX}(95 \% \mathrm{Cl})$ values

\begin{tabular}{lllll}
\hline LCx & Cloeon dipterum & Caenis horaria & Corixidae sp. & Plea minutissima \\
\hline 24-h LC10 & $15(8.9-25)$ & $21.5(-)$ & $17.7(8.3-37.7)$ & $177(83-377)$ \\
24-h LC50 & $28(23-34)$ & $27.5(-)$ & $32.8(25-42.5)$ & $328(253-425)$ \\
24-h LC90 & $52(31-86)$ & $34.9(-)$ & $60.7(21.4-172.6)$ & $607(214-1726)$ \\
48-h LC10 & $5.4(3.3-9.0)$ & $2.8(1.5-5.2)$ & $9.2(5.1-16.5)$ & $92(51-165)$ \\
48-h LC50 & $13(9.9-17)$ & $8.9(6.5-12.3)$ & $21.9(16.6-29.1)$ & $220(166-291)$ \\
48-h LC90 & $30(19-48)$ & $28.7(17.3-47.6)$ & $52.3(30.1-90.9)$ & $523(301-909)$ \\
72-h LC10 & $1.4(0.6-3.1)$ & $2.4(1.4-4.1)$ & $5(2.5-10)$ & $50(25-101)$ \\
72-h LC50 & $6.3(4.2-9.4)$ & $5.9(4.4-8.1)$ & $14(10-19)$ & $139(100-195)$ \\
72-h LC90 & $29.2(14-62)$ & $14.8(9.8-22.4)$ & $39(21-71)$ & $387(210-711)$ \\
$96-h$ LC10 & $0.54(0.2-1.4)$ & $1.4(0.8-2.4)$ & $1.5(0.6-4)$ & $15(5.9-40)$ \\
96-h LC50 & $2.7(1.7-4.4)$ & $3.4(2.5-4.5)$ & $6.8(4.3-11)$ & $68(43-107)$ \\
96-h LC90 & $13.7(6.8-28)$ & $8.2(5.2-13)$ & $30(15-61)$ & $299(147-606)$
\end{tabular}

b. immobility, LCx (95\% confidence interval) values

\begin{tabular}{lllll}
\hline ECx & Cloeon dipterum & Caenis horaria & Corixidae sp. & Plea minutissima \\
\hline 24-h EC10 & $15(-)$ & $9.7(7.4-13)$ & $18(6-53)$ & $179(60-530)$ \\
24-h EC50 & $15(-)$ & $15(12-19)$ & $28(24-34)$ & $286(238-345)$ \\
24-h EC90 & $17(-)$ & $24(17-34)$ & $46(18-113)$ & $458(185-1133)$ \\
48-h EC10 & $2.7(1.6-4.6)$ & $2.7(1.8-3.9)$ & $6.8(3.9-12)$ & $68(39-119)$ \\
48-h EC50 & $6(4.5-8.1)$ & $5.3(4.1-7)$ & $17(13-23)$ & $170(128-226)$ \\
48-h EC90 & $13(8.9-20)$ & $11(7.5-15)$ & $42(25-71)$ & $423(253-708)$ \\
72-h EC10 & $0.31(-)$ & $1.1(0.6-2)$ & $4.4(2.3-8.6)$ & $44(23-86)$ \\
72-h EC50 & $1.8(-)$ & $2.5(1.9-3.3)$ & $11(8.1-15)$ & $111(81-152)$ \\
72-h EC90 & $10(-)$ & $5.5(3.5-8.8)$ & $28(16-49)$ & $281(161-490)$ \\
96-h EC10 & $0.31(0.12-0.83)$ & $1.2(0.6-2.2)$ & $0.95(0.4-2.2)$ & $9.6(4.1-22)$ \\
96-h EC50 & $1.5(0.96-2.4)$ & $1.9(1.4-2.7)$ & $3.6(2.4-5.6)$ & $36(24-56)$ \\
$96-h$ EC90 & $7.6(3.7-16)$ & $3.1(2.3-4.1)$ & $14(7.6-25)$ & $139(76-254)$ \\
\hline
\end{tabular}

$\mathrm{LCx}=$ lethal concentration for $10 \%, 50 \%$ and $90 \%$; $\mathrm{ECx}=$ effective concentration for $10 \%, 50 \%$ and $90 \%$; for values with (-) confidence interval could not be calculated. 
Table S16.3. Datasets of acute toxicity test of imidacloprid to tropical freshwater insects (Cloeon dipterum, Caenis horaria, Corixidae sp. and Plea minutissima) where mortality and immobility endpoints were measured.

\begin{tabular}{|c|c|c|c|c|c|c|c|c|c|c|c|c|c|c|c|c|c|c|c|c|c|c|c|c|c|c|c|}
\hline \multicolumn{7}{|c|}{ Cloeon dipterum: Cumulative mortality } & \multicolumn{7}{|c|}{ Caenis horaria: Cumulative mortality } & \multicolumn{7}{|c|}{ Corixidae sp.: Cumulative mortality } & \multicolumn{7}{|c|}{ Plea minutissima: Cumulative mortality } \\
\hline $\begin{array}{l}\text { Con. } \\
(\mu \mathrm{g} / \mathrm{L})\end{array}$ & $\begin{array}{l}\text { Initial } \\
\text { (\#) }\end{array}$ & $\begin{array}{l}0- \\
d\end{array}$ & $\begin{array}{l}1- \\
\text { d }\end{array}$ & $\begin{array}{l}2- \\
\text { d }\end{array}$ & $\begin{array}{l}\text { 3- } \\
\text { d }\end{array}$ & $\begin{array}{l}\text { 4- } \\
\text { d }\end{array}$ & $\begin{array}{l}\text { Con. } \\
(\mu \mathrm{g} / \mathrm{L})\end{array}$ & $\begin{array}{l}\text { Initial } \\
\text { (\#) }\end{array}$ & $\begin{array}{l}0- \\
d\end{array}$ & $\begin{array}{l}1- \\
\text { d }\end{array}$ & $\begin{array}{l}2- \\
d\end{array}$ & $\begin{array}{l}\text { 3- } \\
\text { d }\end{array}$ & $\begin{array}{l}\text { 4- } \\
\text { d }\end{array}$ & $\begin{array}{l}\text { Con. } \\
(\mu \mathrm{g} / \mathrm{L})\end{array}$ & $\begin{array}{l}\text { Initial } \\
\text { (\#) }\end{array}$ & $\begin{array}{l}0- \\
d\end{array}$ & $\begin{array}{l}1- \\
d\end{array}$ & $\begin{array}{l}2- \\
\text { d }\end{array}$ & $\begin{array}{l}3- \\
d\end{array}$ & $\begin{array}{l}\text { 4- } \\
\text { d }\end{array}$ & $\begin{array}{l}\text { Con. } \\
(\mu \mathrm{g} / \mathrm{L})\end{array}$ & $\begin{array}{l}\text { Initial } \\
\text { (\#) }\end{array}$ & $\begin{array}{l}0- \\
\text { d }\end{array}$ & $\begin{array}{l}\text { 1- } \\
\text { d }\end{array}$ & $\begin{array}{l}2- \\
\text { d }\end{array}$ & $\begin{array}{l}\text { 3- } \\
\text { d }\end{array}$ & $\begin{array}{l}\text { 4- } \\
\text { d }\end{array}$ \\
\hline 0 & 10 & 0 & 0 & 0 & 0 & 1 & 0 & 10 & 0 & 0 & 0 & 0 & 0 & 0 & 10 & 0 & 0 & 0 & 2 & 2 & 0 & 10 & 0 & 0 & 0 & 2 & 2 \\
\hline 0 & 10 & 0 & 0 & 0 & 0 & 0 & 0 & 10 & 0 & 0 & 0 & 0 & 1 & 0 & 10 & 0 & 0 & 0 & 0 & 1 & 0 & 10 & 0 & 0 & 0 & 0 & 1 \\
\hline 0 & 10 & 0 & 0 & 0 & 0 & 1 & 0 & 10 & 0 & 0 & 0 & 1 & 1 & 0 & 10 & 0 & 0 & 1 & 1 & 2 & 0 & 10 & 0 & 0 & 1 & 1 & 2 \\
\hline 0.1 & 10 & 0 & 0 & 0 & 0 & 0 & 0.1 & 10 & 0 & 0 & 0 & 1 & 1 & 0.1 & 10 & 0 & 0 & 0 & 0 & 0 & 1 & 10 & 0 & 0 & 0 & 0 & 0 \\
\hline 0.1 & 10 & 0 & 0 & 1 & 1 & 2 & 0.1 & 10 & 0 & 0 & 0 & 1 & 2 & 0.1 & 10 & 0 & 0 & 0 & 0 & 1 & 1 & 10 & 0 & 0 & 0 & 0 & 1 \\
\hline 0.1 & 10 & 0 & 0 & 0 & 0 & 1 & 0.1 & 10 & 0 & 0 & 0 & 0 & 0 & 0.1 & 10 & 0 & 1 & 1 & 1 & 1 & 1 & 10 & 0 & 1 & 1 & 1 & 1 \\
\hline 0.3 & 10 & 0 & 0 & 0 & 1 & 3 & 0.3 & 10 & 0 & 1 & 1 & 1 & 0 & 0.3 & 10 & 0 & 0 & 1 & 1 & 1 & 3 & 10 & 0 & 0 & 1 & 1 & 1 \\
\hline 0.3 & 10 & 0 & 0 & 0 & 0 & 0 & 0.3 & 10 & 0 & 0 & 1 & 1 & 1 & 0.3 & 10 & 0 & 1 & 1 & 2 & 2 & 3 & 10 & 0 & 1 & 1 & 2 & 2 \\
\hline 0.3 & 10 & 0 & 0 & 0 & 2 & 3 & 0.3 & 10 & 0 & 0 & 0 & 0 & 1 & 0.3 & 10 & 0 & 0 & 0 & 1 & 2 & 3 & 10 & 0 & 0 & 0 & 1 & 2 \\
\hline 1 & 10 & 0 & 1 & 1 & 2 & 4 & 1 & 10 & 0 & 0 & 0 & 0 & 1 & 1 & 10 & 0 & 0 & 1 & 1 & 1 & 10 & 10 & 0 & 0 & 1 & 1 & 1 \\
\hline 1 & 10 & 0 & 0 & 0 & 0 & 2 & 1 & 10 & 0 & 0 & 0 & 0 & 0 & 1 & 10 & 0 & 0 & 1 & 1 & 2 & 10 & 10 & 0 & 0 & 1 & 1 & 2 \\
\hline 1 & 10 & 0 & 0 & 1 & 2 & 2 & 1 & 10 & 0 & 0 & 0 & 0 & 0 & 1 & 10 & 0 & 0 & 0 & 1 & 1 & 10 & 10 & 0 & 0 & 0 & 1 & 1 \\
\hline 3 & 10 & 0 & 0 & 1 & 3 & 5 & 3 & 10 & 0 & 1 & 1 & 2 & 6 & 3 & 10 & 0 & 1 & 1 & 2 & 3 & 30 & 10 & 0 & 1 & 1 & 2 & 3 \\
\hline 3 & 10 & 0 & 0 & 0 & 2 & 6 & 3 & 10 & 0 & 0 & 0 & 2 & 5 & 3 & 10 & 0 & 0 & 0 & 1 & 3 & 30 & 10 & 0 & 0 & 0 & 1 & 3 \\
\hline 3 & 10 & 0 & 0 & 0 & 4 & 6 & 3 & 10 & 0 & 0 & 1 & 1 & 4 & 3 & 10 & 0 & 0 & 0 & 2 & 4 & 30 & 10 & 0 & 0 & 0 & 2 & 4 \\
\hline 10 & 10 & 0 & 1 & 3 & 5 & 9 & 10 & 10 & 0 & 0 & 7 & 9 & 9 & 10 & 10 & 0 & 1 & 2 & 3 & 6 & 100 & 10 & 0 & 1 & 2 & 3 & 6 \\
\hline 10 & 10 & 0 & 0 & 4 & 6 & 7 & 10 & 10 & 0 & 0 & 8 & 9 & 10 & 10 & 10 & 0 & 0 & 1 & 4 & 7 & 100 & 10 & 0 & 0 & 1 & 4 & 7 \\
\hline 10 & 10 & 0 & 0 & 4 & 5 & 9 & 10 & 10 & 0 & 0 & 6 & 8 & 10 & 10 & 10 & 0 & 0 & 2 & 4 & 8 & 100 & 10 & 0 & 0 & 2 & 4 & 8 \\
\hline 30 & 10 & 0 & 5 & 9 & 10 & 10 & 30 & 10 & 0 & 7 & 7 & 8 & 9 & 30 & 10 & 0 & 4 & 8 & 10 & 10 & 300 & 10 & 0 & 4 & 8 & 10 & 10 \\
\hline 30 & 10 & 0 & 6 & 10 & 10 & 10 & 30 & 10 & 0 & 6 & 9 & 10 & 10 & 30 & 10 & 0 & 4 & 6 & 7 & 8 & 300 & 10 & 0 & 4 & 6 & 7 & 8 \\
\hline 30 & 10 & 0 & 6 & 8 & 10 & 10 & 30 & 10 & 0 & 8 & 9 & 10 & 10 & 30 & 10 & 0 & 5 & 7 & 9 & 9 & 300 & 10 & 0 & 5 & 7 & 9 & 9 \\
\hline
\end{tabular}


Table S16.3: Cont'd

\begin{tabular}{|c|c|c|c|c|c|c|c|c|c|c|c|c|c|c|c|c|c|c|c|c|c|c|c|c|c|c|c|}
\hline \multicolumn{7}{|c|}{ Cloeon dipterum: Cumulative Immobility } & \multicolumn{7}{|c|}{ Caenis horaria: Cumulative Immobility } & \multicolumn{7}{|c|}{ Corixidae sp.: Cumulative Immobility } & \multicolumn{7}{|c|}{ Plea minutissima: Cumulative Immobility } \\
\hline $\begin{array}{l}\text { Con. } \\
(\mu \mathrm{g} / \mathrm{L})\end{array}$ & $\begin{array}{l}\text { Initial } \\
\text { (\#) }\end{array}$ & $\begin{array}{l}0- \\
\text { d }\end{array}$ & $\begin{array}{l}\text { 1- } \\
\text { d }\end{array}$ & $\begin{array}{l}2- \\
d\end{array}$ & $\begin{array}{l}\text { 3- } \\
\text { d }\end{array}$ & $\begin{array}{l}\text { 4- } \\
\text { d }\end{array}$ & $\begin{array}{l}\text { Con. } \\
(\mu \mathrm{g} / \mathrm{L})\end{array}$ & $\begin{array}{l}\text { Initial } \\
\text { (\#) }\end{array}$ & $\begin{array}{l}0- \\
d\end{array}$ & $\begin{array}{l}\text { 1- } \\
\text { d }\end{array}$ & $\begin{array}{l}2- \\
\text { d }\end{array}$ & $\begin{array}{l}\text { 3- } \\
\text { d }\end{array}$ & $\begin{array}{l}\text { 4- } \\
\text { d }\end{array}$ & $\begin{array}{l}\text { Con. } \\
(\mu \mathrm{g} / \mathrm{L})\end{array}$ & $\begin{array}{l}\text { Initial } \\
\text { (\#) }\end{array}$ & $\begin{array}{l}0- \\
\text { d }\end{array}$ & $\begin{array}{l}1- \\
\text { d }\end{array}$ & $\begin{array}{l}2- \\
\text { d }\end{array}$ & $\begin{array}{l}3- \\
\text { d }\end{array}$ & $\begin{array}{l}\text { 4- } \\
\text { d }\end{array}$ & $\begin{array}{l}\text { Con. } \\
(\mu \mathrm{g} / \mathrm{L})\end{array}$ & $\begin{array}{l}\text { Initial } \\
\text { (\#) }\end{array}$ & $\begin{array}{l}0- \\
\text { d }\end{array}$ & $\begin{array}{l}\text { 1- } \\
\text { d }\end{array}$ & $\begin{array}{l}2- \\
\text { d }\end{array}$ & $\begin{array}{l}\text { 3- } \\
\text { d }\end{array}$ & $\begin{array}{l}\text { 4- } \\
\text { d }\end{array}$ \\
\hline 0 & 10 & 0 & 0 & 0 & 0 & 1 & 0 & 10 & 0 & 0 & 0 & 0 & 0 & 0 & 10 & 0 & 0 & 0 & 2 & 2 & 0 & 10 & 0 & 0 & 0 & 2 & 2 \\
\hline 0 & 10 & 0 & 0 & 0 & 0 & 0 & 0 & 10 & 0 & 0 & 0 & 0 & 1 & 0 & 10 & 0 & 0 & 0 & 0 & 1 & 0 & 10 & 0 & 0 & 0 & 0 & 1 \\
\hline 0 & 10 & 0 & 0 & 0 & 0 & 1 & 0 & 10 & 0 & 0 & 0 & 1 & 1 & 0 & 10 & 0 & 0 & 1 & 1 & 2 & 0 & 10 & 0 & 0 & 1 & 1 & 2 \\
\hline 0.1 & 10 & 0 & 0 & 0 & 0 & 0 & 0.1 & 10 & 0 & 0 & 0 & 1 & 1 & 0.1 & 10 & 0 & 0 & 0 & 0 & 0 & 1 & 10 & 0 & 0 & 0 & 0 & 0 \\
\hline 0.1 & 10 & 0 & 0 & 1 & 1 & 2 & 0.1 & 10 & 0 & 0 & 0 & 1 & 2 & 0.1 & 10 & 0 & 0 & 0 & 0 & 1 & 1 & 10 & 0 & 0 & 0 & 0 & 1 \\
\hline 0.1 & 10 & 0 & 0 & 0 & 0 & 1 & 0.1 & 10 & 0 & 0 & 0 & 0 & 0 & 0.1 & 10 & 0 & 1 & 1 & 1 & 1 & 1 & 10 & 0 & 1 & 1 & 1 & 1 \\
\hline 0.3 & 10 & 0 & 0 & 0 & 2 & 3 & 0.3 & 10 & 0 & 1 & 1 & 1 & 0 & 0.3 & 10 & 0 & 0 & 1 & 1 & 1 & 3 & 10 & 0 & 0 & 1 & 1 & 1 \\
\hline 0.3 & 10 & 0 & 0 & 1 & 1 & 2 & 0.3 & 10 & 0 & 0 & 1 & 1 & 1 & 0.3 & 10 & 0 & 1 & 1 & 2 & 2 & 3 & 10 & 0 & 1 & 1 & 2 & 2 \\
\hline 0.3 & 10 & 0 & 1 & 1 & 3 & 3 & 0.3 & 10 & 0 & 0 & 0 & 0 & 2 & 0.3 & 10 & 0 & 0 & 0 & 1 & 2 & 3 & 10 & 0 & 0 & 0 & 1 & 2 \\
\hline 1 & 10 & 0 & 1 & 2 & 3 & 4 & 1 & 10 & 0 & 0 & 0 & 1 & 2 & 1 & 10 & 0 & 0 & 1 & 1 & 2 & 10 & 10 & 0 & 0 & 1 & 1 & 2 \\
\hline 1 & 10 & 0 & 1 & 1 & 2 & 4 & 1 & 10 & 0 & 0 & 0 & 2 & 1 & 1 & 10 & 0 & 0 & 1 & 1 & 2 & 10 & 10 & 0 & 0 & 1 & 1 & 2 \\
\hline 1 & 10 & 0 & 1 & 1 & 3 & 5 & 1 & 10 & 0 & 0 & 0 & 2 & 1 & 1 & 10 & 0 & 0 & 0 & 1 & 2 & 10 & 10 & 0 & 0 & 0 & 1 & 2 \\
\hline 3 & 10 & 0 & 1 & 3 & 5 & 6 & 3 & 10 & 0 & 1 & 2 & 7 & 10 & 3 & 10 & 0 & 1 & 1 & 2 & 5 & 30 & 10 & 0 & 1 & 1 & 2 & 5 \\
\hline 3 & 10 & 0 & 1 & 1 & 4 & 6 & 3 & 10 & 0 & 1 & 1 & 6 & 9 & 3 & 10 & 0 & 0 & 0 & 1 & 4 & 30 & 10 & 0 & 0 & 0 & 1 & 4 \\
\hline 3 & 10 & 0 & 1 & 1 & 5 & 6 & 3 & 10 & 0 & 1 & 1 & 5 & 8 & 3 & 10 & 0 & 1 & 0 & 2 & 6 & 30 & 10 & 0 & 1 & 0 & 2 & 6 \\
\hline 10 & 10 & 0 & 1 & 7 & 10 & 10 & 10 & 10 & 0 & 2 & 9 & 10 & 10 & 10 & 10 & 0 & 1 & 3 & 4 & 9 & 100 & 10 & 0 & 1 & 3 & 4 & 9 \\
\hline 10 & 10 & 0 & 0 & 9 & 10 & 10 & 10 & 10 & 0 & 1 & 10 & 10 & 10 & 10 & 10 & 0 & 0 & 2 & 5 & 8 & 100 & 10 & 0 & 0 & 2 & 5 & 8 \\
\hline 10 & 10 & 0 & 0 & 8 & 10 & 10 & 10 & 10 & 0 & 1 & 9 & 10 & 10 & 10 & 10 & 0 & 0 & 3 & 5 & 9 & 100 & 10 & 0 & 0 & 3 & 5 & 9 \\
\hline 30 & 10 & 0 & 10 & 10 & 10 & 10 & 30 & 10 & 0 & 9 & 9 & 10 & 10 & 30 & 10 & 0 & 6 & 9 & 10 & 10 & 300 & 10 & 0 & 6 & 9 & 10 & 10 \\
\hline 30 & 10 & 0 & 10 & 10 & 10 & 10 & 30 & 10 & 0 & 10 & 10 & 10 & 10 & 30 & 10 & 0 & 5 & 7 & 8 & 9 & 300 & 10 & 0 & 5 & 7 & 8 & 9 \\
\hline 30 & 10 & 0 & 10 & 10 & 10 & 10 & 30 & 10 & 0 & 10 & 10 & 10 & 10 & 30 & 10 & 0 & 6 & 8 & 10 & 10 & 300 & 10 & 0 & 6 & 8 & 10 & 10 \\
\hline
\end{tabular}


Table S16.4. Single species toxicity test effect values (96-h L(E)C50 with survival and immobility endpoints) based on literature and this study for the species from order Ephemeroptera and Hemiptera.

\begin{tabular}{|c|c|c|c|c|c|}
\hline Tested Species & $\begin{array}{c}\text { Geographical } \\
\text { origin } \\
\text { of test species }\end{array}$ & $\begin{array}{c}\text { Laboratory } \\
\text { cultured/ } \\
\text { field collected }\end{array}$ & $\begin{array}{l}\text { 96-h LC50 } \\
\text { (Cl; } \mu \mathrm{g} / \mathrm{L})\end{array}$ & $\begin{array}{l}\text { 96-h EC50 } \\
\text { (Cl; } \mu \mathrm{g} / \mathrm{L})\end{array}$ & Reference \\
\hline Cloeon dipterum & $\begin{array}{l}\text { Temperate } \\
\text { (SG) }\end{array}$ & Field collected & $26.3(17.7-39.1)$ & $1.0(0.46-2.3)$ & Roessink et al. 2013 \\
\hline Cloeon dipterum & $\begin{array}{l}\text { Temperate } \\
\text { (WG) }\end{array}$ & Field collected & $34(27-44)$ & $25(-)$ & Van den Brink et al. 2016 \\
\hline Cloeon sp. & $\begin{array}{l}\text { Temperate } \\
\text { (WG) }\end{array}$ & Field collected & $\begin{array}{r}1152(513.1- \\
1790.8)\end{array}$ & $23.1(16.2-33.2)$ & Raby et al. 2018 \\
\hline Cloeon sp. & Sub-tropical & Field collected & $\begin{array}{r}0.024(0.008- \\
0.07)\end{array}$ & $\begin{array}{r}0.0055(0.002- \\
0.017)\end{array}$ & Sumon et al. 2018 \\
\hline Cloeon dipterum & Tropical & Field collected & $2.7(1.7-4.3)$ & $1.5(0.96-2.4)$ & This study \\
\hline Caenis horaria & $\begin{array}{l}\text { Temperate } \\
\text { (SG) }\end{array}$ & Field collected & $6.68(4.19-10.6)$ & $1.8(1.1-3.0)$ & Roessink et al. 2013 \\
\hline Caenis horaria & $\begin{array}{l}\text { Temperate } \\
\text { (WG) }\end{array}$ & Field collected & $28(25-32)$ & $6.0(4.6-7.6)$ & Van den Brink et al. 2016 \\
\hline Caenis sp. & $\begin{array}{l}\text { Temperate } \\
\text { (WG) }\end{array}$ & Field collected & $<21.8$ & $<21.8$ & Raby et al. 2018 \\
\hline Caenis horaria & Tropical & Field collected & $3.4(2.5-4.5)$ & $1.9(1.4-2.7)$ & This study \\
\hline Micronecta sp. & $\begin{array}{l}\text { Temperate } \\
\text { (SG) }\end{array}$ & Field collected & $28.2(17.6-45.2)$ & $10.8(9.72-12.0)$ & Roessink et al. 2013 \\
\hline Trichocorixa sp. & $\begin{array}{l}\text { Temperate } \\
\text { (WG) }\end{array}$ & Field collected & $450(274-627)$ & $63.1(44.6-89.2)$ & Raby et al. 2018 \\
\hline Corixidae sp. & Tropical & Field collected & $6.8(4.3-11)$ & $3.6(2.4-5.6)$ & This study \\
\hline Plea minutissima & $\begin{array}{l}\text { Temperate } \\
\text { (SG) }\end{array}$ & Field collected & $37.5(-)$ & $36(31-42)$ & Roessink et al. 2013 \\
\hline Plea minutissima & $\begin{array}{l}\text { Temperate } \\
\text { (WG) }\end{array}$ & Field collected & $287(-)$ & $189(-)$ & Van den Brink et al. 2016 \\
\hline Plea minutissima & Tropical & Field collected & $68(43-107)$ & $36(24-56)$ & This study \\
\hline
\end{tabular}

Note: SG = summer generations, WG = winter generations, Cl confidence interval (95\%) 
Table SI6.5. Characteristics, experimental setups (a), and estimated effect thresholds for zooplankton and macroinvertebrate communities (b) reported in literature using cosm studies.

\begin{tabular}{|c|c|c|c|c|c|c|}
\hline \multicolumn{7}{|c|}{ a. Characteristics and experimental setups of cosm studies } \\
\hline Location & $\begin{array}{l}\text { Concentration } \\
\text { range }(\mu \mathrm{g} / \mathrm{L})\end{array}$ & $\begin{array}{l}\text { Pond } \\
\text { type }\end{array}$ & $\begin{array}{l}\text { No. of } \\
\text { application }\end{array}$ & $\begin{array}{l}\text { Application } \\
\text { interval } \\
\text { (day) }\end{array}$ & $\begin{array}{l}\text { Cosm } \\
\text { temperature } \\
\left({ }^{\circ} \mathrm{C}\right)\end{array}$ & References \\
\hline Canada & $0,0.1,0.5,1$ & stream & $\begin{array}{l}\text { Several } \\
\text { times }\end{array}$ & $\begin{array}{l}\text { Every } 7 \\
\text { minutes } \\
\text { with water } \\
\text { exchange }\end{array}$ & not reported & $\begin{array}{l}\text { Alexander et al. } \\
2008\end{array}$ \\
\hline Canada & $0,2,20$ & stream & $\begin{array}{l}3 \text { times } \\
\text { pulse for } 24 \\
\text { hours }\end{array}$ & 7 & $14.5-14.9$ & $\begin{array}{l}\text { Pestana et al. } \\
2009\end{array}$ \\
\hline Japan & 49 & $\begin{array}{l}\text { rice } \\
\text { paddy }\end{array}$ & once & - & not reported & $\begin{array}{l}\text { Hayasaka et al. } \\
2012 a\end{array}$ \\
\hline Germany & $\begin{array}{l}0,0.6,1.4,3.2 \\
7.5,17.3,40\end{array}$ & pond & 3 times & 7 & $17-21$ & $\begin{array}{l}\text { Colombo et al. } \\
2013\end{array}$ \\
\hline Portugal & 60 & $\begin{array}{l}\text { rice } \\
\text { paddy }\end{array}$ & once & - & $20-31$ & $\begin{array}{l}\text { Pereira et al. } \\
2017\end{array}$ \\
\hline Japan & 157 & $\begin{array}{l}\text { rice } \\
\text { paddy }\end{array}$ & once & - & not reported & $\begin{array}{l}\text { Kobashi et al., } \\
2017\end{array}$ \\
\hline Bangladesh & $0,0.03,0.3,3$ & Pond & 4 times & 7 & $24.3-31.7$ & $\begin{array}{l}\text { Sumon et al. } \\
2018\end{array}$ \\
\hline Spain & $\begin{array}{l}0,0.2,1,5,25 \\
250\end{array}$ & Pond & Once & - & $16-25$ & Rico et al. 2018 \\
\hline Ethiopia & $0,0.01,0.1,1$ & Pond & 4 times & 7 & $16.6-20.9$ & This study \\
\hline \multicolumn{7}{|c|}{ b. Estimated effect threshold values and recovery period for zooplankton and macroinvertebrate communities } \\
\hline Variable & $\begin{array}{l}\text { Estimated } \\
\text { effect threshold }\end{array}$ & $\begin{array}{l}\text { NOEC } \\
(\mu \mathrm{g} / \mathrm{L}) \\
\end{array}$ & Recovery tim & & & References \\
\hline \multirow{4}{*}{$\begin{array}{l}\text { Zooplankton } \\
\text { community }\end{array}$} & 56-NOEC & $<1$ & \multicolumn{3}{|c|}{16 Weeks (112 days) } & $\begin{array}{l}\text { Hayasaka et al. } \\
2012\end{array}$ \\
\hline & 28-d NOEC & 0.03 & \multicolumn{3}{|c|}{ no recovery studied } & $\begin{array}{l}\text { Sumon et al. } \\
2018\end{array}$ \\
\hline & 42-d NOEC & 5 & \multirow{2}{*}{\multicolumn{3}{|c|}{$\begin{array}{l}56 \text { days } \\
\text { after } 86 \text { days of the } \\
\text { first imidacloprid application }\end{array}$}} & Rico et al. 2018 \\
\hline & 30-d NOEC & $<0.01$ & & & & This study \\
\hline \multirow{8}{*}{$\begin{array}{l}\text { Macroinvertebrate } \\
\text { community }\end{array}$} & 20-d NOEC & 1.63 & \multicolumn{3}{|c|}{ Not studied } & $\begin{array}{l}\text { Pestana et al. } \\
2009\end{array}$ \\
\hline & 28-d NOEC & $<49$ & \multicolumn{3}{|c|}{$>$ Four months } & $\begin{array}{l}\text { Hayasaka et al., } \\
2012\end{array}$ \\
\hline & 49-d NOEC & $2.3^{* *}$ & \multicolumn{3}{|l|}{ Not studied } & $\begin{array}{l}\text { Colombo et al. } \\
2013\end{array}$ \\
\hline & 140-d NOEC & 157 & \multicolumn{3}{|l|}{ not reported } & $\begin{array}{l}\text { Kobashi et al., } \\
2017\end{array}$ \\
\hline & 30-d NOEC & $<60$ & \multicolumn{3}{|c|}{$\begin{array}{l}\text { not recovered within study } \\
\text { period ( i.e., }>28 \text { days) }\end{array}$} & $\begin{array}{l}\text { Pereira et al. } \\
2017\end{array}$ \\
\hline & 28-d NOEC & 0.3 & \multicolumn{3}{|l|}{ not studied } & $\begin{array}{l}\text { Sumon et al. } \\
2018\end{array}$ \\
\hline & 28-d NOEC & 1 & \multicolumn{3}{|l|}{56 days } & Rico et al. 2018 \\
\hline & 168-d NOEC & 0.01 & \multicolumn{3}{|c|}{$\begin{array}{l}\text { not recovered within study } \\
\text { period ( i.e., }>5 \text { months) }\end{array}$} & This study \\
\hline
\end{tabular}


Table SI6.6. Estimated effect thresholds for zooplankton (a) and macroinvertebrate (b) species as reported in literature using cosm studies.

\begin{tabular}{|c|c|c|c|}
\hline Variables & $\begin{array}{l}\text { Estimated effect } \\
\text { threshold }\end{array}$ & NOEC $(\mu \mathrm{g} / \mathrm{L})$ & References \\
\hline \multicolumn{4}{|l|}{ a. Zooplanktons } \\
\hline Diaptomus sp. & 16-d NOEC & $<0.03$ & Sumon et al. 2018 \\
\hline Keratella sp. & 9-d NOEC & $<0.03$ & Sumon et al. 2018 \\
\hline Keratella quadrata & 42-d NOEC & 1 & Rico et al. 2018 \\
\hline Keratella sp. & 44-d NOEC & 0.01 & This study \\
\hline Polyarthra sp. & 16-d NOEC & $<0.03$ & Sumon et al. 2018 \\
\hline Polyarthra sp. & 9-d NOEC & $<0.01$ & This study \\
\hline Brachionus sp. & 28-d NOEC & 0.03 & Sumon et al. 2018 \\
\hline Brachionus calyciflorus & 10-NOEC & $6220^{*}$ & Gharaei et al., 2020 \\
\hline Brachionus sp. & 23-d NOEC & $<0.01$ & This study \\
\hline Filinia sp. & 23-d NOEC & 0.3 & Sumon et al. 2018 \\
\hline Filinia sp. & 58-d NOEC & $<0.01$ & This study \\
\hline Trichocerca sp. & 23-d NOEC & 0.3 & Sumon et al. 2018 \\
\hline Trichocerca sp. & 23-d NOEC & $<0.01$ & This study \\
\hline Cyclops sp. & 9-d NOEC & 0.3 & Sumon et al. 2018 \\
\hline Cyclopoida & 17-d NOEC & 1 & Rico et al. 2018 \\
\hline Afrocyclops sp. & 30-d NOEC & $<0.01$ & This study \\
\hline Nauplius & 9-d NOEC & 0.03 & Sumon et al. 2018 \\
\hline Naupulii & 3-d NOEC & 5 & Rico et al. 2018 \\
\hline Naupulii & 23-d NOEC & $<0.01$ & This study \\
\hline \multicolumn{4}{|l|}{ b. Macroinvertebrates } \\
\hline Epeorus sp. & 20-d NOEC & 0.3 & Alexander et al. 2008 \\
\hline Cloeon dipterum & 28-d EC10 & $0.033^{*}$ & Roessink et al. 2013 \\
\hline Cloeon sp. & 9-d NOEC & $<0.03$ & Sumon et al. 2018 \\
\hline Cloeon dipterum & 28-d NOEC & $<0.09$ & Rico et al. 2018 \\
\hline Cloeon dipterum & 14-d NOEC & $<0.01$ & This study \\
\hline Caenis sp. & 49-d NOEC & $2.3^{* *}$ & Colombo et al. 2013 \\
\hline Caenis horaria & 28-EC10 & $0.024 *$ & Roessink et al. 2013 \\
\hline Caenis horaria & 14-d NOEC & $<0.01$ & This study \\
\hline Chironomidae sp. & 49-d NOEC & $5.2^{* *}$ & Colombo et al. 2013 \\
\hline Chironomus dilutus & 14-d LC20 & $0.47^{*}$ & Cavallaro et al. 2017 \\
\hline Chironomus riparius & $10-d$ LC10 & $1.64 *$ & Chandran et al., 2018 \\
\hline Chironomid larvae & 28-d NOEC & 0.3 & Sumon et al. 2018 \\
\hline Chironomini & 10-d NOEC & $<0.2$ & Rico et al. 2018 \\
\hline Chironomidae sp. & 28-d NOEC & 0.01 & This study \\
\hline Culicidae sp. & 28-d NOEC & 0.01 & This study \\
\hline Notonecta tiguttata & 140-d NOEC & 157 & Kobashi et al., 2017 \\
\hline Notonecta sp. & 16-d NOEC & 0.03 & Sumon et al. 2018 \\
\hline Notonectidae sp. & 28-d NOEC & 0.01 & This study \\
\hline Corixidae sp. & 28-d NOEC & $<0.01$ & This study \\
\hline Gerris sp. & 16-d NOEC & 0.03 & Sumon et al. 2018 \\
\hline Gerris latiabdominis & 120-d NOEC & 49 & Hayasaka et al., 2012 \\
\hline Gerridae sp. & 28-d NOEC & $<0.01$ & This study \\
\hline Plea minutissima & 28-d LC10 & $2.03 *$ & Roessink et al. 2013 \\
\hline Plea minutissima & 42-d NOEC & 0.01 & This study \\
\hline Hydaticus sp. (Dytiscidae family) & 28-d NOEC & $<60$ & Pereira et al. 2017 \\
\hline Dytiscidae sp. & 28-d NOEC & $<0.01$ & This study \\
\hline Planorbella pilsbryi & 28-d EC10 & $15.4^{*}$ & Prosser et al. (2016) \\
\hline Physidae sp. & 28-d NOEC & 0.1 & This study \\
\hline Planorbidae sp. & 28-d NOEC & 0.1 & This study \\
\hline
\end{tabular}

** indicates Time Weighted average (TWA) values, and * indicates single species toxicity test values 
Table S16.7. Water quality values (mean (minimum - maximum)) for dissolved oxygen, temperature, conductivity, pH, alkalinity, total hardness, ammonia, nitrate and phosphate parameters of the cosms measured during experimental period.

\begin{tabular}{|c|c|c|c|c|c|c|c|c|c|}
\hline Treatment & $\begin{array}{l}\text { Temperature } \\
\left({ }^{\circ} \mathrm{C}\right)\end{array}$ & $\mathrm{DO}$ (mg/L) & $\begin{array}{l}\text { Conductivity } \\
(\mu \mathrm{S} / \mathrm{cm})\end{array}$ & $\mathrm{pH}$ & $\begin{array}{l}\text { Alkalinity } \\
\text { (meq/L) }\end{array}$ & $\begin{array}{l}\text { Total hardness } \\
\text { (mg/L) }\end{array}$ & $\begin{array}{l}\text { Ammonia } \\
\text { (mg/L) }\end{array}$ & Nitrate (mg/L) & $\begin{array}{l}\text { Phosphate } \\
\text { (mg/L) }\end{array}$ \\
\hline Control & $18.9(17-20.9)$ & $7.04(6.1$ - 9.05) & $287(254-331)$ & $7.9(7.2-8.4)$ & $1.7(1.4-2.1)$ & $43.3(36-52)$ & $0.21(0.14-0.42)$ & $0.54(0.24-0.92)$ & $0.052(0.01-0.10)$ \\
\hline $0.01 \mu \mathrm{g} / \mathrm{L}$ & $18.7(16.7-20.8)$ & $6.9(5.7-8.39)$ & $289(215-320)$ & $7.8(7.1-8.6)$ & $1.7(1.4-2.0)$ & $43.5(32-50)$ & $0.22(0.14-0.42)$ & $0.57(0.33-1.04)$ & $0.058(0.02-0.10)$ \\
\hline $0.1 \mu \mathrm{g} / \mathrm{L}$ & $18.7(16.6-20.6)$ & $7.0(5.59-8.9)$ & $291(262-327)$ & $7.9(7.5-8.5)$ & $1.7(1.5-2.0)$ & $43.1(36-48)$ & $0.21(0.14-0.42)$ & $0.56(0.30-1.01)$ & $0.056(0.02-0.09)$ \\
\hline $1 \mu \mathrm{g} / \mathrm{L}$ & $18.8(16.8-20.7)$ & $7.2(5.53-8.5)$ & $284(260-312)$ & $8.0(7.1-8.7)$ & $1.7(1.4-2.0)$ & $42.7(36-48)$ & $0.2(0.14-0.42)$ & $0.58(0.31-0.90)$ & $0.048(0.02-0.09)$ \\
\hline
\end{tabular}

Table S16.8. Average organic matter decomposition rate (\%loss/day) of the cosms measured during experimental period.

\begin{tabular}{|c|c|c|c|c|c|c|c|c|}
\hline \multirow[b]{2}{*}{ Treatment } & \multicolumn{8}{|c|}{ Treatment time (Days) } \\
\hline & 2 & 16 & 28 & 42 & 56 & 70 & 84 & 98 \\
\hline Control & $0.95 \pm 0.09$ & $0.79 \pm 0.15$ & $0.69 \pm 0.01$ & $0.58 \pm 0.01$ & $0.53 \pm 0.03$ & $0.51 \pm 0.05$ & $0.49 \pm 0.02$ & $0.48 \pm 0.02$ \\
\hline $0.01 \mu \mathrm{g} / \mathrm{L}$ & $0.92 \pm 0.47$ & $0.60 \pm 0.06$ & $0.70 \pm 0.03$ & $0.56 \pm 0.04$ & $0.54 \pm 0.06$ & $0.53 \pm 0.04$ & $0.48 \pm 0.01$ & $0.48 \pm 0.01$ \\
\hline $0.1 \mu \mathrm{g} / \mathrm{L}$ & $0.89 \pm 0.12$ & $0.68 \pm 0.02$ & $0.69 \pm 0.03$ & $0.49 \pm 0.02$ & $0.51 \pm 0.07$ & $0.51 \pm 0.07$ & $0.50 \pm 0.04$ & $0.48 \pm 0.01$ \\
\hline $1 \mu \mathrm{g} / \mathrm{L}$ & $0.91 \pm 0.14$ & $0.69 \pm 0.09$ & $0.51 \pm 0.03$ & $0.47 \pm 0.03$ & $0.52 \pm 0.02$ & $0.51 \pm 0.06$ & $0.50 \pm 0.05$ & $0.48 \pm 0.02$ \\
\hline
\end{tabular}



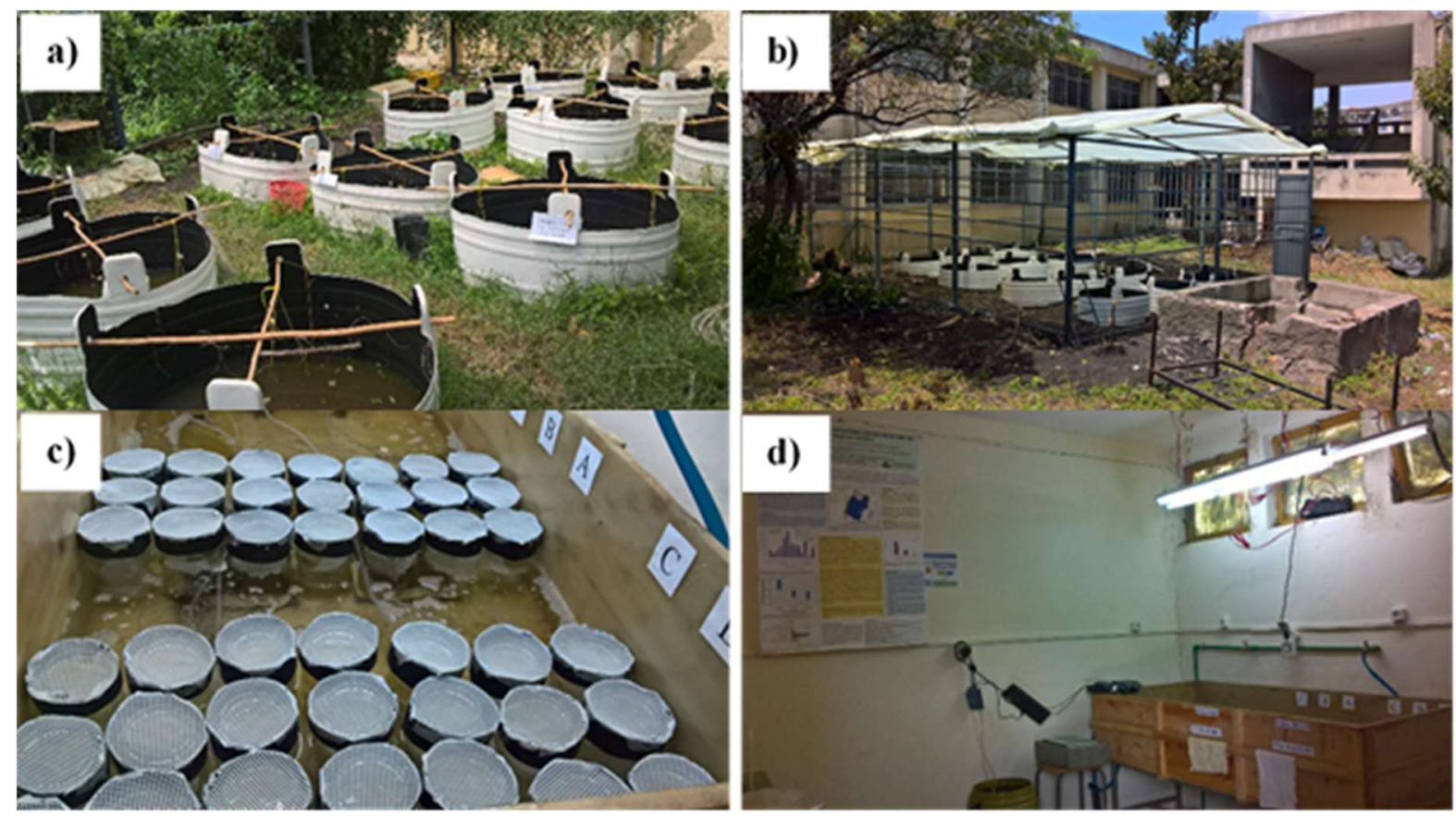

Fig. SI6.1. The experimental setups used for mesocosm ( $a$ and $b$ ) and acute ( $c$ and $d$ ) effect studies of imidacloprid. 


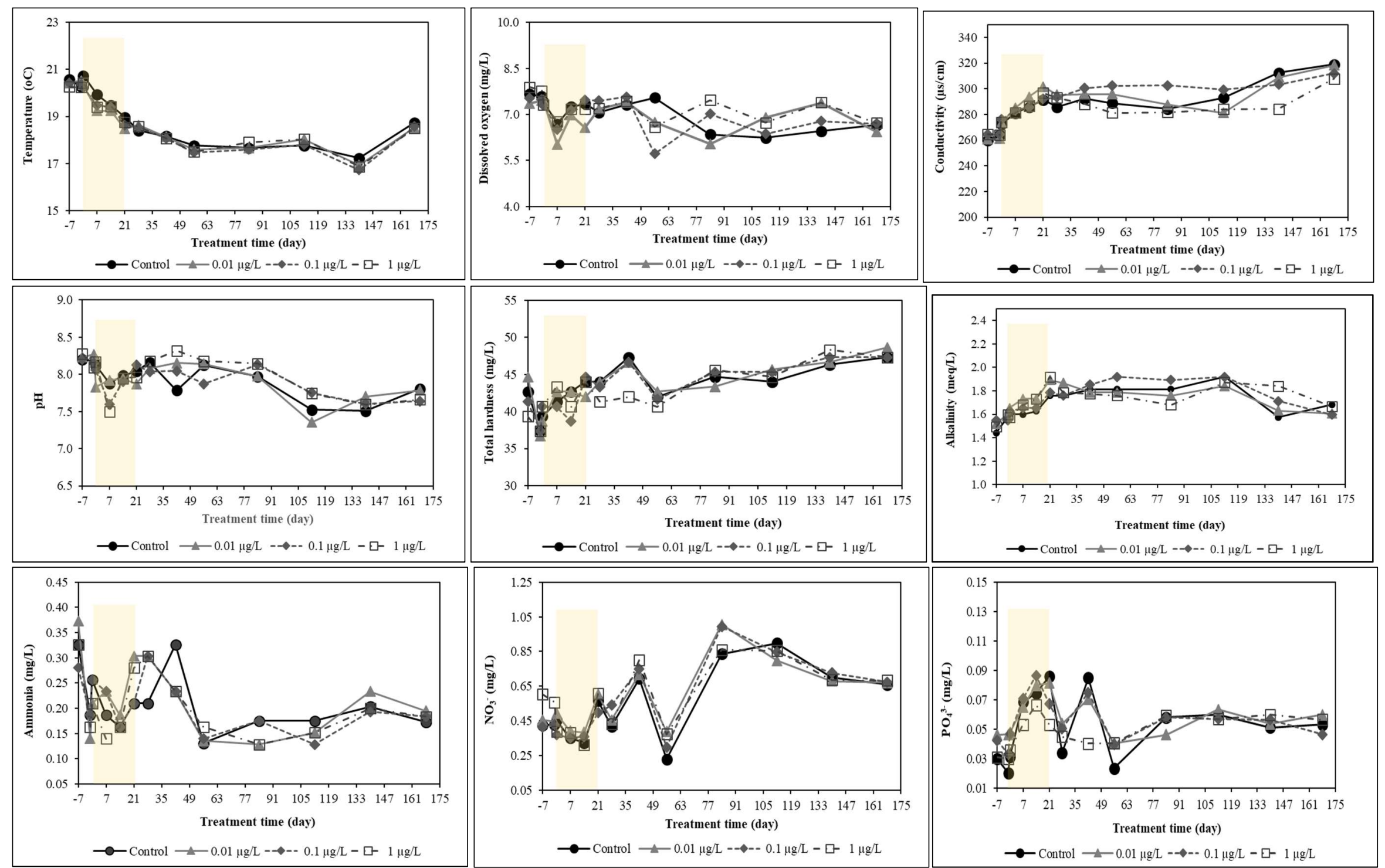

Fig. S16.2. Dynamics of water quality variables measured during the mesocosm experimental period. The shaded area with light yellor color indicates imidacloprid application period. 

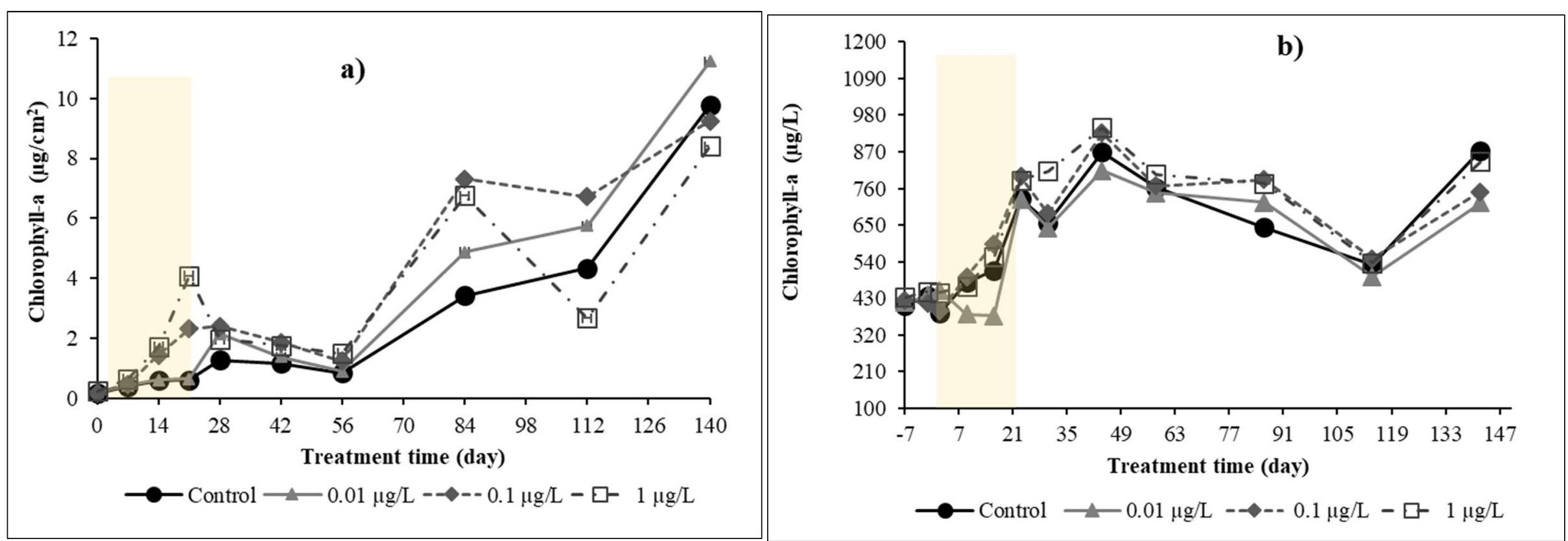

Fig. S16.3. Dynamics of periphyton (a) and phytoplankton (b) as estimated by chlorophyll-a concentration. The shaded area by light yellow color indicates the imidacloprid application period. 


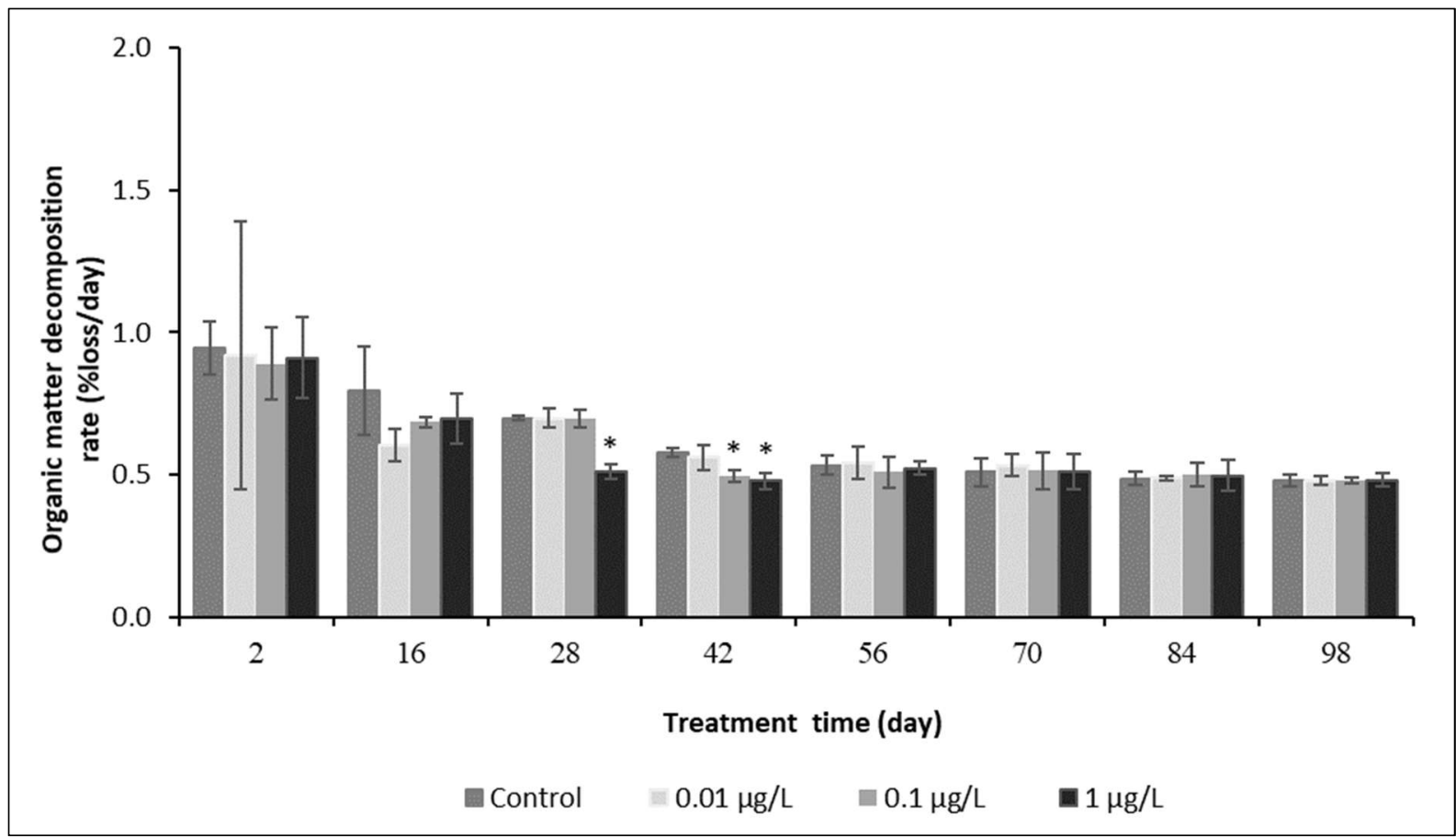

Fig. S16.4. Organic matter decomposition rate $\left(\right.$ mean \pm SD in $\left.\% \mathrm{~d}^{-1}\right)$ result. The measurements were taken during imidacloprid application (day 2 and day 16 ) and post application $(28,42,56,70,84$ and 98 days after the first imidacloprid application) periods, respectively. The * indicates significance difference according to Williams test result $(p<0.05)$. 



\section{CHAPTER 7}

General discussion and conclusion 
The government of Ethiopia is making a large investment in the agricultural sector to promote economic growth and alleviate the food security problem of the country (Mellor and Dorosh, 2010; Bachewe et al., 2018). To ensure the desired economic growth and poverty reduction, the government promotes agricultural technologies such as the use of agrochemicals and improved seed varieties by smallholder farmers (MoFED, 2010; Bachewe et al., 2018). The Central Ethiopia Rift Valley (CERV) region, particularly proximate to Lake Ziway is one of the agricultural development corridors in the country. Production of horticultural crops using irrigation water from Lake Ziway by large-scale companies (e.g., cut flowers and grapes), and by smallholder farmers (e.g., vegetables and fruits) are widely seen around the shores of the lake (Mengistie et al., 2017; Teklu et al., 2018). Agricultural development in the region also stimulates urban expansion and population growth of Batu (population estimated for the year $2017=70,436$ (CSA, 2013)) and Meki (population estimated for the year $2017=58,490($ CSA, 2013)), towns proximate to Lake Ziway (Beneberu and Mengistou, 2009; Fetahi, 2019).

Agricultural and urbanization activities generate various types and large amounts of contaminants (e.g., nutrients, trace metals, microplastics and pesticides) that may enter into Lake Ziway via multiple routes such as surface (urban and agricultural land) runoff, leaching and wastewater drainage canals. Spray drift can also be another potential route of pesticides to enter into Lake Ziway. The contaminants can cause damage to structural and functional characteristics of Lake Ziway and limit its capacity to provide regionally relevant ecosystem goods and services. For instance, high levels of nutrients (e.g., nitrate and phosphate) affect aquatic ecosystem by causing eutrophication (Fetahi, 2019), and pollutants including trace metals (Gheorghe et al., 2017; Costas et al., 2018), microplastics (Eerkes-Medrano and Thompson, 2018; Li et al., 2020) and pesticides (Brock et al., 2000a; Brock et al., 2000b; Fleeger et al., 2003) damage aquatic ecosystem by affecting non-target aquatic organisms.

However, a systemic investigation of impacts of the pollutants (nutrients, trace metals, pesticides and microplastics) on the Lake Ziway ecosystem and its ES was lacking. Moreover, little was known about the pesticide use and handling practices of the smallholder farmers and the large-scale farms found in the shoreline of Lake Ziway. Therefore, this thesis aimed to contribute to the fulfilment of the aforementioned gaps by performing a series of studies that comprise a literature review, household survey, biological and chemical monitoring, singlespecies toxicity experimentation and outdoor model ecosystem study (Chapter 2 to 6). This 
section discusses the main findings of these studies in line with the formulated research objectives (chapter 1).

\subsection{Agriculture related problems in the ecosystem of Lake Ziway}

Catchment degradation and contaminants released from agrochemicals intensive agricultural activities are the key factors for the deterioration of aquatic ecosystems in Ethiopia (Legesse and Ayenew, 2006; Desta et al., 2015; Teklu, 2016; Dibaba et al., 2020). The results of the literature review (Chapter 2) provide an overview of the impacts of human activities (e.g., agricultural activity) in the catchment of Lake Ziway on the ecological status and water quality of the lake. This chapter mainly disclosed the temporal shift in species composition of macrophytes and fish of the lake and the decrease in fish yield, in opposite to an increasing temporal trends of concentrations for some nutrients and trace metals (e.g., $\mathrm{PO}_{4}{ }^{3-}, \mathrm{NO}_{3}{ }^{-}, \mathrm{NH}_{4}{ }^{+}, \mathrm{Ca}^{2+}, \mathrm{Cu}$ and $\mathrm{Ni}$ ). Similarly, a shift in species composition of the fish yield in the lake was reported by Endebu et al. (2015) and Abera et al. (2018). The findings of the study indicated that the water quality of the lake is deteriorating, and the levels of many parameters exceeded national and/or international guideline values for drinking water (e.g., alkalinity, Fe, $\mathrm{Pb}$, endosulfan and diazinon) and for aquatic life (e.g., $\mathrm{NH}_{4}{ }^{+}, \mathrm{Fe}, \mathrm{Cr}, \mathrm{Cu}$ and $\mathrm{Se}$ ). In the monitoring study (Chapter 4), high levels of nutrients (e.g., $\mathrm{NO}_{3}{ }^{-}, \mathrm{NH}_{4}{ }^{+}$and $\mathrm{PO}_{4}{ }^{3-}$ ) were also observed in water samples of the lake. In agreement with our results, Teklu et al. (2018) reported various water quality parameters (e.g., $\mathrm{pH}, \mathrm{NO}_{3}{ }^{-}, \mathrm{K}^{+}, \mathrm{B}$ and $\mathrm{Fe}$ ) in Lake Ziway to be in exceedance of WHO/Ethiopian drinking water guideline values. Moreover, the results (Chapter 2) revealed the excessive irrigation water withdrawal and sedimentation as potential risks that can affect the ecological quality of Lake Ziway. For instance, over-abstraction of irrigation water can cause shrinking of the surface area of the lake that may have adverse effects on marginal wetland ecosystems including macrophytes that support birds population and other aquatic life of the lake. Continued sedimentation may cause a decrease in depth of the lake (i.e., reduce water storage capacity) and reduce water clarity (i.e., affect water quality and photosynthesis).

Inadequate use and handling of pesticides by farmers can aggravate the contamination of the aquatic ecosystem by pesticides (Teklu et al., 2016a; Mengistie et al., 2017; OnwonaKwakye et al., 2019). In Chapter 3, the pesticide use and handling practices of the smallholder 
vegetables producing farmers and large-scale floriculture and viticulture farmers found in the shoreline of Lake Ziway were assessed. The results indicated that smallholder farmers often apply pesticides against recommended use as prescribed on the leaflet . For example, spraying pesticides on vegetables or fruits which they are not prescribed for was reported for the majority of the identified pesticide formulations (63\%). Inappropriate handling practices that expose the aquatic ecosystem to pesticide contamination, including preparation of chemicals near water canals, dumping pesticide wastes into water canals, overdosing and excessive spraying frequency were reported by the majority $(63-73 \%)$ of the sample smallholder farmers found around Lake Ziway. Most respondent farmers also reported practices that pose a human health risk, such as accessible storage in a living house where family members (e.g., children), and insufficient use of protective materials during spraying. Inadequate use of pesticides is common practice in Ethiopia (Teklu et al., 2016a; Mengistie et al., 2017) and other African countries (Ntow et al., 2006; Okonya et al., 2019; Onwona-Kwakye et al., 2019).

In addition to the pesticide use and handling malpractices of farmers, Chapter $\mathbf{3}$ further identified that the effluent discharged from the large-scale farms were the potential sources for pesticide contamination of Lake Ziway that likely enhance the ecological deterioration of the lake reported in Chapter 2. This was confirmed in the pesticide monitoring study evaluating the water and sediment compartments of Lake Ziway (Chapter 4). In Chapter 4 it was observed that shoreline locations of Lake Ziway, particularly sites close to floriculture farms and to irrigation fields owned by smallholder farmers, are contaminated by different types of pesticides at concentrations in water and sediment that pose risks to aquatic organisms. Teklu et al. (2018) reported similar observations. Lack of access to important documents and to a floriculture farm for visiting (see Chapter 3 ) due to unwillingness of the companies to provide access, limited the researcher to assess the pesticides used on the floriculture farms, and the technologies they employ to effectively treat their effluent before release into Lake Ziway. This denial prohibits a transparent assessment of the environmental problems to the lake ecosystem as far as they are caused by pesticide use at floriculture farms.

The results in Chapter $\mathbf{4}$ further showed that the water and sediment samples of the lake were contaminated by different types of pesticides. The pesticides detected in the water column included propamocarb, dimethoate, diazinon, carbaryl, metalaxyl, fenitrothion, malathion, chlorpyrifos, iprovalicarb, endosulfan, $\lambda$-cyhalothrin and $\alpha$-cypermethrin in the concentration range of $<0.02-1.85 \mu \mathrm{g} / \mathrm{L}$ (see Chapter 4 ). In the sediment ethoprophos, 
dimethoate, diazinon, fenitrothion, chlorpyrifos, endosulfan, $\lambda$-cyhalothrin, $\alpha$-cypermethrin and deltamethrin were found in the concentration range of $<0.36-2.95 \mu \mathrm{g} / \mathrm{kg} \mathrm{dw}$ (see Chapter 4). The majority of pesticide compounds (78\%) found in water and sediment of Lake Ziway are used by smallholder vegetable farmers (Chapter $\mathbf{2}$ and 3). This suggests that the pesticides propamocarb, iprovalicarb and ethoprophos reported in Chapter 4 are released solely by the floriculture farms. In line with this, Teklu et al. (2016a) reported the use of metalaxyl, propamocarb and deltamethrin by the large-scale flower farms in the central Ethiopian rift valley region near Debra Zeit, Ethiopia. Relative to the pesticide monitoring for water from Lake Ziway reported elsewhere (Jansen and Harmsen, 2011; Teklu et al., 2018), the results of our study show the presence of more pesticide compounds and higher concentration levels (Table 7.2; Chapter 4). These differences are likely due to irrigation land size expansion by smallholder farmers and their poor practices in using and handling pesticides, and may also result from inadequate management of effluents released into the lake from proximate floriculture farms (see Chapter 3 ).

Spatially, the shoreline locations exposed to floriculture, agricultural and urbanization activities are the most polluted parts of Lake Ziway (see Chapters 2, 3, 4 and 5). Similarly, Teklu et al. (2016a) disclosed the improper use and handling of pesticides by the smallholder farmers near Debre Zeit, Ethiopia and reported high risks of the use of $\lambda$-cyhalothrin, profenofos, endosulfan and diazinon to the aquatic ecosystem. Teklu et al. (2018) also reported the impacts of the nearby agricultural activities by small- and large-scale farmers on Lake Ziway, suggesting effects of the activities on the physicochemical properties of the lake and the contamination of its surface waters by various pesticides (e.g., endosulfan, spiroxamine, teflubenzuron, diazinon).

\subsection{Urban domestic wastes and microplastic pollution of lakes}

This thesis investigated the impacts of pollutants (e.g., nutrients, plastics) originating from urban solid waste and sewage that are mainly released into the lake from the nearby Batu and Meki towns (Chapters 2, 3, 4 and 5). The results of Chapters 2, 3 and 4 showed that these waste disposals/sewage effluents are contributing to the deterioration of the water quality of Lake Ziway. For instance, higher values of nutrients (e.g., $\mathrm{PO}_{4}{ }^{3-}$ and $\mathrm{NH}_{4}{ }^{+}$and $\mathrm{NO}_{3}{ }^{-}$) and trace metals ( $\mathrm{Fe}, \mathrm{Pb}$ and $\mathrm{Cd}$ ) were observed in water and sediment samples collected along the 
shorelines receiving urban wastes through intentionally constructed drainage facilities (e.g., from Batu town) and the Meki River discharge ( that passes through Meki town (Chapters 2, 3 and 4). The high load of nutrients in Lake Ziway is causing eutrophication (i.e., enrichment of nutrients) that can stimulate blooming of toxic algae and hypoxia (oxygen concentration depletion) (Camargo and Alonso, 2006; Conley et al., 2009; Fetahi, 2019).

The results of Chapter $\mathbf{5}$ showed the contamination of the sediment of Lake Ziway by plastic particles and the ingestion of the particles by more than one-third of the sampled fish individuals (Oreochromis niloticus, Clarias gariepinus, Cyprinus carpio and Carassius carassius). Similarly, Biginagwa et al. (2016) reported microplastics in the gastrointestinal tracts of onefourth of the sampled fish individuals (Oreochromis niloticus and Lates niloticus) in the southern shore of Lake Victoria. The findings of Chapter 5 also showed that the contamination of sediment and fish of Lake Ziway by plastic particles was particularly high in shoreline locations that receive wastes and sewage released from nearby towns. For instance, higher plastic ingestion frequency for fish (e.g., up to $52 \%$ of individuals) and higher plastic particles concentrations in sediment (e.g., up to $36,233 \mathrm{mg} / \mathrm{kg} \mathrm{dw}$ ) were observed in urban waste influenced locations (e.g., Korokonch and Kidanemihiret sites) compared to the other parts of the lake. This correlation suggests that urban wastes can be the major source of plastic particles contamination to the sediment and the fishes of Lake Ziway. The ATR-FTIR analysis of the plastic particles found in sediment and in gastrointestinal tracts of fish individual also indicates domestic wastes as the major origin of the particles. This is in agreement with the literature review study (Chapter 2) that identified factors, including the inappropriate dumping of solid wastes and urban wastewater effluents drained into Lake Ziway from Batu and Meki towns, as the principal potential sources of microplastic pollution. The highest estimated plastic particles sediment concentration of $3.6 \%$ on a dry weight basis were around or in exceedance of effect thresholds such as the 28-day EC10 of 1.1\% for growth of Gammarus pulex (Redondo-Hasselerharm et al., 2018), the LOEC of 5\% for long term (15 month) effects on the benthic community (Redondo-Hasselerharm et al., 2020), and the 10-day LOEC of $0.25 \%$ for larval growth of Chironomus riparius (Silva et al., 2019). Thus, these pollution levels are likely to contribute to ecological damage to Lake Ziway, in excess of effects induced by other pollutants as discussed in Chapters 2, 3 and 4. 


\subsection{Assessment of ecosystem goods and services for prioritization of protection of lakes}

Humanity derives a wide range of goods and services from the ecosystem that directly contribute to the key components of human well-being such as security (e.g., protection from flood damage in that case of lakes), the basic material for quality of life, health and good social relations (MEA, 2005; Holland et al., 2011; Lorraine et al., 2018). Aquatic ecosystems also deliver multiple ecosystem goods and services (ES) and largely support the livelihood of local people (Alahuhta et al., 2013; Haines-Young and Potschin, 2013; Schallenberg et al., 2013; Grizzetti et al., 2015; Ondiek et al., 2016). The results of Chapter 3 documented various ES that benefit the communities local to Lake Ziway. The livelihood of these local people depend directly and indirectly on the supply of lake ES. The ES that the local communities take benefit from are dominated by provisioning type of ES (62.5\%), while only a few regulation and maintenance (12.5\%), and cultural (25\%) ES types were identified by the local communities (see Chapter 3 ). The supply of drinking water, fish for consumption, and irrigation water by Lake Ziway were the first, the second and the third prioritized ES, respectively, in terms of relevance to the local community.

Recently, the integration of the ecosystem service concept into ecological risk assessment (ERA) of chemicals has gained momentum (Arts et al., 2015; Munns et al., 2016; Maltby et al., 2018; Faber et al., 2019). Different merits of integration of the ES concept into ERA have been reported. For example, the use of the concept as a communication tool was among the advantages identified (Faber and Van Wensem, 2012). Rather than merely discussing the impact of a given human activity on a given ecosystem, for instance, by showing the impact the activity posed on a service or goods community benefits from an ecosystem, the general public and policymakers can easily understand and be convinced of the importance of protecting the ecosystem. The possibility of economic valuation of ES can be another advantage (Faber and Van Wensem, 2012). For example, valuation of ES gives the chance to risk assessors to inform decision-makers about the possible monetary loss due to contamination of an ecosystem or benefits gained due to intervention measures improving protection. Using the concept it is also possible to show how an impact on an ecosystem due to contamination can affect human welfare (Forbes and Calow, 2012). The ES concept further gives room for stakeholders to be involved in ERA process, which helps building trust among the stakeholders enhancing the acceptance of the results (Faber 2006 Faber and Van Wensem, 
2012; Munns et al., 2016; Maltby et al., 2018). This all helps to create a better insight amongst stakeholders for the necessity for ecosystems protection, conservation and restoration.

In Chapter $\mathbf{3}$ we used the ecosystem service concept in the assessment of the potential impacts of pesticides on Lake Ziway due to intensive and improper use and handling of the chemicals by the small- and large-scale farmers found proximate to the lake. The conceptual approach used to link contamination of Lake Ziway by stressors (e.g., pesticide as used in the chapter) with impact on ES was based on the assumption that the delivery of the ES depends on the condition of biological components of the lake. These biological components are crucial for the ecological functions and processes (supporting services) underlying the ES and the maintenance of the good ecological conditions for the ES delivery. Biological entities essential in ecosystem functioning and associated ES provision are defined as service providing units (SPUs) (Luck et al., 2003; Andersson et al., 2015). Effects caused by stressors on such SPUs, therefore, can harm ecological functions and processes, and subsequently compromise the capacity of the lake to supply ES identified in Chapter 3. The study in Chapter $\mathbf{3}$ demonstrated that improper pesticide use by the smallholder famers and effluents released from floriculture farms may pose ecological risks to Lake Ziway and its ES delivery. The monitoring study (Chapter 4) confirmed the pollution of Lake Ziway by pesticides that are used widely by the smallholder farmers and large-scale floriculture farms found in the region. The study (Chapter 4) further showed that diazinon, fenitrothion, endosulfan, $\lambda$-cyhalothrin and $\alpha$-cypermethrin pose high risks to biological components of the lake that can cause impairment of the lake ecosystem to deliver its ES (Chapter 3).

This approach provides a clear insight regarding the role of aquatic biological units to support human benefits (Grizzetti et al., 2015), and strengthen the reason why it is necessary to protect and conserve the Lake Ziway ecosystem. The study in Chapter $\mathbf{3}$ focuses on pesticides, but the approach can be applied for any other stressors reported in Chapters 2, 4 and 5. Similar approaches that links ES delivery to ecosystems condition was also suggested by Grizzetti et al. (2015).

\subsection{Ecological risk assessment of pesticides in the Lake Ziway ecosystem}

In Chapter 4, a first-tier (acute/chronic tier-1) and a second-tier (Species Sensitivity Distribution (SSD), acute tier-2) based risk quotient (RQ) approach was used to assess the 
ecological risks of residual pesticides measured in water and sediment of Lake Ziway. Sitespecific risks of mixtures of pesticides to two freshwater community groups (arthropods and fishes) were also evaluated by applying mixture toxicity mixed-models (Posthuma et al. 2002). As indicated in Chapter 4, the calculated RQ was $>1$ for most detected and quantified pesticides in both matrixes of Lake Ziway. The pesticides included dimethoate, carbaryl (only in water), chlorpyrifos, diazinon, fenitrothion, endosulfan, $\lambda$-cyhalothrin, $\alpha$-cypermethrin and deltamethrin (only in sediment), which require a further risk evaluation as the acute tier-2 (the higher tier used in this thesis) RQ values calculated for the pesticides were $>1$. The measured concentration levels of the pesticides in the water column and sediment compartments were found to pose risks to aquatic ecosystem of the lake, which contain important species for the delivery of ES of Lake Ziway identified in Chapter 2.

Teklu et al. (2016a) also reported Species Sensitivity Distribution based risk quotients (RQSSD) using the PRIMET model to predict the environmental concentrations of several pesticides for pond ecosystems near the fields of smallholder farmers in Bishoftu/Debre Zeit, Ethiopia. Compared to the reported RQssD by the authors (Teklu et al. 2016a), our result for malathion and $\lambda$-cyhalothrin was higher by more than an order of magnitude (Table 7.1). The $R Q_{s S D}$ for endosulfan and diazinon were comparable to our results. Moreover, Teklu et al. (2018) reported RQssD values based on measured environmental concentrations in Lake Ziway. Compared to the RQSSD values by Teklu et al. (2018), our results were higher by one order of magnitude for diazinon and endosulfan pesticides (Table 7.1), suggesting that their environmental risks to the Lake Ziway and its ES increase over time. More similar studies that strengthen our results are required to clearly show the temporal correlation between pesticide contamination of Lake Ziway versus its ES supply.

Chapter 4 demonstrates that fishes and arthropods community groups of Lake Ziway were found to be highly affected by a mixture of pesticides at locations that are proximate to smallholders' farms, and receive largescale farms' wastewater, and sites where the inflow rivers from catchment area join the lake. It is also shown that the concentrations of fenitrothion, malathion, chlorpyrifos, endosulfan, $\lambda$-cyhalothrin and $\alpha$-cypermethrin pesticides majorly contributed to the evaluated risks of pesticide mixtures. The results in Chapter 4 can be good indicators for other aquatic ecosystems under similar agricultural pressures in Ethiopia. 
The increasing temporal trend of concentration levels of pesticides observed in Lake Ziway and the associated ecological risks (Chapter 4; Table 7.1; Table 7.2), can be associated with yearly expansion of irrigation land by smallholders, and lack of strict monitoring of wastewater effluent from the nearby large-scale farms. The misuse of pesticides and poor waste management practices by smallholder farmers in the central Ethiopian rift valley region, Ethiopia (Chapter 2) can also substantially contribute to the observed risks to Lake Ziway.

Table 7.1: Species Sensitive Distribution (SSD) based risk quotients (RQsSD) values using the PRIMET modelbased predicted environmental concentrations (PRIMET_PECs) and measured maximum environmental concentrations (MECs) values reported by Teklu et al. (2016) ${ }^{\text {a }}$ for pond ecosystem found around Bishoftu (Debre Zeit), Ethiopia, and by Teklu et al. (2018) ${ }^{\mathrm{b}}$ and by this Chapter $4^{\mathrm{c}}$ in Lake Ziway, Ethiopia.

\begin{tabular}{|c|c|c|c|c|c|c|}
\hline Pesticide & $\begin{array}{l}\text { PRIMET_PECs } \\
(\mu \mathrm{g} / \mathrm{L})^{\mathrm{a}}\end{array}$ & $\begin{array}{l}\text { PRIMET_PECs } \\
{\text { based } \text { RQ }_{\text {SSD }} \text { value }}^{\text {a }}\end{array}$ & $\begin{array}{l}\text { Maximum } \\
\operatorname{MECs}(\mu \mathrm{g} / \mathrm{L})^{\mathrm{b}}\end{array}$ & $\begin{array}{l}\text { MEC based } \\
\text { Tier-2 RQ }_{S S D}{ }^{b}\end{array}$ & $\begin{array}{l}\text { Maximum } \\
\text { MECs }(\mu \mathrm{g} / \mathrm{L})^{\mathrm{c}}\end{array}$ & $\begin{array}{l}\text { MEC based } \\
\text { Tier-2 RQ } \\
S S D^{c}\end{array}$ \\
\hline Dimethoate & NP & - & NR & - & 0.99 & 3 \\
\hline Diazinon & 28 & 55.4 & 0.41 & 0.8 & 0.88 & 12 \\
\hline Carbaryl & NP & - & NR & - & 0.38 & 1.01 \\
\hline Fenitrothion & NP & - & NR & - & 0.74 & 12 \\
\hline Malathion & 0.26 & 0.472 & NR & - & 0.85 & 9 \\
\hline Chlorpyrifos & NP & - & $N R$ & - & 0.88 & 102 \\
\hline Endosulfan & 4.93 & 102.2 & 0.14 & 2.9 & 1.85 & 78 \\
\hline$\lambda$-cyhalothrin & 0.05 & 28.6 & NR & - & 0.225 & 595 \\
\hline $\begin{array}{l}\alpha- \\
\text { cypermethrin }\end{array}$ & NP & - & $N R$ & - & 0.81 & 604 \\
\hline Deltamethrin & 0.00086 & NC & 0.01 & 4.1 & ND & - \\
\hline
\end{tabular}

Note: $\mathrm{NP}=$ not predicted, $\mathrm{NR}=$ not reported, $\mathrm{NC}=$ not calculated and $\mathrm{ND}=$ not detected 
Table 7.2. Temporal trend of concentration levels of pesticides reported in literature since 2009.

\begin{tabular}{|c|c|c|c|c|}
\hline Pesticide & $\begin{array}{l}\text { Sampling } \\
\text { year }\end{array}$ & $\begin{array}{l}\text { Maximum } \\
\text { concentration }(\mu \mathrm{g} / \mathrm{L})\end{array}$ & $\begin{array}{l}\text { Sampling shoreline } \\
\text { location }\end{array}$ & References \\
\hline \multirow[t]{5}{*}{ Deltamethrin } & 2014 & 0.01 & Near floriculture & Teklu et al. (2018) \\
\hline & 2017 & ND & Near floriculture & Chapter 4 \\
\hline & 2014 & 0.41 & Near floriculture & Teklu et al. (2018) \\
\hline & 2017 & $<0.08$ & Near floriculture & Chapter 4 \\
\hline & $2009 / 2010$ & 0.09 & $\begin{array}{l}\text { near smallholder irrigation } \\
\text { land in Edo-Kontola area }\end{array}$ & Jansen and Harmsen (2011) \\
\hline \multirow[t]{5}{*}{ Diazinon } & 2014 & 0.28 & $\begin{array}{l}\text { near smallholder irrigation } \\
\text { land in Edo-Kontola area }\end{array}$ & Teklu et al. (2018) \\
\hline & 2017 & 0.19 & $\begin{array}{l}\text { near smallholder irrigation } \\
\text { land in Edo-Kontola area }\end{array}$ & Chapter 4 \\
\hline & 2014 & 0.1 & Near floriculture & Teklu et al. (2018) \\
\hline & 2017 & 0.86 & Near floriculture & Chapter 4 \\
\hline & 2014 & 0.14 & locations where Meki River & Teklu et al. (2018) \\
\hline \multirow[t]{3}{*}{ Endosulfan } & & & and Ketar River join the lake & \\
\hline & 2017 & 1.85 & $\begin{array}{l}\text { locations where Meki River } \\
\text { and Ketar River join the lake }\end{array}$ & Chapter 4 \\
\hline & $2009 / 10$ & 0.05 & $\begin{array}{l}\text { near smallholder irrigation } \\
\text { land in Edo-Kontola area }\end{array}$ & Jansen and Harmsen (2011) \\
\hline \multirow[t]{2}{*}{ Carbaryl } & 2017 & 0.02 & $\begin{array}{l}\text { near smallholder irrigation } \\
\text { land in Edo-Kontola area }\end{array}$ & Chapter 4 \\
\hline & $2009 / 2010$ & 0.03 & $\begin{array}{l}\text { locations where Meki River } \\
\text { and Ketar River join the lake }\end{array}$ & Jansen and Harmsen (2011) \\
\hline \multirow[t]{2}{*}{ Dimethoate } & 2017 & 0.95 & $\begin{array}{l}\text { locations where Meki River } \\
\text { and Ketar River join the lake }\end{array}$ & Chapter 4 \\
\hline & $2009 / 2010$ & 0.08 & $\begin{array}{l}\text { locations where Meki River } \\
\text { and Ketar River join the lake }\end{array}$ & Jansen and Harmsen (2011) \\
\hline \multirow[t]{7}{*}{ Fenitrothion } & 2017 & & $\begin{array}{l}\text { locations where Meki River } \\
\text { and Ketar River join the lake }\end{array}$ & Chapter 4 \\
\hline & $2009 / 2010$ & 0.16 & Near floriculture & Jansen and Harmsen (2011) \\
\hline & 2017 & 0.74 & Near floriculture & Chapter 4 \\
\hline & $2009 / 2010$ & 0.11 & $\begin{array}{l}\text { locations where Meki River } \\
\text { and Ketar River join the lake }\end{array}$ & Jansen and Harmsen (2011) \\
\hline & 2017 & 1.9 & $\begin{array}{l}\text { locations where Meki River } \\
\text { and Ketar River join the lake }\end{array}$ & Chapter 4 \\
\hline & $2009 / 2010$ & 0.51 & Near floriculture & Jansen and Harmsen (2011) \\
\hline & 2017 & 1.25 & Near floriculture & Chapter 4 \\
\hline \multirow[t]{2}{*}{ Metalaxyl } & $2009 / 2010$ & 0.09 & $\begin{array}{l}\text { near smallholder irrigation } \\
\text { land in Edo-Kontola area }\end{array}$ & Jansen and Harmsen (2011) \\
\hline & 2017 & 0.87 & $\begin{array}{l}\text { near smallholder irrigation } \\
\text { land in Edo-Kontola area }\end{array}$ & Chapter 4 \\
\hline \multirow[t]{2}{*}{ Propamocarb } & $2009 / 2010$ & 1 & Near floriculture & Jansen and Harmsen (2011) \\
\hline & 2017 & 0.91 & Near floriculture & Chapter 4 \\
\hline \multirow[t]{2}{*}{ Iprovalicarb } & $2009 / 2010$ & 0.38 & Near floriculture & Jansen and Harmsen (2011) \\
\hline & 2017 & 0.93 & Near floriculture & Chapter 4 \\
\hline
\end{tabular}




\subsection{Sensitivity of tropical aquatic species to imidacloprid; lessons learnt}

In Chapter 6, the acute toxicity of imidacloprid to tropical (Ethiopian) aquatic species (Cloeon dipterum, Caenis horaria, Corixidae sp. and Plea minutissima) is described and model ecosystem (mesocosm) based effects of the compound to endpoints for ecosystem structure (primary producers and invertebrates) and function (physicochemical parameters and organic matter decomposition). Recovery of affected populations and communities was also studied over a 21 weeks period.

The findings of the study (Chapter 6 ) indicated that tropical aquatic invertebrates are more sensitive to the neonicotinoid insecticide imidacloprid than their temperate counterparts. The study (Chapter 6) demonstrated that mayfly C. dipterum (96-h LC50 $=2.7 \mu \mathrm{g} / \mathrm{L}, 96-\mathrm{h}$ EC50 $=$ $1.5 \mu \mathrm{g} / \mathrm{L}$ and $14-\mathrm{d}$ NOEC $<0.01 \mu \mathrm{g} / \mathrm{L}$ ) was found to be the most sensitive arthropods relative to the other tested tropical species. The rotifer Brachionus sp. (NOEC $<0.01 \mu \mathrm{g} / \mathrm{L}$ ) showed the largest response to the imidacloprid treatments in the cosm study relative to the other zooplankton species. Relative to the acute toxicity data from temperate studies reported by Roessink et al. (2013) (96-h LC50 $=26.3 \mu \mathrm{g} / \mathrm{L})$ for summer generation and by Van den Brink et al. (2016) (96-h LC50 = $34 \mu \mathrm{g} / \mathrm{L})$ for winter generation of $C$. dipterum, the effect value measured in Chapter 6 is 10 to 12 times lower. Relative to the results for Cloeon sp. sampled in spring in Canada (96-h LC50 = $1152 \mu \mathrm{g} / \mathrm{L}$ and EC50 $=23.1 \mu \mathrm{g} / \mathrm{L}$ ) by Raby et al. (2018) again our results of 96-h LC50 and EC50 are 427 times and 15 times low, respectively (Table 7.3). Moreover, the estimated no observed effect concentration (NOEC) values of the cosm study (Chapter 6) for tropical invertebrates are also lower compared to their temperate counterparts (Table 7.3).

The sensitivity differences observed between tropical and temperate aquatic species to imidacloprid insecticide likely result from variation in temperature, as an increase in temperature increases the rate of uptake and circulation of the chemicals in the test organisms (Castillo et al., 1997; Kwok et al., 2007; Camp and Buchwalter, 2016; Macaulay et al., 2020). Lack of overwintering generations of tropical aquatic arthropods (Brittain, 1982; Sumon et al., 2018) may also contribute to the variation in sensitivity (Van den Brink et al. 2016). However, further investigation is needed to mechanistically link the difference in sensitivity and spatio-temporal background of the tested populations. 
The cosm study results showed imidacloprid treatment effects on rotifers (Chapter 6; Table 7.3). Similar observations were also reported in cosm studies by Sumon et al. (2018) in Bangladesh and by Rico et al. (2018) in Spain. The only available single species toxicity study of imidacloprid to the rotifer B. calyciflorus (24-h NOEC (mortality) $=17.5 \mathrm{mg} / \mathrm{L} ; 10-\mathrm{d}$ NOEC (population growth) $=6220 \mu \mathrm{g} / \mathrm{L}$; Gharaei et al., 2020) (Table 7.3) indicates that the species is less sensitive to the compound. With this information it is difficult to draw a conclusion whether the observed effect is due to direct toxicity of imidacloprid or is an indirect effect. Further single species toxicity tests with tropical rotifer species should be performed to conclude the results.

The results described in Chapter 6 also showed that zooplankton community quickly recovered (after nine weeks of the last application) compared to macroinvertebrate community, for which no recovery was observed during the 21 weeks recovery period. This is related to the short generation times of zooplanktons compared to the macroinvertebrates (Beketov et al. 2008, Rico and Van den Brink 2015). A long term alteration of macroinvertebrate community structure can be resulted in tropical aquatic ecosystem that repeatedly/chronically exposed to imidacloprid concentration of $0.1 \mu \mathrm{g} / \mathrm{L}$ and above. Imidacloprid is used by smallholder vegetable farmers in the catchment of Lake Ziway (Chapter 3) and the concentrations used in cosm study (Chapter 6) is expected to be environmentally realistic concentrations in Ethiopian aquatic ecosystem as, for instance, an average concentration of $0.16 \mu \mathrm{g} / \mathrm{L}$ was reported in water samples of Lake Ziway (see Chapter 2).

Strikingly the cosm study (Chapter 6) demonstrated that imidacloprid had a significant effect on the microbial-based organic matter decomposition rate at concentrations of $0.1 \mu \mathrm{g} / \mathrm{L}$ and higher. A direct toxic effect (luminescence inhibition) of imidacloprid to the bacteria Vibrio fischeri was reported by Tišler et al. (2009) at much higher concentrations (30 min IC20 = $11200 \mu \mathrm{g} / \mathrm{L})$. However, the result in Chapter 6 is in contrast with previous studies that reported no effect of imidacloprid on microbial mediated leaf decomposition (Kreutzweiser et al. 2007, Pestana et al. 2009, Sumon et al. 2018). As this effect may have large ecological implications (e.g., affect cycling of nutrients), further investigation remains necessary. 
Table 7.3. Acute and chronic toxicity, and cosm study no observed effect concentration (NOEC) values of imidacloprid for macroinvertebrates and zooplanktons reported in the literature.

\begin{tabular}{|c|c|c|c|c|c|c|c|}
\hline \multirow[b]{2}{*}{ Species } & \multicolumn{2}{|c|}{ Acute toxicity } & \multicolumn{2}{|c|}{ Chronic toxicity } & \multicolumn{2}{|c|}{ Cosm NOEC values } & \multirow[b]{2}{*}{ Country } \\
\hline & $\begin{array}{l}\text { 96h LC50 } \\
(\mu \mathrm{g} / \mathrm{L})\end{array}$ & $\begin{array}{l}\text { 96h EC50 } \\
(\mu \mathrm{g} / \mathrm{L})\end{array}$ & $\begin{array}{l}\text { Toxicity } \\
\text { endpoint }\end{array}$ & $\begin{array}{l}\mathrm{L}(\mathrm{C}) \mathrm{x} \\
(\mu \mathrm{g} / \mathrm{L})\end{array}$ & $\begin{array}{l}\text { Exposure } \\
\text { duration }\end{array}$ & $\begin{array}{l}\text { NOEC } \\
(\mu \mathrm{g} / \mathrm{L})\end{array}$ & \\
\hline Cloeon dipterum (WG) & $26.3^{a}$ & $1.0^{\mathrm{a}}$ & 28-d EC10 & $0.033^{a}$ & - & - & Netherlands \\
\hline Cloeon dipterum (WG) & $34^{b}$ & $25^{b}$ & - & - & - & - & Netherlands \\
\hline Cloeon dipterum & - & - & - & - & $28-d$ & $<0.09^{f}$ & Spain \\
\hline Cloeon dipterum & $2.7^{e}$ & $1.5^{\mathrm{e}}$ & - & - & $14-d$ & $<0.01^{\mathrm{e}}$ & Ethiopia \\
\hline Cloeon sp. (WG) & $1152^{c}$ & $23.1^{c}$ & - & - & - & - & Canada \\
\hline Cloeon sp. & $0.024^{d}$ & $0.0055^{d}$ & - & - & $9-d$ & $<0.03^{d}$ & Bangladesh \\
\hline Caenis horaria (SG) & $6.68^{a}$ & $1.8^{\mathrm{a}}$ & 28-EC10 & $0.024^{a}$ & & & Netherlands \\
\hline Caenis horaria (WG) & $28^{b}$ & $6.0^{\mathrm{b}}$ & - & - & - & - & Netherlands \\
\hline Caenis sp. (WG) & $<21.8^{c}$ & $<21.8^{c}$ & - & - & - & - & Canada \\
\hline Caenis sp. & - & - & - & - & - & $2.3^{\mathrm{g}}$ & Germany \\
\hline Caenis horaria & $3.4^{\mathrm{e}}$ & $1.9^{\mathrm{e}}$ & - & - & $14-d$ & $<0.01^{\mathrm{e}}$ & Ethiopia \\
\hline Chironomidae sp. & - & - & - & - & $49-d$ & $5.2^{\mathrm{g}}$ & Germany \\
\hline Chironomus dilutus & - & - & 14-d LC20 & $0.47^{k}$ & - & - & Canada \\
\hline Chironomus riparius & - & - & 10-d LC10 & 1.64 & - & - & $\begin{array}{l}\text { Czech } \\
\text { Republic }\end{array}$ \\
\hline Chironomid larvae & - & - & - & - & $28-d$ & $0.3^{d}$ & Bangladesh \\
\hline Chironomini & - & - & - & - & $10-d$ & $<0.2^{f}$ & Spain \\
\hline Chironomidae sp. & - & - & - & - & $28-d$ & $0.01^{\mathrm{e}}$ & Ethiopia \\
\hline Culicidae sp. & - & - & - & - & $28-d$ & $0.01^{\mathrm{e}}$ & Ethiopia \\
\hline Notonecta tiguttata & - & - & - & - & $140-d$ & $157^{\mathrm{h}}$ & Japan \\
\hline Notonecta sp. & - & - & - & - & $16-d$ & $0.03^{d}$ & Bangladesh \\
\hline Notonectidae sp. & - & - & - & - & $28-d$ & $0.01^{\mathrm{e}}$ & Ethiopia \\
\hline Micronecta sp. (SG) & $28.2^{\mathrm{a}}$ & $10.8^{a}$ & - & - & - & - & Netherlands \\
\hline Trichocorixa sp. (WG) & $450^{c}$ & $63.1^{c}$ & - & - & - & - & Canada \\
\hline Corixidae sp. & $6.8^{e}$ & $3.6^{e}$ & - & - & $28-d$ & $<0.01^{\mathrm{e}}$ & Ethiopia \\
\hline Gerris sp. & - & - & - & - & $16-d$ & $0.03^{d}$ & Bangladesh \\
\hline Gerris latiabdominis & - & - & - & - & $120-d$ & $49^{i}$ & Japan \\
\hline Gerridae sp. & - & - & - & - & $28-d$ & $<0.01^{\mathrm{e}}$ & Ethiopia \\
\hline Plea minutissima (SG) & $37.5^{a}$ & $36^{a}$ & 28-d LC10 & $2.03^{a}$ & - & - & Netherlands \\
\hline Plea minutissima (WG) & $287^{b}$ & $189^{b}$ & - & - & - & - & Netherlands \\
\hline Plea minutissima & $68^{e}$ & $36^{e}$ & - & - & $42-d$ & $0.01^{\mathrm{e}}$ & Ethiopia \\
\hline Hydaticus sp. & - & - & - & - & $28-d$ & $<60^{\mathrm{j}}$ & Portugal \\
\hline Dytiscidae sp. & - & - & - & - & $28-d$ & $<0.01^{\mathrm{e}}$ & Ethiopia \\
\hline Planorbella pilsbryi & - & - & 28-d EC10 & $15.4^{\mathrm{m}}$ & - & - & Canada \\
\hline Physidae sp. & - & - & - & - & $28-d$ & $0.1^{\mathrm{e}}$ & Ethiopia \\
\hline Planorbidae sp. & - & - & - & - & $28-d$ & $0.1^{\mathrm{e}}$ & Ethiopia \\
\hline
\end{tabular}

Note: $\mathrm{a}=$ Roessink et al. (2013); b = Van den Brink et al. (2016); $=$ Raby et al. (2018); d = Sumon et al. (2018); e = Chapter 6; $f=$ Rico et al. (2018); $g$ = Colombo et al. (2013); $h$ = Kobashi et al., (2017); i = Hayasaka et al. (2012); j = Pereira et al. (2017); $k$ = Cavallaro et al. (2017); I = Chandran et al. (2018); $\mathrm{m}$ = Prosser et al. (2016). WG = winter generation; SG = summer generation. Reference $\mathbf{f}$ and $\mathbf{j}$ are from Mediterranean climate, $\mathbf{d}$ is from sub-tropical and $\mathbf{e}$ from tropical. The others are from temperate climate. 
Table 7.3. Cont'd

\begin{tabular}{|c|c|c|c|c|c|c|c|}
\hline \multicolumn{8}{|l|}{ b. Zooplanktons } \\
\hline \multirow[b]{2}{*}{ Species } & \multicolumn{2}{|c|}{ Acute toxicity } & \multicolumn{2}{|c|}{ Chronic toxicity } & \multicolumn{2}{|c|}{ Cosm NOEC values } & \multirow[b]{2}{*}{ Country } \\
\hline & $\begin{array}{l}\text { 96-h LC50 } \\
(\mu \mathrm{g} / \mathrm{L})\end{array}$ & $\begin{array}{l}\text { 96-h EC50 } \\
(\mu \mathrm{g} / \mathrm{L})\end{array}$ & $\begin{array}{l}\text { Toxicity } \\
\text { endpoint }\end{array}$ & $\begin{array}{l}\mathrm{L}(\mathrm{C}) \mathrm{x} \\
(\mu \mathrm{g} / \mathrm{L})\end{array}$ & $\begin{array}{l}\text { Exposure } \\
\text { duration }\end{array}$ & $\begin{array}{l}\text { NOEC } \\
(\mu \mathrm{g} / \mathrm{L})\end{array}$ & \\
\hline Diaptomus sp. & $6.5^{d}$ & $0.0386^{d}$ & - & - & $16-d$ & $<0.03^{d}$ & Bangladesh \\
\hline Keratella sp. & - & - & - & - & $9-d$ & $<0.03^{d}$ & Bangladesh \\
\hline Keratella quadrata & - & - & - & - & $42-d$ & $1^{f}$ & Spain \\
\hline Keratella sp. & - & - & - & - & $44-d$ & $0.01^{\mathrm{e}}$ & Ethiopia \\
\hline Polyarthra sp. & - & - & - & - & $16-d$ & $<0.03^{d}$ & Bangladesh \\
\hline Polyarthra sp. & - & - & - & - & $9-d$ & $<0.01^{\mathrm{e}}$ & Ethiopia \\
\hline Brachionus sp. & - & - & - & - & $28-d$ & $0.03^{d}$ & Bangladesh \\
\hline B. calyciflorus & - & - & 10-NOEC & $6220^{n}$ & - & - & Iran \\
\hline Brachionus sp. & - & - & - & - & $23-d$ & $<0.01^{\mathrm{e}}$ & Ethiopia \\
\hline Filinia sp. & - & - & - & - & $23-d$ & $0.3^{d}$ & Bangladesh \\
\hline Filinia sp. & - & - & - & - & $58-d$ & $<0.01^{e}$ & Ethiopia \\
\hline Trichocerca sp. & - & - & - & - & $23-d$ & $0.3^{d}$ & Bangladesh \\
\hline Trichocerca sp. & - & - & - & - & $23-d$ & $<0.01^{\mathrm{e}}$ & Ethiopia \\
\hline Cyclops sp. & - & - & - & - & $9-d$ & $0.3^{d}$ & Bangladesh \\
\hline Cyclopoida & - & - & - & - & $17-d$ & $1^{f}$ & Spain \\
\hline Afrocyclops sp. & - & - & - & - & $30-d$ & $<0.01^{\mathrm{e}}$ & Ethiopia \\
\hline Nauplius & - & - & - & - & $9-d$ & $0.03^{d}$ & Bangladesh \\
\hline Naupulii & - & - & - & - & $3-d$ & $5^{f}$ & Spain \\
\hline Naupulii & - & - & - & - & $23-d$ & $<0.01^{\mathrm{e}}$ & Ethiopia \\
\hline
\end{tabular}

Note: $\mathrm{d}$ = Sumon et al. (2018); e = Chapter 6; $\mathrm{f}$ = Rico et al. (2018); $\mathrm{n}=$ Gharaei et al. (2020)

The threshold values derived from the single species toxicity test and mesocosm experiment can benefit future ecological risk assessment of imidacloprid insecticide to surface waters in Ethiopia and other tropical countries. The results may, for instance, contribute to the derivation of national water quality guidelines.

\subsection{Reducing pesticide (mis)use and improving urban waste effluents to abate pollution of aquatic ecosystem in Ethiopia}

Teklu (2016) reported risks of pesticides to the ecology of surface waters of Ethiopia while our studies described in Chapters $\mathbf{3}$ and $\mathbf{4}$ demonstrate pesticides contamination of Lake Ziway and effects to aquatic organisms. The misuse of pesticides and inappropriate handling of pesticide-related wastes by small- and large-scale farmers proximate to Lake Ziway has likely exacerbated the pollution and the effects. Mitigation measures are needed to reduce the release of pesticides into the lake ecosystem from the agricultural activities in the catchment area so that the risks of the contamination can be reduced. For instance, Mengistie et al. (2015) mentioned three missing key elements affecting the effective implementation of the available pesticide registration and control policy in Ethiopia that includes poor information 
availability to state and non-state actors, low motivation of state actors to implement the policies, and insufficient financial and human resources to implement them. The enforcement of the policy by overcoming the barriers is strongly advocated to reduce environmental pollution of pesticides and associated risks. Training of smallholder farmers on safe use and handling of pesticide and proper diagnosis/scouting of disease and pest need to be prioritised. Regular monitoring of chemical constituents and proper disposal management of pesticides are also necessary to reduce pesticide pollution of Lake Ziway and to minimize ecological risks (see Chapters 3 and 4).

Moreover, adopting and implementing ecologically sound and effective pest controlling methods such as Integrated Pest Management (IPM) technologies (de Bon et al., 2014; Sumon, 2018; Muriithi et al., 2020) that help reduce the use of synthetic pesticides are highly required. The approach involves biological (e.g., natural enemy, biopesticide and pest-resistant variety), agricultural (e.g., crop rotation, intercropping), and physical (e.g., greenhouses and insectproof nets) pest reducing and controlling strategies (Abate, 2006; de Bon et al., 2014; Muriithi et al., 2020). In Ethiopia, IPM related research has started in the 1980s (Abate, 2006). Various IPM techniques suitable for the agro-ecology of Ethiopia were identified, such as stripcropping of tomatoes with maize, and hot pepper (Capsicum) with lupine (Lupinus sp.) to reduce the African bollworm in vegetables (Abate, 2006), the use of pest-resistant cultivars like the tomato cultivars Serio and Pusa Early Dwarf which are resistant to potato tuber moth and African bollworm (Abate, 2006; Mohammed et al., 2006), and the use of botanical extracts (e.g., Neem seed, Phytolacca dodecandra and Securidaca longepedunculata) to control onion thrips (Mohammed et al., 2006; Shiberu et al., 2013).

However, awareness, adoption and application of IPM among Ethiopian farmers are low, which can be due to the poor and fragmented linkages between research institutes, agricultural consultants and the farmers (Sithanantham, 2004; Abate, 2006). This needs attention from the government and other actors. The government should support the adoption and dissemination of IPM technologies to smallholder farmers by providing training for farmers to create awareness about IPM, strengthen IPM research, and institutionalize the flow of know-how from research to farmers. Some effective IPM technologies require a high amount of investment, which cannot be afforded by smallholder farmers (de Bon et al., 2014). In this case, development partners and non-governmental organizations should play a key role by financially supporting farmers. The majority of large-scale farms around Lake Ziway have 
good experience with the use of IPM, particularly to control spider mites (Elings et al., 2011)(Chapter 3). Expanding the present best experience to farms not yet implementing IPM and adopting new IPM technologies to control other pests is highly needed to further reduce pesticide consumption of the large-scale farms.

Urban waste and sewage are also sources of pollutants of concern to African aquatic ecosystems such as microplastics (Biginagwa et al., 2016), trace metals (Rai, 2008) and nutrients that cause eutrophication (Fetahi, 2019). Ethiopian water bodies suffer similar problems as wastes are uncollected and dumped and released into unauthorized areas such as ditches, rivers, lakes, drains and streets in most Ethiopian cities and towns (Birke, 1999; Tarfasa and Brouwer, 2018; Fetahi, 2019). Our studies also showed the influence of urban wastes released from the proximate towns (Maki and Batu towns) on the ecology of Lake Ziway. High levels of nutrients, trace metals and plastic particles contamination were observed in areas of Lake Ziway close to the towns, receiving effluent from Batu town through intentionally constructed sewage canals by the municipality of the town (see Chapters 2, 4 and 5). To reduce the impact of urban wastes on Lake Ziway, improved waste management practices should be put in place and maintained by the municipalities of the proximate towns. For example, solid waste management techniques such as recycling, composting and incineration (Nigussie et al., 2015; Khan et al., 2018) could help alleviate the problem. Effective and inexpensive sewage treatment technologies are also required to minimize the impact of the liquid waste generated from the towns on Lake Ziway. For instance, employing phytoremediation technologies using wetland plants such as Typha, Cyperus and Phragmites, and buffering strips along the shoreline and wetland parts of the lake should be considered to remove urban effluents sourced nutrients and other pollutants (e.g., heavy metals) (Rai, 2008; Leto et al., 2013; Fetahi, 2019).

\subsection{Concluding remarks and future research outlooks}

The results of the literature review (Chapter 2) and chemical monitoring (Chapter 4) studies reveal the spatio-temporal change of physicochemical properties of Lake Ziway that affected the water quality status of the lake. The water quality of the lake has deteriorated and is not suitable for drinking water and/or for maximally supporting aquatic life based on multiple parameters. The results of the study in Chapter $\mathbf{3}$ showed the potential impacts of 
pesticide to ES of the lake due to the misuse and improper handling of the compounds by the farmers. Intervention measures that mitigate the ill practices of the farmers should be taken by the government, which included law enforcement to implement pesticide registration and control policy, facilitating training that help building the capacity of the farmers and perform environmental auditing for effluents from the floriculture farms. In Chapter 4, it is showed that Lake Ziway was contaminated by vast arrays of pesticides and the majority of the compounds pose high risks to the aquatic organisms of the lake, majorly at shoreline locations of Lake Ziway nearby floriculture and smallholder agricultural activities. The negative correlation observed between biological organisms (macroinvertebrates and fishes) and high concentration levels of stressors (nutrients and pesticides) suggests effects of the variables on structural and functional endpoints of the lake. The Ephemeroptera, Plecoptera and Trichoptera (EPT) richness tool was found to be effective, cheap and simple for water quality assessment of Lake Ziway. It is recommended for general use by the managers of the lake (e.g., Ministry of Water, Irrigation and Energy (MoWIE - Ethiopia)). The ministry (MoWIE) is the responsible governmental body to undertake management of the water resources of the country. Preparing precise guidelines or protocols on how to use the tool that can help the users is needed. The tool can also be used for other aquatic ecosystems in Ethiopia that are under similar anthropogenic pressures.

The risk assessment tools employed in this thesis are novel and can be used by researchers and government bodies (e.g., MoWIE, Ethiopian Environment and Forest Research Institute (EEFRI), and Environment, Forest and Climate Change Commission (EFCCC - Ethiopia)) for future ecological risk assessment of pesticides in different aquatic ecosystems in Ethiopia. Organization of capacity building programmes including training and short courses in collaboration with international institutions (e.g., universities, research institutes) for the users, is necessary. Furthermore, universities of the country should develop programmes in area of environmental risk assessment to fulfil the required human resources.

The results of the study of the plastic particles (Chapter 5) showed that the estimated concentration of plastic particles in sediments of Lake Ziway exceeded effect threshold values. The pollution can cause long term in-situ effects on the benthic community of the lake. The ingestion of plastic particles by the commercially important fishes of Lake Ziway need further ecological risk investigations and could also have implications for human health. 
The findings of the model ecosystem and single species effect studies indicated that imidacloprid is more toxic to tropical aquatic species compared to their temperate counterparts. It is worthy to investigate further whether the observed geographic-based differences between aquatic species is also observed for other chemicals, including other pesticides. A long-term structural alteration of tropical aquatic ecosystems can be expected after a chronic exposure to an environmentally realistic concentration of imidacloprid, as a longer recovery period was observed in Chapter 6 ( 9 weeks for zooplankton and >21 weeks for macroinvertebrates) compared to the result ( $2-8$ weeks) reported by Van Wijngaarden et al. (2005) for other neurotoxic insecticides. Despite their importance in risk assessment, effect studies of pesticides using tools such as simple (e.g., single-species toxicity test) and environmentally realistic (e.g., cosm study) experiments are new in Ethiopia. Our mesocosm study is the first to be performed in Ethiopia. Similar studies are recommended to be performed that help exploring the toxicological effect of chemicals including pesticides on aquatic ecosystems in Ethiopia and expand the toxicity dataset with local species, which is also crucial to support the development of national water quality guidelines. 



\section{References}

Aazami, J., Sari, A.E., Abdoli, A., Sohrabi, H., Van den Brink, P.J., 2015. Assessment of ecological quality of the Tajan River in liran using a multimetric macroinvertebrate index and species traits. Environmental Management 56, 260 - 269.

Abate, T., 2006. IPM in Ethiopia: The Current Status. Bekele, E., Azerefegne, F., Abate, T. (eds). Facilitating the Implementation and Adoption of Integrated Pest Management (IPM) in Ethiopia. Drylands Coordination Group. Addis Ababa, Ethiopia. Available on: https://www.utviklingsfondet.no/dcg/assets/documents/Publications/375-proceedings 17.pdf.

Abbasi, T., Abbasi, S.A., 2011. Water quality indices based on bioassessment: The biotic indices. Journal of Water and Health 9, $330-348$.

Abera, L., Getahun, A., Lemma, B., 2018. Changes in Fish Diversity and Fisheries in Ziway-Shala Basin: The Case of Lake Ziway, Ethiopia. Journal of Fisheries and Livestock Production 6 (1), 263 - 269.

Abobi, S.M., Ampofo-Yehoah, A., Kpodonu, T.A., Alhassan, E.H., Abarike, E.D., Atindaana, S.A., Akongyuure, D.N., Konadu, V., Twumasi, F., 2015. Socio-Ecological Importance of Aquatic Macrophytes to Some Fishing Communities in the Northern Region of Ghana. Elixir Bio Diversity 79, 30432 - 30437.

Abong'O, D.A., Wandiga, S.O., Jumba, I.O., 2018. Occurrence and distribution of organochlorine pesticide residue levels in water, sediment and aquatic weeds in the Nyando River catchment, Lake Victoria, Kenya. African Journal of Aquatic Science 43, 255 - 270.

Abong'O, D.A., Wandiga, S.O., Jumba, I.O., Van den Brink, P.J., Naziriwo, B.B., Madadi, V.O., Wafula, G.A., Nkedi-Kizza, P., Kylin, H., 2015. Occurrence, abundance and distribution of benthic macroinvertebrates in the Nyando River catchment, Kenya. African Journal of Aquatic Science 40:373-392.

Absher, T.M., Ferreira, S.L., Kern, Y., Jr, A.L.F., Christo, S.W., Ando, R.A., 2019. Incidence and identification of microfibers in ocean waters in Admiralty Bay, Antarctica. Environmental Science and Pollution Research 26:292-298.

Affum, A.O., Acquaah, S.O., Osae, S.D., Kwaansa-Ansah, E.E., 2018. Distribution and risk assessment of banned and other current-use pesticides in surface and groundwaters consumed in an agricultural catchment dominated by cocoa crops in the Ankobra Basin, Ghana. Science of the Total Environment 633, 630 - 640.

Aga, A.O., Melesse, A.M., Chane, B., 2019. Estimating the Sediment Flux and Budget for a Data Limited Rift Valley Lake in Ethiopia. Hydrology 6:1 - 23.

Akoueson, F., Sheldon, L.M., Danopoulos, E., Morris, S., Hotten, J., Chapman, E., Li, J., Rotchell, J.M., 2020. A preliminary analysis of microplastics in edible versus non-edible tissues from seafood samples. Environmental Pollution 263:114452.

Alahuhta, J., Joensuu, I., Matero, J., Vuori, K.-M., Saastamoinen, O., 2013. Reports of the Finnish Environment Institute: Freshwater ecosystem services in Finland. Report no. 16. Available on: https://www.academia.edu/24027296/Freshwater ecosystem services in Finland.

Alexander, A.C., Heard, K.S., Culp, J.M., 2008. Emergent body size of mayfly survivors. Freshwater Biology 53, 171 - 180.

Allan, J.D., Smith, S.D.P., McIntyre, P.B., Joseph, C.A., Dickinson, C.E., Marino, A.L., Biel, R.G., Olson, J.C., Doran, P.J., Rutherford, E.S., Adkins, J.E., Adeyemo, A.O., 2015. Using cultural ecosystem services to inform restoration priorities in the Laurentian Great Lakes. Frontiers in Ecology and the Environment 13(8), 418 - 424. 
Amera, T., Abate, A., 2008. Africa Stockpiles Programme: An assessment of the pesticide use, practice and hazards in the Ethiopian rift valley. Available on: http://doczz.net/doc/6422350/anassessment-of-the-pesticide-use--valley.

Añasco, N., Uno, S., Koyama, J., Matsuoka, T., Kuwahara, N., 2010. Assessment of pesticide residues in freshwater areas affected by rice paddy effluents in Southern Japan. Environmental Monitoring and Assessment 160, 371 - 383.

Anderson, J.C., Dubetz, C., Palace, V.P., 2015. Neonicotinoids in the Canadian aquatic environment: A literature review on current use products with a focus on fate, exposure, and biological effects. Science of the Total Environment 505, 409 - 422.

Anderson, J.C., Park, B.J., Palace, V.P., 2016. Microplastics in aquatic environments: Implications for Canadian ecosystems: A Review. Environmental Pollution 218:269-280.

Andersson, E., McPhearson, T., Kremer, P., Gomez-Baggethun, E., Haase, D., Tuvendal, M., Wurster, D., 2015. Scale and context dependence of ecosystem service providing units. Ecosystem Services 12, 157 - 164.

Ansara-Ross, T.M., Wepener, V., Van den Brink, P.J., Ross, M.J., 2012. Pesticides in South African fresh waters. African Journal of Aquatic Science 37:1-16.

Anthonj, C., Fleming, L., Godfrey, S., Ambelu, A., Bevan, J., Cronk, R., Bartram, J., 2018. Health Risk Perceptions Are Associated with Domestic Use of BasicWater and Sanitation Services: Evidence from Rural Ethiopia. International Journal of Environmental Research and Public Health 15, 2112 $-2130$.

ANZECC, 1992. Australian Water Quality Guidelines for Fresh and Marine Waters, Australian and New Zealand Environment and Conservation Council (ANZECC), Canberra.

Armitage, P.D., Moss, D., Wright, J.F., Furse, M.T., 1983. The performance of a new biological water quality score system based on macroinvertebrates over a wide range of unpolluted running-water sites. Water Research 17, 333 - 347.

Arts, G.H.P., Dollinger, M., Kohlschmid, E., Maltby, L., Ochoa-Acuña, H., Poulsen, V., 2015. An ecosystem services approach to pesticide risk assessment and risk management of non-target terrestrial plants: recommendations from a SETAC Europe workshop. Environmental Science and Pollution Research 22, 2350 - 2355.

Awulachew, S.B., Yilma, A.D., Loulseged, M., Loiskandl, W., Ayana, M., Alamirew, T., 2007. Water Resources and Irrigation Development in Ethiopia. Working Paper 123. Colombo, Sri Lanka: International Water Management Institute. doi: http://dx.doi.org/10.3910/2009.305.

Ayenew T., Legesse D., 2007. The changing face of the Ethiopian rift lakes and their environs: call of the time. Lakes \& Reservoirs: Research and Management 12: 149-165.

Ayenew, T., 1998. The hydrogeological system of the Lake District basin: Central Main Ethiopian Rift. PhD Thesis, Free University of Amsterdam, The Netherlands. Avialable on: https://research.utwente.nl/en/publications/the-hydrogeological-system-of-the-lake-districtbasin-central-mai.

Ayenew, T., 2002. Recent changes in the level of Lake Abiyata, central main Ethiopian Rift. Hydrological Sciences Journal 47(3), 493 - 503.

Ayenew, T., 2004. Environmental implications of changes in the levels of lakes in the Ethiopian Rift since 1970. Regional Environmental Change 4:192-204.

Ayenew, T., 2007. Water management problems in the Ethiopian rift: Challenges for development. Journal of African Earth Sciences 48, 222 - 236. 
Bachewe, F.N., Berhane, G., Minten, B., Taffesse, A.S., 2018. Agricultural transformation in Africa? assessing the evidence in Ethiopia. World Development 105, 286 - 298.

Baron, J.S., Poff, N.L., Angermeier, P.L., Dahm, C.N., Gleick, P.H., Hairston, N.G., Jr. Jackson, R.B., Johnston, C.A., Richter, B.D., Stenman, A.D., 2002. Meeting ecological and societal needs for freshwater. Ecological Applications 12:1247-1260.

Bartlett, A.J., Hedges, A.M., Intini, K.D., Brown, L.R., Maisonneuve, F.J., Robinson, S.A., Gillis, P.L., de Solla, S.R., 2019. Acute and chronic toxicity of neonicotinoid and butenolide insecticides to the freshwater amphipod, Hyalella azteca. Ecotoxicology and Environmental Safety 175, 215 - 223.

Bekele, J., Hussien, D,. 2015. Prevalence of Internal Parasites of Oreochromis niloticus and Clarias gariepinus Fish Species in Lake Ziway, Ethiopia. Journal of Aquatic Research Development 6:1-4.

Beketov, M.A., Schäfer, R.B., Marwitz, A., Paschke, A., Liess, M., 2008. Long-term stream invertebrate community alterations induced by the insecticide thiacloprid: Effect concentrations and recovery dynamics. Science of the Total Environment 405, 96-108.

Belay, A., Wood, R.B., 1984. Primary productivity of five Ethiopian Rift Valley lakes. International Society of Limnology 22:1187-1192.

Belay, S., 1988. Zooplankton composition and seasonal dynamics in Lake Ziway, Ethiopia. MSc thesis, Addis Ababa University, Ethiopia. Available on: http://etd.aau.edu.et/bitstream/handle/123456789/7568/Semeneh\%20Belay.pdf?sequence=1 \&isAllowed=y.

Beneberu, G., Mengistou, S., 2009. Oligotrophication trend of lake Ziway, Ethiopia. SINET: Ethiopian Journal of Science 32(2):141-148.

Berhane, M., 2014. Runoff and sediment yield estimation for western part of Ziway lake watershed, central Ethiopia. MSc thesis, Haramaya University, Ethiopia.

Berhanu, B., Seleshi, Y., Melesse, A.M., 2014. Surface Water and Groundwater Resources of Ethiopia: Potentials and Challenges of Water Resources Development. Melesse, A.M., Abtew, W. and Setegn, S.G. (eds), Nile River Basin: Ecohydrological Challenges, Climate Change and Hydropolitics. Pp. 705, Springer International Publishing Switzerland.

Besseling, E., Foekema, E.M., Van Franeker, J.A., Leopold, M.F., Kühn, S., Rebolledo, E.L.B., Heße, E., Mielke, L., IJzer, J., Kamminga, P., Koelmans, A.A., 2015. Microplastic in a macro filter feeder: Humpback whale Megaptera novaeangliae. Marine pollution bulletin 95:248-252.

Besseling, E., Redondo-Hasselerharm, P., Foekema, E.M., Koelmans, A.A., 2019. Quantifying ecological risks of aquatic micro- and nanoplastic. Critical Reviews in Environmental Science and Technology 49(1):32 - 80.

Beyene, A., Addis, T., Kifle, D., Legesse, W., Kloos, H., Triest, L., 2009. Case Study: Comparative study of diatoms and macroinvertebrates as indicators of severe water pollution: Case study of the Kebena and Akaki rivers in Addis Ababa, Ethiopia. Ecological indicators 9, 381 - 392.

Biginagwa, F.J., Mayoma, B.S., Shashoua, Y., Syberg, K., Khan, F.R., 2016. First evidence of microplastics in the African Great Lakes: Recovery from Lake Victoria Nile perch and Nile tilapia: Notes. Journal of Great Lakes Research 42, 146 - 149.

Birke, Y., 1999. Solid waste management in Ethiopia: Integrated development for water supply and sanitation. Addis Ababa, Ethiopia. Available on: https://repository.Iboro.ac.uk/articles/Solid waste management in Ethiopia/9586085/files/17 224778.pdf.

BLI, 2019. BirdLife International (BLI): Country profile: Ethiopia. Available on http://www.birdlife.org/datazone/country/ethiopia. 
Boerger, C.M., Lattin, G.L., Moore, S.L., Moore, C.J., 2010. Plastic ingestion by planktivorous fishes in the North Pacific Central Gyre. Marine pollution bulletin 60, 2275-2278.

Bonmatin, J.M., Giorio, C., Girolami, V., Goulson, D., Kreutzweiser, D.P., Krupke, C., Liess, M., Long, E., Marzaro, M., Mitchell, E.A.D., Noome, D.A., Simon-Delso, N., Tapparo, A., 2015. Environmental fate and exposure; neonicotinoids and fipronil. Environtal Science and Pollution Research 22, 35 $-67$.

Boyd, J., Banzhaf, S., 2007. Analysis: What are ecosystem services? The need for standardized environmental accounting units. Ecological Economics 63, 616 - 626.

Braat, L.C., de Groot, R., 2012. The ecosystem services agenda: bridging the worlds of natural science and economics, conservation and development, and public and private policy: Review. Ecosystem Services 1, 4 - 15.

Bremmer, J., Chaka, K.D., Dijkxhoorn, Y., Mammo, B., 2014. Pesticide risk reduction programme: feasibility study of the proposed pesticide registration and post-registration processes. (MEMORANDUM LEI; No. 14-109). The Hague: LEI Wageningen UR. Avialable on: https://research.wur.nl/en/publications/pesticide-risk-reduction-programme-feasibility-studyof-the-propo.

Briassoulis, D., Hiskakisa, M., Karasali, H., Briassoulis, C., 2014. Design of a European agrochemical plastic packaging wastemanagement scheme-Pilot implementation in Greece. Resources, Conservation and Recycling 87, 72 - 88.

Brittain, J.E., 1982. Biology of mayflies. Annual Review of Entomology 27, 119 - 147.

Brock, T.C.M., Arts, G.H.P., Maltby, L., Van den Brink, P.J., 2006. Aquatic Risks of Pesticides, Ecological Protection Goals, and Common Aims in European Union Legislation. Integrated Environmental Assessment and Management 2(4), e20 - e46.

Brock, T.C.M., Arts, G.H.P., ten Hulscher, T.E.M., de Jong, F.M.W., Luttik, R., Roex, E.W.M., Smit, C.E., van Vliet, P.J.M., 2011. Aquatic effect assessment for plant protection products: Dutch proposal that addresses the requirements of the Plant Protection Product Regulation and Water Framework Directive. Wageningen, Alterra, Alterra Report 2235. Available on: https://edepot.wur.nl/187906.

Brock, T.C.M., Bhatta, R., Van Wijngaarden, R.P.A., Rico, A., 2016. Is the chronic tier-1 effect assessment approach for insecticides protective for aquatic ecosystems? Integrated Environmental Assessment and Management 12, 747 - 758.

Brock, T.C.M., Lahr, J., Van den Brink, P.J., 2000a. Ecological risks of pesticides in freshwater ecosystems, Part 1: Herbicides p. 124, Wageningen, Alterra. Available on: https://research.wur.nl/en/publications/ecological-risks-of-pesticides-in-freshwaterecosystems-part-1-he.

Brock, T.C.M., Roessink, I., Belgers, J.D.M., Bransen, F., Maund, S.J., 2009. Impact of a benzoyl urea insecticide on aquatic macroinvertebrates in ditch mesocosms with and without non-sprayed sections. Environmental Toxicology and Chemistry 28(10), 2191 - 2205.

Brock, T.C.M., Van Wijngaarden, R.P.A., Van Geest, G.J. 2000b. Ecological risks of pesticides in freshwater ecosystems, Part 2: Insecticides, pp. 142, Wageningen, Alterra. Available on: https://research.wur.nl/en/publications/ecological-risks-of-pesticides-in-freshwaterecosystems-part-2-in.

Browne, M.A., Galloway, T.S., Thompson, R.C., 2010. Spatial Patterns of Plastic Debris along Estuarine Shorelines. Environmental Science and Technology 44(9):3404-3409. 
Bryce, D.L., 1931. Report on the Rotifera: Mr. Omer-Cooper's investigation of the Abyssinian freshwater (Dr. HUGH SCOTT Expedition). Proceeding of the Zoological Society of London. pp. 865-878. Avialable on: https://doi.org/10.1111/j.1096-3642.1931.tb01048.x.

Bundschuh, M., Arts, G., Brühl, C.A., Imfeld, G.I., Knäbel, A., Payraudeau, S., Rasmussen, J.J., Rohr, J., Scharmüller, A., Smalling, K., Stehle, S., Schulz, R., Schäfer, R.B., 2019. Fungicides: An Overlooked Pesticide Class? Environmental Science and Technology 53, 3347 - 3365.

Busch, M., Notte, A.L., Laporte, V., Erhard, M., 2012. Potentials of quantitative and qualitative approaches to assessing ecosystem services. Ecological Indicators 21, 89 - 103.

Calow, P., Forbes, V.E., 2003. Viewpoint: Does Ecotoxicology Inform Ecological Risk Assessment? Some argue that ecotoxicology is too simplistic to do the job effectively. Environmental Science and Technology, $147 \mathrm{~A}-151 \mathrm{~A}$.

Camargo, J.A., Alonso, Á., 2006. Review: Ecological and toxicological effects of inorganic nitrogen pollution in aquatic ecosystems: A global assessment. Environment International 32, 831 - 849.

Camp, A.A., Buchwalter, D.B., 2016. Can't take the heat: Temperature-enhanced toxicity in the mayfly Isonychia bicolor exposed to the neonicotinoid insecticide imidacloprid. Aquatic Toxicology 178, 49 - 57.

Cannicci, G., Almagia, F., 1947. Notizie sulla "Facies" planctonica di Alcuni Laghi Della Fossa Galla. Bollettino di pesca, piscicoltura e idrobiologia 23(1):5-28.

Cannon, S.M.E., Lavers, J.L., Figueiredo, B., 2016. Plastic ingestion by fish in the Southern Hemisphere: A baseline study and review of methods. Marine pollution bulletin 107:286-291.

Capowiez, Y., Berard, A., 2006. Assessment of the effects of imidacloprid on the behavior of two earthworm species (Aporrectodea nocturna and Allolobophora icterica) using 2D terraria. Ecotoxicology and Environmental Safety 64198 - 206.

Carbery, M., O'Connor, W., Thavamani, P., 2018. Trophic transfer of microplastics and mixed contaminants in the marine food web and implications for human health. Environment International 115:400 - 409.

Carey, R.O., Migliaccio, K.W., 2009. Contribution of Wastewater Treatment Plant Effluents to Nutrient Dynamics in Aquatic Systems: A Review. Environmental Management 44, 205 - 217.

Castañeda, R.A., Avlijas, S., Simard, M.A., Ricciardi, A., 2014. Microplastic pollution in St. Lawrence River sediments. Canadian Journal of Fisheries and Aquatic Sciences 71:1767-1771.

Castillo, L.E., Cruz, E.D.L., Ruepert, C., 1997. Annual Review: Ecotoxicology and pesticides in tropical aquatic ecosystems of Central America. Environmental Toxicology and Chemistry 16(1), 41 - 51.

Cavallaro, M.C., Liber, K., Headley, J.V., Peru, K.M., Morrissey, C.A., 2018. Community-Level and Phenological Responses of Emerging Aquatic Insects Exposed To 3 Neonicotinoid Insecticides: An In Situ Wetland Limnocorral Approach. Environmental Toxicology and Chemistry 37(9), 2401 2412.

Cavallaro, M.C., Morrissey, C.A., Headley, J.V., Peru, K.M., Liber, K., 2017. Comparative chronic toxicity of imidacloprid, clothianidin, and thiamethoxam to Chironomus dilutus and estimation of toxic equivalency factors. Environmental Toxicology and Chemistry 36(2), 372 - 382.

Ccanccapa, A., Masi, A., Navarro-Ortega, A., Pico, Y., Barcelo, D., 2016. Pesticides in the Ebro River basin: Occurrence and risk assessment. Environmental Pollution 211, 414 - 424.

Chandran, N.N., Fojtova, D., Blahova, L., Rozmankova, E., Blaha, L., 2018. Acute and (sub)chronic toxicity of the neonicotinoid imidacloprid on Chironomus riparius. Chemosphere 209, 568 - 577. 
Chipeta, M., Emana, B., Chanyalew, D., 2015. Ethiopia's Agriculture Sector Policy and Investment Framework (2010-2020) External Mid-term Review. Available on: https://www.agri-learningethiopia.org/wp-content/uploads/2015/10/Agriculture-Policy-MTR FINAL.pdf.

Ciftcioglu, G.C., Ebedi, S., Abak, K., 2019. Evaluation of the relationship between ornamental plants based ecosystem services and human wellbeing: A case study from Lefke Region of North Cyprus. Ecological Indicators 102, 278 - 288.

Cincinelli, A., Scopetani, C., Chelazzi, D., Lombardini, E., Martellini, T., Katsoyiannis, A., Fossi, M.C., Corsolini, S., 2017. Microplastic in the surface waters of the Ross Sea (Antarctica): Occurrence, distribution and characterization by FTIR. Chemosphere 175:391 - 400.

Cole, M., 2016. A novel method for preparing microplastic fibers. Scientific Reports 6:34519.

Cole, M., Lindeque, P., Fileman, E., Halsband, C., Galloway, T.S., 2015. The Impact of Polystyrene Microplastics on Feeding, Function and Fecundity in the Marine Copepod Calanus helgolandicus. Environmental Science and Technology 49:1130 - 1137.

Cole, M., Webb, H., Lindeque, P.K., Fileman, E.S., Halsband, C., Galloway, T.S., 2014. Isolation of microplastics in biota-rich seawater samples and marine organisms. Scientific Reports 4:4528.

Collard, F., Gasperi, J., Gilbert, B., Eppe, G., Azimi, S., Rocher, V., Tassin, B., 2018. Anthropogenic particles in the stomach contents and liver of the freshwater fish Squalius cephalus. Science of the Total Environment 643:1257-1264.

Colombo, V., Mohr, S., Berghahn, R., Pettigrove, V.J., 2013. Structural Changes in a Macrozoobenthos Assemblage After Imidacloprid Pulses in Aquatic Field-Based Microcosms. Archives of Environmental Contamination and Toxicology 65, 683 - 692.

Conley, D.J., Paerl, H.W., Howarth, R.W., Boesch, D.F., Seitzinger, S.P., Havens, K.E., Lancelot, C., Likens, G.E., 2009. Controlling Eutrophication: Nitrogen and Phosphorus. Science 323(5917), 1014 - 1015.

Constant, M., Ludwig, W., Kerhervé, P., Sola, J., Charrière, B., Sanchez-Vidal, A., Canals, M., Heussner, S., 2020. Microplastic fluxes in a large and a small Mediterranean river catchments: The Têt and the Rhône, Northwestern Mediterranean Sea. Science of the Total Environment 716, 136984 136996.

Costas, N., Pardo, I., Méndez-Fernández, L., Martínez-Madrid, M., Rodríguez, P., 2018. Sensitivity of macroinvertebrate indicator taxa to metal gradients in mining areas in Northern Spain. Ecological indicators 93, $207-218$.

Covich, A.P., Palmer, M.A., Crowl, T.A., 1999. The Role of Benthic Invertebrate Species in Freshwate ecosystems. BioScience 49:119-127.

CSA, 2013. Federal Democratic Republic of Ethiopia Central Statistical Agency (CSA): Population Projection of Ethiopia for All Regions At Wereda Level from 2014 - 2017. Avialable on: http://www.csa.gov.et/index.php/ehioinfo-internal\%3Fdownload\%3D724:populationprojection-of-ethiopia-for-all-regions-atwereda-level-from-2014-2017\%26start\%3D5.

Curchod, L., Oltramare, C., Junghans, M., Stamm, C., Dalvie, M.A., Röösli, M., Fuhrimann, S., 2020. Temporal variation of pesticide mixtures in rivers of three agricultural watersheds during a major drought in the Western Cape, South Africa. Water Research X 6, 100039 - 100049.

Daam, M.A., Pereira, A.C.S., Silva, E., Caetano, L., Cerejeira, M.J., 2013. Preliminary aquatic risk assessment of imidacloprid after application in an experimental rice plot. Ecotoxicology and Environmental Safety 97, $78-85$.

Daam, M.A., Van den Brink, P.J., 2007. Effects of Chlorpyrifos, Carbendazim, and Linuron on the Ecology of a Small Indoor Aquatic Microcosm. Archive of Environmental Contamination and Toxicology $53,22-35$. 
Daam, M.A., Van den Brink, P.J., 2011. Conducting model ecosystem studies in tropical climate zones: Lessons learned from Thailand and way forward. Environmental Pollution 159, 940 - 946.

Dagne, A., Herzig, A., Jersabek, C.D., Tadesse, Z., 2008. Abundance, Species Composition and Spatial Distribution of Planktonic Rotifers and Crustaceans in Lake Ziway (Rift Valley, Ethiopia). International Review of Hydrobiology 93:210-226.

Daigneault, C.V., Nichols, K., Hall, M., 2012. The Importance of Wetlands in Ecosystem Services: with Special Attention on Flood Attenuation, Carbon Sequestration, Hydrogeology, Water Quality, Biodiversity, and Social and Local Values. ERSC $3160 \mathrm{H}$ - WETLANDS FINAL REPORT. Available on: http://www.muskokawatershed.org/wp-content/uploads/2012/06/ValuingWetlands1.pdf.

Darko, G., Akoto, O., Oppong, C., 2008. Persistent organochlorine pesticide residues in fish, sediments and water from Lake Bosomtwi, Ghana. Chemosphere 72, 21 - 24.

de Bon, H., Huat, J., Parrot, L., Sinzogan, A., Martin, T., Malézieux, E., Vayssières, J.-F., 2014. Pesticide risks from fruit and vegetable pest management by small farmers in sub-Saharan Africa. A review. Agronomy for Sustainable Development 34, 723 - 736.

de Souza Machado, A.A., Spencer, K., Kloas, W., Toffolon, M., Zarfl, C., 2016. Metal fate and effects in estuaries: A review and conceptual model for better understanding of toxicity. Science of the Total Environment 541, 268 - 281.

Deng, H., Wei, R., Luo, W., Hu, L., Li, B., Di, Y., Shi, H., 2020. Microplastic pollution in water and sediment in a textile industrial area. Environmental Pollution 258, 113658.

Deribe, E., Rosseland, B.O., Borgstrøm, R., Salbu, B., Gebremariam, Z., Dadebo, E., Skipperud, L., Eklo, O.M., 2013. Biomagnification of DDT and its metabolites in four fish species of a tropical lake. Ecotoxicology and Environmental Safety 95, 10 - 18.

Desta, H., Lemma, B., Albert, G., Stellmacher, T., 2015. Degradation of Lake Ziway, Ethiopia: A study of the environmental perceptions of school students. Lakes and Reservoirs: Research and Management 20, 243 - 255.

Dhir, B., Sharmila, P., Saradhi, P.P., 2009. Potential of Aquatic Macrophytes for Removing Contaminants from the Environment. Critical Reviews in Environmental Science and Technology 39, 754-781.

Di, M., Wang, J., 2018. Microplastics in surface waters and sediments of the Three Gorges Reservoir, China. Science of the Total Environment 616-617:1620-1627.

Dibaba, W.T., Demissie, T.A., Miegel, K., 2020. Drivers and Implications of Land Use/Land Cover Dynamics in Finchaa Catchment, Northwestern Ethiopia. Land 9, 113 - 131.

Dickens, C., Graham, P., 2002. The South African Scoring System (SASS) Version 5 rapid bioassessment method for rivers. African Journal of Aquatic Science 27, 1 - 10.

Diepens, N.J., Koelmans, A.A., Baveco, H., Van den Brink, P.J., van den Heuvel-Greve, M.J., Brock, T.C.M., 2017. Prospective Environmental Risk Assessment for Sediment-Bound Organic Chemicals: A Proposal for Tiered Effect Assessment. de Voogt, P., (ed). Reviews of Environmental Contamination and Toxicology. Pp. 184, Springer International Publishing Switzerland.

Diepens, N.J., Pfennig, S., Van den Brink, P.J., Gunnarsson, J.S., Ruepert, C., Castillo, L.E., 2014. Effect of pesticides used in banana and pineapple plantations on aquatic ecosystems in Costa Rica. Journal of Environmental Biology 35, $73-84$.

Duchet, C., Kraft, A., Stark, J.D., 2018. Effects of environmentally realistic concentrations of neonicotinoid insecticides on an aquatic invertebrate community. Salish Sea Ecosystem Conference. Available on: https://cedar.wwu.edu/ssec/2018ssec/allsessions/398. 
Edo, C., Gonzalez-Pleiter, M., Leganes, F., Fernandez-Pinas, F., Rosal, R., 2020. Fate of microplastics in wastewater treatment plants and their environmental dispersion with effluent and sludge. Environmental Pollution 259, 113837.

Eerkes-Medrano, D., Thompson, R., 2018. Occurrence, Fate, and Effect of Microplastics in Freshwater Systems. Zeng, E.Y. (ed). Microplastic Contamination in Aquatic Environments: An Emerging Matter of Environmental Urgency. Pp. 95 - 132, Elsevier Inc.

EFSA, 2010. European Food Safety Authority (EFSA): Scientific Opinion on the development of specific protection goal options for environmental risk assessment of pesticides, in particular in relation to the revision of the Guidance Documents on Aquatic and Terrestrial Ecotoxicology (SANCO/3268/2001 and SANCO/10329/2002). EFSA Journal 8(10), 1821.

EFSA, 2013. European Food Safety Authority (EFSA) Scientific Opinion: Guidance on tiered risk assessment for plant protection products for aquatic organisms in edge-of-field surface waters. EFSA Journal 11(7), 3290.

Elings, A., den Belder, E., Yilma, Y., Dawd, M., Lemessa, F., 2011. Integrated Pest Management in Ethiopian Rose Horticulture. Acta Horticulturae 911, 511 - 518.

Endale, K., 2011. Fertilizer Consumption and Agricultural Productivity in Ethiopia. Ethiopian Development Research Institute, Addis Ababa, Ethiopia. Available on: http://www.edri.org.et/Resources/Working Papers/EDRI WP003 Fertilizer Consumption.pdf.

Endebu, M., Girma, F., 2016. Sesbania sesban, a fodder species potential to rehabilitate wetland vegetation in Lake Ziway, Ethiopia. International Journal of Fisheries and Aquatic Studies 4:298301.

Endebu, M., Lema, A., Genet, T., Mitike, A., Regassa, B., Dejen, E., Abegaz, H., 2015. Fisheries Baseline Survey Describing Status of Fisheries in Lake Zeway, Ethiopia. Journal of Fisheries and Livestock Production 3(2), 129 - 135.

EPP, 2009. Sampling fish communities using seine nets: Environmental Protection (Water) Policy (EPP) - Monitoring and Sampling Manual Biological assessment Version 2017. Avialable on: https://environment.des.qld.gov.au/water/monitoring/sampling-manual/pdf/biologicalassessment-sampling-fish-communities-using-seine-nets.pdf.

Eresso A., 2010. Assessment of water balance of lake Ziway and its temporal variation due to water abstraction. MSc thesis, Haramaya University, Ethiopia. Available on: https://www.academia.edu/40008946/ASSESSMENT OF WATER BALANCE OF LAKE ZIWAY AND ITS TEMPORAL VARIATION DUE TO WATER ABSTRACTION.

Erko, B., Balcha, F., Kifle, D., 2006. The ecology of Biomphalaria sudanica in Lake Ziway, Ethiopia. African Journal of Ecolology 44, 347-352.

EU, 1998. European Communities, Council Directive 98/83/EC on the quality of water intended for human consumption. Avialable on: https://eur-lex.europa.eu/homepage.html?locale=en.

European Commission, 2018. Commission implementing regulation (EU) 2018/783 of 29 May 2018 amending Implementing Regulation (EU) No 540/2011 as regards the conditions of approval of the active substance imidacloprid. Official Journal of European Union 61, 31 - 34.

Faber, J.H., 2006. European Experience on Application of Site-Specific Ecological Risk Assessment in Terrestrial Ecosystems. Human and Ecological Risk Assessment 12(1), 39 - 50.

Faber, J.H., Marshall, S., Van den Brink, P.J., Maltby, L., 2019. Priorities and opportunities in the application of the ecosystem services concept in risk assessment for chemicals in the environment. Science of the Total Environment 651, 1067 - 1077. 
Faber, J.H., Van Wensem, J., 2012. Elaborations on the use of the ecosystem services concept for application in ecological risk assessment for soils. Science of the Total Environment 415, 3 - 8.

Faggiano, L., de Zwart, D., García-Berthou, E., Lek, S., Gevrey, M., 2010. Patterning ecological risk of pesticide contamination at the river basin scale. Science of the Total Environment 408, 2319 2326.

Falco, F.D., Gullo, M.P., Gentile, G., Pace, E.D., Cocca, M., Gelabert, L., Brouta-Agnesa, M., Rovira, A., Escudero, R., Villalba, R., Mossotti, R., Montarsolo, A., Gavignano, S., Tonin, C., Avella, M., 2018. Evaluation of microplastic release caused by textile washing processes of synthetic fabrics. Environmental Pollution 236:916-925.

FAO, 2011. Food and Agriculture Organization of the United Nations (FAO): Ethiopia Country Programming Framework (2012-2015), p. 41, Addis Ababa, Ethiopia. Available on: http://www.fao.org/3/an490e/an490e00.pdf.

FAO, 2016. Food and Agriculture Organization of the United nations (FAO), FAO AQUASTAT Reports: Country Profile - Ethiopia, Rome, Italy. Available on: http://www.fao.org/3/i9732en/19732EN.pdf.

FAO, 2019. Food and agriculture data (FAOSTAT). Available on: http://www.fao.org/faostat/en/\#data.

Fetahi, T., 2019. Eutrophication of Ethiopian water bodies: a serious threat to water quality, biodiversity and public health. African Journal of Aquatic Science 44(4), 303 - 312.

Feyissa, G.S., Ranjan, R., 2012. Growing vulnerability: population pressure, food insecurity and environmental degradation, Central Rift Valley, Ethiopia. Journal of Biodiversity and Environmental Sciences (JBES) 2(3), 33 - 41.

Finnegan, M.C., Baxter, L.R., Maul, J.D., Hanson, M.L., Hoekstra, P.F., 2017. Comprehensive characterization of the acute and chronic toxicity of the neonicotinoid insecticide thiamethoxam to a suite of aquatic primary producers, invertebrates, and fish. Environmental Toxicology and Chemistry 36(10), 2838 - 2848.

Fischer, E.K., Paglialonga, L., Czech, E., Tamminga, M., 2016. Microplastic pollution in lakes and lake shoreline sediments - A case study on Lake Bolsena and Lake Chiusi (central Italy). Environmental Pollution 213, 648-657.

Fleeger, J.W., Carman, K.R., Nisbet, R.M., 2003. Indirect effects of contaminants in aquatic ecosystems. The Science of the Total Environment 317, 207 - 233.

Foekema, E.M., Gruijter, C.D., Mergia, M.T., Van Franeker, J.A., Murk, A.J., Koelmans, A.A., 2013. Plastic in North Sea Fish. Environmental Science and Technology 47, 8818-8824.

Foley, J.A., DeFries, R., Asner, G.P., Barford, C., Bonan, G., Carpenter, S.R., Chapin, F.S., Coe, M.T., Daily, G.C., Gibbs, H.K., Helkowski, J.H., Holloway, T., Howard, E.A., Kucharik, C.J., Monfreda, C., Patz, J.A., Prentice, I.C., Ramankutty, N., Snyder, P.K., 2005. Global Consequences of Land Use: Review. Science 309, 570 - 574.

Forbes, V.E., Calow, P., 2002. Species Sensitivity Distributions Revisited: A Critical Appraisal. Human and Ecological Risk Assessment 8(3), 473 - 492.

Forbes, V.E., Calow, P., 2012. Use of the Ecosystem Services Concept in Ecological Risk Assessment of Chemicals. Integrated Environmental Assessment and Management 9 (2), 269 - 275.

Free, C.M., Jensen, O.P., Mason, S.A., Eriksen, M., Williamson, N.J., Boldgiv, B., 2014. High-levels of microplastic pollution in a large, remote, mountain lake. Marine Pollution Bulletin 85, 156-163.

Frias, J.P.G.L., Sobral, P., Ferreira, A.M., 2010. Organic pollutants in microplastics from two beaches of the Portuguese coast. Marine pollution bulletin 60, 1988-1992. 
Galgani, F., Hanke, G., Maes, T., 2015. Global Distribution, Composition and Abundance of Marine Litter. In: Bergmann, M., Gutow, L., Klages, M., (eds). Marine Anthropogenic Litter. Springer International Publishing AG, Switzerland. PP 445.

Garedew, E., Sandewall, M., Söderberg, U., Campbell, B.M., 2009. Land-Use and Land-Cover Dynamics in the Central Rift Valley of Ethiopia. Environmental Management 44, 683 - 694.

Gari, T., Kenea, O., Loha, E., Deressa, W., Hailu, A., Balkew, M., Gebre-Michael, T., Robberstad, B., Overgaard, H.J., Lindtjørn, B., 2016. Malaria incidence and entomological findings in an area targeted for a cluster-randomized controlled trial to prevent malaria in Ethiopia: results from a pilot study. Malaria Journal 15:145-457.

Gebreselassie, S., 2006. Intensification of Smallholder Agriculture in Ethiopia: Options and Scenarios. Discussion Paper $007 . \quad$ Available on: https://assets.publishing.service.gov.uk/media/57a08c2aed915d3cfd0011f8/FAC Discussion P aper No7.pdf.

Gergs, A., Classen, S., Strauss, T., Ottermanns, R., Brock, T.C.M., Ratte, H.T., Hommen, U., Preuss, T.G., 2016. Ecological Recovery Potential of Freshwater Organisms: Consequences for Environmental Risk Assessment of Chemicals. In de Voogt, P., ed. Reviews of Environmental Contamination and Toxicology. Springer International Publishing, Switzerland.

Getachew, M., Ambelu, A., Tiku, S., Legesse, W., Adugna, A., Kloos, H., 2012. Ecological assessment of Cheffa Wetland in the Borkena Valley, northeast Ethiopia: Macroinvertebrate and bird communities. Ecological indicators 15, $63-71$.

Getahun, A., Stiassny, M.L.J., 1998. The freshwater biodiversity crisis: the case of the Ethiopian fish fauna. SINET: Ethiopian Journal of Science 21, 207-230.

Gharaei, A., Karimi, M., Harijani, J.M., Miri, M., Faggio, C., 2020. Population growth of Brachionus calyciflorus affected by deltamethrin and imidacloprid insecticides. Iranian Journal of Fisheries Sciences 19(2), 588 - 601.

Gheorghe, S., Stoica, C., Vasile, G.G., Nita-Lazar, M., Stanescu, E., Lucaciu, I.E., 2017. Metals Toxic Effects in Aquatic Ecosystems: Modulators of Water Quality. Tutu, H., (ed). In Water Quality. InTech.

Gizaw, B., 1996. The origin of high bicarbonate and fluoride concentrations in waters of the Main Ethiopian Rift Valley, East African Rift system. Journal of African Earth Sciences 22:391-402.

Golubtsov, A.S., Dgebuadze, Y.Y., Mina, M.V., 2002. Fishes of the Ethiopian Rift Valley, in: Tudorancea, C., Taylor, W.D. (eds), Ethiopian Rift Valley Lakes. Leiden, The Netherlands: Backhuys Publishers. pp 167-2587.

Green, J., 1994. The temperate-tropical gradient of planktonic Protozoa and Rotifera. Hydrobiologia 272:13-26.

Grizzetti, B., Lanzanova, D., Liquete, C., Reynaud, A., 2015. Joint Research Centre (JRC) Science and Policy Report: Cook-book for water ecosystem service assessment and valuation, p. 136, European Commission. Available on: https://publications.jrc.ec.europa.eu/repository/bitstream/JRC94681/lbna27141enn.pdf.

Haave, M., Lorenz, C., Primpke, S., Gerdts, G., 2019. Different stories told by small and large microplastics in sediment - first report of microplastic concentrations in an urban recipient in Norway. Marine pollution bulletin 141, 501-513.

Hailu, M., 2011. Ecosystem structure, trophic link and functioning of a shallow rift valley lake: the case of Lake Ziway (Ethiopia). MSc Thesis, Addis Ababa University, Ethiopia. Avialable on: http://etd.aau.edu.et/handle/123456789/6020. 
Haines-Young, R., Potschin, M., 2013. Common International Classification of Ecosystem Services (CICES): Consultation on Version 4, Report to the European Environment Agency No EEA/IEA/09/003. Available on: https://cices.eu/content/uploads/sites/8/2012/07/CICESV43 Revised-Final Report 29012013.pdf.

Halsema, G.E., Lencha, B.K., Assefa, N., Hengsdijk, H., Wesseler, J., 2011. Performance assessment of smallholder irrigation in the central rift valley of Ethiopia. Irrigigation and Drainage 60, 622 - 634.

Hamid, S.A., Rawi, C.S.M., 2017. Application of aquatic insects (ephemeroptera, plecoptera and trichoptera) in water quality assessment of Malaysian headwater. Tropical Life Sciences Research 28, 143 - 162.

Harrison, P.A., Vandewalle, M., Sykes, M.T., Berry, P.M., Bugter, R., de Bello, F., Feld, C.K., Grandin, U., Harrington, R., Haslett, J.R., Jongman, R.H.G., Luck, G.W., da Silva, P.M., Moora, M., Settele, J., Sousa, J.P., Zobel, M., 2010. Identifying and prioritising services in European terrestrial and freshwater ecosystems. Biodiversity and Conservation 19, 2791 - 2821.

Hayasaka, D., Kobashi, K., Hashimoto, K., 2019. Community responses of aquatic insects in paddy mesocosms to repeated exposures of the neonicotinoids imidacloprid and dinotefuran. Ecotoxicology and Environmental Safety 175, 272 - 281.

Hayasaka, D., Korenaga, T., Sánchez-Bayo, F., Goka, K., 2012. Differences in ecological impacts of systemic insecticides with different physicochemical properties on biocenosis of experimental paddy fields. Ecotoxicology 21, 191-201.

Hengsdijk, H., Jansen, H., 2006. Agricultural development in the Central Ethiopian Rift valley: A deskstudy on water-related issues and knowledge to support a policy dialogue. Available on: https://edepot.wur.nl/52323.

Hermsen, E., Pompe, R., Besseling, E., Koelmans, A.A., 2018. Detection of low numbers of microplastics in North Sea fish using strict quality assurance criteria. Marine pollution bulletin 122, 253-258.

Hirpo, L.A., 2016. Current status and trends of fishes and fishery of a shallow rift valley lake, Lake Ziway, Ethiopia. PhD thesis, Addis Ababa University, Ethioppia. Avialable on: http://etd.aau.edu.et/handle/123456789/9710.

Hladik, M.L., Smalling, K.L., Kuivila, K.M., 2009. Methods of analysis-Determination of pyrethroid insecticides in water and sediment using gas chromatography/mass spectrometry: U.S. Geological Survey Techniques and Methods 5-C2, 18 p. Virginia, USA. Avialable on: https://pubs.usgs.gov/tm/tm5c2/tm5c2.pdf.

Holland, R.A., Eigenbrod, F., Armsworth, P.R., Anderson, B.J., Thomas, C.D., Heinemeyer, A., Gillings, S., Roy, D.B., Gaston, K.J., 2011. Spatial covariation between freshwater and terrestrial ecosystem services. Ecological Applications 21(6), 2034 - 2048.

Hommen, U., Veith, D., Düllmer, U. 1994. A computer program to evaluate plankton data from freshwater field tests, Lewis Publishers, Baca Raton, USA, pp. 503 - 513.

Houbraken, M., Habimana, V., Senaeve, D., López-Dávila, E., Spanoghe, P., 2017. Multi-residue determination and ecological risk assessment of pesticides in the lakes of Rwanda. Science of the Total Environment 576, 888 - 894.

Hughes, R.H., Hughes, J.S., 1992. A Directory of African Wetlands. IUCN Gland, Cambridge, UK. Avialable on: https://portals.iucn.org/library/sites/library/files/documents/1992-007.pdf.

IFDC, 2012. International Fertilizer Development Center (IFDC): In support of The African Fertilizer and Agribusiness Partnership. Ethiopia Fertilizer Assessment. Available on: https://africafertilizer.org/wp-content/uploads/2017/04/Ethiopia-fertilizer-market-assessmentIFDC-for-AFAP-Dec-2012.pdf. 
Imhof, H.K., Ivleva, N.P., Schmid, J., Niessner, R., Laforsch, C., 2013. Contamination of beach sediments of a subalpine lake with microplastic particles. Current Biology 23(19), R867 - R868.

Israel, G.D., 2013. Determining Sample Size. Agricultural Education and Communication Department, UF/IFAS Extension. PEOD6. Available on: http://edis.ifas.ufl.edu.

Jabeen, K., Su, L., Li, J., Yang, D., Tong, C., Mu, J., Shi, H., 2017. Microplastics and mesoplastics in fish from coastal and fresh waters of China Environmental Pollution 221, 141-149.

Jâms, I.B., Windsor, F.M., Poudevigne-Durance, T., Ormerod, S.J, Durance, I., 2020. Estimating the size distribution of plastics ingested by animals. Nature Communications 11:1594.

Jansen, H., Hengsdijk, H., Legesse, D., Ayenew, T., Hellegers, P., Spliethoff, P., 2007. Land and water resources assessment in the Ethiopian Central Rift Valley: ecosystems for water, food and economic development in the Ethiopian Central Rift Valley. Alterra Report 1587, Wageningen University and Research, Wageningen, The Netherlands. Available on: https://research.wur.nl/en/publications/land-and-water-resources-assessment-in-theethiopian-central-rift.

Jansen, H.C., Harmsen, J., 2011. Pesticide Monitoring in the Central Rift Valley 2009 - 2010: Ecosystems for Water in Ethiopia. Report No. 2083. Alterra, Wageningen: The Netherlands. Avialable on: https://library.wur.nl/WebQuery/wurpubs/406938.

Jemec, A., Tisler, T., Drobne, D., Sepcic, K., Fournier, D., Trebse, P., 2007. Comparative toxicity of imidacloprid, of its commercial liquid formulation and of diazinon to a non-target arthropod, the microcrustacean Daphnia magna. Chemosphere 68, 1408 - 1418.

Jima, D., Wondabeku, M., Alemu, A., Teferra, A., Awel, N., Deressa, W., Adissie, A., Tadesse, Z., Gebre, T., Mosher, A.W., Richards, F.O., Graves, P.M., 2012. Analysis of malaria surveillance data in Ethiopia: what can be learned from the Integrated Disease Surveillance and Response System? Malaria Journal 11, 330 - 343.

Johnson, P.T.J., Chase, J.M., Dosch, K.L., Hartson, R.B., Gross, J.A., Larson, D.J., Sutherland, D.R., Carpenter, S.R., 2007. Aquatic eutrophication promotes pathogenic infection in amphibians. PNAS 104(40), 15781 - 15786.

Jones, C., Somers, K.M., Craig, B., Reynoldson, T.B., 2007. Ontario Benthos Biomonitoring Network: Protocol. Environment Canada. Available on: http://www.saugeenconservation.com/download/benthos/2009/OBBN\%20Protocol\%20Manual .pdf.

Karthik, R., Robin, R.S., Purvaja, R., Ganguly, D., Anandavelu, I., Raghuraman, R., Hariharan, G., Ramakrishna, A., Ramesh, R., 2018. Microplastics along the beaches of southeast coast of India. Science of the Total Environment 645, 1388 - 1399.

Kassaye, Y.A., Skipperud, L., Einset, J., Salbu, B., 2016. Aquatic macrophytes in Ethiopian Rift Valley lakes; Their traceelements concentration and use as pollution indicators. Aquatic Botany 134, 1825.

Kattwinkel, M., Römbke, J., Liess, M. 2012. Ecological recovery of populations of vulnerable species driving the risk assessment of pesticides. Supporting Publications 2012:EN-338. 98 pp.. Available online: www.efsa.europa.eu/publications.

Kebede, E., G-Mariam, Z., Ahlgren, I., 1994. The Ethiopian Rift Valley lakes: chemical characteristics of a salinity-alkalinity series. Hydrobiologia 288, 1-12.

Kebede, E., Willen, E., 1998. Phytoplankton in a salinity-alkalinity series of lakes in the Ethiopian Rift Valley. Algological Studies 89, 63 - 96. 
Kebede, G., Mushi, D., Linke, R.B., Dereje, O., Lakew, A., Hayes, D.S., Farnleitner, A.H., Graf, W., 2020. Macroinvertebrate indices versus microbial fecal pollution characteristics for water quality monitoring reveals contrasting results for an Ethiopian river. Ecological indicators 108, 105733 105742.

Keeler, B.L., Dalzell, B.J., Gourevitch, J.D., Hawthorne, P.L., Johnson, K.A., Noe, R.R., 2019. Putting people on the map improves the prioritization of ecosystem services. Frontiers in Ecology and the Environment 17(3), 151 - 156.

Khan, F.R., Mayoma, B.S., Biginagwa, F.J., Syberg, K., 2018. Microplastics in Inland African Waters: Presence, Sources, and Fate. Wagner, M., Lambert, S. (eds). Freshwater Microplastics: Emerging Environmental Contaminants? Springer Nature, Switzerland.

Klein, S., Worch, E., Knepper, T.P., 2015. Occurrence and Spatial Distribution of Microplastics in River Shore Sediments of the Rhine-Main Area in Germany. Environmental Science and Technology 49, 6070-6076.

Knoll, L.B., Sharma, S., Denfeld, B.A., Flaim, G., Hori, Y., Magnuson, J.J., Straile, D., Weyhenmeyer, G.A., 2019. Consequences of lake and river ice loss on cultural ecosystem services. Limnology and Oceanography Letters 4, 119 - 131.

Kobashi, K., Harada, T., Adachi, Y., Mori, M., Ihara, M., Hayasaka, D., 2017. Comparative ecotoxicity of imidacloprid and dinotefuran to aquatic insects in rice mesocosms. Ecotoxicology and Environmental Safety 138, 122 - 129.

Koelmans, A.A., Besseling, E., Foekema, E., Kooi, M., Mintenig, S., Ossendorp, B.C., RedondoHasselerharm, P.E., Verschoor, A., Van Wezel, A.P., Scheffer, M., 2017. Risks of Plastic Debris: Unravelling Fact, Opinion, Perception, and Belief. Environmental Science and Technology 51, 11513-11519.

Koelmans, A.A., Nor, N.H.M., Hermsen, E., Kooi, M., Mintenig, S.M., France, J.D., 2019. Microplastics in freshwaters and drinking water: Critical review and assessment of data quality. Water Research 155, 410-422.

Kooi, M., Koelmans, A.A., 2019. Simplifying Microplastic via Continuous Probability Distributions for Size, Shape, and Density. Environmental Science and Technology Letter 6, 551-557.

Kooi, M., van Nes, E.H., Scheffer, M., Koelmans, A.A., 2017. Ups and Downs in the Ocean: Effects of Biofouling on Vertical Transport of Microplastics. Environmental Science and Technology 51, 7963-7971.

Kreutzweiser, D., Good, K., Chartrand, D., Scarr, T., Thompson, D., 2007. Non-target effects on aquatic decomposer organisms of imidacloprid as a systemic insecticide to control emerald ash borer in riparian trees. Ecotoxicology and Environmental Safety 68, 315 - 325.

Kriska, G., 2014. Freshwater invertebrates in Central Europe: A field guide. Springer-Verlag Wien Heidelberg New York Dordrecht London, $394 \mathrm{pp}$.

Kwok, K.W., Leung, K.M., Lui, G.S., Chu, V.K., Lam, P.K., Morritt, D., Maltby, L., Brock, T.C., Van den Brink, P.J., Warne, M.S.J., Crane, M., 2007. Comparison of Tropical and Temperate Freshwater Animal Species' Acute Sensitivities to Chemicals: Implications for Deriving Safe Extrapolation Factors. Integrated Environmental Assessment and Management 3(1), 49 - 67.

Lacasaña, M., López-Flores, I., Rodríguez-Barranco, M., Aguilar-Garduño, C., Blanco-Muñoz, J., PérezMéndez, O., Gamboa, R., Bassol, S., Cebrian, M.E., 2010. Association between organophosphate pesticides exposure and thyroid hormones in floriculture workers. Toxicology and Applied Pharmacology 243, 19 - 26. 
Lake, P.S., 2000. Disturbance, patchiness, and diversity in streams. Journal of the North American Benthological Society 19(4), 573 - 592.

Laurance, W.F., Sayer, J., Cassman, K.G., 2014. Agricultural expansion and its impacts on tropical nature. Trends in Ecology and Evolution 29(2), 107 - 116.

Legesse, D., Ayenew, T., 2006. Effect of improper water and land resource utilization on the central Main Ethiopian Rift lakes. Quaternary International 148, 8 - 18.

Lemma, A., 2005. Site Action Plan for the conservation and sustainable use of the lake Ziway biodiversity, rift valley lakes project. Addis Ababa: Institute of Biodiversity Conservation.

Lemma, B., Desta, H., 2016. Review of the natural conditions and anthropogenic threats to the Ethiopian Rift Valley rivers and lakes. Lakes and Reservoirs: Research and Management 21, 133 151.

Lepper, P., 2005. Manual on the Methodological Framework to Derive Environmental Quality Standards for Priority Substances in accordance with Article 16 of the Water Framework Directive. Available on: http://www.wrrl-info.de/docs/manual-derivation-qs.pdf.

Leslie, H.A., Brandsma, S.H., van Velzena, M.J.M., Vethaak, A.D., 2017. Microplastics en route: Field measurements in the Dutch river delta and Amsterdam canals, wastewater treatment plants, North Sea sediments and biota. Environment International 101, 133-142.

Leto, C., Tuttolomondo, T., Bella, S.L., Leone, R., Licata, M., 2013. Effects of plant species in a horizontal subsurface flow constructed wetland - phytoremediation of treated urban wastewater with Cyperus alternifolius L. and Typha latifolia L. in the West of Sicily (Italy). Ecological Engineering 61, 282 - 291.

LFDP, 1997. Lake Management Plans. Working Paper 23. Ministry of Agriculture, Addis Ababa: Lake Fisheries Development Project (LFDP): Phase II. Addis Ababa, Ethiopia: Ministry of Agriculture.

Li, C., Busquets, R., Campos, L.C., 2020. Assessment of microplastics in freshwater systems: A review. Science of the Total Environment 707:135578.

Li, J., Liu, H., Chen, J.P., 2018. Microplastics in freshwater systems: A review on occurrence, environmental effects, and methods for microplastics detection. Water Research 137, 362 - 374.

Loha, K.M., Lamoree, M., Weiss, J.M., de Boer, J., 2018. Import, disposal, and health impacts of pesticides in the East Africa Rift (EAR) zone: A review on management and policy analysis. Crop Protection 112, 322 - 331.

Lorenz, C., Roscher, L., Meyer, M.S., Hildebrandt, L., Prume, J., Loder, M.G.J., Primpke, S., Gerdts, G., 2019. Spatial distribution of microplastics in sediments and surface waters of the southern North Sea. Environmental Pollution 252:1719-1729.

Luck, G.W., Daily, G.C., Ehrlich, P.R., 2003. Population diversity and ecosystem services. Trends in Ecology and Evolution 18(7), 331 - 336.

Lusher, A.L., McHugh, M., Thompson, R.C., 2013. Occurrence of microplastics in the gastrointestinal tract of pelagic and demersal fish from the English Channel. Marine pollution bulletin 67:94-99.

Lusher, A.L., O'Donnell, C., Officer, R., O'Connor, I., 2016. Microplastic interactions with North Atlantic mesopelagic fish. ICES Journal of Marine Science 73(4):1214-1225.

Macadam, C.G., Stockan, J.A., 2015. More than just fish food: ecosystem services provided by freshwater insects. Ecological Entomology 40, 113-123.

Macaulay, S.J., Buchwalter, D.B., Matthaei, C.D., 2020. Water temperature interacts with the insecticide imidacloprid to alter acute lethal and sublethal toxicity to mayfly larvae. New Zealand Journal of Marine and Freshwater Research, 54(1), 115 - 130. 
Madzena, A., Lasiak, T., 1997. Spatial and Temporal Variations in Beach Litter on the Transkei Coast of South Africa. Marine pollution bulletin 34(11), 900-907.

Maes, J., Paracchini, M.L., Zulian, G., Dunbar, M.B., Alkemade, R., 2012. Synergies and trade-offs between ecosystem service supply, biodiversity, and habitat conservation status in Europe. Biological Conservation 155, 1 - 12.

Magurran, A.E., 1988. Ecological diversity and its measurment. Croom Helm Ltd, UK, 167 pp.

Makin, M.J., Kingham, T.J., Waddams, A.E., Birchall, C.J., Eavis, B.W., 1976. Prospects for irrigation development around Lake Ziway, Ethiopia. Land Resources Study Division, Ministry of Overseas Development, 26, Tolworth, UK. Avialable on: https://library.wur.nl/isric/fulltext/isricu i00005318 001.pdf.

Malev, O., Klobucar, R.S., Fabbretti, E., Trebse, P., 2012. Comparative toxicity of imidacloprid and its transformation product 6 -chloronicotinic acid to non-target aquatic organisms: Microalgae Desmodesmus subspicatus and amphipod Gammarus fossarum. Pesticide Biochemistry and Physiology 104, 178 - 186.

Malison, R.L., Baxter, C.V., 2010. Effects of wildfire of varying severity on benthic stream insect assemblages and emergence. Journal of the North American Benthological Society 29(4), 1324 1338.

Maltby, L., 2013. Ecosystem services and the protection, restoration, and management of ecosystems exposed to chemical stressors. Environmental Toxicology and Chemistry 32(5), 974 - 983.

Maltby, L., Blake, N., Brock, T.C.M., Van den Brink, P.J., 2005. Insecticide species sensitivity distributions: Importance of test species selection and relevance to aquatic ecosystems. Environmental Toxicology and Chemistry 24(2), 379 - 388.

Maltby, L., Brock, T.C.M., Van den Brink, P.J., 2009. Fungicide Risk Assessment for Aquatic Ecosystems: Importance of Interspecific Variation, Toxic Mode of Action, and Exposure Regime. Environmental Science and Technology 43, $7556-7563$.

Maltby, L., Van den Brink, P.J., Faber, J.H., Stuart, M., 2018. Advantages and challenges associated with implementing an ecosystem services approach to ecological risk assessment for chemicals. Science of the Total Environment 621, 1342 - 1351.

Mani, T., Primpke, S., Lorenz, C., Gerdts, G., Burkhardt-Holm, P., 2019. Microplastic Pollution in Benthic Midstream Sediments of the Rhine River. Environmental Science and Technology 53, 6053-6062.

Markic, A., Gaertner, J.-C., Gaertner-Mazouni, N., Koelmans, A.A., 2019. Plastic ingestion by marine fish in the wild. Critical Reviews in Environmental Science and Technology. PP: 1547-6537.

Martens, K., Tudorancea, C., 1991. Seasonality and spatial distribution of the ostracods of Lake Zwai, Ethiopia (Crustacea: Ostracoda). Freshwater Biology 25, 233-241.

Masresha, A.E., Skipperud, L., Rosseland, B.O., Zinabu, G.M., Meland, S., Teien, H.C., Salbu, B., 2011. Speciation of selected trace elements in three Ethiopian Rift Valley Lakes (Koka, Ziway, and Awassa) and their major inflows. Science of the Total Environment 409, 3955-3970.

McKnight, U.S., Rasmussen, J.J., Kronvang, B., Binning, P.J., Bjerg, P.L., 2015. Sources, occurrence and predicted aquatic impact of legacy and contemporary pesticides in streams. Environmental Pollution 200, 64 - 76.

McMahon, T.A., Halstead, N.T., Johnson, S., Raffel, T.R., Romansic, J.M., Crumrine, P.W., Rohr, J.R., 2012. Fungicide-induced declines of freshwater biodiversity modify ecosystem functions and services. Ecology Letters 15, 714 - 722. 
MEA, 2005. Millennium Ecosystem Assessment (MEA), Ecosystems and Human Well-being: synthesis. Island Press, Washington, DC. Available on: https://www.millenniumassessment.org/documents/document.356.aspx.pdf.

MEA, 2007. Millennium Ecosystem Assessment (MEA): Ecosystems and Human Well-being: Policy Responses. Avialable

on: https://www.millenniumassessment.org/documents/document.312.aspx.pdf.

Meena, T., Rout, J., 2016. Macrophytes and their ecosystem services from natural ponds in Cachar district, Assam, India. Indian Journal of Traditional Knowledge 15(4), 553 - 560.

Mekonen, S., Argaw, R., Simanesew, A., Houbraken, M., Senaeve, D., Ambelu, A., Spanoghe, P., 2016. Pesticide residues in drinking water and associated risk to consumers in Ethiopia. Chemosphere $162,252-260$.

Mekonnen, K.N., Ambushe, A.A., Chandravanshi, B.S., Redi-Abshiro, M., Maccrindle, R.I., 2015. Occurrence, distribution, and ecological risk assessment of potentially toxic elements in surface sediments of Lake Awassa and Lake Ziway, Ethiopia. Journal of Environmental Science and Health, Part A 50, 90-99.

Mellor, J.W., Dorosh, P., 2010. Agriculture and the Economic Transformation of Ethiopia. Ethiopia Strategy Support Program 2 (ESSP2), Working Paper No. ESSP2 010. Available on: https://media.africaportal.org/documents/ESSP 2 Working Paper 010.pdf.

Mendi, D., Uluozlu, O.D., 2007. Determination of trace metal levels in sediment and five fish species from lakes in Tokat, Turkey. Food Chemistry 101, $739-745$.

Mengesha, G., Mamo, Y., Sahle, K., Elphick, C., Bekele, A., 2014. Effects of Land-use on Birds Diversity in and around Lake Zeway, Ethiopia. Journal of Science and Development 2(2), 5 - 22.

Mengistie, B.T., 2016. Environmental governance of pesticides in Ethiopian vegetable and cut flower production. PhD thesis, Wageningen University and Research, Wageningen, The Netherlands. Avialable on: https://research.wur.nl/en/publications/environmental-governance-of-pesticidesin-ethiopian-vegetable-and.

Mengistie, B.T., Mol, A.P.J., Oosterveer, P., 2017. Pesticide use practices among smallholder vegetable farmers in Ethiopian Central Rift Valley. Environment, Development and Sustainability 19(1), 301324.

Mengistie, B.T., Mol, A.P.J., Oosterveer, P., Simane, B., 2015. Information, motivation and resources: the missing elements in agricultural pesticide policy implementation in Ethiopia. International Journal of Agricultural Sustainability 13(3), 240 - 256.

Mereta, S.T., Boets, P., Meester, L.D., Goethals, P.L.M., 2013. Development of a multimetric index based on benthic macroinvertebrates for the assessment of natural wetlands in Southwest Ethiopia. Ecological indicators 29, 510 - 521.

Merga L.B., Mengistie A.A., Alemu M.T., Van den Brink P.J., 2020a. Biological and chemical monitoring of the ecological risks of pesticides in Lake Ziway, Ethiopia. Chemosphere (online) https://doi.org/10.1016/i.chemosphere.2020.129214.

Merga, L., Mengistie, A., Faber, J., Van den Brink, P.J., 2020b. Trends in chemical pollution and ecological status of Lake Ziway, Ethiopia: A review focussing on nutrients, metals and pesticides. African Journal of Aquatic Science 45(4), 386 - 400.

Mintenig, S.M., Kooi, M., Erich, M.W., Primpke, S., Hasselerharm, R.-P.E., Dekker, S.C., Koelmans, A.A., van Wezel, A.P., 2020. A systems approach to understand microplastic occurrence and variability in Dutch riverine surface waters. Water Research 176:115723. 
MoANR, 2016. Ministry of Agriculture and Natural Resources (MoANR): Pest Management Support Services Strategy for Ethiopia, Addis Ababa, Ethiopia. Available on: http://extwprlegs1.fao.org/docs/pdf/eth174138.pdf.

MoFED, 2010. Ministry of Finance and Economic Development (MoFED) of Ethiopia: Growth and Transformation Plan (GTP). Available on: http://www.ethiopians.com/Ethiopia GTP 2015.pdf.

$\mathrm{MoH}, 2011$. National drinking water quality monitoring and surveillance strategy. Federal Democratic Republic of Ethiopia, Ministry of Health $(\mathrm{MoH})$, Addis Ababa. https://www.cmpethiopia.org/content/download/384/2301/file/National\%20drinking\%20wate r\%20quality\%20monitoring\%20and\%20surveillance\%20strategy.pdf.

Mohammed, Y., Lemma, D., Gashawbeza, A., Aberra, D., Adam, B., Lidet, S., Giref, S., Sithanantham, S., 2006. Farmers Awareness Building on Integrated Pest Management (IPM) Options of Major Vegetable Pests in the Central Rift Valley Region of Ethiopia. Bekele, E., Azerefegne, F., Abate, T. (eds). Facilitating the Implementation and Adoption of Integrated Pest Management (IPM) in Ethiopia. Drylands Coordination Group. Available on: https://www.utviklingsfondet.no/dcg/assets/documents/Publications/375-proceedings 17.pdf.

Morrissey, C.A., Mineau, P., Devries, J.H., Sanchez-Bayo, F., Liess, M., Cavallaro, M.C., Liber, K., 2015. Neonicotinoid contamination of global surface waters and associated risk to aquatic invertebrates: A review. Environment International 74, 291 - 303.

MoWR, 2002. Federal democratic republic of Ethiopia, ministry of water resources (MoWR): Water sector development program, main report volume I. Available on: http://extwprlegs1.fao.org/docs/pdf/eth180677.pdf.

Munns, W.R., Rea, A.W., Suter-II, G.W., Martin, L., Blake-Hedges, L., Crk, T., Davis, C., Ferreira, G., Jordan, S., Mahoney, M., Barron, M.G., 2016. Ecosystem Services as Assessment Endpoints for Ecological Risk Assessment. Integrated Environmental Assessment and Management 12(3), 522528.

Munz, N.A., Burdon, F.J., de Zwart, D., Junghans, M., Melo, L., Reyes, M., Schonenberger, U., Singer, H.P., Spycher, B., Hollender, J., Stamm, C., 2017. Pesticides drive risk of micropollutants in wastewater-impacted streams during low flow conditions. Water Research 110, 366 - 377.

Muriithi, B., Gathogo, N.G., Diiro, G.M., Mohamed, S.A., Ekesi, S., 2020. Potential Adoption of Integrated Pest Management Strategy for Suppression of Mango Fruit Flies in East Africa: An Ex Ante and Ex Post Analysis in Ethiopia and Kenya. Agriculture 10, 278 - 300.

Murphy, F., Russell, M., Ewins, C., Quinn, B., 2017. The uptake of macroplastic \& microplastic by demersal \& pelagic fish in the Northeast Atlantic around Scotland. Marine pollution bulletin 122:353-359.

Musa, S., Gichuki, J.W., Raburu, P.O., Aura, C.M., 2011a. Risk assessment for organochlorines and organophosphates pesticide residues in water and Sediments from lower Nyando/Sondu-Miriu river within Lake Victoria Basin, Kenya. Lakes and Reservoirs: Research and Management 16, 273 $-280$.

Musa, S., Gichuki, J.W., Raburu, P.O., Aura, C.M., 2011b. Organochlorine and organophosphorus pesticide residues in water and sediment from Yala/Nzoia River within Lake Victoria Basin, Kenya. Journal of Ecology and the Natural Environment 3, 392 - 399.

Nadal, M.A., Alomar, C., Deudero, S., 2016. High levels of microplastic ingestion by the semipelagic fish bogue Boops boops (L.) around the Balearic Islands. Environmental Pollution 214, 517-523. 
Napper, I.E., Thompson, R.C., 2016. Release of synthetic microplastic plastic fibres from domestic washing machines: Effects of fabric type and washing conditions. Marine pollution bulletin 112:39-45.

Ndungu, J., Augustijn, D.C.M., Hulscher, S.J.M.H., Fulanda, B., Kitaka, N., Mathooko, J.M., 2014. A multivariate analysis of water quality in Lake Naivasha, Kenya. Marine and Freshwater Research. 66(2), 177-186.

Negash, B., Azerefegn, F., Ayalew, G., 2020. Insecticide resistance management against thrips (Thysanoptera: Thripidae) on onion in the central Rift Valley of Ethiopia. International Journal of Tropical Insect Science. Online: https://doi.org/10.1007/s42690-020-00127-6.

Negatu, B., Kromhout, H., Mekonnen, Y., Vermeulen, R., 2016. Use of Chemical Pesticides in Ethiopia: A Cross-Sectional Comparative Study on Knowledge, Attitude and Practice of Farmers and Farm Workers in Three Farming Systems. Annals of Occupational Hygiene 60(5), 551 - 566.

Nel, H.A., Dalu, T., Wasserman, R.J., 2018. Sinks and sources: Assessing microplastic abundance in river sediment and deposit feeders in an Austral temperate urban river system. Science of the Total Environment 612, 950-956.

Ngowi, A.V.F., Mbise, T.J., Ijani, A.S.M., London, L., Ajayi, O.C., 2007. Smallholder vegetable farmers in Northern Tanzania: Pesticides use practices, perceptions, cost and health effects. Crop Protection 26, 1617 - 1624.

Ngupula, G.W., Kayanda, R.J., Mashafi, C.A., 2014. Abundance, composition and distribution of solid wastes in the Tanzanian waters of Lake Victoria. African Journal of Aquatic Science 39(2), 229 232.

Nigussie, A., Kuyper, T.W., de Neergaard, A., 2015. Agricultural waste utilisation strategies and demand for urban waste compost: Evidence from smallholder farmers in Ethiopia. Waste Management 44,82 - 93.

Nigussie, K., Chandravanshi, B.S., Wondmu, T., 2010. Correlation among trace metals in Tilapia (Oreochromis niloticus), sediment and water samples of lakes Awassa and Ziway, Ethiopia. International Journal of Biological and Chemical Sciences 4, 1641-1656.

Ntow, W.J., Gijzen, H.J., Kelderman, P., Drechsel, P., 2006. Farmer perceptions and pesticide use practices in vegetable production in Ghana. Pest Management Science 62, 356 - 365.

Nyenje, P.M., Foppen, J.W., Uhlenbrook, S., Kulabako, R., Muwanga, A., 2010. Eutrophication and nutrient release in urban areas of sub-Saharan Africa - A review. Science of the Total Environment 408, 447 - 455.

O'Connor, J.D., Mahon, A.M., Ramsperger, A.F.R.M., Trotter, B., Redondo-Hasselerharm, P.E., Koelmans, A.A., Lally, H.T., Murphy, S., 2019. Microplastics in Freshwater Biota: A Critical Review of Isolation, Characterization, and Assessment Methods. Global Challenges 1800118:1-10.

Odume, O.N., Muller, W.J., Arimoro, F.O., Palmer, C.G., 2012. The impact of water quality deterioration on macroinvertebrate communities in the Swartkops River, South Africa: a multimetric approach. African Journal of Aquatic Science 37, 191 - 200.

OECD, 2011. Test No. 235: Chironomus sp., acute immobilisation test. Organisation for Economic Cooperation and Development (OECD) Guidelines for the Testing of Chemicals. Paris, France. Available on: https://www.oecd-ilibrary.org/environment/test-no-235-chironomus-sp-acuteimmobilisation-test 9789264122383-en.

Oesterlund, A.H., Thomsen, J.F., Sekimpi, D.K., Maziina, J., Racheal, A., Jørs, E., 2014. Pesticide knowledge, practice and attitude and how it affects the health of small-scale farmers in Uganda: a cross-sectional study. African Health Sciences 14(2), 420 - 433. 
Ogonowski, M., Schür, C., Jarsén, Å., Gorokhova, E., 2016. The Effects of Natural and Anthropogenic Microparticles on Individual Fitness in Daphnia magna. PLOS ONE 10:1371.

Okonya, J.S., Petsakos, A., Suarez, V., Nduwayezu, A., Kantungeko, D., Blomme, G., Legg, J.P., Kroschel, J., 2019. Pesticide Use Practices in Root, Tuber, and Banana Crops by Smallholder Farmers in Rwanda and Burundi. International Journal of Environmental Research and Public Health 16, 400 $-417$.

Okoya, A.A., Ogunfowokan, A.O., Asubiojo, O.I., Torto, N., 2013. Organochlorine Pesticide Residues in Sediments and Waters from Cocoa Producing Areas of Ondo State, Southwestern Nigeria. ISRN Soil Science 131647. http://dx.doi.org/10.1155/2013/131647.

Oluwole, O., Cheke, R.A., 2009. Health and environmental impacts of pesticide use practices: a case study of farmers in Ekiti State, Nigeria. International Journal of Agricultural Sustainability 7(3), 153 $-163$.

Ondiek, R.A., Kitaka, N., Oduor, S.O., 2016. Assessment of provisioning and cultural ecosystem services in natural wetlands and rice fields in Kano floodplain, Kenya. Ecosystem Services 21, 166 - 173.

Onwona-Kwakye, M., Hogarh, J.N., Van den Brink, P.J., 2020. Environmental risk assessment of pesticides currently applied in Ghana. Chemosphere 254, 126845 - 126856.

Onwona-Kwakye, M., Mengistie, B., Ofosu-Anim, J., Nuer, A.T.K., Van den Brink, P.J., 2019. Pesticide registration, distribution and use practices in Ghana. Environment, Development and Sustainability 21, 2667 - 2691.

Otieno, P.O., Schramm, K.W., Pfister, G., Lalah, J.O., Ojwach, S.O., Virani, M., 2012. Spatial Distribution and temporal trend in concentration of carbofuran, diazinon and chlorpyrifos ethyl residues in sediment and water in Lake Naivasha, Kenya. Bulletin of Environmental Contamination and Toxicology 88, 526 - 532.

Papadakis, E.N., ZisisVryzas, Kotopoulou, A., Kintzikoglou, K., Makris, K.C., Papadopoulou-Mourkidou, E., 2015. A pesticide monitoring survey in rivers and lakes of northern Greece and its human and ecotoxicological risk assessment. Ecotoxicology and Environmental Safety 116, 1 - 9.

Pathiratne, A., Kroon, F.J., 2016. Using species sensitivity distribution approach to assess the risks of commonly detected agricultural pesticides to Australia's tropical freshwater ecosystems. Environmental Toxicology and Chemistry 35(2), 419 - 428.

Paudyal, K., Baral, H., Keenan, R.J., 2018. Assessing social values of ecosystem services in the Phewa Lake Watershed, Nepal. Forest Policy and Economics 90, 67 - 81.

Pereira, A.S., Cerejeira, M.J., Daam, M.A., 2017. Ecological risk assessment of imidacloprid applied to experimental rice fields: Accurateness of the RICEWQ model and effects on ecosystem structure. Ecotoxicology and Environmental Safety 142, 431 - 440.

Pestana, J.L.T., Alexander, A.C., Culp, J.M., Baird, D.J., Cessna, A.J., Soares, A.M.V.M., 2009. Structural and functional responses of benthic invertebrates to imidacloprid in outdoor stream mesocosms. Environmental Pollution 157, 2328 - 2334.

Peters, C.A., Bratton, S.P., 2016. Urbanization is a major influence on microplastic ingestion by sunfish in the Brazos River Basin, Central Texas, USA. Environmental Pollution 210, 380-387.

Pinel-Alloul, B., Méthot, G., Lapierre, L., Willsie, A., 1996. Macroinvertebrate community as a biological indicator of ecological and toxicological factors in lake saint-francois (Québec). Environmental Pollution 91, 65 - 87.

PMI, 2009. Presidents malaria initiative (PMI): Operational plan Ethiopia. https://www.pmi.gov/docs/default-source/default-document-library/malaria-operationalplans/fy09/ethiopia mop-fy09.pdf?sfvrsn=8. 
Portt, C.B., Coker, G.A., Ming, D.L., Randall, R.G., 2006. A review of fish sampling methods commonly used in Canadian freshwater habitats. Canadian Technical Report of Fisheries and Aquatic Sciences 2604. Canada. Avialable on: https://www3.epa.gov/region1/npdes/merrimackstation/pdfs/ar/AR-1240.pdf.

Possatto, F.E., Barletta, M., Costa, M.F., Ivar do Sul, J.A., Dantas, D.V., 2011. Plastic debris ingestion by marine catfish: An unexpected fisheries impact. Marine pollution bulletin 62, 1098-1102.

Posthuma, L., Suter II, G.W., Traas, T.P., 2002. Species Sensitivity Distributions in Ecotoxicology. Lewis Publishers, Washington, D.C. 564 pp.

Posthuma-Doodeman, C.J.A.M., 2008. Environmental Risk Limits for Imidacloprid. Report 601716018. National Institute for Public Health and the Enviroment, Bilthoven, The Netherlands. Available on: https://www.rivm.nl/bibliotheek/rapporten/601716018.pdf.

Pretty, J., 2011. Sustainable intensification in Africa. International Journal of Agricultural Sustainability 9, 3 - 4.

Prosser, R.S., de Solla, S.R., Holman, E.A.M., Osborne, R., Robinson, S.A., Bartlett A. J., Maisonneuve, F.J., Gillis, P.L., 2016. Sensitivity of the early-life stages of freshwater mollusks to neonicotinoid and butenolide insecticides. Environmental Pollution 218, 428 - 435.

Quintana, J., Martí, I., Ventura, F., 2001. Monitoring of pesticides in drinking and related waters in NE Spain with a multiresidue SPE-GC-MS method including an estimation of the uncertainty of the analytical results. Journal of Chromatography A 938, 3 - 13.

Raby, M., Nowierski, M., Perlov, D., Zhao, X., Hao, C., Poirier, D.G., Sibley, P.K., 2018. Acute Toxicity of 6 Neonicotinoid Insecticides to Freshwater Invertebrates. Environmental Toxicology and Chemistry 37(5), 1430 - 1445.

Rai, P.K., 2008. Heavy metal pollution in aquatic ecosystems and its phytoremediation using wetland plants: An eco-sustainable approach. International Journal of Phytoremediation 10, 133 - 160.

Rämö, R.A., Van den Brink, P.J., Ruepert, C., Castillo L.E., Gunnarsson, J.S., 2018. Environmental risk assessment of pesticides in the River Madre de Dios, Costa Rica using PERPEST, SSD, and msPAF models. Environmental Science and Pollution Research 25, 13254 - 13269.

Rashid, S., Tefera, N., Minot, N., Ayele, G., 2013. Fertilizer in Ethiopia An Assessment of Policies, Value Chain, and Profitability. International Food Policy Research Institute, Addis Ababa, Ethiopia. Available on: https://papers.ssrn.com/sol3/papers.cfm?abstract id=2373214\&download=yes.

Rathore, S.S., Chandravanshi, P., Chandravanshi, A., Jaiswal, K., 2016. Eutrophication: Impacts of Excess Nutrient Inputs on Aquatic Ecosystem. IOSR Journal of Agriculture and Veterinary Science 9, 89 96.

Reddy, V.R., Behera, B., 2006. Impact of water pollution on rural communities: An economic analysis. Ecological Economics 58, 520 - 537.

Redondo-Hasselerharm, P.E., Falahudin, D., Peeters, E.T.H.M., Koelmans, A.A., 2018. Microplastic Effect Thresholds for Freshwater Benthic Macroinvertebrates. Environmental Science and Technology 52, $2278-2286$.

Redondo-Hasselerharm, P.E., Gort, G., Peeters, E.T.H.M., Koelmans, A.A., 2020. Nano- and microplastics affect the composition of freshwater benthic communities in the long term. Science Advances 6 : eaay4054.

Rico, A., Arenas-Sánchez, A., Pasqualini, J., García-Astillero, A., Cherta, L., Nozal, L., Vighi, M., 2018. Effects of imidacloprid and a neonicotinoid mixture on aquatic invertebrate communities under Mediterranean conditions. Aquatic Toxicology 204, 130 - 143. 
Rico, A., Brock, T.C.M., Daam, M.A., 2019. Is the effect assessment approach for fungicides as laid down in the European Food Safety Authority Aquatic Guidance Document sufficiently protective for freshwater ecosystems? Environmental Toxicology and Chemistry 38, 2279 - 2293.

Rico, A., Dimitrov, M.R., Van Wijngaarden, R.P.A., Satapornvanit, K., Smidt, H., Van den Brink, P.J., 2014. Effects of the antibiotic enrofloxacin on the ecology of tropical eutrophic freshwater microcosms. Aquatic Toxicology 147, 92 - 104.

Rico, A., Van den Brink, P.J., 2015. Evaluating aquatic invertebrate vulnerability to insecticides based on intrinsic sensitivity, biological traits, and toxic mode of action. Environmental Toxicology and Chemistry 34(8), 1907 - 1917.

Roch, S., Walter, T., Ittner, L.D., Friedrich, C., Brinker, A., 2019. A systematic study of the microplastic burden in freshwater fishes of south-western Germany - Are we searching at the right scale? Science of the Total Environment 689:1001-1011.

Roessink, I., Merga, L.B., Zweers, H.J., Van den Brink, P.J., 2013. The neonicotinoid imidacloprid shows high chronic toxicity to mayfly nymphs. Environmental Toxicology and Chemistry 32(5), 1096 1100.

Roggeri, H., 1995. Tropical freshwater Wetlands. A Guide to Current Knowledge and Sustainable management. pp 223. Springer Science+Business Media Dordrecht.

Romeo, T., Pietro, B., Pedà, C., Consoli, P., Andaloro, F., Fossi, M.C., 2015. Note: First evidence of presence of plastic debris in stomach of large pelagic fish in the Mediterranean Sea. Marine pollution bulletin 95:358-361.

Rubach, M.N., Crum, S.J.H., Van den Brink, P.J., 2011. Variability in the Dynamics of Mortality and Immobility Responses of Freshwater Arthropods Exposed to Chlorpyrifos. Archives of Environmental Contamination and Toxicology 60, 708 - 721.

Rummel, C.D., Löder, M.G.J., Fricke, N.F., Lang, T., Griebeler, E.-M., Janke, M., Gerdts, G., 2016. Plastic ingestion by pelagic and demersal fish from the North Sea and Baltic Sea. Marine pollution bulletin 102, 134-141.

Ryan, J., Estefan G., Rashid, A., 2001. Soil and Plant Analysis Laboratory Manual. Second Edition. Jointly published by the International Center for Agricultural Research in the Dry Areas (ICARDA) and the National Agricultural Research Center (NARC). Available from ICARDA, Aleppo, Syria. $x+172$ pp.

Ryan, P.G., 1988. The Characteristics and Distribution of Plastic Particles at the Sea-surface off the Southwestern Cape Province, South Africa. Marine Environmental Research 25, 249-273.

Saadati, N., Abdullah, M.P., Zakaria, Z., Sany, S.B.T., Rezayi, M., Hassonizadeh, H., 2013. Limit of detection and limit of quantification development procedures for organochlorine pesticides analysis in water and sediment matrices. Chemistry Central Journal 7, 63 - 72.

Sanchez, W., Bender C., Porcher J.-M., 2014. Wild gudgeons (Gobio gobio) fromFrenchriversarecontaminated bymicroplastics: Preliminary study and first evidence. Environmental Research 128:98-100.

Sánchez-Bayo, F., 2010. Impacts of Agricultural Pesticides on Terrestrial Ecosystems. In Sánchez-Bayo, F., Van den Brink, P.J., Mann, R.M., eds. Ecological Impacts of Toxic Chemicals. pp. 75 - 107, Bentham Science Publishers Ltd.

SAPEA 2019. Science Advice for Policy by European Academies (SAPEA): A Scientific Perspective on Microplastics in Nature and Society. Berlin: https://doi.org/10.26356/microplastics.

Schäfer, R.B., 2012. Biodiversity, ecosystem functions and services in environmental risk assessment: Introduction to the special issue. Science of the Total Environment 415, 1-2. 
Schäfer, R.B., Bundschuh, M., Rouch, D.A., Szöcs, E., Von der Ohe, P.C., Pettigrove, V., Schulz, R., Nugegoda, D., Kefford, B.J., 2012. Effects of pesticide toxicity, salinity and other environmental variables on selected ecosystem functions in streams and the relevance for ecosystem services. Science of the Total Environment 415, 69 - 78.

Schäfer, R.B., Van den Brink, P.J., Liess, M., 2010. Impacts of Pesticides on Freshwater Ecosystems. Sánchez-Bayo, F., Van den Brink, P.J., Mann, R.M., (eds). Ecological Impacts of Toxic Chemicals. Pp. 139 - 173, Bentham Science Publishers Ltd.

Schallenberg, M., de Winton, M.D., Verburg, P., Kelly, D.J., Hamill, K.D., Hamilton, D.P. (2013). Ecosystem services of lakes. In Dymond JR ed. Ecosystem services in New Zealand - conditions and trends. Manaaki Whenua Press, Lincoln, New Zealand.

Schell, T., Rico, A., Vighi, M., 2020. Occurrence, Fate and Fluxes of Plastics and Microplastics in Terrestrial and Freshwater Ecosystems. In; Reviews of Environmental Contamination and Toxicology (Continuation of Residue Reviews). Springer, New York, NY.

Scherer, C., Brennholt, N., Reifferscheid, G., Wagner, M., 2017. Feeding type and development drive the ingestion of microplastics by freshwater invertebrates. Scientific Reports 7:17006.

Scherer, C., Wolf, R., Völker, J., Stock, F., Brennhold, N., Reifferscheid, G., Wagner, M., 2020. Toxicity of microplastics and natural particles in the freshwater dipteran Chironomus riparius: Same same but different? Science of the Total Environment 711:134604.

Schilmann, A., Lacasaña, M., Blanco-Muñoz, J., Aguilar-Garduño, C., Salinas-Rodríguez, A., FloresAldana, M., Cebrián, M.E., 2010. Identifying pesticide use patterns among flower growers to assess occupational exposure to mixtures. Occupational and Environmental Medicine 67(5), 323 $-329$.

Schrank, I., Trotter, B., Dummert, J., Scholz-Bottcher, B.M., Loder, M.G.J., Laforsch, C., 2019. Effects of microplastic particles and leaching additive on the life history and morphology of Daphnia magna. Environmental Pollution 255:113233.

Schuler, L.J., Rand, G.M., 2008. Aquatic Risk Assessment of Herbicides in Freshwater Ecosystems of South Florida. Archives of Environmental Contamination and Toxicology 54, 571-583.

Schulz, R., 2004. Field Studies on Exposure, Effects, and Risk Mitigation of Aquatic Nonpoint-Source Insecticide Pollution: A Review. Journal of Environmental Quality 33, 419 - 448.

Schuwirth, N., Kattwinkel, M., Stamm, C., 2015. How stressor specific are trait-based ecological indices for ecosystem management? Science of the Total Environment 505, 565 - 572.

Schwarzenbach, R.P., Westall, J., 1981. Transport of nonpolar organic compounds from surface water to groundwater. Laboratory sorption studies. Environmental Science and Technology 15, 1360 1367.

Seyoum, W.M., Milewski, A.M., Durham, M.C., 2015. Understanding the relative impacts of natural processes and human activities on the hydrology of the Central Rift Valley lakes, East Africa. Hydrological Processes 29, 4312-4324.

Schmitz, O.J., Krivan, V., Ovadia, O., 2004. Trophic cascades: the primacy of trait-mediated indirect interactions. Ecology Letters 7, 153 - 163.

Sfakianakis, D.G., Renieri, E., Kentouri, M., Tsatsakis, A.M., 2015. Effect of heavy metals on fish larvae deformities: A review. Environmental Research 137, 246 - 255.

Shea, D., Thorsen, W., 2012. Ecological Risk Assessment. Hodgson, E., (ed). Progress in Molecular Biology and Translational Science. Pp. 3233 - 3248, Elsevier Inc.

Sheil, D., Liswanti, N., 2006. Scoring the Importance of Tropical Forest Landscapes with Local People: Patterns and Insights. Environmental Management 38(1), 126-136. 
Shiberu, T., Negeri, M., Selvaraj, T., 2013. Evaluation of Some Botanicals and Entomopathogenic Fungi for the Control of Onion Thrips (Thrips tabaci L.) in West Showa, Ethiopia. Journal of Plant Pathology and Microbiology 4(1), 161 - 167.

Silva, C.J.M., Silva, A.L.P., Gravato, C., Pestana, J.L.T., 2019. Ingestion of small-sized and irregularly shaped polyethylene microplastics affect Chironomus riparius life-history traits. Science of the Total Environment 672, 862 - 868.

Silva, E., Daam, M. A., Cerejeira, M. J., 2015. Predicting the aquatic risk of realistic pesticide mixtures to species assemblages in Portuguese river basins. Journal of Environmental Sciences 31, 12 - 20.

Sissay, L., 2003. Biodiversity potentials and threats to the southern Rift Valley lakes of Ethiopia, in: Abebe, Y.D., Geheb, K., (ed.), Wetlands of Ethiopia. Proceedings of a seminar on the resources and status of Ethiopia's wetlands. Nairobi: IUCN- EARO Publications Service Unit. pp 18-24.

Sithanantham, S., 2004. International Centre of Insect Physiology and Ecology (ICIPE): Development and Dissemination of IPM for Vegetables in Eastern Africa. Available on: http://34.250.91.188:8080/xmlui/handle/123456789/674.

Skei, J., Larsson, P., Rosenberg, R., Jonsson, P., Olsson, M., Broman, D., 2000. Eutrophication and Contaminants in Aquatic Ecosystems. Ambio 29 (4 - 5), 184 - 194.

Smit, C.E., Posthuma-Doodeman, C.J.A.M., Van Vlaardingen, P.L.A., de Jong, F.M.W., 2015. Ecotoxicity of Imidacloprid to Aquatic Organisms: Derivation of Water Quality Standards for Peak and LongTerm Exposure. Human and Ecological Risk Assessment 21, 1608 - 1630.

Smith, V.H., Tilman, G.D., Nekola, J.C., 1999. Eutrophication: impacts of excess nutrient inputs on freshwater, marine, and terrestrial ecosystems. Environmental Pollution 100, 179-196.

Solomon, K.R., Sibley, P., 2002. New concepts in ecological risk assessment: where do we go from here? Marine Pollution Bulletin 44, 279 - 285.

Solomon, O.O., Palanisami, T., 2016. Microplastics in the Marine Environment: Current Status, Assessment Methodologies, Impacts and Solutions. Journal of Pollution Effects and Control 4, 113.

Spliethoff, P., Wudneh, T., Tariku, E., Senbeta, G., 2009. Past, Current and Potential Production of Fish in lake Ziway: Central Rift Valley in Ethiopia. Wageningen International, the Netherlands: Capacity Development and Institutional Change Programme. Available on: https://www.wur.nl/en/Publication-details.htm?publicationld=publication-way-343334313734.

Stadlinger, N., Mmochi, A.J., Dobo, S., Gyllback, E., Kumblad, L., 2011. Pesticide use among smallholder rice farmers in Tanzania. Environment, Development and Sustainability 13, 641 - 656.

Stoughton, S.J., Liber, K., Culp, J., Cessna, A., 2008. Acute and Chronic Toxicity of Imidacloprid to the Aquatic Invertebrates Chironomus tentans and Hyalella azteca under Constant- and PulseExposure Conditions. Archives of Environmental Contamination and Toxicology 54, 662 - 673.

Stroud, A., 1994. Water hyacinth (Eichhornia crassipes [Mart.] Solms) in Ethiopia. Available: https://agris.fao.org/agris-search/search.do?recordID=ET9500033.

Struijs, J., Beusen, A., de Zwart, D., Huijbregts, M., 2011. Characterization factors for inland water eutrophication at the damage level in life cycle impact assessment. The International Journal of Life Cycle Assessment 16, 59 - 64.

Su, L., Xue, Y., Li, L., Yang, D., Kolandhasamy, P., Li, D., Shi, H., 2016. Microplastics in Taihu Lake, China. Environmental Pollution 216, 711-719.

Sumon, K.A., 2018. Effects of insecticides on aquatic ecosystems in Bangladesh. PhD thesis. Wageningen University and Research Wageningen, The Netherlands. Available on: 
https://research.wur.nl/en/publications/effects-of-insecticides-on-aquatic-ecosystems-inbangladesh.

Sumon, K.A., Ritika, A.K., Peeters, E.T.H.M., Rashid, H., Bosma, R.H., Rahman, M.S., Fatema, M.K., van den Brink, P.J., 2018. Effects of imidacloprid on the ecology of sub-tropical freshwater microcosms. Environmental Pollution 236, 432 - 441.

Sweeney, B.W., Bott, T.L., Jackson, J.K., Kaplan, L.A., Newbold, J.D., Standley, L.J., Hession, W.C., Horwitz, R.J., 2004. Riparian deforestation, stream narrowing, and loss of stream ecosystem services. Proceedings of the national Academy of Sciences of the United States of America 101(39), 14132 - 14137.

Taiwo, A.M., 2019. A review of environmental and health effects of organochlorine pesticide residues in Africa. Chemosphere 220, 1126 - 1140.

Talling, J.F., Talling I.B., 1965. The chemical composition of African lake waters. Internationale Revue der gesamten Hydrobiologie 50, 421 - 463.

Tamire, G., Mengistou, S., 2012. Macrophyte species composition, distribution and diversity in relation to some physicochemical factors in the littoral zone of Lake Ziway, Ethiopia. African Journal of Ecology 51, 66-77.

Tanaka, K., Takada, H., 2016. Microplastic fragments and microbeads in digestive tracts of planktivorous fish from urban coastal waters. Scientific Reports 6:34351.

Tarfasa, S., Brouwer, R., 2018. Public preferences for improved urban waste management: a choice experiment. Environment and Development Economics 23, 184 - 197.

Teklemariam, D., Legesse, M., Degarege, A., Liang, S., Erko, B., 2018. Schistosoma mansoni and other intestinal parasitic infections in school children and vervet monkeys in Lake Ziway area, Ethiopia. BMC Res Notes 11, 146-151.

Teklu, B.M., 2016. Environmental risk assessment of pesticides in Ethiopia: A case of surface water systems. PhD thesis. Wageningen University and Research. Available on: http://edepot.wur.nl/380652.

Teklu, B.M., Adriaanse, P.I., Ter Horst, M.M.S., Deneer, J.W., Van den Brink, P.J., 2015. Surface water risk assessment of pesticides in Ethiopia. Science of the Total Environment 508, 566 - 574.

Teklu, B.M., Adriaanse, P.I., Van den Brink, P.J., 2016a. Monitoring and risk assessment of pesticides in irrigation systems in Debra Zeit, Ethiopia. Chemosphere 161, 280 - 291.

Teklu, B.M., Hailu, A., Wiegant, D.A., Scholten, B.S. and van den Brink, P.J., 2018. Impacts of nutrients and pesticides from small- and large-scale agriculture on the water quality of Lake Ziway, Ethiopia. Environmental Science and Pollution Research 25, 13207-13216.

Teklu, B.M., Retta, N., Van den Brink, P.J., 2016b. Sensitivity of Ethiopian aquatic macroinvertebrates to the pesticides endosulfan and diazinon, compared to literature data. Ecotoxicology 25, 1226 1233.

Ter Braak, C.J., Šmilauer, P., 2018. Canoco Reference Manual and User's Guide: Software for Ordination (Version 5.1). Microcomputer Power, Ithaca, USA. 536 pp.

Ter Braak, C.J.F., Smilauer, P., 2012. Canoco Reference Manual and User's Guide: Software for Ordination (Version 5.0). Microcomputer Power, Ithaca, NY, USA, pp. 496.

Teshome, S., 2013. Drinking water and sanitation status in Ethiopia: A literature survey. Journal of Vaccines and Vaccination, USA. Availble on: https://www.longdom.org/proceedings/drinkingwater-and-sanitation-status-in-ethiopia-a-literature-survey-1178.html.

Thompson, R.C., Olsen, Y., Mitchell, R.P., Davis, A., Rowland, S.J., John, A.W.G., McGonigle, D., Russell, A.E., 2004. Lost at Sea: Where Is All the Plastic? Science 304:838. 
Tilahun, G., Ahlgren, G., 2010. Seasonal variations in phytoplankton biomass and primary production in the Ethiopian Rift Valley lakes Ziway,Awassa and Chamo-The basis for fish production. Limnologica 40, 330-342.

Tišler, T., Jemec, A., Mozetic, B., Trebše, P., 2009. Hazard identification of imidacloprid to aquatic environment. Chemosphere 76, 907 - 914.

Tudorancea, C., Baxter, R.M., Femandu, C.M., 1989. A comparative limnological study of zoobenthic associations in lakes of the Ethiopian Rift Valley. Archiv für Hydrobiologie Supplement 83, 12174.

Tufi, S., Stel, J.M., de Boer, J., Lamoree, M.H., Leonards, P.E.G., 2015. Metabolomics to Explore Imidacloprid-Induced Toxicity in the Central Nervous System of the Freshwater Snail Lymnaea stagnalis. Environmental Science and Technology 49, 14529 - 14536.

Ulsido, M.D., Alemu, E., 2014. Irrigation Water Management in Small Scale Irrigation Schemes: the Case of the Ethiopian Rift Valley Lake Basin. Environmental Research, Engineering and Management 67(1), 5 - 15.

UN, 2017. United nations (UN): Household Size and Composition Around the World 2017. Economics and Social Affairs. Available on: https://www.un.org/en/development/desa/population/publications/pdf/ageing/household siz e and composition around the world 2017 data booklet.pdf.

UNDP, 2015. United Nations Development Programme (UNDP): Agricultural Growth and Transformation. Available on: https://www.undp.org/content/dam/ethiopia/docs/UNDP\%20Ethiopia\%20Fact\%20Sheet\%20\%20Agriculture\%20Growth\%20and\%20Transformation\%20-\%20August\%202014.pdf.

Urban, E.K., 1969. Ecology of water birds of four rift valley lakes in Ethiopia. Ostrich 40, 315-322.

USEPA, 1983. United State Environmental Protection Agency (USEPA): Methods for Chemical Analysis of Water and Wastes. Available on: https://www.wbdg.org/FFC/EPA/EPACRIT/epa600 479 020.pdf.

Usman, M.A., Gerber, N., Von Braun, J., 2019. The Impact of Drinking Water Quality and Sanitation on Child Health: Evidence from Rural Ethiopia. The Journal of Development Studies 55(10), 2193 2211.

Väänänen, K., Leppänen, M.T., Chen, X., Akkanen, J., 2018. Metal bioavailability in ecological risk assessment of freshwater ecosystems: From science to environmental management. Ecotoxicology and Environmental Safety 147, 430 - 446.

Van de Meutter, F., Stoks, R., de Meester, L., 2006. Rapid response of macroinvertebrates to drainage management of shallow connected lakes. Journal of Applied Ecology 43, 51-60.

Van den Brink, P.J., Blake, N., Brock, T.C.M., Maltby, L., 2006. Predictive Value of Species Sensitivity Distributions for Effects of Herbicides in Freshwater Ecosystems. Human and Ecological Risk Assessment 12, 645 - 674.

Van den Brink, P.J., Hattink, J., Bransen, F., Donk, E.V., Brock, T.C.M., 2000. Impact of the fungicide carbendazim in freshwater microcosms. II. Zooplankton, primary producers and final conclusions. Aquatic Toxicology 48, 251 - 264.

Van den Brink, P.J., Smeden, K.M.V., Bekele, R.S., Dierick, W., de Gelder, D.M., Noteboom, M., Roessink, I., 2016. Acute and chronic toxicity of neonicotinoids to nymphs of a mayfly species and some notes on seasonal differences. Environmental Toxicology and Chemistry 35(1), 128 - 133. 
Van den Brink, P.J., Ter Braak, C.J.F., 1999. Principal response curves: Analysis of time-dependent multivariate responses of biological community to stress. Environmental Toxicology and Chemistry 18(2), $138-148$.

Van den Brink, P.J., Van Wijngaarden, R.P.A., Lucassen, W.G.H., Brock, T.C.M., Leeuwangh, P., 1996. Effects of the insecticide Dursban ${ }^{\circledast} 4 \mathrm{E}$ (active ingredient chlorpyrifos) in outdoor experimental ditches: II. Invertebrate community responses and recovery. Environmental Toxicology and Chemistry 15(7), 1143 - 1153.

Van Leeuwen, C.J., Vermeire, T.G., 2007. Risk Assessment of Chemicals: An Introduction, Springer, Dordrecht, The Netherlands.

Van Vlaardingen, P.L.A., Traas T.P., Wintersen, A.M., Aldenberg, T., 2003. Normal Distribution based Hazardous Concentration and Fraction Affected ETX-2000. Rijksinstituut voor Volksgezondheid en Milieu,Bilthoven, https://rvs.rivm.nl/risicobeoordeling/modellen-voor-risicobeoordeling/ETX.

Van Wijngaarden, R.P., Maltby, L., Brock, T.C., 2015. Review: Acute tier-1 and tier-2 effect assessment approaches in the EFSA Aquatic Guidance Document: are they sufficiently protective for insecticides? Pest Management Science 71, 1059 - 1067.

Van Wijngaarden, R.P.A., Brock, T.C.M., Van den Brink, P.J., 2005. Threshold Levels for Effects of Insecticides in Freshwater Ecosystems: A Review. Ecotoxicology 14, 355 - 380.

Vanbergen, A.J., 2013. Threats to an ecosystem service: pressures on pollinators. Reviews. Frontiers in Ecology and the Environment 11(5), 251 - 259.

Vega, A.B., Frenich, A.G., Vidal, J.L.M., 2005. Monitoring of pesticides in agricultural water and soil samples from Andalusia by liquid chromatography coupled to mass spectrometry. Analytica Chimica Acta 538, 117 - 127.

Vert, M., Doi, Y., Hellwich, K.-H., Hess, M., Hodge, P., Kubisa, P., Rinaudo, M., Schué, F., 2012. Terminology for biorelated polymers and applications (IUPAC Recommendations 2012). Pure Applied Chemistry 84(2), 377-410.

Von Damm, K.L., Edmond, J.M., 1984. Reverse weathering in the closed-basin lakes of the Ethiopian rift. Americal Journal of Science 284, 835-862.

Vukosav, P., Mlakar, M., Cukrov, N., Kwokal, Ž., Pižeta, I., Pavlus, N., Špoljarić, I., Vurnek, M., Brozinčević, A., Omanović, D., 2014. Heavy metal contents in water, sediment and fish in a karst aquatic ecosystem of the Plitvice Lakes National Park (Croatia). Environmental Science and Pollution Research 21, 3826 - 3839.

Wagner, M., Scherer, C., Alvarez-Muñoz, D., Brennholt, N., Bourrain, X., Buchinger, S., Fries, E., Grosbois, C., Klasmeier, J., Marti, T., Rodriguez-Mozaz, S., Urbatzka, R., Vethaak, A.D., WintherNielsen, M., Reifferscheid, G., 2014. Microplastics in freshwater ecosystems: what we know and what we need to know. Environmental Sciences Europe 26(12), 1 -9.

Walker, C.H., Sibly, R.M., Hopkin S.P., Peakall, D.B., 2012. Principles of ecotoxicology, CRC Press, Taylor and Francis Group, USA.

Wang, J., Peng, J., Tan, Z., Gao, Y., Zhan, Z., Chen, Q., Cai, L., 2017. Microplastics in the surface sediments from the Beijiang River littoral zone: Composition, abundance, surface textures and interaction with heavy metals. Chemosphere 171, 248-258.

Wasswa, J., Kiremire, B.T., Nkedi-Kizza, P., Mbabazi, J., Ssebugere, P., 2011. Organochlorine pesticide residues in sediments from the Uganda side of Lake Victoria. Chemosphere 82, 130 - 136.

Weber, J.B., 1995. Agrochemical environmental fate: state of the art. Leng, M.L., Leovey, E.M.K. and Zubkoff, P.L. (eds), CRC Press, Inc. 
Welteji, D., 2018. A critical review of rural development policy of Ethiopia: access, utilization and coverage. Agriculture and Food Security 7, 55.

Wenaty, A., Mabiki, F., Chove, B., Mdegela, R., 2019. Assessment of persistent organochlorine compounds contamination on the Lake Victoria water and sediments: a case study in Tanzania. African Journal of Aquatic Science 44, 281 - 290.

WHO, 2019. Microplastics in drinking-water. World Health Organization (WHO), Geneva. Licence: CC BY-NC-SA 3.0 IGO., Switzerland.

WHO, 2011. Guidelines for Drinking-water Quality. World Health Organization, Switzerland. https://apps.who.int/iris/bitstream/handle/10665/44584/9789241548151 eng.pdf.

Williams, D.A., 1972. The Comparison of Several Dose Levels with a Zero Dose Control. Biometrics 28(2), $519-531$.

Williamson, S., Ball, A., Pretty, J., 2008. Trends in pesticide use and drivers for safer pest management in four African countries. Crop Protection 27, 1327 - 1334.

Wolff, S., Kerpen, J., Prediger, J., Barkmann, L., Müller, L., 2019. Determination of the microplastics emission in the effluent of a municipal waste water treatment plant using Raman microspectroscopy. Water Research X 2:100014.

Wondefrash, M., 2003. Wetlands, birds and Important Bird Areas in Ethiopia, in: Abebe, Y.D., Geheb, K., (ed.), Wetlands of Ethiopia. Proceedings of a seminar on the resources and status of Ethiopia's wetlands. Nairobi: IUCN- EARO Publications Service Unit. pp 25-36.

Wood, R.B., Prosser, M.V., Baxter, R.M., 1979. Optical characteristics of the Rift Valley Lakes, Ethiopia. SINET: Ethiopian Journal of Science 1, 73-85.

Wood, R.B., Talling, J.F., 1988. Chemical and algal relationships in a salinity series of Ethiopian inland waters. Hydrobioiogia 158, 29-67.

Xu, X., Yang, G., Tan, Y., Zhuang, Q., Li, H., Rongrong Wan, Su, W., Zhang, J., 2016. Ecological risk assessment of ecosystem services in the Taihu Lake Basin of China from 1985 to 2020. Science of the Total Environment (2016) 7-16, 554-555.

Yohannes, Y.B., Ikenaka, Y., Saengtienchai, A., Watanabe K.P., Nakayama, S.M.M., Ishizuka, M., 2014. Concentrations and human health risk assessment of organochlorine pesticides inedible fish species from a Rift Valley lake-Lake Ziway, Ethiopia. Ecotoxicology and Environmental Safety 106, 95-101.

Zbyszewski, M., Corcoran, P.L., Hockin, A., 2014. Comparison of the distribution and degradation of plastic debris along shorelines of the Great Lakes, North America. Journal of Great Lakes Research 40, 288-299.

Zhang, H., 2017. Transport of microplastics in coastal seas. Estuarine, Coastal and Shelf Science 199, 74-86.

Zinabu, G.M., Kebede-Westhead, E., Desta, Z., 2002. Long-term changes in chemical features of waters of seven Ethiopian rift-valley lakes. Hydrobiologia 477, 81-91.

Zinabu, G.M., Pearce, N.J.G., 2003. Concentrations of heavy metals and related trace elements in some Ethiopian rift-valley lakes and their in-flows. Hydrobiologia 429, 171-178.

Zitouni, N., Bousserrhine, N., Belbekhouche, S., Missawi, O., Alphonse, V., Boughatass, I., Banni, M., 2020. First report on the presence of small microplastics $(\leq 3 \mu \mathrm{m})$ in tissue of the commercial fish Serranus scriba (Linnaeus. 1758) from Tunisian coasts and associated cellular alterations. Environmental Pollution 263:114576. 



\section{Summary}

Ethiopia is a predominantly agrarian country where about $85 \%$ of the country's population is engaged in the agricultural sector. The sector has enjoyed substantial growth during the last two decades. To increasing crop production and productivity to achieve high agricultural growth and alleviate food security problems in the growing population through, for example, intensive use of agricultural inputs such as fertilizers and pesticides are priorities for the Ethiopian government. As a result of this agricultural intensification policy of the Ethiopian government, the use of pesticides and fertilizers has increased year to year and will be expected to further increase in the years to come. The central Ethiopian rift valley region, particularly in the vicinity of Lake Ziway, is amongst the regions where agrochemicals (pesticides and fertilizers) are most intensively used by smallholder farmers producing vegetables and fruits (e.g., tomato, onion, cabbage, green bean and pepper) and by large-scale farms producing horticulture crops (e.g., cut-flowers and grape). Residual concentrations of pesticides and nutrients used by the small- and large-scale farmers may enter Lake Ziway through several routes such as agricultural land runoff, effluent discharge, drift during spraying, and inadequate handling of remnant pesticides and empty pesticide containers. Currently, there is high concern about the pollution of Lake Ziway by residuals of agrochemicals (e.g., pesticide) and their ecological effects. In addition, Lake Ziway is under threat of pollution by urban wastes (solid and liquid wastes) sourced from the fast-growing Batu and Meki towns found at the south-west and north-west side of the lake, respectively. Therefore, a systemic investigation that assesses the ecological impacts of pollutants to Lake Ziway (e.g., pesticides, trace metals and microplastics, and nutrients) due to agricultural and urbanization in the catchment area of the lake is needed to support its conservation and protection.

The main objectives of our studies were; 1 ) to review the status, temporal and spatial variability of water quality and biological resources of Lake Ziway, 2) to assess the goods and services that local communities currently derive from the lake, 3 ) to investigate the current use and misuse of pesticides by small- and large-scale farmers in the vicinity of Lake Ziway, monitor pesticide concentrations in lake sediment and water compartments, and evaluate the associated ecological risks, 4) to assess the distribution of microplastics in the sediment and 
some fish species in Lake Ziway, and 5) to assess structural and functional effects of the pesticide imidacloprid to the aquatic ecosystem typical for the Ethiopian tropical climate .

The thesis begins with a literature review (Chapter 2) on the biological resources, and spatio-temporal variation of water quality of the lake focusing on nutrients, metals and pesticides, and other stress factors such as sedimentation and water abstraction for irrigation use. The results of this study indicate the deteriorating trends of several water quality and ecological parameters. Several water concentration levels of nutrients and trace metals (e.g., $\mathrm{PO}_{4}{ }^{3-}, \mathrm{NO}_{3}{ }^{-}, \mathrm{NH}_{4}{ }^{+}, \mathrm{Ca}^{2+}, \mathrm{Cu}$ and $\mathrm{Ni}$ ) of the lake show increasing trends. For some parameters the water quality of the lake exceeded guideline values for safe drinking water (e.g., alkalinity, $\mathrm{Fe}$, and pesticides like diazinon and spiroxamine) and for aquatic life (e.g., $\mathrm{NH}_{4}{ }^{+}, \mathrm{Fe}, \mathrm{Cr}, \mathrm{Cu}$ and Se). The literature review also showed that water samples from shoreline locations of the lake proximate to floriculture farms showed increased values for some physicochemical parameters (e.g., $\mathrm{NO}_{3}{ }^{-}, \mathrm{NH}_{4}{ }^{+}, \mathrm{K}, \mathrm{Na}$ and electrical conductivity) and residual pesticides of various types (e.g., boscalid, methomyl, carbendazim and spiroxamine).

In Chapter 3, the ecosystem goods and services (ES) that the Lake Ziway provides for the communities of the region were identified and prioritized by local people based on the relevance for their livelihood. Concurrently, the pesticide use and handling practices of the small- and large-scale farmers found in proximate to Lake Ziway was assessed. The potential impacts of pesticides on the ES of the lake was also assessed using a conceptual approach that links the effect of pesticides on organisms of the lake due to contamination to effect on ES provision by the lake ecosystem. The results of the study showed that Lake Ziway supplies a wide array of ES for the local communities including 15 classes of provisioning ES , 3 classes of regulating and maintenance ES, and 6 classes of cultural services. The study also indicated misuse and improper handling of pesticides by smallholder farmers. Malpractices of farmers included improper storage, over-dosage, too high application frequencies (up to 12 times/crop/season) in violation of recommended interval days, mixing pesticides near the water canal and dumping pesticide wastes into their surrounding environment. In addition, the wastewater effluent released from the floriculture farms into Lake Ziway is another concern as no evidence is presented that show its effective treatment before it released into the lake ecosystem. The study found that the pesticide use and handling practices of the farmers in the region were unsustainable and likely expose the Lake Ziway ecosystem to pesticide contamination at such levels potential to pose impact to the ES of the lake. 
The environmental levels of pesticides and physicochemical parameters, including nutrients in water and sediment compartments of Lake Ziway were investigated in Chapter 4. Variation in the distribution and composition of biological organisms (macroinvertebrates and fish) were also assessed by correlation with monitored environmental variables (pesticides and physicochemical variables). Ecological risks of the individual pesticide and risks due to the mixture of the pesticides were evaluated using risk quotients (RQ) and mixed-model approaches, respectively. The results showed contamination of water and sediment of Lake Ziway with different types of insecticides and fungicides, where malathion, dimethoate, metalaxyl, diazinon, chlorpyrifos, fenitrothion and endosulfan were detected in more than half of the water samples (> 50\%), and diazinon, $\alpha$-cypermethrin and endosulfan were observed frequently (>25\%) in sediment samples. Effects on physicochemical properties of the water of the lake and higher residual levels of the quantified pesticides were observed at locations proximate to floriculture, smallholder agriculture and urban settlements. The effects on structural and functional endpoints of the lake were also studied in relation to levels of the environmental variables (e.g., nutrients and pesticides). For most of the pesticides quantified in water and sediment the calculated SSD based acute $R Q$ was $>1$, indicating possible to very high ecological risks. Arthropods and fish are expected to be highly affected by the measured mixture of pesticides. The effect was high at locations of the lake that are proximate to smallholders' farms, and receive largescale farms' wastewater and sites where the inflow rivers join the lake.

Spatio-temporal distribution of plastic particles in sediment and in the gastrointestinal tract of fish of Lake Ziway was studied, and discussed in Chapter 5. The effect of the contaminant, plastic particles, are also discussed by comparing its estimated concentration in the sediment of the lake to the threshold effect concentrations reported in the literature. The results of the study indicated that shoreline sediments of Lake Ziway are contaminated by plastic particles and the highest estimated sediment concentration was in exceedance of effect threshold values reported in the literature, thus it is likely to cause effect on benthic communities. More than one-third of the sampled fish individuals were also found with ingested plastic particles in their gastrointestinal tracts, which may also have human health risk implication. The particle size analysis result also demonstrated the benthopelagic transfer of plastic particles from sediment to fish. 
Chapter 6 presents and discusses the results of an effect study of imidacloprid pesticide, using a mesocosm experimental setup with tropical freshwater conditions typical for Ethiopia. Structural (e.g., macroinvertebrates, zooplanktons, phytoplankton and periphyton) and functional (e.g., decomposition of organic matter and physicochemical parameters) endpoints were studied. The recovery of the community from the effect of the pesticide was also studied. In addition, acute single species toxicity of imidacloprid to local freshwater arthropods was studied and discussed. Effect concentrations (L(E)C50 and $L(E) C 10)$ and no observed effect values (NOEC) were calculated for the experimental water quality parameters and biological endpoints. A direct effect of imidacloprid was observed on aquatic organisms, in which the macroinvertebrates: Cloeon dipterum and Caenis horaria, and the zooplankton: Brachionus sp. and Filinia sp. were the most negatively affected species compared to other species. Treatment-related significant increases in chlorophyll-a concentrations of periphyton and phytoplankton were also found, which are likely indirect effects as the primary producers are released from grazing pressure (e.g., by the grazers Cloeon dipterum, Brachionus sp. and Filinia sp. and scrapers Planorbidae sp. and Physidae sp.) as a direct effect of the imidacloprid insecticide. Higher sensitivity of tropical aquatic species to imidacloprid was also demonstrated relative to their temperate counterparts. Recovery was observed for zooplankton community ( 9 weeks), but no recovery was found for macroinvertebrates in 21 weeks of the recovery period of the experiment.

In conclusion, key findings in our studies are discussed in Chapter 7. Agricultural and urbanization activities are affecting the ecology and water quality of Lake Ziway by discharging nutrients, trace metals, residual pesticides and plastic particles among others into the lake. Intervention measures and future research outlooks are pointed out, that can help the protection and conservation of Lake Ziway and other Ethiopian aquatic ecosystems experiencing similar anthropogenic pressures in their catchments. Accordingly, the thesis recommends: 1) training on pesticide safe use and handling for smallholder farmers to improve the skill and knowledge, 2) promotion and adoption of IPM technologies to reduce use and misuse of pesticide, 3) strengthening regulatory control on the registration, and purchase and use of pesticides, 4) implementation and improvement of urban waste management, 5) establishment of modern laboratory facilities to enable risk assessment of pesticides and emerging chemicals and 6) wide application of EPT richness index to monitor the water quality of Lake Ziway and other aquatic ecosystem with similar anthropogenic 
pressures, as it is quick, effective and cheap compared to monitoring of physical and chemical variables. 



\section{Goolaba}

Itoophiyaan biyya dinagdeen ishii qonna iratti hirkateefi caalmaan ummata ishees (harka 85) hojii qonnaa irratti kan boba'an dha. Yeroo muraasaa as, keessayuu wagoottan digdamman (two decades) darbaniif qonni biyyatti guddina saffisaa agarsiisuutti argama. Haaluma walfakatuun mootumman Itoophiyaa guddina biyyattin qonna irratti mul'isaa jirtu caalmaatti itti fufsiisuufi akkasumas nyaataan uummata ishee ofiin of dandeesisuuf oomishaaf oomishtummaa kan guddisuu danda'an fakkeenyaaf kan akka keemikaala farra ilbiisotaa fi xaa'oo qonnaan bultoon baliinaan akka fayyadamaaniif irratti hojjechaa jitti. Poolisii guddinaa biyyi Itoophiyaa hordoftu kan balinaan itti fayyadamuu kemikaalota callaa gudiftuu jajjabeesu waliin wal-qabatee, yeroon dhiyoon as itti fayadamni keemikaala farra ilbiisotaa fi xaa'oo biyyattii wagaatii waggaatti dabalaa kan dhufe yeroo ta'u fi kun caalmaatti akka gara fuulduraatti itti fufus ni eegama. Haaluma wal-fakkaatuun ittifayadamni kemikaalotaa kan akka farra ilbisotaa fi xaa'oo qonnan bultoota naannoo Haroo Ziwaay (Hara Dambal) jiraniin ba'iinaan hojiirraa oolfamaa jiru. Qonaan bultooni kunneen bal'inaan jalisii fayyadamuun lafa xixiqqaa irratti kuduraa fi mudura kan oomishanii fi akkasumas kaampaniiwwan qonnaa lafa bal'aa irratti abaaboo omishanidha. Kemikaalonni hojii qonnaa kan irratti qonnaan bultootaan fayadaman kunneen karaa adda addaa gara haroo itii dhiyoo jiru (Haroo Ziwaay) seenuu ni malu. Fakeenyaaf yeroo roobni roobu lolaan, balfi karaa ujumoo warshaa abaaboo keessaa gar hara kanaa galu irraan, yeroo biifan qileensaa irraan fi haala qabiinsa kemikaalootaa badaa (malpractice) ta'uu irraan kan ka'e kemikaalii farra ilbiisotaa gara Haroo Ziwaay seenuu ni danda'u. Kanuma waliin walqabatee yeroo amma yaaddoon kemikaalotaan faalamuu hara kanaa fi gaaga'iinsa inni haricha irratti fiduu malu guddachaa dhufee jira. Akkasumas, balfa dhangala'aa fi gogaa magaalota naanno Haroo Ziwaay jiran kan akka magaala Baatuu fi magaala Maqii irraa madduu fi gara harichaa karaa adda addaan seenu yaaddoo harichaa mancaasuu dabalataa uumee jira. Kanaaf eegumsa Haroo Ziwaay gargaruuf, qo'annoon gaaga'iinsa keemikaalonni fi balfi adda addaa kan hojii qonnaa fi balfa magaalotaa irraa maddan hara kana irratti geessisan fi qaqqabsiisu danda'an gaggeessuun baayyee barbaachisaadha.

Kaayyoon waraqaa qo'annoo fi qorannoo kana; 1) qorrannoo fi qorannoowan Haroo Ziwaay irratti kanaan dura hojjetamaan fayyadamuun haalaa qulqullinni bishaan hara kanaa irra jiru, bakkaa bakkatti fi barootan keessa maal ta'aa akka deemaa jiru fi lubbuu qabeeyyiin harchaas maal irra akka jiran cuunfuu, 2) faayidaa Haroon Ziwaay uummattoota naannootiif 
kennaa jiru gadifageenyaan qo'achuu fi add baasuu, 3) rakkina itti fayyadama keemikaala farra ilbiisotaa (pesticides) karaa qonnaan bultoota naannoo Haroo Ziwaay jiran jiru qorachuu, keemikaala farra ilibiisotaan faalamuu harichaa sakata'uu fi gaaga'iinsa (risk) falamuu kana waliin wal-qabatee dhufuu danda'u adda baasuu, 4) tatamsa'iinsa caccabaa laastikii xixiqqaa (microplastics) cirracha (sediment) Haroo Ziwaay fi qurxummii harichaa kan nyaataaf oolan kessatti qorachuu fi 5) gaaga'iinsa keemikaalli farra ilbiisotaa kan ta'e immiidaakloopriid (Imidacloprid) qabeenya bishaanii fi lubbu-qabeeyyii bishaan keessa jiraatan irra gessisuu danda'u haroo nam-tolcheen (artificial pond) Itoophiyaa keessatti qophaa'ee fayadamuun qoranna gaggeessuu dha.

Hojjin waraqaa qorannoo kun kan jalqabe qorannoo fi qowannoowwan kanaan dura Haroo Ziwaay irratti hojjetamanii maxxanfaman fayadamuun haala qabeenyi uumamaa harichaa irra jiran, qulquliina bishaa harichaa bakka bakkatti fi baraa-baratti maal akka fakkaatu keesa iyyuu hangi kemikaalootaa kan akka xaa'oo (nutrients), sibiilotaa (metals) fi keemikaala farra ilbiisotaa (pesticides) kan cuunfedha (Boqonnaa 2). Akkasumas, dhiibbaa faaltotaa kaanii (other pollutants) kan keemikaalota hin ta'iin fakkeenyaaf cirrachaa karaa lolaa harichaatti dabalamuu (sedimentation) fi bishaa jalisiif harichaa irraa harkifamuu (water abstraction for irrigation) qorannaa kan keessatti adda baafamaniiru. Bu'aan qoranichaa akka agarsiisutti lubuu qabeeyyiin Haroo Ziwaay mancaatiin akka hubamaa jiruu fi qulqullinni bishaan harchaas bakka-bakkatti fi baraa-baratti akka hedduminaan faalamaa dhufe agarsiisa. Keessayyuu bishaan keessatti hangi (water concentration levels) kemikaalota tokko tokkoo (fakkenyaaf; $\mathrm{PO}_{4}{ }^{3-}, \mathrm{NO}_{3}{ }^{-}, \mathrm{NH}_{4}{ }^{+}, \mathrm{Ca}^{2+}, \mathrm{Cu}$ fi $\mathrm{Ni}$ ) baraa-baratti dabaluu agarsiisanii jiru. Akka hangi safartuuwwan (parameters) tokko tokko agarsiisanitti qulqullinni bishaan Haroo Ziwaay tajaajila bishaan dhugaatiif (fakkeennaaf; alkalinity, Fe, fi hangi keemikaalota farra ilbiisaa tokko tokko kan akka di'aazinoonii (diazinon) fi spaayirooksamiinii ( spiroxamine)) fi lubbuu qabeeyyii harichaa keessa jirataniif (fakkeenyaaf; $\mathrm{NH}_{4}{ }^{+}, \mathrm{Fe}, \mathrm{Cr}, \mathrm{Cu}$ fi Se) mijataa akka hin taanee mul'isa. Dabalataan qorannichii akka ibsutti saamudoota bishaanii (water samples) qarqara Haroo Ziwaay bakkeewwan oomisha warshaa abaabootti dhiyeenyaan argaman irraa guuraman keesatti hangi fiizikookeemikaalotaa (physicochemical) baayeen (fakkeenyaaf: $\mathrm{NO}_{3}{ }^{-}, \mathrm{NH}_{4}{ }^{+}, \mathrm{K}, \mathrm{Na}$ fi elektiriikaal kondaaktiiviitii (electrical conductivity)) fi hangi keemikaalota farra ilbiisotaa tokko tokko (fakkeenyaaf: boscalid, methomyl, carbendazim fi spiroxamine) yeroo bakkeewwan biroo waliin wal-bira qabamee ilaalamu guddaadha. 
Qorannoo Boqonnaa 3 keessatti, faayidaawwan (ecosystem services) ummanni naannoo Haroo Ziwaay jiraatan haroo kana irraa argachaa jiru kan adda baafaman yeroo ta'u, dabalataan faydaawwan kanneen harchi umattoota naannootiif kennu akkaataa wal-caalmaa faydaa isaan hawaasaaf laataniin uummataan sadarkeeffamaniiru. Walcinaan (Concurrently) boqonnaa kan keessatti (Boqonnaa 3) haalli itti fayyadamaa fi qabiinsaa keemikaala farra ilbiisotaa qonnaan bultoota naannoo Haroo Ziwaay jiran maal akka fakkaatuu fi kanaan walqabatee rakina harichaa irratti dhuumuu/fiduu malus qoratamee jira. Qonnaan bultoonni as keessatti hamataman bishaan Haroo Ziwaay fayyadamuun kanneen qonna xixiqqaa irratti jalisiin kuduraa fi mudura oomishanii fi warshaa qonnaa lafa balla'aa irratti oomisha abaaboo (cut flowers) fi waynii (grape) kan hojjechaa jiran faadha. Balinaan qonnaan bultootaan fayyadamuu keemikaala farra ilbiisotaa kana irraan kan ka'ee miidhaan fayidaa Haroon Ziwaay uummata naannoo jiraniif laachaa jiru irratti geessisuu malus boqonnaan kun adda baasee jira. Akka bu'aa qorannoo kanaatti Haroo Ziwaay irraa walumaa gala faaydaawwan dhigdamii afur (24) uummanni naannoo argachaa jira. Dabalataan qorannichi akka ibsutti haalli qonnaan bultoonni kuduraa fi mudura oomishan keemikaala farra ilbiisotaa itti fayyadama jiran qixa sirriin akka hin taanedha. Fakkeenya itti fayyadam sirrii hin ta'iin keessaa: keemikaalota kana iddoo sirrii hin taane kuusuu/ka'u, kan gorfamaniin olitti fayyadamuu (over-dosage), kan eeyyamamun olitti daddafiin biifuu, haroo/burqaa/laga bishaaniitti dhiyaatanii keemikaalota kana bulbuluu, balfa keemikaalota kanaan wal-qabatan naannootti (environment) of eeggannaa tokko malee gatuu fi KKFfaadha. Akkasumas ragaan keemikaalota qabeenya bishaanii irratti midhaa geesisan irraa bilisa ta'u balfa dhanga'aa lafa qonnaa warshaa abaaboo keessaa ba'e gara Haroo Ziwaaytti dabalmu agarsiisu qorannoo kanan hin argamne. Kanaafuu, balfi kun hara kana keemikaala farra ilbisootaan fi kemikaalota biroon faaluu akka malu qoranoon kun ni agarsiisa. Walumaagala akka qorannoo kanaatti haalli qonnan bultootni keemikaala farra ilbiisotaa itti fayyadamaa jiran qixa sirri akaa hin taanee fi kun immo Haroo Ziwaay faaluu irra darbee faaydaawwan inni uummata naannoof kennaa jiru midhaa guddaa irraan gahuu danda'a.

Boqonnaa 4 keessatti hangi fiizikookeemikaalootaa fi hangi keemikaala farra ilbisootaa saamudoota (samples) bishaanii fi cirrachaa Haroo Ziwaay irraa funaanaman fayyadamuun safaramuun adda baafamaniiru. Akkasuman hariiroon tatamsa'inni lubbu qabeeyyii (macroinvertebrates and fish) harichaa fi keemikaalota farra ilbisotaan faalamni harichaa maal akka fakaatu boqonnicha keessatti addaan baafamee jira. Dabalataan, keemikaalota farra 
ilbiisotaan falamnuu Haroo Ziwaay waliin wal-qabatee midhaa/gaaga'iinsa (ecological risks) isaan qabeenya uumamaa haroo kanaa irratti fiduu danda'an qoranichi ifoomsee jira. Akka bu'aan qorannoo kana ifa godhetti bishaan fi cirrachii Haroo Ziwaay keemikaalota farra ilbiisotaa gara garaan faalamuu mul'isa. Keessayyuu keemikaalonni kanneen akka maalaatayiinii (malathion), daymeettooyaatii (dimethoate), meetaalakziilii (metalaxyl), di'aaziinoonii (diazinon), kilooroopayiiriifoosii (chlorpyriphos), feeniitirootayoonii (fenitrothion) fi indoosulfaanii (endosulfan) harka caalaa (> 50\%) saamuuda bishaanii Haroo Ziwaay irraa funaaname keessatti argamaniiru. Haaluma wal-fakkaatuun saamuda cirrachaa hara kanaa keessatti keemikaalonni kan akka di'aaziinoonii, alfa-sayippermetiriinii ( $\alpha$ cypermethrin) fi indoosulfaanii (endosulfan) iddo/bakkeewwan hedduutti (> 25\%) argamanii jiru. Keessaayyuu saamudoota qarqara Haroo Ziwaay iddoowaan qonna abaabootii dhiyeenyaan argaman, iddoowwan qonna jalisii muduraa fi kuduran itti omishamanti dhiyaatanii argaman fi iddoowwan balfi magaala Baatuu irraa gara haraatti galu irraa funaanaman hangi fiizikookeemikaalaa fi hangi keemikaala farra ilbiisotaa safarme iddoowwan kan irra guddadha. Akka qorannoon kun mul'isutti keemikaalotin kun lubbuu qabeeyyii harichaa irratti midhaa qaqabsiisaa jiru. Akka shalaggiin riiskii koosheentii (RQs) agarsiisutti hangi keemikaalota farra ilbiisotaa bishaanii fi cirracha Haroo Ziwaay keesatti argaman baayeen harichaa irratti midhaa salphaa (possible) tii hanga gaaga'iinsa cimaa (very high) geessisuu ni malu. Akka bu'aa qorannoo kanaatti, lubuu qabeeyyii harichii qabu keessaa artiroopoodii (arthropods) fi qurxummiin (fish) warra gaaga'iinsii cimmaan faalama walmakaa keemikaala farra ilbiisotaan irra qaqabudha. Qarqara Haroo Ziwaay iddoowwan balfa warshaa abaaboo irra yaa'u fudhatan, dhiiyeenyan qonna jalisii kuduraa fi mudurii itti oomishamu argaman fi iddoowwaan lageewwan kan akka Laga Maqii (Meki River) fi Laga Kataar (Ketar River) gara harichaatti dabalamanitti gaaga'iinsi keemikaala farra ilbiisotaan gahuu danda'u shalagame iddoowwan kaan caalaa hedduu gudaadha.

Qorannoon Boqonnaa 5 keessatti gaggeefame tatamsa'iinni laastika caccabaa (plastic particles) cirrachaa Haroo Ziwaay fi miya-garaa/mar'immaan (gastrointestinal tract) qurxummii harichaa keessa jiraatan keessatti maal akka fakkaatu adda baasee jira. Dabalataan hangi (concentration) laastika caccabaa cirracha Haroo Ziwaay keessatti shalagame miidhaa inni lubbuu-qabeeyyii haroo kanaa irratti geessisuu danda'us qorannichaan ifa godhameera. Akka bu'aan qorannoo kanaa ibsutti cirrachii qarqara (shoreline sediments) Haroo Ziwaay caccabaa laastikaan faalamuu fi hangi laastikaa shalagame inni guddaan lubbuu-qabeeyyii 
harichaa keessaayyuu cirracha irratti maxxananii warra jiraatan (benthic communities) miidhaa irraan gahuu mala. Qurxummiiwwan saamudaaf walitti qabaman keessaa harkii tokko-sadaffaan (one-third) isaanii mar'immaan isaanii keessatti caccabaan laastikaa argamee jira. Qurxummiiwwan qorannoof oolan kunneen nyaataaf waan olfamaniif faalamni kun fayya namaa irrattis miidhaa qaqqabsiisuu akka danda'u ni shakkama. Akka ragaan hanga dheerina laastikoota cirrachaa fi mar'immaan qurxummii keessatti argamanii ibsutti laastikoonni caccaboon mar'immaan qurxummii keesatti argaman maddi isaanii cirracha irraati.

Qorannoon Boqonnaa 6 keessatti gaggeefame miidhaa keemikaala farra ilbiisotaa kan ta'e immiidaakloopriid (imidacloprid) qabeenya bishaanii Itoophiyaa irratti qaqqabsiisu danda'u ifa godhee jira. Qorannoon kun kan gaggeefame haroo nam-tolchee (artificial pond/mesocosm) fayyadamuun yoo ta'u kana keessatti miidhaan keemikaala kanaan lubbuu-qabeeyyii (fakeenyaaf: maakirooinvertaabireetii, zuupilaankitoonii, faayitoopilaankitoonii fi peeriifaayitoonii) fi tajaajila maaykiroo-orgaanizimootaa (fakeenyaaf: baala bulleessuu/caccabsuu) irra qaqqabuu danda'u sakatta'amee jira. Kanumaan wal-qabatee faalamni dhaabbatee yeroo hagamii keessatti miidhaa mula'ate irraa lubuu-qabeeyyiin bishaanii kunneen fi tajaajilli maayikiroo-orgaanizimoota miidhaan irra gahe deebi'anii bayyaanachuu (recovery) akka danda'an qoratamee jira. Dabalataan, miidhaa immiidaakloopriidiin qofa qofaa ilbiisota bishaan keessa jiraatan irratti geessisuu danda'u yaalii to'atamaa yeroo gabaabaa mana keessaa (acute single species toxicity test) fayyadamuun qorannoon gaggeefamee jira. Safartuuwwan miidhamaa keemikaala kan ibsan fakkeenyaaf; L(E)C50, L(E)C10 fi NOEC bu'aawwan qorannoo kanaa ibsuuf shalagamanii jiru. Akka bu'aa qorannoo kanaatti immiidaakloopridiin lubbuu-qabeeyyii bishaan keessa jiraatan irratti kalattin fi al-kalaattiin midhaa geessisa. Maakirooinvertaabiratii keessaa kaan caalaa hubamni/miidhaan kan irra qaqabe ilbiisota Kiliyoon diipteram (Cloeon dipterum) fi Sayaannis horaari'aa (Caenis horaria) yoo ta'u zuupilaankitoonii keessaa immoo Biraankiinoos (Brachionus sp.) fi Filiini'aa (Filinia sp.) dha. Akkasumas bu'aan qorannoo hara-namtolchee fayadamuun hojjetame akka ibsutti akkuma hangi immiidaakloopriidii dabaleen hangi kilooroofilii-a (chlorophyll-a) saphaphuuwan peeriifaayitoonii fi faaytoopilaankitonii dabaleera. Daballiin kilooroofilii-a kun kan agarssiisu keemikaallichi midhaa kalattiin (direct effect) lubbuu-qabeeyii biroo kan saphaphuuwwan kana nyaatan (fakkeenyaaf: Kiliyoon diipteram, Biraankiinoos, Filiini'aa) irraan geessisuu isaati. Akka ragaan qorannoo kana irraa argame ibsutti lubbu-qabeeyyiin bishaanii naannoo qilleensa ho'aa (tropical aquatic species) 
keessatti argaman kan qilleensa diilallaa'aa (temperate aquatic species) caalaa keemikaala immiidaakiloopridiitiin miidhamu. Dabalataan, miidhaan qaqqabe irraa zuupilaankitooniin torban sagal (9 weeks) keessatti yoo damdhamatan, maakirooinvertaabiretoonni garu hanga torban 21 ttuu (21 weeks) miidhaa isaan irra gahe irraa hin bayyaannanne. Kun kan agarsiisu biyyoota qilleensa ho' aa qaban keessatti lagni/haroon/burqaan immiiidakiloopriidii hangii isaa $\geq 0.1 \mu \mathrm{g} / \mathrm{L}$ ta'een faalame tokko gaaga'iinsa yeroo dheeraa qaama bishaanii kan irratti qaqqabsiisuu akka danda'u dha.

Akka walii-galaatti, argannoowwan qorannoo kitaaba kanaa Boqonnaa 7 keessatti ibsamee jira. Haaluma kanaan hojiin qonnaa fi babalachuun magaalootaa naannno Haroo Ziwaaytti mulachaa jiru haricha miidhaa akka jiruu fi akkasumas qulqullina bishaan isaa mancaasaa akka jiru qorannoo kanaan adda bahee jira. Xaa'oo, sibiiloota, keemikaalota farra ilbiisaa fi caccabaawwan laastikaa kanneen adda durumaan yeroo amma kanatti Haroo Ziwaay faalaa fi miidhaa gurguddaa irraan gahaa jiraanidha. Haroo kana eeguuf fi mancaatiin isaa akka baraaramu gochuu irratti yaadota gargaaran akka yaada furmaataatti boqqonnaa kan keessatti adda baafamanii jiru. Haaluma kanaan waraqaan qorannoo kun yaada furmaataa akka armaan gadiitti lafa kaa'ee jira. Isaanis: 1) haalaa qabiinsaa fi itti fayyadama keemikaalota farra ilbiisa irratti qonnaan bultoota naannoo Haroo Ziwaay jiraniif leenjii beekumsaa fi shaakallii isaanii gabbisu/cimsu kennu, 2) itti fayyadama keemikaalota farra ilbiisaa hirrisuuf tekinoologiiwwan keemikaalaa ala ilbiisota biqiltuu irraa ittisuu dandeessisan (fakkenyaaf: tekinooloojii akka intiigiritid pesti manaajiiment) qonnaan bultoonni akka itti fayyadamaniif hojii hubannoo uumu hojjechuu fi deeggarsa kennuu, 3) seerota/labsiiwwan towanna keemikaalota farra ilbiisa to'achuuf labsamanii jiran cimsanii hojiitti hiikuu fi itti fayyadama keemikaalota kanaa irratti fayyadamtoota towachuu, 4) haala magaalonni naannoo Haroo Ziwaay jiran balfa isaanii itti maksan fooyyessuu, 5) laaboraatoriiwwan ammayya'aa ta'an kan faalama naannoo qorachuu fi to'achuu keessatti shoora ola'aanaa qaban akka biyyaatti hundeesuu fi 6) maloota salphaa fi baasii salphaa barbaadan, fakkeenyaaf lubbuu-qabeeyyii Haroo Ziwaay keessa jiraatan warra akka efemeroopteraa, pliikoopteraa fi tiraayikoopteraa (Ephemeroptera, Plecoptera and Trichoptera (EPT)) jedhaman fayyadamuun haala qulqullina harichaa hordofuu fi to'annaa gochuu. 


\section{qM\$QP}

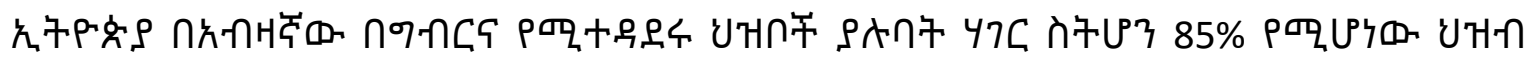

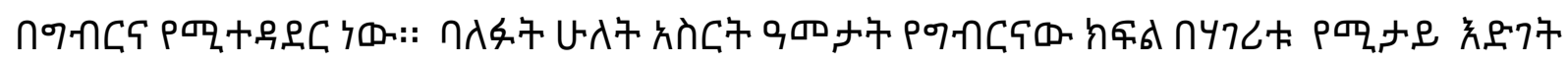

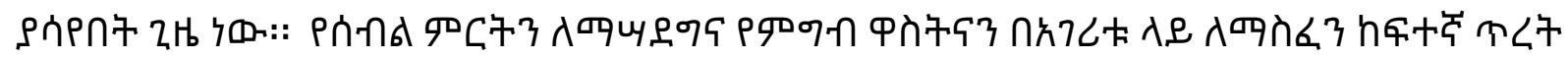

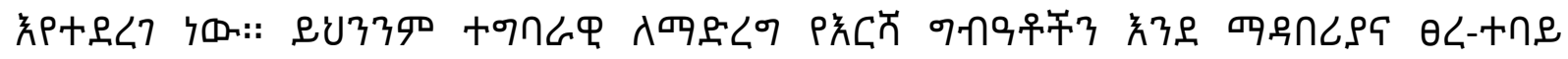

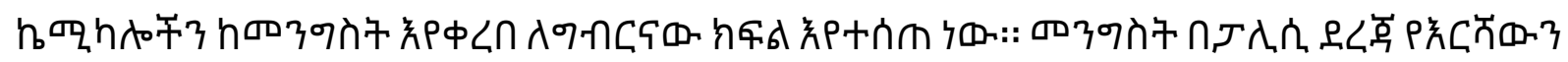

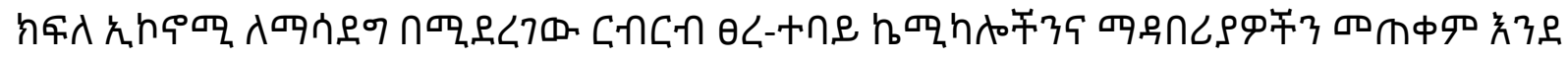

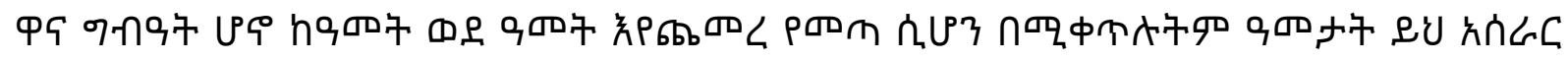

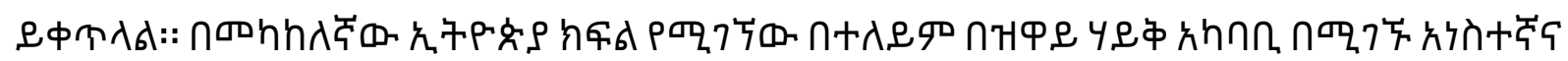

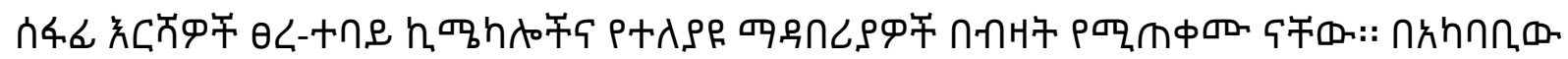

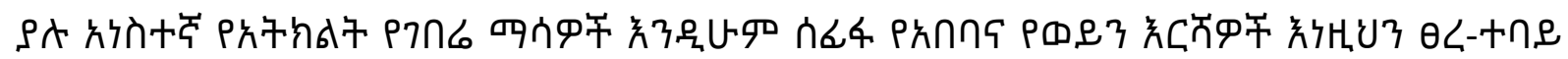

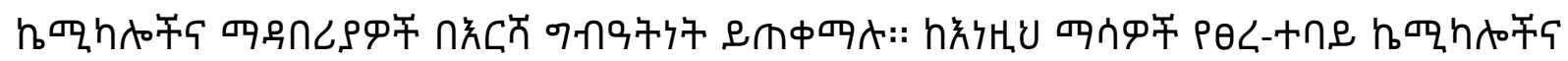

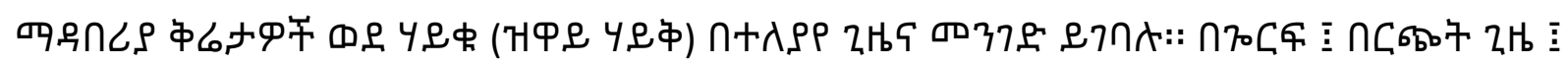

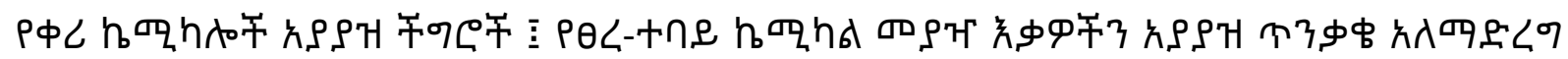

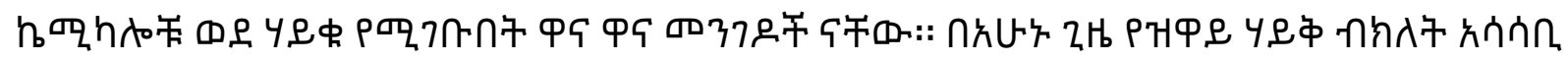

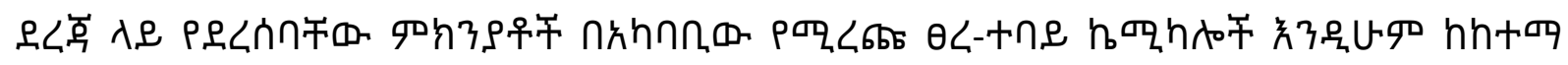

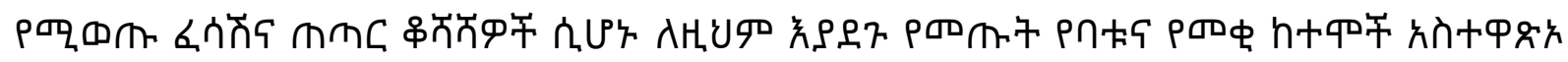

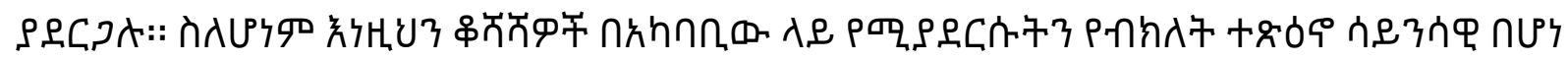

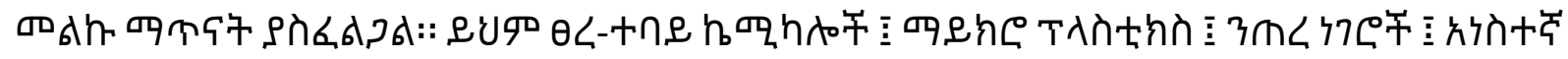

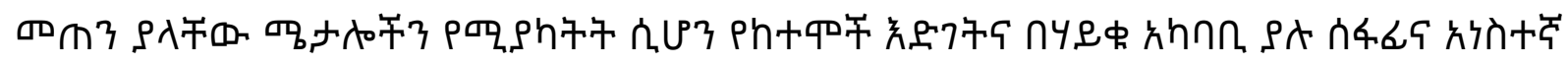

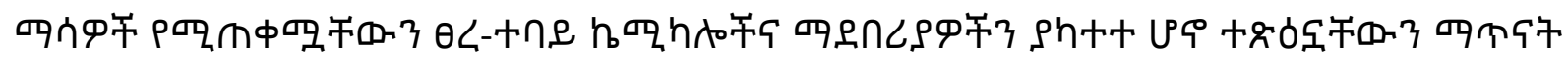

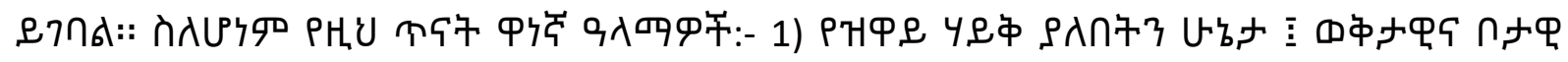

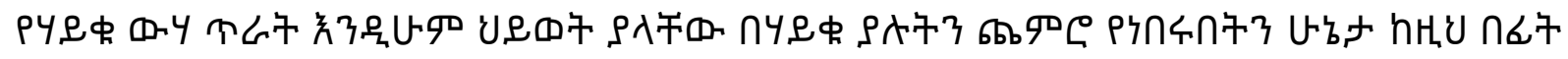

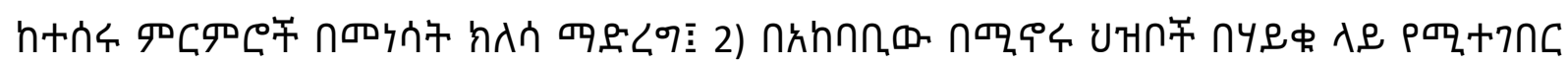

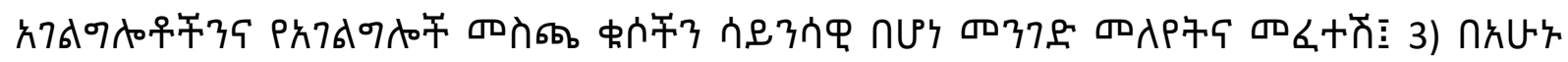

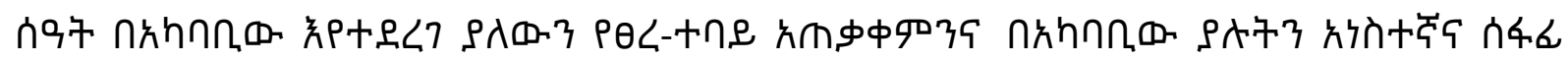

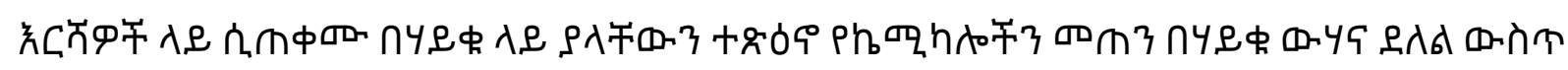

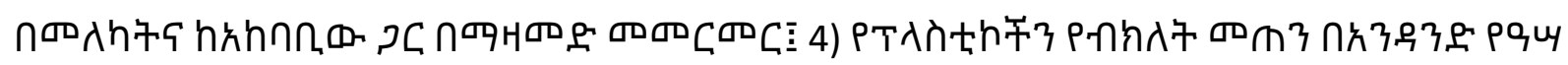


고

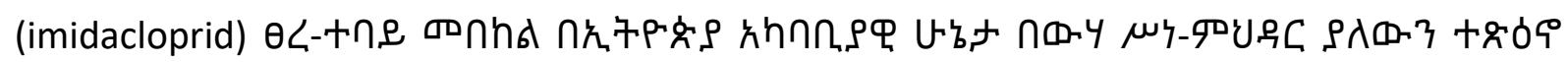

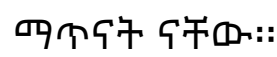

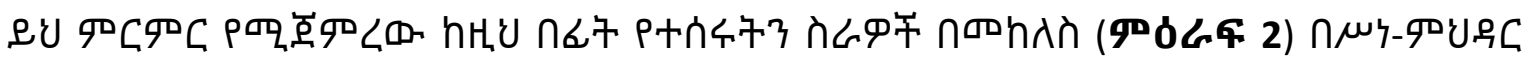

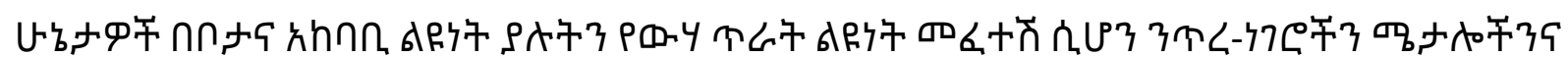

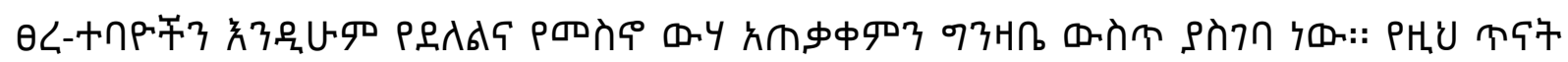

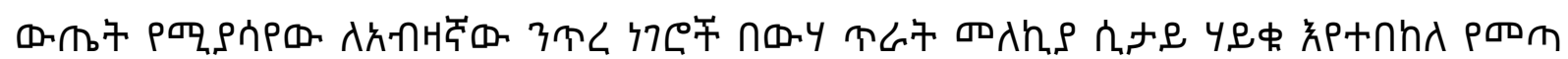

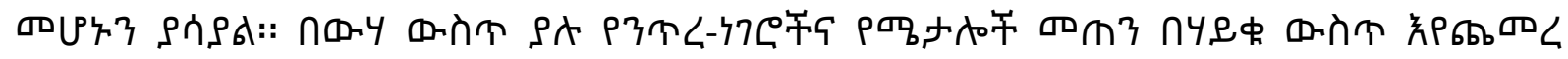

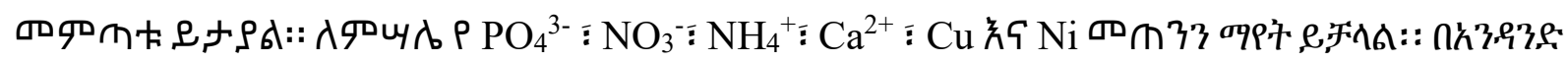

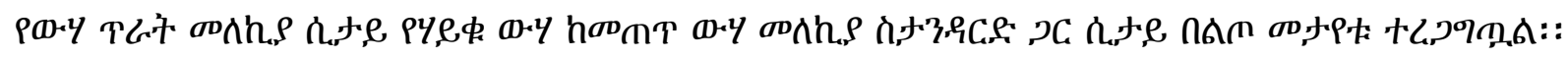

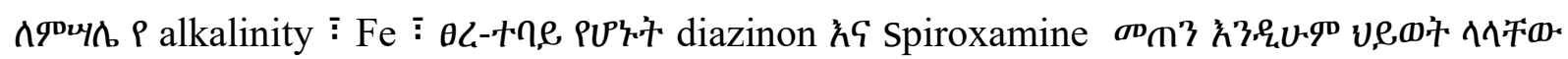

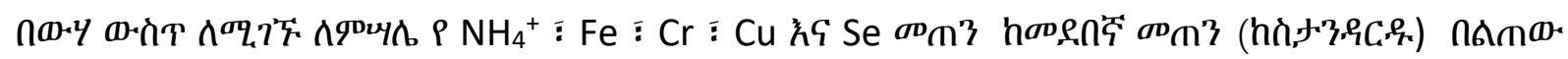

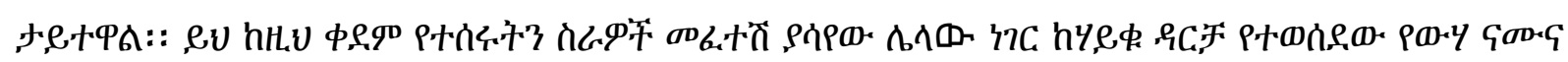

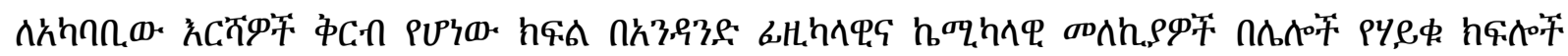

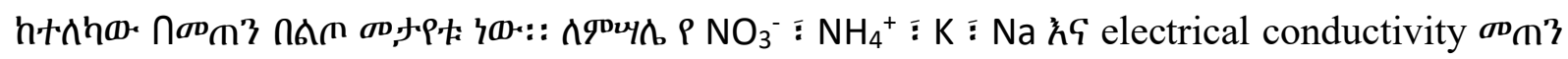
ก†ณव

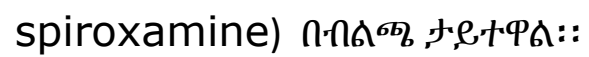

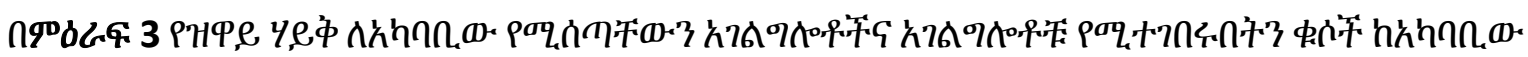

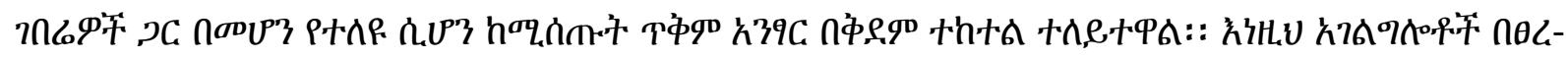

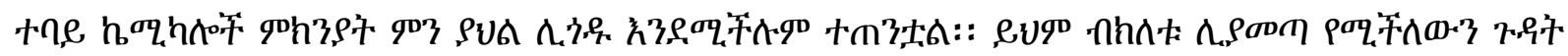

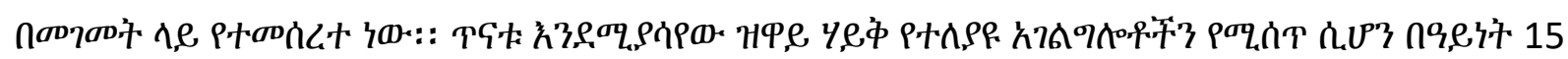

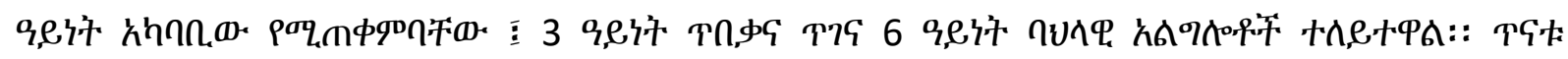

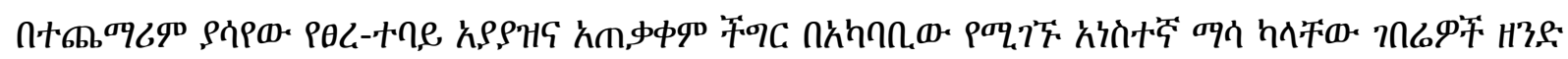

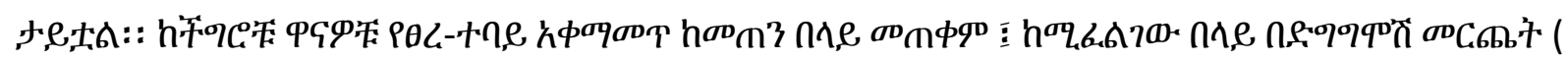

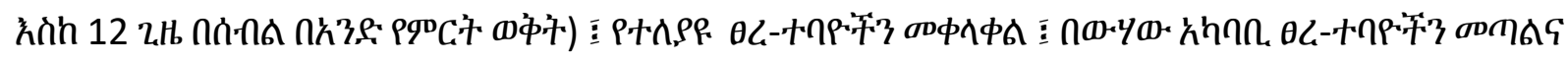

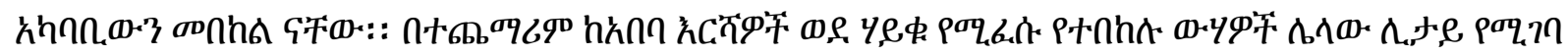

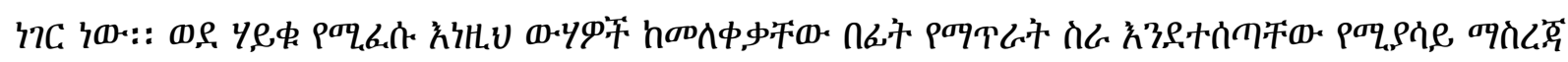

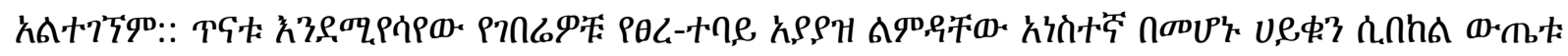

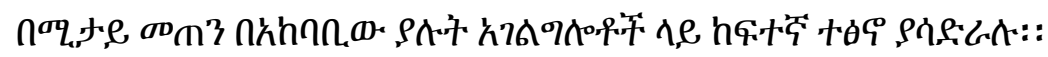

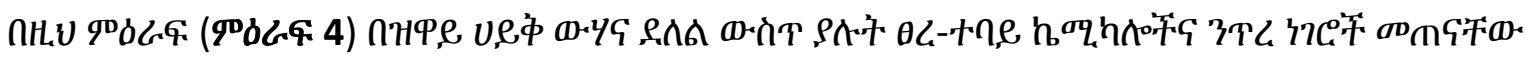

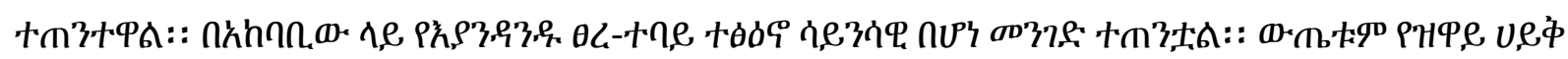




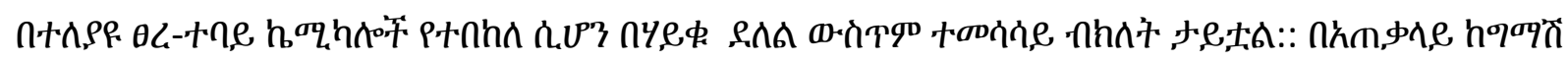

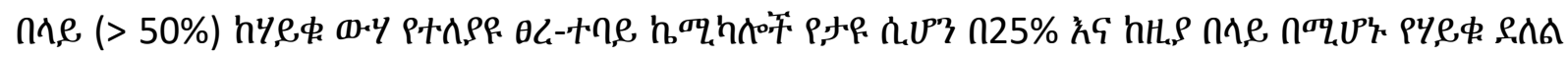

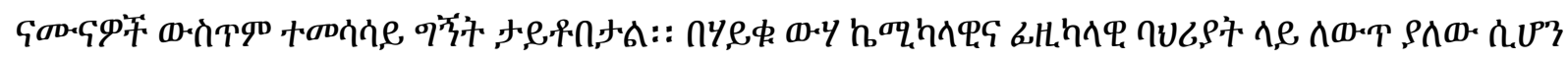

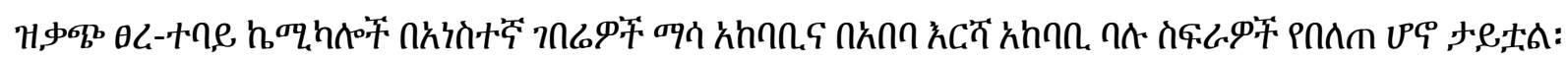

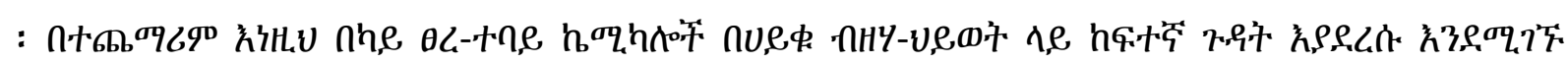

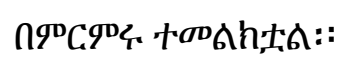

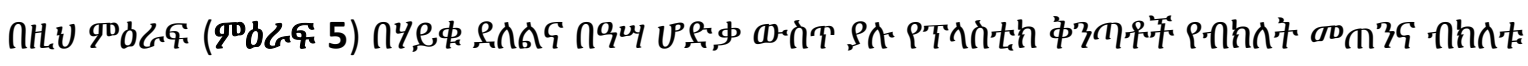

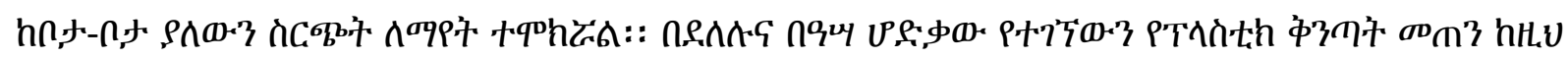

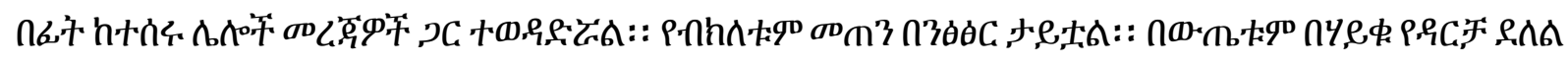

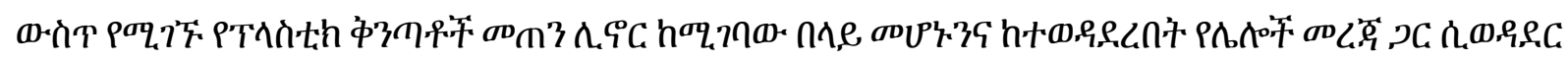

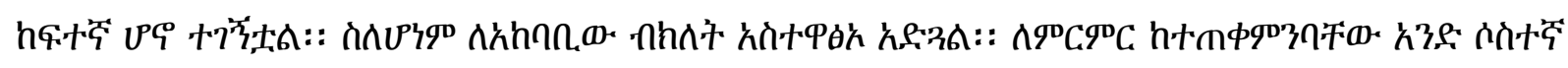

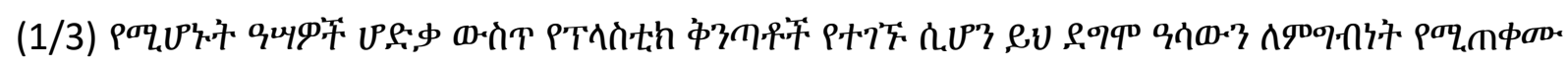

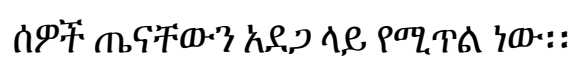

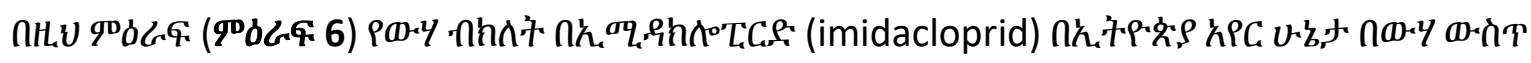

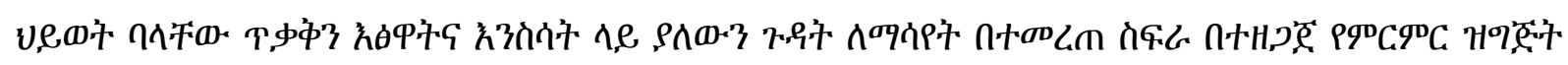

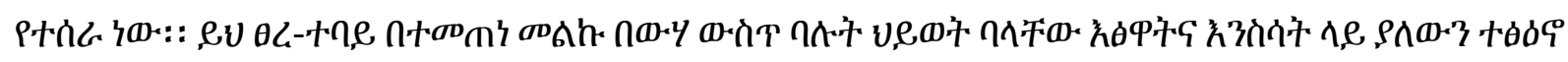

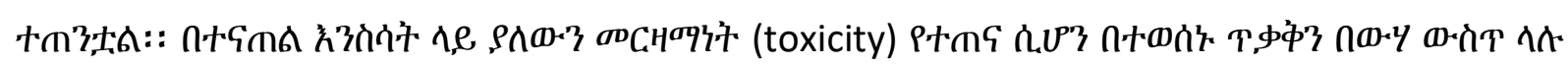
え

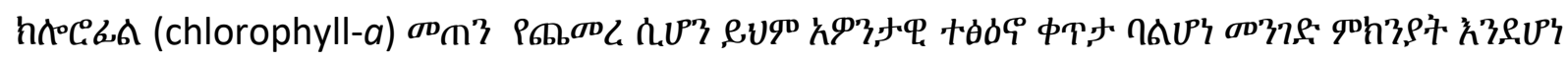

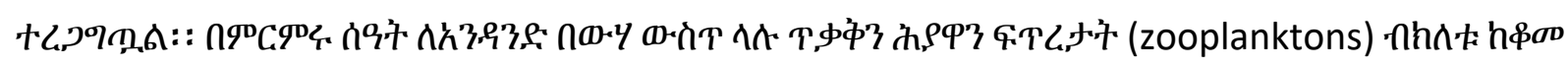

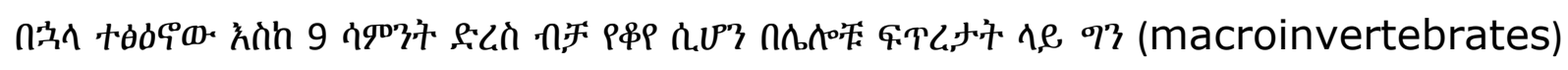

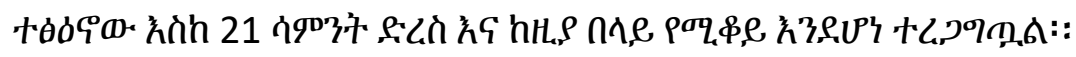

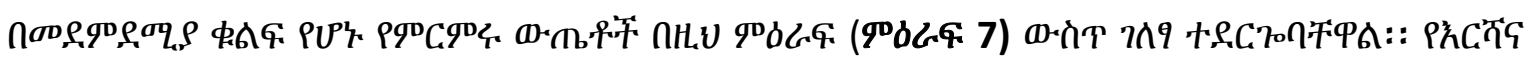

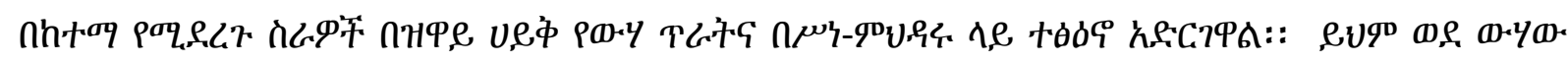

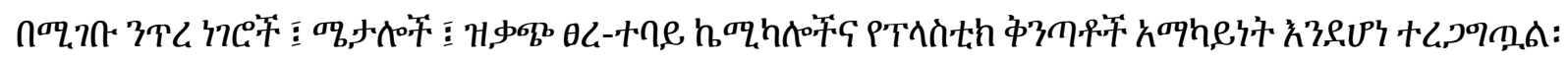

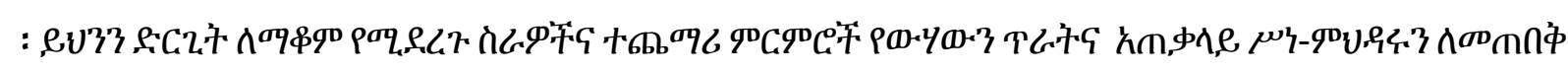

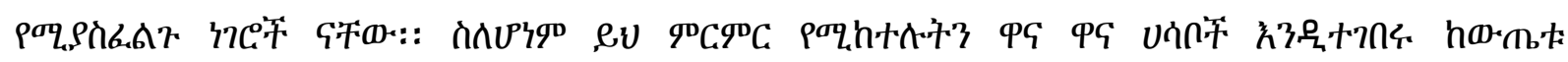

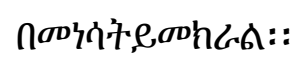

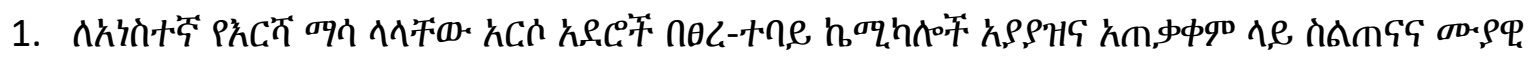

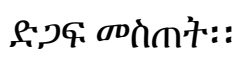

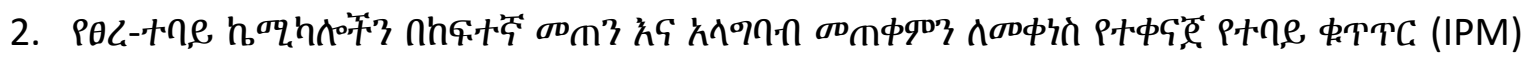

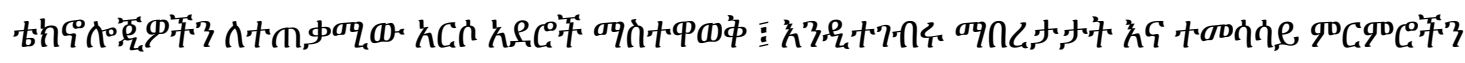
oqhaw?: 


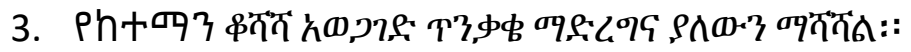

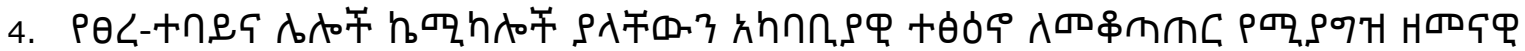

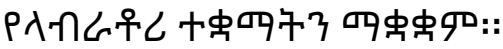

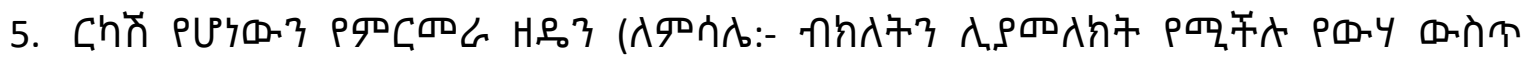

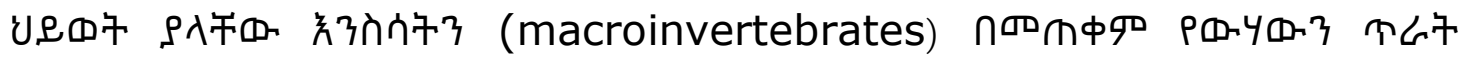

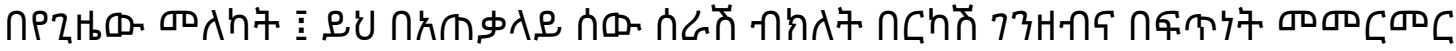

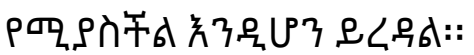




\section{Acknowledgements}

PhD study encompasses many challenges. It is obvious that without the support and encouragement of many people, for me it is difficult to successfully completed my study. With great pleasure I would like to extend my sincere appreciation for those who were around me in many ways during my PhD study.

First of all, I would like to thank my promotor Prof. Dr. Ir. Paul J. Van den Brink, and copromotors Dr. Jack H. Faber and Dr. Alemayehu A. Mengistie. Your advice, guidance, support and inspirational feedbacks throughout my PhD study were wonderful and I am thankful for these. Your patience, commitment and energy to read several versions of the thesis were extremely amazing. Your kindness and understanding were exceptional. Professor Paul, your mentorship and support in establishing experimental setups in Ethiopia and in data analysis were so wonderful. Dear all, you are so special in making my dream true. Thanks a lot!

I deepest gratitude also goes to many colleagues and staffs at the Aquatic Ecology and Water Quality Management (AEW) who supported me in multiple ways and made my stay in Wageningen, The Netherlands safe, exciting and comfortable. I am thankful to AEW chair group for the care you showed me while I was sick. My special thanks also go to Nancy van der Werf and Ramazan Turk for their support by facilitating my logistic and administrative issues. I am thankful to Frits Gillissen And John Beijer for their support in processing the procurement of laboratory tools and chemical for my research. I would also like to thank Dr. Edwin T.H.M. Peeters for his kind help in data analysis. From Wageningen Environmental Research, Team Environmental Risk Assessment my special gratitude goes to Laura Buijse for her tremendous support in processing and analyzing samples for me to quantify residual pesticides. Thanks to my colleagues Sanne Van den Berg, Lara Schuijt, Anna Huang, Zhao Qinghua, Markus Hermann , Annika Mangold-Doering and Goraw Y. Goshu for the support they gave me in various ways and for the great time we had together during my PhD study.

My warmest appreciation to the people and government of Netherland for making my stay in the country happy, safe and comfortable. Thank you so much for funding my PhD education through NUFFIC scholarship.

I am very grateful to members of Emanuel Evangelical Church, Wageningen for their support by praying for me and for the fellowship we had together in Wageningen during my PhD study. Especially I am indeed thankful to Bereket and Araya, for the care and love they showed me. 
I am indebted to my best friend Dr. Shiferaw Tafese Gobena for his support in many ways during my PhD study. My dear brother Shife your contribution for this achievement is irreplaceable. Thanks a lot and God bless you! I would also like to thank Geda Kebede for his great encouragement and support.

I would like to thank my home university, Ambo University, Ethiopia for the support the institution provided for me during my PhD study. Your support were incredible by allowing me to use the laboratory facilities the university owned, by arranging necessary logistics while my field work in Ziway, Ethiopia. My warmest thank also to Ambo University staff including Yilma Hunde, Tigist Mengistu, Abi Legese, Merga H/Mariam, Solomon Zekarias, Firehiwot Girma and Almaz Hordofa for all your kind support during my laboratory work in Ambo University. Especially, I would like to extend my profound gratitude to Miresa Tadese Alemu. Your support in sample collection and laboratory analysis was amazing. Miresa you are so special for me in making my PhD research work so fruitful. My dear Miresa thank you very much. Waaqayyo siif maatiikee haa eebbisu!

I am indeed thankful to Batu Fishery and Other Aquatic Life Research Centre, Ethiopia and staffs of the Centre for permitting me to use its laboratory facilities for my research. I would like to extend deepest gratitude especially to Mr. Mathewos Hailu, Alemu Lemma, Getachew Senbete and Dr. Lemma Abera who were provided me enormous supports during my field work in Ziway, Ethiopia.

My deepest gratitude to Dr. Dula Benti and his family, Dr. Kasahun Benti and his family, Endale Benti for their support in many ways during my PhD study. Dear my beloved brothers your moral support and pray were a fuel to successfully finish my PhD. I am also thankful to Lemi Negeri and Abebe Negeri for their moral support and encouragement during my PhD study. Gooftaan isin haa eebbisu!

Lastly but not least, I am indebted to my beloved wife, Haymanot Desalegn Negeri, for her amazing support and encouragement throughout this challenging PhD journey. Haymo, I never forget the support you gave me through your prayer and thanks a lot for taking care of our kids, Shalom and Milto, without my full help. Without your support I could not imagine this success. I thank and love you! 


\section{About the author}

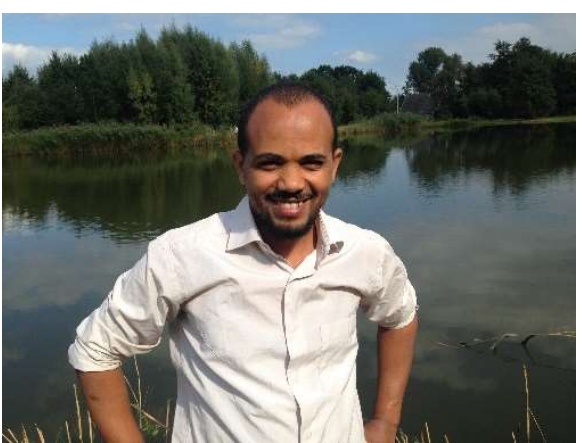

Lemessa Benti Merga was born on 18 July 1984 in a small village known as Hageya located in Horo Guduru Wollega zone of Oromia regional state, Ethiopia. After completed primary school in his home village where he was born, Lemessa moved to Nekemte town, zonal town of East Wollega, Ethiopia, and completed his high school education. He obtained a two year diploma in Chemistry Laboratory Technician from Ambo University, Ethiopia in July 2005 and employed by the University in Chemistry Department as a staff of laboratory technician where he served from September 2005 to July 2009. Working as a technician Lemessa has continued his BSc education in Ambo University in part-time program and obtained BSc degree in Chemistry in July 2009 and promoted to graduate assistant position in Ambo University, Chemistry department. As graduate assistant he served the department from July 2009 to December 2011. He then won NUFFIC scholarship to attend his MSc in Wageningen University and Research (WUR), The Netherlands in January 2011 and awarded his MSc degree in environmental sciences in January 2013. From 2013 to 2016 Lemessa served Ambo University with lecturer position. In 2016 he was awarded NUFFIC scholarship to pursue his PhD study in WUR. Lemessa conducted his doctoral study in Aquatic Ecology and Water Quality Management (AEW) chair group under the supervision of professor Dr. Ir. Paul J. Van den Brink. In his PhD project, Lemessa assessed the impacts of various pollutants including pesticides, trace metals, nutrients and microplastics on the ecology and ecosystem service delivery of Lake Ziway, Ethiopia. 


\section{SENSE}

Netherlands Research School for the

Socio-Economic and Natural Sciences of the Environment

\section{I P L O M A \\ for specialised PhD training}

The Netherlands research school for the Socio-Economic and Natural Sciences of the Environment

(SENSE) declares that

\section{Lemessa Benti Merga}

born on 18 July 1984 in Hageya, Ethiopia

has successfully fulfilled all requirements of the educational PhD programme of SENSE.

Wageningen, 27 January 2021
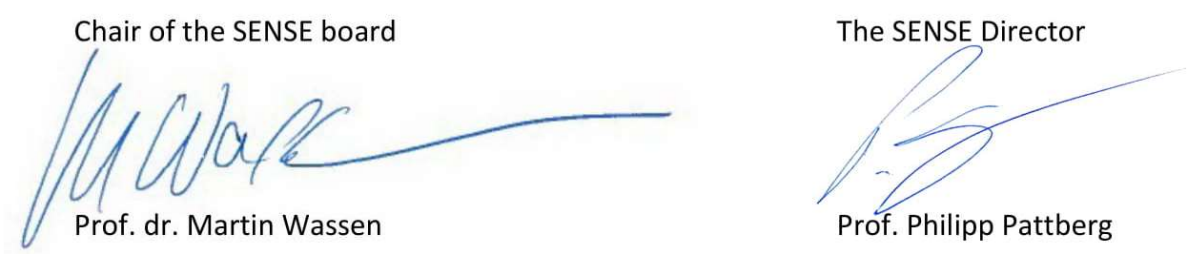

The SENSE Research School has been accredited by the Royal Netherlands Academy of Arts and Sciences (KNAW)

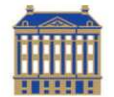

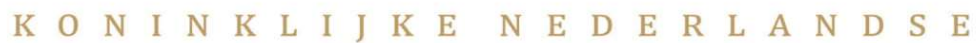

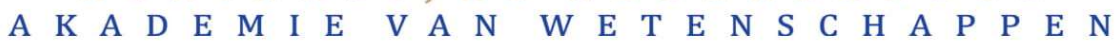




\section{$\underset{\text { SENSE }}{\longrightarrow}$}

The SENSE Research School declares that Lemessa Benti Merga has successfully fulfilled all requirements of the educational PhD programme of SENSE with a

work load of $35.0 \mathrm{EC}$, including the following activities:

\section{SENSE PhD Courses}

- Environmental research in context (2016)

- Research in context activity: 'Organizing and coordinating expert and stakeholder workshop on Ecological Risk Assessment of Chemicals to Lake Ziway: An Ecosystem Service Approach (12 January 2017, Batu Fishery and other Aquatic Life Research Centre)'

\section{Other PhD and Advanced MSc Courses}

- Risk Assessment, Wageningen University and Research (2016)

- The Essentials of Scientific Writing and Presenting, Wageningen Graduate Schools (2016)

- Reviewing a Scientific Paper, Wageningen Graduate Schools (2016)

- Information Literacy Including EndNote Introduction, Wageningen Graduate Schools (2016)

- Project and time management, Wageningen Graduate Schools (2018)

- Basic Statistics, PE\&RC and WIMEK graduate Schools Wageningen (2018)

- Ecotoxicology, Wageningen University and Research and VU Amsterdam University (2019)

- Generalized Linear Models, PE\&RC and WIMEK graduate Schools Wageningen (2020)

\section{Management and Didactic Skills Training}

- Organized scientific workshop 'Ecological risk assessment of chemicals', Ambo University, Ethiopia (2019)

- Teaching in the BSc course 'Environmental Chemistry and Toxicology' (2017 and 2019)

\section{Oral Presentations}

- Occurrence of microplastics in sediment and fish of an African Lake, Lake Ziway of Ethiopia, 7th Annual National Research Conference, 3-4 May 2019, Ambo, Ethiopia

SENSE coordinator PhD education

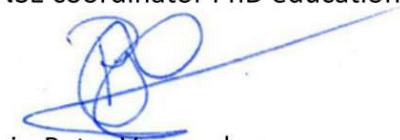

Dr. ir. Peter Vermeulen 
The research described in this thesis was financially supported by The Netherlands Organization for International Cooperation in Higher Education (NUFFIC) under The Netherlands Fellowship Programme (NFP), NUFFIC/ PhD studies, grant NFP - PhD.16/0019, reference number WIMEK2015 02 (project number: 5160957265) and co-funded by the GETREAL (Incorporating spatial and seasonal variability in community sensitivity into chemical risk assessment) project, which was funded by the European Chemical Industry Council longrange research initiative (CEFIC-LRi project ECO 50).

Printing of this thesis was financially supported by Wageningen University, The Netherlands.

Cover design and printed by: Digiforce-ProefschriftMaken, Wageningen, The Netherlands 


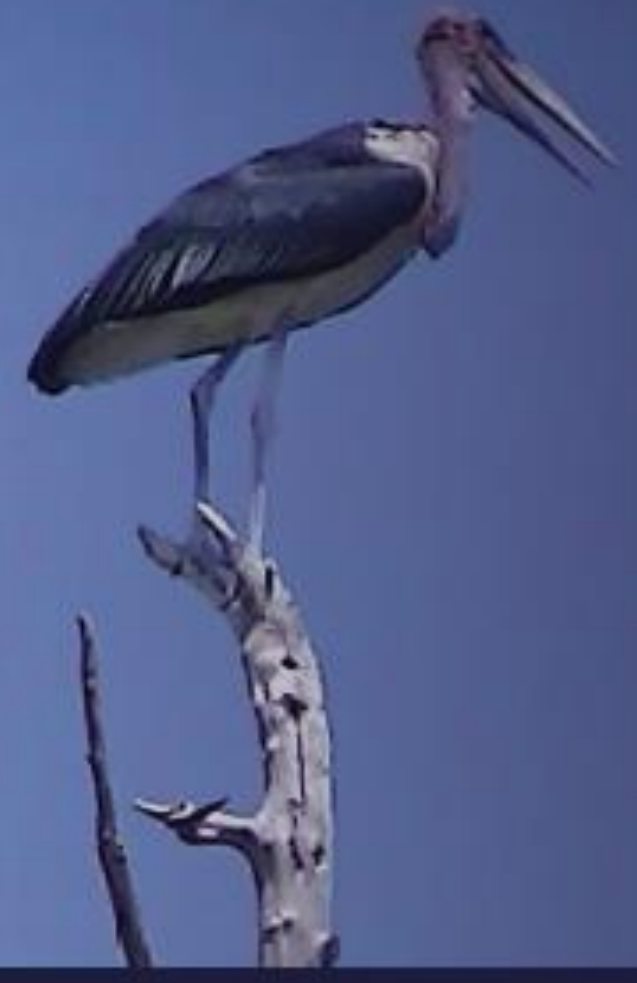

